Álvaro Ricieri Castro e Souza

\title{
Eficiência Energética e Espectral em Sistemas de Comunicação sem Fio: Diversidade Cooperativa, Espacial e em Frequência.
}



Álvaro Ricieri Castro e Souza

\section{Eficiência Energética e Espectral em Sistemas de Comunicação sem Fio: Diversidade Cooperativa, Espacial e em Frequência.}

Tese apresentada à Escola Politécninca da Universidade de São Paulo para obtenção do Título de Doutor em Ciências.

Área de Concentração:

Engenharia Elétrica - Sistemas Eletrônicos

Orientador: Prof. Dr. José Roberto de Almeida Amazonas

Coorientador: Prof. Dr. Taufik Abrão 
Este exemplar foi revisado e corigido em relação à versão original, sob responsabilidade única do autor $\mathrm{e}$ com a anuência de seu orientador.

São Paulo, do

de

Assinalura do autor

Assinatura do orientador:

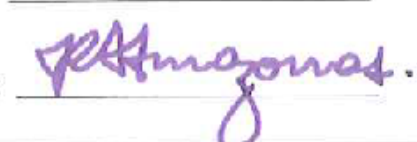

Catảlogação-na-publicação

Castro e Souza, Alvaro Ricieri

Eficiôncia Energética e Espectral em Sistemas de Comunicação sem Fin: Diversidade Coopcrativa, Espacial e em Frequência. / . H. Castro e Souza -- versäo corr. -- Säo Paulo, 2018.

$258 \mathrm{p}$.

Tese (Doulorado) - Escola Politécnica da Universidade de São Paulo. Departamento de Engenharia de Sistemas Eletrônicos.

1.Comunicaçöes Digitais 2.Processamento Digital de Sinais I.Univcrsidade do Săo Paulo. Escola Politécnica. Departamento de Engenharia de Sistemas Eletrônicos II.t. 


\section{Eficiência Energética e Espectral em Sistemas de Comunicação sem Fio: Diversidade Cooperativa, Espacial e em Frequência.}

Tese apresentada à Escola Politécninca da Universidade de São Paulo para obtenção do Título de Doutor em Ciências.

Trabalho aprovado. São Paulo, 2018.

Prof. Dr. José Roberto de Almeida Amazonas

Orientador

Prof. Dr. Taufik Abrão

Co-Orientador

Prof. Dr. Cristiano Magalhães Panazio

Membro Externo

Prof. Dr. Glauber Gomes de Oliveira Brante

Membro Externo

Prof. Dr. Gustavo Fraidenraich

Membro Externo

Prof. Dr. Ivan Roberto Santana Casella

Membro Externo

São Paulo

2018 

Dedico este trabalho a Deus, que durante toda a minha caminhada proveu tudo para que este trabalho fosse realizado.

Dedico também a minha avó, Mercedes Gonçalves Ricieri, falecida perto do fim da conclusão deste trabalho.

Dedico também a Marco Antônio Pupo Coelho, que luta contra um câncer. Que sua luta seja em breve compensada com a vitória.

Por fim, dedico a todos os estudantes e acadêmicos que sucumbiram (ou sucumbem) à falta de esperança, pressão, depressão e tantos outros males durante suas caminhadas acadêmicas. Que possam reencontrar alegria, paz e motivação. 



\section{AGRADECIMENTOS}

Primeiramente agradeço a Deus. Pela oportunidade de chegar tão longe na caminhada acadêmica, por toda sorte de bençãos e misericórdia.

Agradeço a minha família: meu pai, Álvaro Roberto Castro e Souza, minha mãe, Cleonice Maria Ricieri Castro e Souza, e minhas irmãs, Talita Ricieri Castro e Souza e Isabela Ricieri Castro e Souza. Agradeço pela provisão financeira, moral, espiritual, psicológica. Cada um a sua maneira, com o que tinham ao alcance, foram fundamentais em toda minha caminhada como pessoa e também na vida acadêmica.

Agradeço ao meu orientador, Prof. Dr. José Roberto de Almeida Amazonas. Nestes 5 anos de trabalho conjunto, me ensinou muito mais do que conhecimento acadêmico. Me deu a honra de ser seu último orientando em seu período na Universidade de São Paulo, soube cuidar e cobrar nos períodos mais complicados deste trabalho, quando a depressão se mostrou mais forte. Se eu conseguir ser apenas parte do que o senhor foi para mim na caminhada acadêmica, me sentirei realizado.

Agradeço também ao meu co-orientador, Prof. Dr. Taufik Abrão. Ao longo dos 8 anos que trabalhamos juntos, o senhor moldou um estudante em um pesquisador inquieto, que não gosta de deixar perguntas sem resposta, que gosta de ser desafiado. Com sua responsabilidade, rigor científico, conhecimento e um espírito de jamais se deixar levar pela média, foi fundamental desde minha graduação até a conclusão deste trabalho. Espero que mais artigos, mais colaboração e, principalmente, a amizade jamais se desfaçam.

Agradeço também aos vários amigos feitos durante essa caminhada. Amigos relacionados à atividade acadêmica, como Fábio Gava, Tiago Ramos, Vitor Mori, Tiago Sanches e Luciano Caldas. Os amigos do Ministério Universidades Renovadas, responsável pelos Grupos de Oração Universitários, fonte de sustentação nos momentos bons e ruins: Jean Carlos Alves Barbara, Luckas André Farias, Karoline Carvalho Burger, Inaiara Andrade, Uanda Paula, Nayara Fernanda Pereira, Melissa Tertuliano da Costa, Rafaella Monteiro, Bruno Tenório, Camila Honorato, Ana Clara, Pedro Silva, Marielle Tavares, Francine Franzotti, Tiago Rodrigues, Túlio Pellegrini, Lorena Alves Mendes, Aleksandro Gomes, Maykon Assis, Jéssica Oliveira, Renan Rodrigues, Iacy Batista. A todos vocês, Luquinhas, meu agradecimento. E também ao amigos do grupo Ruah, do Movimento de Emaús: Fátima Hernández, Luiz de Assunção, Larissa do Val, Vanice Cestari, José Donizeti Cestari, Cecília Brayner e Fernando Cabral. Por fim, aos amigos da etapa de docência, Elaine Barbosa, Paulo Nietto, Maurício Faria. Foram muitos outros ao longo desses anos, e peço desculpas se esqueci alguém. 

Quanto mais aumenta nosso conhecimento, mais evidente fica nossa ignorância.

(John F. Kennedy) 



\section{RESUMO}

Sistemas modernos de comunicação móvel sem fio, como os de quarta geração (4G), têm como principais metas prover elevada capacidade e alta qualidade de serviço (QoS) para os usuários. Para prover tal aumento de capacidade e QoS, sistemas 4G empregam diversas técnicas avançadas de transmissão e maior largura de banda, combinados com algoritmos de alocação de recursos que possam explorar de maneira eficiente tais técnicas, como por exemplo aproveitando as dimensões de diversidade do sistema. Em geral, porém, é necessário também aumentar a potência de transmissão para se atingir o ganho de capacidade desejado, o que implica maior custo para os provedores de serviço, menor tempo de vida para os dispositivos móveis e impacto ambiental cada vez mais pronunciado. Dado que a expectativa é que o número de usuários e a necessidade de dados continuem crescendo rapidamente, torna-se evidente a importância de analisar a relação entre capacidade e potência dispendida pelo sistema. Essa relação pode ser vista através da métrica de eficiência energética (EE), que é dada pela razão entre o número de bits efetivamente recebidos e a energia consumida no processo, revelando quão eficientemente o sistema transforma a energia consumida em informação efetivamente recuperada no receptor. Um sistema otimizado em relação à EE é capaz de transmitir mais informação por unidade de energia consumida, resultando em utilização mais racional e eficiente dos escassos recursos energéticos.

Uma segunda questão acerca das metas é em relação à distribuição dos ganhos de capacidade/QoS pela célula, i.e., quais usuários serão capazes de usufruir da maior capacidade e QoS. Em ambientes macrocelulares urbanos, a perda de percurso pode chegar a várias dezenas de decibéis em distâncias relativamente pequenas, além dos obstáculos naturais, como relevo, e artificiais, como prédios, o que limita ainda mais o desenvolvimento de sistemas energeticamente eficientes. Em abordagens tradicionais, tais problemas exigem a utilização de potências elevadas, em geral superiores à potência que os dispositivos podem utilizar, ou então requerem o aumento da densidade de estações rádio-base (BSs), o que geralmente resulta em custos inviáveis do ponto de vista dos operadores. Assim, busca-se em sistemas $4 \mathrm{G}$ emular o aumento da densidade de BSs através do conceito de redes heterogêneas, que são células com menor área de cobertura instaladas em pontos críticos de cobertura da célula original, como por exemplo a região de borda de célula, atendendo de maneira eficiente os usuários. No cenário de redes heterogêneas, um dos principais paradigmas é o conceito de redes cooperativas, no qual estações retransmissoras (RSs) reenviam o sinal recebido da estação fonte para estação destino, reduzindo a potência consumida com o canal móvel sem fio. Como utilizam conexão sem fio com a BS, as RSs podem ser instaladas em regiões com pouca infraestrutura sem a necessidade de grandes modificações, resultando em implantações bastante flexíveis. 
Assim, este trabalho de doutorado visa investigar estratégias de alocação de recursos baseadas no incremento da eficiência energética para sistemas celulares de quarta e quinta gerações utilizando o paradigma de redes cooperativas, determinando potencialidades e também itens que necessitam ser modificados, otimizados ou mesmo redefinidos, tendo em vista um aumento substancial da eficiência energética global da rede de comunicação sem fio. Busca-se durante o desenvolvimento do modelo de sistema capturar e quantificar as principais características de importantes sistemas celulares em uso atualmente, i.e., LTE-A e WiMAX, de modo que as decisões de design considerem os esforços de padronização, porém não se limitem a eles. Como a abordagem de alocação de recursos baseada em EE pode impactar nas métricas de desempenho do sistema, investiga-se também o compromisso entre as eficiências energética e espectral (SE), de modo que o aumento da EE não seja causado apenas pela degradação da SE e que seja possível obter maior EE para uma mesma SE e QoS.

Palavras-Chave: Sistemas de quarta geração, redes cooperativas, estações retransmissoras, eficiência energética, eficiência espectral, compromisso EE-SE. 


\section{ABSTRACT}

Modern wireless communication systems, such as the fourth generation (4G) ones, have as main objectives to provide high capacity and quality of service (QoS) for the users. In order to provide such capacity and QoS gain, 4G systems use several advanced transmission techniques and higher bandwidth, combined with resource allocation algorithms that are able to efficiently exploit such techniques, as for example taking advantage of the diversity dimensions of the system. Generally, however, it is also necessary to increase the transmission power to achieve the desired capacity gain, which implies increased costs for service providers, shorter lifetime for the mobile devices and increasingly pronounced environmental impact. Since the expectation is that the number of users and data necessity will continue growing rapidly, it is evident the importance of analyzing the relation between capacity and power expended by the system. This relation can be seen through the energy efficiency (EE) metric, which is given by the ratio between the number of effectively received information bits and the energy consumed in the transmission process, revealing how efficiently the system transform consumed energy into effectively recovered information at the receiver. A system optimized regarding EE is able to transmit more information per unit of energy consumed, resulting in a more rational and efficient utilization of the scarce energetic resources.

A second issue is relative to the distribution of the capacity/QoS gains over the whole cell, i.e, which users will be able to take advantage of the higher capacity and QoS. In urban macrocellular environments, the path-loss can reach several tens of decibels in relatively short distances, in addition to natural obstacles, such as land relief, or artificial, such as buildings, which further limits the development of energetically efficient systems. In traditional approaches, such problems require the use of high transmission power, generally greater than the power that the devices can use, or else require increased density of base-stations (BSs), which generally results in unviable costs from the operators point of view. Thus, in $4 \mathrm{G}$ systems it is sought to emulate the increase in the density of BSs through the concept of heterogeneous networks, which are cells with smaller coverage area installed in critical points of the original macrocell coverage, as for example the cell-edge area, serving efficiently the users. In the heterogeneous networks scenario, one of the main paradigms is the concept of cooperative networks, in which relay stations (RSs) retransmit the signal received from the source station to the destination station, reducing the power consumed with the mobile wireless channel. As the RSs use a wireless connection to the BS, they can be installed in places with poor infrastructure without requiring major modifications, resulting in very flexible deployments.

Thus, this $\mathrm{PhD}$ work aims to investigate resource allocation strategies based on the improvement of the energy efficiency for fourth and fifty generation cellular systems using the cooperative networks paradigm, determining potentialities and also items that need 
to be modified, optimized or even redefined, aiming to a substantial increase in the overall energy efficiency of the wireless communication network. It is sought during the development of the system model to capture and quantify the main features of important cellular systems currently in use, i.e., LTE-A and WiMAX, so that the design decisions consider the standardization efforts, but do not be limited by them. Since the EE-based resource allocation approach can impact the performance metrics of the system, it will be investigated also the tradeoff between energy and spectral (SE) efficiencies, so that the increase in energy efficiency is not caused by degradation of the SE and also to be possible to obtain a higher EE for a same SE and QoS.

Keywords: Fourth generation systems, cooperative networks, relay stations, energy efficiency, spectral efficiency, EE-SE tradeoff. 


\section{LISTA DE ILUSTRAÇÕES}

Figura 1.1 - Diagrama da solução adotada. . . . . . . . . . . . . . . . . . . . 9

Figura 2.1 - Fluxo de transmissão e recepção em sistemas OFDM. . . . . . . . . . . 14

Figura 2.2 - Topologia básica de uma rede cooperativa, com identificação dos enlaces. 20

Figura 2.3 - Topologias de dois saltos. . . . . . . . . . . . . . . . . . . . . 22

Figura 2.4 - Classificação do sistema cooperativo em relação ao número de enlaces entre fonte e destino. . . . . . . . . . . . . . . . . 24

Figura 2.5 - Interferência gerada pela operação conjunta dos enlaces de acesso e backhaul. . . . . . . . . . . . . . . . 25

Figura 2.6 - Eficiência energética em relação à eficiência espectral, com potência de circuitaria nula. . . . . . . . . . . . . . . . . . . . 34

Figura 2.7 - Eficiência energética em relação à eficiência espectral, com potência de circuitaria não-nula.

Figura 2.8 - Topologias de retransmissão inband e o número de janelas necessárias para completar uma transmissão em downlink e uplink. . . . . . . . . . 42

Figura 2.9 - Estratégias de alocação de RSs. . . . . . . . . . . . . . . . . . . . . . . 44

Figura 3.1 - Modelo de célula adotado neste trabalho. . . . . . . . . . . . . . . . 51

Figura 3.2 - Esquema de alocação de subportadoras, com $N=7$ e modo half-duplex inband. . . . . . . . . . . . . . . . . . . 53

Figura 3.3 - Fluxo do processo de retransmissão para AF e DF em um sistema de múltiplo acesso por divisão de frequência.

Figura 4.1 - Área de busca definida pela aproximação dos multiplicadores obtida com o Algoritmo 4.3, e os valores obtidos após o método baseado em bissecção e após a convergência do algoritmo DKB+LDD para diferentes valores de $p_{k}^{\max } \ldots \ldots \ldots \ldots \ldots$. . . . . . . . . . . . . . .

Figura 4.2 - Gráfico de dispersão do nível da água $\chi_{k}$ em relação ao valor ótimo da variável de atualização $\phi_{k}^{*}$ obtido ao se testar o vetor candidato $\bar{\phi}$. . . .

Figura 4.3 - Gráfico de dispersão para o nível da água e o valor ótimo da variável de atualização $\phi_{k}^{*}$ obtido via simulação, assim como a função de fitting obtida para estimar $\phi_{k}^{*}$ para diferentes valores de $p_{k}^{\max }$. . . . . . . . 85

Figura 4.4 - Média do número de iterações executadas após a execução do algoritmo TIPSA-EE usando o algoritmo DKB+LDD-EE. . . . . . . . . . . . . . 86

Figura 4.5 - Distribuição cumulativa do número de iterações duais para as três estratégias de otimização. . . . . . . . . . . . . . . . . . . . . . 87

Figura 4.6 - EE dos algoritmos propostos, para diferentes valores de $p_{k}^{\max }, K$ e $N . \quad$. 89

Figura 4.7 - CDF da EE atingida pelos algoritmos sub-ótimos. . . . . . . . . . . . . 90 
Figura 4.8-CDF da porcentagem de usuários com ao menos uma subportadora alocada ............................ 92

Figura 4.9- CDF do número de execuções do algoritmo WF para os algoritmos SIPA-EE e TIPSA-EE. . . . . . . . . . . . . . . . . . . . . . 92

Figura 4.10-CDF do número total de execuções do Algoritmo 4.2 para os algoritmos: a) TIPSA-EE e b) TIPSA-EE mais DKB+LDD-EE até que a convergência seja atingida. . . . . . . . . . . . . . . . 93

Figura 7.1 - Intervalos rudimentares de busca para o stepsize da inicialização de variáveis, para $N=256$ e diversos valores de $K$. . . . . . . . . . . 173

Figura 7.2 - Intervalos rudimentares de busca para o stepsize da inicialização de variáveis, para $N=512$ e diversos valores de $K \ldots \ldots$. . . . . . . 173

Figura 7.3 - Intervalos rudimentares de busca para o stepsize da inicialização de variáveis, para $N=1024$ e diversos valores de $K$. . . . . . . . . . . 174

Figura 7.4 - Intervalos rudimentares de busca para o stepsize da inicialização de variáveis, para $N=2048$ e diversos valores de $K$. . . . . . . . . . 174

Figura 7.5 - Intervalos reduzidos de busca para o stepsize da inicialização de variáveis, para $N=256$ e diversos valores de $K \ldots \ldots$. . . . . . . 175

Figura 7.6 - Intervalos reduzidos de busca para o stepsize da inicialização de variáveis, para $N=512$ e diversos valores de $K \ldots \ldots$. . . . . . . . 175

Figura 7.7 - Intervalos reduzidos de busca para o stepsize da inicialização de variáveis, para $N=1024$ e diversos valores de $K \ldots$. . . . . . . 176

Figura 7.8 - Intervalos reduzidos de busca para o stepsize da inicialização de variáveis, para $N=2048$ e diversos valores de $K$. . . . . . . . . . . 176

Figura A.1-Razão entre o path-loss direto e cooperativo para que haja igualdade na energia consumida nos links MS-RS e MS-BS. . . . . . . . . . . . . 201 


\section{LISTA DE TABELAS}

Tabela 2.1 - Classificação de RSs. . . . . . . . . . . . . . . . . . . . . . . . 29

Tabela 2.2 - Componentes de custos CAPEX e OPEX. . . . . . . . . . . . . 38

Tabela 2.3 - Resumo dos aspectos de otimização relevantes em redes cooperativas. . 47

Tabela 3.1 - Definições do modelo cooperativo adotado neste trabalho. . . . . . . . . 55

Tabela 4.1 - Parâmetros de simulação . . . . . . . . . . . . . . . . . . . . 81

Tabela 4.2 - Coeficientes obtidos com o processo de fitting para a equação (4.24). 84

Tabela 4.3 - Número (porcentagem) de ocorrência de diferenças de alocação de subportadoras quando compara-se uma busca exaustiva e o algoritmo DKB+LDD-EE para 10000 realizações de canal. . . . . . . . . . . . . . 88

Tabela 4.4 - Métodos DKB e/ou LDD empregados para solucionar o problema de maximização de EE . . . . . . . . . . . . . . . . . . . . . . 9 95

Tabela 7.1 - Valores para a variável de stepsize para a inicialização de variáveis, para cada valor de $K$ e $N$ considerados. . . . . . . . . . . . . . . . . 177

Tabela 7.2 - Valores mínimos para o intervalo de teste da variável de stepsize dos multiplicadores $\boldsymbol{v}$ para o Algoritmo 7.2. . . . . . . . . . . . . . . 177

Tabela 7.3 - Valores máximos para o intervalo de teste da variável de stepsize dos multiplicadores $v$ para o Algoritmo 7.2. . . . . . . . . . . . 177

Tabela 7.4 - Porcentagem de convergência do Algoritmo 7.2 com os valores candidatos testados. . . . . . . . . . . . . . . . . . . 178 



\title{
LISTA DE ABREVIATURAS E SIGLAS
}

\author{
3GPP 3rd Generation Partnership Project \\ 4G Quarta Geração - Fourth Generation \\ 5G Quinta Geração - Fifth Generation \\ AF $\quad$ Amplifica e Transmite - Amplify and Forward \\ AMC Modulação e Codificação Adaptativas - Adaptive Modulation and Co- \\ ding \\ APC Consumo de Potência por Área - Area Power Consumption \\ AWGN Ruído Gaussiano Branco Aditivo - Additive White Gaussian Noise \\ BER Taxa de Erro de Bit - Bit Error Rate \\ BS Estação Rádio-Base - Base-Station \\ CAPEX Despesas de Capital - Capital Expenditure \\ CDF Função Distribuição Acumulada - Cumulative Distribution Function \\ CDMA Múltiplo Acesso por Divisão de Código - Code Division Multiple Access \\ CF Comprime e Transmite - Compress and Forward \\ CG Grupo de Custo - Cost Group \\ CINR Relação Portadora-Ruído mais Interferência - Carrier to Noise plus \\ Interference Ratio \\ CoMP Coordenação Multiponto - Coordinated Multipoint \\ CP Prefixo Cíclico - Cyclic Prefix \\ CRC Verificação Cíclica de Redundância - Cyclic Redundancy Check \\ CSI Informação de Estado de Canal - Channel State Information \\ DCP Programação de Diferença de Funções Côncavas - Difference of Con- \\ cave functions Programming \\ DF Decodifica e Transmite - Decode and Forward \\ DFT Transformada Discreta de Fourier - Discrete Fourier Transform
}


DKB Dinkelbach

DSL Linha Digital de Assinante - Digital Subscriber Line

EE Eficiência Energética - Energy Efficiency

EF $\quad$ Estima e Transmite - Estimate and Forward

EPA Alocação Igualitária de Potência - Equal Power Allocation

FDD Duplexação por Divisão de Frequência - Frequency-Division Duplexing

FDMA Múltiplo Acesso por Divisão de Frequência - Frequency Division Multiple Access

FFT Transformada Rápida de Fourier - Fast Fourier Transform

FRS Estação Retransmissora Fixa - Fixed Relay Station

GSM Global System for Mobile Communications

IC Cancelamento de Interferência - Interference Cancelation

ICI Interferência Inter-Portadora - Inter-Carrier Interference

IEEE Institute of Electrical and Electronics Engineers

IFFT Transformada Rápida Inversa de Fourier - Inverse Fast Fourier Transform

IMT International Mobile Telecommunications

IMT-A IMT-Advanced

ISI Interferência Inter-Simbólica - Inter-Symbol Interference

ITU International Telecommunication Union

KKT Karush-Kuhn-Tucker

LDD Decomposição Dual de Lagrange - Lagrange Dual Decomposition

LF Processa linearmente e Transmite - Linear processing and Forward

LoS Linha de Visada - Line of Sight

LTE Long Term Evolution

LTE-A LTE-Advanced 
M-PSK Modulação por Chaveamento de Fase $M$-ário - M-ary Phase Shift Keying

M-QAM Modulação por Chaveamento de Amplitude em Quadratura $M$-ário $M$-ary Quadrature Amplitude Modulation

MA Múltiplo Acesso - Multiple Access

MAC Controle de Acesso ao Meio - Media Access Control

MAI Interferência de Múltiplo Acesso - Multiple Access Interference

MCS Simulação Monte Carlo - Monte Carlo Simulation

MIMO Múltiplas Entradas e Múltiplas Saídas - Multiple Input Multiple Output

MRC Combinação de Máxima Razão - Maximal Ratio Combining

MRS Estação Retransmissora Móvel - Mobile Relay Station

MS Estação Móvel - Mobile Station

MSE $\quad$ Erro Quadrático Médio - Mean Squared Error

nLF Processa não-Linearmente e Transmite - non-Linear Processing and Forward

NLoS Sem Linha de Visada - Non-Line of Sight

OFDM Multiplexação por Divisão Ortogonal de Frequência - Orthogonal Frequency Division Multiplexing

OFDMA Múltiplo Acesso por Divisão Ortogonal de Frequência - Orthogonal Frequency Division Multiple Access

OLoS Linha de Visada Obstruída - Obstructed Line of Sight

OPEX Despesa de Operação - Operational Expenditure

PA Amplificador de Potência de Rádio-Frequência - Power Amplifier

PAPR Razão entre Potência Máxima e Média - Peak to Average Power Ratio

PL Perda de Percurso - Path-Loss

PSR Taxa de Sucesso de Pacote - Package Success Rate

QoS Qualidade de Serviço - Quality of Service

RAN Rede de Acesso aos Recursos de Rádio - Radio Access Network 
RO Ordenação de Relays - Relay Ordering

RS Estação Retransmissora - Relay Station

RX Receptor - Receiver

SA Recozimento Simulado - Simulated Annealing

SC-FDMA FDMA de Portadora Única - Single Carrier FDMA

SE $\quad$ Eficiência Espectral - Spectral Efficiency

SER Taxa de Erro de Símbolo - Symbol Error Rate

SF $\quad$ Encurta e Transmite - Shorten and Forward

SINR Relação Sinal-Interferência mais Ruído - Signal to Interference plus Noise Ratio

SMC Sequências de Máximo Comprimento - Maximum Length Sequence

STR Transmissão e Recepção Simultânea - Simultaneous Transmit and Receive

TDD Duplexação por Divisão de Tempo - Time-Division Duplexing

TDMA Múltiplo Acesso por Divisão de Tempo - Time Division Multiple Access

TIPSA Two-Iteration Power and Subcarrier Allocation

TIPSA-WA TIPSA Without Adjustment

TR Relatório Técnico - Technical Report

TTR Transmissão e Recepção por Divisão de Tempo - Time-division Transmit and Receive

TX Transmissor - Transmitter

WiMAX Worldwide Interoperability for Microwave Access

WLAN Rede de Área Local Sem Fio - Wireless Local Area Network 


\section{LISTA DE NOTAÇÕES}

\section{Definição de variáveis}

$k, \gamma, M$

a, A

$\mathcal{A}$

$A[\cdot]$

Escalar, caractere em itálico

Vetor ou matriz, caractere em negrito

Conjunto, caractere maiúsculo estilizado

Variável no domínio da frequência, caractere maiúsculo e acompanhado de colchetes

\section{Operadores}

$\begin{array}{ll}\max (\cdot) & \text { Retorna o maior elemento do argumento } \\ \min (\cdot) & \text { Retorna o menor elemento do argumento } \\ \max .(\cdot) & \text { Operador maximização do argumento } \\ \min .(\cdot) & \text { Operador minimização argumento } \\ \underset{a \in A}{\arg \max .[\cdot]} & \text { Elemento do conjunto } A \text { que maximiza o argumento } \\ \underset{a \in A}{\arg \min .[\cdot]} & \text { Elemento do conjunto } A \text { que minimiza o argumento } \\ \overline{[\cdot]} & \text { Valor médio do argumento } \\ \mathbb{E}\{\cdot\} & \text { Operador esperança estatística } \\ * & \text { Operador convolução linear } \\ \otimes & \text { Operador convolução circular } \\ |a| & \text { Operador módulo (valor absoluto) } \\ |\mathbf{a}| & \text { Cardinalidade do vetor a } \\ \text { FFT }\{\cdot\} & \text { Transformada rápida de Fourier do argumento }\end{array}$

\section{Índices sobrescritos}

$[\cdot]^{\varpi} \quad$ Argumento em relação ao índice $\varpi$, que representa os protocolos AF ou DF

$[\cdot]^{\varpi, 1 \mathrm{~h}} \quad$ Argumento em relação ao índice $\varpi$, que representa os protocolos AF ou DF, para o link MS-RS

$[\cdot]^{\varpi, 2 \mathrm{~h}} \quad$ Argumento em relação ao índice $\varpi$, que representa os protocolos AF ou DF, para o link RS-BS

$[\cdot]^{*},[\cdot]^{*,(\cdot)} \quad$ Argumento ótimo

\section{Índices subscritos}

$[\cdot]_{n} \quad$ Argumento em relação à $n$-ésima subportadora 
$[\cdot]_{k, n}$

$[\cdot]_{k, 0}$

$[\cdot]_{k, l}$

$[\cdot]_{n, 0}$

$[\cdot]_{n, l}$

$[\cdot]_{k, n, 0}$

$[\cdot]_{k, n, l}$

Argumento em relação à $k$-ésima MS e $n$-ésima subportadora da BS (quando em modo não-cooperativo) ou em relação à $k$-ésima MS e $n$-ésima subportadora (nos demais casos)

Argumento em relação à $k$-ésima MS e a BS

Argumento em relação à $k$-ésima MS e a l-ésima RS

Argumento em relação à $n$-ésima subportadora da BS

Argumento em relação à $n$-ésima subportadora da l-ésima RS

Argumento em relação à $k$-ésima MS e $n$-ésima subportadora da BS

Argumento em relação à $k$-ésima MS e $n$-ésima subportadora da l-ésima RS 


\section{LISTA DE SÍMBOLOS}

$\beta_{k, n, l} \quad$ Fator de amplificação do protocolo AF na l-ésima RS e $n$-ésima subportadora

\%. Relação sinal-interferência mais ruído (SINR) em relação aos índices

$\gamma^{\text {th }} \quad$ Threshold de SINR para os protocolos de retransmissão seletivos

$\quad$ : $\quad$ Relação portadora-interferência mais ruído (CINR) em relação aos índices

$\Delta_{\theta} \quad$ Incremento para a discretização dos ângulos candidatos para implantação das RSs

$\Delta_{d} \quad$ Incremento entre duas distâncias candidatas para implantação das RSs

$\Delta_{t}^{1 \mathrm{~h}} \quad$ Duração do slot temporal para o primeiro salto, i.e., MS-RS

$\Delta_{t}^{2 \mathrm{~h}} \quad$ Duração do slot temporal para o segundo salto, i.e., RS-BS

$\Delta_{t}^{\text {dir }} \quad$ Duração do slot temporal para transmissão direta, i.e., MS-BS

$\zeta, \zeta(\gamma) \quad$ Eficiência espectral

$\zeta^{\mathrm{EE}} \quad$ SE obtida no ponto de máxima EE

$\zeta^{\max } \quad$ Máxima SE do sistema

$\eta$ Ruído de fundo adicionado por receptor, canal e transmissor em relação ao índice

$\boldsymbol{\eta} \quad$ Vetor de amostras de ruído de fundo no domínio do tempo

$\boldsymbol{\theta} \quad$ Vetor de ângulos candidatos para discretização da implantação das RSs

$\theta_{l} \quad$ Ângulo de instalação da $l$-ésima RS

$\Lambda \quad$ Gap entre a máxima SE do sistema e a SE obtida no ponto de máxima EE

$\boldsymbol{\lambda} \quad$ Matriz de alocação de subportadoras

$\lambda_{k, n} \quad$ Indicador da alocação da $n$-ésima subportadora à $k$-ésima MS

$\xi \quad$ Eficiência energética do sistema em relação ao índice 


\begin{tabular}{|c|c|}
\hline$\xi_{k}$ & Eficiência energética da $k$-ésima MS em relação ao índice \\
\hline$\varrho$ & Ineficiência do amplificador de potência do transmissor \\
\hline$\varrho_{k}$ & Ineficiência do amplificador de potência da $k$-ésima MS \\
\hline$\varrho_{r_{l}}$ & Ineficiência do amplificador de potência da $l$-ésima RS \\
\hline$\sigma^{2}$ & Potência do ruído de fundo em relação ao índice \\
\hline$\varsigma_{k, l}$ & $\begin{array}{l}\text { Fração da potência de circuitaria da } l \text {-ésima RS dispendida para atender } \\
\text { a } k \text {-ésima MS }\end{array}$ \\
\hline$\alpha_{\max }$ & Delay spread \\
\hline$\Phi[n]$ & Resposta em frequência do ruído de fundo na $n$-ésima subportadora \\
\hline$\psi$ & Matriz de alocação de dispositivos receptores \\
\hline$\tau$ & $\begin{array}{l}\text { Vetor de multiplicadores de Lagrange associados à restrição de potência } \\
\text { máxima das MSs }\end{array}$ \\
\hline$v$ & $\begin{array}{l}\text { Vetor de multiplicadores de Lagrange associados à restrição de unici- } \\
\text { dade da alocação de subportadoras }\end{array}$ \\
\hline$\nu$ & $\begin{array}{l}\text { Vetor de multiplicadores de Lagrange associados à restrição de potência } \\
\text { máxima das RSs }\end{array}$ \\
\hline$\psi_{k, l}$ & Indicador da alocação da $k$-ésima MS ao $l$-ésimo dispositivo receptor \\
\hline$\varepsilon_{(.)}$ & Erro de convergência em relação ao argumento \\
\hline$\varepsilon_{(.)}^{\max }$ & Erro de convergência máximo em relação ao argumento \\
\hline$a_{R x}$ & Altura da antena do dispositivo receptor \\
\hline $\mathrm{a}_{\mathrm{TX}}$ & Altura da antena do dispositivo transmissor \\
\hline $\mathrm{a}_{\mathrm{RX}}^{\prime}$ & Altura efetiva da antena do dispositivo receptor \\
\hline $\mathrm{a}_{\mathrm{TX}}^{\prime}$ & Altura efetiva da antena do dispositivo transmissor \\
\hline b & Vetor de sequências de bits a serem transmitidos \\
\hline$\widehat{\mathbf{b}}$ & Vetor de sequências de bits detectadas no receptor \\
\hline$\widehat{\mathbf{b}}_{l}$ & Vetor de sequências de bits detectadas pela $l$-ésima RS \\
\hline 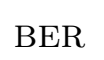 & Máxima taxa de erro de bit tolerada \\
\hline
\end{tabular}


$C_{\mathrm{mc}}$

$C_{\mathrm{sc}}$

d

d

$\mathrm{d}_{\mathrm{BP}}^{\prime}$

$E_{\text {dyn }}$

$E_{\mathrm{T}}$

$f_{c}$

$f_{c, n}$

$f(\gamma)$

$g_{n, l}$

$\left|g_{n, l}\right|^{2}$

g.

$\mathbf{h}$

$h$.

h.

$|h .|^{2}$

$\left|h_{k, n, l, 0}^{\mathrm{DF}}\right|^{2}$

$H[n]$

$\widehat{H}[n]$

Velocidade da luz

Área de cobertura da célula

Capacidade do sistema multi-portadora

Capacidade do sistema de portadora única

Vetor de distâncias candidatas para o problema de implantação das RSs discretizado

Distância entre os dispositivos transmissor e receptor

Distância de transição para modelo de perda de percurso C2 em condição de LoS

Ponderação do termo dinâmico da potência de circuitaria

Energia total consumida no processo de transmissão

Frequência central da portadora

Frequência central da $n$-ésima subportadora

Função-eficiência

Coeficiente complexo de canal entre a $l$-ésima $\mathrm{RS}$ e a BS na $n$-ésima subportadora

Ganho de canal entre a l-ésima RS e a BS na $n$-ésima subportadora

Termo referente ao desvanecimento rápido em $g$.

Vetor de coeficientes de canal no domínio do tempo

Coeficiente complexo de canal em relação ao índice

Termo referente ao desvanecimento rápido em $h$.

Ganho de canal em relação ao índice

Ganho de canal equivalente aos dois saltos para a $k$-ésima MS se comunicando através da $l$-ésima RS com a BS na $n$-ésima subportadora com protocolo DF

Coeficiente complexo de canal da $n$-ésima subportadora no domínio da frequência

Estimativa de canal na $n$-ésima subportadora no domínio da frequência 


\begin{tabular}{|c|c|}
\hline$\widehat{H}_{l}[n]$ & $\begin{array}{l}\text { Estimativa de canal na } n \text {-ésima subportadora da l-ésima RS no domínio } \\
\text { da frequência }\end{array}$ \\
\hline$r$ : & Gap de SINR para os índices \\
\hline$K$ & Número de usuários ativos \\
\hline$L$ & Número de bits de informação por pacote \\
\hline$\ell$. & $\begin{array}{l}\text { Fração de um pacote de bits correspondente a bits de informação, em } \\
\text { relação ao índice }\end{array}$ \\
\hline$M$ & Número de bits em um pacote \\
\hline$N$ & Número de subportadoras \\
\hline$N_{\text {bits }}$ & Número de bits de informação efetivamente recebidos \\
\hline$N_{\mathrm{cp}}$ & Comprimento do prefixo cíclico \\
\hline$N_{o}$ & Densidade espectral de potência do ruído AWGN \\
\hline$N_{\mathrm{RS}}$ & Número de estações retransmissoras instaladas \\
\hline$p$ & Potência de transmissão em relação ao índice \\
\hline$p^{\text {th }}$ & $\begin{array}{l}\text { Limiar de potência que define se a cópia recebida de um sinal é signi- } \\
\text { ficativa ou não }\end{array}$ \\
\hline$p_{\text {st }}$ & Termo de potência estático relativo à potência de circuitaria \\
\hline$P_{\mathrm{T}}$ & Potência total consumida no processo de transmissão \\
\hline$P_{n, l}$ & Potência do sinal recebido na $n$-ésima subportadora da l-ésima RS \\
\hline$p_{c}$ & Potência de circuitaria considerando apenas termos constantes \\
\hline$p_{c}(r)$ & $\begin{array}{l}\text { Potência de circuitaria com termo dinâmico em função da taxa de da- } \\
\text { dos, } r\end{array}$ \\
\hline$p_{c, k}$ & Potência de circuitaria da $k$-ésima MS \\
\hline$p_{c, r_{l}}^{\varpi}$ & Potência de circuitaria da l-ésima RS utilizando protocolo AF ou DF \\
\hline $\mathbf{P}$ & Matriz de alocação de potência de transmissão das MSs \\
\hline $\mathbf{P}_{r}$ & Matriz de alocação de potência das RSs \\
\hline$p_{k}^{\max }$ & Potência máxima de transmissão para a $k$-ésima MS \\
\hline
\end{tabular}




\begin{tabular}{|c|c|}
\hline$p_{r_{l}}^{\max }$ & Potência máxima de transmissão na l-ésima RS \\
\hline PL. & Termo referente à perda de percurso em $h_{(.)}$ou $g_{(.)}$ \\
\hline $\mathrm{PL}_{\mathrm{LoS}}$ & Modelo de perda de percurso C2 com LoS, em dB \\
\hline $\mathrm{PL}_{\mathrm{NLOS}}$ & Modelo de perda de percurso C2 sem LoS, em dB \\
\hline $\operatorname{Pr}^{\mathrm{LoS}}$ & $\begin{array}{l}\text { Probabilidade de comunicação LoS para o modelo de perda de percurso } \\
\text { C2 }\end{array}$ \\
\hline$q_{(.)}^{(\cdot)}$ & Parâmetro do algoritmo de Dinkelbach em relação aos argumentos \\
\hline$r:, r(\gamma)$ & Taxa de dados, de acordo com a equação de capacidade de Shannon \\
\hline$r_{\text {fix }}$ & Taxa de dados fixa do sistema \\
\hline$R_{\text {liq }}$ & Taxa líquida de dados do sistema \\
\hline$r_{k}^{\min }$ & Taxa mínima para o atendimento dos requisitos de QoS \\
\hline$R$ & Raio da célula \\
\hline$T_{s}$ & Período de símbolo \\
\hline$T_{s, n}$ & Período de símbolo da $n$-ésima subportadora \\
\hline$v$ & $\begin{array}{l}\text { Número de cópias do sinal transmitido devido à propagação multiper- } \\
\text { curso }\end{array}$ \\
\hline$W$ & Largura de banda disponível \\
\hline $\mathrm{w}$ & Largura de banda disponível em cada subportadora \\
\hline$W_{c}$ & Banda de coerência \\
\hline $\mathbf{x}$ & Vetor de amostras do sinal transmitido no domínio do tempo \\
\hline $\mathbf{x}_{\mathrm{cp}}$ & Vetor de amostras do sinal transmitido estendido pelo prefixo cíclico \\
\hline $\mathbf{x}_{l}$ & Vetor de amostras do sinal transmitido pela $l$-ésima RS \\
\hline$X[n]$ & Símbolo transmitido na $n$-ésima subportadora no domínio da frequência \\
\hline$\widehat{X}[n]$ & Estimativa hard do símbolo transmitido na $n$-ésima subportadora \\
\hline$\widetilde{X}_{l}[n]$ & $\begin{array}{l}\text { Estimativa soft do símbolo recebido na } n \text {-ésima subportadora da } l \text { - } \\
\text { ésima RS }\end{array}$ \\
\hline $\mathrm{x}$. & Símbolo transmitido em relação ao índice \\
\hline
\end{tabular}


$\hat{\mathrm{x}}_{k, n, l} \quad$ Símbolo transmitido pela $k$-ésima MS na $n$-ésima subportadora detectado pela l-ésima RS utilizando protocolo DF

$\mathcal{X}_{n} \quad$ Conjunto dos símbolos da constelação utilizada na n-ésima subportadora

y. $\quad$ Sinal recebido em relação aos índices

$y_{n, l}^{\prime \varpi, 1 \mathrm{~h}} \quad$ Sinal recebido na $n$-ésima subportadora pela $l$-ésima RS após a remoção de MSs não alocadas

$\mathbf{y} \quad$ Vetor de amostras do sinal recebido no domínio do tempo

$\mathbf{y}_{\mathrm{cp}} \quad$ Vetor de amostras do sinal recebido estendido pelo prefixo cíclico no domínio do tempo

$\mathbf{y}_{l} \quad$ Vetor de amostras do sinal recebido na l-ésima RS

$Y[n] \quad$ Sinal recebido na $n$-ésima subportadora no domínio da frequência

$Y_{l}[n] \quad$ Sinal recebido na $n$-ésima subportadora da $l$-ésima RS 


\section{SUMÁRIO}

INTRODUÇÃO $\ldots \ldots \ldots \ldots \ldots \ldots \ldots \ldots$

1.1 Conceitos Introdutórios e Motivação . . . . . . . . . . . . . 1

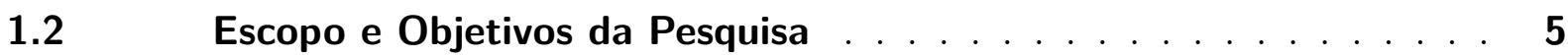

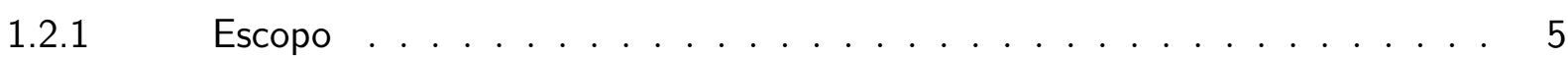

1.2 .2 Objetivos ...................... 6

$1.3 \quad$ Organização do Texto $\ldots \ldots \ldots \ldots \ldots \ldots$

1.4 Resumo das Publicações Geradas . . . . . . . . . . . . . 8

1.4.1 Publicações Diretamente Associadas ao Tema . . . . . . . . . . . . . . . 8

1.4.2 Publicações Indiretamente Associadas ao Tema . . . . . . . . . . . . . . 9

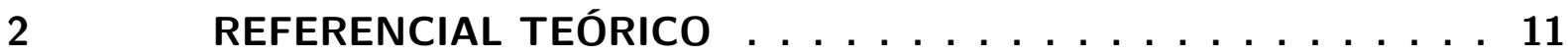

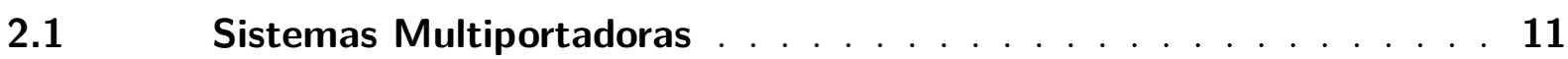

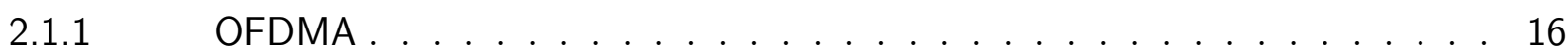

$2.2 \quad$ Redes Cooperativas . . . . . . . . . . . . . . . . 18

2.2.1 Parâmetros de Redes Cooperativas em Sistemas 4G . . . . . . . . . . . . 27

$2.3 \quad$ Eficiência Energética . . . . . . . . . . . . . . . . . . 28

2.3.1 Compromisso EE-SE . . . . . . . . . . . . . . . . . . . . . 32

2.4 Técnicas de Otimização em Redes Cooperativas . . . . . . . . . . . . 34

2.4.1 Implantação de RSs . . . . . . . . . . . . . . . . . . . . 35

2.4.2 Protocolos de Retransmissão . . . . . . . . . . . . . . . . . . . . 38

2.4.3 Modos de Duplexação . . . . . . . . . . . . . . . . . . . . . . 40

2.4 .4 Seleção de RSs . . . . . . . . . . . . . . . . . . . . . 43

3 DESCRIÇÃO DO SISTEMA E ABORDAGEM DE ALOCAÇÃO BA-

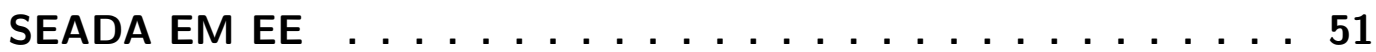

3.1 Definição do Modelo de Sistema Empregado . . . . . . . . . . . 51

3.2 Descrição Matemática para Modos Não-Cooperativo e Cooperativo 55

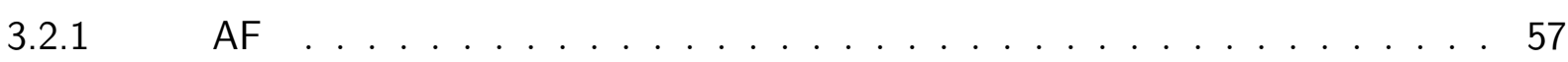

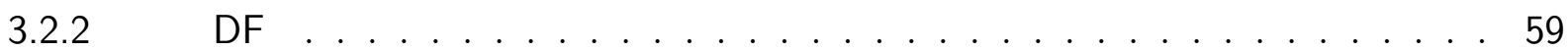

3.3 Descrição do Modelo de Eficiência Energética . . . . . . . . . . . 62

3.3.1 EE para o Modo Cooperativo . . . . . . . . . . . . . . . . 62

3.3.2 EE para o Modo Não-Cooperativo . . . . . . . . . . . . 63

4 ALOCAÇÃO DE RECURSOS PARA UPLINK NÃO COOPERATIVO 65

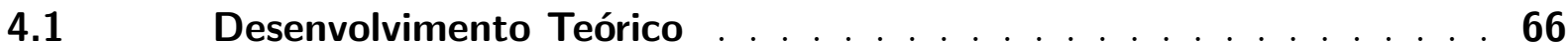

$4.2 \quad$ Implementação Computacional Robusta e Efetiva . . . . . . . . 71 
4.2.1 Inicialização de Variáveis . . . . . . . . . . . . . . . . 72

4.2.2 Violação da Restrição de Potência . . . . . . . . . . . . . . . . . . . 73

$4.2 .3 \quad$ Superestimação de $\tau_{k} \ldots \ldots \ldots \ldots \ldots$. . . . . . . . . . . . . . . . .

4.2.4 Soluções Sub-ótimas . . . . . . . . . . . . . . . . . . . . . 76

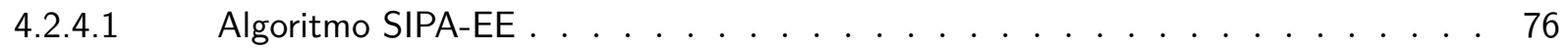

4.2.4.2 Algoritmo TIPSA-EE . . . . . . . . . . . . . . . . 77

4.2.5 Complexidade dos Algoritmos Propostos . . . . . . . . . . . . . . . . 79

$4.3 \quad$ Resultados Numéricos . . . . . . . . . . . . . . . . . . 80

4.3.1 Otimização da Variável de Atualização $\phi_{k} \ldots \ldots$. . . . . . . . . . . 81

4.3.2 Validação do Algoritmo DKB+LDD-EE . . . . . . . . . . . . . . 87

4.3.3 Resultados para Maximização de EE . . . . . . . . . . . . . . . . 88

4.3.4 Análise de Complexidade . . . . . . . . . . . . . . . . . . . . . . 91

4.3.5 Comparação com Implementações Anteriores . . . . . . . . . . . . . . . . 94

5 ALOCAÇÃO DE RECURSOS COM FAIRNESS PARA UPLINK NÃO-COOPERATIVO . . . . . . . . . . . . . . . . . . . . . 97

$5.1 \quad$ Discussão de Funções-Utilidade . . . . . . . . . . . . . . . . . 98

5.2 Relaxação do Problema de Otimização . . . . . . . . . . . . . . . . 100

5.3 Solução para Somatório de Logaritmos . . . . . . . . . . . . . . . . 100

5.4 Solução para produtório . . . . . . . . . . . . . . . 110

6 ALOCAÇÃO DE RECURSOS COM FAIRNESS E ESTAÇÕES RETRANSMISSORAS . . . . . . . . . . . . . . . . 117

6.1 Expressões de Taxa de Dados e Considerações . . . . . . . . . . . 119

6.2 Restrições do Problema de Alocação . . . . . . . . . . . . . . . . 120

6.3 Relaxação do Problema . . . . . . . . . . . . . . . . 121

6.4 Solução via Somatório de Logaritmos . . . . . . . . . . . . . . . . . 123

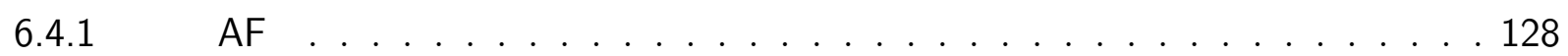

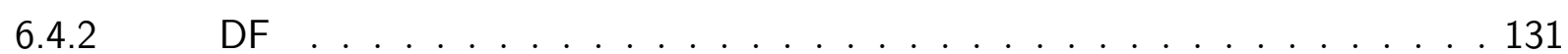

6.5 Solução via Produtório . . . . . . . . . . . . . . . . . . 135

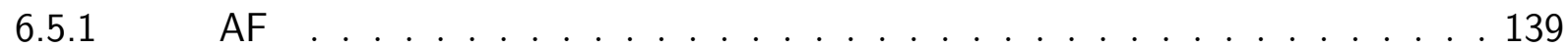

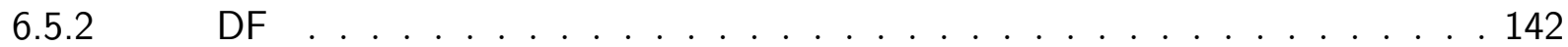

7 IMPLEMENTAÇÃO COMPUTACIONAL DOS PROBLEMAS COM FAIRNESS PROPORCIONAL . . . . . . . . . . . . . 147

7.1 Limitações de Implementação com Somatório de Logaritmos sem RSs

7.1.1 Necessidade de Calcular Conjuntamente a Alocação de Potência em Todas as $N$ Subportadoras da $k$-ésima MS 
7.1.2 Necessidade de Calcular Conjuntamente Todas as $N$ Métricas de Alocação de Subportadoras da $k$-ésima MS . . . . . . . . . . . . . . . . . . . . . 148

7.1.3 Custo Computacional da Função W de Lambert . . . . . . . . . . . . . . . 148

7.1.4 Determinação de $\lambda_{k, n}$ a partir de $s_{k, n} \ldots \ldots$. . . . . . . . . 149

7.1.5 MSs sem Subportadoras e Discretização da Alocação de Subportadoras . 149

7.1.6 Oscilação e Erros na Alocação de Subportadoras . . . . . . . . . . . . . . 150

7.2 Limitações de Implementação com Produtório sem RSs . . . . . . . 151

7.2.1 Acoplamento das MSs no Cômputo das Alocações de Potência e Subportadoras . . . . . . . . . . . . . . . . . . . . . 151

7.2.2 Solução Distribuída e Custo Computacional . . . . . . . . . . . . . . . . 152

7.2.3 Inicialização de Variáveis . . . . . . . . . . . . . . . . . . 152

7.2.4 Evolução da Métrica de Alocação de Subportadoras e dos Multiplicadores de Lagrange . . . . . . . . . . . . . . . . . . . . . . . . . . . 153

7.2.5 Controle de Convergência do Loop DKB . . . . . . . . . . . . . . . . . . 153

7.3 Limitações de Implementação para Fairness Proporcional em Modo Cooperativo . . . . . . . . . . . . . . . . . . . . . . . . 154

7.3.1 Solução por Somatório de Logaritmos . . . . . . . . . . . . . . . . . . . . 154

7.3 .2 Solução por Produtório . . . . . . . . . . . . . . . . 156

7.4 Solução Híbrida para Maximização de EE com Fairness Proporcional sem RSs . . . . . . . . . . . . . . . . . . . . . . . . . . . 157

7.4.1 Simplificação da Alocação de Potência . . . . . . . . . . . . . . . 158

7.4.2 Modificações na Alocação de Subportadoras . . . . . . . . . . . . . . . 163

7.4.3 Controle de Convergência . . . . . . . . . . . . . . . 166

7.5 Definição dos Valores Iniciais . . . . . . . . . . . . . . . 167

7.6 Resultados Numéricos Parciais . . . . . . . . . . . . . . . . 170

7.6.1 Estratégia de Inicialização de Variáveis . . . . . . . . . . . . . . . 170

7.6.2 Resultados Parciais Obtidos com o Algoritmo Híbrido . . . . . . . . . . . . 172

7.7 Solução Híbrida para Modo Cooperativo com Fairness Proporcional 179

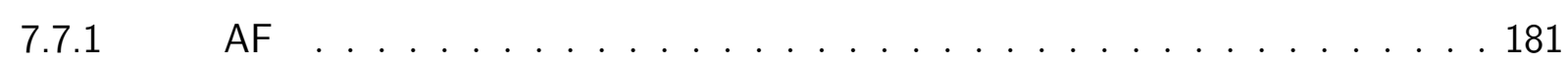

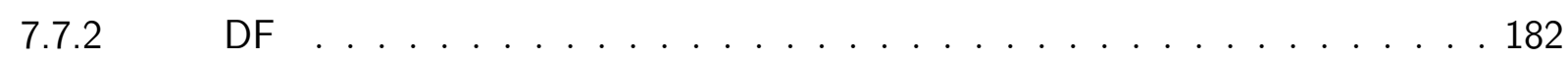

8 CONCLUSÕES E TRABALHOS FUTUROS . . . . . . . . 185

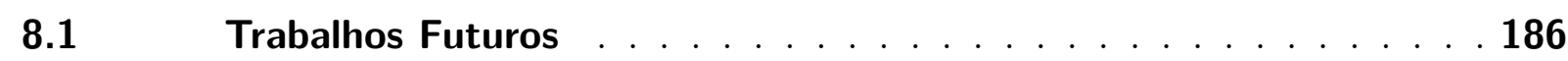

REFERÊNCIAS . . . . . . . . . . . . . . . . 187

ANEXO A - DEMONSTRAÇÃO DA REGRA DE SELEÇÃO DE RSS . . . . . . . . . . . . . . . 197

ANEXO B - DEMONSTRAÇÃO DOS TEOREMAS E LEMAS PRO-

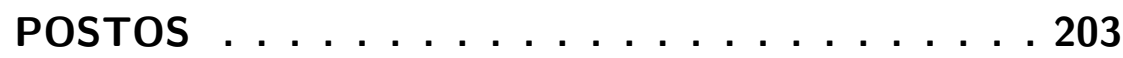


B.1 Prova do Teorema $4.1 \ldots \ldots \ldots 2 \ldots \ldots \ldots$

B.2 Prova do Teorema $5.1 \ldots \ldots \ldots 4 \ldots \ldots \ldots$

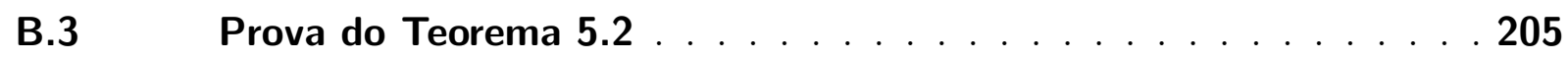

B.4 Prova do Teorema $6.1 \ldots \ldots \ldots \ldots$

B.4.1 Protocolo AF . . . . . . . . . . . . . . . . . . . . . 206

B.4.2 Protocolo DF . . . . . . . . . . . . . . . . 208

B.5 Prova do Teorema $6.2 \ldots \ldots \ldots 9 . \ldots \ldots \ldots$

B.5.1 Protocolo AF . . . . . . . . . . . . . . . . . . . . . . . . 210

B.5.2 Protocolo DF . . . . . . . . . . . . . . . . . . 211

ANEXO C - PROPORÇÕES DE POTÊNCIA PARA PROTOCOLO AF . . . . . . . . . . . . . 213

C.1 Determinação da Proporção de Potência em Protocolo AF para Somatório de Logaritmos . . . . . . . . . . . . . . . . . . . 213

C.2 Determinação da Proporção de Potência para AF para Produtório . 217

C.3 Cálculo da Proporção de Potência para AF para Método Híbrido . . 219

ANEXO D - FERRAMENTAIS UTILIZADOS NA TESE . . . . . 221

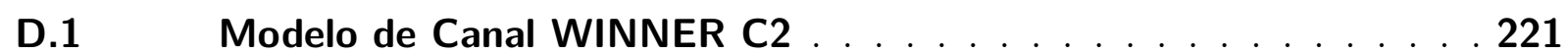

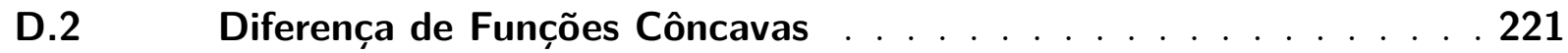




\section{INTRODUÇÃO}

Este capítulo introduz os conceitos básicos referentes às técnicas adotadas, objetos e objetivos de pesquisa, além de elencar as principais contribuições e análises desenvolvidas e descrever brevemente a estruturação desta tese de doutorado.

\subsection{Conceitos Introdutórios e Motivação}

Sistemas de comunicação móvel celular passaram por uma grande transformação de paradigma desde os primeiros sistemas comerciais até os padrões mais recentes para sistemas de quarta geração (4G), como LTE-A (Long Term Evolution - Advanced) e WiMAX (Worldwide Interoperability for Microwave Access). Inicialmente planejados para ofertar apenas serviços de comunicação de voz, sistemas celulares modernos tratam principalmente de tráfego de dados, sendo o serviço de voz apenas mais um dos serviços providos [1]. Observa-se também nesse período a significativa redução no custo para os usuários, em termos de equipamentos e acesso, de modo que tais sistemas estão cada vez mais acessíveis e massificados, e a crescente oferta de aplicações e serviços móveis, que aumentam constantemente a quantidade de dados trafegados e impulsionam o desenvolvimento de novos sistemas que possam atender tal demanda [2].

No relatório técnico (TR) M.2134 [3] do ITU (International Telecommunication Union) são definidos os requisitos de sistemas IMT-A (International Mobile TelecommunicationsAdvanced), que são a base dos sistemas celulares 4G. Entre os principais desafios para os grupos padronizadores, encontram-se:

- suporte a uma grande variedade de serviços e aplicações;

- serviços móveis de alta qualidade;

- maior taxa de dados para suportar serviços e aplicações avançados, citando-se como alvo taxa de dados de 100 megabits por segundo (Mbps) para cenários de alta mobilidade, i.e., mobilidade veicular, e 1 gigabit por segundo (Gbps) em baixa mobilidade.

Além dos requisitos descritos no TR M.2134, outro desafio para qualquer sistema de comunicação sem fio é o canal de comunicação. Dois dos principais limitantes em canais em fio são a perda de percurso (PL), proporcional à distância entre os dispositivos e de grande relevância em ambientes urbanos, e o desvanecimento multipercurso, que pode atenuar o sinal transmitido em dezenas de decibéis [4]. Apesar de presentes até mesmo em sistemas de comunicação com fio, esses dois componentes são de grande impacto em 
sistemas sem fio e não podem ser anulados, de modo que técnicas que possam mitigar tais efeitos são fundamentais no projeto de sistemas de comunicação eficientes.

Os sistemas LTE-A, padronizado pelo 3GPP (3rd Generation Partnership Project), e WiMAX, padronizado pelo IEEE (Institute of Electrical and Electronics Engineers), empregam diversas técnicas para se adequar aos pontos levantados, tais como utilização de sistemas multiportadoras, como por exemplo multiplexação por divisão ortogonal de frequência (OFDM) e múltiplo acesso por divisão ortogonal de frequência (OFDMA), múltiplas antenas para recepção e/ou transmissão, modulação e codificação adaptativa (AMC), aproveitamento de diversidade espacial, multiusuário e em frequência, entre outras $[4,5,6]$. Porém, para os efeitos de perda de percurso e o número de usuários cobertos, existem limites que exigem a instalação de mais estações rádio-base (BSs) por parte dos provedores de serviço, cujo custo pode não compensar o ganho obtido, demonstrando um compromisso entre a satisfação dos usuários móveis, a satisfação dos provedores de serviço e os custos para ambos.

Nesse cenário, o paradigma de redes heterogêneas se mostra uma abordagem interessante, pela implantação de células com menor área de cobertura em locais específicos da macro-célula original, nos quais a cobertura apenas pela BS se mostra insuficiente [7]. Em geral, os equipamentos instalados para operar essas células de menor cobertura possuem custo de aquisição, operação e instalação reduzidos, intervindo de maneira mais precisa nos problemas de cobertura [8]. A utilização de redes heterogêneas é prevista também para os sistemas de quinta geração $(5 \mathrm{G})$, conforme apontado em [9], para otimização de capacidade e eficiência energética (EE). Dentre as possíveis abordagens para a implementação de redes heterogêneas, a instalação de estações retransmissoras (RSs), ou relays, é interessante por não exigir ligação dedicada com a BS ou outros equipamentos do sistema, de modo que a comunicação é feita também pelo canal sem fio, e por possuir custo de aquisição e operação menores que equipamentos como micro-BSs, dado que possuem menos funcionalidades $[10,11]$.

A segunda vantagem na utilização de RSs é a flexibilidade de instalação. Conforme descrito em [12], até mesmo estações móveis (MSs) podem ser utilizadas como RSs para outras MSs. Essa abordagem é apontada no documento de padronização do sistema WiMAX 802.16.1a [13] para sistemas de alta confiabilidade, de modo que MSs podem servir de RS ou até mesmo de BS para outras MSs. No caso de sistemas LTE-A, o TR 36.836 [14] descreve a possibilidade de instalar RSs em veículos de transporte público de alta velocidade, reduzindo os efeitos da mobilidade para as MSs, tais como efeito Doppler e elevada quantidade de handovers, transferindo para a RS a implementação de técnicas que mitiguem tais efeitos. Além disso, relays podem ser instalados em estruturas que recebam grande quantidade de pessoas apenas em poucos momentos, como por exemplo estádios de futebol, sendo desligados quando não utilizados [7].

Apesar das vantagens listadas, a utilização de relays possui uma limitação oriunda de 
uma de suas vantagens: ao não contar com estrutura dedicada de conexão com uma BS, as retransmissões devem ser realizadas com o mesmo recurso espectral e temporal disponível às MSs, ou então novos recursos espectrais devem ser adicionados para acomodar os sinais retransmitidos. A primeira técnica pode reduzir a capacidade do sistema, uma vez que recursos são gastos com sinais que são redundantes [8], enquanto a segunda afeta fundamentalmente a eficiência espectral (SE) do sistema, pois em parte do recurso espectral apenas redundância é transmitida. Tal limitação em relação à conexão com a BS ainda gera uma segunda dificuldade: como a transmissão das MSs é dividida em dois ou mais saltos (hops), ao menos todos os usuários que utilizam relays precisam manter requisitos de capacidade mais elevados no primeiro salto para que, ao final da transmissão, a capacidade do sistema seja mantida [15], o que pode impedir a utilização de RSs a partir de uma determinada capacidade alvo; em [16], mostra-se que a partir de uma determinada eficiência espectral mínima a utilização de RSs não mais otimiza a métrica analisada.

Tais limitações resultam em um campo bastante interessante de análise, pois os sistemas de quarta geração descrevem a utilização de relays como ferramenta para otimizar o atendimento das MSs, porém os modelos descritos nos padrões de LTE-A e WiMAX são ainda bastante simples, de modo que há espaço significativo para otimizações [17]. Por exemplo, o TR 36.814 do 3GPP [18] define dois tipos de RSs para LTE-A, sendo garantida ao menos a especificação do tipo-1 nos modos half-duplex inband e full-duplex outband e apenas citando a possibilidade do modo full-duplex inband. Além do modo de duplexação, algoritmos de alocação de recursos e de implantação das estações em termos de performance/custo financeiro podem ser explorados, e também combinações das técnicas já descritas nos documentos de padronização. Outro ponto de interesse está na apresentação de Dino Flore, chairman do 3GPP RAN (Radio Access Network) [19], em que se destaca que técnicas que melhorem a capacidade do sistema e a performance na borda da célula são o foco para o grupo que especifica o RAN, sendo principalmente a segunda uma das grandes funcionalidades associadas à utilização de relays. Finalmente, espera-se que com os sistemas $5 \mathrm{G}$ técnicas ainda mais sofisticadas para RSs sejam utilizadas, como multi-hop, RSs móveis e MSs operando como RSs [20].

Além da utilização de relays, outro ponto que merece consideração em sistemas de quarta geração é o consumo de potência decorrente do aumento de capacidade, que possui implicações para usuários, provedores de serviço e também para o meio ambiente. Do ponto de vista dos usuários, os dispositivos móveis possuem pouca autonomia ao utilizarem os serviços de comunicação móvel, necessitando de recarga de energia em intervalos de tempo menores, dado que a capacidade das baterias não acompanha a evolução e complexidade dos serviços providos [21]. Em relação aos operadores, aponta-se em [22] que cerca de $50 \%$ das despesas gerais dos operadores móveis se devem apenas ao consumo de energia com as BSs, tanto em termos de potência de transmissão quanto de circuitaria. A implicação ambiental se dá pela poluição gerada na produção da energia consumida e 
na radiação eletromagnética gerada: de acordo com [22] e [23], 2\% da emissão global de $\mathrm{CO}_{2}$ e $3 \%$ do consumo global de energia são causados pela tecnologia de comunicação e informação.

Assim sendo, é fundamental a adoção de métricas que ponderem a capacidade dos sistemas em relação à potência que deve ser gasta para obtê-la, como é o caso da métrica de eficiência energética [24, 25, 26]. A eficiência energética é dada pela razão entre a quantidade de bits de informação efetivamente recebidos/detectados em um determinado período de tempo e a quantidade de energia necessária para transmitir esses bits, apontando quão eficientemente o sistema é capaz de transformar os recursos energéticos em informação efetivamente detectada, alterando-se o balanço entre maximização de capacidade e consumo energético [16]. Por essa razão, tal metodologia ${ }^{1}$ deve ser analisada também em relação aos requisitos mínimos de capacidade e/ou qualidade de serviço (QoS), pois de nada adianta propor uma abordagem de alocação de recursos que não seja capaz de atender aos requisitos de sistema [26, 27, 28]. Assim, a análise do compromisso entre a maximização de eficiência energética e os requisitos de capacidade e/ou QoS, como a SE, é essencial [29].

A importância da eficiência energética pode ser vista também através do release 12 para LTE-A, que inclui em seu overview de março de 2014 [6] grupos de estudo que buscam métricas, casos de uso e melhorias de sistema que sejam capazes de aumentar a eficiência energética do sistema; vide principalmente os itens 8.8 (UID 600044) e 15.3 (UID 500037). Além desses dois itens, afirma-se em [6] que mesmo que as MSs estejam conectadas a uma fonte de energia, é interessante que o consumo de potência seja reduzido. Conforme descrito em [30], a preocupação com a eficiência energética atinge também os operadores de rede, devido à pressão dos custos com energia, ambiental e governamental, e até mesmo por questões de marketing, ao se colocar o apelo ambiental na decisão de escolha por parte dos usuários.

A pesquisa com ênfase em eficiência energética também é de grande importância para os futuros sistemas 5G. Em [9], afirma-se que é amplamente aceito que os sistemas 5G deverão apresentar um ganho de pelo menos 10 vezes em termos de eficiência energética, mesmo com a previsão de um incremento de 1000 vezes na capacidade do sistema e de 10 vezes na eficiência espectral. Tal preocupação com a eficiência energética em sistemas $5 \mathrm{G}$ pode ser vista também em [31], que destaca a importância de um sistema com projeto conjunto para as eficiências energética e espectral, e com o projeto GreenTouch, que tem como meta aumentar a eficiência energética em sistemas celulares por um fator de 1000 até o ano de 2020, comparando com a EE atingível no ano de 2010 [32].

Assim, a combinação da utilização de relays otimizados e de algoritmos de alocação de recursos tendo em vista o incremento da eficiência energética, do compromisso com

1 Segundo o dicionário Caldas Aulete, metodologia é o conjunto de métodos (http://www.aulete.com.br/metodologia). 
métricas de desempenho e/ou QoS bem como o impacto financeiro proporcionado com a adoção de técnicas de green communications constituem uma abordagem de comprovado apelo, com diversas possibilidades de pesquisa e proposição de técnicas relevantes.

\subsection{Escopo e Objetivos da Pesquisa}

A partir do conteúdo apresentado na Seção 1.1, destacam-se os cinco principais conceitos considerados na Tese:

- Eficiência energética: principal métrica de avaliação e otimização descrita neste trabalho;

- Eficiência espectral: métrica escolhida para analisar a vazão do sistema sob o ponto de vista da eficiência energética e também para caracterizar o compromisso entre energia e capacidade do sistema, conforme destacado em [29];

- Redes cooperativas: paradigma de comunicação escolhido para análise e obtenção de EE otimizada, bem como para distribuir tal melhoria sob o ponto de vista da área de cobertura do sistema, principalmente para usuários em áreas de cobertura crítica;

- OFDM(A): modelo de transmissão e múltiplo acesso de interesse neste trabalho, dada a dominância dos esquemas multiportadoras em sistemas 4G;

- Fairness: a partir de resultados numéricos obtidos no decorrer da tese, observouse que a adoção de critérios de fairness era necessário para que o sistema proposto obtivesse maior apelo prático em situações reais, dado que a otimização de EE resultou em concentração de recursos espectrais. Com isso, definir uma métrica de fairness e algoritmos capazes de alocar os recursos sob tal aspecto tornou-se fundamental no contexto sistêmico abordado nesta tese.

\subsubsection{Escopo}

Esta tese desenvolve uma abordagem sistemática dos seguintes aspectos em redes celulares cooperativas baseadas em OFDM e OFDMA:

- implantação de estações retransmissoras fixas;

- topologia de retransmissão em dois saltos, preferencialmente utilizando retransmissão de apoio (supportive relaying);

- algoritmos computacionalmente eficientes para alocação de potência e de subportadoras; 
- análise e proposição de métricas e algoritmos que possam prover fairness aos dispositivos na rede;

Os aspectos listados a seguir, apesar de possibilitarem ganhos em termos de eficiência energética e/ou outras métricas analisadas neste trabalho, não foram abordados nesta tese.

- seleção dinâmica de RSs;

- seleção dinâmica de protocolos de cooperação;

- MIMO (Multiple-Input Multiple-Output), coordenação multiponto (CoMP);

- retransmissão em múltiplos saltos (multi-hop relaying);

- múltiplo acesso em uma subportadora entre usuários móveis ${ }^{2}$;

\subsubsection{Objetivos}

O objetivo geral desta tese é a proposição, análise e caracterização de técnicas que resultem em otimização de eficiência energética e melhor compromisso entre as eficiências energética e espectral, através da utilização de redes cooperativas, com possibilidade de aplicação e utilização em sistemas comerciais de quarta geração ou mesmo de quinta geração.

Para alcançar o objetivo geral foi necessário formular e responder três questões:

- Como obter maior eficiência energética em sistemas cooperativos baseados em OFDM e/ou OFDMA?

- Qual o custo da maior eficiência energética no compromisso EE-SE?

- As técnicas propostas podem ser diretamente adotadas em cenário comercial ou adaptações/simplificações são necessárias?

Considerando o objetivo geral e as três questões formuladas, definiram-se os seguintes objetivos específicos:

1. Desenvolvimento de técnicas que possibilitem aumento sistemático de EE em todo o intervalo factível de SE ou pelo menos em subintervalo(s) de interesse. Conforme mencionado em [31], uma das principais metas no desenvolvimento de sistemas eficientes em energia é aumentar a eficiência energética para todos os valores de eficiência espectral, de modo que em todo e qualquer ponto de operação do sistema haja algum ganho em termos de EE. Analisando os resultados obtidos na dissertação de mestrado do candidato [28] e também na literatura

2 Alguns protocolos de duplexação dos links de acesso e backhaul podem inserir múltiplo acesso nas subportadoras, porém o múltiplo acesso acontece entre uma MS e a BS. 
$[15,31]$, a EE em sistemas cooperativos tende a ser rapidamente reduzida quando se faz necessária uma maior SE. A partir do fato de que sistemas $4 \mathrm{G}$ demandam SEs elevadas, além da garantia de cobertura em toda a célula, desenvolver um conjunto de técnicas que possa resultar em maior EE ao menos em cenários de elevada SE é de claro interesse tecnológico e de estimado valor comercial;

2. Otimização do compromisso entre as eficiências energética e espectral para as técnicas propostas. Em geral, a relação EE-SE é caracterizada inicialmente por uma região em que ambas as figuras de mérito são crescentes, e posteriormente por uma região de redução de EE conforme exige-se maior SE. Assim, é necessário analisar o impacto das técnicas descritas no Objetivo 1 também em relação ao compromisso EE-SE, de modo que o aumento de EE não seja causado apenas pela degradação da SE. Esse objetivo inclui, portanto, a caracterização do compromisso EE-SE e o desenvolvimento de métodos que possam otimizar tal compromisso. A necessidade de elevada SE em sistemas 4G e 5G sobretudo mostra a importância da otimização do compromisso EE-SE;

3. Proposição de soluções de baixa complexidade, e possivelmente distribuídas, para maximização de EE e/ou melhoria do compromisso EE-SE. Dado que o problema de alocação ótima de potência/subportadoras para a maximização de EE tende a resultar em complexidade exponencial em relação ao tamanho do problema [33, 34], busca-se desenvolver soluções quase-ótimas (ou sub-ótimas), porém com reduzida complexidade, as quais possam reunir as vantagens das técnicas propostas e manter a aplicabilidade em sistemas comerciais, ou seja, que possam ser executadas em tempo real. Para que se possa avaliar a qualidade dessas soluções, o primeiro passo quando da proposição de novas técnicas é determinar o desempenho ótimo, mesmo que os algoritmos propostos para obter tal desempenho sejam de implementação impraticável em sistemas comerciais.

\subsection{Organização do Texto}

Após este capítulo introdutório, no Capítulo 2 faz-se uma revisão da literatura das técnicas que são utilizadas neste trabalho, incluindo os conceitos de sistemas multiportadoras, destacando-se a técnica OFDMA, redes cooperativas, eficiência energética e também uma revisão do estado atual dos documentos de padronização para os principais sistemas de comunicação móvel de quarta geração.

No Capítulo 3 define-se o modelo de sistema adotado, determinando-se quais das técnicas descritas no Capítulo 2 são utilizadas e justificando tais escolhas. A partir da definição, as equações que regem o sistema são desenvolvidas e apresenta-se a função de eficiência energética que é utilizada no decorrer do trabalho. 
A partir do equacionamento proposto no Capítulo 3, apresenta-se no Capítulo 4 o problema de otimização que será a base de comparação para as demais propostas: alocação de recursos em ambiente OFDMA não-cooperativo e sem proposição de métrica de fairness. Tal problema, além dos resultados de comparação, lança motivação e justificativas para a busca de algoritmos que considerem algum tipo de fairness em sua formulação, dado que os recursos espectrais se mostraram concentrados em poucas MSs.

A abordagem com fairness, ainda em ambiente não-cooperativo, é apresentada no Capítulo 5. São elaboradas duas formulações matemáticas, bem como os respectivos algoritmos de alocação de recursos necessários à implementação de um modelo capaz de melhor distribuir os recursos entre as MSs.

Já no Capítulo 6, inclui-se o paradigma de redes cooperativas ao problema de alocação de recursos para maximização de EE com fairness proporcional. Apresenta-se o problema sob duas formulações analíticas possíveis, e desenvolve-se, a partir dos ferramentais disponíveis, as equações necessárias para o processo de alocação de potência e subportadoras em MSs e RSs.

No Capítulo 7 discutem-se questões que dificultam uma efetiva implementação computacional das soluções apresentadas nos Capítulos 5 e 6 . Busca-se analisar as situações e apresentar soluções aos problemas analisados. Discute-se também a construção de algoritmos que sejam capazes de superar as limitações elencadas. Dado que alguns dos problemas não foram completamente resolvidos, apresentam-se resultados preliminares que identificaram características associadas à solução com fairness proporcional.

Finalmente, o Capítulo 8 apresenta as principais conclusões desta tese e possíveis direções de pesquisa a serem seguidas no futuro.

A Figura 1.1 apresenta o fluxograma da solução adotada, mostrando os principais componentes dos Capítulos 4 a 7 .

\subsection{Resumo das Publicações Geradas}

Elenca-se a seguir a produção científica direta e indiretamente relacionadas ao desenvolvimento deste trabalho de Doutorado a partir de 2013.

\subsubsection{Publicações Diretamente Associadas ao Tema}

1. Á. R. C. Souza, J. R. A. Amazonas, T. Abrão. Energy Efficiency Maximisation for Cooperative and Non-cooperative OFDMA Cellular Networks A Survey. Artigo publicado na revista Transactions on Emerging Telecommunications Technologies, Vol. 27, Issue 2, Fev. 2016.

2. Á. R. C. Souza, J. R. A. Amazonas, T. Abrão. Power and Subcarrier Allocation Strategies for Energy-Efficient Uplink OFDMA Systems. Publicado no 
Figura 1.1 - Diagrama da solução adotada.

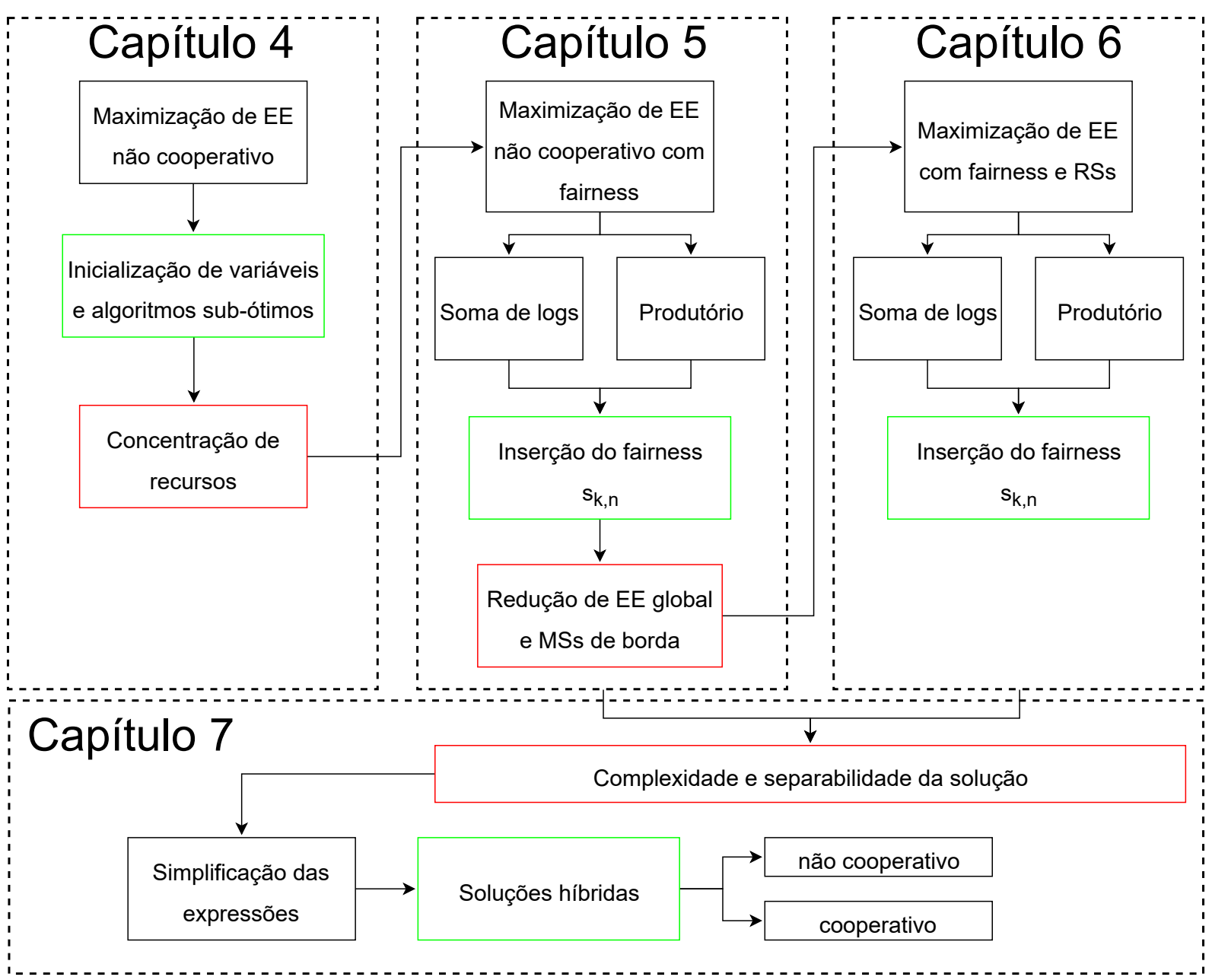

Fonte: o autor

IEEE Journal of Selected Areas in Communications, Vol. 34, No. 12, Dez. 2016.

3. Á. R. C. Souza, J. R. A. Amazonas, T. Abrão. Power and Subcarrier Allocation Strategies for Proportional Fairness Based Energy-Efficient Uplink OFDMA Systems. Em processo de escrita.

4. Á. R. C. Souza, J. R. A. Amazonas, T. Abrão. Power and Subcarrier Allocation Strategies for Proportional Fairness Based Energy-Efficient Uplink OFDMA Systems with Relay Stations. Em processo de escrita.

\subsubsection{Publicações Indiretamente Associadas ao Tema}

1. Á. R. C. Souza, T. Abrão, J. Pérez-Romero, F. Casadevall, L. D. H. Sampaio, P. J. E. Jeszensky. Energy and spectral efficiencies trade-off with filter optimisation in multiple access interference-aware networks. Transactions 
on Emerging Telecommunications Technologies, publicação online, Jun. 2013. ISSN 2161-3915.

2. Á. R. C. Souza, T. Abrão, Interference-limited fixed relaying-aided macrocellular CDMA networks. In: Green Networking and Communications: ICT for Sustentability. Boca Raton, EUA: CRC Press, 2013. p. 165-210. ISBN 9781466568747.

3. L. D. H. Sampaio, A. R. C. Souza, T. Abrão, P. J. E. Jeszensky. Game Theoretic Energy Efficiency Design in MC-CDMA Cooperative Networks. IEEE Sensors Journal, v. 14, p. 3065-3075, Set. 2014. ISSN 1530-437X.

4. L. D. H. Sampaio, A. R. C. Souza, T. Abrão, P. J. E. Jeszensky. Energy efficiency design in MC-CDMA cooperative networks. IEEE 24th PIMRC, p. 207-212, Set. 2013. ISSN 2166-9570. 


\section{REFERENCIAL TEÓRICO}

Este capítulo discute três importantes conceitos que são a base desta tese:

- comunicação por OFDMA;

- redes cooperativas;

- eficiência energética.

Além da caracterização, discutem-se vantagens, limitações e tópicos de interesse associados aos sistemas decorrentes da aplicação desses conceitos, de modo que a definição do modelo de sistema e equacionamento desenvolvidos no Capítulo 3 possuam a devida justificativa e fundamentação teórica.

\subsection{Sistemas Multiportadoras}

Sistemas celulares modernos devem ser capazes de prover taxas de dados elevadas para os usuários cobertos, o que pode ser obtido, entre outros modos, pela elevação da ordem de modulação do sistema, de forma que mais bits sejam transmitidos a cada símbolo em uma mesma largura de banda de transmissão. Alternativamente, pode-se reduzir o período de símbolo $T_{s}$, produzindo aumento da largura de banda $(W)$ necessária para a operação do sistema, visando a manutenção do critério de Nyquist [35].

O principal problema dessa segunda abordagem, particularmente em cenários de comunicação sem linha de visada (NLoS), é a interferência inter-simbólica (ISI), causada pela propagação multipercurso. Devido à reflexão, difração e espalhamento do sinal transmitido, o sinal recebido em um determinado instante de tempo $t$ é dado por uma combinação de sinais transmitidos em instantes anteriores, de modo que a relação sinal interferência mais ruído (SINR) é reduzida [36]. Uma das figuras sob as quais a propagação multipercurso pode ser caracterizada é o chamado delay spread ${ }^{1}$, equivalente à diferença de tempo entre a recepção da primeira e da última cópia com potência significativa ${ }^{2}$ do sinal transmitido, e denotado por $\alpha_{\max }$. A característica dual do delay spread é a banda de coerência $W_{c}$, que indica o intervalo entre duas faixas de frequência no qual ainda existe correlação significativa do canal e é calculada por [4]:

$$
W_{c} \approx \frac{1}{\alpha_{\max }} \quad[\text { Hertz }] .
$$

1 Em tradução livre, espalhamento por atraso, porém o termo em inglês é consagrado na literatura.

2 Por última cópia significativa entenda-se a última cópia recebida acima de um determinado limiar de potência $p^{\text {th }}$ 
Para se obter um sistema livre de ISI, é necessário que $T_{s} \gg \alpha_{\max }$, o que é equivalente a $W_{c} \gg W$. Porém, a necessidade de maior taxa de dados faz com que, em geral, se tenha exatamente o contrário. Para se minimizar (ou mesmo eliminar) a ISI, utiliza-se o conceito de sistemas multiportadoras. Nesse tipo de sistema, a largura de banda total $W$ é dividida em $N$ subportadoras, cada uma com largura de banda $\mathrm{w}=\frac{W}{N}$, de modo que em cada subportadora se transmite parte dos símbolos da fonte. Por consequência, tem-se que o período de símbolo em cada subportadora é dado por $T_{s, n}=N T_{s}$, e com a devida escolha do número de subportadoras $N$, é possível obter $T_{s, n} \gg \alpha_{\max }$ e prover robustez à ISI [4].

Considerando um canal sem interferência e limitado apenas por ruído gaussiano aditivo branco (AWGN), cuja densidade espectral de potência é dada por $N_{o}$, pode-se demonstrar que a capacidade teórica é a mesma para sistemas multiportadoras ou de portadora única, i.e., o aumento do período de símbolo em cada subportadora não afeta a capacidade do sistema. Considerando que a potência disponível para o sistema de portadora única, $p$, é dividida igualmente entre todas as subportadoras, a capacidade do sistema multiportadora, $C_{\mathrm{mc}}$, calculada utilizando a equação de capacidade de Shannon [37], é dada por:

$$
\begin{aligned}
C_{\mathrm{mc}} & =\frac{W}{N} \sum_{n=1}^{N} \log _{2}\left(1+\frac{\frac{p}{N}}{N_{o}\left(\frac{W}{N}\right)}\right) \quad\left[\frac{\text { bits }}{\mathrm{s}}\right] \\
& =\frac{W}{N} \sum_{n=1}^{N} \log _{2}\left(1+\frac{p}{N_{o} W}\right) \\
& =W \log _{2}\left(1+\frac{p}{N_{o} W}\right)=C_{\mathrm{sc}},
\end{aligned}
$$

que é equivalente à capacidade de um sistema de portadora única, dada por $C_{\mathrm{sc}}$. Caso o sistema esteja sujeito a desvanecimento rápido, pode-se ainda utilizar a diversidade em frequência no processo de alocação de potência, de modo que a capacidade é maximizada através de um algoritmo de waterfilling [4, 38].

Um dos modelos mais adotados para implementação de divisão de frequência em sistemas de comunicação modernos é o OFDM [4]. Nesse modelo, as subportadoras são sobrepostas no domínio da frequência, porém com a propriedade de que, sob perfeita sincronia em frequência, apenas a $n$-ésima subportadora apresenta amplitude diferente de zero em sua frequência central. A sobreposição das subportadoras faz com que o sistema OFDM apresente maior eficiência espectral [36], porém é muito sensível à interferência inter-portadora (ICI) quando não for possível obter perfeita sincronia em frequência no processo de deteç̧ão. De fato, a garantia de perfeita sincronia é de difícil obtenção principalmente em cenários de mobilidade aos quais os sistemas 4G estão sujeitos [4, 3].

A implementação da modulação das subportadoras em sistemas OFDM se dá pela utilização da transformada discreta de Fourier (DFT), através de sua implementação rápida, a transformada rápida de Fourier (FFT). Empregando FFT para modular os símbolos 
em cada subportadora, não é necessário que os equipamentos de recepção e transmissão possuam $N$ equipamentos de rádio-frequência $(\mathrm{RF})$, reduzindo os custos operacionais e tornando viável sua utilização em dispositivos portáteis, tais como os aparelhos móveis utilizados em comunicação celular.

Para que um sistema OFDM utilizando FFT seja capaz de prover comunicação livre de ISI, a convolução entre o sinal transmitido no tempo e os coeficientes do canal sem fio deve ser equivalente à convolução circular, pois [4]:

$$
\mathbf{y}=\mathbf{x} \otimes \mathbf{h} \quad \stackrel{\mathrm{FFT}}{\longrightarrow} \quad Y[n]=X[n] H[n],
$$

onde $\mathbf{x}$ é o vetor de amostras do sinal transmitido pela fonte; $\mathbf{h}$ é o vetor de amostras do canal; y é o vetor de amostras do sinal recebido; e $Y[n], X[n]$ e $H[n]$ são, respectivamente, a $n$-ésima amostra da FFT de $\mathbf{y}, \mathbf{x}$ e $\mathbf{h}$.

Apesar de se desejar que a convolução do sinal transmitido e os coeficientes de canal seja circular, o processo de transmissão resulta em convolução linear. Porém, podese emular a convolução linear como circular com a introdução do prefixo cíclico (CP). Considerando que o delay spread, e por consequência o vetor de coeficientes de canal $\mathbf{h}$, tenha duração de no máximo $v+1$ amostras, a cópia das últimas $v$ amostras do sinal $\mathbf{x}$ para o início de $\mathbf{x}$, e a devida remoção de algumas amostras do sinal recebido $\mathbf{y}$, fazem com que a convolução linear apresentada pela transmissão sem fio seja equivalente à convolução circular [4]. Considerando o sinal x com $N$ amostras e o prefixo cíclico de comprimento $N_{\text {cp }} \geq v$, o sinal estendido é dado por:

$$
\mathbf{x}_{\mathrm{cp}}=\left[x\left[N-N_{\mathrm{cp}}\right], x\left[N-N_{\mathrm{cp}}+1\right], \cdots, x[N-1], x[0], x[1], \cdots, x[N-1]\right] .
$$

Após a convolução linear de $\mathbf{x}_{\mathrm{cp}}$ com $\mathbf{h}$, e descartando-se nesse momento o ruído aditivo, obtém-se o sinal recebido $\mathbf{y}$, de comprimento $N+N_{\mathrm{cp}}+v$. Como o delay spread é de $v+1$ amostras, as primeiras $v$ amostras de $\mathbf{y}$ estão sujeitas à ISI do símbolo anterior. Porém, como o conteúdo do prefixo cíclico é constituído de informação redundante, excluem-se as $N_{\mathrm{cp}}$ primeiras amostras, removendo-se a ISI vinda do símbolo anterior. De maneira análoga, as $v$ últimas amostras de $\mathbf{y}$, resultantes do delay spread, são sujeitas à ISI do símbolo posterior, devendo também ser descartadas. O sinal resultante, de comprimento $N$, é completamente livre de ISI de símbolos adjacentes, e de acordo com o demonstrado em [4] é equivalente à convolução circular descrita na equação (2.3). Assim, os símbolos no domínio da frequência podem ser vistos como o símbolo original $X[n]$ escalado pelo coeficiente complexo de canal $H[n]$, resultando que $X[n]$ pode ser estimado a partir da estimativa de canal na $n$-ésima subportadora, $\widehat{H}[n]$.

O diagrama de blocos para transmissão e recepção em OFDM é dado na Figura 2.1. No lado transmissor, um vetor de sequências de bits b é modulado, de acordo com a técnica desejada, e os símbolos são então mapeados a cada uma das subportadoras, obtendose o símbolo $X[n]$ na $n$-ésima subportadora. Esses símbolos são então paralelizados e 
modulados nas respectivas subportadoras no domínio da frequência, utilizando a transformada rápida inversa de Fourier (IFFT). Assim, obtém-se o vetor de amostras do sinal no domínio do tempo, $\mathbf{x}$, cujo $m$-ésimo componente é dado por:

$$
x[m]=\frac{1}{\sqrt{N}} \sum_{n=0}^{N-1} X[n] \exp \left(\frac{i 2 \pi m n}{N}\right),
$$

$\operatorname{com} i=\sqrt{-1}$.

Figura 2.1 - Fluxo de transmissão e recepção em sistemas OFDM.

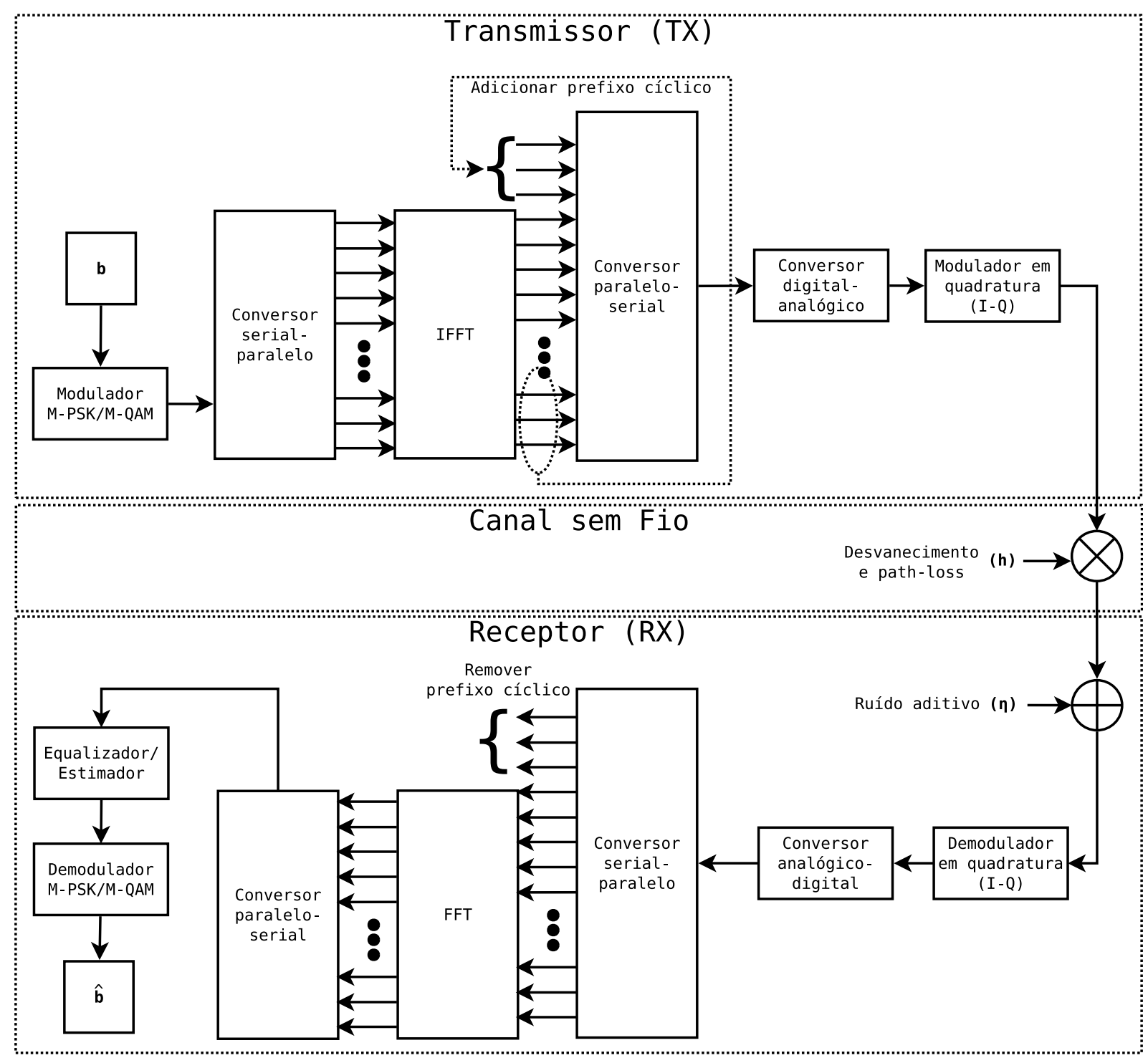

Fonte: o autor

Após a modulação das $N$ subportadoras, adiciona-se o prefixo cíclico ao vetor $\mathbf{x}$, de acordo com a equação (2.4), obtendo-se o sinal estendido $\mathbf{x}_{\mathrm{cp}}$. O sinal estendido é então serializado, convertido para analógico através do conversor digital-analógico e modulado pelo modulador em fase e quadratura. Finalmente, o sinal é transmitido pelo canal sem fio, sendo sujeito aos efeitos de perda de percurso, sombreamento e desvanecimento rápido, representados pelos coeficientes do vetor $\mathbf{h}$. 
No receptor, soma-se ao sinal desvanecido o ruído de fundo, obtendo-se o seguinte vetor de amostras do sinal recebido:

$$
\mathbf{y}_{\mathrm{cp}}=\mathbf{x}_{\mathrm{cp}} * \mathbf{h}+\boldsymbol{\eta}
$$

com $\left|\mathbf{y}_{\mathrm{cp}}\right|=N+N_{\mathrm{cp}}+v$; e $\boldsymbol{\eta}$ correspondente ao vetor de amostras do ruído de fundo. O sinal $\mathbf{y}_{\text {cp }}$ passa pelo demodulador em fase e quadratura, pelo conversor analógico-digital e pelo conversor serial-paralelo. Após esses blocos, retira-se o prefixo cíclico de $\mathbf{y}_{\mathrm{cp}}$, obtendo-se

$$
\mathbf{y}=\left[y_{\mathrm{cp}}\left[N_{\mathrm{cp}}\right], y_{\mathrm{cp}}\left[N_{\mathrm{cp}}+1\right], \cdots, y_{\mathrm{cp}}\left[N_{\mathrm{cp}}+N-1\right]\right]
$$

As amostras y são então processadas pelo algoritmo de FFT, de modo que as amostras no domínio da frequência são dadas por:

$$
\begin{aligned}
Y[n] & =\operatorname{FFT}\{\mathbf{x} * \mathbf{h}+\boldsymbol{\eta}\} \\
& =X[n] H[n]+\Phi[n],
\end{aligned}
$$

onde $\Phi[n]$ é a resposta em frequência do ruído de fundo na $n$-ésima subportadora.

O processo de transmissão pode ser também analisado no domínio do tempo. Considerando a $n$-ésima subportadora, o sinal recebido $y_{n}$ é dado por:

$$
y_{n}=\sqrt{p_{n}} \mathrm{x}_{n} h_{n}+\eta_{n},
$$

onde $\sqrt{p_{n}}$ é a potência de transmissão; $\mathrm{x}_{n}$ é o símbolo transmitido; $h_{n}$ é o coeficiente complexo de canal; e $\eta_{n}$ é o ruído de fundo, todos em relação à $n$-ésima subportadora. Nesse cenário, a SINR na $n$-ésima subportadora é dada por:

$$
\begin{aligned}
\gamma_{n} & =\frac{\mathbb{E}\left\{p_{n}\left|\mathrm{x}_{n}\right|^{2}\left|h_{n}\right|^{2}\right\}}{\mathbb{E}\left\{\left|\eta_{n}\right|^{2}\right\}} \\
& =\frac{p_{n}\left|h_{n}\right|^{2} \mathbb{E}\left\{\left|\mathbf{x}_{n}\right|^{2}\right\}}{\sigma_{n}^{2}},
\end{aligned}
$$

sendo $\left|h_{n}\right|^{2}$ o ganho de canal; e $\sigma_{n}^{2}$ a potência do ruído de fundo, ambos em relação à $n$-ésima subportadora. Admitindo que o símbolo transmitido $\mathbf{x}_{n}$ tenha potência unitária, i.e., $\mathbb{E}\left\{\left|\mathbf{x}_{n}\right|^{2}\right\}=1[27,39]$, obtém-se a expressão comumente associada à SINR:

$$
\gamma_{n}=\frac{p_{n}\left|h_{n}\right|^{2}}{\sigma_{n}^{2}}=p_{n} \Gamma_{n}
$$

Através do sinal recebido na $n$-ésima subportadora no domínio da frequência, dado pela equação (2.8), os símbolos transmitidos podem ser detectados, por exemplo, utilizando uma regra de minimização do erro quadrático médio (MSE), resultando em

$$
\widehat{X}[n]=\underset{X[n] \in \mathcal{X}_{n}}{\arg \min }|X[n] \widehat{H}[n]-Y[n]|^{2},
$$


onde $\mathcal{X}_{n}$ é o conjunto contendo todos os símbolos da constelação utilizada na $n$-ésima subportadora. Note-se que a estimativa $\widehat{X}[n]$ pode conter diversas fontes de erro, tais como o ruído de fundo, interferência inter-portadora, interferência inter-celular e erros oriundos da estimativa de canal $\widehat{H}[n]$. A partir das estimativas $\widehat{X}[n]$ obtém-se o vetor de bits estimados no receptor, denotado por $\widehat{\mathbf{b}}$.

Embora o problema da ISI seja resolvido, a utilização de OFDM gera dois problemas principais [4]: elevada razão entre potência de pico e média (PAPR) e necessidade de rígido sincronismo em frequência. O primeiro problema se dá pelo fato de que o sinal transmitido em esquemas multiportadoras pode ser visto como a soma de $N$ sinais de banda estreita, fazendo com que a potência de pico resultante da soma desses sinais possa ser muito maior do que a potência média, principalmente quando $N$ cresce. Nessa condição, o amplificador de potência (PA) tende a operar em região de saturação, distorcendo o sinal transmitido [36]. Tal problema é ainda mais significativo no uplink, dado que o amplificador de potência presente nos dispositivos móveis, por limitações de custo, deve ser mais simples do que o utilizado nas BSs [4].

O problema do sincronismo em frequência é causado pelo fato de que as subportadoras são ortogonais somente em suas respectivas frequências centrais, resultado do janelamento do sinal recebido por uma janela retangular. Assim, o sinal recebido em cada subportadora no domínio da frequência, $Y[n]$, é espalhado pela função sinc resultante da transformada de Fourier da janela retangular, de modo que apenas quando $f=f_{c, n}$ o símbolo da n-ésima subportadora é recebido sem ICI [40]. Quando o número de subportadoras é aumentado, estreita-se o lóbulo principal da função sinc em cada uma das subportadoras, de modo que os erros de sincronização em frequência se tornam cada vez menos tolerados. Considerando que sistemas $4 \mathrm{G}$ estão sujeitos a cenários de mobilidade veicular, o efeito Doppler pode ter grande impacto no desempenho do sistema [36].

Dado que OFDM é uma técnica de multiplexação, é possível combiná-la com técnicas de múltiplo acesso (MA), tais como múltiplo acesso por divisão de tempo (TDMA), de frequência (FDMA) ou de código (CDMA). Considerando os sistemas 4G, uma das técnicas mais utilizadas é o OFDMA [5, 13], de modo que a cada usuário é alocado um conjunto de subportadoras a cada janela (slot) de tempo de acordo com as métricas definidas pelo sistema, como por exemplo a informação de estado de canal (CSI). Na Subseção 2.1.1, discute-se a técnica OFDMA, considerando também aspectos de implementação nos sistemas $4 \mathrm{G}$.

\subsubsection{OFDMA}

A técnica OFDMA permite que se escolha quais usuários serão alocados a quais subportadoras em cada janela de tempo. A noção de janela de tempo faz com que o algoritmo de alocação não opere necessariamente sobre cada símbolo OFDM, pois é necessário operar em tempo real. Por exemplo, para o downlink de sistemas LTE-A considera-se como 
menor unidade de alocação o bloco de recursos (resource block), constituído de 12 subportadoras alocadas por um período de 0,5 ms [41]. Assim, há ao menos duas dimensões de diversidade que podem ser aproveitadas pelo algoritmo de alocação de recursos: a primeira é a diversidade multiusuário, dado que pode-se definir qual usuário será alocado a cada subportadora, e a segunda dimensão é a dimensão temporal, visto que é possível determinar em quais janelas temporais cada usuário irá transmitir, de modo que se pode associar uma melhor condição de canal para que ocorra a transmissão.

Outra vantagem associada ao sistema OFDMA é a capacidade de reduzir o problema relativo à PAPR, apesar de técnicas mais eficientes para tal, como FDMA de portadora única (SC-FDMA), estarem disponíveis. Conforme descrito em [4], a PAPR é proporcional ao número de subportadoras alocadas. Considerando um sistema OFDM em que cada usuário transmite utilizando todas as subportadores em uma determinada janela, usa-se elevada potência e uma grande porção de subportadoras em um pequeno intervalo de tempo, o que aumenta a probabilidade de operação na região de saturação do PA. No caso de utilização de OFDMA, o gasto de potência pode ser distribuído no tempo e em um número menor de subportadoras, reduzindo a probabilidade de ocorrência de PAPR elevada.

Com a exploração das dimensões de diversidade do sistema OFDMA, é possível desenvolver diversos algoritmos de alocação de recursos que utilizem diferentes métricas de otimização, por exemplo, para maximizar a vazão (throughput), minimizar o delay, prover fairness, otimizar eficiência energética ou mesmo combinações dessas métricas. Os algoritmos de alocação de recursos não são especificados nas normas dos sistemas LTE-A e WiMAX [4], de modo que novas métricas podem ser desenvolvidas e aplicadas aos sistemas, de acordo com as necessidades dos operadores. A flexibilidade no processo de alocação de subportadoras e janelas temporais permite também que usuários com diferentes requisitos de taxa de dados e outras métricas de QoS possam ser alocados conjuntamente, sem a necessidade de reserva prévia de recursos.

Em relação ao modo de operação dos algoritmos de alocação de recursos, há duas abordagens principais: centralizado ou distribuído [42]. No primeiro modo, todas as informações necessárias ao processo de alocação, tais como CSI de todas as MSs, requisitos de QoS e quantidade de informação disponível para transmissão devem ser reunidas em um nó central, representado pela BS em sistemas celulares [43]. A partir dessas informações, o nó central define a estratégia de alocação de subportadoras e potência. Obrigatoriamente deve-se transmitir às MSs quais subportadoras estão alocadas a elas e em quais janelas de tempo, enquanto a comunicação de outras variáveis depende do sentido do fluxo de dados [4]. Soluções centralizadas tem como vantagem a capacidade de considerar todos os dados necessários no processo de alocação, de modo que, em geral, soluções ótimas são atingidas somente com abordagens centralizadas; como pontos negativos, tem-se os altos custos associados à obtenção de todos os parâmetros, principalmente quando o número 
de usuários e portadoras cresce, de se comunicar a estratégia definida para os usuários e também de se manter um canal com capacidade e confiabilidade suficientes para transmitir tais informações [42].

Em soluções distribuídas, o processamento é realizado em cada uma das MSs, ou mesmo com participação reduzida da BS, no caso de soluções semi-distribuídas. Nesse caso, o overhead de comunicação de parâmetros é reduzido, porém a natureza de concorrência por subportadoras, as quais devem ser alocadas exclusivamente por uma MS em uma determinada janela temporal, faz com que uma solução completamente distribuída seja bastante difícil de ser implementada em sistemas multiportadoras. Como cada MS tem acesso somente aos seus parâmetros de sistema e canal, perde-se parte da diversidade disponível, o que pode resultar em desempenho não-ótimo. A busca por algoritmos distribuídos para alocação tem bastante interesse na literatura [44, 45, 46], principalmente para uplink, pois uma solução centralizada em uplink exige a comunicação de muitos parâmetros da BS para cada uma das MSs.

Em termos de sistemas comerciais, o padrão WiMAX considera a utilização de OFDMA em uplink e downlink [5], enquanto que o padrão LTE-A mantém a utilização de OFDMA no downlink, porém utiliza SC-FDMA no uplink para a redução do PAPR [47].

\subsection{Redes Cooperativas}

Um dos grandes desafios em sistemas celulares é prover uma qualidade de serviço mínima a todos os usuários dentro da célula, não importando sua proximidade em relação à BS. Porém, características geográficas, populacionais e, principalmente, a perda de percurso, fazem com que usuários localizados na borda das células experimentem qualidade de serviço bastante reduzida, além de um consumo de potência elevado para conseguir estabelecer conexão com a BS. Conforme descrito em [36], uma possível solução para sistemas celulares em ambiente urbano é a utilização de células com menor área de cobertura, de modo que os usuários não fiquem muito distantes da BS com a qual se comunicam.

Apesar da redução da área de cobertura atenuar os efeitos da perda de percurso, essa abordagem não pode ser continuamente utilizada de maneira eficiente, pois para se reduzir a área de cobertura de cada célula mantendo a área de cobertura total é necessário instalar cada vez mais BSs, o que possui um custo financeiro que pode se tornar inviável, além de tornar cada vez mais crítico os processos de handoff e coordenação entre as células. Acrescente-se aos problemas de natureza prática a dificuldade para desenvolver modelos teóricos para análise dos sistemas [36]. Assim, a instalação de estações retransmissoras visa emular o aumento da densidade de BSs, diminuindo a distância entre as MSs e o equipamento de rede responsável pelo processamento da informação dessas MSs sem a necessidade de modificar a área de cobertura da célula original.

A função das RSs é retransmitir a informação recebida de um nó fonte para um nó 
destino, introduzindo saltos (hops) intermediários na comunicação entre MSs e BS. Como a perda de percurso é não-linear em relação à distância entre fonte e destino, dividir a transmissão em saltos com menores distâncias tende a reduzir a potência total consumida no processo de transmissão [8]. As RSs podem ser instaladas em qualquer local da célula original, tendo apenas como restrição que sejam instaladas em uma região coberta pela BS com a qual cooperam, dado que a conexão entre RSs e BS é feita através do canal sem fio. Apesar das RSs serem utilizadas na melhoria da cobertura celular, elas podem ser também instaladas para prover maximização de taxa de dados e/ou atendimento de requisitos de QoS [12], além de otimização da EE do sistema [34, 16, 23].

As principais vantagens da utilização de RSs em relação ao aumento na densidade de BSs ou instalação de BSs com menor área de cobertura são:

- custo reduzido de compra e manutenção dos equipamentos, dado que possuem menos funcionalidades e menor área de cobertura [10];

- facilidade de instalação, pois o acesso à rede do provedor de serviços utiliza o canal sem fio já existente ou então um canal sem fio dedicado, porém sem necessidade de infraestrutura dedicada para a conexão RS-BS [8];

- flexibilidade de instalação, podendo ser implantadas em locais nos quais a cobertura proporcionada pela BS seja insuficiente [48] ou então em locais sujeitos a grande variação de densidade de usuários [7].

As principais desvantagens na utilização de RSs são resultantes, principalmente, da característica de utilizar os recursos espectrais da célula original para a conexão RS-BS: a primeira delas é o compartilhamento dos recursos espectrais e temporais utilizados na comunicação entre MSs e BS, introduzindo concorrência extra pelos recursos e, sob uma perspectiva pessimista, desperdiçando tais recursos ao retransmitir redundância. A segunda desvantagem é a necessidade de um enlace de qualidade entre as RSs e a BS, para que a redundância inserida pelas RSs possa ser transmitida sem prejuízo à capacidade do sistema [49].

A topologia básica de uma rede cooperativa é mostrada na Figura 2.2, onde também podem ser identificados os três tipos de enlaces existentes em redes cooperativas [50]:

- enlace direto, no qual ocorre comunicação MS-BS;

- enlace de acesso, no qual ocorre a comunicação MS-RS;

- enlace backhaul, no qual ocorre a comunicação RS-BS. A nomenclatura desse enlace segue o descrito para LTE-A, sendo que nos padrões WiMAX o nome adotado é enlace de relay;

As estações retransmissoras podem ser classificadas de acordo com diversas características de implantação, tais como: 
Figura 2.2 - Topologia básica de uma rede cooperativa, com identificação dos enlaces.

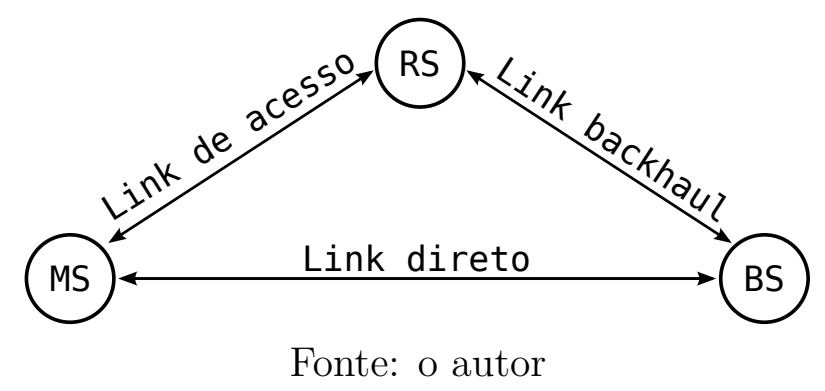

- estações fixas ou móveis;

- protocolo de retransmissão;

- topologia de comunicação MS-RS-BS;

- identificação do equipamento na rede;

- modo de duplexação dos enlaces de acesso e backhaul;

A instalação/implantação das estações retransmissoras pode ser feita de duas maneiras distintas: a) com equipamentos dedicados, que são parte da infraestrutura da célula e se conectam sempre com a mesma BS, denominadas RSs fixas (FRSs) ou b) possibilitando mobilidade para as RSs, de modo que possam trocar de célula, conhecidas como RSs móveis (MRSs). As principais vantagens na utilização de RSs fixas são [51]:

- instalação dos equipamentos em áreas estratégicas da célula original;

- emprego de técnicas avançadas de transmissão, como múltiplas antenas de transmissão/recepção;

- suprimento de energia, já que os equipamentos fixos podem ser conectados à infraestrutura energética da célula.

No caso de RSs móveis, é possível utilizar RSs dedicadas ou até mesmo os usuários móveis como retransmissores. No caso de usuários móveis atuando como RSs, é possível explorar a maior quantidade e posicionamento aleatório dos terminais, possibilitando maior diversidade espacial. No caso de RSs dedicadas, é possível um melhor aproveitamento da qualidade dos canais. Em [12] afirma-se que limitações em tamanho (para aproveitamento de múltiplas antenas), potência (dada alimentação por bateria), capacidade de processamento e principalmente a divisão dos recursos para transmissão e retransmissão, tornam a utilização de MSs como RSs menos prática que a abordagem fixa. Em termos de padronização, a principal diferença entre RSs fixas e móveis é a reconfigurabilidade em relação à BS servida, i.e., capacidade de realizar handover [52]. 
Os protocolos de retransmissão são divididos em duas categorias principais: nãoregenerativos e regenerativos. A primeira categoria se refere a protocolos que são capazes apenas de realizar processamentos analógicos no sinal recebido, o que impossibilita a detecção dos bits/símbolos transmitidos. A operação básica de um protocolo não-regenerativo é a amplificação do sinal recebido, compensando assim os efeitos de desvanecimento e perda de percurso no canal fonte-relay, podendo ser precedido, opcionalmente, por algum tipo de processamento analógico no sinal recebido. O mais comum dos protocolos nãoregenerativos é conhecido como Amplifica e Transmite (AF), e atua basicamente como um repetidor. Apesar da baixa complexidade computacional e do melhor aproveitamento da diversidade espacial [53], a grande desvantagem do AF é a amplificação de ruído e propagação de possíveis sinais interferentes, pois o processo de detecção não é executado.

Em relação aos protocolos regenerativos, antes do processo de retransmissão ocorre a estimação e/ou deteç̧ão e/ou decodificação da informação transmitida, o que torna possível remover ruído de fundo e interferência, ao custo da complexidade computacional e delay resultantes de tais processos [8]. Além disso, torna-se possível inserir codificação no sinal retransmitido ou mesmo alterar a ordem de modulação, flexibilizando o processo de retransmissão. As principais desvantagens dos protocolos regenerativos são a possibilidade de propagação de erro de detecção, principalmente quando a qualidade do sinal é baixa, o delay inserido pelo próprio processo de detecção e retransmissão e o custo do processo de detecção, tanto em termos computacionais quanto energéticos [8]. Sua principal implementação se dá pelo protocolo Decodifica e Transmite (DF).

Para utilizar o protocolo DF em sistemas multiportadoras baseados em OFDMA, é necessário executar uma FFT para ter acesso aos símbolos transmitidos, realizar o processo de detecção, remodular e então executar uma IFFT, enquanto um protocolo do tipo AF pode apenas amplificar o sinal por um fator constante [54].

A escolha de qual protocolo a ser empregado depende das características do sistema adotado. Por exemplo, protocolos não-regenerativos limitam a aplicação da técnica de AMC, afinal a adaptação de modulação e código deve ser feita considerando o enlace completo, i.e., MS-RS-BS [50]. No caso de utilização de protocolos regenerativos, é possível que as adaptações sejam realizadas separadamente nos enlaces de acesso e backhaul, de modo que até mesmo o número de bits em cada subportadora pode ser alterado [50], além da possibilidade de se utilizar buffers nas RSs para que limitações nos enlaces possam ser eficientemente tratadas [54]. Por outro lado, é necessário avaliar se o processo de detecção/estimação para os protocolos regenerativos não incorre em delay e complexidade excessivos.

Em relação à topologia de comunicação em redes cooperativas, existem dois métodos principais: comunicação em dois saltos (two-hops) e comunicação com múltiplos saltos (multi-hop). No modo de dois saltos, a comunicação envolve uma transmissão do nó fonte para a RS, chamada de primeiro salto, e uma transmissão da RS para o nó destino, 
correspondente ao segundo salto. Uma transmissão de dois saltos pode ser feita de várias maneiras diferentes, conforme mostrado na Figura 2.3, dependendo da existência do enlace direto. Os principais métodos são:

a) na primeira janela, o nó fonte transmite para o nó destino, enquanto a RS escuta essa transmissão. Na segunda janela, a RS transmite informação referente à transmissão escutada para o nó destino;

b) com a baixa qualidade do enlace direto, a fonte transmite diretamente para a RS na primeira janela, enquanto a RS retransmite essa informação na segunda janela;

c) na primeira janela, o nó fonte transmite ao nó destino e a RS escuta a transmissão. Na segunda janela, a RS retransmite a informação para o nó destino, enquanto o nó fonte também transmite para o nó destino, podendo ser uma nova informação ou até mesmo uma cópia da informação da primeira janela, visando aproveitar a janela em que ficaria ocioso no esquema a);

d) variação do esquema b), no qual na primeira janela o nó fonte transmite para a RS, enquanto que na segunda janela a informação recebida pela RS é retransmitida para o nó destino, e também o nó fonte transmite informação para o nó destino, podendo ser uma cópia da informação original, para aproveitar diversidade, ou uma nova informação para aumentar a vazão do sistema;

Figura 2.3 - Topologias de dois saltos, em que: a) O enlace direto está disponível, e o nó S transmite apenas no primeiro salto; b) O enlace direto não está disponível, e o nó S transmite apenas no primeiro salto; c) O enlace direto está disponível, e o nó S transmite nos dois saltos; d) O enlace direto não está disponível no primeiro salto, e o nó $\mathrm{S}$ transmite nos dois saltos.

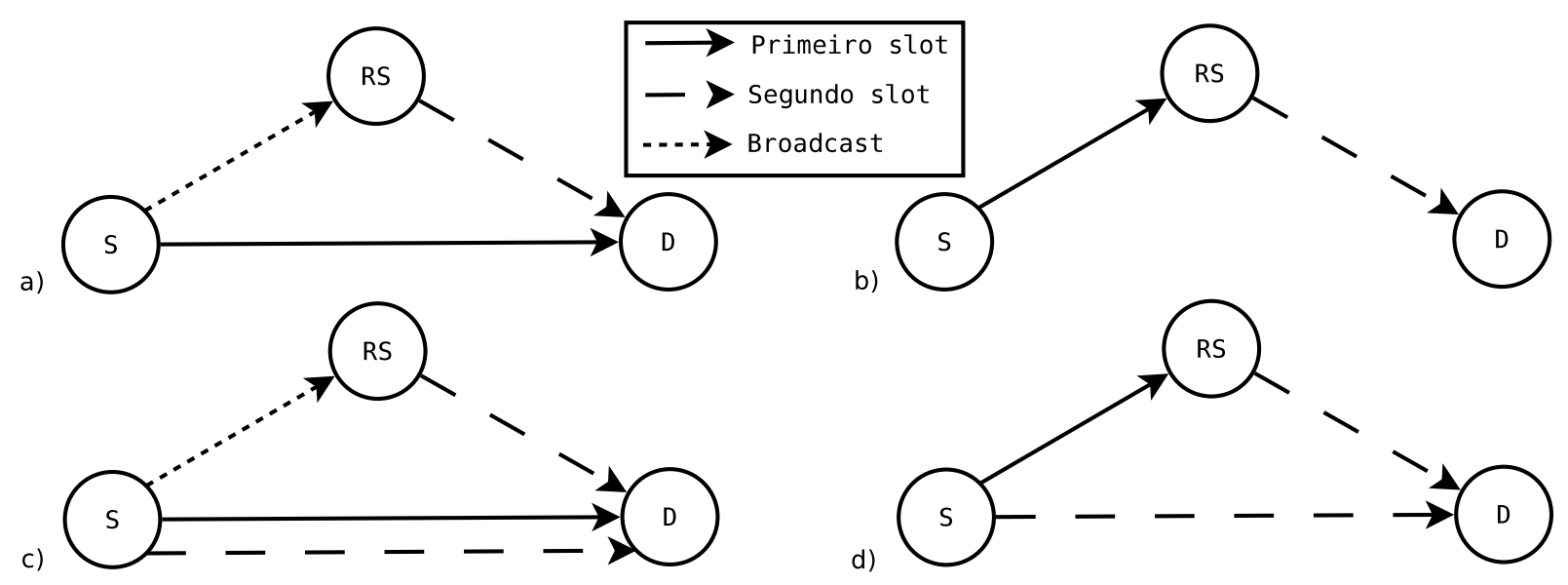

Fonte: o autor

Já em sistemas de múltiplos saltos, ocorre ao menos uma transmissão $\mathrm{RS}_{i}-\mathrm{RS}_{j}$ no processo de retransmissão, ou seja, existe uma topologia de relays em série para a retransmissão da informação do nó fonte, como pode ser visto na coluna da direita da Figura 2.4. A principal vantagem de sistemas com múltiplos saltos é a divisão da distân- 
cia de transmissão do enlace direto em distâncias menores, de modo que o consumo de potência em decorrência da perda de percurso é bastante reduzido, enquanto a principal desvantagem se dá pela redução de capacidade do sistema, dado que em apenas um dos saltos a informação transmitida não é redundante.

Observando os topologias descritas na Figura 2.3, percebe-se que existem ao menos dois modos de operação para as RSs em relação ao modo como são identificadas na célula [55, 56]. Nas Figuras 2.3.b) e 2.3.d), o nó fonte enxerga a RS como um equipamento ativo da célula, de modo semelhante ao que acontece com uma BS. Esse método é denominado não-transparente, e é empregado principalmente quando as MSs não estão na área de cobertura da BS, fazendo com que a RS emule as funcionalidades de uma BS. Relays nãotransparentes são responsáveis por controlar a sua área de cobertura, exercendo funções como a geração de mensagens de controle [57]. A funcionalidade de extensão de cobertura se dá exatamente pela capacidade de controlar sua área de cobertura: ao gerar as próprias mensagens de controle, qualquer MS que esteja na área de cobertura da RS pode estabelecer conexão, enquanto a RS é responsável por enviar os dados recebidos para a BS.

Já nas Figuras 2.3.a) e 2.3.c), a MS não enxerga a RS como um equipamento de rede, tanto que continua transmitindo diretamente para a BS, sendo por isso chamado de modo transparente. Tal modo implica que a MS esteja na área de cobertura da BS [50], pois as mensagens de controle não são retransmitidas pelas RSs transparentes. A alocação de recursos é feita de maneira centralizada, com a BS sendo responsável por coordenar e alocar os recursos de rádio tanto para MSs quanto para RSs, distribuindo mensagens de controle e controlando as requisições de acesso. Às RSs resta apenas a tarefa de retransmitir a informação das MSs para a BS e vice-versa. Em geral, considerase a utilização de RSs transparentes para melhoria de capacidade do sistema, em termos de vazão e/ou confiabilidade, visto que o sinal recebido do nó fonte e da RS podem ser combinados para se aproveitar diversidade espacial [57].

Os sistemas cooperativos podem também ser classificados de acordo com o número de enlaces entre fonte e destino. O primeiro modelo considera que existe apenas um enlace entre fonte e destino, utilizando uma ou mais RSs em série, denominado retransmissão de apoio (supportive relaying), de modo que considera-se que o enlace direto não existe. Esse modelo, mostrado na Figura 2.4.a), se adapta aos casos nos quais a qualidade do enlace MS-BS é ruim, como por exemplo em um caso de macro-célula urbana onde a MS está localizada próxima da borda da célula. O segundo modelo considera a existência de dois ou mais enlaces entre fonte e destino, podendo incluir ou não o enlace direto, denominada retransmissão multi-ramos (multi-branch relaying), e mostrado nas Figuras 2.4.b)-c). Para esse modelo, cada um dos enlaces que utiliza RSs pode empregar uma ou mais RSs em série, e até mesmo interação entre os enlaces pode ser considerada [58].

Finalmente, tem-se a questão da interferência gerada pela operação conjunta dos en- 
Figura 2.4 - Classificação do sistema cooperativo em relação ao número de enlaces entre fonte e destino, onde: a) Retransmissão de apoio; b) Multi-ramos com enlace direto; c) Multi-ramos sem enlace direto.

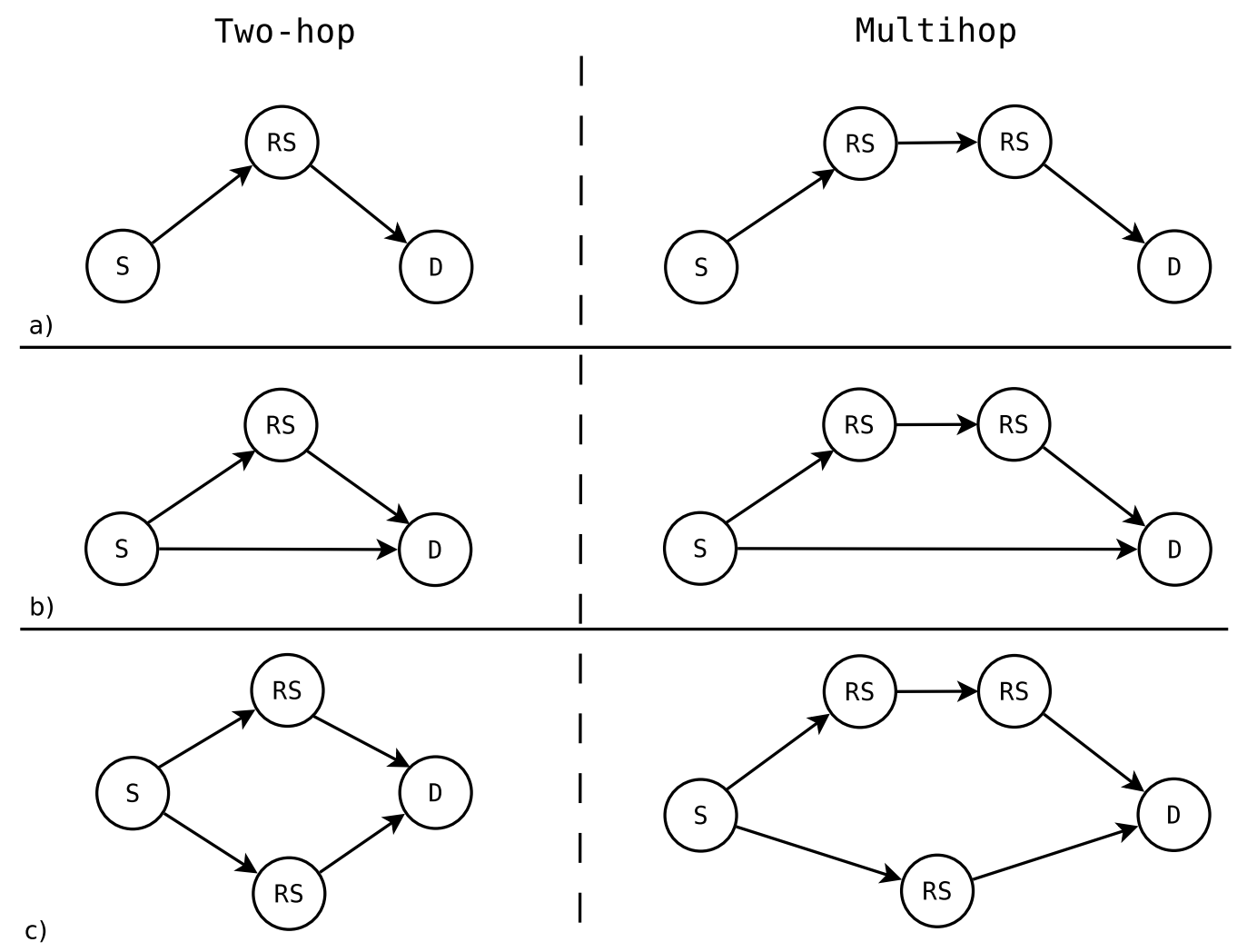

Fonte: o autor

laces de acesso e backhaul. Conforme pode ser visto na Figura 2.5, para qualquer combinação de operação em downlink/uplink dos dois enlaces citados haverá interferência. Considerando que os dois enlaces operam no mesmo sentido, as Figuras 2.5.a) e 2.5.c) mostram que o enlace que se inicia na $\mathrm{RS}$ interfere na recepção do outro enlace, sendo que tal efeito é conhecido como auto-interferência (self-interference). Quando o sentido de tráfego é invertido em um dos enlaces, o problema ainda é mantido, porém com ambos os enlaces sendo afetados.

Desse modo, destacam-se duas abordagens distintas para enfrentar a interferência entre os enlaces de acesso e backhaul: a primeira é prover ortogonalidade entre os enlaces, de modo que a interferência seja anulada, enquanto a segunda emprega técnicas de cancelamento de interferência (IC) para atenuar a interferência. Na técnica que provê ortogonalidade, o objetivo é separar os enlaces de acesso e backhaul em alguma dimensão, definindo que ambos operam no mesmo sentido de comunicação em uma determinada janela. Para tal, existem dois procedimentos básicos:

- retransmissão inband: Os enlaces de acesso e backhaul compartilham os mesmos recursos temporais e espectrais, porém não acessam as mesmas subportadoras ao 
Figura 2.5 - Interferência gerada pela operação conjunta dos enlaces de acesso e backhaul, considerando: a) ambos em downlink ; b) uplink no enlace de acesso, downlink no backhaul; c) ambos em uplink; d) downlink no enlace de acesso, uplink no enlace backhaul.

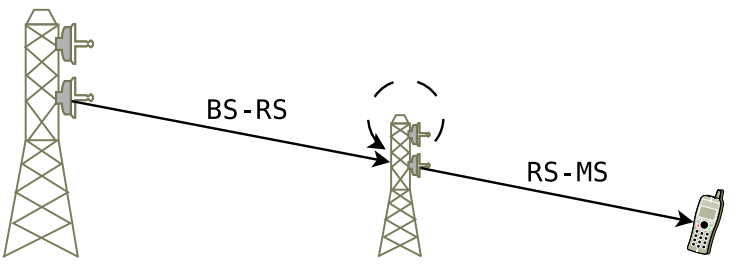

a) Transmissão RS-MS interfere na recepção da transmissão BS-RS

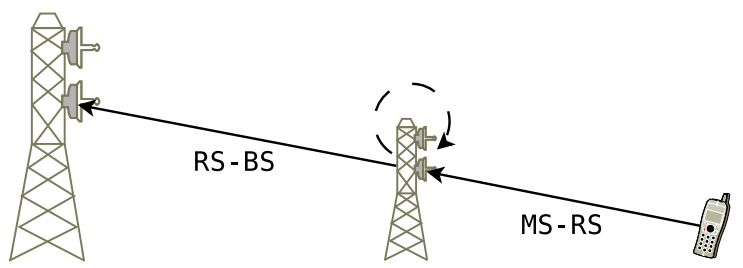

c) Transmissão RS-BS interfere na recepção da transmissão MS-RS

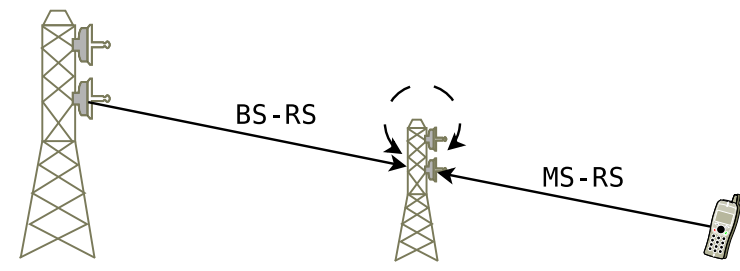

b) Cada transmissão em um link interfere na recepção do outro link

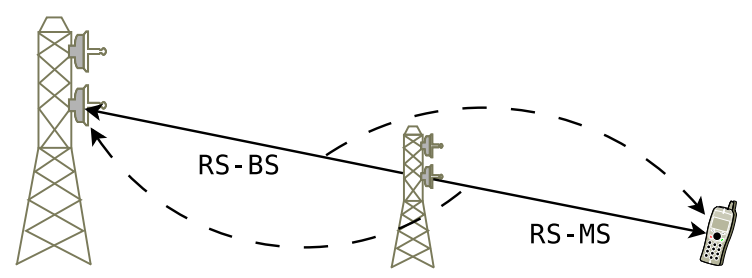

d) Cada transmissão em um link interfere na recepção do outro link

Fonte: o autor

mesmo tempo. No modo half-duplex, pode ser implementado com duplexação por divisão de tempo (TDD) ou então alocando grupos disjuntos de subportadoras para cada enlace, equivalente à duplexação por divisão em frequência (FDD). Caso exista isolamento espacial entre as antenas transmissoras e receptoras, é possível utilizar transmissão full-duplex;

- retransmissão outband: Um recurso espectral extra é disponibilizado, de modo que os enlaces operem no mesmo sentido, porém em bandas de frequência distintas e não interfiram entre si. Tal método é conhecido como retransmissão full-duplex outband.

Apesar de investigado na literatura, o isolamento necessário ao método full-duplex inband é bastante complicado de se conseguir, existindo um termo residual de interferência. Portanto, essa técnica será vista no contexto de métodos que empregam técnicas de cancelamento de interferência. Outra possibilidade para implementar o modo full-duplex inband é a instalação de antenas diretivas para ambos os enlaces, porém em implantações mais elaboradas, como as definidas em [49, 59] e no item de agenda R1-104460 [60] do 3GPP, é praticamente impossível isolar os enlaces de acesso e backhaul com antenas diretivas. Outro problema é o possível vazamento de RF que pode ocorrer com o uso de antenas diretivas, de modo que mesmo que se consiga isolar os enlaces de acesso e backhaul com antenas diretivas, a diferença de potência entre os dois enlaces pode resultar em significativa interferência.

Apesar de anularem a interferência de múltiplo acesso, esses métodos resultam em 
redução da capacidade do sistema, pois a ortogonalidade é obtida com a reserva de recursos, no caso de sistemas inband, ou com a inserção de recursos que são utilizados apenas para redundância, no caso de sistemas outband. Para se manter o nível de desempenho do sistema em termos de SE, é necessário que os requisitos mínimos sejam aumentados em relação aos valores estabelecidos para métodos que não utilizam RSs. Assim sendo, dependendo do rigor dos requisitos mínimos, os sistemas cooperativos não mais apresentam ganho de desempenho em relação a abordagens não-cooperativas $[15,16]$.

Os métodos que admitem a existência de interferência possibilitam que os dois enlaces operem sob o mesmo recurso espectral ao mesmo tempo. Assim, evita-se o desperdício de recursos do sistema ao custo do termo residual do cancelador de interferência, o que pode resultar em perda de desempenho considerável caso o termo residual seja elevado. Pela possibilidade de limitação pela interferência, esse método é considerado quando as antenas transmissora e receptora das RSs podem ser instaladas com um isolamento natural [61], o que pode ser atingido em comunicação indoor-outdoor, como shopping centers e estações de metrô. Observando a Figura 2.5, existem dois modos de operar os enlaces de acesso e backhaul: ambos operando no mesmo sentido, mostrado nas Figuras 2.5.a) e 2.5.c), ou operando em sentidos contrários, conforme mostrado nas Figuras 2.5.b) e 2.5.d). O primeiro é denominado retransmissão full-duplex inband, enquanto o segundo é uma adaptação da técnica de retransmissão two-way para ambientes celulares.

No modo full-duplex inband, a transmissão da RS para o nó destino (MSs no downlink e BS no uplink) interfere na recepção do sinal transmitido pelo nó fonte (BS no downlink e MSs no uplink). Porém, como a RS tem conhecimento da informação que transmite ao nó destino, é possível utilizar essa informação para cancelar a interferência gerada, sem impor aumento de complexidade às MSs. A grande desvantagem desse método ocorre quando o isolamento entre as antenas transmissora e receptora é insuficiente ou inexistente: nesse caso, a potência do sinal recebido do nó fonte tende a ser várias ordens de magnitude inferior à do sinal interferente, de modo que mesmo com boas técnicas de cancelamento de interferência, o termo residual ainda é bastante significativo, causando apreciável perda de desempenho [61]. Esse problema tem grande impacto em sistemas celulares, principalmente nos casos em que a perda de percurso é bastante significativa, como é o caso de ambientes metropolitanos.

No modelo de retransmissão two-way, na primeira janela as MSs e a BS transmitem informação às RSs. Essa informação é então combinada e transmitida tanto para a BS quanto para as MSs na segunda janela. Como cada dispositivo tem conhecimento da informação que enviou na primeira janela, técnicas de cancelamento de interferência podem ser aplicadas, de maneira análoga à descrita para o modo full-duplex inband. O interessante no caso do método two-way é que tende-se a reduzir o problema da grande diferença de potência entre o sinal de interesse e o interferente, ao custo de que a interferência a ser cancelada pode sofrer maior distorção, pois é transmitida para a RS e depois 
retransmitida antes de ser cancelada.

\subsubsection{Parâmetros de Redes Cooperativas em Sistemas 4G}

Esta subseção tem por objetivo descrever os métodos de implementação de estações retransmissoras nos padrões de redes $4 \mathrm{G}$, porém não tem como objetivo definir o modelo de sistema que será utilizado.

A grande maioria das estratégias em LTE-A e WiMAX utilizam RSs fixas. Algumas modificações podem ser observadas no TR 36.836 [14], que é parte dos estudos para LTE-A release 12, no qual RSs são instaladas em veículos de transporte público de alta velocidade. Para esse caso, as RSs são instaladas com uma antena no interior do veículo, que controla o enlace de acesso, enquanto uma antena no exterior é responsável pelo enlace backhaul. No enlace de acesso, a comunicação MS-RS apresenta baixa mobilidade, de modo que o número de handovers é reduzido e as condições de canal são melhores [52]. Já para o link backhaul, a antena exterior anula a elevada perda de penetração à qual a comunicação MS-BS é sujeita [14]. Para WiMAX, o padrão 802.16 .1 [13] descreve a técnica de retransmissão multimodo (multimode relaying), que possibilita que uma MS atue como RSs ou BS para outras MSs, e até mesmo que uma BS atue como RS.

Em termos de protocolos de retransmissão, a preferência se dá por protocolos regenerativos, utilizando principalmente protocolo DF [5, 50]. Considerando o padrão LTE-A, existem três classificações para a implementação de relays, dependendo do nível em que ocorre o processo de retransmissão [50, 17]:

- Layer 1: retransmissão no nível de rádio-frequência, operando apenas com protocolos não-regenerativos;

- Layer 2: retransmissão no nível da camada física, utilizando protocolos regenerativos;

- Layer 3: retransmissão no nível da sub-camada de Controle de Acesso ao Meio (MAC), por meio de protocolos regenerativos. Essa abordagem torna possível que uma RS atue como uma BS simplificada, controlando a célula sob sua cobertura.

Apenas retransmissores Layer 2 e Layer 3 são considerados para LTE-A, sendo reconhecidos como Tipo 2 ( Type 2) e Tipo 1 (Type 1), respectivamente [50]. Além disso, apenas relays Tipo 1 são necessariamente suportados pelo padrão LTE-A, enquanto RSs do Tipo 2 ainda aguardam mais estudos [17]. Para WiMAX, considera-se que os relays atuam no Layer $3[5]$.

Em relação ao número de saltos, afirma-se em [62] que para LTE-A apenas comunicação em dois saltos é suportada, enquanto a utilização de multi-hop ainda necessita de investigação. Para a família de padrões WiMAX, o padrão 802.16 de 2012 [63] descreve tanto o modo de dois hops quanto o modo multi-hop, sendo que o último foi adicionado 
pelo padrão 802.16j em 2009. Porém, o padrão 802.16 descrito em [63] implementa apenas as normas do IMT-2000, que é a base dos sistemas de terceira geração [64]. A especificação para sistemas 4G, denominada WirelessMAN-Advanced, foi então transferida para o padrão 802.16.1 [5], derivado basicamente do padrão 802.16m de 2011 [65], que descreve na seção de escopo que atende aos requisitos definidos para IMT-A. No caso desse padrão, descreve-se apenas o suporte para o modo de dois saltos.

Tanto LTE-A quanto WiMAX definem que as RSs controlam sua própria célula, i.e., empregam RSs não-transparentes [66]. Essa definição, em conjunto com a utilização de comunicação em dois saltos, resulta que as RSs são utilizadas exclusivamente em modo de apoio. Admitindo que uma dada MS está alocada para a $j$-ésima RS, tanto o enlace MS-BS como qualquer enlace com outra $i$-ésima RS são considerados apenas como interferência inter-celular.

Considerando o padrão LTE-A, existem três possibilidades de duplexação previstas para relays Tipo 1: a) full-duplex outband com um segundo canal de RF; b) half-duplex inband empregando TDD; ou c) full-duplex inband com separação espacial. Conforme descrito no TR 36.912 [67], ao menos os modos half-duplex inband e full-duplex outband com segundo canal de RF serão suportados como parte do LTE-A. Para WiMAX, o padrão 802.16.1 descreve os modos de retransmissão half-duplex inband utilizando TDD ou fullduplex outband com dois canais de RF, com a primeira sendo denominada Transmissão e Recepção por Divisão de Tempo (TTR) e a segunda como Transmissão e Recepção Simultânea (STR). A utilização de full-duplex inband é citada no TR 36.814 [18] e também nos itens de agenda R1-100139 [61] e R1-101659 [68] do 3GPP, porém ainda não é utilizada no LTE-A.

A Tabela 2.1 lista os principais critérios de classificação em redes cooperativas, listando também qual é a abordagem de implementação para os padrões de sistemas $4 \mathrm{G}$.

\subsection{Eficiência Energética}

A abordagem de alocação de recursos com ênfase em eficiência energética se diferencia das técnicas comumente consideradas na otimização de taxa/potência ao se basear na razão entre taxa de dados e a potência consumida para se obter tal taxa, buscando maximizar o número de bits de informação corretamente recebidos por unidade de energia [24, 26] ou minimizar a quantidade de energia consumida para se receber corretamente um bit [69, 70, 71]. Com a evolução dos padrões e protocolos de transmissão, além da crescente necessidade de serviço de dados e cobertura em sistemas celulares, a métrica de eficiência espectral tem se tornado o principal aspecto a ser otimizado, o que pode ser demonstrado através da evolução da SE em sistemas de segunda geração, como GSM (Global System for Mobile Communications), cuja SE é de 0,05 bps/Hz, para SE de pico de $30 \mathrm{bps} / \mathrm{Hz}$ (downlink) e 15 bps/Hz (uplink) em sistemas de quarta geração, no caso LTE-A [72]. 
Tabela 2.1 - Itens de classificação de RSs, indicando possibilidades de implantação e definições adotadas nos sistemas $4 \mathrm{G}$

\begin{tabular}{|c|c|c|}
\hline Critérios & Técnicas & Implementação $4 \mathrm{G}$ \\
\hline \multirow{2}{*}{ Mobilidade } & RSs fixas & \multirow{2}{*}{$\begin{array}{l}\text { RSs fixas predominam, porém } \\
\text { consideram-se RSs móveis }\end{array}$} \\
\hline & RSs móveis & \\
\hline \multirow{2}{*}{$\begin{array}{l}\text { Protocolo de } \\
\text { retransmissão }\end{array}$} & Regenerativos & \multirow{2}{*}{ Regenerativos } \\
\hline & Não-regenerativos & \\
\hline \multirow{2}{*}{$\begin{array}{l}\text { Topologia de } \\
\text { comunicação }\end{array}$} & Dois saltos & \multirow{2}{*}{ Dois saltos } \\
\hline & Múltiplos saltos & \\
\hline \multirow{2}{*}{ Controle de célula } & Transparente & \multirow{2}{*}{ Não-transparente } \\
\hline & Não-transparente & \\
\hline \multirow{2}{*}{ Número de enlaces } & Retransmissão de apoio & \multirow{2}{*}{ Retransmissão de apoio } \\
\hline & Retransmissão multi-ramos & \\
\hline \multirow{6}{*}{$\begin{array}{l}\text { Duplexação acesso } \\
\text { e backhaul }\end{array}$} & Half-duplex inband TDD & \multirow{6}{*}{$\begin{array}{l}\text { Half-duplex inband TDD e } \\
\text { Full-duplex outband }\end{array}$} \\
\hline & Half-duplex inband FDD & \\
\hline & $\begin{array}{l}\text { Full-duplex inband por separa- } \\
\text { ção espacial }\end{array}$ & \\
\hline & Full-duplex outband & \\
\hline & Full-duplex inband por IC & \\
\hline & Retransmissão two-way & \\
\hline
\end{tabular}

Fonte: o autor

Tais avanços são obtidos através do emprego de diversas técnicas, como MIMO e adoção de sistemas multi-portadoras, porém também são acompanhados de maior consumo de energia. Como os equipamentos em redes celulares são, em sua maioria, alimentados por baterias que possuem limitações de capacidade devido à mobilidade e também pelos avanços na área de capacidade energética de baterias não ter acompanhado a taxa de crescimento do consumo de energia em dispositivos móveis, faz-se necessário balancear os ganhos em capacidade com a disponibilidade energética, demonstrando a importância da eficiência energética em sistemas celulares modernos [23]. Além dessa preocupação, há ainda o apelo ambiental: a produção e distribuição de energia incorre em poluição, além da exigência de racionalidade no uso de recursos. Afirma-se em [23] que a infraestrutura de redes celulares, redes com fio e Internet são responsáveis por 3\% do consumo mundial de energia, e em [22] que $2 \%$ da emissão total de $\mathrm{CO}_{2}$ é devida à tecnologia de comunicação e informação.

A eficiência energética é medida sob duas métricas principais, ambas envolvendo o número de bits de informação efetivamente recebidos, $N_{\text {bits }}$, e a energia total gasta para transmiti-los, $E_{\mathrm{T}}$, em um determinado intervalo de tempo $\Delta_{t}$. A expressão "efetivamente recebido" é utilizada para se descartar bits referentes a codificação, protocolos e qualquer tipo de redundância, e também os bits detectados incorretamente no receptor, de modo que se determina quão eficiente o sistema é em transformar energia em informação efetiva. A primeira das métricas de eficiência energética é a razão entre o número de bits efeti- 
vamente recebidos e a energia gasta, demonstrando quantos bits de informação podem ser corretamente recebidos por unidade de energia. Quanto mais bits forem efetivamente comunicados em uma unidade de energia, mais eficiente será o sistema. A segunda métrica considera a razão entre a energia gasta no processo de transmissão e o número de bits de informação efetivamente transmitidos, revelando o custo energético para se receber/detectar corretamente cada bit de informação. Ambas as técnicas são consideradas na literatura, e neste trabalho será considerada a primeira definição, de modo que a eficiência energética $\xi$ é dada por

$$
\xi=\frac{N_{\text {bits }}}{E_{\mathrm{T}}} \quad\left[\frac{\text { bits }}{\text { Joule }}\right] .
$$

Essa equação pode ser reescrita em termos da taxa de dados líquida do sistema $\left(R_{\text {liq }}\right)$, i.e., considerando apenas os bits de informação corretamente detectados, medida em bits por segundo, e da potência total utilizada para transmissão $\left(P_{\mathrm{T}}\right)$, em Watts, resultado na expressão comumente associada para $\xi[24]$ :

$$
\xi=\frac{R_{\mathrm{liq}} \Delta_{t}}{P_{\mathrm{T}} \Delta_{t}}=\frac{R_{\mathrm{liq}}}{P_{\mathrm{T}}} \quad\left[\frac{\mathrm{bits}}{\mathrm{s} \cdot \text { Watts }}\right] \equiv\left[\frac{\mathrm{bits}}{\text { Joule }}\right] .
$$

Tomando o logaritmo da equação (2.14), percebe-se que o denominador da função de EE atua como precificador do consumo de energia, de modo que a partir de um determinado ponto o crescimento da taxa de dados não compensa o gasto de energia e observa-se redução em $\log (\xi)$.

$$
\log (\xi)=\log \left(\frac{R_{\mathrm{liq}}}{P_{\mathrm{T}}}\right)=\log \left(R_{\mathrm{liq}}\right)-\log \left(P_{\mathrm{T}}\right) .
$$

Em geral são definidas duas abordagens para a descrição de $R_{\text {liq }}$ : a primeira abordagem considera que o sistema possui uma taxa de dados fixa, dada por $r_{\text {fix }}$, para a qual a taxa efetivamente recebida é controlada por uma função-eficiência $f(\gamma)$, que visa modelar a taxa de sucesso de pacote (PSR) em relação à SINR no receptor, $\gamma$. A função-eficiência é estritamente não-decrescente em relação à SINR, de modo que quanto maior a SINR, maior será a taxa efetivamente alcançada [73]. Em geral, utiliza-se uma aproximação da PSR para $f(\gamma)$ devido à PSR em $\gamma=0$. Considerado um pacote com $M$ bits, a menor PSR quando $\gamma=0$ é igual a $0,5^{M}$, o que pode, sob algumas condições, fazer com que a máxima EE seja atingida simplesmente não utilizando potência alguma e adivinhando os bits no receptor, pois o numerador da EE seria não-nulo e positivo dividido por denominador nulo, ou seja, $\xi \rightarrow \infty$ [74]. Assim, costuma-se definir a função $f(\gamma)$ como uma função distribuição acumulada (CDF) [73, 75], de modo que:

$$
f(\gamma)= \begin{cases}0, & \gamma \leq 0 \\ 1, & \gamma \rightarrow \infty\end{cases}
$$

cujo intervalo de existência é $[0, \infty)$. 
A segunda abordagem define a taxa de dados de acordo com a SINR atingida [27, 34, 76], a partir da equação de capacidade de Shannon, com a inserção de um gap $\imath$ que reflete imperfeições de canal/modulação [77], resultando em:

$$
r(\gamma)=W \zeta(\gamma)=W \log _{2}(1+\gamma \imath) \quad\left[\frac{\mathrm{bits}}{\mathrm{s}}\right],
$$

onde $\zeta$ é a eficiência espectral do sistema; e $\imath$ é dado por [77]

$$
\imath=\frac{-1,5}{\ln (5 \mathrm{BER})}, \quad 0<\imath \leq 1
$$

onde BER é a taxa de erro de bit (BER) tolerada, desconsiderando codificação. Neste trabalho, opta-se pela formulação de taxa variável, e utiliza-se a convenção $r=r(\gamma)$.

A taxa de dados líquida $R_{\text {liq }}$ é obtida descartando bits de código, redundância e de cabeçalho, além de descontar os bits perdidos devido a erros. Considerando o número de bits de informação por pacote, $L$, e o tamanho total de um pacote, $M$, pode-se definir $R_{\text {liq }}$ como:

$$
R_{\mathrm{liq}}=\frac{\operatorname{Lr}(\gamma)}{M}=\operatorname{lr}(\gamma) \quad\left[\frac{\mathrm{bits}}{\mathrm{s}}\right]
$$

A potência total gasta no processo de transmissão envolve não somente a potência convertida em sinal transmitido, mas também o gasto com processamento de sinais, arrefecimento e obtenção de parâmetros de canal, entre outros, além da ineficiência do amplificador de potência $[23,16,78]$. A importância da inclusão da potência de circuitaria na descrição da EE é discutida em [23], onde se aponta que diversas das técnicas consideradas para maximização de taxa e/ou redução de consumo de potência, como por exemplo MIMO, inserem novos custos de circuitaria. Como a EE é estritamente decrescente com o aumento da potência de circuitaria [31], é necessário avaliar se o ganho inserido por essas técnicas compensa a potência de circuitaria extra. Pode-se mostrar o efeito da potência de circuitaria através da comparação de dois resultados da literatura para EE em sistemas MIMO densos: em [79], um aumento significativo no número de antenas na BS resulta em maior EE para o sistema, porém sem considerar o impacto da potência de circuitaria; já em [80], ao se considerar a potência de circuitaria de cada antena adicionada, mostra-se que o sistema proposto tende a utilizar menos antenas para atingir maior EE.

A partir dessas considerações, define-se $P_{\mathrm{T}}$ como a soma da potência consumida para transmissão e um termo de circuitaria, sendo equivalente a:

$$
P_{\mathrm{T}}=\varrho p+p_{c}(r) \quad[\text { Watts }]
$$

sendo $\varrho$ a ineficiência do amplificador de potência, com $\varrho \geq 1$; e $p_{c}(r)$ a potência de circuitaria. Em geral, os modelos de potência de circuitaria consideram a existência de um termo estático $\left(p_{\mathrm{st}}\right)$ e um termo dinâmico $\left(E_{\mathrm{dyn}}\right)$, associado à taxa de dados, resultando em [78]:

$$
p_{c}(r)=p_{\mathrm{st}}+E_{\mathrm{dyn}} r \quad[\text { Watts }]
$$


Neste trabalho, considera-se que o único termo de circuitaria dependente da taxa de dados está relacionado com a ineficiência do amplificador de potência, mapeado através de $\varrho$, resultando que $p_{c}$ é constante [81], o que é um modelo bastante aceito e adotado na literatura $[34,80,82]$. Desse modo, tem-se que $p_{c}(r)=p_{c}=p_{\text {st }}$.

Finalmente, a função de eficiência energética $\xi$ é dada por:

$$
\xi=\frac{\ell r(\gamma)}{\varrho p+p_{c}} \quad\left[\frac{\text { bits }}{\text { Joule }}\right]
$$

A alocação de recursos tendo como única métrica a maximização de eficiência energética pode resultar em comprometimento de outras métricas importantes de desempenho, como é o caso da eficiência espectral.

\subsubsection{Compromisso EE-SE}

A eficiência espectral é um dos mais importantes critérios de desempenho em sistemas de comunicação, especialmente em comunicação sem fio devido ao espectro limitado disponível, o qual é dividido entre diversos sistemas e aplicações. Assim, desenvolver um sistema que transmita o máximo número de bits por unidade de frequência possibilita que uma menor largura de banda seja utilizada ou então que mais dados sejam transmitidos dada uma largura de banda fixa. Além disso, a eficiência espectral é diretamente relacionada com a taxa de dados do sistema, que é um dos principais critérios de QoS para sistemas de comunicação.

Conforme descrito em [29], o compromisso entre as eficiências energética e espectral é um dos compromissos fundamentais em Green Communications, juntamente com os compromissos entre eficiência energética e eficiência de implantação (em termos de custo de equipamentos e operação), consumo de potência e consumo de espectro e, por último, consumo de potência e performance em termos de atraso, sendo que os termos de consumo de potência e eficiência energética podem ser mapeados em termos de emissão de poluentes, como gás $\mathrm{CO}_{2}[83]$.

Considerando sistemas na ausência de interferência de múltiplo acesso (MAI), a máxima taxa de dados é atingida com consumo máximo de potência. Tomando como exemplo o downlink de um sistema OFDMA, a maior taxa de dados é obtida alocando o usuário com maior ganho de canal em cada subportadora e então executando um algoritmo de waterfilling $[4,84]$. Para o uplink, é necessário testar todas as combinações de alocação de subportadoras, e cada usuário deve realizar, no subgrupo de portadoras que receber, um algoritmo de waterfilling para distribuir sua potência disponível, selecionando-se a combinação que resultar na maior capacidade [85]. A necessidade de testar todas as combinações de subportadoras é devido ao fato de que a restrição de potência máxima em uplink se aplica a cada usuário, de modo que determinar a alocação de subportadoras como feito no downlink pode resultar em perda de capacidade, como mostrado em [85]. 
De qualquer modo, tanto para downlink quanto para uplink a máxima SE é obtida com a utilização de potência máxima.

Analisando ainda o mesmo sistema OFDMA, a maximização de eficiência energética aloca a potência necessária para maximizar a razão definida em (2.22), que não necessariamente representa a potência máxima disponível. Assim sendo, existe uma possível redução da taxa de dados, e portanto da eficiência espectral do sistema, indicando um compromisso entre as eficiências energética e espectral [26, 27, 76]. Tal compromisso pode ser avaliado a partir da diferença (gap) entre a SE máxima do sistema ( $\left.\zeta^{\text {max }}\right)$ e a SE que é alcançada após a maximização de $\mathrm{EE}\left(\zeta^{\mathrm{EE}}\right)$, dada por:

$$
\Lambda=\zeta^{\max }-\zeta^{\mathrm{EE}}, \quad\left[\frac{\mathrm{bits}}{\mathrm{s} \cdot \mathrm{Hz}}\right] .
$$

Uma evidência desse compromisso pode ser observada nos resultados apresentados em [33]. Considerando o caso em que não há restrição de taxa mínima por usuário, apenas taxa de dados mínima do sistema, demonstra-se que a função-objetivo da EE é quasecôncava em termos do nível de água resultante do algoritmo de waterfilling, de modo que apenas quando a potência necessária para manter o nível de água que maximiza a EE é maior ou igual à potência máxima disponível o algoritmo de waterfilling resultaria em máxima EE. Mesmo no caso em que as restrições individuais são consideradas, a iteração de remoção/atualização apresentada no Algoritmo 1 em [33] evidencia que ocorre diminuição da taxa de dados, e portanto da SE, quando a alocação de recursos considera EE.

Em sistemas limitados por MAI, mostra-se em [86] que o aumento de interferência reduz o gap entre as duas eficiências, pois a MAI limita mais drasticamente a máxima SE do que a SE obtida após o problema de maximização de EE. Nessa análise, considera-se que um usuário tenta maximizar a SE enquanto os demais estão com a potência fixada para atingir a máxima EE. Em [26], analisa-se o compromisso EE-SE em sistemas OFDMA sujeitos a interferência nas subportadoras, e demonstra-se de maneira análoga que conforme a MAI cresce, diminui o gap entre EE e SE.

Em [31], analisa-se o projeto conjunto para as métricas de eficiência energética e espectral, medindo-se o efeito da capacidade de Shannon, da potência de circuitaria e da ineficiência do amplificador de potência. Quando o termo de potência de circuitaria é nulo, mostra-se que existe um compromisso monotônico entre as eficiências energética e espectral, de modo que conforme a SE cresce a EE decresce. Tal comportamento pode ser visto na Figura 2.6, onde a EE decresce monotonicamente em relação à SE quando a potência de circuitaria é nula. Quando a potência de circuitaria é não-nula, existe uma região de crescimento mútuo de $\mathrm{EE}$ e $\mathrm{SE}$ e, posteriormente, uma região de compromisso na qual o incremento de SE reduz a EE, conforme mostrado na Figura 2.7. Além disso, afirma-se que uma pequena perda de SE resulta em ganho exponencial em termos de 
EE, mostrando o compromisso entre EE e SE. Assim, listam-se em [31] três necessidades básicas para melhorar o compromisso EE-SE:

- aumentar a eficiência energética para todos os valores de SE;

- aumentar a região na qual tanto a eficiência energética quanto a espectral são aumentadas conjuntamente;

- reduzir a inclinação da curva de EE em relação à SE na região de compromisso, de modo que se reduza a perda em EE com o aumento de SE;

Figura 2.6 - Eficiência energética em relação à eficiência espectral, com potência de circuitaria nula, evidenciando o compromisso monotônico entre EE e SE. Adota-se $\ell=0,8 ; p_{c}=10 \mathrm{~mW} ; \imath=0,6 ; \frac{|h|^{2}}{\sigma^{2}}=1,57.10^{3} ;$ e $W=100 \mathrm{kHz}$.

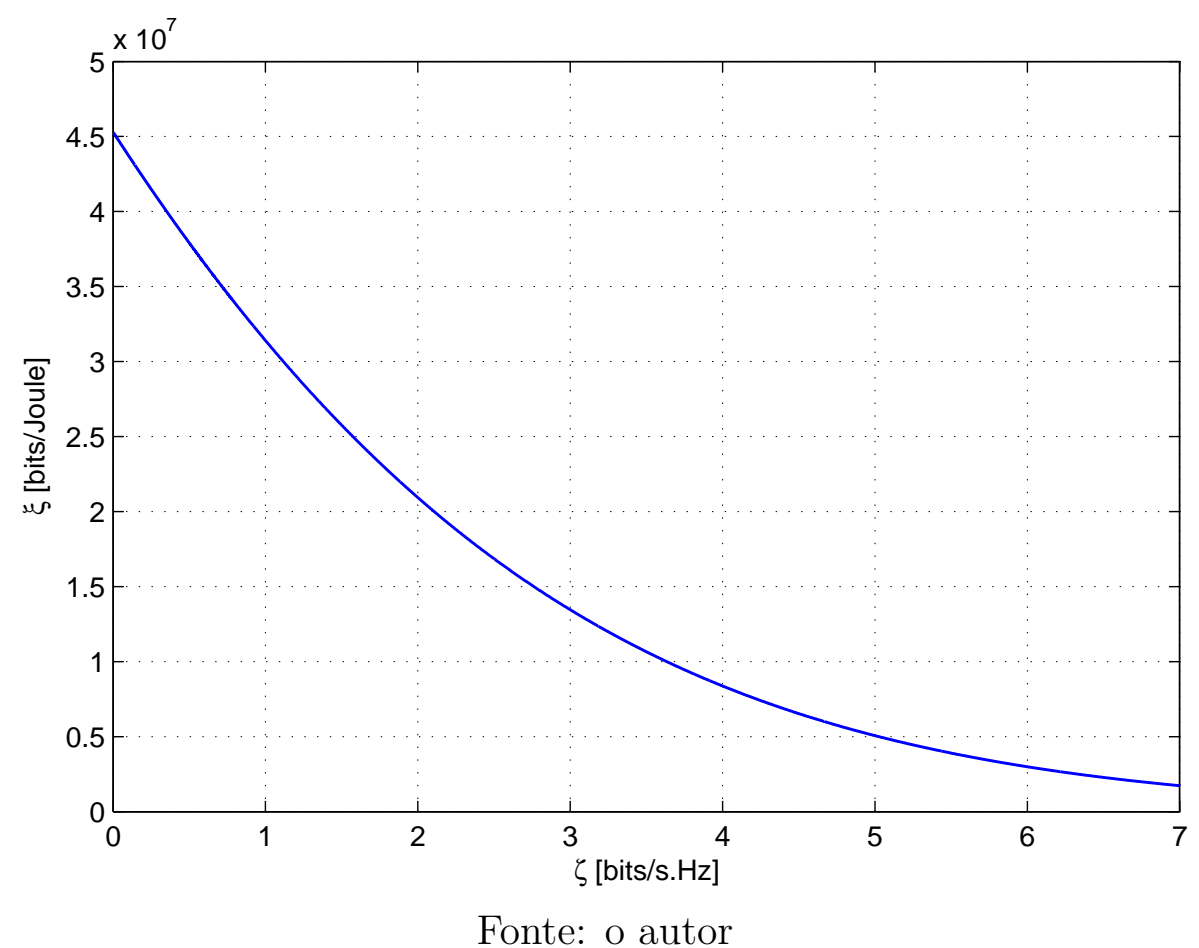

\subsection{Técnicas de Otimização em Redes Cooperativas}

Além da otimização da alocação de subportadoras e potência, que é inerente ao sistema OFDMA, existem diversos aspectos que podem ser otimizados em sistemas cooperativos. Quatro deles são aplicáveis a qualquer tipo de sistema que se baseia na utilização de RSs, independente do esquema de múltiplo acesso considerado:

- implantação otimizada de RSs, em termos de posicionamento e quantidade;

- aperfeiçoamentos nos protocolos de retransmissão; 
Figura 2.7 - Eficiência energética em relação à eficiência espectral, com potência de circuitaria não-nula, evidenciando as regiões de crescimento mútuo e de compromisso EE-SE. Adota-se $\ell=0,8 ; p_{c}=10 \mathrm{~mW} ; \imath=0,6 ; \frac{|h|^{2}}{\sigma^{2}}=1,57.10^{3} ; \mathrm{e}$ $W=100 \mathrm{kHz}$.

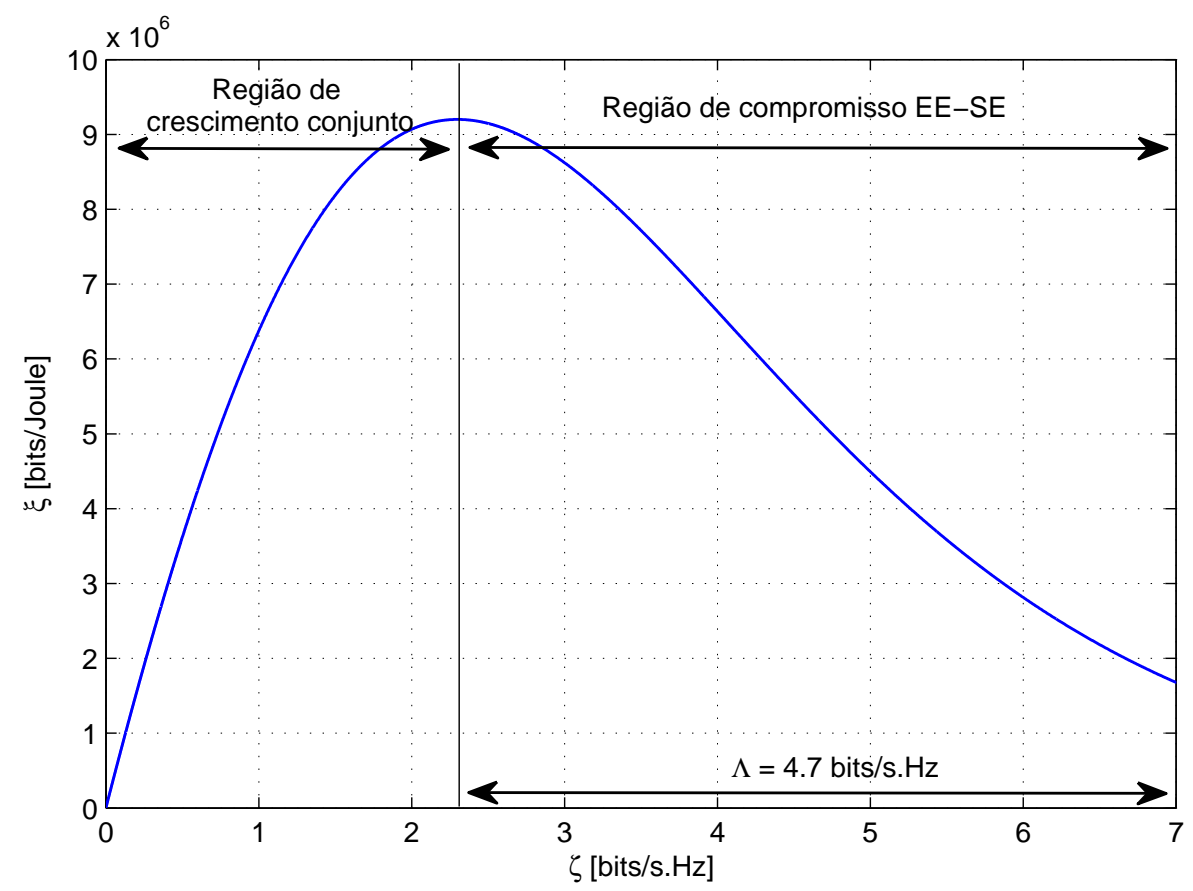

Fonte: o autor

- modo de duplexação dos enlaces de acesso/backhaul;

- seleção de relays, não somente em termos de quantidade, mas também de coordenação na alocação para evitar sobrecarga.

Desses quatro aspectos, os três primeiros são considerados nesta tese. Outros aspectos e técnicas podem ser encontrados no survey publicado [87].

\subsubsection{Implantação de RSs}

O primeiro aspecto em redes cooperativas que merece atenção refere-se à estratégia de implantação de RSs, cuja complexidade computacional associada ao método de otimização impacta apenas a fase de instalação. O processo de implantação visa determinar os locais na célula em que as RSs devem ser instaladas para otimizar alguma métrica desejada, como taxa de dados, potência, cobertura e/ou EE. As técnicas de otimização de implantação consideram três cenários:

- teóricos/empíricos, i.e., baseados em simulação de modelos como os descritos nos padrões comerciais; 
- implantações comerciais, considerando mapas de cobertura de operadoras e os equipamentos instalados nessas áreas;

- Estocásticos, na qual o layout de célula, a quantidade e a distribuição espacial de BSs, MSs e RSs são tomadas como variáveis aleatórias.

Os modelos empíricos são aqueles em geral baseados em layouts de célula bem definidos, nos quais se conhece a distribuição estocástica dos usuários no espaço, tomada usualmente uniforme. Em geral, tais modelos consideram células com layout hexagonal, apresentando geometria regular e desconsiderando condições geográficas e variação da densidade de usuários na célula $[28,88,89]$. O modelo mais comum de implantação de RSs em cenário empírico é a escolha de uma circunferência de implantação, na qual as RSs são espalhadas de maneira uniforme [28, 89, 90]. Essa topologia pode ser vista como a combinação de dois resultados descritos na literatura: em [91], utiliza-se um algoritmo baseado em K-means para minimizar a distância quadrática média entre MSs e RSs, e o resultado obtido indica que com a distribuição uniforme das MSs, uma topologia com 6 relays ou menos resulta em uma distribuição uniforme em torno de uma circunferência centrada na BS, enquanto que com mais RSs esperam-se duas ou mais circunferências, porém com distribuição uniforme das RSs em cada uma. Apesar de utilizar uma abordagem diferente, com a discretização do espaço de busca, os resultados descritos em [59] são bastante semelhantes, indicando a existência das circunferências e o posicionamento uniforme das RSs nessas circunferências.

O modelo discretizado apresentado em [59] também possui bastante interesse prático, pois possibilita que outras distribuições de MSs possam ser atendidas de maneira eficiente. Nesse modelo, as RSs podem ser instaladas em posições candidatas da célula, em geral obtidas com a utilização de circunferências concêntricas e diferentes raios de implantação. Em [49], assume-se também a discretização do espaço de busca, com a implementação de um algoritmo heurístico baseado em simulated annealing (SA) para determinar o posicionamento de RSs que maximiza a capacidade da célula, considerando relays inband e outband. A discretização do espaço de implantação também é empregada em [88], sendo que nesse caso apenas a célula central possui espaço de busca discretizado, enquanto as células vizinhas utilizam a implantação de RSs com distribuição uniforme descrita no parágrafo anterior.

Em relação aos modelos que operam em cenários comerciais, em [48] considera-se uma área de cobertura macro-celular de uma operadora em Londres, com a localização das BSs e um mapa de PL em diferentes pontos da área analisada. O objetivo do algoritmo de implantação proposto é adicionar iterativamente RSs na região, de modo que a cada iteração a RS que maximiza uma determinada métrica seja instalada, até que se esgotem as posições candidatas ou as RSs disponíveis. A métrica utilizada pelos autores leva em conta a qualidade do enlace backhaul, número de usuários com serviço interrompido (outage), 
throughput dos enlaces direto e backhaul e cobertura da macro-célula, utilizando pesos para determinar a importância de cada um desses componentes. Métodos semelhantes ao descrito podem ser utilizados mesmo quando são considerados modelos empíricos, como o descrito em [92], em que uma abordagem bastante similar é analisada, porém com diferente métrica de decisão.

Existe também a possibilidade de descrição estocástica do problema, através da geometria estocástica (stochastic geometry) [93], na qual o layout de célula, a quantidade e a distribuição espacial de BSs, MSs e RSs são tomadas como variáveis aleatórias. Considerando alocação fixa de potência e um protocolo de cooperação baseado em DF com cooperação codificada, o problema de maximização de eficiência energética é resolvido de maneira analítica, sendo a validade do modelo estocástico corroborada por resultados numéricos obtidos via simulação Monte Carlo (MCS). Outro ponto interessante é que os layouts de célula gerados tendem a ser bastante irregulares, o que torna o modelo estocástico mais próximo às implantações comerciais do que os modelos regulares.

Uma questão a ser considerada na implantação das RSs é o impacto da variação de tráfego, incluindo diferentes tipos de requisitos de QoS entre os usuários e também o número de usuários atendidos a cada momento. Considerando ambiente CDMA, apontase em [16] que a melhor implantação de RSs varia de acordo com os parâmetros de QoS necessários, tanto em termos de distância quanto em número de RSs. Como se considera a utilização de RSs fixas, o problema apresenta uma segunda faceta: dadas as variações que existem na requisição de serviços em redes celulares, como implantar as RSs de forma a balancear custo e desempenho? Considerando apenas desempenho, uma estratégia é determinar a melhor instalação de RSs para os casos de tráfego existentes na rede e instalar todas as RSs necessárias para atender cada um dos casos, desligando e ligando as estações de acordo com a situação atual. Um possível problema desse modelo é a questão financeira para os operadores de serviço, pois o custo de aquisição/instalação das RSs seria muito elevado, além do uso ineficiente, pois várias delas estariam desligadas em determinados momentos.

A análise de custo de instalação e operação de RSs é discutida em [11, 10, 94]. Em [11], considera-se um modelo que combina os custos de capital (CAPEX) e de operação (OPEX) para a implantação/manutenção de RSs, micro-BS e macro-BS, e então curvas de iso-desempenho são obtidas e o ponto com menor custo é selecionado, considerando uma demanda de tráfego gerada por uma determinada quantidade/densidade de usuários.

A estratégia de desligar algumas RSs em determinadas situações de tráfego é considerada em [95]. O interessante nessa etapa é traduzir os ganhos em eficiência energética e atendimento de QoS em termos financeiros, para que se possa observar o compromisso entre as métricas analisadas e o custo financeiro associado, além de ferramentas que possam auxiliar na decisão de quantas estações devem ser instaladas.

Em [10], os custos de CAPEX e OPEX são divididos em 5 grupos, dos quais três 
podem ser considerados como parte do escopo deste trabalho, sendo descritos na Tabela 2.2. A partir desses componentes de custo, pode-se analisar o problema de implantação de RSs sobre a perspectiva de custo dos operadores de rede, ao comparar o gasto com estratégias com e sem RSs e a relação entre custo de instalação/operação e retorno para usuários e operadores. Assim, é possível comprovar e quantificar, tanto para MSs quanto operadores, a vantagem da utilização de RSs.

Tabela 2.2 - Componentes de custos CAPEX e OPEX para os três primeiros grupos analisados em [10]

\begin{tabular}{|c|c|c|c|}
\hline Grupo & Proporcionalidade & CAPEX & OPEX \\
\hline CG1 & Número de BSs & $\begin{array}{l}\text { Local de instalação das } \\
\text { BSs. } \\
\text { Aquisição das BSs. } \\
\text { Implantação das BSs. } \\
\text { Conectividade RAN. }\end{array}$ & $\begin{array}{l}\text { Fornecimento de energia } \\
\text { para as BSs. } \\
\text { Aluguel para conectivi- } \\
\text { dade RAN. } \\
\text { Aluguel do local de insta- } \\
\text { lação das BSs. } \\
\text { Manutenção. }\end{array}$ \\
\hline CG2 & Número de RSs & $\begin{array}{l}\text { Local de instalação das } \\
\text { RSs. } \\
\text { Aquisição das RSs. } \\
\text { Implantação das RSs. }\end{array}$ & $\begin{array}{l}\text { Fornecimento de energia } \\
\text { para as RSs. } \\
\text { Aluguel do local de insta- } \\
\text { lação das RSs. } \\
\text { Manutenção. }\end{array}$ \\
\hline CG3 & Único por rede & $\begin{array}{l}\text { Equipamentos de gerenci- } \\
\text { amento centralizado dos } \\
\text { recursos de rádio. } \\
\text { Gateways. } \\
\text { Otimização inicial (insta- } \\
\text { lação). }\end{array}$ & $\begin{array}{l}\text { Operação da rede. } \\
\text { Atualizações de software. }\end{array}$ \\
\hline
\end{tabular}

Fonte: o autor

\subsubsection{Protocolos de Retransmissão}

Em relação aos protocolos de retransmissão, a primeira otimização que pode ser formulada provém da introdução de um limiar de SINR, que determinará se uma RS está apta a cooperar. Considerando protocolos do tipo não-regenerativo, se a SINR do sinal é baixa, amplifica-se uma quantidade considerável de ruído e interferência, de modo que o sinal recebido pelo nó destino pouco pode ser aproveitado. Para protocolos regenerativos, a baixa SINR entre fonte e relay pode resultar em decodificação com alta probabilidade de erro, de modo que a informação retransmitida possui baixa confiabilidade. Desse modo, apenas nos casos em que uma SINR mínima $\gamma^{\text {th }}$ é alcançada o relay retransmite. Os protocolos que utilizam tal abordagem são chamados de protocolos seletivos, sendo descritos em [96]. 
Ainda considerando a análise descrita em [96], pode-se ainda otimizar os protocolos de retransmissão ao se definir se é necessário que a RS retransmita o sinal de um determinado usuário. Tal procedimento é denominado retransmissão incremental, e define-se que a retransmissão ocorre somente se o nó destino exigir que ela ocorra, como por exemplo quando for detectado um erro de detecção que não pode ser corrigido. Quando tal evento ocorre, o nó destino envia um sinal de requisição de retransmissão para a(s) RS(s), de modo que a retransmissão possa ser utilizada para prover diversidade espacial. Quando a retransmissão não é necessária, obtém-se menor consumo de potência e economia de janelas devido a não utilização das RSs. Percebe-se que as duas técnicas descritas exigem que o enlace direto esteja ativo, o que pode não ser garantido em cenário macro-celular. Em termos de impacto em EE, avalia-se o protocolo DF seletivo e AF convencional com e sem retransmissão incremental em [70], cuja utilização é representada pela presença do canal de retorno. Os resultados numéricos mostram que a retransmissão incremental é benéfica em todas as topologias e protocolos considerados, resultando em maior EE.

Conforme apontado em [8], é possível ainda utilizar protocolos híbridos, que selecionam os protocolos AF e DF de acordo com as condições do sistema. A justificativa para a utilização de protocolos híbridos pode ser compreendida a partir de trabalhos como [70], no qual os resultados numéricos mostram que nenhum dos protocolos é sempre melhor que os demais. O protocolo proposto pelos autores de [8] consiste em selecionar os protocolos de acordo com a capacidade do relay de detectar corretamente a informação transmitida pelo nó fonte, o que pode ser feito a partir de códigos como CRC (Cyclic Redundancy Check) ou do limiar de SINR $\gamma^{\text {th }}$. Quando o relay é capaz de detectar corretamente a informação transmitida, utiliza-se o protocolo DF para evitar a amplificação de ruído. Quando a detecção falha, utiliza-se o protocolo AF para evitar que o erro de detecção seja propagado para o nó destino. Tal abordagem pode ser estendida para o caso de múltiplos relays, e é descrito pelos autores como um caso especial do protocolo DF seletivo, no qual o erro de detecção não mais silencia uma RS, apenas a faz trocar de protocolo. Protocolos híbridos são também descritos em [97] e [80].

Além dos protocolos AF e DF, existem outros diversos protocolos de retransmissão disponíveis na literatura. Na classe de protocolos não-regenerativos, destacam-se em [8] os métodos Processa Linearmente e Transmite (LF) e Processa Não-linearmente e Transmite (nLF), que são utilizados para realizar processamentos no domínio analógico após a amplificação do sinal transmitido. Por exemplo, descreve-se em [8] a possibilidade de mudança de fase para o protocolo LF, facilitando a implantação de beamforming distribuído. Um possível problema para os protocolos não regenerativos em sistemas OFDMA é a necessidade de um prefixo cíclico mais longo para evitar a ISI, o que resulta em menor eficiência espectral. Conforme mostrado em [98], quando um sinal é retransmitido utilizando protocolo não-regenerativo, o canal equivalente nos dois saltos é dado pela convolução dos canais em cada salto, de modo que se cada um tiver comprimento equivalente 
a $v+1$ amostras, o canal equivalente terá $2 v+1$ amostras. Para atenuar os efeitos do maior delay spread, discute-se em [98] o protocolo Encurta e Transmite (SF), que utiliza técnicas de encurtamento de canal para evitar a necessidade de prefixo cíclico mais longo. Ao reduzir o tamanho do prefixo cíclico necessário, utilizam-se menos bits com informação redundante e aumenta-se a capacidade do sistema.

Para os protocolos regenerativos, discute-se em [8] os protocolos Estima e Transmite (EF) e Comprime e Transmite (CF). Para o primeiro protocolo, a informação retransmitida é a estimativa soft do sinal recebido pela $j$-ésima $\mathrm{RS}$, que pode ser obtida através de uma adaptação do detector apresentado na equação (2.12), dada por

$$
\widetilde{X}_{j}[n]=\underset{X[n]}{\arg \min }\left|X[n] \widehat{H}_{j}[n]-Y_{j}[n]\right|^{2},
$$

onde $Y_{j}[n]$ é o sinal recebido na $n$-ésima subportadora da $j$-ésima RS, após a realização da operação de FFT, e $\widehat{H}_{j}[n]$ é a FFT da estimativa de canal do enlace fonte-relay na $n$-ésima subportadora da $j$-ésima RS. Percebe-se nessa formulação que $X[n]$ não é mais limitado à constelação utilizada na $n$-ésima subportadora, caracterizando a estimativa soft. O principal objetivo do protocolo EF é reduzir a propagação de erros de detecção, principalmente em cenário de baixa SINR, e evitar o desperdício de potência com amplificação de ruído resultante de um protocolo não-regenerativo [8]. Já para o protocolo CF, explora-se a correlação entre o sinal recebido no enlace direto e no enlace fonte-RS, que podem ser vistos como cópias distorcidas e ruidosas da mesma informação original. A partir dessa correlação, as RSs são capazes de realizar compressão da informação recebida, usando por exemplo codificação Wyner-Ziv ou Slepian-Wolf [99, 8].

\subsubsection{Modos de Duplexação}

Em relação aos modos de duplexação, existem métodos propostos para combinar os modos half-duplex inband e full-duplex outband, principalmente devido ao fato do enlace backhaul geralmente determinar o desempenho-limite do sistema [50, 100]. Para esse modelo híbrido, empregam-se duas faixas de frequência, onde uma é exclusiva para o enlace backhaul e a segunda compartilhada entre os dois enlaces, usando half-duplex inband com a utilização de grupos disjuntos de subportadoras. É possível também otimizar a divisão de recursos quando da utilização do modo half-duplex inband, como descrito em [90, 101]. No primeiro, discute-se a otimização da divisão de recursos operando com half-duplex inband TDD ou FDD para minimização de consumo de potência, e afirma-se que ambos são equivalentes se as restrições de potência forem consideradas em relação ao ciclo de transmissão, e não em relação à potência de pico, enquanto o segundo discute-se a adaptação da divisão das janelas temporais entre os enlaces, de modo a se maximizar a capacidade ponderada dos usuários.

Conforme destacado na Subseção 2.2.1, os padrões para LTE-A e WiMAX consideram principalmente a utilização de duplexação inband e outband. Apesar de proverem 
comunicação sem auto-interferência, os métodos inband e outband reduzem a eficiência da utilização dos recursos do sistema. Para exemplificar, analisa-se o caso de um sistema que utiliza duplexação no tempo, em que a comunicação entre dois equipamentos tem a duração de $T$ segundos, e deseja-se transmitir $N_{\text {data }}$ bits em cada um dos fluxos de comunicação, i.e., uplink e downlink, como mostrado na Figura 2.8. Para o método half-duplex inband, a taxa de dados é dada por $\frac{2 N_{\text {data }}}{4 T}$ bits por segundo; já para os modos full-duplex inband e retransmissão two-way, a taxa de dados é equivalente a $\frac{2 N_{\text {data }}}{2 T}$ bits por segundo, a mesma que seria obtida se utilizada transmissão direta

Essa perda de capacidade pode ser resolvida com a transmissão de $2 N_{\text {data }}$ bits em cada fluxo quando se utiliza retransmissão half-duplex inband, porém tal abordagem acaba resultando em um segundo problema, conforme descrito em [16]: como potência e taxa de dados não apresentam relação linear, dobrar a taxa de dados significa que a potência de transmissão terá que ser mais do que dobrada, de modo que a partir de uma determinada taxa de dados a utilização de relays se torna desvantajosa. Observando os resultados em [16], quando se exige uma eficiência espectral de 1,25 bps/Hz, o consumo de potência por área (APC) em modo cooperativo supera o necessário para comunicação direta, dado que para o modo cooperativo é necessário obter uma SE de 2,5 bps/Hz nos enlaces de acesso e backhaul para compensar a segunda banda espectral alocada.

Tal comportamento é descrito também em [15], em que a eficiência energética para transmissão direta, half-duplex inband e retransmissão two-way é comparada. Considerando tráfego assimétrico entre os nós e utilização de protocolo AF, os autores mostram que nenhum dos três modos de transmissão resulta em maior eficiência energética para qualquer valor de eficiência espectral, porém possui como resultado mais interessante o fato do método de retransmissão two-way resultar em maior eficiência energética em ambientes de elevada perda de percurso e de crescente SE. Por exemplo, considerando um expoente de perda de percurso igual a 4, típico para cenários urbanos, e uma SE maior que 2 bps/Hz, o método two-way resulta em maior EE do que o método half-duplex inband e transmissão direta. Em baixa SE, o custo extra de circuitaria do cancelador de interferência faz com que o método two-way tenha menor EE. Como sugestão para otimização de desempenho, os autores sugerem uma abordagem que seja capaz de escolher qual modo será utilizado, a depender da SE necessária e das condições de propagação.

Uma análise similar é desenvolvida em [102], comparando transmissão direta, halfduplex inband e full-duplex inband. De maneira similar ao resultado obtido no caso anterior, não há um modo que resulte em maior capacidade para qualquer condição, e os autores apresentam limiares de SINR e expressões analíticas que determinam quando um dos modos deve ser selecionado, visando maximizar a capacidade do sistema. A análise ainda considera o impacto do termo residual do cancelamento da auto-interferência no desempenho final, de modo que quanto mais interferência é cancelada, maior a probabilidade que o método full-duplex inband seja selecionado. Como o sistema proposto visa 
Figura 2.8 - Topologias de retransmissão inband e o número de janelas necessárias para completar uma transmissão em downlink e uplink.

\section{Half-duplex inband - quatro slots}
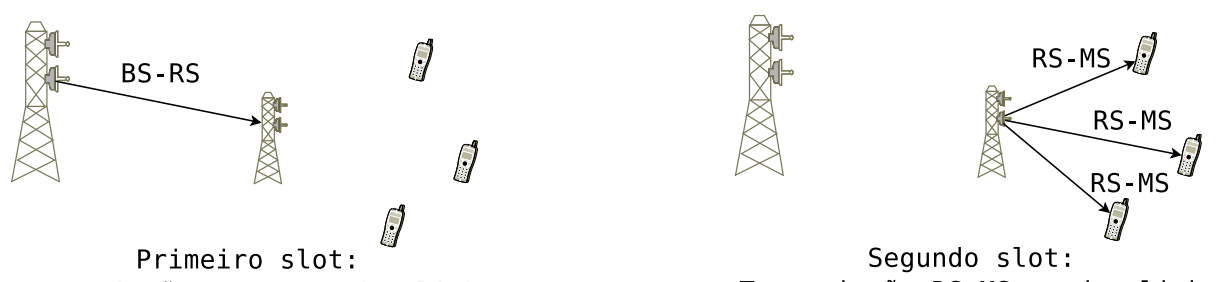

Transmissão BS-RS em downlink

Segundo slot:

Transmissão RS-MS em downlink

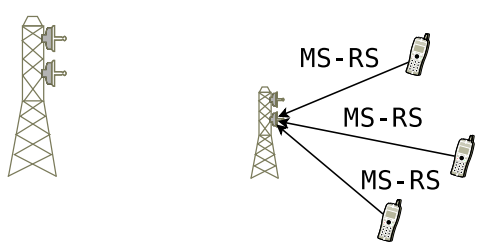

Terceiro slot:

Transmissão MS-RS em uplink

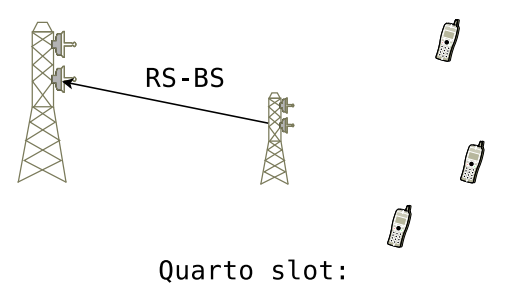

Full-duplex inband - dois slots

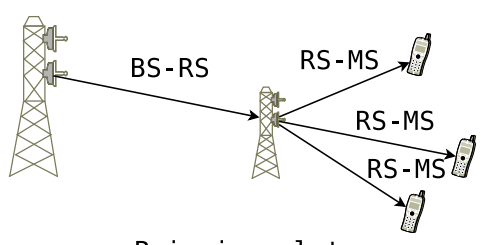

Primeiro slot:

Transmissões BS-RS e RS-MS em downlink

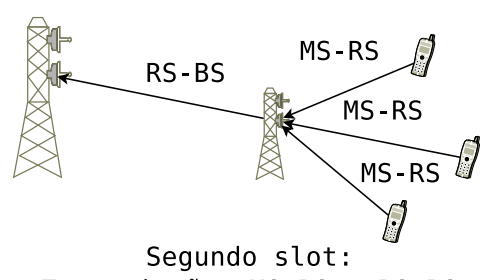

Transmissões MS-RS e RS-BS em uplink

Retransmissão two-way inband - dois slots

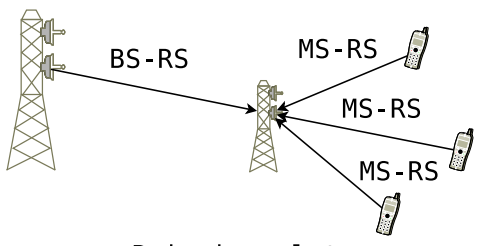

Primeiro slot:

Transmissão BS-RS em downlink e MS-RS em uplink

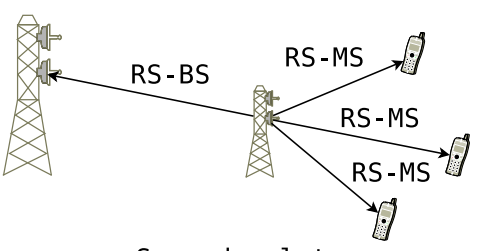

Segundo slot:

Transmissão RS-BS em uplink e RS-MS em downlink

\section{Retransmissão two-way inband - três slots}

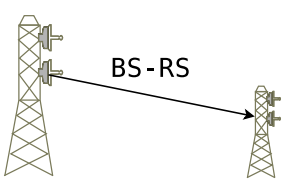

Primeiro slot:

Transmissão BS-RS em downlink

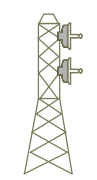

Segundo slot:

Transmissão MS-RS em uplink

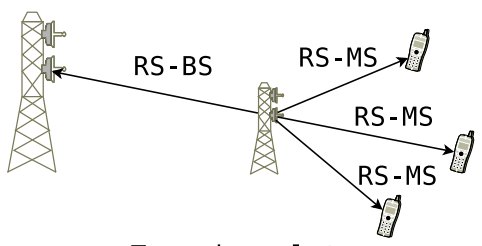

Terceiro slot:

Transmissão RS-BS em uplink e RS-MS em downlink

Fonte: o autor 
maximização de capacidade, o custo energético do cancelamento de interferência não afeta a estratégia de alocação de recursos, e a escolha entre os métodos half-duplex e full-duplex inband é dada, principalmente, pela quantidade de interferência residual e pela economia de janelas.

Resultado semelhante é obtido em [97], onde é possível escolher tanto o modo de duplexação, full-duplex inband ou half-duplex inband, e o protocolo de cooperação, AF ou DF, para maximizar a vazão ponderada média do sistema. Quando o termo residual do cancelamento de interferência tem potência baixa ou moderada, o modo full-duplex é largamente utilizado, dada a maior capacidade que propicia. Nesse mesmo cenário, conforme a potência de transmissão disponível cresce, decresce a probabilidade de utilização do protocolo AF, dado que esse protocolo amplifica o termo residual de interferência. Conforme a interferência residual aumenta, a combinação mais utilizada é full-duplex com protocolo DF, porém com a utilização de half-duplex DF se mostrando mais provável que full-duplex AF. Percebe-se desse modo que sistemas baseados em protocolo AF são especialmente suscetíveis ao aumento da auto-interferência, exatamente pela característica de amplificação de interferência.

Finalmente, em [103] analisa-se a SINR do método full-duplex inband para relays que operam como repetidores, i.e., utilizando protocolo AF na camada de RF, considerando um modelo de comunicação indoor-outdoor. Mostra-se através dos resultados numéricos que a escolha otimizada do fator de amplificação para AF é fundamental para atenuar os efeitos da interferência residual, dada que essa é gerada pelo cancelador de interferência instalado na RS e amplificada no processo de retransmissão.

Esses trabalhos resumem os dois principais aspectos que devem ser analisados para determinar se os modos full-duplex inband e retransmissão two-way resultarão em maior eficiência energética: a interferência residual e a potência de circuitaria extra inserida pelo cancelamento de interferência. Por um lado, o simples fato de não ser mais necessário dobrar a capacidade nos enlaces de acesso e backhaul já demonstra que uma significativa redução na potência de transmissão pode ser atingida. Porém, a interferência residual reduz a capacidade atingida, e portanto um aumento de potência de transmissão é necessário para se garantir a taxa de dados mínima. Além disso, a adição do termo constante de circuitaria do cancelador de interferência pode fazer com que a redução na potência de transmissão seja anulada, indicando que half-duplex inband ou transmissão direta devam ser utilizados. Dado que sistemas $4 \mathrm{G}$ requerem elevada eficiência espectral e ambientes urbanos impõem restrições severas para comunicação de longa distância, a utilização de full-duplex inband e retransmissão two-way possui apelo significativo.

\subsubsection{Seleção de RSs}

A partir de uma determinada topologia de RSs, é possível otimizar o processo de alocação de RSs para cada um dos usuários, para evitar sobrecarga de uma RS ou até mesmo 
aproveitar a diversidade de se ter múltiplas RSs. Dado que o interesse deste trabalho está em sistemas de dois saltos, estabelecem-se três estratégias para o problema de seleção de RSs, conforme mostrado na Figura 2.9. Do ponto de vista do aproveitamento de diversidade, utilizar todos os relays disponíveis aparenta ser a melhor escolha, pois mais cópias do sinal original poderão ser combinadas, conforme mostrado na Figura 2.9.c). Porém, algumas limitações práticas fazem com que a utilização de todas as RSs seja dificultada [104]: a primeira delas é a quantidade de informação no link backhaul, que seria bastante aumentada e poderia limitar o desempenho do sistema; a segunda é a perda de eficiência espectral e/ou vazão de dados, visto que mais janelas ou mais recursos espectrais seriam necessários para operar as RSs extras; e a terceira é a possível redução da eficiência energética do sistema, dado o custo energético de operação das RSs. Portanto, é necessário avaliar objetivamente como e quantas RSs selecionar para o processo de cooperação.

Figura 2.9 - Estratégias de alocação de RSs, selecionando: a) uma RS; b) subconjunto de RSs; c) todas as RSs disponíveis.

a)

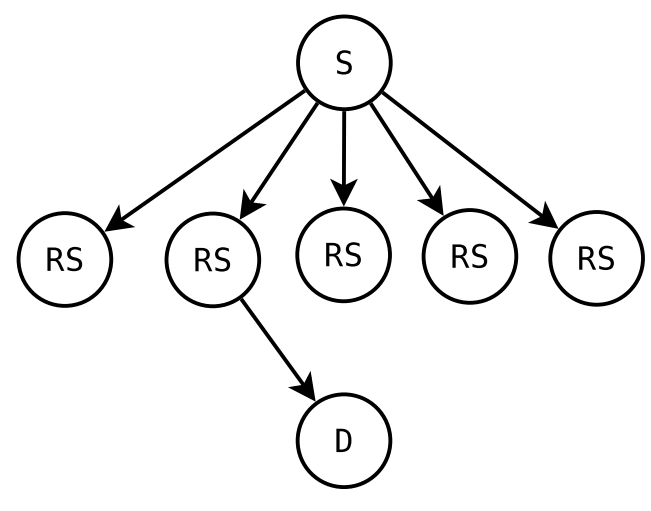

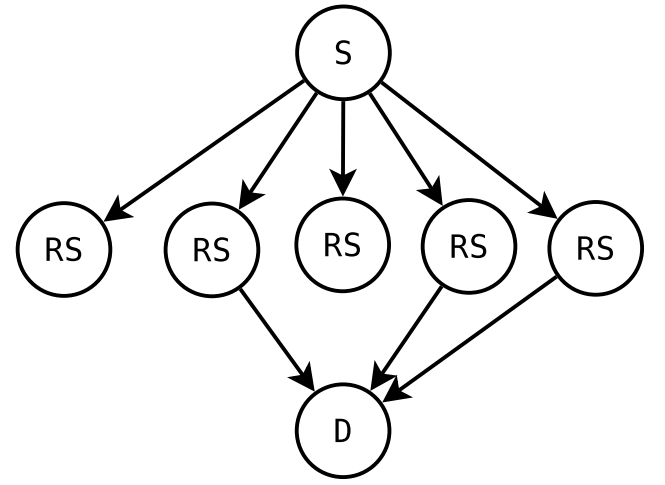

b)

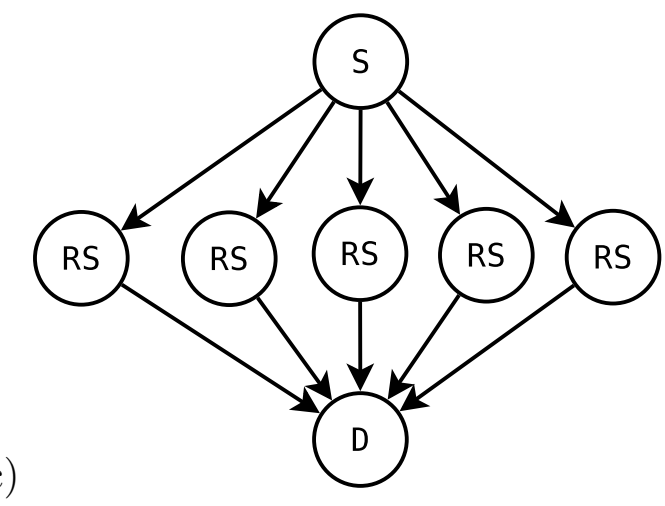

Fonte: o autor

A estratégia mais simples é adotar apenas uma RS por usuário, como mostrado na Figura 2.9.a). A política de seleção pode ser até mesmo aleatória, selecionando qualquer uma das RSs disponíveis, porém a seleção otimizada, baseada em parâmetros de sistema, tende a apresentar resultados otimizados. Por exemplo, em [105] propõe-se a seleção da RS que apresenta a melhor qualidade de canal no enlace MS-RS-BS, medida por meio de 
duas políticas distintas. Essa técnica de seleção, chamada de retransmissão oportunista pelos autores, apresenta como principal vantagem a ordem de diversidade semelhante à obtida com a utilização de todas as RSs, com a clara vantagem do menor número de slots para completar uma transmissão. Ainda considerando a seleção de um único relay por usuário, uma simplificação bastante adotada é considerar que cada usuário utiliza a RS mais próxima de $\mathrm{si}^{3}$ [90, 101, 106], visando reduzir a potência consumida no salto MS-RS. Tal método reduz o overhead de comunicação de parâmetros e estimação de canal, ao custo de aproveitamento marginal de diversidade. Outro possível problema dessa abordagem, e que também se aplica à retransmissão oportunista, é que determinadas RSs podem ser sobrecarregadas enquanto outras RSs podem ser marginalmente utilizadas.

Em relação às técnicas que selecionam um grupo de RSs, pode-se destacar a técnica de ordenação de relays (RO), proposta em [58] para protocolo AF e posteriormente estendida para DF em [107]. Nessa técnica, considera-se um sistema multi-hop no qual a ordem de transmissão das múltiplas RSs é definida para se maximizar a SINR em cada salto, utilizando combinação de máxima razão (MRC) em cada RS e também no nó destino. No primeiro salto, o nó fonte transmite, enquanto as RSs e nó destino recebem o sinal. Em cada um dos saltos seguintes, as RSs transmitem a combinação do sinal recebido do nó fonte com os sinais que foram transmitidos pelas RSs anteriores para o nó destino, de modo a aproveitar toda a diversidade possível. No caso do protocolo DF, é proposto em [107] um método que pode alternar entre o modo de operação RO e a utilização de apenas um relay, dado que a ordem de diversidade para DF é menor que para AF [39, 53]. Em [108], seleciona-se um grupo de RSs para cooperação, utilizando beamforming das RSs selecionadas e considerando o custo de obtenção do feedback necessário para essa operação. Todos os relays que são capazes de atingir um threshold de SINR podem ser selecionados para o beamforming, porém não necessariamente todos são utilizados.

Em [109] e [110] descrevem-se técnicas de seleção de RSs baseadas em eficiência energética. Considerando o primeiro trabalho, cada MS determina a posição em que uma RS resultaria na máxima EE, dada a restrição de taxa de erro de símbolo (SER). Em seguida, cada MS escolhe a RS que estiver mais próxima da posição calculada, visando obter a máxima EE possível. A posição ótima pode ser calculada para obter a maior EE considerando todo o sistema ou então priorizando MSs ou RSs. Em [110], são determinadas regiões nas quais a instalação de RSs resultam em ganho de EE para uma determinada MS, considerando conjuntamente o tráfego em uplink e downlink, e também levando em conta assimetria entre os dois sentidos. A consideração dos dois sentidos é feita para que a alocação de RSs seja a mesma tanto em downlink quanto em uplink, de modo que o overhead do processo de seleção é reduzido. As MSs podem tanto utilizar transmissão direta quanto cooperativa, escolhendo a que resultar em maior EE.

3 Considerar a RS mais próxima admite que as condições de propagação entre um usuário e todas as RSs são sujeitas ao mesmo modelo, de modo que, em termos médios, escolher a RS mais próxima equivale a escolher a RS com melhor condição de propagação. 
Em [111], propõe-se um sistema que alterna entre transmissão direta e cooperativa de dois saltos tendo como métrica a eficiência energética dos dois modos, sendo denominada pelos autores como retransmissão oportunista em EE. O problema é resolvido de duas formas distintas: na primeira delas, considera-se apenas a eficiência energética do sistema, de modo que se escolhe o modo de transmissão que resulta em maior EE. No segundo método, considera-se também a possível perda de capacidade causada pela adoção do modo cooperativo em relação à transmissão direta. Para tal, assume-se no problema de otimização que a capacidade do sistema cooperativo deve ao menos garantir parte da capacidade obtida com transmissão direta, podendo variar entre 0 (nenhuma garantia de taxa) e 1 (garantir ao menos a taxa resultante da transmissão direta).

Um ponto importante na decisão de utilização de transmissão não-cooperativa ou cooperativa com uma ou mais RSs é a potência de circuitaria adicionada pelas RSs. Por exemplo, em [112] consideram-se custos operacionais distintos para MSs, RSs e BS, incluindo o custo de técnicas de processamento digital de sinais. A partir desses custos, os resultados numéricos mostram que a utilização de modo cooperativo com apenas uma RS pode aumentar o custo energético do sistema, dado que a redução na potência de transmissão pode ser suplantada pelo custo extra de circuitaria.

Além de se limitar o número de RSs que um usuário pode utilizar, é possível também determinar quais usuários devem utilizar RSs. Por exemplo, a técnica de retransmissão oportunista em [105] prevê que caso o enlace direto seja melhor que o enlace cooperativo resultante, deve-se utilizar transmissão direta. Em [88], apenas os usuários que não são capazes de atingir uma eficiência espectral mínima podem utilizar as RSs, enquanto em [113] todos os usuários que não atingirem os requisitos mínimos de QoS devem utilizar RSs. Pode-se também determinar que apenas usuários em piores condições de cobertura, como por exemplo localizados em borda de célula, possam utilizar as RSs, evitando que se mantenha cobertura de reduzida qualidade (em termos de taxa de dados e/ou desempenho) com a implantação de RSs. Os protocolos AF e DF seletivos também podem ser vistos como restrições ao processo de seleção de RSs, pois limitam o conjunto de RSs disponíveis para cada usuário.

A Tabela 2.3 resume os aspectos de otimização relacionados às redes cooperativas descritos nesta seção. 


\begin{tabular}{|c|c|c|c|c|c|c|c|}
\hline \multirow{4}{*}{ 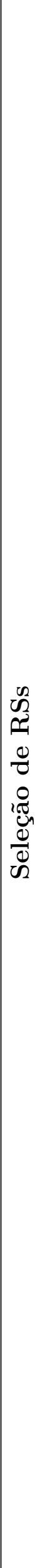 } & 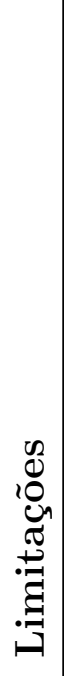 & 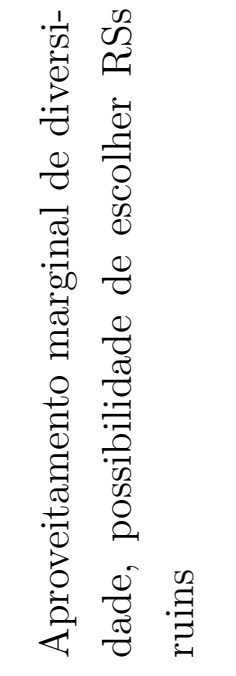 & 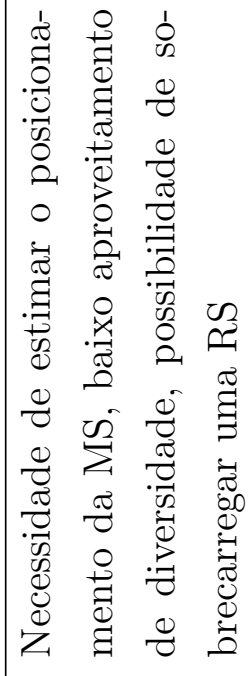 & 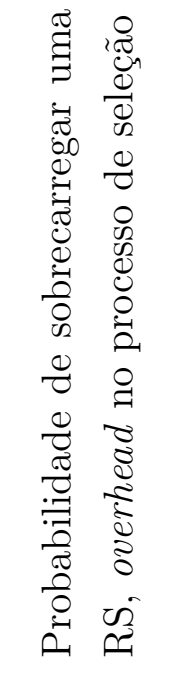 & 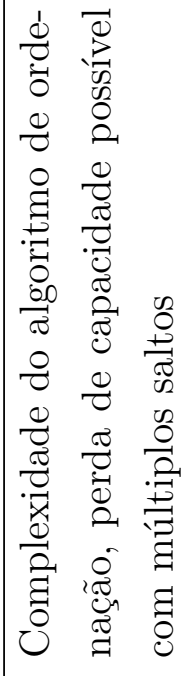 & 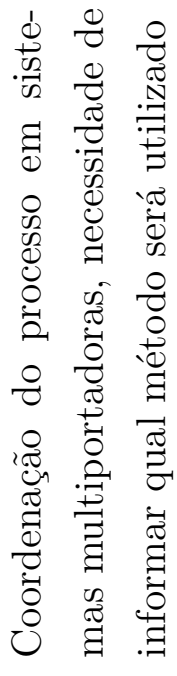 & 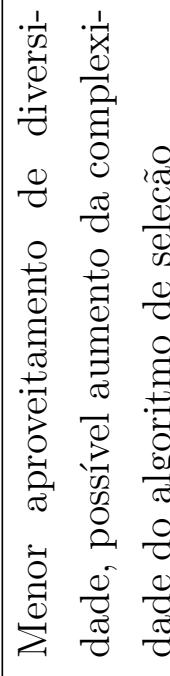 \\
\hline & 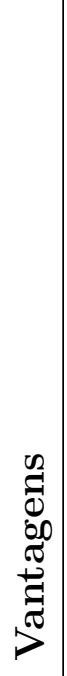 & 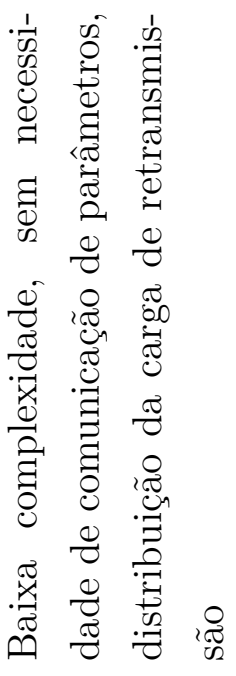 & 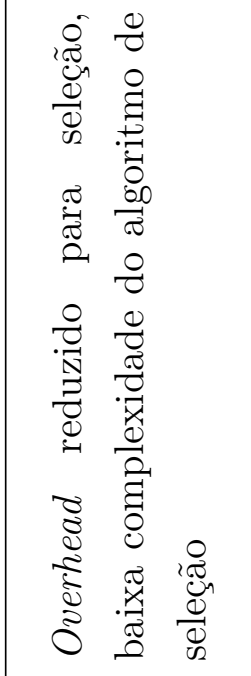 & 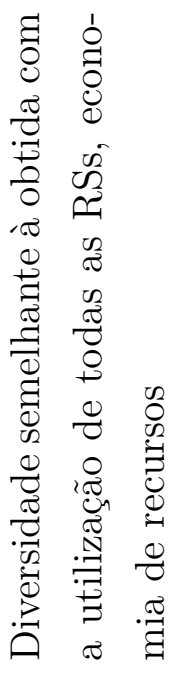 & 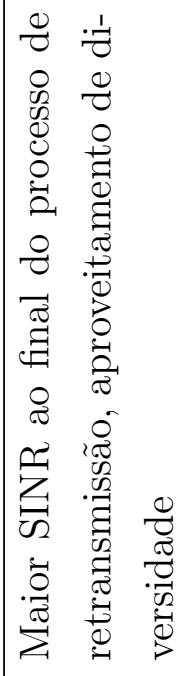 & 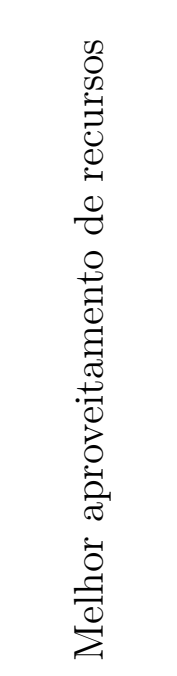 & 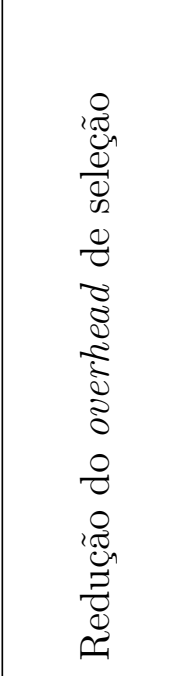 \\
\hline & 号 & 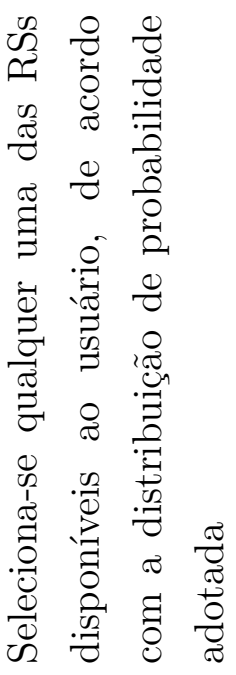 & 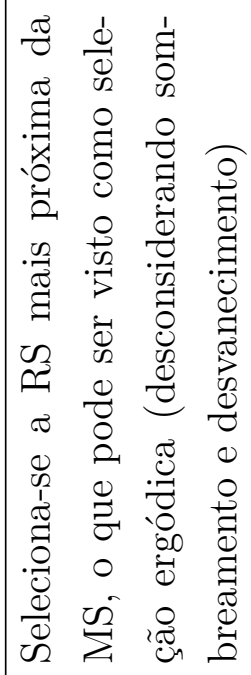 & 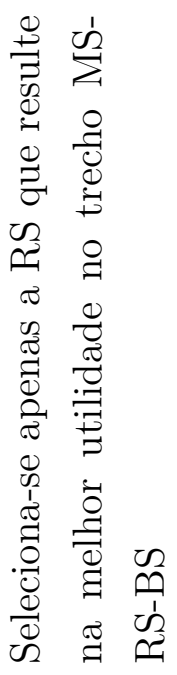 & 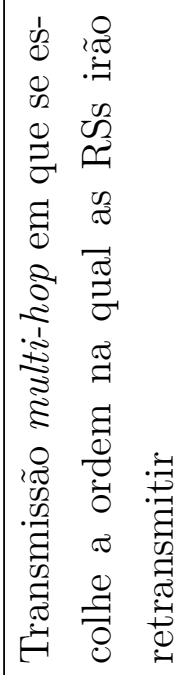 & 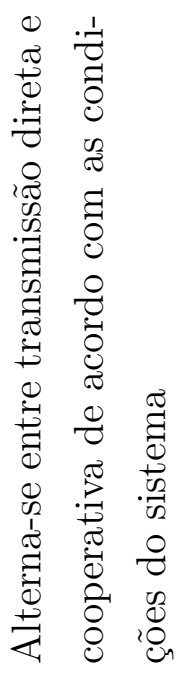 & 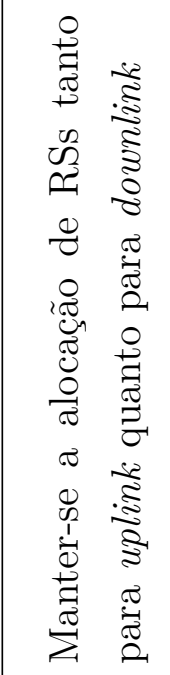 \\
\hline & 苍苞 & 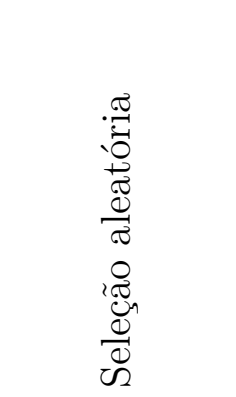 & 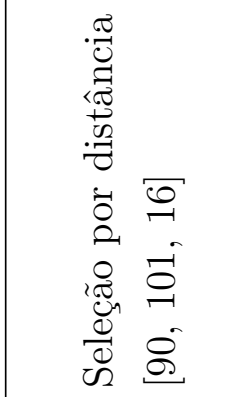 & 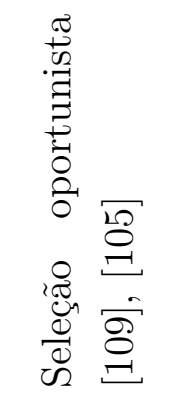 & 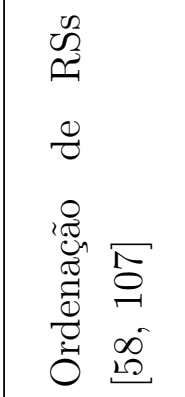 & 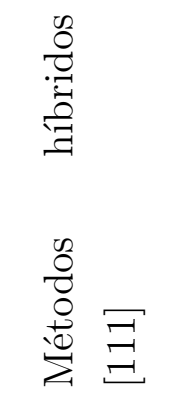 & 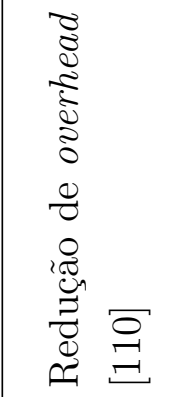 \\
\hline
\end{tabular}




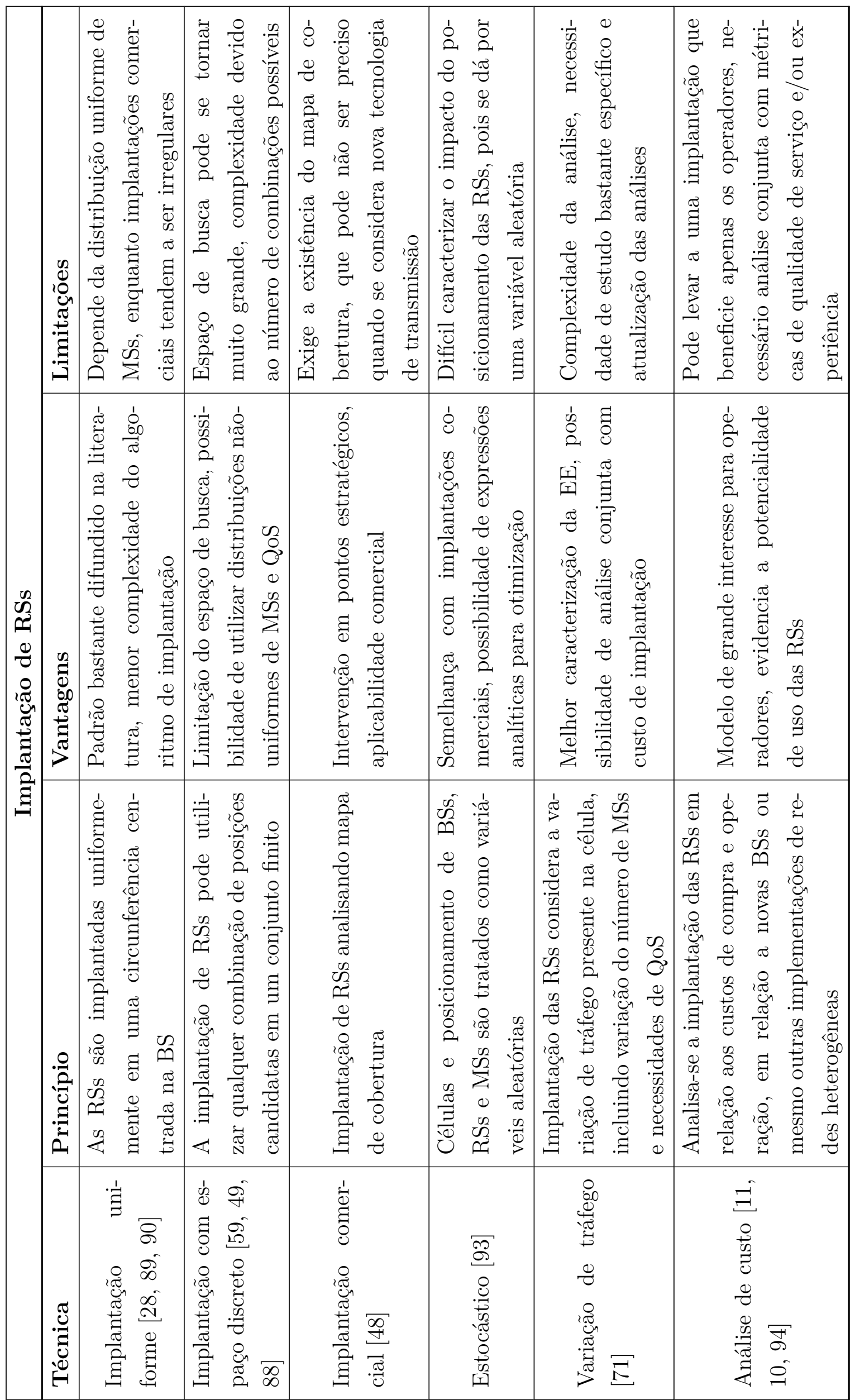




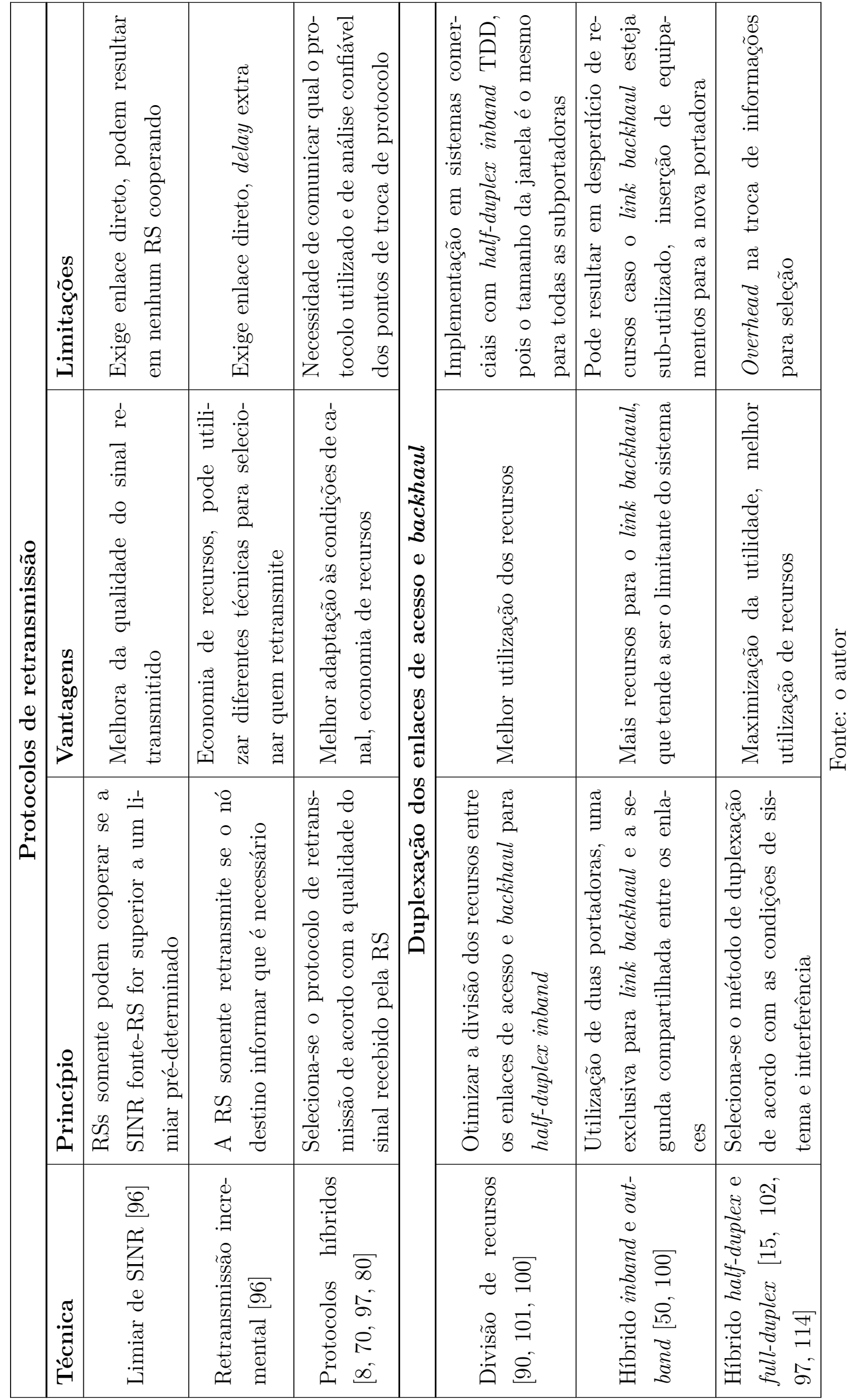





\section{DESCRIÇÃO DO SISTEMA E ABORDA- GEM DE ALOCAÇÃO BASEADA EM EE}

Este capítulo apresenta o modelo de sistema utilizado, justifica tais escolhas e descreve o modelo matemático para eficiência energética.

\subsection{Definição do Modelo de Sistema Empregado}

Adota-se como base o uplink de um sistema OFDMA com largura de banda de $W$ Hertz, dividida igualmente em $N$ subportadoras nas quais o desvanecimento rápido é considerado flat. Considerando ambiente uni-celular, uma célula hexagonal de raio de $R$ metros possui uma BS e $N_{\mathrm{RS}}$ RSs e deve atender $K$ usuários. Considerando a definição clássica de OFDMA, cada subportadora deve ser associada a apenas um par de dispositivos em cada instante de tempo, ou seja, não existe MAI.

Figura 3.1 - Modelo de célula adotado neste trabalho, considerando $N_{\mathrm{RS}}=6$ e $K=20$.

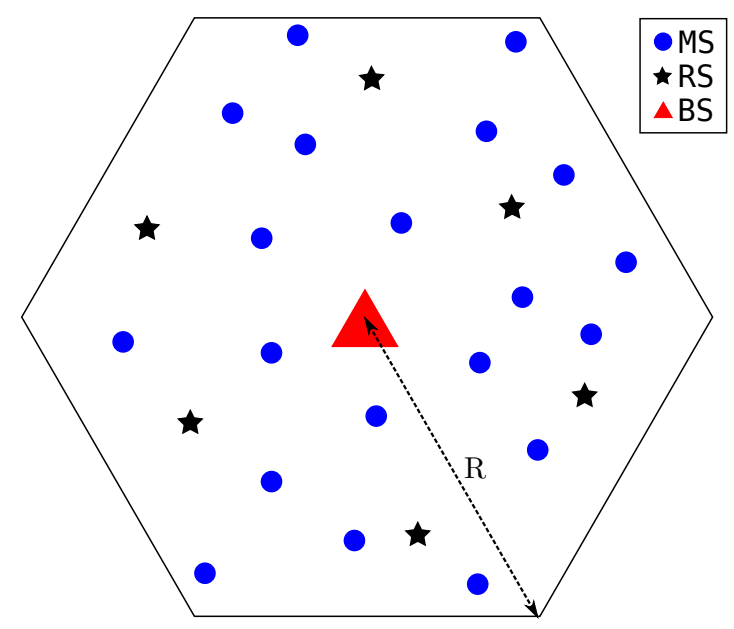

Fonte: o autor

Define-se a utilização de estações retransmissoras fixas, que têm como objetivo auxiliar os usuários em condição desfavorável de comunicação, i.e., usuários que estejam posicionados em região de borda de célula. A métrica de instalação das RSs será apresentada no Capítulo 6, e adota-se abordagem não-transparente de dois saltos (two-hop) e sem enlace direto, i.e., retransmissão de apoio. A não consideração do enlace direto é justificada pela condição de comunicação em borda de célula, em que seria necessário potência de transmissão excessivamente elevada para se obter um sinal cuja qualidade fosse suficientemente boa para combinação de diversidade. Além disso, os resultados apresentados em [27] mostram que o modelo de dois saltos sem enlace direto apresenta maior EE que o caso 
com enlace direto, pois o custo energético da manutenção do enlace direto é muito elevado em relação ao ganho que produz. A utilização do modelo de dois saltos em detrimento do modelo de múltiplos saltos (multi-hop) se dá por redução de complexidade, pois seria necessário investigar mais uma variável do tipo combinatória para solução ótima, e também por análise do cenário proposto nos documentos de padronização, em que as soluções de dois saltos são dominantes. Finalmente, a consideração de modo não-transparente é resultante da não-existência do enlace direto, fazendo com que os dispositivos se comuniquem com a RS a que forem alocados para atingir a BS.

A duplexação dos links acesso/backhaul adota modelo half-duplex inband por divisão temporal, com divisão igualitária do tempo de comunicação MS-BS $\left(\Delta_{t}^{\text {dir }}\right)$ entre os links de acesso $\left(\Delta_{t}^{1 \mathrm{~h}}\right)$ e backhaul $\left(\Delta_{t}^{2 \mathrm{~h}}\right)$, conforme mostrado na Figura 3.2. Apesar dos problemas inerentes ao modo inband, como por exemplo o tempo gasto na troca entre os links de acesso e backhaul [100], a principal justificativa na adoção desse modelo é a limitação espectral. Como o recurso espectral é escasso, com diversas tecnologias concorrendo pelas faixas disponíveis, a alocação de uma faixa de espectro exclusivamente para a retransmissão das RSs somente aumentaria essa concorrência. Além disso, seria necessária a instalação de novos equipamentos de transmissão para essa nova banda licenciada, enquanto que o modelo inband necessita de alterações apenas no equipamento que realiza o controle dos recursos, que no caso de abordagem centralizada também deveria ser alterado em cenário outband. Em caso de alocação de recursos centralizada, e considerando as definições do parágrafo anterior, as alterações no controle de recursos podem ser feitas apenas nas estações sob controle das operadoras, facilitando a migração de tecnologia do ponto de vista dos usuários do serviço.

O problema de seleção de RSs é simplificado de modo que uma MS seja alocada à RS que resulte no melhor ganho de canal médio no link MS-RS, evitando a necessidade de se estimar o CSI de todos os possíveis links MS-RS-BS ao custo de perda de diversidade [90, 101]. Considerando que os efeitos de shadowing e desvanecimento rápido sejam modelados pelos mesmos modelos estatísticos para qualquer par MS-RS, o fator de decisão será fundamentalmente a perda de percurso, que é determinística e possui como parâmetro variável, em geral, apenas a distância entre os dispositivos. O modelo descrito neste trabalho utiliza um conceito semelhante ao desenvolvido em [110], porém analisando apenas o link direto e o link do primeiro salto, i.e., MS-RS. No modelo proposto, verificase a possibilidade de existir ganho em termos de EE comparando a energia gasta para suportar uma determinada taxa de dados por subportadora em modo não-cooperativo e cooperativo, resultando no seguinte procedimento de alocação de RSs:

1. as RSs determinam a região na qual sua cobertura pode resultar em economia de recursos, por meio de duas regras:

a) perda de percurso do link MS-RS deve ser menor que a PL do link MS-BS;

b) distância RS-BS deve ser menor que a distância MS-BS. 
Figura 3.2 - Esquema de alocação de subportadoras, com $N=7$ e modo half-duplex inband. $\Delta_{t}^{1 \mathrm{~h}}$ e $\Delta_{t}^{2 \mathrm{~h}}$ indicam o intervalo de tempo alocado para os enlaces de acesso e backhaul, respectivamente, enquanto $\Delta_{t}^{\text {dir }}$ indica o intervalo de tempo alocado para o enlace direto. As MSs dos índices $a, b, c, d$ se comunicam diretamente com a BS, enquanto as MSs $x, y, z$ são auxiliadas pelas RSs $l, m, p$, respectivamente.

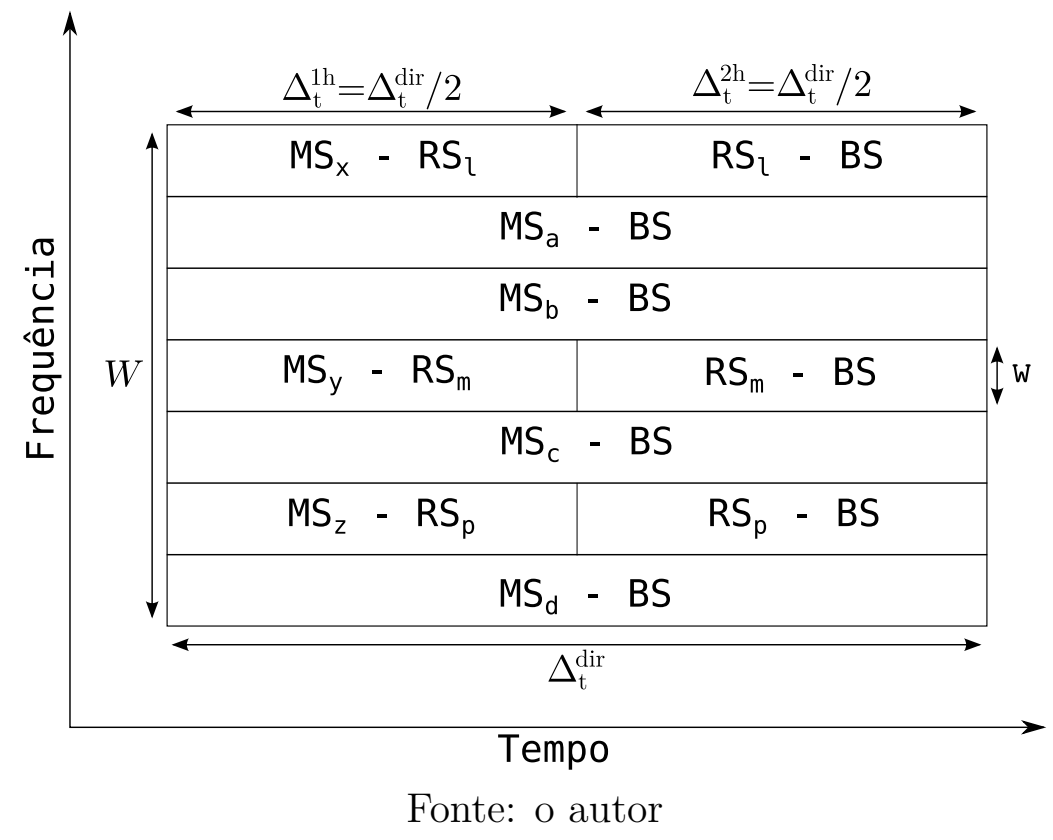

2. Caso duas ou mais RSs tenham áreas de cobertura em comum, organiza-se a divisão dessas áreas de modo que em cada ponto se escolha a RS mais próxima.

A regra 1.a) resulta da análise do consumo de energia para transmissão direta e cooperativa. Se uma MS gasta a mesma quantidade de energia, ou mais, para transmitir uma certa quantidade de bits para uma RS em relação ao que consumiria para transmitir para a BS, o gasto extra de energia na RS, que não é nulo, reduz a eficiência energética. Considera-se somente a perda de percurso na seleção de RSs pois o cálculo é baseado na média do sistema, evitando a repetição da etapa de seleção. A regra 1.b) deve-se à decisão de que as RSs devem servir àqueles usuários que estejam em condição desfavorável de comunicação, mais afastados da BS do que a própria RS. Finalmente, a regra 2 é determinada para que cada MS utilize apenas uma RS ou transmissão direta. A demonstração da regra 1.a) é apresentada no Apêndice A.

Com relação aos protocolos de retransmissão, os resultados observados na literatura apresentam uma grande variação nas conclusões, principalmente devido aos diferentes cenários avaliados, como pode ser visto comparando as conclusões de [39] e [70]. Assim, propõe-se a comparação dos protocolos regenerativos e não-regenerativos, considerando suas duas implementações mais comuns: para o caso regenerativo, considera-se o protocolo DF, enquanto se adota o protocolo AF para não-regenerativo, ambos não-seletivos. A 
operação do protocolo DF é feita unicamente no domínio da frequência, porém para AF é possível escolher em qual dimensão operar [54]. Apesar da simplicidade do protocolo AF indicar que o processamento no tempo é a melhor escolha, a abordagem inicial do trabalho será operar o AF também no domínio da frequência. Essa estratégia se torna necessária devido ao fato de que uma determinada MS pode ser coberta por mais de uma RS, apesar de estar alocada a apenas uma delas, devido à natureza de broadcast do canal sem fio. Devido à cobertura múltipla, é possível que ocorra MAI no salto RS-BS, resultando que é preciso anular, em cada RS, os sinais das MSs que não estão alocadas para si, o que é possível somente com o processamento no domínio da frequência. O fluxograma do processo de retransmissão é apresentado na Figura 3.3.

Figura 3.3 - Fluxo do processo de retransmissão para AF e DF em um sistema de múltiplo acesso por divisão de frequência.

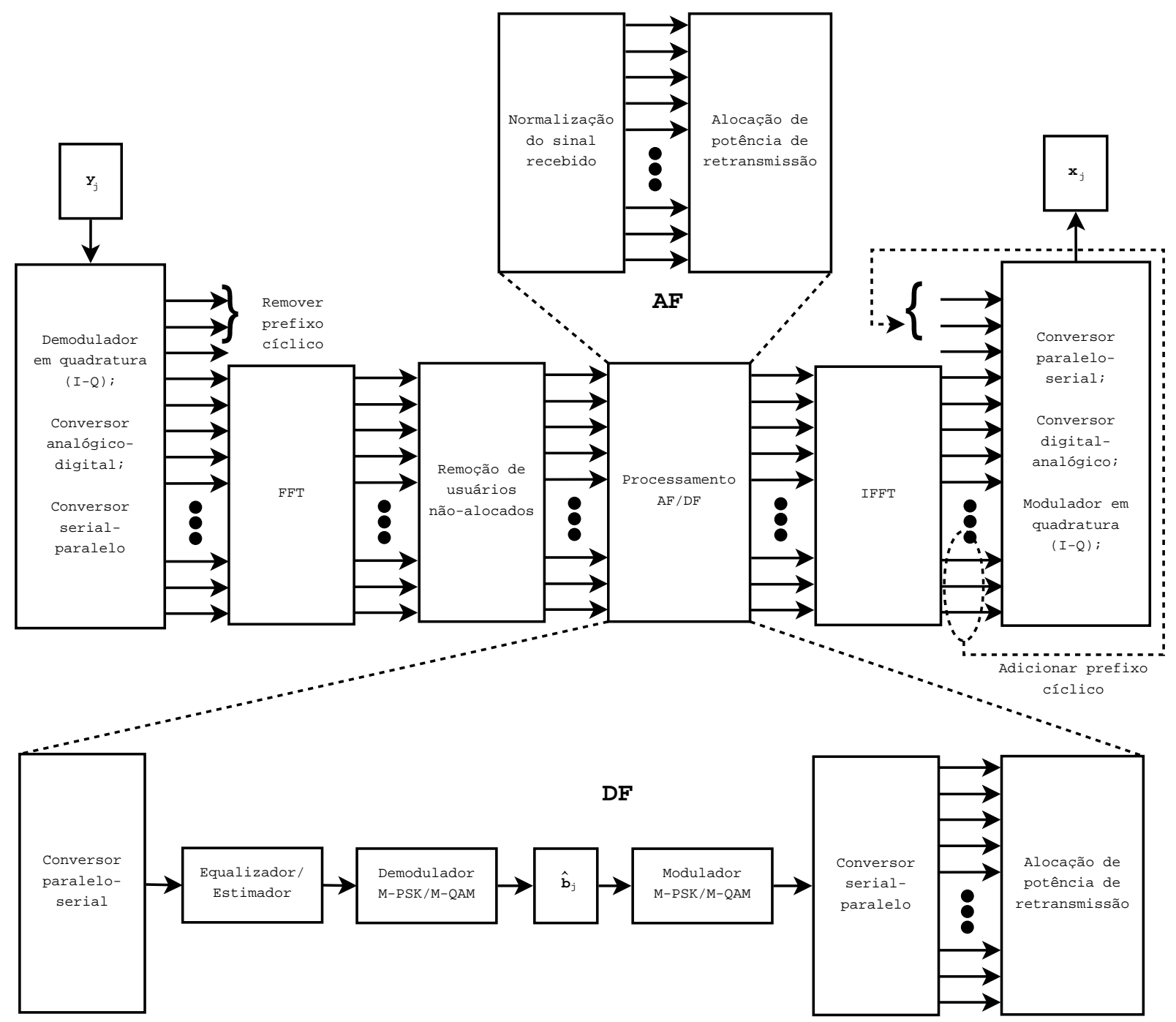

Fonte: o autor

A Tabela 3.1 lista os parâmetros do sistema cooperativo utilizado neste trabalho. 
Tabela 3.1 - Definições do modelo cooperativo adotado neste trabalho.

\begin{tabular}{|l|l|}
\hline Critérios & Modelo adotado \\
\hline \hline Mobilidade & RSs fixas \\
\hline Protocolo de retransmissão & $\begin{array}{l}\text { AF e DF não-seletivos e sem possibilidade de escolha } \\
\text { dinâmica }\end{array}$ \\
\hline Topologia de comunicação & Dois saltos \\
\hline Controle de célula & Não-transparente \\
\hline Número de enlaces & Retransmissão de apoio \\
\hline $\begin{array}{l}\text { Duplexação acesso e } \\
\text { backhaul }\end{array}$ & Half-duplex inband \\
\hline Seleção de RSs & $\begin{array}{l}\text { Determinada pelo posicionamento das MSs e estática em } \\
\text { cada intervalo de alocação }\end{array}$ \\
\hline
\end{tabular}

Fonte: o autor

\subsection{Descrição Matemática para Modos Não-Cooperativo e Coope- rativo}

As seguintes convenções são utilizadas no decorrer da descrição: todos os índices que envolvem MSs, RSs, BS e subportadoras são apresentados como sub-índices. As seguintes variáveis, quando indicadas, se referem diretamente a um dos seguintes casos: $k$-ésimo usuário, $n$-ésima subportadora e $l$-ésimo dispositivo receptor, onde $l=0$ indica a $\mathrm{BS}$ e $1 \leq l \leq N_{\mathrm{RS}}$ indica uma RS. Para o caso não-cooperativo, as variáveis são indexadas somente por $k$ e/ou $n$, pois não existem RSs.

Em um sistema não-cooperativo o sinal recebido pela BS na $n$-ésima subportadora é dado por:

$$
y_{n}=\sum_{k=1}^{K} \lambda_{k, n}\left[\sqrt{p_{k, n}} h_{k, n} \mathrm{x}_{k, n}\right]+\eta_{n}
$$

sendo $\lambda_{k, n}$ o indicador de alocação da $n$-ésima subportadora à $k$-ésima MS, $\operatorname{com} \lambda_{k, n} \in$ $\{0,1\} ; p_{k, n}$ a potência de transmissão da $k$-ésima MS na $n$-ésima subportadora; $h_{k, n} \mathrm{o}$ coeficiente complexo de canal entre a $k$-ésima MS e BS na $n$-ésima subportadora, incluindo os efeitos de desvanecimento rápido e perda de percurso; $\mathrm{x}_{k, n}$ é o símbolo transmitido pela $k$-ésima MS na $n$-ésima subportadora; e $\eta_{n}$ é o ruído de fundo na $n$-ésima subportadora.

A alocação de subportadoras é descrita através da matriz $\boldsymbol{\lambda}_{[K \times N]}$, relacionando os $K$ usuários com as $N$ subportadoras, em que $\lambda_{k, n}=1$ indica que a $k$-ésima MS utiliza a $n$ ésima subportadora. Estabelece-se que não existe múltiplo acesso nas subportadoras, i.e., $\sum_{k=1}^{K} \lambda_{k, n} \in\{0,1\}$, admitindo a possibilidade de que existam subportadoras não-alocadas a nenhuma das MSs. Essa não-alocação pode ser resultado de poucas MSs utilizando o sistema ou então por uma condição severa de atenuação na $n$-ésima subportadora no instante de execução do algoritmo de alocação de recursos.

A SINR da $k$-ésima MS na $n$-ésima subportadora para comunicação não-cooperativa 
é dada por:

$$
\gamma_{k, n}=\frac{p_{k, n}\left|h_{k, n}\right|^{2}\left|\mathrm{x}_{k, n}\right|^{2}}{\sigma_{n}^{2}}
$$

que pode ser simplificada como:

$$
\gamma_{k, n}=\frac{p_{k, n}\left|h_{k, n}\right|^{2}}{\sigma_{n}^{2}}=p_{k, n} \Gamma_{k, n}
$$

assumindo-se que a potência do símbolo transmitido é unitária $[27,39]$, i.e., $\mathbb{E}\left\{|\mathrm{x} .|^{2}\right\}=1$, hipótese que é adotada neste trabalho.

Finalmente, a máxima taxa de dados do $k$-ésimo usuário na $n$-ésima subportadora corresponde a:

$$
\begin{aligned}
r_{k, n} & =\mathrm{w} \log _{2}\left(1+\gamma_{k, n} \imath_{k}\right) \quad\left[\frac{\mathrm{bits}}{\mathrm{s}}\right] \\
& =\mathrm{w} \log _{2}\left(1+p_{k, n} \imath_{k} \Gamma_{k, n}\right) \quad\left[\frac{\mathrm{bits}}{\mathrm{s}}\right],
\end{aligned}
$$

em que $\imath_{k}$ se refere ao gap de SINR para a $k$-ésima MS.

Para o modo cooperativo, além da matriz $\boldsymbol{\lambda}$ para descrever a alocação de subportadoras, adiciona-se a matriz de alocação $\boldsymbol{\psi}_{\left[K \times N_{\mathrm{RS}}+1\right]}$, que indica a alocação dos dispositivos receptores (RSs ou BS) para servir as MSs. Admite-se que cada MS pode utilizar somente uma das RSs disponíveis no sistema, ou se comunicar diretamente com a BS, i.e., $\sum_{l=0}^{N_{\mathrm{RS}}} \psi_{k, l}=1$

A adição das $N_{\mathrm{RS}}$ RSs faz com que as variáveis de ganho de canal e ruído de fundo indiquem a qual dispositivo se referem, de modo que o sub-índice $l$ é adicionado a essas variáveis, com $l=0$ indicando a BS e $1 \leq l \leq N_{\mathrm{RS}}$ indicando as RSs. Como as MSs transmitem para apenas um único dispositivo (BS ou uma das $N_{\mathrm{RS}} \mathrm{RSs}$ ) no primeiro salto, omite-se o sub-índice $l$ das variáveis de potência de transmissão $p_{k, n}$ e do símbolo transmitido $\mathrm{x}_{k, n}$.

Considerando as MSs que se comunicam diretamente com a BS, i.e., $l=0$, o sinal recebido na $n$-ésima subportadora da BS é dado por

$$
y_{n, 0}^{\varpi}=\sum_{k=1}^{K} \lambda_{k, n} \psi_{k, 0}\left[\sqrt{p_{k, n}^{\varpi}} h_{k, n, 0} \mathrm{x}_{k, n}\right]+\eta_{n, 0},
$$

em que $\varpi$ indica qual protocolo de retransmissão será utilizado, i.e., $\varpi=\mathrm{AF}$ ou $\varpi=\mathrm{DF}$.

A partir da equação (3.5), a SINR do $k$-ésimo usuário na $n$-ésima subportadora na BS é dada por

$$
\gamma_{k, n, 0}^{\varpi}=\frac{p_{k, n}^{\varpi}\left|h_{k, n, 0}\right|^{2}}{\sigma_{n, 0}^{2}},
$$

e a máxima taxa de dados do $k$-ésimo usuário na $n$-ésima subportadora equivale a:

$$
r_{k, n, 0}=\mathrm{w} \log _{2}\left(1+p_{k, n}^{\varpi} \imath_{k} \Gamma_{k, n, 0}^{\varpi} \imath_{k}\right) \quad\left[\frac{\mathrm{bits}}{\mathrm{s}}\right] .
$$


em que

$$
\Gamma_{k, n, 0}^{\varpi}=\frac{\left|h_{k, n, 0}\right|^{2}}{\sigma_{n, 0}^{2}}
$$

Para as MSs que utilizam as RSs para se comunicar com a BS, i.e., MSs de dois saltos, as equações de capacidade, SINR e sinal recebido no segundo salto dependem do protocolo de retransmissão, e serão discutidas nas subseções 3.2.1 e 3.2.2 para AF e DF, respectivamente. O sinal recebido na $n$-ésima subportadora da $l$-ésima RS no primeiro salto é dado por:

$$
y_{n, l}^{\varpi, 1 \mathrm{~h}}=\sum_{k=1}^{K} \lambda_{k, n} \psi_{k, l}\left[\sqrt{p_{k, n}^{\varpi}} h_{k, n, l} \mathbf{x}_{k, n}\right]+\eta_{n, l}, \quad l=\left[1,2, \cdots, N_{\mathrm{RS}}\right] .
$$

Dada a natureza de broadcast do canal sem fio e a utilização de antenas omnidirecionais nas RSs, é possível que algumas MSs sejam cobertas por uma ou mais RSs que não estejam originalmente alocadas para si. Assim, é necessário efetuar uma etapa de processamento para remover os sinais indesejados, evitando assim a possibilidade de duas ou mais RSs retransmitindo na mesma subportadora ao mesmo tempo, o que geraria MAI no segundo salto. O processamento realizado pela l-ésima RS segue o fluxograma mostrado na Figura 3.3 até a saída do bloco de FFT. Após essa operação, o sinal de usuários não alocados à l-ésima RS são descartados, o que pode ser visto no domínio do tempo através da seguinte relação:

$$
y_{n, l}^{\prime \varpi, 1 \mathrm{~h}}=\left\{\begin{array}{ll}
y_{n, j}^{\varpi, 1 \mathrm{~h}}, & \lambda_{k, n}=1 \text { e } \psi_{k, l}=1, \quad k=1,2, \cdots, K \\
0, & \text { caso contrário }
\end{array} .\right.
$$

O sinal somente é mantido na $l$-ésima RS no caso em que essa está alocada à $k$-ésima MS, $\psi_{k, l}=1$, e a $n$-ésima subportadora está alocada a essa mesma $k$-ésima MS, $\lambda_{k, n}=1$. Se a $l$-ésima RS não estiver alocada à $k$-ésima MS para a qual $\lambda_{k, n}=1$, o sinal recebido deve ser descartado nessa $l$-ésima RS.

Após esse processamento, a implementação dos protocolos é distinta, e para facilitar a notação considera-se que a $n$-ésima portadora está alocada para a l-ésima RS, i.e., $\sum_{k=1}^{K} \lambda_{k, n} \psi_{k, l}=1$. Tal afirmação não incorre em perda de generalidade, e é utilizada para evitar que se descreva uma segunda equação para os casos em que uma determinada subportadora foi anulada.

\subsubsection{AF}

Para o protocolo AF, o sinal recebido na $n$-ésima subportadora pela $l$-ésima RS é normalizado pela esperança da potência do sinal recebido, denotado por $P_{n, l}$ e dada por [115]:

$$
P_{n, l}=E\left\{\left|y_{n, l}^{\mathrm{AF}}\right|^{2}\right\}
$$


Considerando que a informação transmitida e o ruído são descorrelacionados [115], $P_{n, l}$ pode ser calculado como:

$$
P_{n, l}=\sum_{k=1}^{K}\left[\lambda_{k, n} \psi_{k, l} p_{k, n}^{\mathrm{AF}}\left|h_{k, n, l}\right|^{2}\right]+\sigma_{n, l}^{2}
$$

Após a normalização do sinal recebido, a l-ésima RS retransmite o sinal na $n$-ésima subportadora com potência $p_{r_{n, l}}^{\mathrm{AF}}$, de modo que o sinal recebido pela BS a partir da l-ésima RS na $n$-ésima subportadora é dado por

$$
y_{n, l}^{\mathrm{AF}, 2 \mathrm{~h}}=\sqrt{\frac{p_{r_{n, l}}^{\mathrm{AF}}}{P_{n, l}}}\left\{\sum_{k=1}^{K} \lambda_{k, n} \psi_{k, l}\left[\sqrt{p_{k, n}^{\mathrm{AF}}} h_{k, n, l} \mathrm{x}_{k, n}\right]+\eta_{n, l}\right\} g_{n, l}+\eta_{n, 0},
$$

em que $g_{n, l}$ equivale ao coeficiente complexo de canal entre a $l$-ésima RS e a BS na $n$-ésima subportadora, incluindo os efeitos de desvanecimento rápido e perda de percurso. Desse modo, a SINR do $k$-ésimo usuário é dada por:

$$
\begin{aligned}
\gamma_{k, n, l}^{\mathrm{AF}, 2 \mathrm{~h}} & =\left(\frac{p_{r_{n, l}}^{\mathrm{AF}} p_{k, n}^{\mathrm{AF}}\left|h_{k, n, l}\right|^{2}\left|g_{n, l}\right|^{2}}{P_{n, l}}\right) /\left(\frac{p_{r_{n, l}}^{\mathrm{AF}}\left|g_{n, l}\right|^{2} \sigma_{n, l}^{2}}{P_{n, l}}+\sigma_{n, 0}^{2}\right) \\
& =\frac{p_{r_{n, l}}^{\mathrm{AF}} p_{k, n}^{\mathrm{AF}}\left|h_{k, n, l}\right|^{2}\left|g_{n, l}\right|^{2}}{p_{r_{n, l}}^{\mathrm{AF}}\left|g_{n, l}\right|^{2} \sigma_{n, l}^{2}+P_{n, l} \sigma_{n, 0}^{2}}
\end{aligned}
$$

Considerando que a $k$-ésima MS aloca a $n$-ésima subportadora e utiliza a l-ésima RS, e que não existe MAI nas subportadoras, a equação (3.12) pode ser reescrita como

$$
P_{n, l}=p_{k, n}^{\mathrm{AF}}\left|h_{k, n, l}\right|^{2}+\sigma_{n, l}^{2}
$$

de modo que

$$
\gamma_{k, n, l}^{\mathrm{AF}, 2 \mathrm{~h}}=\frac{p_{r_{n, l}}^{\mathrm{AF}} p_{k, n}^{\mathrm{AF}}\left|h_{k, n, l}\right|^{2}\left|g_{n, l}\right|^{2}}{p_{r_{n, l}}^{\mathrm{AF}}\left|g_{n, l}\right|^{2} \sigma_{n, l}^{2}+p_{k, n}^{\mathrm{AF}}\left|h_{k, n, l}\right|^{2} \sigma_{n, 0}^{2}+\sigma_{n, l}^{2} \sigma_{n, 0}^{2}} .
$$

Para o protocolo AF, a taxa de dados após os dois saltos é determinada pela SINR do segundo salto. Portanto, para a $k$-ésima MS na $n$-ésima subportadora utilizando a l-ésima RS tem-se que a máxima taxa de dados é equivalente a

$$
r_{k, n, l}^{\mathrm{AF}}=\frac{\mathrm{w}}{2} \log _{2}\left(1+\gamma_{k, n, l}^{\mathrm{AF}, 2 \mathrm{~h}} \imath_{k}^{\mathrm{AF}}\right), \quad l \neq 0 \quad\left[\frac{\mathrm{bits}}{\mathrm{s}}\right] .
$$

Como ocorre divisão no tempo entre os enlaces MS-RS e RS-BS, a taxa de dados obtida deve ser dividida pela metade, por isso a introdução do fator $\frac{1}{2}$ na equação (3.17).

Percebe-se pela equação (3.16) que a SINR do primeiro salto é um upper-bound para a SINR no segundo salto, aproximado somente quando $p_{r_{n, l}}^{\mathrm{AF}} \rightarrow \infty$, conforme demonstrado em (3.18): 


$$
\begin{aligned}
\lim _{p_{r_{n, l}}^{\mathrm{AF}} \rightarrow \infty} \gamma_{k, n, l}^{\mathrm{AF}, 2 \mathrm{~h}} & =\lim _{p_{r_{n, l}}^{\mathrm{AF}} \rightarrow \infty} \frac{p_{r_{n, l}}^{\mathrm{AF}} p_{k, n}^{\mathrm{AF}}\left|h_{k, n, l}\right|^{2}\left|g_{n, l}\right|^{2}}{p_{r_{n, l}}^{\mathrm{AF}}\left|g_{n, l}\right|^{2} \sigma_{n, l}^{2}+p_{k, n}^{\mathrm{AF}}\left|h_{k, n, l}\right|^{2} \sigma_{n, 0}^{2}+\sigma_{n, l}^{2} \sigma_{n, 0}^{2}} \\
& <\lim _{p_{r_{n, l}}^{\mathrm{A}} \rightarrow \infty} \frac{p_{r_{n, l}}^{\mathrm{AF}} p_{k, n}^{\mathrm{AF}}\left|h_{k, n, l}\right|^{2}\left|g_{n, l}\right|^{2}}{p_{r_{n, l}}^{\mathrm{AF}}\left|g_{n, l}\right|^{2} \sigma_{n, l}^{2}} \\
& <\lim _{p_{r_{n, l}}^{\mathrm{A}} \rightarrow \infty} \frac{p_{k, n}^{\mathrm{AF}}\left|h_{k, n, l}\right|^{2}}{\sigma_{n, l}^{2}} \\
& <\gamma_{k, n, l}^{\mathrm{AF}, 1 \mathrm{~h}} .
\end{aligned}
$$

Como pode ser visto por meio das equações (3.16) e (3.17), uma mesma taxa de dados $r_{k, n, l}^{\mathrm{AF}}$ pode ser obtida com diversas combinações de potência de transmissão das MSs e RSs. Por esse motivo, não se estabelece nesta subseção uma relação entre $p_{r_{n, l}}^{\mathrm{AF}}$ e $p_{k, n}^{\mathrm{AF}}$. Note-se ainda que caso a l-ésima RS esteja utilizando toda a potência de transmissão disponível e a $k$-ésima MS alocada a essa l-ésima RS esteja em condição de outage, a $k$-ésima MS é capaz de alocar mais potência de transmissão visando obter maior taxa de dados ao fim dos dois saltos. Conforme mostrado na Subseção 3.2.2, o protocolo DF com divisão fixa de tempo não é capaz de tal adaptação, o que caracteriza uma vantagem do protocolo $\mathrm{AF}$.

\subsubsection{DF}

Considerando o sinal recebido descrito na equação (3.10), a SINR da $k$-ésima MS na $n$-ésima portadora não-nula da l-ésima RS é dada por

$$
\gamma_{k, n, l}^{\mathrm{DF}}=\frac{p_{k, n}^{\mathrm{DF}}\left|h_{k, n, l}\right|^{2}}{\sigma_{n, l}^{2}},
$$

resultando na seguinte máxima taxa de dados na $n$-ésima subportadora no primeiro salto:

$$
\begin{aligned}
r_{k, n, l}^{\mathrm{DF}, 1 \mathrm{~h}} & =\mathrm{w} \log _{2}\left(1+\gamma_{k, n, l}^{\mathrm{DF}} l_{k}^{\mathrm{DF}}\right) \\
& =\mathrm{w} \log _{2}\left(1+p_{k, n} \Gamma_{k, n, l} l_{k}^{\mathrm{DF}}\right) \quad\left[\frac{\mathrm{bits}}{\mathrm{s}}\right] .
\end{aligned}
$$

em que

$$
\Gamma_{k, n, l}=\frac{\left|h_{k, n, l}\right|^{2}}{\sigma_{n, l}^{2}}
$$

Conforme mostrado na Figura 3.3, após a conversão paralelo-serial e realização da operação de FFT, a l-ésima RS detecta/estima $\sum_{n=1}^{N} \sum_{k=1}^{K} \lambda_{k, n} \psi_{k, l}$ símbolos, obtendo o vetor $\hat{\mathbf{b}}_{l}$ de sequências de bits a ser retransmitido. A l-ésima RS então realiza o processo de transmissão, modulando as sequências do vetor $\hat{\mathbf{b}}_{l}$ e mapeando os símbolos às devidas 
subportadoras, adicionando zeros às subportadoras que não foram alocadas na atual janela, e então executa a operação de IFFT. Após esse processo, o sinal recebido na $n$-ésima subportadora da BS oriundo da l-ésima RS é descrito como

$$
y_{l, n, 0}^{\mathrm{DF}}=\sum_{k=1}^{K} \lambda_{k, n} \psi_{k, l} \sqrt{p_{r_{n, l}}} \hat{\mathrm{x}}_{k, n, l} g_{n, l}+\eta_{n, 0},
$$

em que $\hat{\mathrm{x}}_{k, n, l}$ é o símbolo detectado e retransmitido pela l-ésima RS.

Pela definição do sinal recebido no segundo salto, a SINR do $k$-ésimo usuário na $n$ ésima subportadora na BS, i.e., após a retransmissão da l-ésima RS, é dada por

$$
\gamma_{l, n, 0}^{\mathrm{DF}}=\frac{p_{r_{n, l}}\left|g_{n, l}\right|^{2}}{\sigma_{n, 0}^{2}}
$$

de modo que a máxima taxa de dados na n-ésima subportadora no segundo salto é equivalente a:

$$
\begin{aligned}
r_{l, n, 0}^{\mathrm{DF}, 2 \mathrm{~h}} & =\mathrm{w} \log _{2}\left(1+\gamma_{l, n, 0}^{\mathrm{DF}} \imath_{r_{l}}^{\mathrm{DF}}\right) \\
& =\mathrm{w} \log _{2}\left(1+p_{r_{n, l}} \Gamma_{l, n, 0} \imath_{r_{l}}^{\mathrm{DF}}\right) \quad\left[\frac{\mathrm{bits}}{\mathrm{s}}\right] .
\end{aligned}
$$

A principal diferença no processo de alocação de recursos para o protocolo DF é a definição da taxa de dados do $k$-ésimo usuário após os dois saltos. Observando a expressão de SINR para AF na equação (3.16), uma mesma SINR, e portanto mesma capacidade, pode ser atingida com diferentes combinações de potência de transmissão nas MSs e nas RSs. Porém, considerando protocolo DF sem utilização de buffer, a quantidade de bits transmitida no primeiro e segundo saltos deve ser a mesma [54], de modo que a capacidade é limitada pelo salto de menor capacidade, i.e.:

$$
r_{k, n, l}^{\mathrm{DF}}=\frac{\min \left(\Delta_{t}^{\mathrm{1h}} r_{k, n, l}^{\mathrm{DF}, 1 \mathrm{~h}},\left(\Delta_{t}^{\mathrm{dir}}-\Delta_{t}^{\mathrm{1h}}\right) r_{l, n, 0}^{\mathrm{DF}, 2 \mathrm{~h}}\right)}{\Delta_{t}^{\mathrm{dir}}} \quad\left[\frac{\mathrm{bits}}{\mathrm{s}}\right] .
$$

Uma vez que não se considera otimização da divisão de tempo entre os enlaces de acesso e backhaul, deve-se assumir então $\Delta_{t}^{1 \mathrm{~h}}=\frac{\Delta_{t}^{\text {dir }}}{2}$, resultando:

$$
r_{k, n, l}^{\mathrm{DF}}=\frac{\min \left(r_{k, n, l}^{\mathrm{DF}, 1 \mathrm{~h}}, r_{l, n, 0}^{\mathrm{DF}, 2 \mathrm{~h}}\right)}{2} \quad\left[\frac{\mathrm{bits}}{\mathrm{s}}\right] .
$$

Assim sendo, a estratégia ótima é obter a mesma taxa de dados nas subportadoras em cada um dos saltos no processo de alocação, evitando-se desperdício de potência. Dessa forma, deve-se impor a condição:

$$
r_{k, n, l}^{\mathrm{DF}, 1 \mathrm{~h}}=r_{l, n, 0}^{\mathrm{DF}, 2 \mathrm{~h}}
$$

Considerando a igualdade da equação (3.27), a potência de retransmissão da l-ésima RS na $n$-ésima subportadora, admitindo-se que a $k$-ésima MS está alocada para essa 
configuração, é dada por:

$$
\begin{aligned}
\mathrm{w} \log _{2}\left(1+p_{r_{n, l}} \Gamma_{l, n, 0} l_{r_{l}}^{\mathrm{DF}}\right) & =\mathrm{w} \log _{2}\left(1+p_{k, n} \Gamma_{k, n, l} l_{k}^{\mathrm{DF}}\right) \\
p_{r_{n, l}} \Gamma_{l, n, 0} l_{r_{l}}^{\mathrm{DF}} & =p_{k, n} \Gamma_{k, n, l} l_{k}^{\mathrm{DF}} \\
p_{r_{n, l}} & =p_{k, n} \frac{\Gamma_{k, n, l} l_{k}^{\mathrm{DF}}}{\Gamma_{l, n, 0} l_{r_{l}}^{\mathrm{DF}}}
\end{aligned}
$$

em que se percebe que a potência que a RS utilizará no segundo salto depende da razão do ganho de canal dos enlaces MS-RS e RS-BS.

Para evitar a utilização da função min na equação (3.26), considera-se a formulação apresentada em [116], na qual se define $r_{k, n, l}^{\mathrm{DF}}$ a partir da potência total gasta nos dois saltos, i.e.:

$$
p_{k, n, l}=p_{k, n}+p_{r_{n, l}}
$$

em que as potências do lado direito da igualdade são obtidas por meio da equação (3.28). A partir dessa expressão, e trocando-se $p_{r_{n, l}}$ pelo resultado descrito na equação (3.28), tem-se:

$$
\begin{aligned}
p_{k, n, l} & =p_{k, n}+p_{k, n} \frac{\Gamma_{k, n, l} l_{k}^{\mathrm{DF}}}{\Gamma_{l, n, 0} 2_{r_{l}}^{\mathrm{DF}}} \\
p_{k, n, l} & =p_{k, n}\left(\frac{\Gamma_{l, n, 0} \imath_{r_{l}}^{\mathrm{DF}}+\Gamma_{k, n, l} l_{k}^{\mathrm{DF}}}{\Gamma_{l, n, 0} l_{r_{l}}^{\mathrm{DF}}}\right) \\
p_{k, n} & =p_{k, n, l}\left(\frac{\Gamma_{l, n, 0} l_{r_{l}}^{\mathrm{DF}}}{\Gamma_{l, n, 0} \imath_{r_{l}}^{\mathrm{DF}}+\Gamma_{k, n, l} l_{k}^{\mathrm{DF}}}\right) .
\end{aligned}
$$

Substituindo $p_{k, n}$ obtido na equação (3.30) na equação (3.28), a potência de transmissão alocada pela $l$-ésima RS na $n$-ésima subportadora é dada por:

$$
p_{r_{n, l}}=p_{k, n, l}\left(\frac{\Gamma_{k, n, l} l_{k}^{\mathrm{DF}}}{\Gamma_{l, n, 0} v_{r_{l}}^{\mathrm{DF}}+\Gamma_{k, n, l} l_{k}^{\mathrm{DF}}}\right)
$$

Substituindo as equações (3.30) e (3.31) na equação (3.26), obtém-se:

$$
\begin{aligned}
r_{k, n, l}^{\mathrm{DF}}= & \frac{1}{2} \min \left\{\operatorname{wog}_{2}\left(1+p_{k, n} \Gamma_{k, n, l} l_{k}^{\mathrm{DF}}\right), \mathrm{w} \log _{2}\left(1+p_{r_{n, l}} \Gamma_{l, n, 0} l_{r_{l}}^{\mathrm{DF}}\right)\right\} \\
= & \frac{\mathrm{w}}{2} \min \left\{\log _{2}\left(1+p_{k, n, l}\left(\frac{\Gamma_{l, n, 0} l_{r_{l}}^{\mathrm{DF}}}{\Gamma_{l, n, 0} \imath_{r_{l}}^{\mathrm{DF}}+\Gamma_{k, n, l} l_{k}^{\mathrm{DF}}}\right) \Gamma_{k, n, l} l_{k}^{\mathrm{DF}}\right),\right. \\
& \left.\log _{2}\left(1+p_{k, n, l}\left(\frac{\Gamma_{k, n, l} l_{k}^{\mathrm{DF}}}{\Gamma_{l, n, 0} l_{r_{l}}^{\mathrm{DF}}+\Gamma_{k, n, l} l_{k}^{\mathrm{DF}}}\right) \Gamma_{l, n, 0} \imath_{r_{l}}^{\mathrm{DF}}\right)\right\} \\
= & \frac{\mathrm{w}}{2} \log _{2}\left(1+p_{k, n, l}\left(\frac{\Gamma_{k, n, l} \Gamma_{l, n, 0} l_{k}^{\mathrm{DF}} \imath_{r_{l}}^{\mathrm{DF}}}{\Gamma_{l, n, 0} l_{r_{l}}^{\mathrm{DF}}+\Gamma_{k, n, l} l_{k}^{\mathrm{DF}}}\right)\right)
\end{aligned}
$$


Assim, é possível determinar qual é a potência total $p_{k, n, l}$ necessária para satisfazer o problema de otimização proposto, e então obter as potências no primeiro e segundo saltos. Nem todos os valores $p_{k, n, l}$ são atingíveis, dependendo da potência disponível nas MSs e RSs.

\subsection{Descrição do Modelo de Eficiência Energética}

\subsubsection{EE para o Modo Cooperativo}

Em cada situação de avaliação, $\varpi$ pode assumir apenas um dos dois modos de transmissão disponíveis: $\varpi=$ AF ou $\varpi=\mathrm{DF}$, ou seja, não é possível que se escolha dinamicamente os protocolos de retransmissão para cada combinação MS-RS. Como o sistema cooperativo opera em duas janelas temporais de igual duração, pode-se normalizar a duração da transmissão e então aplicar um fator $\frac{1}{2}$ na potência consumida pelas MSs de dois saltos e pelas RSs, pois cada uma opera em uma única janela. Por outro lado, as MSs diretas transmitem nas duas janelas, de modo que nenhum fator de tempo de transmissão deve ser inserido. Assim, a equação de EE global do sistema é dada por:

$$
\xi^{\varpi}=\frac{\sum_{k=1}^{K} \sum_{n=1}^{N} \lambda_{k, n} \psi_{k, 0} \ell_{k, n} r_{k, n, 0}+\sum_{l=1}^{N_{\mathrm{RS}}} \sum_{k=1}^{K} \sum_{n=1}^{N} \lambda_{k, n} \psi_{k, l} \ell_{k, n} r_{k, n, l}^{\varpi}}{\underbrace{\sum_{k=1}^{K} \varrho_{k} p_{k}^{\varpi}}_{\text {(I) }}+\underbrace{\sum_{k=1}^{K} p_{c_{k}}}_{\text {(II) }}+\underbrace{\frac{1}{2} \sum_{l=1}^{N_{\mathrm{RS}}} \sum_{k=1}^{K} \sum_{n=1}^{N} \lambda_{k, n} \psi_{k, l} \varrho_{r_{l}} p_{r_{n, l}}^{\varpi}}_{\text {(III) }}+\underbrace{\sum_{l=1}^{N_{\mathrm{RS}}} p_{c, r_{l}}^{\varpi}}_{(\mathrm{IV})}} \quad\left[\frac{\mathrm{bits}}{\text { Joule }}\right],
$$

em que $\ell_{k, n}$ indica a razão entre bits de informação e a quantidade total de bits transmitidos, incluindo fatores de codificação e prefixo cíclico; (I) representa o consumo de potência para transmissão nas MSs, considerando a ineficiência do amplificador de potência da $k$-ésima MS, $\varrho_{k}$, com $p_{k}^{\varpi}$ equivalente a:

$$
p_{k}^{\varpi}=\sum_{n=1}^{N} \lambda_{k, n} \psi_{k, 0} p_{k, n}^{\varpi}+\frac{1}{2} \sum_{l=1}^{N_{\mathrm{RS}}} \sum_{n=1}^{N} \lambda_{k, n} \psi_{k, l} p_{k, n}^{\varpi} \quad \text { [Watts]; }
$$

(II) é a potência de circuitaria das MSs; (III) é referente ao consumo de potência das RSs, considerando a ineficiência do amplificador de potência da l-ésima RS, $\varrho_{r}$; e (IV) representa a potência de circuitaria das RSs, que pode variar de acordo com o protocolo utilizado.

Para o caso individual, a EE do $k$-ésimo usuário, mensurada em bits por Joule, pode ser definida como

$$
\xi_{k}^{\varpi}=\frac{\psi_{k, 0} \sum_{n=1}^{N} \lambda_{k, n} \ell_{k, n} r_{k, n, 0}+\sum_{l=1}^{N_{\mathrm{RS}}} \psi_{k, l} \sum_{n=1}^{N} \lambda_{k, n} \ell_{k, n} r_{k, n, l}^{\varpi}}{\psi_{k, 0} \sum_{n=1}^{N} \lambda_{k, n} \varrho_{k} p_{k, n}+\sum_{l=1}^{N_{\mathrm{RS}}} \psi_{k, l}\left[\frac{1}{2} \sum_{n=1}^{N} \lambda_{k, n}\left(\varrho_{k} p_{k, n}+\varrho_{r_{l}} p_{r_{n, l}}\right)+\varsigma_{k, l} p_{c, r_{l}}^{\varpi}\right]+p_{c, k}}
$$


onde $\varsigma_{k, l}$ é um fator de proporcionalidade da potência de circuitaria da $l$-ésima RS para a $k$-ésima MS, indicando a possibilidade de que a $k$-ésima MS seja responsabilizada por parte do consumo de potência de circuitaria da RS a qual está alocado. A utilização do termo $\varsigma_{k}$ guarda semelhança com o modelo sub-ótimo para EE em downlink descrito em $[117]^{1}$, porém considerando neste trabalho que $\varsigma_{k, l}$ assume somente valores positivos.

O fator de proporcionalidade $\varsigma_{k, l}$ pode considerar diferentes cenários. É possível definir que esse fator é estático ou dinâmico, se as MSs deverão assumir entre si a potência de circuitaria toda ou apenas parte dela, entre outros. Possíveis interpretações para definir esse fator incluem:

- Dividir o ônus da potência de circuitaria da RS igualmente entre as MSs que utilizam a l-ésima RS;

- Dividir este ônus de acordo com o total de subportadoras que a $l$-ésima RS é responsável por auxiliar;

- Dividir a potência de circuitaria das RSs pelo total de subportadoras do sistema, atribuindo um custo por subportadora alocada;

- Dividir a potência de circuitaria das RSs de acordo com o nível de potência utilizado pelas MSs;

- Não dividir o ônus e assumir que a MS é responsável pelo consumo total de circuitaria da RS;

- Não impor nenhuma responsabilidade relativa ao consumo da potência de circuitaria das RSs às MSs.

Minimamente deve-se atender à condição de não-negatividade de todos os fatores, i.e, $\varsigma_{k, l} \geq 0 \forall k, l$, e também não imputar valor superior ao gasto pela l-ésima RS, i.e., $\varsigma_{k, l} \leq 1 \forall k, l$.

\subsubsection{EE para o Modo Não-Cooperativo}

Como não há as $N_{\mathrm{RS}} \mathrm{RSs}$, a EE é dada pela soma da taxa dos $K$ usuários na comunicação com a BS dividida pela soma da potência de transmissão e circuitaria gastas pelas MSs, o que é descrito, do ponto de vista do sistema, como:

$$
\xi^{\text {nco }}=\frac{\sum_{k=1}^{K} \sum_{n=1}^{N} \lambda_{k, n} \ell_{k, n} r_{k, n}}{\sum_{k=1}^{K} \sum_{n=1}^{N} \lambda_{k, n} \varrho_{k} p_{k, n}+\sum_{k=1}^{K} p_{c_{k}}} \quad\left[\frac{\text { bits }}{\text { Joule }}\right] .
$$

$\overline{1}$ Em [117], o termo de proporcionalidade imputado à $k$-ésima MS não tem o mesmo objetivo que o descrito neste trabalho, de modo que pode assumir valores negativos. 
Em termos individuais, a formulação é bastante semelhante à descrita para a primeira abordagem do caso cooperativo, equação (3.35), com a devida remoção dos índices e somatórios em $l$. Reescrevendo para clarificar a notação, a EE do $k$-ésimo usuário em sistema não-cooperativo é dada por:

$$
\xi_{k}^{\mathrm{nco}}=\frac{\sum_{n=1}^{N} \lambda_{k, n} \ell_{k, n} r_{k, n}}{\sum_{n=1}^{N} \lambda_{k, n} \varrho_{k} p_{k, n}+p_{c_{k}}} \quad\left[\frac{\mathrm{bits}}{\text { Joule }}\right] .
$$




\section{ALOCAÇÃO DE RECURSOS PARA UPLINK NÃO COOPERATIVO}

A maximização de EE em sistema OFDMA não-cooperativo tem por finalidade servir de métrica de comparação com os resultados obtidos nos próximos capítulos desta tese, além de fornecer intuições e possíveis direções para a continuidade da pesquisa. Uma vez que a disposição das MSs é pré-determinada e a posição da BS é fixa na célula, o algoritmo de alocação de recursos deve operar conjuntamente sobre duas variáveis:

- Matriz de alocação de subportadoras, $\boldsymbol{\lambda}_{[K \times N]}$, sendo $\lambda_{k, n}$ correspondente ao elemento na $k$-ésima linha e $n$-ésima coluna de $\boldsymbol{\lambda}$;

- Matriz de alocação de potência de transmissão das MSs em cada subportadora, $\mathbf{P}_{[K \times N]}$, sendo $p_{k, n}$ correspondente ao elemento na $k$-ésima linha e $n$-ésima coluna de $\mathbf{P}$;

Assim, o problema de otimização visa determinar as matrizes $\boldsymbol{\lambda}$ e $\mathbf{P}$ que maximizem a eficiência energética definida na equação (3.36), resultando no seguinte problema de otimização com restrições:

$$
\begin{aligned}
& \mathbf{P}^{*}, \boldsymbol{\lambda}^{*}= \underset{\mathbf{P}, \boldsymbol{\lambda}}{\arg \max } \boldsymbol{\xi}(\mathbf{P}, \boldsymbol{\lambda}) \\
& \text { s. a: } \quad p_{k, n} \geq 0 \quad \forall k, n \\
& \lambda_{k, n} \in\{0,1\} \quad \forall k, n \\
& \sum_{n=1}^{N} \lambda_{k, n} p_{k, n} \leq p_{k}^{\max } \quad \forall k \\
& \sum_{k=1}^{K} \lambda_{k, n} \leq 1 \quad \forall n
\end{aligned}
$$

As restrições impostas no problema são:

- (4.1b): Todas as potências alocadas devem ser positivas;

- (4.1c): A alocação de subportadoras é binária para cada par usuário-portadora;

- (4.1d): Somatório de potência de transmissão de cada MS não pode superar o limite individual de potência;

- (4.1e): Cada subportadora é alocada a, no máximo, uma MS, não ocorrendo múltiplo acesso temporal nas subportadoras; 
O problema (4.1) pode ser estendido de diversas maneiras, como pode ser visto na literatura. Por exemplo, em [117] e [118] adiciona-se uma restrição de taxa mínima para cada MS. Um modelo detalhado de consumo de potência para o downlink de sistemas OFDMA é descrito em [119]. Em [118] e [78], o termo de potência de circuitaria também inclui um componente que é proporcional à taxa de dados de cada MS. No entanto, uma vez que o intuito nessa etapa é a obtenção da máxima EE possível, apenas as restrições de sistema (4.1b)-(4.1e) são consideradas.

A restrição de alocação inteira de subportadoras descrita na equação (4.1c) faz com que o problema (4.1) seja um problema misto de variáveis inteiras e também não-polinomial [34]. Assim, a alocação ótima de potência e subportadoras somente pode ser obtida com a busca exaustiva em todas as matrizes de alocação de subportadoras $\boldsymbol{\lambda}$ que respeitem as restrições (4.1c) e (4.1e). Considerando que todas as portadoras são atribuídas a algum usuário, existem $K^{N}$ diferentes matrizes de alocação de subportadoras no espaço de busca, resultando em um problema de complexidade exponencial que não pode ser processado pela BS ou pelas MSs em uma janela de otimização factível. Busca-se, então, uma solução que possa garantir convergência para a solução ótima e que também seja computacionalmente eficiente e adaptável às características de uplink do sistema OFDMA. Tal abordagem de alocação de recursos será descrita na seção seguinte.

\subsection{Desenvolvimento Teórico}

A primeira tática para reduzir a complexidade do problema (4.1) é relaxar a restrição de alocação inteira das subportadoras. Assim, a restrição (4.1c) é modificada, trocando a variável inteira binária $\lambda_{k, n}$ por uma variável real $\widetilde{\lambda}_{k, n}$, definida no intervalo $0 \leq \widetilde{\lambda}_{k, n} \leq 1$. Conjuntamente, adota-se uma mudança de variável, definindo $\widetilde{p}_{k, n}=\widetilde{\lambda}_{k, n} p_{k, n}$. A relaxação das variáveis inteiras em problemas como (4.1) é uma solução bastante difundida na literatura [34, 120], cuja convergência é garantida sob determinadas condições. Com a relaxação, obtém-se o seguinte problema de otimização:

$$
\begin{aligned}
\widetilde{\mathbf{P}}^{*}, \widetilde{\boldsymbol{\lambda}}^{*}= & \underset{\widetilde{\mathbf{P}}, \widetilde{\boldsymbol{\lambda}}}{\arg \max } \tilde{\xi}(\widetilde{\mathbf{P}}, \widetilde{\boldsymbol{\lambda}}) \\
\text { s. a.: } \quad & \widetilde{p}_{k, n} \geq 0 \quad \forall k, n \\
& \widetilde{\lambda}_{k, n} \geq 0 \quad \forall k, n \\
& 1-\widetilde{\lambda}_{k, n} \geq 0 \quad \forall k, n \\
& p_{k}^{\max }-\sum_{n=1}^{N} \widetilde{p}_{k, n} \geq 0 \quad \forall k \\
& 1-\sum_{k=1}^{K} \widetilde{\lambda}_{k, n} \geq 0 \quad \forall n
\end{aligned}
$$


com

$$
\widetilde{\xi}(\widetilde{\mathbf{P}}, \widetilde{\boldsymbol{\lambda}})=\frac{\sum_{k=1}^{K} \sum_{n=1}^{N} \widetilde{\lambda}_{k, n} \ell_{k, n} \mathrm{w} \log _{2}\left(1+\frac{\widetilde{p}_{k, n} \Gamma_{k, n} \imath_{k}}{\widetilde{\lambda}_{k, n}}\right)}{\sum_{k=1}^{K} \sum_{n=1}^{N} \varrho_{k} \widetilde{p}_{k, n}+\sum_{k=1}^{K} p_{c_{k}}}
$$

Mesmo com a relaxação de $\lambda_{k, n}$, a função-objetivo $\widetilde{\xi}(\widetilde{\mathbf{P}}, \widetilde{\boldsymbol{\lambda}})$ é não-polinomial, o que dificulta a solução numérica do problema. Caso o problema tenha uma função-objetivo nãopolinomial que seja quase-côncava, é possível utilizar o algoritmo de Dinkelbach (DKB) [121] para obter uma função-objetivo côncava, resultando em um problema de otimização linear e iterativo que converge para a solução ótima dado um erro de convergência máximo $\varepsilon_{\mathrm{dkb}}^{\max }$ e sujeito a um limite de iterações $N_{\mathrm{dkb}}^{i t}$. Desse modo, deve demonstrar-se que $\tilde{\xi}(\widetilde{\mathbf{P}}, \widetilde{\boldsymbol{\lambda}})$ é quase-côncavo em relação às variáveis de otimização $\widetilde{p}_{k, n}$ e $\widetilde{\lambda}_{k, n}$. Para tal, formula-se o seguinte teorema:

Teorema 4.1. $\widetilde{\xi}(\widetilde{\mathbf{P}}, \widetilde{\boldsymbol{\lambda}})$ é quase-côncavo em relação a $\widetilde{p}_{k, n}$ e $\widetilde{\lambda}_{k, n}$.

Demonstração. A prova é apresentada no Apêndice B.1.

Garantida a quase-concavidade de $\widetilde{\xi}(\widetilde{\mathbf{P}}, \widetilde{\boldsymbol{\lambda}})$, formula-se a função-objetivo iterativa do algoritmo DKB. Considerando que executa-se a $i$-ésima iteração do algoritmo DKB, temse que

$$
\mathcal{F}_{\mathrm{dkb}}^{i}=\sum_{n=1}^{N} \sum_{k=1}^{K} \widetilde{\lambda}_{k, n} \ell_{k, n} \mathrm{w} \log _{2}\left(1+\frac{\widetilde{p}_{k, n} \Gamma_{k, n} \iota_{k}}{\widetilde{\lambda}_{k, n}}\right)-q^{i-1} \sum_{n=1}^{N} \sum_{k=1}^{K} \varrho_{k} \widetilde{p}_{k, n}-q^{i-1} \sum_{k=1}^{K} p_{c_{k}},
$$

em que $q^{i-1}$ é o parâmetro de DKB utilizado na $i$-ésima iteração.

As matrizes de alocação de subportadoras e potência que maximizam $\mathcal{F}_{\text {dkb }}^{i}$, denotadas por $\widetilde{\mathbf{P}}^{*, i}$ e $\widetilde{\boldsymbol{\lambda}}^{*, i}$, respectivamente, são obtidas pela solução do seguinte problema de otimização:

$$
\begin{gathered}
\widetilde{\mathbf{P}}^{*, i}, \widetilde{\boldsymbol{\lambda}}^{*, i}=\underset{\widetilde{\mathbf{P}}, \widetilde{\boldsymbol{\lambda}}}{\arg \max } \cdot \mathcal{F}_{\mathrm{dkb}}^{i} \\
\text { s. a: }(4.2 \mathrm{~b})-(4.2 \mathrm{f})
\end{gathered}
$$

Ao final da $i$-ésima iteração, o parâmetro $q^{i-1}$ é atualizado com as matrizes $\widetilde{\mathbf{P}}^{*, i}$ e $\widetilde{\boldsymbol{\lambda}}^{*, i}$ obtidas. O parâmetro que será utilizado na $(i+1)$-iteração do algoritmo DKB, denotado por $q^{i}$, é dado por:

$$
q^{i}=q\left(\mathbf{P}^{*, i}, \boldsymbol{\lambda}^{*, i}\right)=\frac{\mathrm{w} \sum_{k=1}^{K} \sum_{n=1}^{N} \lambda_{k, n}^{*, i} \ell_{k, n} \log _{2}\left(1+p_{k, n}^{*, i} \Gamma_{k, n} \iota_{k}\right)}{\sum_{k=1}^{K} \sum_{n=1}^{N} \lambda_{k, n}^{*, i} \varrho_{k} p_{k, n}^{*, i}+\sum_{k=1}^{K} p_{c_{k}}}
$$

O erro de convergência na $i$-ésima iteração do algoritmo DKB é dado por $\varepsilon_{\mathrm{dkb}}=\left|q^{i}-q^{i-1}\right|$, e afirma-se que a convergência foi atingida se $\varepsilon_{\mathrm{dkb}} \leq \varepsilon_{\mathrm{dkb}}^{\max }$. 
Com a relaxação e o algoritmo DKB, obtém-se um problema polinomial, côncavo e composto apenas de variáveis contínuas, porém ainda sujeito a restrições. Uma ferramenta clássica para se converter um problema com restrições em um problema sem restrições é a utilização de Decomposição Dual de Lagrange (LDD) [122]. Apesar de a técnica definir que seja utilizado um multiplicador de Lagrange (ou variável dual) para cada restrição do problema de otimização, a solução adotada aqui só utilizará multiplicadores na restrição de potência máxima em cada MS, equação (4.2e). Para a restrição de positividade de potência, equação (4.2b), a própria equação de alocação garantirá que a potência não seja menor que zero. Já em relação às restrições para as subportadoras, o método que será definido irá garantir que as restrições sejam atendidas. Definindo o vetor $\boldsymbol{\tau}=\left[\tau_{1}, \cdots, \tau_{k}, \cdots, \tau_{K}\right]$ como os multiplicadores de Lagrange associados às restrições individuais de potência máxima, a função-objetivo a ser otimizada é dada por:

$$
\begin{aligned}
\mathcal{L}(\boldsymbol{\tau}, \widetilde{\mathbf{P}}, \widetilde{\boldsymbol{\lambda}})=\sum_{k=1}^{K} & \sum_{n=1}^{N}\left[\ell_{k, n} \widetilde{\lambda}_{k, n} \mathrm{w} \log _{2}\left(1+\frac{\widetilde{p}_{k, n} \Gamma_{k, n} \iota_{k}}{\widetilde{\lambda}_{k, n}}\right)-\left(q^{i-1} \varrho_{k}+\tau_{k}\right) \widetilde{p}_{k, n}\right] \\
& +\sum_{k=1}^{K}\left(\tau_{k} p_{k}^{\max }-q^{i-1} p_{c_{k}}\right) .
\end{aligned}
$$

A combinação de relaxação da alocação de subportadoras, DKB e LDD permite o desenvolvimento de um problema de otimização linear e sem restrições. Na $i$-ésima iteração do DKB, o problema a ser resolvido é dado por:

$$
\widetilde{\mathbf{P}}^{*, i}, \widetilde{\boldsymbol{\lambda}}^{*, i}=\arg \min _{\boldsymbol{\tau} \succeq 0} \max _{\widetilde{\mathbf{P}}, \widetilde{\boldsymbol{\lambda}}} \mathcal{L}(\boldsymbol{\tau}, \widetilde{\mathbf{P}}, \widetilde{\boldsymbol{\lambda}})
$$

Apesar de todo o ferramental empregado, ainda não é possível determinar diretamente as variáveis duais ótimas e nem as matrizes de alocação de subportadoras e potência a partir da equação (4.8). Assim, adota-se uma solução iterativa para a obtenção destas variáveis, ou seja, cada iteração do algoritmo de DKB contará com um conjunto de iterações do algoritmo LDD. Tal solução consiste em, na $j$-ésima iteração do algoritmo LDD: a) resolver o problema de maximização, com os multiplicadores de Lagrange constantes e definidos pela $(j-1)$-ésima iteração;

$$
\widetilde{\mathbf{P}}^{i, j}, \tilde{\boldsymbol{\lambda}}^{i, j}=\left.\underset{\widetilde{\mathbf{P}}, \widetilde{\boldsymbol{\lambda}}}{\arg \max } \mathcal{L}(\boldsymbol{\tau}, \widetilde{\mathbf{P}}, \widetilde{\boldsymbol{\lambda}})\right|_{\tau=\tau^{i, j-1}}
$$

e b) resolver o problema de minimização com as variáveis de potência e alocação de subportadoras obtidas no passo a).

$$
\boldsymbol{\tau}^{i, j}=\left.\underset{\boldsymbol{\tau} \succeq 0}{\arg \min } \mathcal{L}(\boldsymbol{\tau}, \widetilde{\mathbf{P}}, \widetilde{\boldsymbol{\lambda}})\right|_{\widetilde{\mathbf{P}}=\widetilde{\mathbf{P}}^{i, j}, \widetilde{\boldsymbol{\lambda}}=\widetilde{\boldsymbol{\lambda}}^{i, j}}
$$

O algoritmo LDD é executado até que o erro de convergência máximo $\varepsilon_{\text {ldd }}^{\max }$ seja atingido ou até que um número limite de iterações seja executado.

A partir da formulação adotada, é possível utilizar as condições de Karush-KuhnTucker (KKT) para determinar $\widetilde{\mathbf{P}}^{*, i, j}$ e $\widetilde{\boldsymbol{\lambda}}^{*, i, j}[122]$. Usando as condições de primeira 
ordem para calcular $p_{k, n}^{*, i, j}$, deve-se derivar $\mathcal{L}(\boldsymbol{\tau}, \widetilde{\mathbf{P}}, \widetilde{\boldsymbol{\lambda}})$ em relação a $\widetilde{p}_{k, n}$ e então igualar o resultado a zero. Começando pelo processo de derivação, tem-se que:

$$
\begin{aligned}
\frac{\partial \mathcal{L}(\boldsymbol{\tau}, \widetilde{\mathbf{P}}, \tilde{\boldsymbol{\lambda}})}{\partial \widetilde{p}_{k, n}}= & \frac{\partial\left[\sum_{k=1}^{K} \sum_{n=1}^{N}\left[\ell_{k, n} \widetilde{\lambda}_{k, n} \mathrm{w} \log _{2}\left(1+\frac{\widetilde{p}_{k, n} \Gamma_{k, n}}{\bar{\lambda}_{k, n}}\right)-\left(q^{i-1} \varrho_{k}+\tau_{k}\right) \widetilde{p}_{k, n}\right]\right]}{\partial \widetilde{p}_{k, n}} \\
& +\frac{\partial\left[\sum_{k=1}^{K}\left(\tau_{k} p_{k}^{\max }-q^{i-1} p_{c_{k}}\right)\right]}{\partial \widetilde{p}_{k, n}} \\
= & \frac{\partial\left[\ell_{k, n} \widetilde{\lambda}_{k, n} \mathrm{w} \log _{2}\left(1+\frac{\widetilde{p}_{k, n} \Gamma_{k, n}}{\widetilde{\lambda}_{k, n}}\right)-\left(q^{i-1} \varrho_{k}+\tau_{k}\right) \widetilde{p}_{k, n}\right]}{\partial \widetilde{p}_{k, n}} \\
= & \ell_{k, n} \widetilde{\lambda}_{k, n} \mathrm{w} \frac{\Gamma_{k, n}}{\log (2) \widetilde{\lambda}_{k, n}\left(1+\frac{\widetilde{p}_{k, n} \Gamma_{k, n}}{\widetilde{\lambda}_{k, n}}\right)}-\left(q^{i-1} \varrho_{k}+\tau_{k}\right) \\
= & \frac{\ell_{k, n} \mathrm{w} \Gamma_{k, n}}{\log (2)\left(1+p_{k, n} \Gamma_{k, n}\right)}-\left(q^{i-1} \varrho_{k}+\tau_{k}\right)
\end{aligned}
$$

Rearranjando os termos e igualando a derivada a zero, obtém-se a seguinte expressão para calcular a potência ótima de cada usuário em cada subportadora:

$$
p_{k, n}^{*, i, j}=\left[\chi_{k, n}-\frac{1}{\Gamma_{k, n} \imath_{k}}\right]^{+},
$$

onde o operador $[\cdot]^{+}$retorna o valor máximo entre o argumento e zero, e

$$
\chi_{k, n}=\frac{\mathrm{w} \ell_{k, n}}{\log (2)\left(q^{i-1} \varrho_{k}+\tau_{k}^{i, j-1}\right)}
$$

pode ser visto como o nível da água de um algoritmo baseado em waterfilling. Vale notar que no uplink cada usuário pode ter um nível da água $\chi_{k, n}$ diferente, mesmo que todos tenham os mesmos parâmetros de sistema. Isso é causado pela presença do multiplicador de Lagrange $\tau_{k}^{i, j-1}$ no denominador de $\chi_{k, n}$, indicando que as restrições individuais de potência podem afetar o nível da água e, por consequência, a alocação de recursos.

A alocação de subportadoras segue o modelo discutido em [34]. Para se definir $\lambda_{k, n}^{*, i, j}$, primeiro calcula-se a primeira derivada de $\mathcal{L}(\boldsymbol{\tau}, \widetilde{\mathbf{P}}, \widetilde{\boldsymbol{\lambda}})$ em relação a $\widetilde{\lambda}_{k, n}$, que será denominada $s_{k, n}$ e servirá como uma métrica para se decidir para qual usuário será alocada a $n$-ésima subportadora. Com isso, $s_{k, n}$ é dado, na $i$-ésima iteração do algoritmo DKB e 
j-ésima iteração do algoritmo LDD, por:

$$
\begin{aligned}
& s_{k, n}=\frac{\partial \mathcal{L}(\boldsymbol{\tau}, \widetilde{\mathbf{P}}, \widetilde{\boldsymbol{\lambda}})}{\partial \widetilde{\lambda}_{k, n}} \\
& =\frac{\partial\left[\sum_{k=1}^{K} \sum_{n=1}^{N}\left[\ell_{k, n} \widetilde{\lambda}_{k, n} \mathrm{w} \log _{2}\left(1+\frac{\widetilde{p}_{k, n} \Gamma_{k, n} \imath_{k}}{\widetilde{\lambda}_{k, n}}\right)-\left(q^{i-1} \varrho_{k}+\tau_{k}\right) \widetilde{p}_{k, n}\right]+\sum_{k=1}^{K}\left(\tau_{k} p_{k}^{\max }-q^{i-1} p_{c_{k}}\right)\right]}{\partial \widetilde{\lambda}_{k, n}} \\
& =\frac{\partial\left[\ell_{k, n} \widetilde{\lambda}_{k, n} \mathrm{w} \log _{2}\left(1+\frac{\widetilde{p}_{k, n} \Gamma_{k, n} \imath_{k}}{\widetilde{\lambda}_{k, n}}\right)\right]}{\partial \widetilde{\lambda}_{k, n}} \\
& =\ell_{k, n} \mathrm{w} \log _{2}\left(1+\frac{\widetilde{p}_{k, n} \Gamma_{k, n} \imath_{k}}{\widetilde{\lambda}_{k, n}}\right)-\frac{\ell_{k, n} \widetilde{\lambda}_{k, n} \mathrm{w} \widetilde{p}_{k, n} \Gamma_{k, n} \imath_{k}}{\log (2)\left(\widetilde{\lambda}_{k, n}\right)^{2}\left(1+\frac{\widetilde{p}_{k, n} \Gamma_{k, n} \imath_{k}}{\widetilde{\lambda}_{k, n}}\right)} \\
& =\ell_{k, n} \mathrm{w} \log _{2}\left(1+p_{k, n} \Gamma_{k, n} \imath_{k}\right)-\frac{\ell_{k, n} \mathrm{w} p_{k, n} \Gamma_{k, n} \imath_{k}}{\log (2)\left(1+p_{k, n} \Gamma_{k, n} \imath_{k}\right)} \\
& =\frac{\mathrm{w} \ell_{k, n}}{\log (2)}\left[\log \left(1+p_{k, n} \Gamma_{k, n} \imath_{k}\right)-\frac{p_{k, n} \Gamma_{k, n} \iota_{k}}{1+p_{k, n} \Gamma_{k, n} \imath_{k}}\right]
\end{aligned}
$$

Aplicando a alocação de potência obtida na $i$-ésima iteração do DKB e $j$-ésima iteração do LDD, a métrica de alocação é dada por:

$$
s_{k, n}^{i, j}=\frac{\mathrm{w} \ell_{k, n}}{\log (2)}\left[\log \left(1+p_{k, n}^{*, i, j} \Gamma_{k, n} \imath_{k}\right)-\frac{p_{k, n}^{*, i, j} \Gamma_{k, n} \imath_{k}}{1+p_{k, n}^{*, i, j} \Gamma_{k, n} \imath_{k}}\right]
$$

A métrica $s_{k, n}^{i, j}$ pode ser interpretada como a taxa de crescimento da EE quando a $n$-ésima subportadora é alocada à $k$-ésima MS na $i$-ésima iteração do algoritmo DKB e $j$-ésima iteração do algoritmo LDD [34]. Ainda, tem-se que $s_{k, n}^{i, j}>0$ quando $p_{k, n}^{*, i, j}>0$, indicando que a EE não pode ser reduzida ao se alocar a $n$-ésima subportadora à $k$-ésima MS.

Como $s_{k, n}$ pode ser visto como a taxa de crescimento da EE, para se obter o maior crescimento basta alocar a $n$-ésima subportadora ao usuário que resultar na maior taxa de crescimento, ou seja,

$$
\lambda_{k, n}^{*, i, j}= \begin{cases}1, & \text { se } s_{k, n}^{i, j}=\max _{k}\left(s_{k, n}^{i, j}\right) \text { e } s_{k, n}^{i, j}>0 \\ 0, & \text { caso contrário }\end{cases}
$$

Como a solução de (4.9) é única e $\mathcal{L}(\boldsymbol{\tau}, \widetilde{\mathbf{P}}, \widetilde{\boldsymbol{\lambda}})$ é diferenciável em relação aos multiplicadores de Lagrange, métodos de gradiente podem ser utilizados para calcular $\boldsymbol{\tau}^{i, j}$ [34]. Na $j$-ésima iteração do algoritmo LDD, e considerando a $i$-ésima iteração do algoritmo DKB, os multiplicadores de Lagrange são atualizados como:

$$
\tau_{k}^{j}=\left[\tau_{k}^{j-1}-\phi_{k}\left(p_{k}^{\max }-\sum_{n=1}^{N} \lambda_{k, n} p_{k, n}^{*, i, j}\right)\right]^{+},
$$


com $\phi_{k}$ correspondendo ao fator de atualização que controla a convergência dos multiplicadores de Lagrange.

A convergência do algoritmo LDD é atingida se o erro de convergência $\varepsilon_{\text {ldd }}$, definido por

$$
\varepsilon_{1 \mathrm{dd}}=\max _{k}\left(\left|\tau_{k}^{i, j}-\tau_{k}^{i, j-1}\right|\right)
$$

for menor que o erro limite $\varepsilon_{\text {ldd }}^{\max }$.

A metodologia apresentada até o momento é clássica, e bastante difundida na literatura. Porém, como será visto na seção seguinte, sua implementação computacional ainda apresenta limitações, em geral ignoradas ou resolvidas empiricamente.

\subsection{Implementação Computacional Robusta e Efetiva}

O pseudocódigo para alocação de potência e subportadoras em uplink de sistemas OFDMA utilizando DKB e LDD é dado no Algoritmo 4.1, destacando o loop de cálculo e definição de potência e subportadoras no Algoritmo 4.2. Apesar da simplicidade do método e sua difusão no meio científico, existem aspectos fundamentais para a implementação computacional do algoritmo de alocação de recursos que geralmente não são resolvidos ou mesmo sequer abordados na literatura. Os principais aspectos são: a) Os valores iniciais do parâmetro do algoritmo DKB, $q^{0}$, e dos multiplicadores de Lagrange, $\boldsymbol{\tau}^{1,0}$; e b) A variável de atualização $\phi$. Mesmo sem apresentarem uma metodologia para a obtenção desses parâmetros, a literatura mostra que uma definição adequada dos parâmetros é fundamental para acelerar e até mesmo garantir a reprodutividade do método, bem como a convergência da solução em um número adequado de iterações.

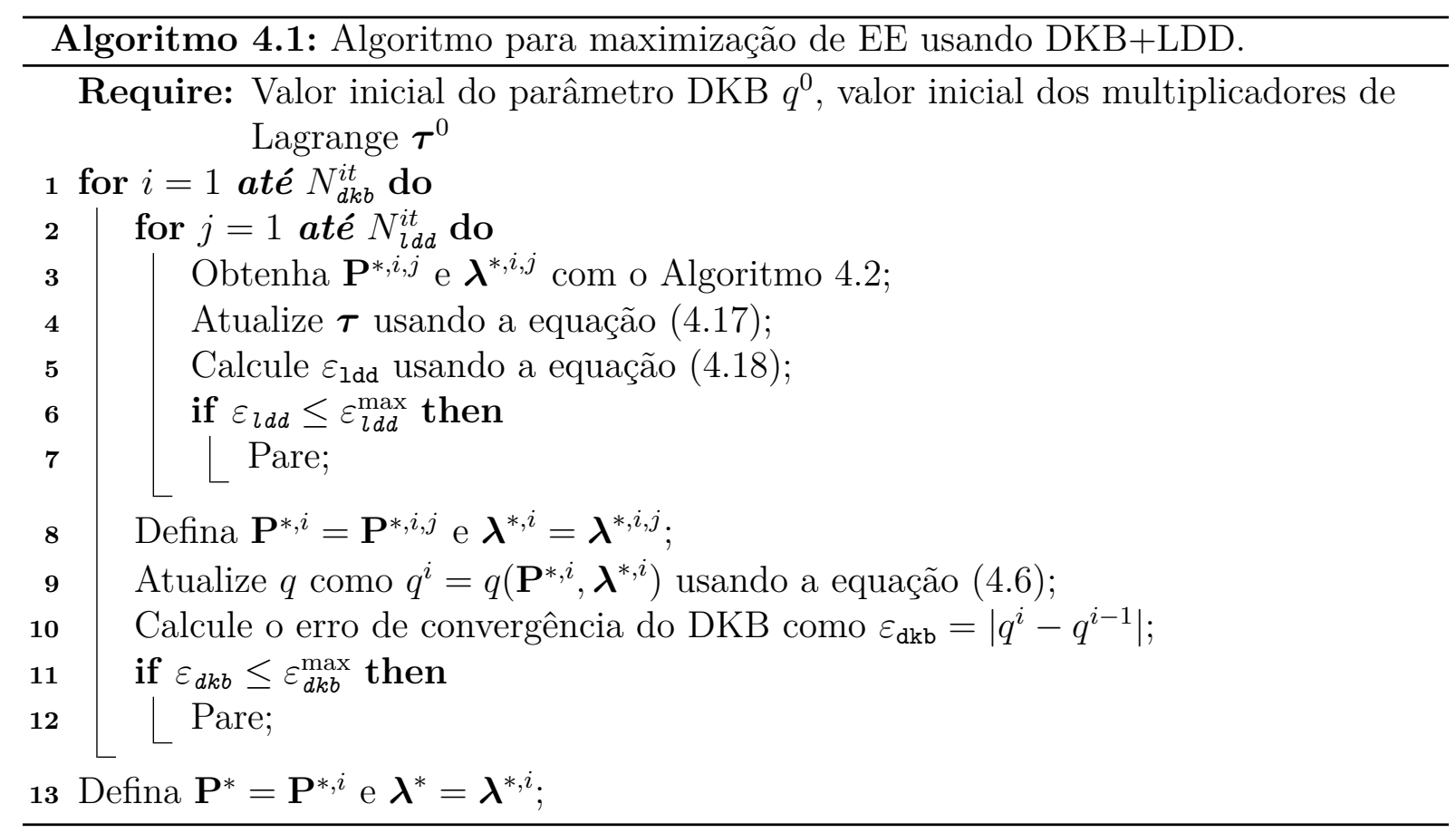




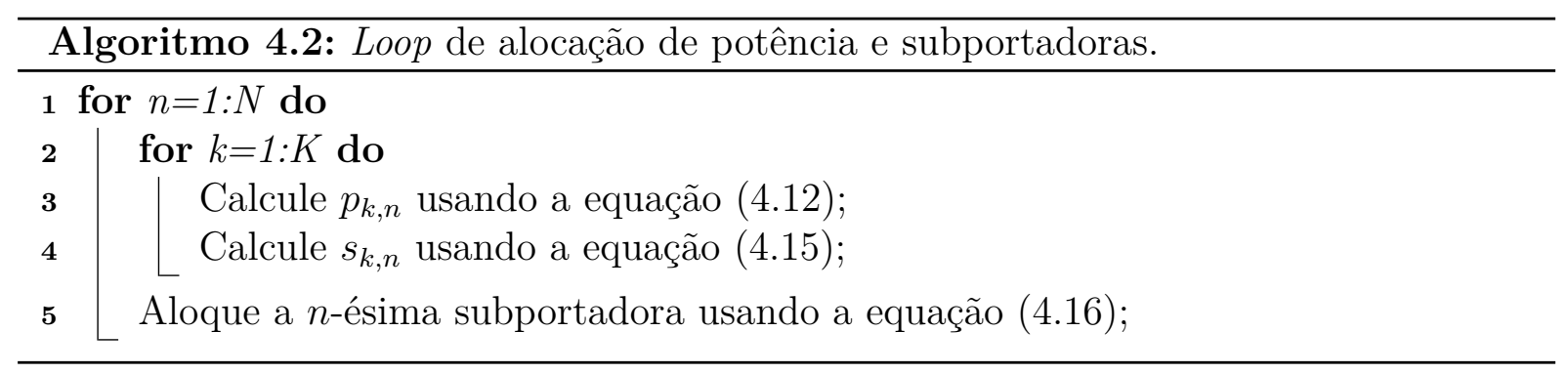

Em [34], a variável de atualização $\phi$ e o valor inicial dos multiplicadores $\boldsymbol{\tau}$ são otimizados empiricamente para se atingir a EE ótima no menor número de iterações possível, enquanto o desenvolvimento de uma solução robusta e efetiva para realizar esses procedimentos é citado pelos autores como uma questão em aberto. Em [123], apenas é afirmado que o valor inicial do parâmetro do DKB deve ser inferior à EE ótima, porém nenhum procedimento é apresentado.

A definição desses valores afeta diretamente o número de iterações executadas, ou seja, a velocidade de obtenção da solução, e também a convergência tanto do algoritmo DKB quanto do LDD. Por exemplo, se a variável de atualização $\phi$ for definida com um valor muito alto, os multiplicadores de Lagrange podem oscilar na região do ponto de ótimo sem jamais serem capazes de convergir para esse ponto, fazendo com que o algoritmo continue sendo executado até que o número limite de iterações seja atingido; por outro lado, se for atribuído valores muito baixos para $\phi$, o algoritmo pode consumir muitas iterações até convergir, ou mesmo não convergir até que o limite de iterações seja atingido. Em relação à inicialização de $q$ e $\boldsymbol{\tau}$, o desenvolvimento de um procedimento capaz de atingir valores significativos e próximos da EE ótima e também de aproximar rapidamente o valor dos multiplicadores do valor ótimo, ou ao menos da região onde o ponto de ótimo se localiza, terá um impacto significante na redução do número de iterações, e portanto do tempo de convergência, do Algoritmo 4.2. A definição da variável de atualização será feita na Subseção 4.3.1, enquanto os demais aspectos de implementação serão desenvolvidos nas subseções seguintes.

\subsubsection{Inicialização de Variáveis}

Se tanto $q$ quanto $\boldsymbol{\tau}$ forem definidos como zero ao mesmo tempo, o nível da água $\chi_{k, n}$ na equação (4.12) se torna infinito, o que implica em alocação de potência infinita de acordo com a equação (4.12). Se $q^{0}=0$, com $\boldsymbol{\tau} \succ \mathbf{0}$, a primeira iteração do algoritmo DKB se assemelha a um problema de maximização de taxa de dados, dado que o custo da potência se torna nulo na função-objetivo (4.4). É o caso observado, por exemplo, em [34], onde se define que $q^{0}=0$, enquanto a inicialização das variáveis duais foi obtida empiricamente.

A solução proposta para o problema de inicialização de variáveis tem sua base nos resultados obtidos em [124]. Uma possível interpretação do problema de otimização de 
EE é maximizar a capacidade do sistema para cada nível de potência possível, e então selecionar o nível que resulta na máxima EE. Quando as restrições do problema são suficientemente frouxas, ou um cenário de downlink é considerado, a capacidade do sistema será maximizada quando para cada subportadora for alocada à MS com maior ganho de canal. Assim, é possível definir a alocação inicial de subportadoras como aquela que aloca a $n$-ésima subportadora à $k$-ésima MS de acordo com o ganho de canal $\Gamma_{k, n}$, ou seja:

$$
\lambda_{k, n}=\left\{\begin{array}{ll}
1, & \text { se } k=\underset{k}{\arg \max } .\left(\Gamma_{k, n}\right) \\
0, & \text { caso contrário }
\end{array} \quad \forall n .\right.
$$

Definida a alocação de subportadoras, uma alocação igualitária de potência (EPA) é feita, de modo que $p_{k, n}=\frac{p_{k}^{\max }}{N} \forall k, n$. Finalmente, $q^{0}$ é calculado usando a equação (4.6).

Utiliza-se $q^{0}$ aqui para obter a alocação de potência a partir da equação (4.12), sem alterar a alocação de subportadoras definida pela equação (4.19). A motivação para tal recalculo é que a alocação de potência por EPA não considera a diversidade entre as subportadoras, ou seja, a taxa de dados resultante é, certamente, inferior à máxima taxa que pode ser obtida. Além disso, no EPA se utiliza toda a potência disponível, o que, geralmente, não é ótimo. Após o recálculo da alocação de potência, para todas as MSs que violarem a potência máxima $p_{k}^{\max }$, utiliza-se um algoritmo clássico do tipo waterfilling $(\mathrm{WF})$ para adequar a restrição de potência. Considerando que $p_{k, n}>0$ após o algoritmo WF, o valor do multiplicador de Lagrange $\tau_{k}$ pode ser calculado como

$$
\tau_{k}=\frac{\Gamma_{k, n} \imath_{k} \mathrm{w} \ell_{k, n}}{\log (2)\left(\Gamma_{k, n} \imath_{k} p_{k, n}+\Gamma_{k, n} \imath_{k}\right)}-q^{0} \varrho_{k} .
$$

Finalmente, a alocação de potência atualizada é utilizada para atualizar o parâmetro $q^{0}$.

\subsubsection{Violação da Restrição de Potência}

Apesar do cálculo de $\tau_{k}$ na etapa anterior, é possível que a primeira execução subsequente do Algoritmo 4.2 possa resultar em nova violação das restrições de potência máxima do problema de otimização. Considere que apenas uma $k$-ésima MS viole a restrição de potência máxima no passo anterior: nesse caso, $\tau_{k}$ é aumentado, o que reduz o nível da água e, consequentemente, a potência alocada. Como a métrica de alocação $s_{k, n}$ é crescente em relação à potência alocada, a $k$-ésima MS se torna menos competitiva na alocação de subportadoras, e pode perder várias subportadoras para a $k^{\prime}$-ésima MS. Finalmente, essa $k^{\prime}$-ésima MS pode alocar tantas subportadoras que ela mesmo pode vir a violar a restrição de potência máxima. Caso tal situação ocorra, o Algoritmo 4.1 pode consumir dezenas de iterações para retornar a um estado válido, ou até mesmo não convergir devido ao limite de iterações ou oscilações na alocação de subportadoras.

Para solucionar tal problema, define-se $\boldsymbol{\tau}=\mathbf{0}$ após o passo anterior e executa-se novamente o Algoritmo 4.2, utilizando o parâmetro $q^{0}$ calculado ao fim do passo anterior. 
Caso todas as MSs respeitem a restrição de potência máxima, encerram-se as etapas de aproximação e o algoritmo DKB+LDD é efetivamente iniciado. Caso contrário, calculase $\tau_{k}$ utilizando o algoritmo WF para essas MSs, adequando o limite de potência, e recalcula-se o parâmetro q. Com o novo parâmetro, reinicia-se o procedimento até que todas as MSs respeitem a restrição de potência máxima. No Algoritmo 4.3 é apresentada a implementação desse procedimento.

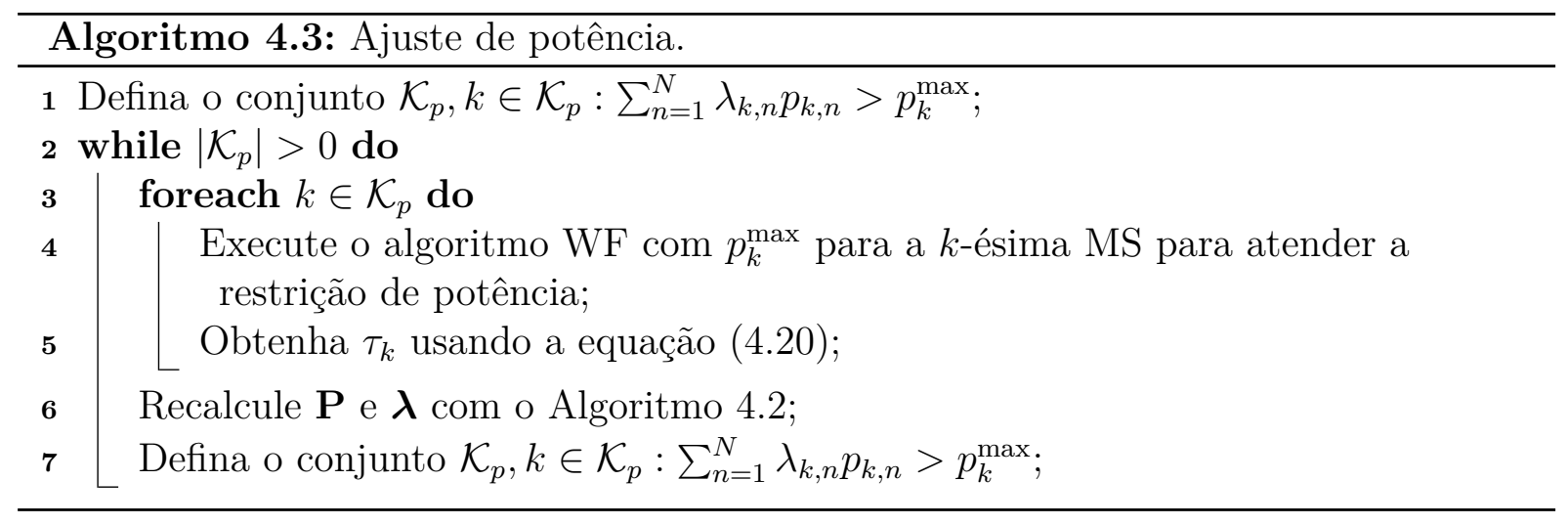

\subsubsection{Superestimação de $\tau_{k}$}

Em diversos outros casos, percebeu-se que a segunda repetição do Algoritmo 4.2 resultou em redução de EE, ou seja, em um menor parâmetro $q^{0}$. Tal problema resulta do fato que $\tau_{k}$ pode ser superestimado pelo procedimento descrito no Algoritmo 4.3, e um exemplo similar ao da Subseção anterior auxilia no entendimento do problema. Considerando novamente que a $k$-ésima MS viole a restrição de potência máxima, o multiplicador $\tau_{k}$ é aumentado, reduzindo tanto a potência alocada quanto a métrica $s_{k, n}$. Com isso, a $k$-ésima MS pode perder algumas das subportadoras anteriormente alocadas, o que reduz ainda mais a potência total alocada por essa $k$-ésima MS, de modo que a potência efetivamente alocada pela $k$-ésima MS, ao fim do Algoritmo 4.3, pode ser bastante inferior a $p_{k}^{\max }$. Porém, em geral, quando uma MS estoura o limite de potência no problema de otimização proposto, o motivo é que a condição de canal dessa MS é bastante favorável e que, para maximizar a EE do sistema, deveria utilizar potência máxima.

Para solucionar essa limitação, propõe-se um novo procedimento de atualização para todas as MSs nas quais $\tau_{k}>0$ após a execução do Algoritmo 4.3. Assim, após todas as restrições de potência terem sido atendidas, os multiplicadores de Lagrange são atualizados utilizando um método baseado em bissecção: A cada nova iteração, define-se um valor válido $\left(\tau_{k}^{\text {ok }}\right)$ e outro inválido $\left(\tau_{k}^{\text {err }}\right)$ para cada $\tau_{k}>0$, ou seja, um valor em que a restrição de potência da $k$-ésima MS é garantida e outro em que a restrição é violada, respectivamente. Com esses dois valores, define-se um valor médio a ser testado a cada iteração,

$$
\widehat{\tau}_{k}=\left(\tau_{k}^{\mathrm{ok}}+\tau_{k}^{\mathrm{err}}\right) / 2
$$


Com $\widehat{\tau}_{k}$, calcula-se a alocação de potência e subportadoras e verifica-se se as restrições da $k$-ésima MS são respeitadas. Em caso positivo, define-se $\tau_{k}^{\text {ok }}=\widehat{\tau}_{k}$; caso contrário, definese $\tau_{k}^{\text {err }}=\widehat{\tau}_{k}$. Após a execução de um número pré-determinado de iterações, toma-se $\tau_{k}=\tau_{k}^{\text {ok }}$, e a alocação de potência e subportadoras é refeita.

Para ilustrar a superestimação de $\tau_{k}$, utiliza-se um dos casos do conjunto de simulações, assumindo que $K=30, N=2048$ e $p_{c_{k}}=100 \mathrm{~mW}$, enquanto os demais parâmetros são dados na Tabela 4.1, Seção 4.3. Foram testados dois limites de potência distintos, $p_{k}^{\max }=200 \mathrm{~mW}$ e $p_{k}^{\max }=120 \mathrm{~mW}$. Para o primeiro limite de potência, existem duas MSs, identificados como MS 10 e MS 18, que violam a restrição de potência após a execução do Algoritmo 4.3. A EE antes da execução do Algoritmo 4.3 é de $\xi=782,732$ bits por Joule por Hertz (b/J·Hz), e após a execução do algoritmo é reduzida para $\xi=774,886 \mathrm{~b} / \mathrm{J} \cdot \mathrm{Hz}$. Tal redução é causada pela superestimação de $\tau_{10}$ e $\tau_{18}$, resultante da necessidade de garantir um estado válido para a alocação de potência, e que serão denotados por $\widehat{\tau}_{10} \mathrm{e} \widehat{\tau}_{18}$. O ponto gerado por esses dois valores é plotado na Figura 4.1.a), onde também é plotado o ponto de ótimo obtido após a convergência do algoritmo DKB+LDD, representado por $\tau_{10}^{*}$ e $\tau_{18}^{*}$. Após a execução do procedimento baseado em bissecção, com limite de 10 iterações, obtém-se uma $\mathrm{EE}$ de $\xi=790,837$ b/J·Hz, e os multiplicadores de Lagrange, dados por $\tau_{10}$ e $\tau_{18}$, estão significativamente mais próximos dos obtidos após a convergência do $\mathrm{DKB}+\mathrm{LDD}$.

Figura 4.1 - Área de busca definida pela aproximação dos multiplicadores obtida com o Algoritmo 4.3 (marcador circular), e os valores obtidos após o método baseado em bissecção (marcador quadrado) e após a convergência do algoritmo $\mathrm{DKB}+\mathrm{LDD}$ (marcador asterisco) para: a) $p_{k}^{\max }=200 \mathrm{~mW}$ e b) $p_{k}^{\max }=120$ $\mathrm{mW}$.

a)

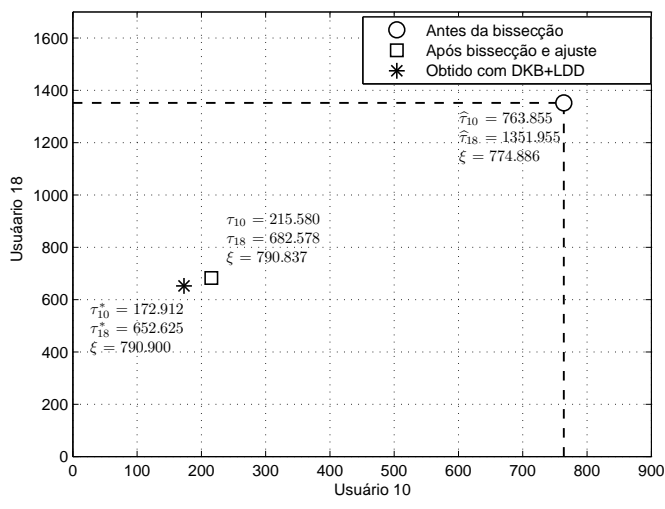

b)

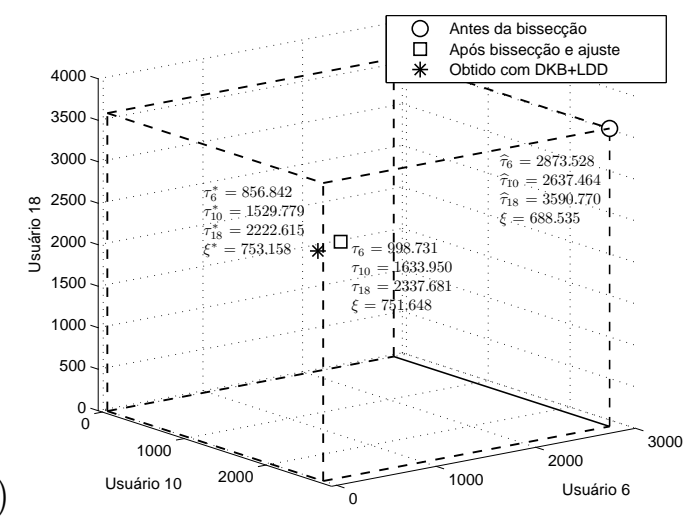

Fonte: o autor

Note que o resultado também se aplica para $p_{k}^{\max }=120 \mathrm{~mW}$, como mostrado na Figura 4.1.b), onde os multiplicadores de três MSs tiveram que ser calculados para que o sistema atingisse um estado válido. No caso desse exemplo, a redução de EE pela superestimação dos multiplicadores foi mais significativa: antes do Algoritmo 4.3 ser executado, a EE do sistema era de $\xi=730,666 \mathrm{~b} / \mathrm{J} \cdot \mathrm{Hz}$, enquanto que após a execução 
resultou em $\xi=688,535 \mathrm{~b} / \mathrm{J} \cdot \mathrm{Hz}$. Observe que o ponto aproximado pelo procedimento baseado em bissecção é muito mais próximo do ótimo do que a estimativa do Algoritmo 4.3, o que resulta em uma EE de $\xi=751,648 \mathrm{~b} / \mathrm{J} \cdot \mathrm{Hz}$, diferença próxima dos $10 \%$ entre as duas estimativas. Assim, pode ser inferido que o ponto de ótimo dos multiplicadores de Lagrange $\left(\tau_{k_{1}}^{*}, \tau_{k_{2}}^{*}, \cdots, \tau_{K^{\prime}}^{*}\right)$ está localizado no interior do hiper-retângulo definido pela estimativa $\widehat{\tau}_{k_{1}}, \widehat{\tau}_{k_{2}}, \cdots, \widehat{\tau}_{K^{\prime}}$ obtida com o Algoritmo 4.3.

O procedimento de inicialização descrito acima é usado apenas antes da primeira iteração do algoritmo DKB. Após a atualização do parâmetro $q$ e da verificação de convergência do algoritmo DKB, outra técnica é utilizada para definir os valores iniciais em cada uma das iterações seguintes do algoritmo DKB. O cerne do método é que o nível da água na primeira iteração do algoritmo LDD e $(i+1)$-ésima iteração do algoritmo DKB seja o mesmo nível da última iteração (denotada por $j$ ) do algoritmo LDD na $i$-ésima iteração do algoritmo DKB, ou seja,

$$
\frac{\mathrm{w} \ell_{k, n}}{\log (2)\left(q^{i-1} \varrho_{k}+\tau_{k}^{i, j}\right)}=\frac{\mathrm{w} \ell_{k, n}}{\log (2)\left(q^{i} \varrho_{k}+\tau_{k}^{i+1,0}\right)} .
$$

Desse modo, o valor inicial dos multiplicadores de Lagrange na $(i+1)$-ésima iteração do algoritmo DKB são dados por

$$
\tau_{k}^{i+1,0}=\left[\left(q^{i-1}-q^{i}\right) \varrho_{k}+\tau_{k}^{i, j}\right]^{+}, \quad k=1, \cdots, K .
$$

\subsubsection{Soluções Sub-ótimas}

Durante o desenvolvimento das técnicas de inicialização de $q$ e $\boldsymbol{\tau}$, os excelentes resultados, em termos de EE, obtidos com as simulações preliminares indicavam a possibilidade do desenvolvimento de dois algoritmos sub-ótimos para maximização de EE. Esses algoritmos são capazes de atingir uma percentagem significativa da máxima EE, obtida com o algoritmo DKB+LDD, porém com reduzida complexidade computacional. Além da menor complexidade, outra vantagem dos algoritmos propostos é que nenhum deles depende de variáveis que precisem ser cuidadosamente escolhidas e otimizadas para cada cenário de simulação, isto é, cada realização de canal e número de subportadoras e MSs, tornando o processo de otimização muito mais robusto. Vale lembrar que para o algoritmo $\mathrm{DKB}+\mathrm{LDD}$, a variável de atualização $\phi$ e os valores iniciais $q^{0}$ e $\boldsymbol{\tau}^{0}$ precisam ser definidos para cada novo cenário de canal e de sistema. Os algoritmos sub-ótimos propostos neste contexto, denominados SIPA-EE e TIPSA-EE, são descritos a seguir.

\subsubsection{Algoritmo SIPA-EE}

No algoritmo sub-ótimo single iteration power allocation (SIPA-EE), primeiro aloca-se as subportadoras, como descrito na equação (4.19). Em seguida, aplica-se o algoritmo EPA para alocação de potência, o que possibilita a aproximação inicial para o parâmetro $q$ de 
Dinkelbach. Tendo um valor de $q$ disponível, e definindo $\boldsymbol{\tau}=\mathbf{0}$, é possível calcular a alocação de potência baseada em WF, como descrito na equação (4.12). Essa alocação de potência deve ser verificada para evitar que alguma MS viole a restrição de potência máxima. Caso seja verificado que a $k$-ésima MS alocou mais potência do que a disponível, reduz-se o nível da água $\chi_{k, n}$ através do aumento de $\tau_{k, n}$, e então a alocação de potência é recalculada. Por simplicidade, não se recalcula a alocação de subportadoras nem antes nem após esse procedimento. O pseudocódigo para o algoritmo SIPA-EE é mostrado no Algoritmo 4.4.

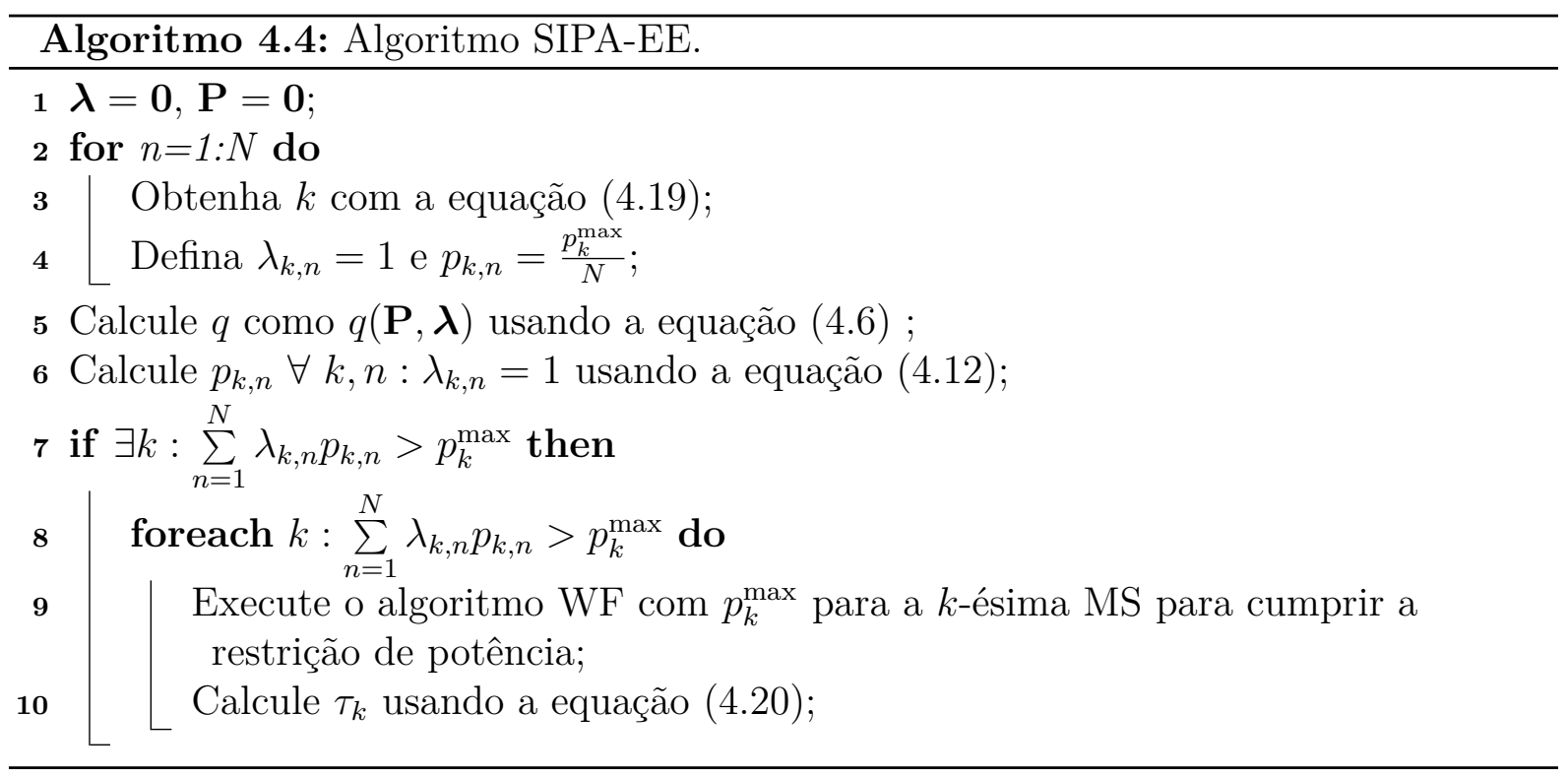

Como se considera o uplink de um sistema de comunicação com restrições individuais de potência, é possível que a alocação ótima de subportadoras para maximização de EE seja diferente da alocação obtida por meio da equação (4.19). Apesar disso, a solução apresentada pela equação (4.19) é interessante e bastante simples para ser utilizada como uma primeira aproximação para o problema de alocação de subportadoras.

O algoritmo SIPA-EE pode ser visto como a execução de uma única iteração simplificada do algoritmo DKB+LDD para downlink, no qual a alocação de subportadoras não seria alterada a partir do definido na equação (4.19) ${ }^{1}$. Como discutido na Seção 4.3, a execução de apenas uma iteração é suficiente para aumentar significativamente a porcentagem de EE atingida com a estratégia de alocação de potência por EPA.

\subsubsection{Algoritmo TIPSA-EE}

O segundo algoritmo quase-ótimo considera a execução de mais uma iteração de alocação de subportadoras e potência após o algoritmo SIPA-EE, sendo chamado de two-iteration

1 Note-se que a alocação de subportadoras não é alterada em downlink quando o problema é modelado como o deste trabalho, ou seja, apenas com restrições de potência. Caso outras restrições fossem consideradas, como por exemplo um critério de taxa mínima, não seria possível fazer tal afirmação. 
power and subcarrier allocation (TIPSA-EE). A EE resultante da execução do algoritmo SIPA-EE é considerado como a primeira estimativa do parâmetro $q$, enquanto os multiplicadores de Lagrange são definidos como $\boldsymbol{\tau}=\mathbf{0}$. Estes parâmetros são então usados para se calcular uma nova alocação de potência e subportadoras utilizando o Algoritmo 4.2. Novamente, a alocação de potência é checada para verificar se alguma MS violou a restrição de potência máxima. Adicionalmente, implementa-se também a atualização dos multiplicadores de Lagrange discutida na Subseção 4.2.3, definindo um número fixo de iterações $N_{\mathrm{it}}^{\text {upd }}$ a serem executadas. Após a atualização de $\boldsymbol{\tau}$, checa-se novamente a alocação de potência para evitar violação de restrição ${ }^{2}$. O pseudocódigo do algoritmo TIPSA-EE é apresentado no Algoritmo 4.5.

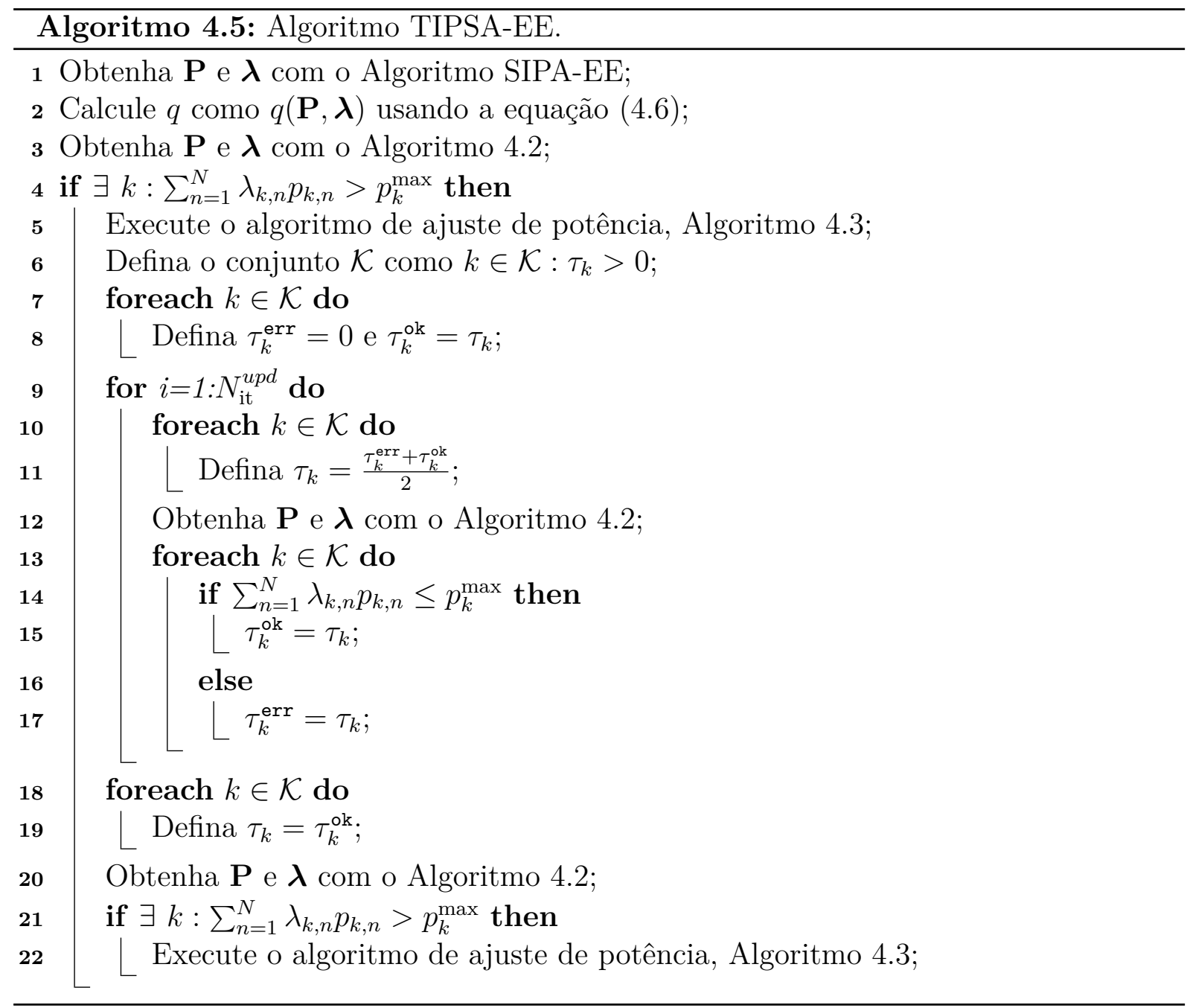

Decide-se por uma novo cálculo da alocação de potência e subportadoras após o algoritmo SIPA-EE devido às restrições individuais de potência. Se a $k$-ésima MS aloca

2 Esse procedimento é necessário apenas por uma questão de precisão numérica da ferramenta computacional. Foi percebido que, em alguns poucos casos, a EE obtida com o algoritmo TIPSA-EE era maior que a EE obtida após a convergência do algoritmo DKB+LDD, que é considerado como ótimo. Quando verificada a alocação de potência nesses casos, percebeu-se que havia um estouro mínimo na alocação de potência do TIPSA-EE, provavelmente vinda de erros de arredondamento do ferramental computacional. Com essa etapa extra, nenhum caso de EE maior que a EE ótima foi verificado. 
mais potência que $p_{k}^{\max }$, o multiplicador $\tau_{k}$ é aumentado, reduzindo o nível da água e, consequentemente, a potência alocada em cada subportadora. Na perspectiva do uplink do sistema OFDMA, é possível que algumas dessas subportadoras resultem em melhor EE para o sistema se forem alocadas para outra MS, o que não é tratado no algoritmo SIPA-EE.

Para validar a discussão sobre a superestimação de $\tau_{k}$ apresentada na Subseção 4.2.3 e presente no algoritmo TIPSA-EE na linha 5, será analisada também a EE obtida quando as linhas 6-22 do Algoritmo 4.5 não são executadas, denominando tal algoritmo por TIPSA-EE sem ajuste (without adjustment), isto é, TIPSA-EE (WA). Além de ser um dos algoritmos sub-ótimos propostos, o TIPSA-EE também será utilizado para prover os parâmetros iniciais $q^{0}$ e $\tau^{0}$ do algoritmo DKB+LDD, que será então utilizado para determinar a alocação ótima de recursos.

\subsubsection{Complexidade dos Algoritmos Propostos}

A complexidade do algoritmo SIPA-EE é determinada pelas etapas: a) determinação da melhor MS para cada subportadora, linha 3; b) cálculo de $q$, linha 5; e c) execução do procedimento WF, linha 9.

Para o item a), a complexidade é da ordem de $\mathcal{O}(K N)$, afinal comparam-se $K$ ganhos de canal por subportadora e existem $N$ subportadoras no sistema. Para o item b), a complexidade também é da ordem de $\mathcal{O}(K N)$, dado que o cômputo de $q$ envolve dois somatórios em $K$ e $N$ com um número constante de multiplicações reais em cada componente do somatório, além de uma divisão real e $K N$ cômputos de logaritmos. Para o item c), a complexidade do algoritmo WF é da ordem de $\mathcal{O}(N \log (N))$ [125], e ocorre quando uma única MS aloca todas as subportadoras disponíveis. Porém, quando apenas uma MS aloca todas as subportadoras, o algoritmo WF é executado uma única vez, dado que apenas uma MS possui potência alocada não nula. Em geral, o algoritmo WF é executado para apenas algumas poucas MSs com um número significativamente grande de subportadoras, considerando os parâmetros testados, conforme discutido na seção de resultados numéricos. Com tais considerações, afirma-se aqui que a complexidade do item c) é da ordem de $\mathcal{O}(N \log (N))$, e a complexidade do algoritmo SIPA-EE é, portanto, da ordem de $\mathcal{O}(K N+N \log (N))$.

Para o algoritmo TIPSA-EE, os procedimentos que contribuem para o incremento de complexidade computacional são: a) O algoritmo SIPA-EE, linha 1; b) As execuções do Algoritmo 4.2, linhas 3, 12 e 20, cuja complexidade é da ordem de $\mathcal{O}(K N)$ [34]; e c) As execuções do Algoritmo 4.3, linhas 5 e 22.

Em relação ao Algoritmo 4.3, o procedimento na linha 4 tem complexidade da ordem de $\mathcal{O}(N \log (N))$, enquanto que a linha 6 possui complexidade da ordem de $\mathcal{O}(K N)$. Porém, a linha 4 está inserida em um laço foreach que pode ser executado para todas as $K \mathrm{MSs}$, o que pode resultar em uma complexidade de pior caso da ordem de $\mathcal{O}(K N \log (N))$. 
Apesar da possibilidade, tal cenário de pior caso é bastante improvável, pois quando um grande número de MSs possuem subportadoras alocadas:

i) Um grande número de MSs possuem poucas subportadoras, e apenas algumas poucas dessas MSs violam a restrição de potência máxima, ou;

ii) As subportadoras estão bem distribuídas entre as MSs, e a probabilidade de todas elas alocarem mais potência que $p_{k}^{\max }$ é baixa.

O laço foreach está inserido em um laço while cuja contagem de repetições é difícil de ser estimada em termos de $K$ e $N$, porém afirma-se aqui que tal número é bastante inferior a $K$ e $N$. Para corroborar as afirmações sobre o número de execuções dos laços foreach e while associados à linha 4, o número de execuções de ambos os laços será analisado. Com os argumentos e afirmações apresentados, define-se que a complexidade do Algoritmo 4.3, e consequentemente do algoritmo TIPSA-EE, é da ordem de $\mathcal{O}(K N+N \log (N))$ para cenários práticos.

Para o algoritmo DKB+LDD-EE, a complexidade é dominada pelo algoritmo TIPSAEE e pelo Algoritmo 4.2, cuja complexidade é da ordem de $\mathcal{O}(K N)$ [34] e é executado a cada iteração dual. Dado que afirma-se que a complexidade do algoritmo TIPSA-EE é da ordem de $\mathcal{O}(K N+N \log (N))$, será investigada também a complexidade do algoritmo DKB+LDD-EE em cenários práticos. Nesses cenários, percebe-se que a complexidade computacional é dominada pela execução do Algoritmo 4.2, isto é, é da ordem de $\mathcal{O}(K N)$.

\subsection{Resultados Numéricos}

Para avaliar a EE atingida pelo algoritmo ótimo DKB+LDD-EE e pelos algoritmos subótimos SIPA-EE e TIPSA-EE, são analisadas $10^{4}$ realizações de canal, representando posições geográficas aleatórias das MSs distribuídas no interior da célula. As MSs foram posicionados de modo aleatório na célula, segundo uma distribuição uniforme da distância entre MS e BS e também uniforme do ângulo em relação à BS ${ }^{3}$. A amplitude dos coeficientes de desvanecimento rápido para todas as MSs é modelada utilizando uma distribuição de Rayleigh com média unitária, gerada por uma distribuição complexa Gaussiana com média nula e variância de $\sqrt{2 / \pi}$ por dimensão ${ }^{4}$.

A perda de percurso é baseada no modelo WINNER C2, que é apresentado no Apêndice D.1. Para modelar a existência ou não de linha de visada (LoS), utiliza-se a probabilidade de LoS do modelo WINNER C2 para gerar uma variável aleatória do tipo binomial para cada MS, que define a condição de propagação. A não ser que sejam explicitamente modificados, os demais parâmetros de simulação são apresentados na Tabela 4.1.

3 Como não há setorização ou utilização de RSs, o ângulo não influi nos resultados.

4 Mesmo nos casos em que o modelo de perda de percurso prevê a existência de uma linha de visada, foi considerada a utilização da distribuição de Rayleigh para os coeficientes de desvanecimento. 
Tabela 4.1 - Parâmetros de simulação

\begin{tabular}{|c|c|}
\hline Parâmetro & Valor \\
\hline \multicolumn{2}{|c|}{ Sistema de comunicação } \\
\hline Número de subportadoras $(N)$ & $\overline{[256,512,1024,2048]}$ \\
\hline Número de MSs $(K)$ & {$[30,60,90,120]$} \\
\hline Largura de banda das subportadoras (w) & $12 \mathrm{kHz}$ \\
\hline Raio da macro-célula $(R)$ & $750 \mathrm{~m}$ \\
\hline PSD do ruído AWGN $\left(N_{o}\right)$ & $-174 \mathrm{dBm} / \mathrm{Hz}$ \\
\hline Proporção de bits de informação $\left(\ell_{k, n}\right)$ & 0.8 \\
\hline \multicolumn{2}{|l|}{ MS } \\
\hline Potência máxima por MS $\left(p_{k}^{\max }\right)$ & $200 \mathrm{~mW}$ \\
\hline Potência de circuitaria $\left(p_{c_{k}}\right)$ & $100 \mathrm{~mW}$ \\
\hline Máxima BER tolerada $\left(\right.$ BER $\left._{k}\right)$ & $10^{-3}$ \\
\hline Ineficiência do amplificador de potência $\left(\varrho_{k}\right)$ & 4 \\
\hline \multicolumn{2}{|l|}{ Perda de percurso } \\
\hline Frequência da portadora $\left(f_{c}\right)$ & $2 \mathrm{GHz}$ \\
\hline Altura da antena da BS ( $\left.h_{\mathrm{BS}}\right)$ & $25 \mathrm{~m}$ \\
\hline Altura da antena da MS $\left(h_{\mathrm{MS}}\right)$ & $1.5 \mathrm{~m}$ \\
\hline
\end{tabular}

\begin{tabular}{c|c}
\hline \hline \multicolumn{2}{c}{ DKB e LDD } \\
\hline \hline Erro máximo para convergência (DKB) $\left(\varepsilon_{\mathrm{dkb}}^{\max }\right)$ & $10^{-8}$ \\
Erro máximo para convergência (LDD) $\left(\varepsilon_{\mathrm{ldd}}^{\max }\right)$ & $10^{-8}$ \\
Limite de iterações (DKB) $\left(N_{\mathrm{dkb}}^{i t}\right)$ & 50 \\
Limite de iterações (LDD) $\left(N_{\mathrm{ldd}}^{i t}\right)$ & 100
\end{tabular}

Fonte: o autor

Os resultados numéricos foram gerados tendo em vista a análise dos seguintes aspectos da alocação de potência e subportadoras em OFDMA uplink: a) Otimização da variável de atualização $\phi$, para acelerar a convergência; b) Validação do algoritmo DKB+LDD-EE; c) Comparação da EE alcançada pelos algoritmos DKB+LDD-EE, SIPA-EE e TIPSA-EE; e d) Análise da EE em relação a diversos valores de $p_{k}^{\max }$.

\subsubsection{Otimização da Variável de Atualização $\phi_{k}$}

A determinação do valor da variável de atualização $\phi$ é discutido em [126], tendo em vista a aplicação do gerenciamento dinâmico de espectro em sistemas DSL (Digital Subscriber Line). O trabalho afirma que é bastante difícil determinar o valor da variável de atualização quando métodos baseados em subgradiente são utilizados em conjunto com LDD, e os resultados numéricos apresentados mostram que tomar uma variável de atualização fixa é melhor para a velocidade de convergência do que um modelo em que a variável de atualização decresce ao longo do tempo, apesar da possibilidade de erro de convergência (ou não-convergência). De qualquer modo, como mostrado na Subseção 4.3.3, o valor inicial do parâmetro $q$ utilizado no algoritmo DKB+LDD-EE é suficientemente próximo da 
EE ótima, de modo que não se espera que a não-convergência seja um problema. Assim, opta-se por utilizar um valor fixo para $\phi$.

Tendo em vista a obtenção do valor ótimo para a variável de atualização da $k$-ésima MS, $\phi_{k}^{*}$, definiu-se um vetor de valores candidatos $\bar{\phi}$, o qual foi avaliado exaustivamente em todos os cenários de simulação, incluindo diferentes realizações de canal, número de MSs, número de subportadoras e limites de potência. Escolheu-se o $\bar{\phi}_{k}$ capaz de gerar menor número de iterações duais, mantida a convergência do algoritmo DKB+LDD-EE. Se o vetor de candidatos $\bar{\phi}$ fosse testado em cada uma das MSs, o problema de otimização de $\phi$ envolveria um teste exaustivo em $K$ dimensões, o que tornaria o problema impraticável. Assim, considera-se $\phi_{k}=\phi \forall k$. Adicionalmente, considera-se que $\ell_{k, n}=\ell_{k} \forall n$, o que resulta em $\chi_{k}=\chi_{k, n} \forall n$. Mesmo com tais definições e simplificações, a metodologia apresentada aqui possui limitações significantes:

1 os resultados de simulação mostraram que $\phi_{k}^{*}$ está espalhado em um intervalo grande para os mesmos valores de $K$ e $N$, o que implica em considerável uso de recursos computacionais e também impossibilita uma solução de grupo;

2 o tempo necessário para avaliar todos os valores candidatos $\bar{\phi}$ tende a ser mais elevado do que o tempo de coerência do canal e a janela de cada transmissão ${ }^{5}$, mesmo reduzindo o número de dimensões;

3 em geral, a partir de um determinado ponto do vetor candidato $\bar{\phi}$, qualquer valor maior que seja testado tende a fazer com que o DKB+LDD-EE não convirja, implicando no término de execução do algoritmo apenas no limite de iterações, desperdiçando tempo e recursos computacionais.

Apesar das diversas desvantagens, os resultados obtidos com essa abordagem exaustiva proveram informações interessantes. Quando se analisa o nível da água $\chi_{k}$, equação (4.12), obtido após a execução do algoritmo TIPSA-EE (o qual fornece a estimativa inicial de $q$ ) e os valores ótimos obtidos para $\phi_{k}^{*}$ com a abordagem anterior, uma possível correlação é percebida ${ }^{6}$. Na Figura 4.2 é mostrado o gráfico de dispersão entre $\chi_{k}$ e $\phi_{k}^{*}$, considerando os casos onde apenas um dos multiplicadores de Lagrange $\tau_{k}$ é maior que zero após a execução do algoritmo TIPSA-EE ${ }^{7}$. Limitando o nível da água no intervalo $2.2 \times 10^{-4} \leq \chi_{k} \leq 2.4 \times 10^{-4}$ para facilitar a visualização, percebe-se que existe uma relação inversa entre $\chi_{k}$ e $\phi_{k}^{*}$. Essa relação se mostra independente de $K$ e $N$, alterando-

5 Considerando a capacidade de processamento disponível e implementável em uma BS atualmente

6 A correlação foi observada a partir dos valores obtidos considerando os parâmetros de sistema adotados. Pode ser que tal correlação não aconteça em outros casos.

7 Se mais de um $\tau_{k}$ é maior que zero, não é possível determinar qual deles está correlacionado com $\phi_{k}^{*}$, o que pode ser também visto mais adiante, quando é proposto que se adote apenas um valor de $\phi$ para todos os usuários em uma janela de otimização. Quando nenhum dos elementos de $\tau$ é maior que zero, a convergência do algoritmo DKB+LDD-EE tende a não depender das variáveis de atualização, dado que o ponto de ótimo tende a estar em uma região que atende todas as restrições. 
se somente com o limite de potência $p_{k}^{\max }$ adotado: quanto menor for o limite de potência, maior é a variável de atualização ótima $\phi_{k}^{*}$.

Figura 4.2 - Gráfico de dispersão do nível da água $\chi_{k}$ em relação ao valor ótimo da variável de atualização $\phi_{k}^{*}$ obtido ao se testar o vetor candidato $\bar{\phi}$.

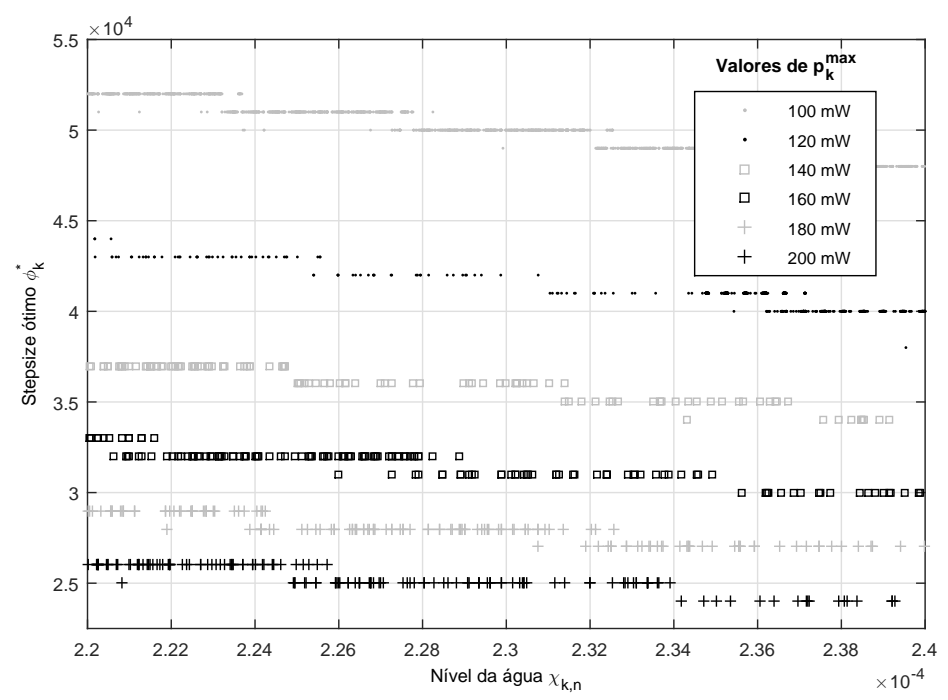

Fonte: o autor

Separando os pontos obtidos para cada valor de $p_{k}^{\max }$, observa-se que quanto maior o nível da água, menor o valor de $\phi_{k}^{*}$. Desse modo, a primeira tentativa em se determinar uma expressão para $\phi_{k}^{*}$ é considerá-lo como o resultado de uma função inversamente proporcional ao nível da água $\chi_{k}$ mais uma constante $b^{8}$. Usando $\chi_{k}$ como definido na equação (4.13) e considerando que tanto $q$ quanto $\boldsymbol{\tau}$ são obtidos do algoritmo TIPSA-EE, propõe-se a seguinte equação de fitting:

$$
\phi_{k}^{*}=a \cdot \frac{\log (2)}{\mathrm{w} \ell_{k}}\left(q^{\mathrm{TIPSA}} \varrho_{k}+\tau_{k}^{\mathrm{TIPSA}}\right)+b .
$$

Assim, os coeficientes para determinar $\phi_{k}^{*}$ podem ser obtidos com o seguinte procedimento de 5 passos:

s.1. Para cada valor de $p_{k}^{\max }$, obtém-se uma primeira equação de fitting usando a função polyfit do MatLab ${ }^{\circledR}$.

s.2. Os pontos que estiverem $25 \%$ abaixo do valor de $\phi_{k}^{*}$ obtido com a função de fitting são definidos como outliers.

s.3. Uma nova função de fitting é calculada com a função polyfit do MatLab ${ }^{\circledR}$, desconsiderando os pontos definidos como outliers.

8 A correlação foi observada a partir dos valores obtidos considerando os parâmetros de sistema adotados. Pode ser que a função de fitting precise ser modificada para outros parâmetros de sistema. 
s.4. Considerando a nova função de fitting, os pontos que estiverem $15 \%$ abaixo do $\phi_{k}^{*}$ estimado são definidos como outliers.

s.5. Com os pontos restantes, uma última função de fitting é calculada com a função polyfit do MatLab ${ }^{\circledR}$, obtendo-se os coeficientes $a$ e $b$.

A Figura 4.3 mostra as funções de fitting determinadas pelo processo anterior e utilizadas para determinar o valor ótimo da variável de atualização $\phi_{k}^{*}$ para cada valor de $p_{k}^{\max }$, e também o gráfico de dispersão dos valores de $\phi_{k}$ obtidos por simulação, em relação ao nível da água $\chi_{k}$. O gráfico de dispersão mostra a correlação para diversos pontos, além da presença de outliers, que são os pontos abaixo da curva de fitting e representados por pontos em vermelho. Considerando o menor valor de $\chi_{k}$, o valor ótimo da variável de atualização aumenta conforme a potência máxima é reduzida. Tal resultado sugere que o coeficiente $a$ cresce conforme $p_{k}^{\max }$ decresce. Os valores dos coeficientes obtidos com o procedimento de fitting corroboram a suposição, sendo mostrados na Tabela 4.2. Uma das limitações do procedimento de fitting desenvolvido é que ele não pode ser utilizado para qualquer valor de nível da água, pois sendo os coeficientes $b$ negativos, a partir de determinados valores de $\chi_{k}$ a variável de atualização estimada tornar-se-ia negativa. Por exemplo, quando $p_{k}^{\max }=200 \mathrm{~mW}$, é necessário que $\chi_{k}<3.291 \times 10^{-2}$ para garantir que $\phi_{k}^{*}>0$. Contudo, todos os valores obtidos para $\chi_{k}$ neste trabalho foram inferiores a $2 \times 10^{-3}$. Tal limitação sugere que a equação de fitting seja uma curva exponencial decrescente. Porém, no intervalo de interesse do problema, uma função polinomial de primeiro grau é suficiente para uma boa estimativa.

Tabela 4.2 - Coeficientes obtidos com o processo de fitting para a equação (4.24).

\begin{tabular}{|c|c|c|c|c|c|c|}
\hline$p_{k}^{\max }$ & $200 \mathrm{~mW}$ & $180 \mathrm{~mW}$ & $160 \mathrm{~mW}$ & $140 \mathrm{~mW}$ & $120 \mathrm{~mW}$ & $100 \mathrm{~mW}$ \\
\hline$a$ & 4.334 & 4.808 & 5.409 & 6.178 & 7.207 & 8.649 \\
\hline$b$ & -151.974 & -75.566 & -96.908 & -57.431 & -66.065 & -82.078 \\
\hline
\end{tabular}

Fonte: o autor

Para mostrar a validade e acuidade do processo de fitting de $\phi_{k}^{*}$, executa-se novamente o problema de otimização de EE pelo algoritmo DKB+LDD-EE para todas as realizações de canal, agora utilizando o valor de $\phi_{k}$ obtido pelas funções de fitting. Nesse contexto de simulação, consideram-se duas estratégias para determinar $\phi_{k}$. Na primeira delas, denominada "fitting (max.)", todas as MSs utilizam o mesmo $\phi_{k}$, que é determinado pelo máximo valor do multiplicador de Lagrange $\tau_{k}^{\text {TIPSA }}$

$$
\phi_{k}^{* \max }=\phi^{*, \max }=a \frac{\log (2)}{\mathrm{w} \ell_{k}}\left[q^{\mathrm{TIPSA}} \varrho_{k}+\max \left(\tau_{k}^{\mathrm{TIPSA}}\right)\right]+b .
$$

Na segunda estratégia, denominada "fitting (ind.),"cada MS individualmente calcula $\phi_{k}$ usando seu próprio multiplicador $\tau_{k}^{\text {TIPSA }}$, como mostrado na equação (4.24). Compara-se o 
Figura 4.3 - Gráfico de dispersão para o nível da água e o valor ótimo da variável de atualização $\phi_{k}^{*}$ obtido via simulação, assim como a função de fitting obtida para estimar $\phi_{k}^{*}$ para $p_{k}^{\max }=[\mathrm{a}) 200$, b) 180 , c) 160 , d) 140 , e) 120, f) 100] $\mathrm{mW}$.
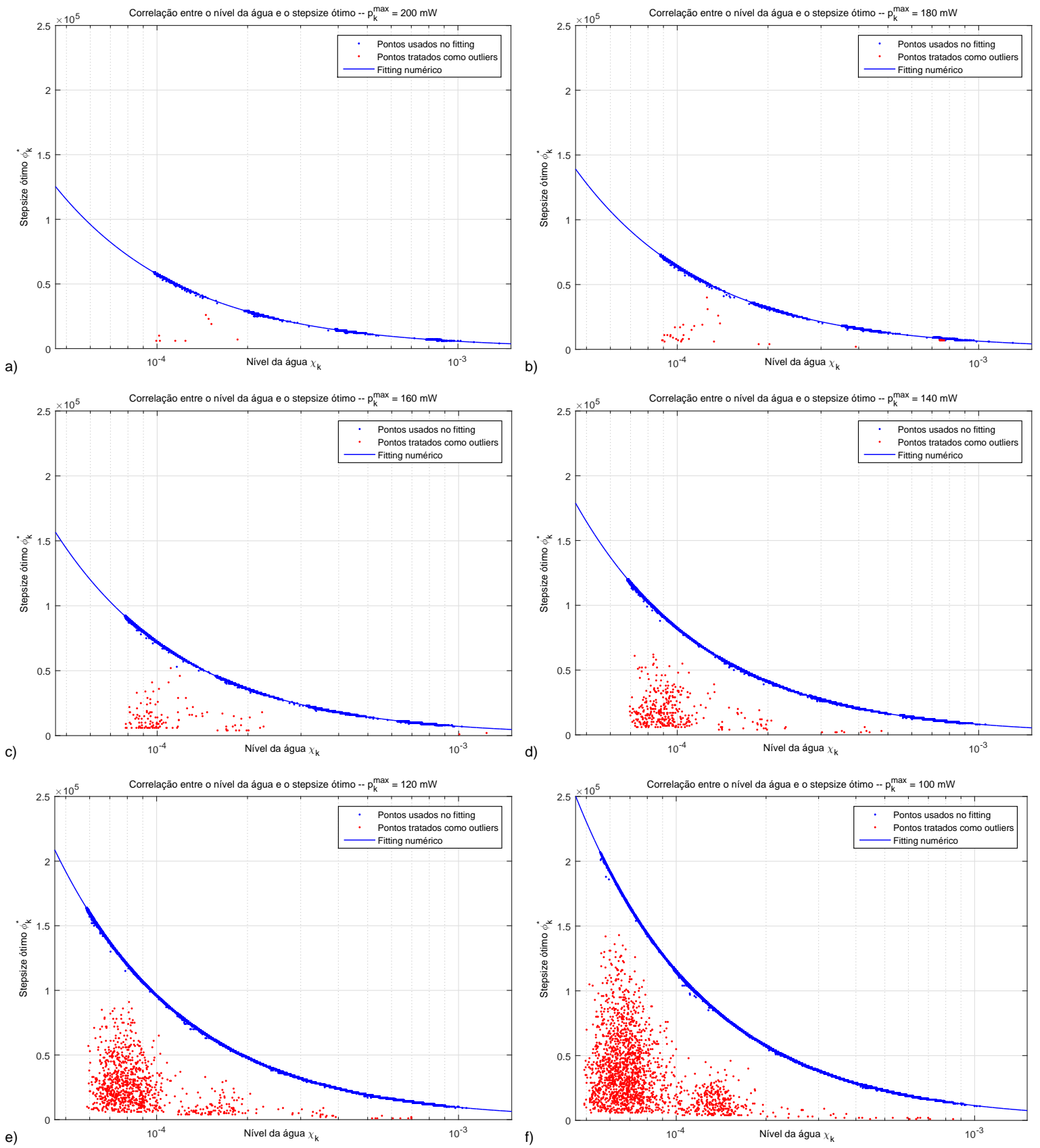

Fonte: o autor

número de iterações duais executadas pelo algoritmo DKB+LDD-EE através das figuras de mérito de média e função de distribuição acumulada do número de iterações duais nas Figuras 4.4 e 4.5, respectivamente, que também trazem os resultados obtidos com a busca exaustiva, base dos métodos de fitting.

Comparando os valores médios, observa-se que o fitting individual resulta na menor 
média, seguida pelo fitting com valor único e pela busca exaustiva. Os resultados obtidos com a busca exaustiva podem ser justificados pela discretização do espaço de busca e também por utilizar um valor único de $\phi_{k}$ para todas as MSs. A principal limitação em se utilizar o mesmo $\phi_{k}$ para todas as MSs é que o número de iterações duais necessárias para a convergência de uma MS pode ser aumentado se $\phi$ for otimizado para a convergência de outras MSs. Considerar a utilização de apenas um $\phi$ para todas as MSs implica em utilizar uma solução de compromisso, que geralmente não é ótima para nenhuma das MSs.

Figura 4.4 - Média do número de iterações executadas após a execução do algoritmo TIPSA-EE usando o algoritmo DKB+LDD-EE, para $N=$ [a) 256, b) 512, c) 1024, d) 2048] subportadoras.
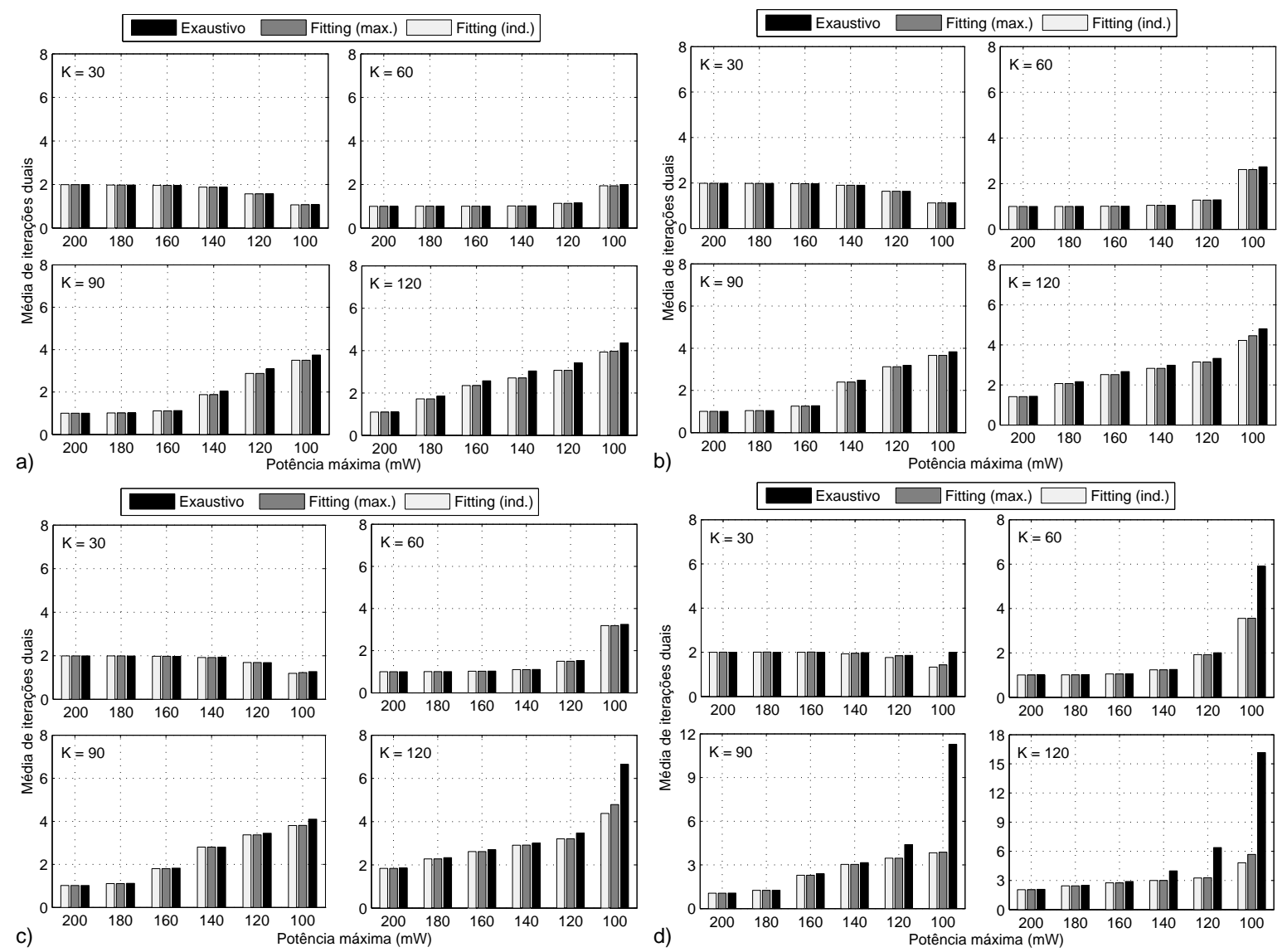

Fonte: o autor

Considerando a distribuição cumulativa do número de iterações duais na Figura 4.5, pode-se confirmar que o fitting individual é a melhor estratégia para otimização da variável de atualização $\phi_{k}$. Considerando o intervalo de [0-99]\%, a distribuição do número de iterações entre as estratégias é bastante semelhante, justificando os valores médios similares obtidos na Figura 4.4. A busca exaustiva resulta em um número maior de iterações do que os métodos de fitting quando a distribuição cumulativa é maior que 95\%, justificando a baixa performance em termos médios. O fitting individual resulta em um máximo de 43 iterações duais sendo executadas, enquanto que a busca exaustiva e o fitting com apenas 
um valor resultam em um máximo de 469 e 700 iterações duais, respectivamente.

Figura 4.5 - Distribuição cumulativa do número de iterações duais para as três estratégias de otimização.

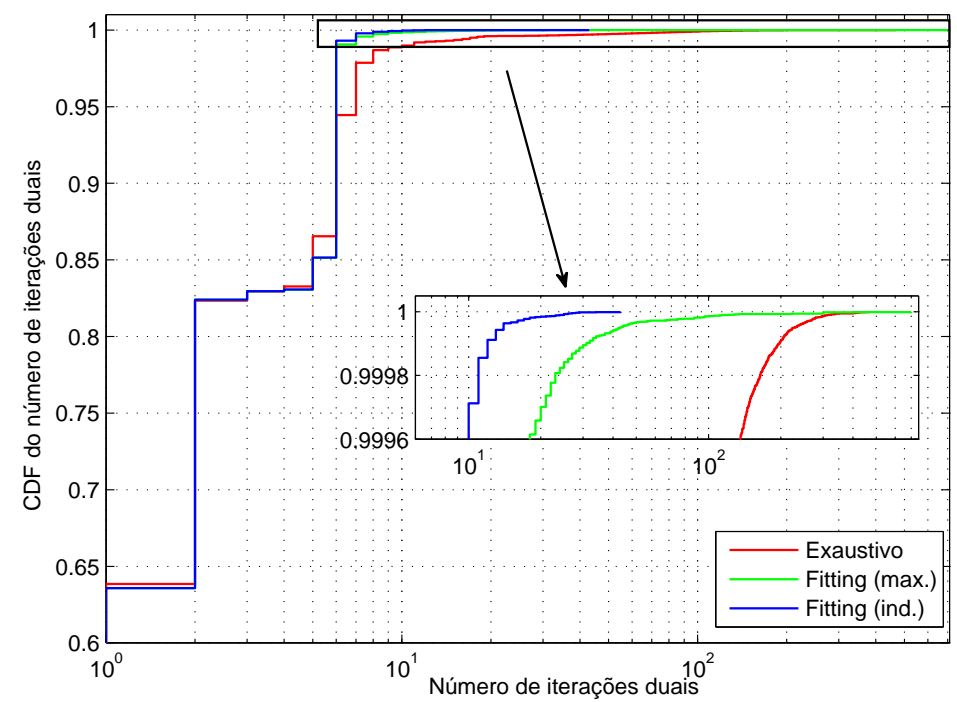

Fonte: o autor

Com tais resultados, decidiu-se pelo método de fitting individual, considerando-o como o método de definição das variáveis de atualização $\phi$ no decorrer dos resultados numéricos seguintes neste capítulo.

\subsubsection{Validação do Algoritmo DKB+LDD-EE}

Definida a utilização do método de fitting individual para determinar o valor ótimo da variável de atualização, é necessário verificar se a solução desenvolvida converge para a solução ótima, que pode ser obtida apenas através de uma busca exaustiva. Para tanto, compara-se a alocação de subportadoras e a EE obtidas por busca exaustiva com aqueles obtidos via algoritmo DKB+LDD-EE em casos de complexidade controlada, isto é, valores reduzidos de $K$ e $N$. Dado que a solução por DKB e LDD incorpora a relaxação da variável de alocação de subportadoras, é possível, e até mesmo esperado, que a matriz de alocação de subportadoras $\boldsymbol{\lambda}$ obtida via algoritmo DKB+LDD-EE seja diferente da obtida por busca exaustiva. Espera-se, no entanto, que tal alteração na alocação de subportadoras não cause um impacto substancial no valor final da EE, o que poderia indicar que relaxar e depois voltar à alocação inteira pode resultar em máximos locais pronunciados. Para cada uma das possíveis alocações de subportadoras, foram analisadas $5 \times 10^{6}$ possíveis alocações de potência, com as potências individuais de cada usuário em cada subportadora distribuídas no intervalo $10^{-6} \leq p_{k, n} \leq p_{k}^{\max }=200 \mathrm{~mW}$.

Devido à complexidade exponencial da busca exaustiva, define-se $K=[2,3,4]$ MSs e $N=[2,3,4]$ subportadoras para os casos de testes exaustivos. Para cada combinação de 
$K$ e $N$, foram geradas $10^{4}$ realizações diferentes de canal (posicionamento das MSs na célula e os coeficientes de desvanecimento rápido). Na Tabela 4.3, listam-se o número de realizações (e a porcentagem) nas quais houve diferenças na alocação de subportadoras entre a busca exaustiva e o algoritmo DKB+LDD-EE. Os resultados mostram que o algoritmo proposto resulta em uma elevada taxa de sucesso sem apresentar a complexidade computacional proibitiva da busca exaustiva.

As diferenças apresentadas na Tabela 4.3 para $N=2$ são causadas pelo método de fitting, que definiu valores negativos para $\phi_{k}$ nesses casos e resultou na não-convergência destes cinco cenários individuais. Nestes casos, define-se um valor arbitrário e suficientemente pequeno para a variável de atualização $\left(\phi_{k}=10^{-3}\right)$, e então o algoritmo proposto é executado novamente. Com isso, o algoritmo proposto converge e as diferenças de alocação são eliminadas. Já para o caso onde $N=4$ e $K=2$, mesmo que realmente ocorram diferenças na alocação de subportadoras, a EE do sistema é marginalmente afetada. A maior diferença de EE observada é de 0.018 b/J.Hz, o que representa um erro de $0.01 \%$ em relação à EE obtida nesse caso particular. Tal resultado é esperado, pois com as propriedades de otimização convexa analisadas na modelagem da solução, o gap de dualidade deve ser nulo [34].

Tabela 4.3 - Número (porcentagem) de ocorrência de diferenças de alocação de subportadoras quando compara-se uma busca exaustiva e o algoritmo DKB+LDD-EE para 10000 realizações de canal.

\begin{tabular}{|l|c|c|c|}
\hline & $N=2$ & $N=3$ & $N=4$ \\
\hline$K=2$ & $1(0.01 \%)$ & $0(0 \%)$ & $2(0.02 \%)$ \\
\hline$K=3$ & $2(0.02 \%)$ & $0(0 \%)$ & $0(0 \%)$ \\
\hline$K=4$ & $2(0.02 \%)$ & $0(0 \%)$ & $0(0 \%)$ \\
\hline
\end{tabular}

Fonte: o autor

\subsubsection{Resultados para Maximização de EE}

Tendo validado o método de otimização de $\phi_{k}$ e o algoritmo DKB+LDD-EE, analisase agora a EE obtida pelo algoritmo DKB+LDD-EE e também pelos dois algoritmos quase-ótimos, SIPA-EE e TIPSA-EE, além da EE obtida com os passos intermediários desses dois algoritmos: Para o SIPA-EE, o passo intermediário é a EE obtida apenas com a execução da estratégia EPA; para o TIPSA-EE, verifica-se a EE antes do ajuste dos multiplicadores de Lagrange, ou seja, o algoritmo TIPSA-EE (WA) definido na Subseção 4.2.4.

A Figura 4.6 mostra a EE média para cada combinação de $K, N$ e $p_{k}^{\max }$. Conforme o número de subportadoras $N$ cresce, assim também cresce a EE, dado que há aumento de diversidade. Quando o número de MSs é aumentado, a EE é diminuída. Tal diminuição é causada pela potência de circuitaria, adicionada como termo constante na formulação 
de EE, em conjunto com o baixo número de MSs que transmitem em cada janela de otimização, resultado que ainda será apresentado. Os piores resultados em termos de EE, principalmente quando $K$ é pequeno, foram obtidos com o algoritmo EPA-EE, dado que este é o único dos algoritmos propostos a não utilizar uma solução baseada em WF. Nos casos em que o número de MSs é pequeno, o somatório da potência de circuitaria também será reduzido, resultando em um total de potência de transmissão alocada pelas MSs também menor para atingir a EE ótima [16], o que não é atingível com a estratégia EPA. Quando $K=[90,120]$, observa-se um comportamento distinto: nesses casos, o total de potência de transmissão alocada em algumas MSs para se atingir a máxima EE tende a ser maior que o limite de potência disponível, o que geralmente faz com que seja necessário rearranjar a alocação de subportadoras em relação à usada pelo EPA-EE, fazendo com que novamente a EE seja reduzida.

Figura 4.6 - EE dos algoritmos propostos, para diferentes valores de $p_{k}^{\max }$ e $K$, com $N=$ [a) 256 , b) 512 , c) 1024 , d) 2048] subportadoras.
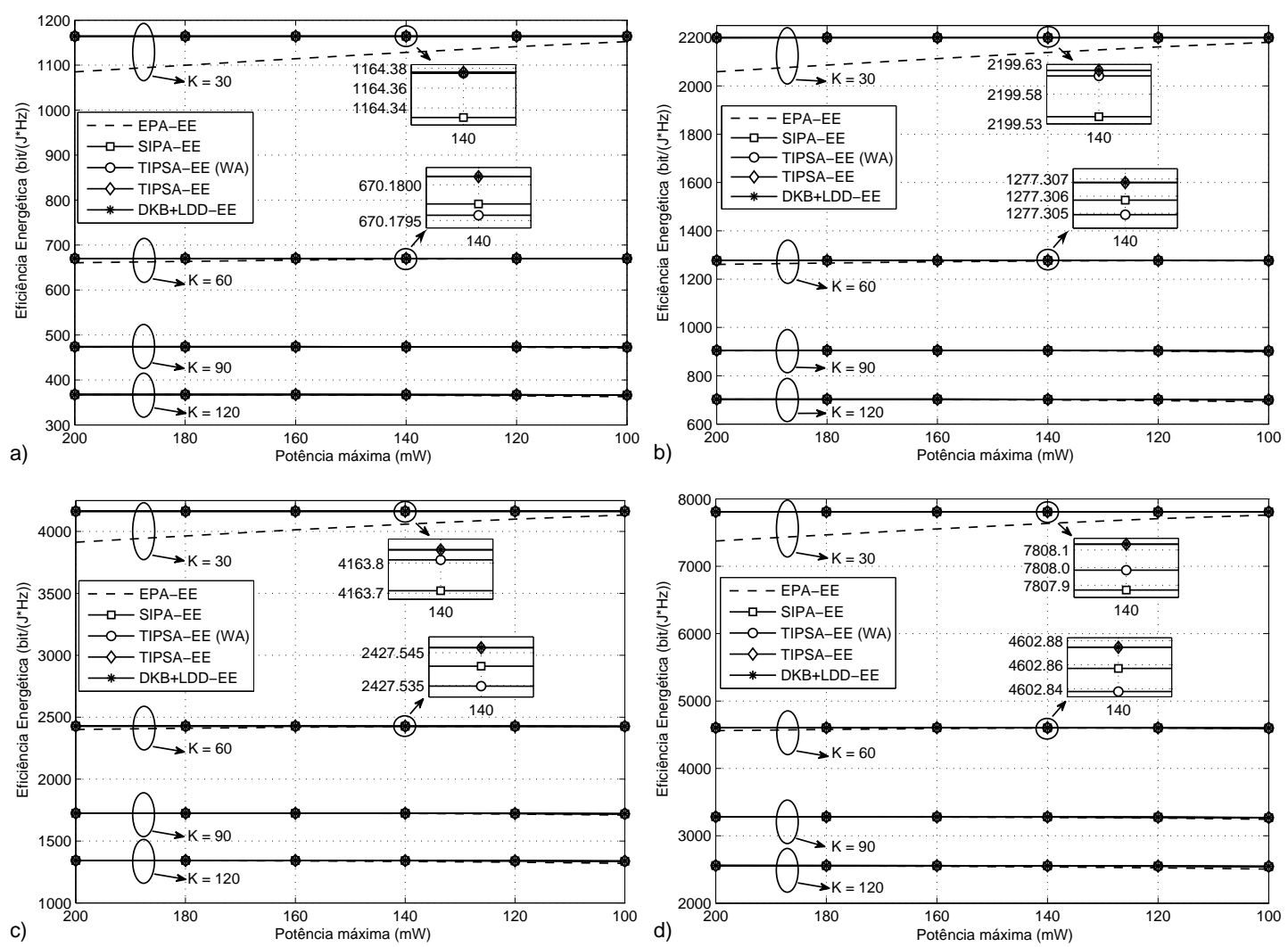

Fonte: o autor

Para $K=30$ e $p_{k}^{\max }=140 \mathrm{~mW}$, o algoritmo TIPSA-EE (WA) resulta em maior EE do que a obtida via SIPA-EE, enquanto que para $K=60$ e mesma potência máxima, observa-se o comportamento contrário. Analisa-se esse resultado em detalhes na Figura 4.7, e conjuntamente com a Figura 4.6 corrobora-se a significância da etapa de ajuste dos multiplicadores de Lagrange $\boldsymbol{\tau}$ proposta no algoritmo TIPSA-EE. Quando o número de 
MSs é pequeno, são poucos os casos nos quais existem multiplicadores de Lagrange maiores do que zero. Assim, ajustes feitos em $\tau$ impactam em poucas situações, enquanto a execução de uma etapa extra de alocação de potência e subportadoras no algoritmo TIPSA-EE (WA) impacta substancialmente em todos os casos. Porém, quando $K$ aumenta, aumenta também o número de casos nos quais ao menos uma MS possui $\tau_{k}>0$ ${ }^{9}$, a partir do ponto que se percebe i) um decréscimo de EE para o TIPSA-EE (WA) em relação ao SIPA-EE, mesmo com uma execução extra do laço de alocação de potência e subportadoras, e ii) que o algoritmo TIPSA-EE é superior ao SIPA-EE (em termos de EE) apenas com o passo extra de recalculo dos multiplicadores e atualização de alocação de potência e subportadoras, nota-se a importância da atualização, mesmo que por uma aproximação simples, dos multiplicadores de Lagrange. Finalmente, o algoritmo TIPSAEE obtém o resultado mais próximo à EE ótima, obtida com o algoritmo DKB+LDD-EE para todas as combinações de parâmetros de simulação.

Figura 4.7 - CDF da EE atingida pelos algoritmos sub-ótimos, tendo como referência o algoritmo DKB+LDD-EE. a) Todos os algoritmos sub-ótimos considerados, b) Imagem ampliada do eixo $\mathrm{x}$, descartando o algoritmo EPA-EE.
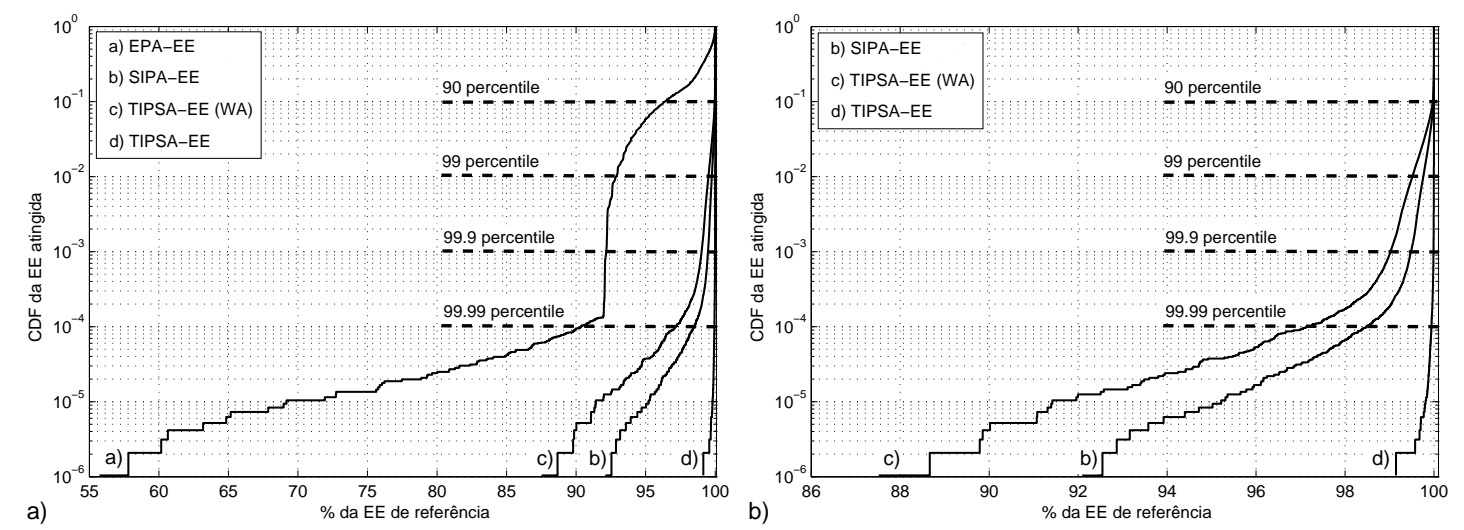

Fonte: o autor

Para analisar com mais detalhes a EE atingida pelos algoritmos sub-ótimos propostos, é necessário avaliar não só a EE atingida em termos médios, mas também quanto da EE ótima é atingida pelos algoritmos em cada caso individual. Considerando que a EE ótima tenha sido obtida pelo algoritmo DKB+LDD-EE, plota-se na Figura 4.7 a CDF das porcentagens da EE ótima atingidas pelos algoritmos sub-ótimos propostos. Considerando os percentis indicados na Figura 4.7.a), é possível concluir que até mesmo o algoritmo EPA-EE é uma escolha razoável e interessante, dado que garante ao menos 90,360\% da EE de referência (ótima) para 99,99\% dos cenários de simulação com complexidade computacional bastante reduzida. Por sua vez, os algoritmos SIPA-EE e TIPSA-EE

\footnotetext{
9 Quando $K$ cresce, cresce também o consumo com circuitaria, e em geral as MSs alocam mais potência para atingir o ponto de máxima EE. Com isso, mais MSs tendem a requerer mais potência de transmissão do que o limite disponível, sendo necessário modificar (aumentar) o multiplicador de Lagrange $\tau_{k}$ para essas MSs.
} 
garantem ao menos 98, 480\% da EE de referência para 99, 99\% dos cenários, sem depender de nenhuma otimização de parâmetros. Os excelentes resultados dos algoritmos SIPAEE e TIPSA-EE podem ser melhor analisados na Figura 4.7.b), onde os resultados do algoritmo EPA-EE são removidos para diminuir o intervalo do eixo $x$. O algoritmo TIPSAEE é capaz de garantir o mais alto nível de EE em relação aos valores de referência, resultando em ao menos 99,994\% da EE ótima para 99, 99\% dos casos.

Porém, quando se analisa o pior caso de cada um dos algoritmos sub-ótimos, i.e., a menor porcentagem de EE garantida pelos algoritmos, as conclusões do parágrafo anterior devem ser cuidadosamente examinadas. Na Figura 4.7.a), nota-se que o algoritmo EPA-EE resulta em apenas 55,724\% da EE de referência para um cenário individual. É possível também reforçar o impacto do ajuste dos multiplicadores de Lagrange no algoritmo TIPSA-EE, afinal o algoritmo TIPSA-EE (WA) consegue assegurar apenas 87, 517\% da EE de referência no pior caso, enquanto que o algoritmo SIPA-EE assegura ao menos 92, 092\% da EE de referência. Já o algoritmo TIPSA-EE resulta, novamente, na melhor performance, garantindo 99,147\% da EE de referência no pior caso.

Infelizmente, a maximização de EE como proposto neste capítulo tem um ponto negativo: a concentração de recursos espectrais (subportadoras) em poucas MSs (ou até mesmo em uma única MS). Para analisar a concentração dos recursos, plota-se na Figura 4.8 a porcentagem de MSs que, em uma determinada janela de otimização, alocaram ao menos uma subportadora, sem discriminar o número de MSs ou de subportadoras disponíveis. Percebe-se que em 90\% dos casos analisados, no máximo 7\% das MSs receberam algum recurso espectral, enquanto os demais $93 \%$ não transmitem nenhum dado no referido caso, enquanto que em $70 \%$ dos casos menos de $5 \%$ das MSs recebem ao menos uma subportadora. Agravando a situação, em 99\% dos cenários simulados, menos de 14\% das MSs ativas na rede transmitem alguma informação. Mesmo no melhor caso, mais da metade das MSs ficam inativas, o que é inaceitável em termos de QoS. Infelizmente, a concentração de recursos é inerente à formulação do problema como apresentado na equação (4.1): a maximização de EE no problema de otimização (4.1) pode ser vista como a maximização da taxa de dados do sistema em um determinado nível de potência, e para se maximizar a taxa de dados tende-se a alocar potência para as MSs com melhor condição de canal em cada subportadora, conforme predito pela solução WF. Com isso, os recursos tendem a ficar concentrados nas MSs mais próximas da BS, a não ser que o limite de potência faça com que outras MSs assumam algumas subportadoras. Para evitar tais situações de concentração, a reformulação do problema (4.1) é fundamental, em termos de restrições ou modificação da função-utilidade.

\subsubsection{Análise de Complexidade}

A Figura 4.9.a) mostra a CDF do número de execuções do algoritmo WF para o algoritmo SIPA-EE. O número máximo de execuções dessa etapa é igual a 3, e para $80 \%$ dos casos 
Figura 4.8 - CDF da porcentagem de usuários com ao menos uma subportadora alocada. A porcentagem é obtida normalizando o número de usuários não-nulos pelo total de usuários em cada simulação.

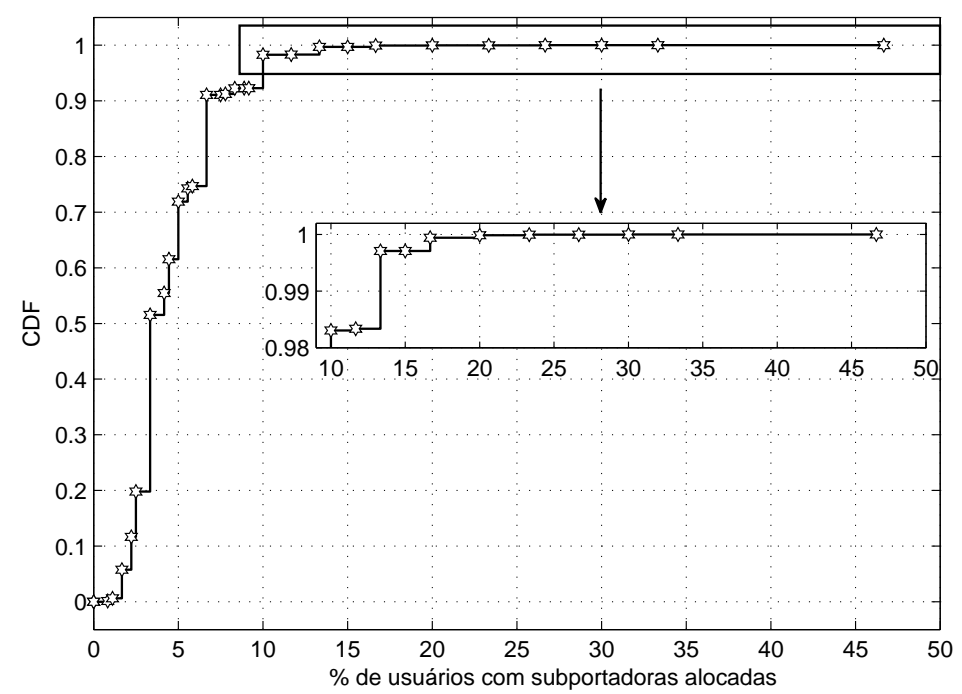

Fonte: o autor

simulados as instruções do laço foreach não são sequer executadas. Assim, a complexidade do algoritmo SIPA-EE pode ser definida por $\mathcal{O}(K N+N \log (N))$. Além disso, a Figura 4.9.b) mostra a CDF do mesmo algoritmo WF para o algoritmo TIPSA-EE. Observa-se que o algoritmo WF é executado no máximo 7 vezes para o algoritmo TIPSA-EE, e para cerca de 98,97\% dos casos simulados no máximo uma execução é feita. Adicionando as execuções do algoritmo WF em ambos os algoritmos SIPA-EE e TIPSA-EE, o algoritmo WF é executado no máximo 15 vezes, e em 99,996\% dos casos esse algoritmo é executado menos de 10 vezes.

Figura 4.9 - CDF do número de execuções do algoritmo WF para os algoritmos: a) SIPAEE e b) TIPSA-EE.
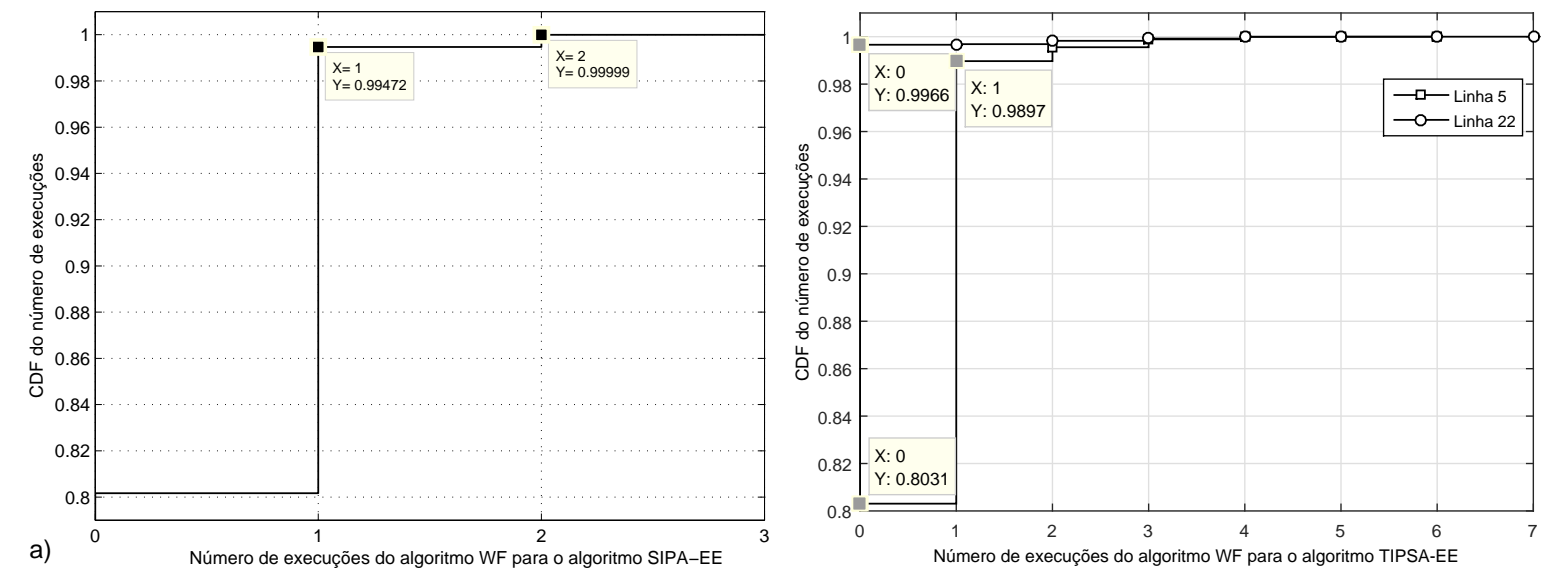

Fonte: o autor 
A CDF do número de execuções do Algoritmo 4.2 durante as etapas de ajuste de potência das linhas 5 e 22 do algoritmo TIPSA-EE é mostrada na Figura 4.10.a). O Algoritmo 4.2 é executado no máximo 5 vezes em cada caso, e para 99,99\% dos casos apenas 3 repetições são executadas. Assim, pode-se mostrar que a complexidade do algoritmo TIPSA-EE é da ordem de $\mathcal{O}(K N+N \log (N))$, como previamente afirmado na Subseção 4.2.5.

Figura 4.10 - CDF do número total de execuções do Algoritmo 4.2 para os algoritmos: a) TIPSA-EE e b) TIPSA-EE mais DKB+LDD-EE até que a convergência seja atingida.

a)

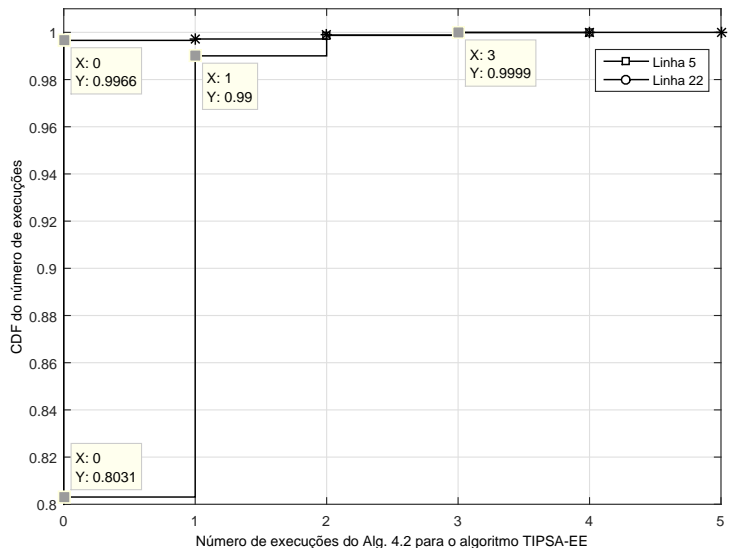

b)

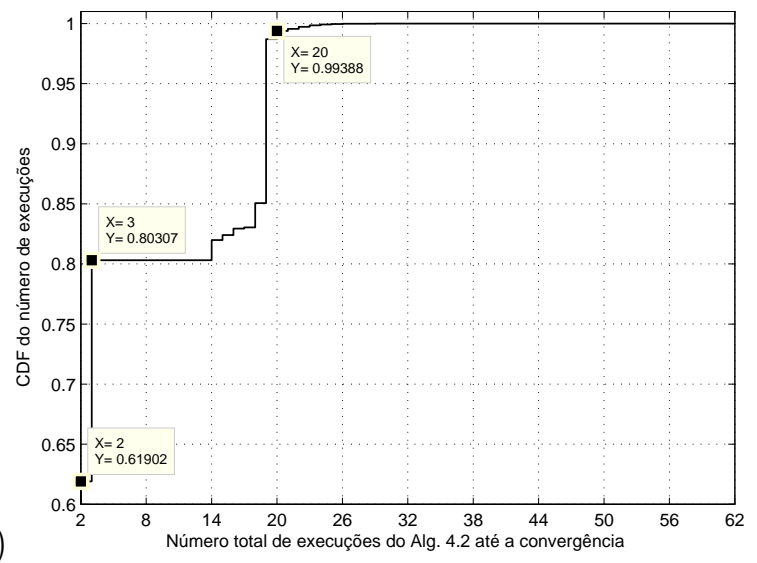

Fonte: o autor

Finalmente, para o algoritmo DKB+LDD-EE, considera-se o número total de execuções do Algoritmo 4.2, incluindo as executadas pelo algoritmo TIPSA-EE, o que possibilita uma comparação justa com os demais algoritmos presentes na literatura, como o descrito em [34]. Essa figura de mérito é apresentada na Figura 4.10.b), em termos de CDF. No pior caso, são executadas 62 repetições do laço de alocação de potência e subportadoras, enquanto uma média de 5,422 iterações são executadas até que a convergência seja atingida, o que é um número significativamente baixo. Quando o algoritmo TIPSA-EE não é executado, o número médio de repetições do Algoritmo 4.2 é reduzido pra 4,073, porém no pior caso foram executadas 800 iterações até que a convergência fosse atingida. Quando se consideram apenas os casos em que ao menos um $\tau_{k}$ é maior que zero, o número médio de repetições do Algoritmo 4.2 é igual a 18,442, enquanto que usando o algoritmo TIPSA-EE (WA) na etapa de inicialização esse número é reduzido para 11,594; no entanto, há a ocorrência do caso extremo de 800 repetições. Assim, a utilização do algoritmo TIPSA-EE mostra um melhor compromisso entre número médio e máximo de repetições.

Como o algoritmo DKB+LDD-EE utiliza o algoritmo TIPSA-EE para inicialização, a complexidade da solução apresentada para obter a máxima EE é da ordem de $\mathcal{O}(K N+$ $N \log (N))$. O termo de complexidade $N \log (N)$ não é visto em outras abordagens para a maximização de EE em sistemas OFDMA como o proposto nesse capítulo [34]; porém, 
o presente método provê uma maneira determinística para se obter os parâmetros $q^{0}, \boldsymbol{\tau}^{0}$, e $\phi$. Finalmente, o número de execuções do algoritmo WF, que é o responsável pelo componente $N \log (N)$, é pequeno, e tende a ser dominado pelo Algoritmo 4.2.

\subsubsection{Comparação com Implementações Anteriores}

Existem diversas implementações dos algoritmos DKB e LDD para a solução do problema de maximização de EE em sistemas OFDMA, e uma comparação direta entre a implementação proposta nesse capítulo e outras disponíveis na literaturas precisa ser cuidadosamente feita, devido aos diferentes modelos de sistema, parâmetros e restrições associados a cada trabalho. Em [34], mostra-se que a solução proposta pelos autores converge para a solução ótima em no máximo 40 iterações, mas os resultados são mostrados em termos de EE média e para um número pequeno de subportadoras e MSs. Adicionalmente, o modelo de sistema em [34] inclui RSs. Em [123], apenas o algoritmo DKB é empregado, e se descreve apenas condições necessárias para o parâmetro do algoritmo DKB, e qualquer comparação em termos de iterações executadas pode ser enviesada. Em [127], o método proposto pelos autores utiliza apenas LDD para resolver o problema de otimização, e apenas condições necessárias são discutidas. Em [76], comenta-se sobre a otimização da variável de atualização $\phi$, porém otimização é descartada do escopo do artigo, e os valores iniciais necessários não são descritos. Não obstante, o modelo de sistema em [76] considera um sistema em downlink, e duas restrições de taxa mínima são utilizadas, para duas diferentes classes de usuários. A estratégia DKB+LDD é também empregada para a maximização de EE em downlink em [128], considerando um critério de taxa mínima, e a definição da inicialização de variáveis é bastante semelhante ao descrito em [34]. Na Tabela 4.4, compara-se algumas dessas estratégias em relação à apresentada nesse capítulo.

Apesar das diferenças entre o modelo proposto nesse Capítulo e as propostas da literatura, algumas conclusões importantes podem ser observadas. Como ponto principal, os algoritmos propostos formam uma maneira sistemática de prover os valores iniciais e também um stepsize suficientemente adequado, além de terem sido avaliados para um número realístico de MSs e subportadoras, resultando em baixa complexidade. Adicionalmente, tais algoritmos apresentam resultados quase-ótimos em termos de EE, atingindo significativos níveis de EE em relação ao obtido com a combinação DKB+LDD, i.e., a combinação que converge à solução ótima. 
Tabela 4.4 - Métodos DKB e/ou LDD empregados para solucionar o problema de maximização de EE

\begin{tabular}{|c|c|c|c|c|}
\hline Artigo & $\begin{array}{l}\text { Modelo de } \\
\text { Sistema }\end{array}$ & Implementação & Def. de Variáveis & \# Iterações \\
\hline$[34]$ & $\begin{array}{l}\text { OFDMA com } \\
\text { RSs }\end{array}$ & $\mathrm{DKB}+\mathrm{LDD}$ & $\begin{array}{l}\text { Empírica (Parâmetro } \\
\text { DKB igual a zero) }\end{array}$ & $\begin{array}{l}\text { Até } 40 \text { (média } \\
\text { de EE) }\end{array}$ \\
\hline$[123]$ & $\begin{array}{l}\text { Canais Gaussi- } \\
\text { anos Paralelos }\end{array}$ & Apenas DKB & $\begin{array}{l}\text { Apenas condições ne- } \\
\text { cessárias }\end{array}$ & Não descrito \\
\hline$[127]$ & OFDMA & Apenas LDD & $\begin{array}{l}\text { Apenas condições ne- } \\
\text { cessárias }\end{array}$ & Não descrito \\
\hline$[76]$ & OFDMA & $\begin{array}{l}\text { Bissecção com } \\
\text { LDD }\end{array}$ & $\begin{array}{l}\text { Apenas condições ne- } \\
\text { cessárias }\end{array}$ & Não descrito \\
\hline [128] & OFDMA & $\mathrm{DKB}+\mathrm{LDD}$ & $\begin{array}{l}\text { Não Definido (Parâ- } \\
\text { metro DKB igual a } \\
\text { zero) }\end{array}$ & Não descrito \\
\hline $\begin{array}{l}\text { Modelo } \\
\text { pro- } \\
\text { posto }\end{array}$ & OFDMA & $\mathrm{DKB}+\mathrm{LDD}$ & Determinística & $\begin{array}{l}\text { Max. de } 62 \\
\text { iterações, } \\
\text { média de } \\
5.422\end{array}$ \\
\hline
\end{tabular}





\section{ALOCAÇÃO DE RECURSOS COM FAIRNESS PARA UPLINK NÃO- COOPERATIVO}

Os resultados descritos no Capítulo 4 indicam a concentração excessiva de recursos espectrais (subportadoras) em poucas MSs, como mostrado na Figura 4.8. O resultado não chega a ser uma surpresa, dado que a formulação de EE adotada no problema (4.1) busca a máxima EE do sistema como um todo, o que implicitamente condiciona que as MSs com melhores coeficientes de canal sejam escolhidas. De fato, as demais MSs só serão admitidas se em determinado momento as melhores MSs não conseguirem lidar com a limitação de potência.

Tal concentração de recursos inviabiliza a adoção da solução do problema (4.1) em sistemas comerciais, afinal uma grande quantidade de MSs não atingiriam critérios mínimos de QoS necessários para os serviços desejados. Tal problema seria ainda mais severo em MSs distantes das BSs ou sujeitas a alguma condição que impacte a qualidade de canal, afinal muitas MSs teriam que estar afetadas pela limitação de potência individual para que essas MSs afastadas pudessem transmitir alguma informação. Poderiam ser adotados aqui diversos critérios para solucionar (ou atenuar) esse problema, tais como a adoção de uma taxa mínima por MS (ou outros critérios individuais de QoS), somatório de EEs individuais com pesos diferenciados, com prioridade aos usuários em piores condições de canal, ou ainda a adoção de formulações com critérios de fairness. A escolha nesse trabalho recai sobre o modelo de fairness, e em específico o modelo de fairness proporcional.

Decide-se pela utilização do fairness proporcional como uma solução de compromisso [129]. Sabe-se que a maior EE possível, ao menos em termos globais, é obtida pelo problema (4.1). Com isso, qualquer outra alocação de subportadoras (e por consequência, de potência) adotada resultará em menor EE. Para que se consiga um fairness total (ou seja, todos os usuários com mesma EE), a tendência é que muitas subportadoras tenham que ser alocadas às MSs em pior condição de canal, de modo que a EE do sistema, como um todo, será muito prejudicada. Por sua vez, o modelo de fairness proporcional permite que algumas MSs em boa condição de canal mantenham mais recursos, porém sem negar acesso às MSs em piores condições de propagação. Pode-se, ainda, adicionar restrições de QoS ao problema de fairness proporcional, evitando que algumas MSs recebam recursos espectrais apenas para que sua utilidade individual não seja nula.

Problemas de fairness proporcional tem suas funções-objetivo apresentadas sob duas formas principais [129]: um somatório de logaritmos das funções-utilidade de cada indivíduo, equação (5.1), ou então como o produtório das funções-utilidade individuais, 
equação (5.2). É importante destacar que o valor numérico das duas funções-utilidade são diferentes, porém o argumento $x^{*}$ que as maximiza é o mesmo. Assim, adotar um modelo ou o outro depende das características do problema e da facilidade de obtenção de uma solução numérica.

$$
\begin{aligned}
U_{\log }(x) & =\sum_{k \in K} \log \left(U_{k}(x)\right) \\
U_{\text {prod }}(x) & =\prod_{k \in K} U_{k}(x)
\end{aligned}
$$

A seguir será discutida a aplicação do modelo de fairness proporcional ao problema de maximização de EE, em um primeiro momento ainda sem a utilização de RSs.

\subsection{Discussão de Funções-Utilidade}

É possível descrever a função-utilidade da maximização de EE em OFDMA em uplink com fairness proporcional, tanto como um somatório de logaritmos das EEs individuais, quanto como o produtório dessas mesmas EEs. Não serão consideradas restrições de QoS na formulação do problema de otimização a ser desenvolvido, buscando, assim como no Capítulo 4, a máxima EE possível no modelo adotado. As funções-utilidade, para os casos de somatório de logaritmos e produtório são dadas, respectivamente, por

$$
\begin{aligned}
\xi_{\log }^{\mathrm{fair}}(\mathbf{P}, \boldsymbol{\lambda})= & \sum_{k=1}^{K} \log _{b}\left(\xi_{k}\right) \\
= & \sum_{k=1}^{K} \log _{b}\left(\frac{\mathrm{w} \sum_{n=1}^{N} \lambda_{k, n} \ell_{k, n} \log _{2}\left(1+p_{k, n} \Gamma_{k, n}\right)}{\sum_{n=1}^{N} \varrho_{k} \lambda_{k, n} p_{k, n}+p_{c, k}}\right) \\
= & \sum_{k=1}^{K} \log _{b}\left(\mathrm{w} \sum_{n=1}^{N} \lambda_{k, n} \ell_{k, n} \log _{2}\left(1+p_{k, n} \Gamma_{k, n} \imath_{k}\right)\right) \\
& \quad-\sum_{k=1}^{K} \log _{b}\left(\sum_{n=1}^{N} \varrho_{k} \lambda_{k, n} p_{k, n}+p_{c, k}\right)
\end{aligned}
$$

$\mathrm{e}$

$$
\begin{aligned}
\xi_{\text {prod }}^{\text {fair }}(\mathbf{P}, \boldsymbol{\lambda}) & =\prod_{k=1}^{K} \xi_{k} \\
& =\prod_{k=1}^{K}\left[\frac{\mathrm{w} \sum_{n=1}^{N} \lambda_{k, n} \ell_{k, n} \log _{2}\left(1+p_{k, n} \Gamma_{k, n} \iota_{k}\right)}{\sum_{n=1}^{N} \varrho_{k} \lambda_{k, n} p_{k, n}+p_{c, k}}\right]
\end{aligned}
$$

onde $\xi_{k}$ é descrito pela equação (3.37).

O problema de otimização opera as mesmas duas variáveis do problema (4.1), isto é, as matrizes de alocação de potência, $\mathbf{P}$, e de subportadoras, $\boldsymbol{\lambda}$, e sua estrutura básica 
independe de qual das funções-utilidade é escolhida. Pode-se, então, definir o problema de otimização como:

$$
\begin{array}{lc}
\mathbf{P}^{*}, \boldsymbol{\lambda}^{*}=\underset{\mathbf{P}, \boldsymbol{\lambda}}{\arg \max } . \xi_{(.)}^{\mathrm{fair}}(\mathbf{P}, \boldsymbol{\lambda}) & \\
\text { s.a: } \quad p_{k, n} \geq 0 & \forall k, n \\
\lambda_{k, n} \in\{0,1\} & \forall k, n \\
\sum_{n=1}^{N} \lambda_{k, n} p_{k, n} \leq p_{k}^{\max } & \forall k \\
\sum_{k=1}^{K} \lambda_{k, n} \leq 1 & \forall n
\end{array}
$$

cujas restrições são as mesmas descritas para o problema (4.1), e o índice subscrito (.) corresponde à escolha pelo somatório de logaritmos ou produtório.

Note que para ambas as formulações não se admite que exista alguma MS com EE nula, ou seja, sem recursos espectrais. Considerando primeiro a formulação como soma de logaritmos, equação (5.3), caso uma MS não possua nenhuma subportadora, o logaritmo da taxa em (5.3) será igual a menos infinito, e como o objetivo é maximizar a utilidade, tal resultado deve ser descartado. Já no caso do produtório de EEs individuais, uma MS que não tenha nenhuma subportadora alocada terá EE individual nula, anulando assim todo o produtório. Sabendo que as EEs individuais são todas maiores ou iguais a zero, o menor valor que se pode obter no produtório é zero, e portanto uma alocação que permita pelo menos um usuário sem recursos será, certamente, não ótima. Com isso, e sabendo que em nenhum caso descrito no Capítulo 4 todas as MSs possuíam ao menos uma subportadora alocada, fica evidente que haverá uma redução na EE global, que deverá então ser quantificada. Por outro lado, uma MS que esteja em condição desfavorável de propagação não conseguirá alocar muitos recursos espectrais. Em ambas as formulações, se uma MS em condição desfavorável alocar muitos recursos espectrais, terá um impacto significativo no resultado final, de modo que em algum momento do processo de convergência essa MS será limitada no processo de alocação.

Independente da função-utilidade adotada, o problema de maximização de EE com fairness proporcional é um problema misto de variáveis inteiras e contínuas, de modo que a solução ótima somente pode ser atingida pela busca exaustiva em todas as alocações de subportadoras para as quais

$$
\sum_{n=1}^{N} \lambda_{k, n}>0 \quad \forall k .
$$

Para suplantar tal limitação, será adotada a estratégia de relaxação da variável inteira $\lambda_{k, n}$, adotando a variável real contínua $\tilde{\lambda}_{k, n}$ no intervalo $0 \leq \widetilde{\lambda}_{k, n} \leq 1$. A adoção dessa técnica será abordada na subseção seguinte, para ambas as funções-utilidade. 


\subsection{Relaxação do Problema de Otimização}

O passo inicial na solução do problema 5.5 é a relaxação das variáveis de alocação de subportadoras $\lambda_{k, n}$. O processo utilizado é o mesmo definido no Capítulo 4, com a substituição de $\lambda_{k, n}$ por $\widetilde{\lambda}_{k, n}$, sendo $0 \leq \widetilde{\lambda}_{k, n} \leq 1$, além da definição de $\widetilde{p}_{k, n}=\widetilde{\lambda}_{k, n} p_{k, n}$. Para o caso de somatório de logaritmos, a função-objetivo relaxada é dada por:

$$
\begin{gathered}
\widetilde{\xi}_{\log }^{\text {fair }}(\widetilde{\mathbf{P}}, \tilde{\boldsymbol{\lambda}})=\sum_{k=1}^{K} \log _{b}\left(\mathrm{w} \sum_{n=1}^{N} \widetilde{\lambda}_{k, n} \ell_{k, n} \log _{2}\left(1+\frac{\widetilde{p}_{k, n} \Gamma_{k, n} \iota_{k}}{\widetilde{\lambda}_{k, n}}\right)\right) \\
-\sum_{k=1}^{K} \log _{b}\left(\sum_{n=1}^{N} \varrho_{k} \widetilde{p}_{k, n}+p_{c, k}\right)
\end{gathered}
$$

enquanto que para a modelagem com produtório a relaxação resulta em:

$$
\widetilde{\xi}_{\text {prod }}^{\text {fair }}(\widetilde{\mathbf{P}}, \widetilde{\boldsymbol{\lambda}})=\prod_{k=1}^{K}\left[\frac{\mathrm{w} \sum_{n=1}^{N} \widetilde{\lambda}_{k, n} \ell_{k, n} \log _{2}\left(1+\frac{\widetilde{p}_{k, n} \Gamma_{k, n} \iota_{k}}{\widetilde{\lambda}_{k, n}}\right)}{\sum_{n=1}^{N} \varrho_{k} \widetilde{p}_{k, n}+p_{c, k}}\right] .
$$

Assim, o problema de otimização relaxado é reescrito como:

$$
\begin{aligned}
& \widetilde{\mathbf{P}}^{*}, \widetilde{\boldsymbol{\lambda}}^{*}=\underset{\widetilde{\mathbf{P}}, \widetilde{\boldsymbol{\lambda}}}{\arg \max } . \widetilde{\xi}_{(.)}^{\text {fair }}(\widetilde{\mathbf{P}}, \widetilde{\boldsymbol{\lambda}}) \\
& \text { s.a: } \quad \widetilde{p}_{k, n} \geq 0 \quad \forall k, n \\
& \tilde{\lambda}_{k, n} \geq 0 \quad \forall k, n \\
& 1-\tilde{\lambda}_{k, n} \geq 0 \quad \forall k, n \\
& p_{k}^{\max }-\sum_{n=1}^{N} \widetilde{p}_{k, n} \geq 0 \quad \forall k \\
& 1-\sum_{k=1}^{K} \widetilde{\lambda}_{k, n} \geq 0 \quad \forall n
\end{aligned}
$$

Devido às características das diferentes funções-objetivo, cada uma delas demanda uma solução com ferramentais diferentes.

\subsection{Solução para Somatório de Logaritmos}

Para o somatório de logaritmos, utiliza-se uma solução de programação de diferença de funções côncavas (DCP), que é uma adaptação do ferramental de diferença de funções convexas apresentado em [130], combinado à utilização de LDD para a construção de um algoritmo iterativo que convirja para a solução ótima em um determinado número de iterações. O algoritmo iterativo é construído em duas etapas:

- Na primeira etapa, utiliza-se o ferramental de DCP para obter uma solução iterativa para o problema de otimização, ainda sem incorporar as restrições; 
- Na segunda etapa, as restrições do problema de otimização são incorporadas à função-objetivo iterativa utilizando LDD.

A função-objetivo para o somatório de logaritmos pode ser visto como a diferença de duas funções côncavas, uma dada pelo somatório do logaritmo de todas as taxas e a outra pelo somatório do logaritmo da potência consumida por todas as MSs. Como não se pode afirmar que a diferença de duas funções côncavas resulta em uma função côncava [122], é necessário buscar um ferramental que possibilite encontrar uma solução para a função-objetivo (5.7). Conforme descrito no Apêndice D.2, com a utilização do DCP é possível solucionar problemas do tipo

$$
\mathbf{x}^{*}=\underset{\mathbf{x} \in \mathbb{R}^{n}}{\arg \max } f(\mathbf{x})-g(\mathbf{x})
$$

com funções $f$ e $g$ côncavas, através da seguinte estratégia iterativa [130]:

$$
\mathbf{x}^{*, i}=\underset{\mathbf{x} \in \mathbb{R}^{n}}{\arg \max } f(\mathbf{x})-g\left(\mathbf{x}^{i-1}\right)-\sum_{l=1}^{L}\left[\left.\left(x_{l}-x_{l}^{i-1}\right) \frac{\partial g(\mathbf{x})}{\partial x_{l}}\right|_{\mathbf{x}=\mathbf{x}^{i-1}}\right] .
$$

A utilização do ferramental de DCP garante que a função-objetivo da estratégia resultante é côncava, i.e., tem-se que a equação (5.11) pode ser resolvida através do ferramental de otimização convexa.

Aplicando a estratégia iterativa do DCP, tem-se que o problema de maximização (5.9), utilizando a função-objetivo da equação (5.7), pode ser resolvido com a utilização do ferramental DCP com a seguinte escolha das funções $f(\widetilde{\mathbf{P}}, \widetilde{\boldsymbol{\lambda}})$ e $g(\widetilde{\mathbf{P}}, \widetilde{\boldsymbol{\lambda}})$ :

$$
\begin{aligned}
& f(\widetilde{\mathbf{P}}, \tilde{\boldsymbol{\lambda}})=\sum_{k=1}^{K} \log _{b}\left(\mathrm{w} \sum_{n=1}^{N} \widetilde{\lambda}_{k, n} \ell_{k, n} \log _{2}\left(1+\frac{\widetilde{p}_{k, n} \Gamma_{k, n} \iota_{k}}{\widetilde{\lambda}_{k, n}}\right)\right) \\
& g(\widetilde{\mathbf{P}}, \tilde{\boldsymbol{\lambda}})=\sum_{k=1}^{K} \log _{b}\left(\sum_{n=1}^{N} \varrho_{k} \widetilde{p}_{k, n}+p_{c, k}\right)
\end{aligned}
$$

Para continuar com a solução, é necessário garantir que as funções escolhidas como $f(\widetilde{\mathbf{P}}, \tilde{\boldsymbol{\lambda}})$ e $g(\widetilde{\mathbf{P}}, \widetilde{\boldsymbol{\lambda}})$ sejam côncavas em relação às variáveis de otimização. Para tanto, define-se o seguinte teorema:

Teorema 5.1. As funções $f(\widetilde{\mathbf{P}}, \widetilde{\boldsymbol{\lambda}})$ e $g(\widetilde{\mathbf{P}}, \widetilde{\boldsymbol{\lambda}})$ são côncavas em relação às variáveis de otimização $\widetilde{p}_{k, n}$ e $\widetilde{\lambda}_{k, n}$.

Demonstração. A prova é apresentada no Apêndice B.2.

Tendo demonstrado a concavidade das funções $f(\widetilde{\mathbf{P}}, \widetilde{\boldsymbol{\lambda}})$ e $g(\widetilde{\mathbf{P}}, \widetilde{\boldsymbol{\lambda}})$ em relação às variáveis de otimização, é necessário determinar a função-objetivo iterativa que será utilizada no decorrer da solução. De acordo com o apresentado na equação (5.11), o problema de 
otimização a ser resolvido na $i$-ésima iteração do DCP é dado por:

$$
\begin{aligned}
& \mathbf{P}^{*, i}, \boldsymbol{\lambda}^{*, i}=\underset{\mathbf{P}, \boldsymbol{\lambda}}{\arg \max } . \sum_{k=1}^{K} \log _{b}\left(\mathrm{w} \sum_{n=1}^{N} \widetilde{\lambda}_{k, n} \ell_{k, n} \log _{2}\left(1+\frac{\widetilde{p}_{k, n} \Gamma_{k, n} \imath_{k}}{\widetilde{\lambda}_{k, n}}\right)\right) \\
& -\sum_{k=1}^{K} \log _{b}\left(\sum_{n=1}^{N} \varrho_{k} \widetilde{p}_{k, n}^{*, i-1}+p_{c, k}\right)-\sum_{k=1}^{K} \sum_{n=1}^{N}\left[\left.\left(\widetilde{p}_{k, n}-\widetilde{p}_{k, n}^{*, i-1}\right) \frac{\partial g(\widetilde{\mathbf{P}}, \widetilde{\boldsymbol{\lambda}})}{\partial \widetilde{p}_{k, n}}\right|_{\substack{\widetilde{\mathbf{\lambda}}=\widetilde{\mathbf{P}}^{*, i-1} \\
\widetilde{\boldsymbol{\lambda}}^{*, i-1}}}\right] \\
& -\sum_{k=1}^{K} \sum_{n=1}^{N}\left[\left.\left(\widetilde{\lambda}_{k, n}-\widetilde{\lambda}_{k, n}^{*, i-1}\right) \frac{\partial g(\widetilde{\mathbf{P}}, \widetilde{\boldsymbol{\lambda}})}{\partial \widetilde{\lambda}_{k, n}}\right|_{\substack{\widetilde{\mathbf{P}}=\widetilde{\mathbf{P}}^{*, i-1} \\
\widetilde{\boldsymbol{\lambda}}^{*, i-1}}}\right]
\end{aligned}
$$

A derivada parcial $\frac{\partial g(\widetilde{\mathbf{P}}, \widetilde{\boldsymbol{\lambda}})}{\partial \widetilde{p}_{k, n}}$ é dada por:

$$
\begin{gathered}
\frac{\partial \sum_{k=1}^{K} \log _{b}\left(\sum_{m=1}^{N} \varrho_{k} \widetilde{p}_{k, m}+p_{c, k}\right)}{\partial \widetilde{p}_{k, n}}=\frac{1}{\log (b)\left(\sum_{m=1}^{N} \varrho_{k} \widetilde{p}_{k, m}+p_{c, k}\right)} \frac{\partial\left(\sum_{m=1}^{N} \varrho_{k} \widetilde{p}_{k, m}+p_{c, k}\right)}{\partial \widetilde{p}_{k, n}} \\
=\frac{\varrho_{k}}{\log (b)\left(\sum_{m=1}^{N} \varrho_{k} \widetilde{p}_{k, m}+p_{c, k}\right)}
\end{gathered}
$$

Já a derivada parcial $\frac{\partial g(\widetilde{\mathbf{P}}, \widetilde{\boldsymbol{\lambda}})}{\partial \widetilde{\lambda}_{k, n}}$ é igual a zero, dado que $g(\widetilde{\mathbf{P}}, \widetilde{\boldsymbol{\lambda}})$ é constante em relação a $\tilde{\lambda}_{k, n}$. Perceba que o índice no somatório de subportadoras foi alterado de $n$ para $m$ para evitar conflito de notação com os somatórios presentes na equação da solução iterativa, equação (5.13).

Assim, o problema de otimização a ser resolvido na $i$-ésima iteração do DCP é dado por:

$$
\begin{gathered}
\mathbf{P}^{*, i}, \boldsymbol{\lambda}^{*, i}=\underset{\mathbf{P}, \boldsymbol{\lambda}}{\arg \max } \cdot U_{\log }^{i}(\widetilde{\mathbf{P}}, \widetilde{\boldsymbol{\lambda}}) \\
\text { s.a: } \quad(5.9 \mathrm{~b})-(5.9 \mathrm{f})
\end{gathered}
$$

em que

$$
\begin{aligned}
U_{\log }^{i}(\widetilde{\mathbf{P}}, \widetilde{\boldsymbol{\lambda}})= & \sum_{k=1}^{K} \log _{b}\left(\mathrm{w} \sum_{n=1}^{N} \widetilde{\lambda}_{k, n} \ell_{k, n} \log _{2}\left(1+\frac{\widetilde{p}_{k, n} \Gamma_{k, n} \imath_{k}}{\widetilde{\lambda}_{k, n}}\right)\right)-\sum_{k=1}^{K} \log _{b}\left(\sum_{n=1}^{N} \varrho_{k} \widetilde{p}_{k, n}^{*, i-1}+p_{c, k}\right) \\
& -\sum_{k=1}^{K} \sum_{n=1}^{N} \frac{\varrho_{k}\left(\widetilde{p}_{k, n}-\widetilde{p}_{k, n}^{*, i-1}\right)}{\log (b)\left(\sum_{m=1}^{N} \varrho_{k} \widetilde{p}_{k, m}^{*, i-1}+p_{c, k}\right)}
\end{aligned}
$$

Para incorporar as restrições à função-objetivo, utiliza-se o algoritmo LDD. Nesse sentido, incorporam-se os multiplicadores $\boldsymbol{\tau}_{[1 \times K]}$ e $\boldsymbol{v}_{[1 \times N]}$ às restrições $(5.9 \mathrm{e})$ e $(5.9 \mathrm{f})$, respectivamente. Ao contrário do que é descrito no Capítulo 4, não é possível garantir a unicidade da alocação de subportadoras utilizando uma função de máximo, como visto na equação (4.16). Caso uma função de máximo seja empregada para decidir quais MSs 
alocarão as subportadoras, é possível que alguma MS não aloque nenhuma subportadora, o que resulta em $\widetilde{\xi}_{\log }^{\text {fair }}(\widetilde{\mathbf{P}}, \widetilde{\boldsymbol{\lambda}})=-\infty$. Como será visto no desenvolvimento das equações de alocação de recursos, a existência de uma MS sem subportadoras alocadas fará com que o sistema seja incapaz de convergir. Com tais considerações, a função-objetivo com aplicação de DCP+LDD é dada por:

$$
\begin{aligned}
\widetilde{\mathbf{P}}^{*, i}, \widetilde{\boldsymbol{\lambda}}^{*, i} & =\underset{\substack{\boldsymbol{\tau} \succeq \mathbf{0} \\
\boldsymbol{v} \succeq \mathbf{0}}}{\arg \min _{k=1} \max .} \sum_{k=1}^{K} \log _{b}\left(\mathrm{w} \sum_{n=1}^{N} \widetilde{\lambda}_{k, n} \ell_{k, n} \log _{2}\left(1+\frac{\widetilde{p}_{k, n} \Gamma_{k, n} \iota_{k}}{\widetilde{\lambda}_{k, n}}\right)\right) \\
& -\sum_{k=1}^{K} \log _{b}\left(\sum_{n=1}^{N} \varrho_{k} \widetilde{p}_{k, n}^{*, i-1}+p_{c, k}\right)-\sum_{k=1}^{K} \sum_{n=1}^{N} \frac{\varrho_{k}\left(\widetilde{p}_{k, n}-\widetilde{p}_{k, n}^{*, i-1}\right)}{\log (b)\left(\sum_{m=1}^{N} \varrho_{k} \widetilde{p}_{k, m}^{*, i-1}+p_{c, k}\right)} \\
& +\sum_{k=1}^{K} \tau_{k}\left(p_{k}^{\max }-\sum_{n=1}^{N} \widetilde{p}_{k, n}\right)+\sum_{n=1}^{N} v_{n}\left(1-\sum_{k=1}^{K} \widetilde{\lambda}_{k, n}\right)
\end{aligned}
$$

Dado que não é possível determinar os valores ótimos de $\boldsymbol{\tau}$ e $\boldsymbol{v}$ diretamente a partir da equação (5.17), adota-se uma solução iterativa, em que os valores dos multiplicadores de Lagrange são atualizados até que a convergência seja atingida. O problema de otimização do tipo min max da equação (5.17) será resolvido em duas etapas: na primeira, se resolve o problema de maximização considerando que os multiplicadores de Lagrange $\boldsymbol{\tau}$ e $\boldsymbol{v}$ são tratados como constantes, obtidas na iteração anterior do LDD, resultando no seguinte subproblema:

$$
\widetilde{\mathbf{P}}^{*, i, j}, \widetilde{\boldsymbol{\lambda}}^{*, i, j}=\arg \max . U_{\log }^{i, j}(\widetilde{\mathbf{P}}, \widetilde{\boldsymbol{\lambda}})
$$

em que

$$
\begin{aligned}
U_{\log }^{i, j}(\widetilde{\mathbf{P}}, \widetilde{\boldsymbol{\lambda}})= & \sum_{k=1}^{K} \log _{b}\left(\mathrm{w} \sum_{n=1}^{N} \widetilde{\lambda}_{k, n} \ell_{k, n} \log _{2}\left(1+\frac{\widetilde{p}_{k, n} \Gamma_{k, n} \iota_{k}}{\widetilde{\lambda}_{k, n}}\right)\right) \\
& -\sum_{k=1}^{K} \sum_{n=1}^{N} \frac{\varrho_{k}\left(\widetilde{p}_{k, n}-\widetilde{p}_{k, n}^{*, i-1}\right)}{\log (b)\left(\sum_{m=1}^{N} \varrho_{k} \tilde{p}_{k, m}^{*, i-1}+p_{c, k}\right)}-\sum_{k=1}^{K} \sum_{n=1}^{N} \tau_{k}^{j-1} \widetilde{p}_{k, n}-\sum_{k=1}^{K} \sum_{n=1}^{N} v_{n}^{j-1} \widetilde{\lambda}_{k, n} .
\end{aligned}
$$

Posteriormente, o subproblema de minimização considera as variáveis de alocação de potência e subportadoras constantes, dadas pela solução do problema de maximização anteriormente resolvido, e otimiza os multiplicadores $\boldsymbol{\tau}$ e $\boldsymbol{v}$.

$$
\boldsymbol{\tau}^{j}, \boldsymbol{v}^{j}=\underset{\substack{\boldsymbol{v} \boldsymbol{v} \succeq \mathbf{0} \\ \arg \min }}{K} \sum_{k=1}^{K} \tau_{k}\left(p_{k}^{\max }-\sum_{n=1}^{N} \tilde{p}_{k, n}^{*, i, j}\right)+\sum_{n=1}^{N} v_{n}\left(1-\sum_{k=1}^{K} \tilde{\lambda}_{k, n}^{*, i, j}\right)
$$

As equações (5.19) e (5.20) são repetidas até que um determinado número limite de iterações $N_{\text {ldd }}^{i t}$ sejam executadas ou o algoritmo LDD convirja. Perceba ainda que a função-objetivo da equação (5.19) pode ser separada nas $K$ MSs, resultando na seguinte 
função-objetivo:

$$
\begin{aligned}
U_{k, \log }^{i, j}(\widetilde{\mathbf{P}}, \widetilde{\boldsymbol{\lambda}})= & \log _{b}\left(\mathrm{w} \sum_{n=1}^{N} \widetilde{\lambda}_{k, n} \ell_{k, n} \log _{2}\left(1+\frac{\widetilde{p}_{k, n} \Gamma_{k, n} \imath_{k}}{\widetilde{\lambda}_{k, n}}\right)\right)-\sum_{n=1}^{N} \frac{\varrho_{k}\left(\widetilde{p}_{k, n}-\widetilde{p}_{k, n}^{*, i-1}\right)}{\log (b)\left(\sum_{m=1}^{N} \varrho_{k} \widetilde{p}_{k, m}^{*, i-1}+p_{c, k}\right)} \\
& -\sum_{n=1}^{N} \tau_{k}^{j-1} \widetilde{p}_{k, n}-\sum_{n=1}^{N} v_{n}^{j-1} \widetilde{\lambda}_{k, n} .
\end{aligned}
$$

A resolução do problema de maximização, utilizando a função-objetivo dada na equação (5.21), será feita em duas etapas, utilizando as condições de KKT. Na primeira etapa, deriva-se $U_{k, \log }^{i, j}(\widetilde{\mathbf{P}}, \widetilde{\boldsymbol{\lambda}})$ em relação a $\widetilde{p}_{k, n}$ e iguala-se a derivada a zero para obter a alocação de potência ótima $\tilde{p}_{k, n}^{*, i, j}$. Calculando inicialmente a derivada, tem-se que:

$$
\begin{aligned}
\frac{\partial U_{k, \log }^{i, j}(\widetilde{\mathbf{P}}, \tilde{\boldsymbol{\lambda}})}{\partial \widetilde{p}_{k, n}}= & \frac{1}{\log (b) \mathrm{w} \sum_{m=1}^{N} \widetilde{\lambda}_{k, m} \ell_{k, m} \log _{2}\left(1+\frac{\widetilde{p}_{k, m} \Gamma_{k, m} \iota_{k}}{\widetilde{\lambda}_{k, m}}\right)} \frac{\mathrm{w} \widetilde{\lambda}_{k, n} \ell_{k, n}}{\log (2)\left(1+\frac{\widetilde{p}_{k, n} \Gamma_{k, n} \iota_{k}}{\widetilde{\lambda}_{k, n}}\right)} \frac{\Gamma_{k, n} \iota_{k}}{\widetilde{\lambda}_{k, n}} \\
& -\tau_{k}^{j-1}-\frac{\varrho_{k}}{\log (b)\left(\sum_{m=1}^{N} \varrho_{k} \widetilde{p}_{k, m}^{*, i-1}+p_{c, k}\right)} \\
= & \frac{\ell_{k, n} \Gamma_{k, n} \iota_{k}}{\log (b)\left(1+p_{k, n} \Gamma_{k, n} \iota_{k}\right) \sum_{m=1}^{N} \widetilde{\lambda}_{k, m} \ell_{k, m} \log \left(1+p_{k, m} \Gamma_{k, m} \imath_{k}\right)} \\
& -\frac{\tau_{k}^{j-1} \log (b)\left(\sum_{m=1}^{N} \varrho_{k} \widetilde{p}_{k, m}^{i-1, j}+p_{c, k}\right)+\varrho_{k}}{\log (b)\left(\sum_{m=1}^{N} \varrho_{k} \widetilde{p}_{k, m}^{* i-1}+p_{c, k}\right)}
\end{aligned}
$$

Igualando $\frac{\partial U_{k, \log }^{i, j}(\widetilde{\mathbf{P}}, \widetilde{\boldsymbol{\lambda}})}{\partial \widetilde{p} k, n}$ a zero, tem-se que:

$$
\begin{aligned}
& \frac{\ell_{k, n} \Gamma_{k, n} \iota_{k}}{\log (b)\left(1+p_{k, n} \Gamma_{k, n} \imath_{k}\right) \sum_{m=1}^{N} \tilde{\lambda}_{k, m} \ell_{k, m} \log \left(1+p_{k, m} \Gamma_{k, m}\right) \imath_{k}}= \\
& \frac{\tau_{k}^{j-1} \log (b)\left(\sum_{m=1}^{N} \varrho_{k} \widetilde{p}_{k, m}^{*, i-1}+p_{c, k}\right)+\varrho_{k}}{\log (b)\left(\sum_{m=1}^{N} \varrho_{k} \widetilde{p}_{k, m}^{*, i-1}+p_{c, k}\right)}
\end{aligned}
$$


A equação (5.23) pode ainda ser reescrita como:

$$
\begin{aligned}
& \frac{1}{\left(1+p_{k, n} \Gamma_{k, n} \iota_{k}\right) \sum_{m=1}^{N} \frac{\widetilde{\lambda}_{k, m} \ell_{k, m}}{\ell_{k, n}} \log \left(1+p_{k, m} \Gamma_{k, m} \imath_{k}\right)}= \\
& \frac{\tau_{k}^{j-1} \log (b)\left(\sum_{m=1}^{N} \varrho_{k} \widetilde{p}_{k, m}^{*, i-1}+p_{c, k}\right)+\varrho_{k}}{\Gamma_{k, n} \iota_{k}\left(\sum_{m=1}^{N} \varrho_{k} \widetilde{p}_{k, m}^{*, i-1}+p_{c, k}\right)} \\
& \left(1+p_{k, n} \Gamma_{k, n} \imath_{k}\right) \sum_{m=1}^{N} \frac{\widetilde{\lambda}_{k, m} \ell_{k, m}}{\ell_{k, n}} \log \left(1+p_{k, m} \Gamma_{k, m} \imath_{k}\right)= \\
& \frac{\Gamma_{k, n} \iota_{k}\left(\sum_{m=1}^{N} \varrho_{k} \widetilde{p}_{k, m}^{*, i-1}+p_{c, k}\right)}{\tau_{k}^{j-1} \log (b)\left(\sum_{m=1}^{N} \varrho_{k} \widetilde{p}_{k, m}^{*, i-1}+p_{c, k}\right)+\varrho_{k}} \\
& \left(1+p_{k, n} \Gamma_{k, n} \imath_{k}\right) \sum_{m=1}^{N} \log \left(\left(1+p_{k, m} \Gamma_{k, m} \imath_{k}\right)^{\frac{\tilde{\lambda}_{k, m} \ell_{k, m}}{\ell_{k, n}}}\right)= \\
& \frac{\Gamma_{k, n} \iota_{k}\left(\sum_{m=1}^{N} \varrho_{k} \widetilde{p}_{k, m}^{*, i-1}+p_{c, k}\right)}{\tau_{k}^{j-1} \log (b)\left(\sum_{m=1}^{N} \varrho_{k} \widetilde{p}_{k, m}^{*, i-1}+p_{c, k}\right)+\varrho_{k}}
\end{aligned}
$$

Como pode ser visto na equação (5.24), determinar a potência a ser alocada pela $k$-ésima MS na $n$-ésima subportadora depende da potência alocada nas demais subportadoras pela mesma MS. Isso acontece pela formulação de logaritmo adotada no problema, dado que a derivada de uma função log resulta em seu argumento sendo repetido no denominador da derivada resultante. Tal fato é um complicador para a adoção da solução pelo ferramental DCP, pois seria necessário resolver conjuntamente $N$ equações na forma da equação (5.24) para que o conjunto de potências ótimas da $k$-ésima MS seja conhecido. Mesmo que algum tipo de simplificação ou aproximação possa ser adotada para que não seja necessário resolver as $N$ equações conjuntamente, a solução de equações semelhantes à equação (5.24) ainda é bastante complexa, pois não é possível, diretamente a partir da equação (5.24), isolar $p_{k, n}$ conforme procedimento adotado no Capítulo 4.

Uma possível solução para a obtenção de $p_{k, n}^{*, i, j}$, considera o caso em que a $k$-ésima MS possui apenas uma subportadora disponível para alocação, ou seja, $N=1$ e $\widetilde{\lambda}_{k, n}=1$. Para esse caso particular, a equação (5.24) pode ser simplificada como:

$$
\left(1+p_{k, n} \Gamma_{k, n} \imath_{k}\right) \log \left(1+p_{k, n} \Gamma_{k, n} \iota_{k}\right)=\frac{\Gamma_{k, n} \iota_{k}\left(\varrho_{k} p_{k, n}^{*, i-1}+p_{c, k}\right)}{\tau_{k}^{j-1} \log (b)\left(\varrho_{k} p_{k, n}^{*, i-1}+p_{c, k}\right)+\varrho_{k}}
$$

A partir da definição da função $W$ de Lambert, equações na forma

$$
x \log \left(x D_{2}\right)=D_{3}
$$


tem como solução

$$
x=\frac{\mathrm{e}^{W\left(D_{2} D_{3}\right)}}{D_{2}}
$$

onde $W($.$) é a função W$ de Lambert [131].

Assim, para o cenário de apenas uma subportadora descrito acima, determina-se

$$
\begin{gathered}
x=1+p_{k, n} \Gamma_{k, n} \imath_{k}, \\
D_{2}=1, \\
D_{3}=\frac{\Gamma_{k, n} \imath_{k}\left(\varrho_{k} p_{k, n}^{*, i-1}+p_{c, k}\right)}{\tau_{k}^{j-1} \log (b)\left(\varrho_{k} p_{k, n}^{*, i-1}+p_{c, k}\right)+\varrho_{k}},
\end{gathered}
$$

resultando em:

$$
\begin{aligned}
1+p_{k, n}^{*, i, j} \Gamma_{k, n} \imath_{k} & =\exp \left(W\left(\frac{\Gamma_{k, n} \imath_{k}\left(\varrho_{k} p_{k, n}^{*, i-1}+p_{c, k}\right)}{\tau_{k}^{j-1} \log (b)\left(\varrho_{k} p_{k, n}^{*, i-1}+p_{c, k}\right)+\varrho_{k}}\right)\right) \\
p_{k, n}^{*, i, j} & =\left[\frac{\exp \left(W\left(\frac{\Gamma_{k, n} \iota_{k}\left(\varrho_{k} p_{k, n}^{*, i-1}+p_{c, k}\right)}{\tau_{k}^{j-1} \log (b)\left(\varrho_{k} p_{k, n}^{*, i-1}+p_{c, k}\right)+\varrho_{k}}\right)\right)}{\Gamma_{k, n} \imath_{k}}-\frac{1}{\Gamma_{k, n} \imath_{k}}\right]^{+}
\end{aligned}
$$

em que o operador $[a]^{+}=\max (0, a)$.

Para o caso de múltiplas portadoras, é necessário adaptar a equação (5.24) para que seja possível obter os termos $D_{2}$ e $D_{3}$ e utilizar a função $W$ de Lambert. Sabendo que a soma de logaritmos é equivalente ao logaritmo do produtório dos argumentos de cada logaritmo, a equação (5.24) pode ser reescrita como:

$$
\left(1+p_{k, n} \Gamma_{k, n} \imath_{k}\right) \log \left(\left(1+p_{k, n} \Gamma_{k, n} \iota_{k}\right)^{\widetilde{\lambda}_{k, n}} \prod_{\substack{m=1 \\ m \neq n}}^{N}\left(1+p_{k, m} \Gamma_{k, m} \imath_{k}\right)^{\frac{\widetilde{\lambda}_{k, m} \ell_{k, m}}{\ell_{k, n}}}\right)=D_{3}
$$

em que

$$
D_{3}=\frac{\Gamma_{k, n} \imath_{k}\left(\sum_{m=1}^{N} \varrho_{k} p_{k, m}^{*, i-1}+p_{c, k}\right)}{\tau_{k}^{j-1} \log (b)\left(\sum_{m=1}^{N} \varrho_{k} p_{k, m}^{*, i-1}+p_{c, k}\right)+\varrho_{k}} .
$$

Como se considera que a alocação de recursos é feita de modo iterado no algoritmo DCP+LDD, primeiro calculando a alocação de potência e posteriormente atualizando a alocação de subportadoras, é plausível considerar que a alocação de subportadoras à esquerda da igualdade na equação (5.30) seja dada pela alocação obtida na iteração imediatamente anterior, i.e., a ( $j-1)$-ésima iteração do LDD, durante a $i$-ésima iteração do DCP. Caso não se considere essa alteração na equação (5.30), será necessário calcular conjuntamente a alocação de potência e subportadoras em todas as $N$ subportadoras da 
k-ésima MS, o que é computacionalmente custoso. Com essa alteração, a equação (5.30) é reescrita como:

$$
\left(1+p_{k, n} \Gamma_{k, n} \imath_{k}\right) \log \left(\left(1+p_{k, n} \Gamma_{k, n} \imath_{k}\right)^{\tilde{\lambda}_{k, n}^{i, j-1}} \prod_{\substack{m=1 \\ m \neq n}}^{N}\left(1+p_{k, m} \Gamma_{k, m} \iota_{k}\right)^{\frac{\widetilde{\lambda}_{k, m}^{i, j-1} \ell_{k, m}}{\ell_{k, n}}}\right)=D_{3}
$$

A segunda definição é referente ao termo $\tilde{\lambda}_{k, n}^{i, j-1}$ presente à esquerda da igualdade, antes do produtório. Como deseja-se calcular a potência da $k$-ésima MS na $n$-ésima subportadora, define-se que $\widetilde{\lambda}_{k, n}^{i, j-1}=1$, ou seja, a $n$-ésima portadora está alocada à $k$ ésima MS. Desse modo, evita-se que a alocação de potência dependa da alocação (ou não) da $n$-ésima portadora à $k$-ésima MS na iteração anterior. A partir dessa definição, reescreve-se a equação (5.30) como:

$$
\left(1+p_{k, n} \Gamma_{k, n} \imath_{k}\right) \log \left(\left(1+p_{k, n} \Gamma_{k, n} \imath_{k}\right) D_{2}\right)=D_{3}
$$

em que

$$
D_{2}=\prod_{\substack{m=1 \\ m \neq n}}^{N}\left(1+p_{k, m} \Gamma_{k, m} \imath_{k}\right)^{\frac{\tilde{\lambda}_{k, m}^{i, j-1} \ell_{k, m}}{\ell_{k, n}}}
$$

Com essas definições, a solução da equação (5.33) é dada por

$$
p_{k, n}^{*, i, j}=\left[\chi_{k, n}-\frac{1}{\Gamma_{k, n} \imath_{k}}\right]^{+}
$$

em que

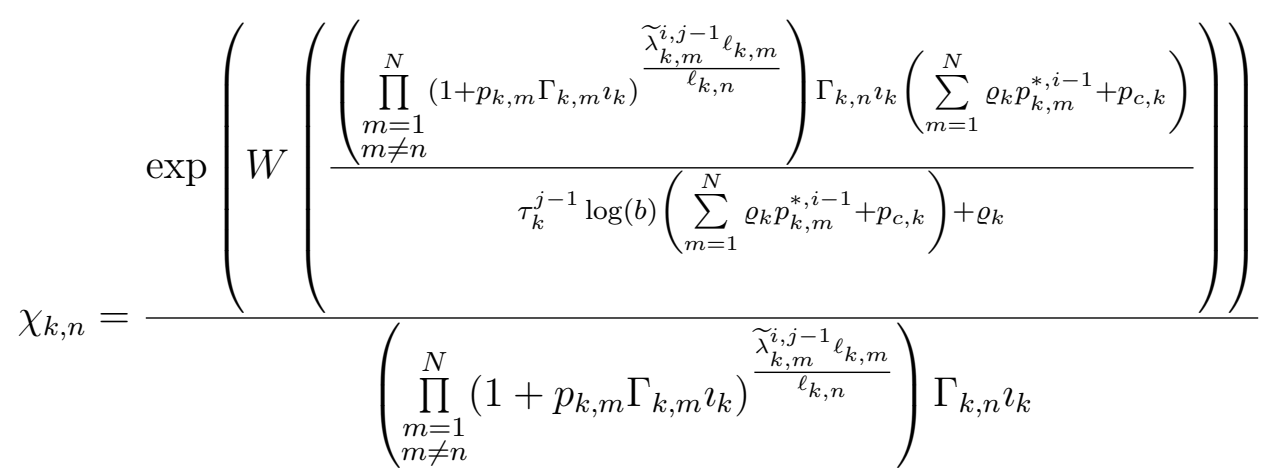

Definida a alocação de potência, busca-se agora a alocação de subportadoras. To- 
mando então a derivada da equação (5.19) em relação a $\widetilde{\lambda}_{k, n}$, tem-se que:

$$
\begin{aligned}
& \frac{\partial U_{k, \log }^{i, j}(\widetilde{\mathbf{P}}, \widetilde{\boldsymbol{\lambda}})}{\partial \widetilde{\lambda}_{k, n}}=\frac{\mathrm{w} \ell_{k, n} \log _{2}\left(1+\frac{\widetilde{p}_{k, n} \Gamma_{k, n} \imath_{k}}{\widetilde{\lambda}_{k, n}}\right)-\frac{\widetilde{\mathrm{w}}_{k, n} \ell_{k, n}}{\log (2)\left(1+\frac{\widetilde{p}_{k, n} \Gamma_{k, n} \imath_{k}}{\widetilde{\lambda}_{k, n}}\right)}\left(\frac{\frac{\widetilde{p}_{k, n} \Gamma_{k, n^{\imath} k}}{\widetilde{\lambda}_{k, n}}}{\widetilde{\lambda}_{k, n}}\right)}{\log (b) \mathrm{W} \sum_{m=1}^{N} \widetilde{\lambda}_{k, m} \ell_{k, m} \log _{2}\left(1+\frac{\widetilde{p}_{k, m} \Gamma_{k, m} \iota_{k}}{\widetilde{\lambda}_{k, m}}\right)}-v_{n}^{j-1} \\
& =\frac{\mathrm{w} \ell_{k, n} \log \left(1+\frac{\widetilde{p}_{k, n} \Gamma_{k, n} \imath_{k}}{\widetilde{\lambda}_{k, n}}\right)-\frac{\widetilde{\mathrm{\lambda}}_{k, n} \ell_{k, n}}{\left(1+\frac{\widetilde{p}_{k, n} \Gamma_{k, n^{2} k}}{\widetilde{\lambda}_{k, n}}\right)}\left(\frac{\frac{\widetilde{p}_{k, n} \Gamma_{k, n}{ }^{2} k}{\widetilde{\lambda}_{k, n}}}{\widetilde{\lambda}_{k, n}}\right)}{\log (b) \mathrm{W} \sum_{m=1}^{N} \widetilde{\lambda}_{k, m} \ell_{k, m} \log \left(1+\frac{\widetilde{p}_{k, m} \Gamma_{k, m} \iota_{k}}{\widetilde{\lambda}_{k, m}}\right)}-v_{n}^{j-1} \\
& =\frac{\ell_{k, n}\left(\log \left(1+p_{k, n} \Gamma_{k, n} \imath_{k}\right)-\frac{p_{k, n} \Gamma_{k, n} \imath_{k}}{\left(1+p_{k, n} \Gamma_{k, n} \imath_{k}\right)}\right)}{\log (b) \sum_{m=1}^{N} \tilde{\lambda}_{k, m} \ell_{k, m} \log \left(1+p_{k, m} \Gamma_{k, m} \imath_{k}\right)}-v_{n}^{j-1}
\end{aligned}
$$

Considerando que será utilizada a alocação de potência obtida no passo imediatamente anterior, i.e., a potência obtida na própria j-ésima iteração do LDD, a métrica de alocação da $n$-ésima subportadora da $k$-ésima MS, dada pela equação (5.37), pode ser reescrita como:

$$
s_{k, n}^{i, j}=\frac{\ell_{k, n}\left(\log \left(1+p_{k, n}^{*, i, j} \Gamma_{k, n} \imath_{k}\right)-\frac{p_{k, n}^{*, i, j} \Gamma_{k, n} \imath_{k}}{\left(1+p_{k, n}^{*, j} \Gamma_{k, n} \imath_{k}\right)}\right)}{\log (b) \sum_{m=1}^{N} \tilde{\lambda}_{k, m} \ell_{k, m} \log \left(1+p_{k, m}^{*, i, j} \Gamma_{k, m} \imath_{k}\right)}-v_{n}^{j-1}
$$

Observe que o termo no numerador da equação (5.38) é o mesmo obtido no Capítulo 4, equação (4.15), porém agora existe uma espécie de normalização, que considera a taxa de dados obtida pela $k$-ésima MS. Como a taxa de dados está no denominador, quanto maior a taxa de dados da $k$-ésima MS, menor será sua métrica de alocação de subportadoras, e por consequência menor será a competitividade dessa $k$-ésima MS no processo de alocação. Por outro lado, uma taxa de dados muito baixa faz com que a $k$-ésima MS tenha uma maior métrica de alocação, conseguindo competir por subportadoras. É esse denominador da métrica de alocação de subportadoras que impõe a métrica de fairness ao problema de alocação de recursos: quanto mais recursos espectrais uma determinada MS tiver, menor será seu poder de concorrência com outras MSs, possibilitando que mais MSs tenham a capacidade de disputar os recursos do sistema.

Há, porém, o risco de uma MS não alocar nenhum recurso espectral, resultando em taxa de dados nula e, por consequência, sua métrica de alocação tenderia a infinito. Tal risco é possível com a utilização de uma decisão de máximo, como a elaborada no Capítulo 4, de modo que o procedimento adotado é considerar que todas as portadoras que resultem em ganho de EE para a $k$-ésima MS sejam alocadas na $j$-ésima iteração do LDD, mesmo que resulte na $n$-ésima subportadora alocada por mais de uma MS [128]. Em termos 
matemáticos, define-se a seguinte relação:

$$
\lambda_{k, n}^{*, i, j}= \begin{cases}1, & \text { caso } s_{k, n}^{*, i, j}>0 \\ 0, & \text { caso contrário }\end{cases}
$$

Com essa definição, as restrições (5.9c) e (5.9d) do problema de otimização são atendidas, porém a restrição de unicidade, equação (5.9f), somente será garantida com a convergência do algoritmo de LDD, ou seja, quando o valor ótimo dos multiplicadores $\boldsymbol{v}$ estiver definido.

Finalizadas as alocações de potência e de subportadoras na $j$-ésima iteração do LDD, é possível utilizar métodos de subgradiente para atualizar os multiplicadores $\boldsymbol{\tau}$ e $\boldsymbol{v}$, de modo semelhante ao descrito no Capítulo 4:

$$
\begin{gathered}
\tau_{k}^{j}=\left[\tau_{k}^{j-1}-\phi_{\tau}\left(p_{k}^{\max }-\sum_{n=1}^{N} \lambda_{k, n}^{*, i, j} p_{k, n}^{*, i, j}\right)\right]^{+}, \quad k=1, \cdots, K \\
v_{n}^{j}=\left[v_{n}^{j-1}-\phi_{v}\left(1-\sum_{k=1}^{K} \lambda_{k, n}^{*, i, j}\right)\right]^{+}, \quad n=1, \cdots, N
\end{gathered}
$$

A solução da questão de múltiplas MSs alocando uma mesma subportadora pode ser analisada com ajuda da equação de atualização de $\boldsymbol{v}$, equação (5.40b). Caso uma mesma $n$-ésima subportadora seja alocada por mais de uma MS, o valor de $v_{n}$ é elevado em cada uma das iterações do algoritmo LDD, até que apenas uma MS seja capaz de alocar a $n$-ésima subportadora, i.e, para apenas uma MS se tenha $s_{k, n}^{i, j}>0$ na equação (5.38).

A convergência do LDD é verificada através de um erro máximo permitido, calculado pela diferença dos multiplicadores entre duas iterações consecutivas do LDD. Pode-se adotar aqui um valor único para o máximo erro tolerado em ambos os multiplicadores, $\varepsilon_{1 \mathrm{dd}}^{\max }$, ou então adotar um erro máximo para $\boldsymbol{\tau}$ e outro para $\boldsymbol{v}$, i.e., $\varepsilon_{\tau}^{\max }$ e $\varepsilon_{v}^{\max }$, respectivamente. Adota-se a segunda estratégia, de modo que o erro de convergência dos multiplicadores $\boldsymbol{\tau}$ e $\boldsymbol{v}$ são dados, respectivamente, por

$$
\varepsilon_{\tau}^{j}=\max _{k}\left(\left|\tau_{k}^{j}-\tau_{k}^{j-1}\right|\right)
$$

$\mathrm{e}$

$$
\varepsilon_{v}^{j}=\max _{n}\left(\left|v_{n}^{j}-v_{n}^{j-1}\right|\right) .
$$

Caso a convergência não seja atingida em um número limite de iterações $N_{1 d d}^{\mathrm{it}}$, o algoritmo LDD é finalizado.

As matrizes de alocação de potência de subportadoras e potência obtidas na iteração de parada do LDD, durante a $i$-ésima iteração do DCP, são definidas como as matrizes de alocação ótimas da $i$-ésima iteração do DCP. Obtidas as matrizes ótimas na $i$-ésima iteração do DCP, verifica-se se o algoritmo convergiu, calculando o erro de convergência como

$$
\varepsilon_{\mathrm{dcp}}^{i}=\left|U_{\log }^{i}\left(\widetilde{\mathbf{P}}^{*, i}, \widetilde{\boldsymbol{\lambda}}^{*, i}\right)-U_{\log }^{i-1}\left(\widetilde{\mathbf{P}}^{*, i-1}, \widetilde{\boldsymbol{\lambda}}^{*, i-1}\right)\right|
$$


e comparando-o com um erro máximo pré-estabelecido, dado por $\varepsilon_{\mathrm{dcp}}^{\max }$. O algoritmo é encerrado se $\varepsilon_{\mathrm{dcp}}^{i} \leq \varepsilon_{\mathrm{dcp}}^{\max }$ ou o limite de iterações, dado por $N_{\mathrm{dcp}}^{i t}$, for atingido.

O processo de execução da solução do problema de maximização de EE com fairness proporcional com função-objetivo de somatório de logaritmos utilizando DCP e LDD é sumarizado no Algoritmo 5.1.

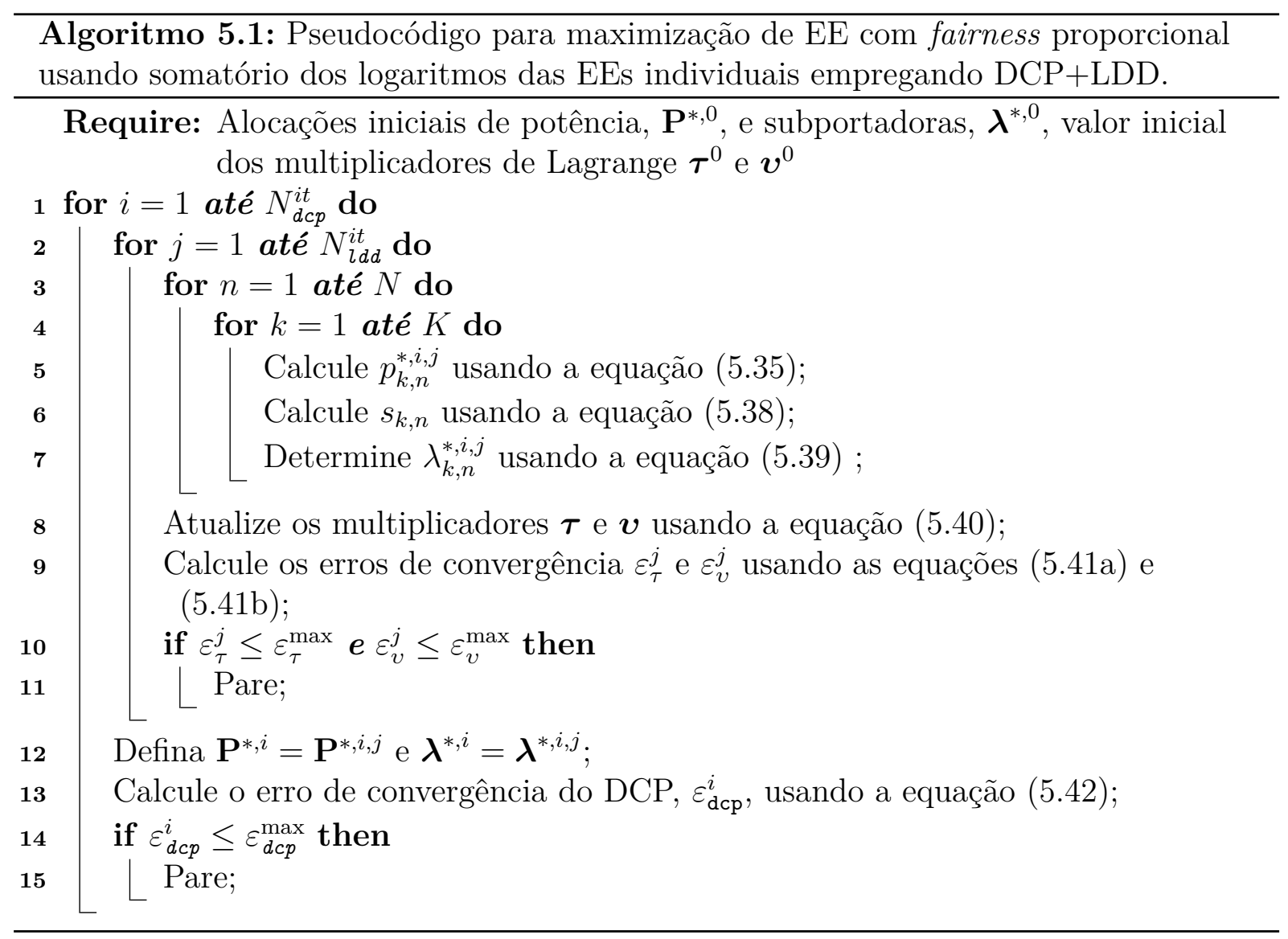

\subsection{Solução para produtório}

Considera-se agora o problema com utilização da função-utilidade definida como o produtório das EEs individuais, equação (5.8). Por se tratar de um produtório de funções fracionárias, a equação (5.8) pode ser reescrita como:

$$
\widetilde{\xi}_{\text {prod }}^{\text {fair }}(\widetilde{\mathbf{P}}, \widetilde{\boldsymbol{\lambda}})=\frac{\prod_{k=1}^{K}\left[\mathrm{w} \sum_{n=1}^{N} \widetilde{\lambda}_{k, n} \ell_{k, n} \log _{2}\left(1+\frac{\widetilde{p}_{k, n} \Gamma_{k, n} \iota_{k}}{\widetilde{\lambda}_{k, n}}\right)\right]}{\prod_{k=1}^{K}\left[\sum_{n=1}^{N} \varrho_{k} \widetilde{p}_{k, n}+p_{c, k}\right]}
$$

O problema de otimização, juntamente com as restrições associadas, é dado pela equação (5.9).

Assim como no Capítulo 4, percebe-se que a função-utilidade é dada por uma função fracionária. Caso $\widetilde{\xi}_{\text {prod }}^{\text {fair }}(\widetilde{\mathbf{P}}, \widetilde{\boldsymbol{\lambda}})$ seja quase-côncavo em relação a $\widetilde{p}_{k, n}$ e $\widetilde{\lambda}_{k, n}$, é possível utilizar 
o algoritmo de Dinkelbach para obter uma função-objetivo linear, côncava e iterativa para obter as alocações ótimas de potência e subportadoras, dado um erro de convergência máximo $\varepsilon_{\mathrm{dkb}}^{\max }$. Para demonstrar a quase-concavidade, define-se o seguinte teorema:

Teorema 5.2. A função-objetivo $\widetilde{\xi}_{\text {prod }}^{\text {fair }}(\widetilde{\mathbf{P}}, \widetilde{\boldsymbol{\lambda}})$ é quase-côncava em relação às variáveis de otimização $\widetilde{p}_{k, n}$ e $\widetilde{\lambda}_{k, n}$.

Demonstração. A prova é apresentada no Apêndice B.3.

Tendo garantido que a solução via algoritmo de DKB pode ser utilizada para se obter a solução ótima, dado um erro de convergência máximo $\varepsilon_{\mathrm{dkb}}^{\max }$, aplica-se o parâmetro $q$ à função-utilidade $\widetilde{\xi}_{\text {prod }}^{\text {fair }}(\widetilde{\mathbf{P}}, \widetilde{\boldsymbol{\lambda}})$, resultando no seguinte problema de otimização:

$$
\begin{aligned}
& \widetilde{\mathbf{P}}^{*}, \widetilde{\boldsymbol{\lambda}}^{*}=\arg \max . \prod_{k=1}^{K}\left[\mathrm{w} \sum_{n=1}^{N} \widetilde{\lambda}_{k, n} \ell_{k, n} \log _{2}\left(1+\frac{\widetilde{p}_{k, n} \Gamma_{k, n} \iota_{k}}{\widetilde{\lambda}_{k, n}}\right)\right] \\
&-q^{*} \prod_{k=1}^{K}\left[\sum_{n=1}^{N} \varrho_{k} \widetilde{p}_{k, n}+p_{c, k}\right] \\
& \text { s. a: } \quad(5.9 \mathrm{~b})-(5.9 \mathrm{f}) .
\end{aligned}
$$

onde $q$ é dado por:

$$
q^{*}=q\left(\widetilde{\mathbf{P}}^{*}, \widetilde{\boldsymbol{\lambda}}^{*}\right)=\frac{\prod_{k=1}^{K}\left[\mathrm{w} \sum_{n=1}^{N} \widetilde{\lambda}_{k, n} \ell_{k, n} \log _{2}\left(1+\frac{\widetilde{p}_{k, n}^{*} \Gamma_{k, n} \imath_{k}}{\widetilde{\lambda}_{k, n}^{*}}\right)\right]}{\prod_{k=1}^{K}\left[\sum_{n=1}^{N} \varrho_{k} \widetilde{p}_{k, n}^{*}+p_{c, k}\right]} .
$$

Aplicando a estrutura iterativa de solução do algoritmo de Dinkelbach, o problema de otimização a ser resolvido na $i$-ésima iteração do DKB é dado por:

$$
\begin{aligned}
\widetilde{\mathbf{P}}^{*, i}, \widetilde{\boldsymbol{\lambda}}^{*, i}=\arg \max . & \prod_{k=1}^{K}\left[\mathrm{w} \sum_{n=1}^{N} \widetilde{\lambda}_{k, n} \ell_{k, n} \log _{2}\left(1+\frac{\widetilde{p}_{k, n} \Gamma_{k, n} \iota_{k}}{\widetilde{\lambda}_{k, n}}\right)\right] \\
& -q^{i-1} \prod_{k=1}^{K}\left[\sum_{n=1}^{N} \varrho_{k} \widetilde{p}_{k, n}+p_{c, k}\right]
\end{aligned}
$$

s. a: $(5.9 b)-(5.9 f)$.

Tendo agora uma função-utilidade polinomial, é necessário incorporar as restrições do problema de otimização a essa mesma função. De maneira análoga à desenvolvida no Capítulo 4, o ferramental de LDD será utilizado para tal tarefa. Assim como acontece quando da utilização de função-utilidade com somatório de logaritmos, é necessário manter um multiplicador de Lagrange para controlar a restrição de proibição de múltiplo acesso nas subportadoras, equação (5.9f). Tal necessidade será percebida com as equações de alocação de recursos e também pelo fato de que, caso nenhuma portadora seja alocada para alguma das MSs, a utilidade resultante será nula, afinal a EE dessa MS em particular 
será nula. Assim, associam-se os vetores de multiplicadores de Lagrange $\boldsymbol{\tau}_{[1 \times K]}$ e $\boldsymbol{v}_{[1 \times N]}$ às restrições (5.9e) e (5.9f), respectivamente, resultando no seguinte problema de otimização:

$$
\begin{aligned}
& \widetilde{\mathbf{P}}^{*, i}, \widetilde{\boldsymbol{\lambda}}^{*, i}=\arg \min _{\substack{\boldsymbol{v} \boldsymbol{v} \succeq 0 \\
\text { ¿ }}} \max _{\widetilde{\mathbf{P}}, \widetilde{\boldsymbol{\lambda}}} . \prod_{k=1}^{K}\left[\mathrm{w} \sum_{n=1}^{N} \widetilde{\lambda}_{k, n} \ell_{k, n} \log _{2}\left(1+\frac{\widetilde{p}_{k, n} \Gamma_{k, n} \ell_{k}}{\widetilde{\lambda}_{k, n}}\right)\right] \\
& -q^{i-1} \prod_{k=1}^{K}\left[\sum_{n=1}^{N} \varrho_{k} \widetilde{p}_{k, n}+p_{c, k}\right]+\sum_{k=1}^{K} \tau_{k}\left(p_{k}^{\max }-\sum_{n=1}^{N} \widetilde{p}_{k, n}\right)+\sum_{n=1}^{N} v_{n}\left(1-\sum_{k=1}^{K} \widetilde{\lambda}_{k, n}\right)
\end{aligned}
$$

Assim como no caso da função-utilidade por somatório de logaritmos, as restrições (5.9b) - (5.9d) serão garantidas diretamente nas equações de alocação de recursos.

Como não é possível calcular explicitamente os valores ótimos dos multiplicadores $\boldsymbol{\tau}$ e $\boldsymbol{v}$, utiliza-se uma abordagem iterativa de resolução, similar à descrita no Capítulo 4. Em uma primeira etapa, calcula-se a alocação ótima de potência e subportadoras na $i$-ésima iteração do DKB e j-ésima iteração do LDD, considerando que o valor dos multiplicadores é fixado e dado pelo valor obtido na $(j-1)$-ésima iteração do LDD, ou seja:

$$
\begin{aligned}
\widetilde{\mathbf{P}}^{*, i, j}, \widetilde{\boldsymbol{\lambda}}^{*, i, j}= & \underset{\widetilde{\mathbf{P}}, \widetilde{\boldsymbol{\lambda}}}{\arg \max } . \widetilde{R}_{\bar{k}}(\widetilde{\mathbf{P}}, \widetilde{\boldsymbol{\lambda}})\left(\mathrm{w} \sum_{n=1}^{N} \widetilde{\lambda}_{k, n} \ell_{k, n} \log _{2}\left(1+\frac{\widetilde{p}_{k, n} \Gamma_{k, n} \ell_{k}}{\widetilde{\lambda}_{k, n}}\right)\right) \\
& -q^{i-1} \widetilde{P}_{\bar{k}}(\widetilde{\mathbf{P}}, \widetilde{\boldsymbol{\lambda}})\left(\sum_{n=1}^{N} \varrho_{k} \widetilde{p}_{k, n}+p_{c, k}\right)+\sum_{k=1}^{K} \tau_{k}^{j-1}\left(p_{k}^{\max }-\sum_{n=1}^{N} \widetilde{p}_{k, n}\right) \\
& +\sum_{n=1}^{N} v_{n}^{j-1}\left(1-\sum_{k=1}^{K} \widetilde{\lambda}_{k, n}\right) \\
\equiv & \underset{\widetilde{\mathbf{P}}, \widetilde{\boldsymbol{\lambda}}}{\arg \max .} \widetilde{R}_{\bar{k}}(\widetilde{\mathbf{P}}, \widetilde{\boldsymbol{\lambda}})\left(\mathrm{w} \sum_{n=1}^{N} \widetilde{\lambda}_{k, n} \ell_{k, n} \log _{2}\left(1+\frac{\widetilde{p}_{k, n} \Gamma_{k, n} \iota_{k}}{\widetilde{\lambda}_{k, n}}\right)\right) \\
& -q^{i-1} \widetilde{P}_{\bar{k}}(\widetilde{\mathbf{P}}, \widetilde{\boldsymbol{\lambda}})\left(\sum_{n=1}^{N} \varrho_{k} \widetilde{p}_{k, n}+p_{c, k}\right)-\sum_{k=1}^{K} \sum_{n=1}^{N}\left(\tau_{k}^{j-1} \widetilde{p}_{k, n}+v_{n}^{j-1} \widetilde{\lambda}_{k, n}\right)
\end{aligned}
$$

em que

$$
\begin{aligned}
& \widetilde{R}_{\bar{k}}(\widetilde{\mathbf{P}}, \widetilde{\boldsymbol{\lambda}})=\prod_{k^{\prime}=1, k^{\prime} \neq k}^{K}\left[\mathrm{w} \sum_{n=1}^{N} \widetilde{\lambda}_{k^{\prime}, n} \ell_{k^{\prime}, n} \log _{2}\left(1+\frac{\widetilde{p}_{k^{\prime}, n} \Gamma_{k^{\prime}, n} l_{k^{\prime}}}{\widetilde{\lambda}_{k^{\prime}, n}}\right)\right] \\
& \widetilde{P}_{\bar{k}}(\widetilde{\mathbf{P}}, \widetilde{\boldsymbol{\lambda}})=\prod_{k^{\prime}=1, k^{\prime} \neq k}^{K}\left[\sum_{n=1}^{N} \varrho_{k^{\prime}} \widetilde{p}_{k^{\prime}, n}+p_{c, k^{\prime}}\right]
\end{aligned}
$$

A partir das alocações de potência e subportadoras obtidas nesse passo, resolve-se o problema de minimização, que opera sobre os multiplicadores, admitindo agora que a alocação de potência e subportadoras estão fixadas e definidas por $\widetilde{\mathbf{P}}^{*, i, j}$ e $\widetilde{\boldsymbol{\lambda}}^{*, i, j}$, respectivamente. Este problema de minimização é dado por:

$$
\begin{gathered}
\boldsymbol{\tau}^{j}, \boldsymbol{v}^{j}=\underset{\substack{\boldsymbol{\tau} \boldsymbol{v} \succeq 0 \\
\arg \min }}{\ln } \prod_{k=1}^{K}\left[\mathrm{w} \sum_{n=1}^{N} \widetilde{\lambda}_{k, n}^{*, i, j} \ell_{k, n} \log _{2}\left(1+\frac{\widetilde{p}_{k, n}^{*, i, j} \Gamma_{k, n} \iota_{k}}{\widetilde{\lambda}_{k, n}^{*, i, j}}\right)\right]-q^{i-1} \prod_{k=1}^{K}\left[\sum_{n=1}^{N} \varrho_{k} \widetilde{p}_{k, n}^{*, i, j}+p_{c, k}\right] \\
\quad+\sum_{k=1}^{K} \tau_{k}\left(p_{k}^{\max }-\sum_{n=1}^{N} \widetilde{p}_{k, n}^{*, i, j}\right)+\sum_{n=1}^{N} v_{n}\left(1-\sum_{k=1}^{K} \widetilde{\lambda}_{k, n}^{*, i, j}\right)
\end{gathered}
$$


Assim como no Capítulo 4, é possível utilizar as condições de KKT para se obter a alocação ótima de potência e subportadoras na $i$-ésima iteração do DKB e $j$-ésima iteração do LDD, para o problema de otimização na forma de produtórios. Tomando inicialmente a derivada da função-utilidade em (5.48) em relação a $\widetilde{p}_{k, n}$, tem-se que:

$$
\begin{aligned}
& \frac{\partial(5.48)}{\partial \widetilde{p}_{k, n}}=\frac{\partial\left\{\widetilde{R}_{\bar{k}}(\widetilde{\mathbf{P}}, \widetilde{\boldsymbol{\lambda}})\left(\mathrm{w} \sum_{n=1}^{N} \widetilde{\lambda}_{k, n} \ell_{k, n} \log _{2}\left(1+\frac{\widetilde{p}_{k, n} \Gamma_{k, n} \imath_{k}}{\widetilde{\lambda}_{k, n}}\right)\right)\right\}}{\partial \widetilde{p}_{k, n}} \\
& -\frac{\partial\left\{q^{i-1} \widetilde{P}_{\bar{k}}(\widetilde{\mathbf{P}}, \widetilde{\boldsymbol{\lambda}})\left(\sum_{n=1}^{N} \varrho_{k} \widetilde{p}_{k, n}+p_{c, k}\right)\right\}}{\partial \widetilde{p}_{k, n}}-\frac{\partial\left\{\sum_{k=1}^{K} \sum_{n=1}^{N}\left(\tau_{k}^{j-1} \widetilde{p}_{k, n}+v_{n}^{j-1} \widetilde{\lambda}_{k, n}\right)\right\}}{\partial \widetilde{p}_{k, n}} \\
& =\mathrm{w} \widetilde{R}_{\bar{k}}(\widetilde{\mathbf{P}}, \widetilde{\boldsymbol{\lambda}}) \frac{\partial\left(\sum_{n=1}^{N} \widetilde{\lambda}_{k, n} \ell_{k, n} \log _{2}\left(1+\frac{\widetilde{p}_{k, n} \Gamma_{k, n} \imath_{k}}{\widetilde{\lambda}_{k, n}}\right)\right)}{\partial \widetilde{p}_{k, n}} \\
& -q^{i-1} \widetilde{P}_{\bar{k}}(\widetilde{\mathbf{P}}, \widetilde{\boldsymbol{\lambda}}) \frac{\partial\left(\sum_{n=1}^{N} \varrho_{k} \widetilde{p}_{k, n}+p_{c, k}\right)}{\partial \widetilde{p}_{k, n}}-\frac{\partial \sum_{k=1}^{K} \sum_{n=1}^{N}\left(\tau_{k}^{j-1} \widetilde{p}_{k, n}+v_{n}^{j-1} \widetilde{\lambda}_{k, n}\right)}{\partial \widetilde{p}_{k, n}} \\
& =\mathrm{w} \widetilde{R}_{\bar{k}}(\widetilde{\mathbf{P}}, \widetilde{\boldsymbol{\lambda}}) \widetilde{\lambda}_{k, n} \ell_{k, n} \frac{\partial \log _{2}\left(1+\frac{\widetilde{p}_{k, n} \Gamma_{k, n} \iota_{k}}{\widetilde{\lambda}_{k, n}}\right)}{\partial \widetilde{p}_{k, n}}-q^{i-1} \widetilde{P}_{\bar{k}}(\widetilde{\mathbf{P}}, \widetilde{\boldsymbol{\lambda}}) \varrho_{k} \frac{\partial \widetilde{p}_{k, n}}{\partial \widetilde{p}_{k, n}}-\tau_{k}^{j-1} \frac{\partial \widetilde{p}_{k, n}}{\partial \widetilde{p}_{k, n}} \\
& =\frac{\mathrm{w} \widetilde{R}_{\bar{k}}(\widetilde{\mathbf{P}}, \widetilde{\boldsymbol{\lambda}}) \widetilde{\lambda}_{k, n} \ell_{k, n} \frac{\Gamma_{k, n} \imath_{k}}{\widetilde{\lambda}_{k, n}}}{\log (2)\left(1+\frac{\widetilde{p}_{k, n} \Gamma_{k, n} \imath_{k}}{\widetilde{\lambda}_{k, n}}\right)}-q^{i-1} \widetilde{P}_{\bar{k}}(\widetilde{\mathbf{P}}, \widetilde{\boldsymbol{\lambda}}) \varrho_{k}-\tau_{k}^{j-1} \\
& =\frac{\mathrm{w} \widetilde{R}_{\bar{k}}(\widetilde{\mathbf{P}}, \widetilde{\boldsymbol{\lambda}}) \ell_{k, n} \Gamma_{k, n} \imath_{k}}{\log (2)\left(1+p_{k, n} \Gamma_{k, n} \imath_{k}\right)}-q^{i-1} \widetilde{P}_{\bar{k}}(\widetilde{\mathbf{P}}, \widetilde{\boldsymbol{\lambda}}) \varrho_{k}-\tau_{k}^{j-1}
\end{aligned}
$$

Igualando a derivada parcial a zero, e isolando $p_{k, n}$ à esquerda da igualdade, tem-se que:

$$
\begin{aligned}
\frac{\mathrm{w} \widetilde{R}_{\bar{k}}(\widetilde{\mathbf{P}}, \widetilde{\boldsymbol{\lambda}}) \ell_{k, n} \Gamma_{k, n} \imath_{k}}{\log (2)\left(1+p_{k, n} \Gamma_{k, n} \imath_{k}\right)} & =q^{i-1} \widetilde{P}_{\bar{k}}(\widetilde{\mathbf{P}}, \widetilde{\boldsymbol{\lambda}}) \varrho_{k}+\tau_{k}^{j-1} \\
\log (2)\left(1+p_{k, n} \Gamma_{k, n} \imath_{k}\right) & =\frac{\mathrm{w} \widetilde{R}_{\bar{k}}(\widetilde{\mathbf{P}}, \widetilde{\boldsymbol{\lambda}}) \ell_{k, n} \Gamma_{k, n} \iota_{k}}{q^{i-1} \widetilde{P}_{\bar{k}}(\widetilde{\mathbf{P}}, \widetilde{\boldsymbol{\lambda}}) \varrho_{k}+\tau_{k}^{j-1}} \\
p_{k, n} \Gamma_{k, n} \imath_{k} & =\frac{\mathrm{w} \widetilde{R}_{\bar{k}}(\widetilde{\mathbf{P}}, \widetilde{\boldsymbol{\lambda}}) \ell_{k, n} \Gamma_{k, n} \iota_{k}}{\log (2)\left(q^{i-1} \widetilde{P}_{\bar{k}}(\widetilde{\mathbf{P}}, \widetilde{\boldsymbol{\lambda}}) \varrho_{k}+\tau_{k}^{j-1}\right)}-1 \\
p_{k, n} & =\frac{\mathrm{w} \widetilde{R}_{\bar{k}}(\widetilde{\mathbf{P}}, \widetilde{\boldsymbol{\lambda}}) \ell_{k, n}}{\log (2)\left(\tau_{k}^{j-1}+q^{i-1} \widetilde{P}_{\bar{k}}(\widetilde{\mathbf{P}}, \widetilde{\boldsymbol{\lambda}}) \varrho_{k}\right)}-\frac{1}{\Gamma_{k, n} \iota_{k}}
\end{aligned}
$$

Finalmente, aplicando a alocação de subportadoras obtida na $(j-1)$-ésima iteração do LDD aos termos $\widetilde{R}_{\bar{k}}$ e $\widetilde{P}_{\bar{k}}$, e adicionando a restrição de potência positiva, tem-se que:

$$
p_{k, n}^{*, i, j}=\left[\frac{\mathrm{w} \widetilde{R}_{\bar{k}}\left(\widetilde{\mathbf{P}}, \widetilde{\boldsymbol{\lambda}}^{*, i, j-1}\right) \ell_{k, n}}{\log (2)\left(\tau_{k}^{j-1}+q^{i-1} \widetilde{P}_{\bar{k}}\left(\widetilde{\mathbf{P}}, \widetilde{\boldsymbol{\lambda}}^{*, i, j-1}\right) \varrho_{k}\right)}-\frac{1}{\Gamma_{k, n} \iota_{k}}\right]^{+}
$$


Tomando agora a derivada parcial em relação a $\widetilde{\lambda}_{k, n}$ para computar a alocação de subportadoras, tem-se que:

$$
\begin{aligned}
& \frac{\partial(5.48)}{\partial \widetilde{\lambda}_{k, n}}=\frac{\partial\left\{\widetilde{R}_{\bar{k}}(\widetilde{\mathbf{P}}, \widetilde{\boldsymbol{\lambda}})\left(\mathrm{w} \sum_{n=1}^{N} \widetilde{\lambda}_{k, n} \ell_{k, n} \log _{2}\left(1+\frac{\widetilde{p}_{k, n} \Gamma_{k, n} \imath_{k}}{\widetilde{\lambda}_{k, n}}\right)\right)\right\}}{\partial \widetilde{\lambda}_{k, n}} \\
& -\frac{\partial\left\{q^{i-1} \widetilde{P}_{\bar{k}}(\widetilde{\mathbf{P}}, \widetilde{\boldsymbol{\lambda}})\left(\sum_{n=1}^{N} \varrho_{k} \widetilde{p}_{k, n}+p_{c, k}\right)\right\}}{\partial \widetilde{\lambda}_{k, n}}-\frac{\partial\left\{\sum_{k=1}^{K} \sum_{n=1}^{N}\left(\tau_{k}^{j-1} \widetilde{p}_{k, n}+v_{n}^{j-1} \widetilde{\lambda}_{k, n}\right)\right\}}{\partial \widetilde{\lambda}_{k, n}} \\
& =\mathrm{w} \widetilde{R}_{\bar{k}}(\widetilde{\mathbf{P}}, \widetilde{\boldsymbol{\lambda}}) \frac{\partial\left(\sum_{n=1}^{N} \widetilde{\lambda}_{k, n} \ell_{k, n} \log _{2}\left(1+\frac{\widetilde{p}_{k, n} \Gamma_{k, n} \imath_{k}}{\widetilde{\lambda}_{k, n}}\right)\right)}{\partial \widetilde{\lambda}_{k, n}} \\
& -q^{i-1} \widetilde{P}_{\bar{k}}(\widetilde{\mathbf{P}}, \widetilde{\boldsymbol{\lambda}}) \frac{\partial\left(\sum_{n=1}^{N} \varrho_{k} \widetilde{p}_{k, n}+p_{c, k}\right)}{\partial \widetilde{\lambda}_{k, n}}-\frac{\partial \sum_{k=1}^{K} \sum_{n=1}^{N}\left(\tau_{k}^{j-1} \widetilde{p}_{k, n}+v_{n}^{j-1} \widetilde{\lambda}_{k, n}\right)}{\partial \widetilde{\lambda}_{k, n}} \\
& =\mathrm{w} \widetilde{R}_{\bar{k}}(\widetilde{\mathbf{P}}, \widetilde{\boldsymbol{\lambda}}) \ell_{k, n} \frac{\partial \widetilde{\lambda}_{k, n} \log _{2}\left(1+\frac{\widetilde{p}_{k, n} \Gamma_{k, n} \imath_{k}}{\widetilde{\lambda}_{k, n}}\right)}{\partial \widetilde{\lambda}_{k, n}}-0-v_{n}^{j-1} \frac{\partial \widetilde{\lambda}_{k, n}}{\partial \widetilde{\lambda}_{k, n}} \\
& =\mathrm{w} \widetilde{R}_{\bar{k}}(\widetilde{\mathbf{P}}, \widetilde{\boldsymbol{\lambda}}) \ell_{k, n}\left[\log _{2}\left(1+\frac{\widetilde{p}_{k, n} \Gamma_{k, n} \imath_{k}}{\widetilde{\lambda}_{k, n}}\right)-\frac{\frac{\widetilde{p}_{k, n} \Gamma_{k, n} \imath_{k}}{\widetilde{\lambda}_{k, n}}}{\log (2)\left(1+\frac{\widetilde{p}_{k, n} \Gamma_{k, n} \imath_{k}}{\widetilde{\lambda}_{k, n}}\right)}\right]-v_{n}^{j-1} \\
& =\frac{\mathrm{w} \widetilde{R}_{\bar{k}}(\widetilde{\mathbf{P}}, \widetilde{\boldsymbol{\lambda}}) \ell_{k, n}}{\log (2)}\left(\log \left(1+p_{k, n} \Gamma_{k, n} \imath_{k}\right)-\frac{p_{k, n} \Gamma_{k, n} \imath_{k}}{\left(1+p_{k, n} \Gamma_{k, n} \imath_{k}\right)}\right)-v_{n}^{j-1}
\end{aligned}
$$

Definindo $s_{k, n}^{i, j}=\frac{\partial(5.48)}{\partial \widetilde{\lambda}_{k, n}}$, e aplicando a alocação de potência obtida com a equação (5.53), tem-se que:

$$
s_{k, n}^{i, j}=\frac{\widetilde{R}_{\bar{k}}\left(\widetilde{\mathbf{P}}^{*, i, j}, \widetilde{\boldsymbol{\lambda}}\right) \ell_{k, n}}{\log (2)}\left(\log \left(1+p_{k, n}^{*, i, j} \Gamma_{k, n} \iota_{k}\right)-\frac{p_{k, n}^{*, i, j} \Gamma_{k, n} \imath_{k}}{1+p_{k, n}^{*, i, j} \Gamma_{k, n} \iota_{k}}\right)-v_{n}^{j-1}
$$

O termo $\widetilde{R}_{\bar{k}}$ é o responsável por introduzir a noção de fairness na métrica de alocação $s_{k, n}$. Considere que a $k$-ésima MS possua uma reduzida taxa de dados, seja pela escassez de recursos espectrais, limitação de potência e/ou piores condições de propagação. Nesse cenário, a taxa de dados da $k$-ésima MS é reduzida (ou ao menos comprometida) em relação às demais MSs. Como $\widetilde{R}_{\bar{k}}$ é o produtório de taxa de todas as MSs, exceto a própria $k$-ésima MS, a taxa de dados mais baixa da $k$-ésima MS não compromete a sua própria métrica de alocação, porém compromete a métrica de alocação de todas as demais MSs, de modo que a métrica das demais MSs sofre uma penalização pela existência de uma MS com baixa taxa de dados. Por outro lado, considere agora que a $k$-ésima MS possui a taxa de dados mais elevada entre todas as MSs, por qualquer motivo que seja. Nesse caso, o seu produtório de taxa $\widetilde{R}_{\bar{k}}$ será o menor entre todas as $K$ MSs, de modo que se introduz uma punição na métrica de alocação, que pode ser interpretada como uma 
redução na utilidade de se alocar a $n$-ésima subportadora a essa $k$-ésima MS com alta taxa de dados. Tal punição não ocorre no caso de adoção de uma estratégia sem fairness, a qual observaria somente a utilidade de se alocar a $n$-ésima subportadora à $k$-ésima MS comparando apenas dados para aquela $n$-ésima subportadora, sem nenhum outro dado de sistema.

A alocação de subportadoras na $j$-ésima iteração do LDD e $i$-ésima iteração do DKB é feita de acordo com a equação (5.39), enquanto a atualização dos multiplicadores de Lagrange é feita de acordo com a equação (5.40), e os erros de convergência do LDD calculados de acordo com as equações (5.41a) e (5.41b). A convergência do algoritmo LDD é também verificada de maneira análoga ao definido para o somatório de logaritmos.

A partir da finalização do algoritmo LDD, e definindo $j$ como a última iteração executada, define-se $\widetilde{\mathbf{P}}^{*, i}=\widetilde{\mathbf{P}}^{*, i, j}$ e $\widetilde{\boldsymbol{\lambda}}^{*, i}=\widetilde{\boldsymbol{\lambda}}^{*, i, j}$, e então o parâmetro $q$ é atualizado como $q^{i}=q\left(\widetilde{\mathbf{P}}^{*, i}, \widetilde{\boldsymbol{\lambda}}^{*, i}\right)$. Define-se ainda a convergência do algoritmo DKB caso o erro da $i$ ésima iteração, dado por $\varepsilon_{\mathrm{dkb}}=\left|q^{i}-q^{i-1}\right|$, seja menor que o erro máximo de convergência tolerado, i.e., $\varepsilon_{\mathrm{dkb}} \leq \varepsilon_{\mathrm{dkb}}^{\max }$.

O pseudocódigo para a solução do problema de otimização por produtório das EEs individuais é apresentado no Algoritmo 5.2.

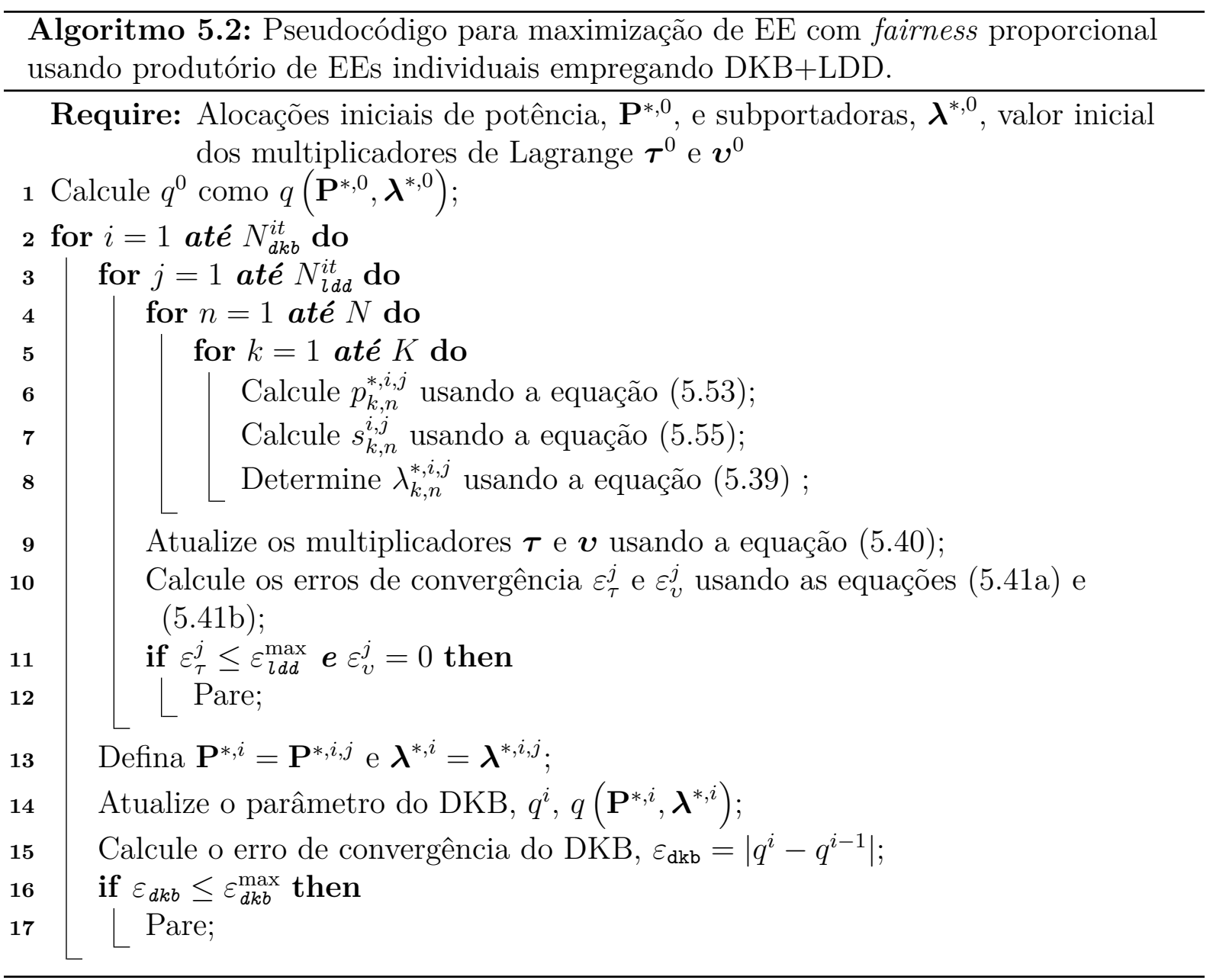





\section{ALOCAÇÃO DE RECURSOS COM FAIR- NESS E ESTAÇÕES RETRANSMISSO- RAS}

A adoção de fairness proporcional no Capítulo 5 atenua o problema de concentração de recursos espectrais em poucas MSs observado no Capítulo 4, porém possui a tendência de reduzir a EE do sistema como um todo. Ao alocar subportadoras para MSs distantes da BS ou severamente atenuados por desvanecimento, é necessário gastar mais potência para transmitir uma mesma quantidade de informação, o que impacta negativamente na EE global. Para que um sistema possa ser efetivamente mais justo sem prejudicar de maneira tão severa o desempenho global, é necessário também prover métodos para que as MSs mais afastadas da BS, em especial as MSs de borda, possuam canais de comunicação de melhor qualidade.

Para isso, esse capítulo tratará da inserção de estações retransmissoras (RSs) na macrocélula. Com a inserção das RSs, espera-se que as MSs que impactaram negativamente na EE do sistema possuam melhores condições de propagação, de modo que gastem menos potência na transmissão e/ou transmitam mais informação. Espera-se também que o ganho das MSs seja significativo o suficiente para compensar os gastos energéticos da operação das RSs, tanto em termos de potência de transmissão como o gasto energético fixo dessas estações.

Assim como para o caso não-cooperativo, serão discutidas as duas possibilidades de implementação da função-objetivo com fairness proporcional, i.e., somatório dos logaritmos das EEs individuais ou produtório das EEs individuais, como mostrado nas equações (6.1) e (6.2).

$$
\begin{aligned}
U_{\log }^{\varpi}(x) & =\sum_{k \in K} \log _{b}\left(U_{k}^{\varpi}(x)\right) \\
U_{\text {prod }}^{\varpi}(x) & =\prod_{k \in K} U_{k}^{\varpi}(x)
\end{aligned}
$$

onde o índice (.) ${ }^{\varpi}$ indica a utilização de um dos protocolos cooperativos, i.e., Amplifica e Transmite (AF) ou Decodifica e Transmite (DF).

A função de EE individual usada nesse capítulo é definida na Subseção 3.3.1, equação (3.35), sendo repetida aqui por conveniência na equação (6.3). Mantém-se a função individual sem especificar a equação de taxa de dados, dado que existem diferenças entre os protocolos de retransmissão. A EE da $k$-ésima MS, mensurada em bits por Joule, é dada 
por:

$$
\xi_{k}^{\varpi}=\frac{\psi_{k, 0} \sum_{n=1}^{N} \lambda_{k, n} \ell_{k, n} r_{k, n, 0}+\sum_{l=1}^{N_{\mathrm{RS}}} \psi_{k, l} \sum_{n=1}^{N} \lambda_{k, n} \ell_{k, n} r_{k, n, l}^{\varpi}}{\psi_{k, 0} \sum_{n=1}^{N} \lambda_{k, n} \varrho_{k} p_{k, n}+\sum_{l=1}^{N_{\mathrm{RS}}} \psi_{k, l}\left[\sum_{n=1}^{N} \frac{1}{2} \lambda_{k, n}\left(\varrho_{k} p_{k, n}+\varrho_{r_{l}} p_{r_{n, l}}\right)+\varsigma_{k, l} p_{c, r_{l}}^{\varpi}\right]+p_{c, k}},
$$

onde $\psi_{k, 0}$ indica se a $k$-ésima MS se comunica direto com a BS, i.e., sem o auxílio de uma RS; $\psi_{k, l}$ indica se o $k$-ésimo usuário se comunicará com a BS através da $l$-ésima RS; $r_{k, n, 0}$ é a taxa de dados em comunicação direta; $r_{k, n, l}^{\varpi}$ é a taxa de dados obtida utilizando a l-ésima RS com protocolo $\varpi ; \varrho_{r_{l}}$ é a eficiência do amplificador da l-ésima RS; $p_{r_{n, l}}$ corresponde à potência de transmissão da $l$-ésima RS na $n$-ésima subportadora; $p_{c, r_{l}}^{\varpi}$ é a potência de circuitaria da $l$-ésima RS com protocolo $\varpi$; e $\varsigma_{k, l}$ é um fator de proporcionalidade da potência de circuitaria da $l$-ésima RS para a $k$-ésima MS, indicando a possibilidade de que a $k$-ésima MS seja responsabilizada por parte do consumo de potência de circuitaria da RS a qual está alocado.

É necessário definir o fator de proporcionalidade $\varsigma_{k, l}$, ou ao menos algumas características mínimas. Deve definir-se, por exemplo, se esse fator de proporcionalidade será estático ou dinâmico ao longo do processo de alocação, se as MSs deverão assumir entre si a potência de circuitaria toda ou apenas parte dela, entre outros. Algumas possibilidades para a determinação de $\varsigma_{k, l}$ são apresentadas na Subseção 3.3.1, e cada uma delas pode afetar a resolução do problema de alocação de recursos, principalmente no que diz respeito à separabilidade da solução. Por exemplo, se for escolhido utilizar a definição de $\varsigma_{k, l}$ pelo número de portadoras alocadas pela $l$-ésima RS, cada MS vai depender da alocação de subportadoras dos demais MSs alocados à l-ésima RS, e o problema tenderá a ser significativamente mais complexo. Além disso, o custo da potência de circuitaria será alterado a cada iteração, a depender do número de subportadoras alocadas, e pode ser que a solução não convirja. A única definição assumida na construção do problema tratado neste capítulo é que $\varsigma_{k, l}$ é constante em relação às potências alocadas por MSs e RSs e ao número de subportadoras alocadas.

Partindo da definição de EE individual da equação (6.3), as funções-objetivo de EE com fairness em modo cooperativo para somatório de logaritmos e produtório são dadas, respectivamente, por

$$
\begin{aligned}
& \xi_{\log }^{\varpi}\left(\mathbf{P}, \mathbf{P}_{r}, \boldsymbol{\lambda}\right) \\
& =\sum_{k=1}^{K} \log _{b}\left(\frac{\psi_{k, 0} \sum_{n=1}^{N} \lambda_{k, n} \ell_{k, n} r_{k, n, 0}+\sum_{l=1}^{N_{\mathrm{RS}}} \psi_{k, l} \sum_{n=1}^{N} \lambda_{k, n} \ell_{k, n} r_{k, n, l}^{\varpi}}{\psi_{k, 0} \sum_{n=1}^{N} \lambda_{k, n} \varrho_{k} p_{k, n}+\sum_{j=1}^{N_{\mathrm{RS}}} \psi_{k, l}\left[\sum_{n=1}^{N} \frac{1}{2} \lambda_{k, n}\left(\varrho_{k} p_{k, n}+\varrho_{r_{l}} p_{r_{n, l}}\right)+\varsigma_{k, l} p_{c, r_{l}}^{\varpi}+p_{c, k}\right.}\right) \\
& =\sum_{k=1}^{K} \log _{b}\left(\psi_{k, 0} \sum_{n=1}^{N} \lambda_{k, n} \ell_{k, n} r_{k, n, 0}+\sum_{l=1}^{N_{\mathrm{RS}}} \psi_{k, l} \sum_{n=1}^{N} \lambda_{k, n} \ell_{k, n} r_{k, n, l}^{\varpi}\right) \\
& \quad-\sum_{k=1}^{K} \log _{b}\left(\psi_{k, 0} \sum_{n=1}^{N} \lambda_{k, n} \varrho_{k} p_{k, n}+\sum_{l=1}^{N_{\mathrm{RS}}} \psi_{k, l}\left[\sum_{n=1}^{N} \frac{1}{2} \lambda_{k, n}\left(\varrho_{k} p_{k, n}+\varrho_{r_{l}} p_{r_{n, l}}\right)+\varsigma_{k, l} p_{c, r_{l}}^{\varpi}\right]+p_{c, k}\right)
\end{aligned}
$$


e

$$
\begin{aligned}
& \xi_{\text {prod }}^{\varpi}\left(\mathbf{P}, \mathbf{P}_{r}, \boldsymbol{\lambda}\right) \\
& =\prod_{k=1}^{K}\left(\frac{\psi_{k, 0} \sum_{n=1}^{N} \lambda_{k, n} \ell_{k, n} r_{k, n, 0}+\sum_{l=1}^{N_{\mathrm{RS}}} \psi_{k, l} \sum_{n=1}^{N} \lambda_{k, n} \ell_{k, n} r_{k, n, l}^{\varpi}}{\psi_{k, 0} \sum_{n=1}^{N} \lambda_{k, n} \varrho_{k} p_{k, n}+\sum_{l=1}^{N_{\mathrm{RS}}} \psi_{k, l}\left[\sum_{n=1}^{N} \frac{1}{2} \lambda_{k, n}\left(\varrho_{k} p_{k, n}+\varrho_{r_{l}} p_{r_{n, l}}\right)+\varsigma_{k, l} p_{c, r_{l}}^{\varpi}\right]+p_{c, k}}\right) \\
& =\frac{\prod_{k=1}^{K}\left(\psi_{k, 0} \sum_{n=1}^{N} \lambda_{k, n} \ell_{k, n} r_{k, n, 0}+\sum_{l=1}^{N_{\mathrm{RS}}} \psi_{k, l} \sum_{n=1}^{N} \lambda_{k, n} \ell_{k, n} r_{k, n, l}^{\varpi}\right)}{\prod_{k=1}^{K}\left(\psi_{k, 0} \sum_{n=1}^{N} \lambda_{k, n} \varrho_{k} p_{k, n}+\sum_{l=1}^{N_{\mathrm{RS}}} \psi_{k, l}\left[\sum_{n=1}^{N} \frac{1}{2} \lambda_{k, n}\left(\varrho_{k} p_{k, n}+\varrho_{r_{l}} p_{r_{n, l}}\right)+\varsigma_{k, l} p_{c, r_{l}}^{\varpi}\right]+p_{c, k}\right)} \\
& =\frac{R_{\bar{k}}^{\varpi}\left(\mathbf{P}, \mathbf{P}_{r}, \boldsymbol{\lambda}\right)\left(\psi_{k, 0} \sum_{n=1}^{N} \lambda_{k, n} \ell_{k, n} r_{k, n, 0}+\sum_{l=1}^{N_{\mathrm{RS}}} \psi_{k, l} \sum_{n=1}^{N} \lambda_{k, n} \ell_{k, n} r_{k, n, l}^{\varpi}\right)}{P_{\bar{k}}^{\varpi}\left(\mathbf{P}, \mathbf{P}_{r}, \boldsymbol{\lambda}\right)\left(\psi_{k, 0} \sum_{n=1}^{N} \lambda_{k, n} \varrho_{k} p_{k, n}+\sum_{l=1}^{N_{\mathrm{RS}}} \psi_{k, l}\left[\sum_{n=1}^{N} \frac{1}{2} \lambda_{k, n}\left(\varrho_{k} p_{k, n}+\varrho_{r_{l}} p_{r_{n, l}}\right)+\varsigma_{k, l} p_{c, r_{l}}^{\varpi}\right]+p_{c, k}\right)},
\end{aligned}
$$

com

$$
R_{\bar{k}}^{\varpi}\left(\mathbf{P}, \mathbf{P}_{r}, \boldsymbol{\lambda}\right)=\prod_{\substack{k^{\prime}=1, k^{\prime} \neq k}}^{K}\left(\psi_{k^{\prime}, 0} \sum_{n=1}^{N} \lambda_{k^{\prime}, n} \ell_{k^{\prime}, n} r_{k^{\prime}, n, 0}+\sum_{l=1}^{N_{\mathrm{RS}}} \psi_{k^{\prime}, l} \sum_{n=1}^{N} \lambda_{k^{\prime}, n} \ell_{k^{\prime}, n} r_{k^{\prime}, n, l}^{\varpi}\right)
$$

$$
\begin{aligned}
& P_{\bar{k}}^{\varpi}\left(\mathbf{P}, \mathbf{P}_{r}, \boldsymbol{\lambda}\right)= \\
& \prod_{\substack{k^{\prime}=1, k^{\prime} \neq k}}^{K}\left(\psi_{k^{\prime}, 0} \sum_{n=1}^{N} \lambda_{k^{\prime}, n} \varrho_{k^{\prime}} p_{k^{\prime}, n}+\sum_{l=1}^{N_{\mathrm{RS}}} \psi_{k^{\prime}, l}\left[\frac{1}{2} \sum_{n=1}^{N} \lambda_{k^{\prime}, n}\left(\varrho_{k^{\prime}} p_{k^{\prime}, n}+\varrho_{r_{l}} p_{r_{n, l}}\right)+\varsigma_{k^{\prime}, l} p_{c, r_{l}}^{\varpi}\right]+p_{c, k^{\prime}}\right)
\end{aligned}
$$

\subsection{Expressões de Taxa de Dados e Considerações}

As expressões de taxa de dados para os casos direto, cooperativo com AF e cooperativo com DF, mensuradas em bits por segundo, descritas no Capítulo 3 e copiadas aqui por conveniência, são dadas por:

$$
\begin{gathered}
r_{k, n, 0}=r_{k, n}=\mathrm{w} \log _{2}\left(1+p_{k, n} \Gamma_{k, n, 0} \imath_{k}\right), \\
r_{k, n, l}^{\mathrm{AF}}=\frac{\mathrm{w}}{2} \log _{2}\left(1+\frac{\imath_{k}^{\mathrm{AF}} p_{r_{n, l}} p_{k, n} \Gamma_{k, n, l} \Gamma_{l, n, 0}}{p_{r_{n, l}} \Gamma_{l, n, 0}+p_{k, n} \Gamma_{k, n, l}+1}\right), \quad l \neq 0, \\
r_{k, n, l}^{\mathrm{DF}}=\frac{\mathrm{w}}{2} \min \left(\log _{2}\left(1+\imath_{k}^{\mathrm{DF}} p_{k, n} \Gamma_{k, n, l}\right), \log _{2}\left(1+\imath_{r_{l}}^{\mathrm{DF}} p_{r_{n, l}} \Gamma_{l, n, 0}\right)\right), \quad l \neq 0 .
\end{gathered}
$$

Prefere-se aqui a equação de taxa com função de mínimo apenas para relembrar que a taxa de dados depende das potências alocadas pela $k$-ésima MS e $l$-ésima RS. No decorrer da solução, será utilizada a versão descrita pela equação (3.32), em que se utiliza a potência total dos dois saltos. 
A taxa de dados do protocolo AF apresenta uma limitação em relação ao ferramental que pretende se utilizar para a solução numérica. Como citado em [34], a equação de taxa de dados do protocolo AF, como apresentada na equação (3.17), não é côncava em relação às variáveis de otimização $p_{k, n}$ e $p_{r_{n, l}}$. Como pretende-se manter os ferramentais de DCP+LDD e DKB+LDD, é necessário que se tenha funções côncavas para a manutenção das propriedades de convergência. Uma das maneiras mais utilizadas na literatura para se obter uma expressão côncava para a taxa de dados em protocolo AF é a adoção de uma aproximação do regime de alta SINR, no qual o termo 1 presente no denominador é removido, de modo que a taxa de dados da $k$-ésima MS na $n$-ésima subportadora usando a l-ésima RS com protocolo AF é dada por:

$$
r_{k, n, l}^{\mathrm{AF}}=\frac{\mathrm{w}}{2} \log _{2}\left(1+\frac{\imath_{k}^{\mathrm{AF}} p_{r_{n, l}} p_{k, n} \Gamma_{k, n, l} \Gamma_{j, n, 0}}{p_{r_{n, l}} \Gamma_{j, n, 0}+p_{k, n} \Gamma_{k, n, l}}\right), \quad j \neq 0 \quad\left[\frac{\mathrm{bits}}{\mathrm{s}}\right],
$$

Se diz que tal simplificação é para regime de alta SINR pois, nessa condição, $p_{r_{n, l}} \Gamma_{j, n, 0}+$ $p_{k, n} \Gamma_{k, n, l} \gg 1$.

\subsection{Restrições do Problema de Alocação}

As restrições do problema de otimização são basicamente as mesmas vistas nos Capítulos 4 e 5, com a adição das restrições de não-negatividade e limite individual de potência das RSs e alocação inteira e binária de nenhuma ou apenas uma única RS por MS. Com tais adições, tem-se o seguinte conjunto de restrições:

$$
\begin{aligned}
p_{k, n} \geq 0 & \forall k, n \\
p_{r_{n, l}} \geq 0 & \forall n, l=1, \cdots, N_{\mathrm{RS}} \\
p_{k}^{\max }-\sum_{n=1}^{N} \lambda_{k, n} p_{k, n} \geq 0 & \forall k \\
p_{r_{l}}^{\max }-\sum_{k=1}^{K} \sum_{n=1}^{N} \lambda_{k, n} \psi_{k, l} p_{r_{n, l}} \geq 0 & \forall l=1, \cdots, N_{\mathrm{RS}} \\
\sum_{l=0}^{N_{\mathrm{RS}}} \psi_{k, l}-1=0 & \forall k \\
\psi_{k, l} \in\{0,1\} & \forall n, l=0, \cdots, N_{\mathrm{RS}} \\
\sum_{k=1}^{K} \lambda_{k, n} \in\{0,1\} & \forall n \\
\lambda_{k, n} \in\{0,1\} & \forall k, n
\end{aligned}
$$

com:

- (6.9a) e (6.9b): Potências alocadas pelas MSs e RSs, respectivamente, devem ser positivas em todas as subportadoras; 
- (6.9c): Somatório de potência de transmissão das MSs não pode superar o limite individual;

- (6.9d): Somatório de potência de transmissão das RSs não pode superar o limite individual;

- (6.9e): Cada usuário é servido por uma única RS ou diretamente pela BS. Pode ocorrer cobertura múltipla, porém apenas um dispositivo receptor é efetivamente alocado à $k$-ésima MS;

- (6.9f): A alocação de uma RS é inteira e binária;

- (6.9g): Cada subportadora é alocada para, no máximo, um par fonte-destino, ou seja, não ocorre MAI em cada banda das subportadoras;

- (6.9h): A alocação de subportadoras é inteira e binária.

As restrições (6.9e) e (6.9f) serão garantidas antes do processo de alocação de recursos, de modo que não é necessário considerá-las no algoritmo de alocação de recursos. Assim, as restrições efetivamente adotadas são:

$$
\begin{array}{rlrl}
p_{k, n} & \geq 0 & \forall k, n \\
p_{r_{n, l}} \geq 0 & \forall n, l=1, \cdots, N_{\mathrm{RS}} \\
p_{k}^{\max }-\sum_{n=1}^{N} \lambda_{k, n} p_{k, n} \geq 0 & \forall k \\
p_{r_{l}}^{\max }-\sum_{k=1}^{K} \sum_{n=1}^{N} \lambda_{k, n} \psi_{k, l} p_{r_{n, l}} \geq 0 & \forall l=1, \cdots, N_{\mathrm{RS}} \\
\sum_{k=1}^{K} \lambda_{k, n} \in\{0,1\} & \forall n
\end{array}
$$

\subsection{Relaxação do Problema}

Assim como nas soluções adotadas nos Capítulos 4 e 5, a primeira etapa para obter uma solução numérica se dá pela relaxação da variável de alocação de subportadoras, $\lambda_{k, n}$, substituindo-a por $\widetilde{\lambda}_{k, n}$, com $0 \leq \widetilde{\lambda}_{k, n} \leq 1$. Considera-se também $\widetilde{p}_{k, n}=p_{k, n} \widetilde{\lambda}_{k, n} \mathrm{e}$ $\widetilde{p}_{r_{n, l}}=p_{r_{n, l}} \widetilde{\lambda}_{k, n}$. Reescrevendo as funções-objetivo (6.4) e (6.5), tem-se que:

$$
\begin{aligned}
\widetilde{\xi}_{\log }^{\varpi}\left(\widetilde{\mathbf{P}}, \widetilde{\mathbf{P}}_{r}, \widetilde{\boldsymbol{\lambda}}\right) & =\sum_{k=1}^{K} \log _{b}\left(\psi_{k, 0} \sum_{n=1}^{N} \widetilde{\lambda}_{k, n} \ell_{k, n} \widetilde{r}_{k, n, 0}+\sum_{l=1}^{N_{\mathrm{RS}}} \psi_{k, l} \sum_{n=1}^{N} \widetilde{\lambda}_{k, n} \ell_{k, n} \widetilde{r}_{k, n, l}^{\varpi}\right) \\
- & \sum_{k=1}^{K} \log _{b}\left(\psi_{k, 0} \sum_{n=1}^{N} \varrho_{k} \widetilde{p}_{k, n}+\sum_{l=1}^{N_{\mathrm{RS}}} \psi_{k, l}\left[\sum_{n=1}^{N} \frac{1}{2}\left(\varrho_{k} \widetilde{p}_{k, n}+\varrho_{r_{l}} \widetilde{p}_{r_{n, l}}\right)+\varsigma_{k, l} p_{c, r_{l}}^{\varpi}\right]+p_{c, k}\right)
\end{aligned}
$$


e

$$
\begin{aligned}
& \widetilde{\xi}_{\text {prod }}^{\varpi}\left(\widetilde{\mathbf{P}}, \widetilde{\mathbf{P}}_{r}, \widetilde{\boldsymbol{\lambda}}\right)= \\
& \frac{\widetilde{R}_{\bar{k}}^{\varpi}\left(\widetilde{\mathbf{P}}, \widetilde{\mathbf{P}}_{r}, \widetilde{\boldsymbol{\lambda}}\right)\left(\psi_{k, 0} \sum_{n=1}^{N} \widetilde{\lambda}_{k, n} \ell_{k, n} \widetilde{r}_{k, n, 0}+\sum_{l=1}^{N} \psi_{k, l} \sum_{n=1}^{N} \widetilde{\lambda}_{k, n} \ell_{k, n} \widetilde{r}_{k, n, l}^{\varpi}\right)}{\widetilde{P}_{\bar{k}}^{\varpi}\left(\widetilde{\mathbf{P}}, \widetilde{\mathbf{P}}_{r}, \widetilde{\boldsymbol{\lambda}}\right)\left(\psi_{k, 0} \sum_{n=1}^{N} \varrho_{k} \widetilde{p}_{k, n}+\sum_{l=1}^{N_{\mathrm{RS}}} \psi_{k, l}\left[\sum_{n=1}^{N} \frac{1}{2}\left(\varrho_{k} \widetilde{p}_{k, n}+\varrho_{r_{l}} \widetilde{p}_{r_{n, l}}\right)+\varsigma_{k, l} p_{c, r_{l}}^{\varpi}\right]+p_{c, k}\right)}
\end{aligned}
$$

com

$$
\widetilde{R}_{\bar{k}}^{\varpi}\left(\widetilde{\mathbf{P}}, \widetilde{\mathbf{P}}_{r}, \widetilde{\boldsymbol{\lambda}}\right)=\prod_{\substack{k^{\prime}=1, k^{\prime} \neq k}}^{K}\left(\psi_{k^{\prime}, 0} \sum_{n=1}^{N} \widetilde{\lambda}_{k^{\prime}, n} \ell_{k^{\prime}, n} \widetilde{r}_{k^{\prime}, n, 0}+\sum_{l=1}^{N_{\mathrm{RS}}} \psi_{k^{\prime}, l} \sum_{n=1}^{N} \widetilde{\lambda}_{k^{\prime}, n} \ell_{k^{\prime}, n} \widetilde{r}_{k^{\prime}, n, l}^{\varpi}\right)
$$

$\widetilde{P}_{\bar{k}}^{\varpi}\left(\widetilde{\mathbf{P}}, \widetilde{\mathbf{P}}_{r}, \widetilde{\boldsymbol{\lambda}}\right)=$

$$
\prod_{\substack{k^{\prime}=1, k^{\prime} \neq k}}^{K}\left(\psi_{k^{\prime}, 0} \sum_{n=1}^{N} \varrho_{k^{\prime}} \widetilde{p}_{k^{\prime}, n}+\sum_{l=1}^{N_{\mathrm{RS}}} \psi_{k^{\prime}, l}\left[\sum_{n=1}^{N} \frac{1}{2}\left(\varrho_{k^{\prime}} \widetilde{p}_{k^{\prime}, n}+\varrho_{r_{l}} \widetilde{p}_{r_{n, l}}\right)+\varsigma_{k^{\prime}, l} p_{c, r_{l}}^{\varpi}\right]+p_{c, k^{\prime}}\right)
$$

As restrições, então, são dadas por:

$$
\begin{array}{rlrl}
\widetilde{p}_{k, n} & \geq 0 & & \forall k, n \\
\widetilde{p}_{r_{n, l}} \geq 0 & & \forall n, l=1, \cdots, N_{\mathrm{RS}} \\
\widetilde{\lambda}_{k, n} \geq 0 & \forall k, n \\
1-\widetilde{\lambda}_{k, n} \geq 0 & \forall k, n \\
p_{k}^{\max }-\sum_{n=1}^{N} \widetilde{p}_{k, n} \geq 0 & \forall k & \\
p_{r_{l}}^{\max }-\sum_{k=1}^{K} \sum_{n=1}^{N} \psi_{k, l} \widetilde{p}_{r_{n, l}} \geq 0 & \forall l=1, \cdots, N_{\mathrm{RS}} \\
1-\sum_{k=1}^{K} \widetilde{\lambda}_{k, n} \geq 0 & \forall n
\end{array}
$$

As expressões de taxa de dados, mensuradas em bits por segundo, são dadas por:

$$
\begin{gathered}
\widetilde{r}_{k, n, 0}=\mathrm{w} \log _{2}\left(1+\frac{\Gamma_{k, n, 0} \widetilde{p}_{k, n}}{\widetilde{\lambda}_{k, n}}\right), \\
\widetilde{r}_{k, n, l}^{\mathrm{AF}}=\frac{\mathrm{w}}{2} \log _{2}\left(1+\frac{\imath_{k}^{\mathrm{AF}} \widetilde{p}_{r_{n, l}} \widetilde{p}_{k, n} \Gamma_{k, n, l} \Gamma_{l, n, 0}}{\widetilde{\lambda}_{k, n}\left(\widetilde{p}_{r_{n, l}} \Gamma_{l, n, 0}+\widetilde{p}_{k, n} \Gamma_{k, n, l}\right)}\right), \quad l \neq 0, \\
\widetilde{r}_{k, n, l}^{\mathrm{DF}}=\frac{\mathrm{w}}{2} \min \left(\log _{2}\left(1+\imath_{k}^{\mathrm{DF}} \frac{\widetilde{p}_{k, n} \Gamma_{k, n, l}}{\widetilde{\lambda}_{k, n}}\right), \log _{2}\left(1+\imath_{r_{l}}^{\mathrm{DF}} \frac{\widetilde{p}_{r_{n, l}} \Gamma_{l, n, 0}}{\widetilde{\lambda}_{k, n}}\right)\right), \quad l \neq 0 .
\end{gathered}
$$




\subsection{Solução via Somatório de Logaritmos}

Será utilizada a combinação de $\mathrm{DCP}+\mathrm{LDD}$ para a resolução do problema de alocação de recursos com função-objetivo de somatório de logaritmos. O primeiro passo para a obtenção da solução se dá pela aplicação do DCP, a partir da seguinte escolha das funções $f$ e $g$ :

$$
\begin{aligned}
& f\left(\widetilde{\mathbf{P}}, \widetilde{\mathbf{P}}_{r}, \widetilde{\boldsymbol{\lambda}}\right)=\sum_{k=1}^{K} \log _{b}\left(\psi_{k, 0} \sum_{n=1}^{N} \widetilde{\lambda}_{k, n} \ell_{k, n} \widetilde{r}_{k, n, 0}+\sum_{l=1}^{N_{\mathrm{RS}}} \psi_{k, l} \sum_{n=1}^{N} \widetilde{\lambda}_{k, n} \ell_{k, n} \widetilde{r}_{k, n, l}^{\varpi}\right) \\
& g\left(\widetilde{\mathbf{P}}, \widetilde{\mathbf{P}}_{r}, \widetilde{\boldsymbol{\lambda}}\right)= \\
& \sum_{k=1}^{K} \log _{b}\left(\psi_{k, 0} \sum_{n=1}^{N} \varrho_{k} \widetilde{p}_{k, n}+\sum_{l=1}^{N_{\mathrm{RS}}} \psi_{k, l}\left[\sum_{n=1}^{N} \frac{1}{2}\left(\varrho_{k} \widetilde{p}_{k, n}+\varrho_{r_{l}} \widetilde{p}_{r_{n, l}}\right)+\varsigma_{k, l} p_{c, r_{l}}^{\varpi}\right]+p_{c, k}\right)
\end{aligned}
$$

para se obter a seguinte solução iterativa:

$$
\mathbf{x}^{*, i}=\underset{\mathbf{x} \in \mathbb{R}^{n}}{\arg \max } f(\mathbf{x})-g\left(\mathbf{x}^{i-1}\right)-\left.\sum_{l=1}^{L}\left(x_{l}-x_{l}^{i-1}\right) \frac{\partial g(\mathbf{x})}{\partial x_{l}}\right|_{\mathbf{x}=\mathbf{x}^{i-1}}
$$

No contexto do problema de otimização apresentado nesta seção, a solução iterativa a ser obtida tem a seguinte forma:

$$
\begin{aligned}
& \widetilde{\mathbf{P}}^{*, i}, \widetilde{\mathbf{P}}_{r}^{*, i}, \widetilde{\boldsymbol{\lambda}}^{*, i}=\underset{\widetilde{\mathbf{P}}, \widetilde{\mathbf{P}}_{r}, \widetilde{\boldsymbol{\lambda}}}{\arg \max } f\left(\widetilde{\mathbf{P}}, \widetilde{\mathbf{P}}_{r}, \widetilde{\boldsymbol{\lambda}}\right)-g\left(\widetilde{\mathbf{P}}^{*, i-1}, \widetilde{\mathbf{P}}_{r}^{*, i-1}, \widetilde{\boldsymbol{\lambda}}^{*, i-1}\right) \\
& -\sum_{k=1}^{K} \sum_{n=1}^{N}\left[\left.\left(\widetilde{p}_{k, n}-\widetilde{p}_{k, n}^{*, i-1}\right) \frac{\partial g\left(\widetilde{\mathbf{P}}, \widetilde{\mathbf{P}}_{r}, \widetilde{\boldsymbol{\lambda}}\right)}{\partial \widetilde{p}_{k, n}}\right|_{\substack{\widetilde{\mathbf{P}}=\widetilde{\mathbf{P}}_{r, i-1} \\
\widetilde{\mathbf{P}}_{r}^{*, i-1} \\
\widetilde{\boldsymbol{\lambda}}=\widetilde{\boldsymbol{\lambda}}^{*, i-1}}}\right]
\end{aligned}
$$

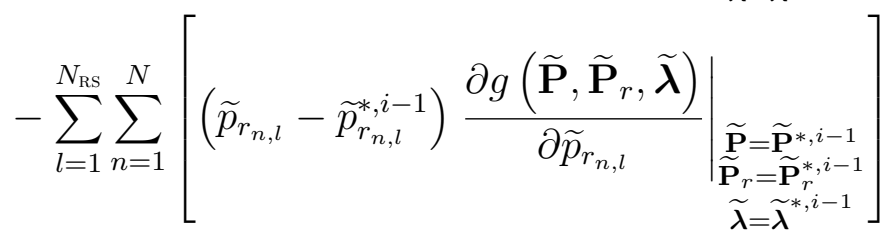

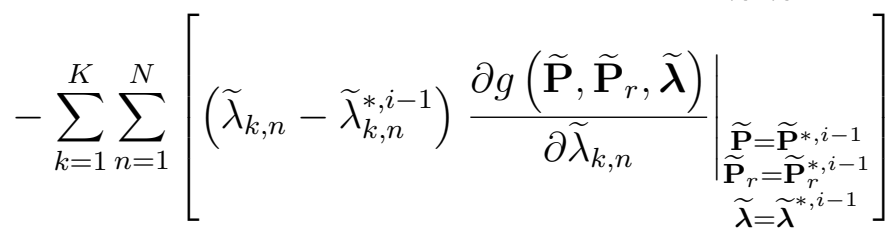

Para que o processo iterativo resultante do DCP possa ser empregado, deve-se garantir que as funções $f\left(\widetilde{\mathbf{P}}, \widetilde{\mathbf{P}}_{r}, \widetilde{\boldsymbol{\lambda}}\right)$ e $g\left(\widetilde{\mathbf{P}}, \widetilde{\mathbf{P}}_{r}, \widetilde{\boldsymbol{\lambda}}\right)$ sejam côncavas em relação às variáveis de otimização. Para tanto, define-se o seguinte teorema:

Teorema 6.1. As funções $f\left(\widetilde{\mathbf{P}}, \widetilde{\mathbf{P}}_{r}, \widetilde{\boldsymbol{\lambda}}\right)$ e $g\left(\widetilde{\mathbf{P}}, \widetilde{\mathbf{P}}_{r}, \widetilde{\boldsymbol{\lambda}}\right)$ são côncavas em relação às variáveis de otimização $\widetilde{p}_{k, n}, \widetilde{p}_{r_{n, l}}$ e $\widetilde{\lambda}_{k, n}$.

Demonstração. A prova é apresentada no Apêndice B.4. 
Com as funções $f\left(\widetilde{\mathbf{P}}, \widetilde{\mathbf{P}}_{r}, \widetilde{\boldsymbol{\lambda}}\right)$ e $g\left(\widetilde{\mathbf{P}}, \widetilde{\mathbf{P}}_{r}, \widetilde{\boldsymbol{\lambda}}\right)$ côncavas, tem-se que a formulação iterativa fornecida pelo DCP é também côncava [130]. É necessário agora calcular as derivadas parciais de $g\left(\widetilde{\mathbf{P}}, \widetilde{\mathbf{P}}_{r}, \widetilde{\boldsymbol{\lambda}}\right)$ em relação às variáveis de otimização, i.e, $\widetilde{p}_{k, n}, \widetilde{p}_{r_{n, l}}$ e $\widetilde{\lambda}_{k, n}$, necessárias à equação (6.18). Assim, tem-se que:

$$
\frac{\partial g\left(\widetilde{\mathbf{P}}, \widetilde{\mathbf{P}}_{r}, \tilde{\boldsymbol{\lambda}}\right)}{\partial \widetilde{p}_{k, n}}=
$$

$\frac{2 \psi_{k, 0} \varrho_{k}+\sum_{l=1}^{N_{\mathrm{RS}}} \psi_{k, l} \varrho_{k}}{2 \log (b)\left[\psi_{k, 0} \sum_{m=1}^{N} \varrho_{k} \widetilde{p}_{k, m}+\sum_{q=1}^{N_{\mathrm{RS}}} \psi_{k, q}\left[\sum_{m=1}^{N} \frac{\varrho_{k} \widetilde{p}_{k, m}+\varrho_{r_{q}} \widetilde{p}_{r_{m, q}}}{2}+\varsigma_{k, q} p_{c, r_{q}}^{\varpi}\right]+p_{c, k}\right]}$

$$
\begin{aligned}
& \frac{\partial g\left(\widetilde{\mathbf{P}}, \widetilde{\mathbf{P}}_{r}, \tilde{\boldsymbol{\lambda}}\right)}{\partial \widetilde{p}_{r_{n, l}}}= \\
& \sum_{k=1}^{K}\left[\frac{\psi_{k, l} \varrho_{r_{l}}}{\left.2 \log (b)\left[\psi_{k, 0} \sum_{m=1}^{N} \varrho_{k} \widetilde{p}_{k, m}+\sum_{q=1}^{N_{\mathrm{RS}}} \psi_{k, q}\left[\sum_{m=1}^{N} \frac{1}{2}\left(\varrho_{k} \widetilde{p}_{k, m}+\varrho_{r_{q}} \widetilde{p}_{r_{m, q}}\right)+\varsigma_{k, q} p_{c, r_{q}}^{\varpi}\right]+p_{c, k}\right]\right]}\right.
\end{aligned}
$$

$$
\frac{\partial g\left(\widetilde{\mathbf{P}}, \widetilde{\mathbf{P}}_{r}, \widetilde{\boldsymbol{\lambda}}\right)}{\partial \widetilde{\lambda}_{k, n}}=0
$$

Os índices dos somatórios nos denominadores das equações (6.19a) e (6.19b) foram alterados para evitar conflito de notação com os somatórios já existentes na equação (6.18). Nos denominadores dessas equações, adota-se o índice $m$ para subportadoras e $q$ para RSs.

Aplicando as definições e derivadas parciais à solução iterativa apresentada na equação (6.18), o problema de otimização a ser resolvido na $i$-ésima iteração do DCP é dado por:

$$
\begin{array}{r}
\widetilde{\mathbf{P}}^{*, i}, \widetilde{\mathbf{P}}_{r}^{*, i}, \widetilde{\boldsymbol{\lambda}}^{*, i}=\underset{\widetilde{\mathbf{P}}, \widetilde{\mathbf{P}}_{r}, \widetilde{\boldsymbol{\lambda}}}{\arg \max } U_{\log }^{\varpi, i}\left(\widetilde{\mathbf{P}}, \widetilde{\mathbf{P}}_{r}, \widetilde{\boldsymbol{\lambda}}\right) \\
\text { s. a: } \quad(6.14 \mathrm{a})-(6.14 \mathrm{~g})
\end{array}
$$


em que

$$
\begin{aligned}
& U_{\log }^{\varpi, i}\left(\widetilde{\mathbf{P}}, \widetilde{\mathbf{P}}_{r}, \tilde{\boldsymbol{\lambda}}\right)=\sum_{k=1}^{K} \log _{b}\left(\psi_{k, 0} \sum_{n=1}^{N} \tilde{\lambda}_{k, n} \ell_{k, n} \widetilde{r}_{k, n, 0}+\sum_{l=1}^{N_{\mathrm{RS}}} \psi_{k, l} \sum_{n=1}^{N} \tilde{\lambda}_{k, n} \ell_{k, n} \widetilde{r}_{k, n, l}^{\varpi}\right) \\
& -\sum_{k=1}^{K} \log _{b}\left(\psi_{k, 0} \sum_{n=1}^{N} \varrho_{k} \widetilde{p}_{k, n}^{*, i-1}+\sum_{l=1}^{N_{\mathrm{RS}}} \psi_{k, l}\left[\sum_{n=1}^{N} \frac{1}{2}\left(\varrho_{k} \widetilde{p}_{k, n}^{*, i-1}+\varrho_{r_{l}} \widetilde{p}_{r_{n, l}, i-1}^{*}\right)+\varsigma_{k, l} p_{c, r_{l}}^{\varpi}\right]+p_{c, k}\right) \\
& -\sum_{k=1}^{K} \sum_{n=1}^{N}\left[\frac{\left(\widetilde{p}_{k, n}-\widetilde{p}_{k, n}^{*, i-1}\right)\left(2 \psi_{k, 0} \varrho_{k}+\sum_{l=1}^{N_{\mathrm{RS}}} \psi_{k, l} \varrho_{k}\right)}{2 \log (b)\left[\psi_{k, 0} \sum_{m=1}^{N} \varrho_{k} \widetilde{p}_{k, m}^{*, i-1}+\sum_{q=1}^{N_{\mathrm{RS}}} \psi_{k, q}\left[\sum_{m=1}^{N} \frac{1}{2}\left(\varrho_{k} \widetilde{p}_{k, m}^{*, i-1}+\varrho_{r_{q}} \widetilde{p}_{r_{m, q}^{*}, i-1}\right)+\varsigma_{k, q} p_{c, r_{q}}^{\varpi}\right]+p_{c, k}\right]}\right] \\
& -\sum_{k=1}^{K} \sum_{n=1}^{N} \sum_{l=1}^{N_{\mathrm{RS}}}\left[\frac{\left(\widetilde{p}_{r_{n, l}}-\widetilde{p}_{r_{n, l}}^{*, i-1}\right) \psi_{k, l} \varrho_{r_{l}}}{2 \log (b)\left[\psi_{k, 0} \sum_{m=1}^{N} \varrho_{k} \widetilde{p}_{k, m}^{*, i-1}+\sum_{q=1}^{N_{\mathrm{RS}}} \psi_{k, q}\left[\sum_{m=1}^{N} \frac{1}{2}\left(\varrho_{k} \widetilde{p}_{k, m}^{*, i-1}+\varrho_{r_{q}} \widetilde{p}_{r_{m, q}^{*, i-1}}\right)+\varsigma_{k, q} p_{c, r_{q}}^{\varpi}\right]+p_{c, k}\right]}\right]
\end{aligned}
$$

Para incorporar as restrições ao problema de otimização (6.20), utiliza-se o ferramental de LDD. São utilizados os vetores de multiplicadores de Lagrange $\boldsymbol{\tau}_{[1 \times K]}$ e $\boldsymbol{v}_{[1 \times N]}$ para as restrições de potência das MSs, equação (6.14e), e alocação de subportadoras, equação $(6.14 \mathrm{~g})$, respectivamente. Considera-se ainda o vetor $\boldsymbol{\nu}_{\left[1 \times N_{\mathrm{RS}}\right]}$ de multiplicadores para a restrição de potência máxima das RSs, equação (6.14f). Assim, o problema de otimização é dado por:

$$
\begin{aligned}
& \widetilde{\mathbf{P}}^{*, i}, \widetilde{\mathbf{P}}_{r}^{*, i}, \widetilde{\boldsymbol{\lambda}}^{*, i}=\underset{\substack{\boldsymbol{c} \geq \mathbf{0} \\
\boldsymbol{\nu} \geq \mathbf{0}}}{\arg \min } \max _{\widetilde{\mathbf{P}}, \widetilde{\mathbf{P}}_{r}, \tilde{\widetilde{\boldsymbol{\lambda}}}_{k=1}} \sum_{k=1}^{K} \log _{b}\left(\psi_{k, 0} \sum_{n=1}^{N} \widetilde{\lambda}_{k, n} \ell_{k, n} \widetilde{r}_{k, n, 0}+\sum_{l=1}^{N_{\mathrm{RS}}} \psi_{k, l} \sum_{n=1}^{N} \widetilde{\lambda}_{k, n} \ell_{k, n} \widetilde{r}_{k, n, l}^{\varpi}\right) \\
& -\sum_{k=1}^{K} \log _{b}\left(\psi_{k, 0} \sum_{n=1}^{N} \varrho_{k} \widetilde{p}_{k, n}^{*, i-1}+\sum_{l=1}^{N_{\mathrm{RS}}} \psi_{k, l}\left[\sum_{n=1}^{N} \frac{1}{2}\left(\varrho_{k} \widetilde{p}_{k, n}^{*, i-1}+\varrho_{r_{l}} \widetilde{p}_{r_{n, l}, i-1}^{*}\right)+\varsigma_{k, l} p_{c, r_{l}}^{\varpi}\right]+p_{c, k}\right) \\
& -\sum_{k=1}^{K}\left[\frac{\sum_{n=1}^{N}\left(2 \psi_{k, 0} \varrho_{k}+\sum_{l=1}^{N_{\mathrm{RS}}} \psi_{k, l} \varrho_{k}\right)\left(\widetilde{p}_{k, n}-\widetilde{p}_{k, n}^{*, i-1}\right)+\sum_{n=1}^{N} \sum_{l=1}^{N_{\mathrm{RS}}}\left(\widetilde{p}_{r_{n, l}}-\widetilde{p}_{r_{n, l}}^{*, i-1}\right) \psi_{k, l} \varrho_{r_{l}}}{2 \log (b)\left[\psi_{k, 0} \sum_{m=1}^{N} \varrho_{k} \widetilde{p}_{k, m}^{*, i-1}+\sum_{q=1}^{N_{\mathrm{RS}}} \psi_{k, q}\left[\sum_{m=1}^{N} \frac{1}{2}\left(\varrho_{k} \widetilde{p}_{k, m}^{*, i-1}+\varrho_{r_{q}} \widetilde{p}_{r_{m, q}}^{*, i-1}\right)+\varsigma_{k, q} p_{c, r_{q}}^{\varpi}\right]+p_{c, k}\right]}\right] \\
& +\sum_{k=1}^{K} \tau_{k}\left(p_{k}^{\max }-\sum_{n=1}^{N} \tilde{p}_{k, n}\right)+\sum_{l=1}^{N_{\mathrm{RS}}} \nu_{l}\left(p_{r_{l}}^{\max }-\sum_{k=1}^{K} \sum_{n=1}^{N} \psi_{k, l} \widetilde{p}_{r_{n, l}}\right)+\sum_{n=1}^{N} v_{n}\left(1-\sum_{k=1}^{K} \tilde{\lambda}_{k, n}\right)
\end{aligned}
$$

Como não é possível determinar os valores ótimos dos multiplicadores de Lagrange, e nem as matrizes de alocação de potência e subportadoras, diretamente a partir da equação (6.22), utiliza-se o método iterativo para obtenção dos valores ótimos. Primeiramente é resolvido o problema de maximização, considerando os multiplicadores de Lagrange fixos, 
i.e.,

$$
\begin{aligned}
& \widetilde{\mathbf{P}}^{*, i, j}, \widetilde{\mathbf{P}}_{r}^{*, i, j}, \widetilde{\boldsymbol{\lambda}}^{*, i, j}=\underset{\widetilde{\mathbf{P}}, \widetilde{\mathbf{P}}_{r}, \widetilde{\boldsymbol{\lambda}}}{\arg \max } \sum_{k=1}^{K} \log _{b}\left(\psi_{k, 0} \sum_{n=1}^{N} \widetilde{\lambda}_{k, n} \ell_{k, n} \widetilde{r}_{k, n, 0}+\sum_{l=1}^{N_{\mathrm{RS}}} \psi_{k, l} \sum_{n=1}^{N} \widetilde{\lambda}_{k, n} \ell_{k, n} \widetilde{r}_{k, n, l}^{\varpi}\right) \\
& -\sum_{k=1}^{K}\left[\frac{\left(2 \psi_{k, 0} \varrho_{k}+\sum_{l=1}^{N_{\mathrm{RS}}} \psi_{k, l} \varrho_{k}\right) \sum_{n=1}^{N}\left(\widetilde{p}_{k, n}-\widetilde{p}_{k, n}^{*, i-1}\right)+\sum_{n=1}^{N} \sum_{l=1}^{N_{\mathrm{RS}}}\left(\widetilde{p}_{r_{n, l}}-\widetilde{p}_{r_{n, l}}^{*, i-1}\right) \psi_{k, l} \varrho_{r_{l}}}{\left.2 \log (b)\left[\psi_{k, 0} \sum_{m=1}^{N} \varrho_{k} \widetilde{p}_{k, m}^{*, i-1}+\sum_{q=1}^{N_{\mathrm{RS}}} \psi_{k, q}\left[\sum_{m=1}^{N} \frac{1}{2}\left(\varrho_{k} \widetilde{p}_{k, m}^{*, i-1}+\varrho_{r_{q}} \widetilde{p}_{r, m, q}^{*, i-1}\right)+\varsigma_{k, q} p_{c, r_{q}}^{\varpi}\right]+p_{c, k}\right]\right]}\right. \\
& -\sum_{k=1}^{K}\left[\sum_{n=1}^{N} \tau_{k}^{j-1} \widetilde{p}_{k, n}+\sum_{l=1}^{N_{\mathrm{RS}}} \sum_{n=1}^{N} \nu_{l}^{j-1} \psi_{k, l} \widetilde{p}_{r_{n, l}}+\sum_{n=1}^{N} v_{n}^{j-1} \widetilde{\lambda}_{k, n}\right] .
\end{aligned}
$$

Tendo resolvido o problema de maximização e obtido $\mathbf{P}^{*, j}, \mathbf{P}_{r}^{*, j}$ e $\boldsymbol{\lambda}^{*, j}$, resolve-se o problema de minimização, tomando as matrizes de alocação de recursos citadas anteriormente, i.e.,

$$
\begin{aligned}
& \boldsymbol{\tau}^{j}, \boldsymbol{v}^{j}, \boldsymbol{\nu}^{j}=\underset{\substack{\boldsymbol{\tau} \geq \mathbf{0} \\
\boldsymbol{\nu} \geq \mathbf{0}}}{\arg \min } \sum_{k=1}^{K} \tau_{k}\left(p_{k}^{\max }-\sum_{n=1}^{N} \widetilde{p}_{k, n}^{*, j}\right)+\sum_{l=1}^{N_{\mathrm{RS}}} \nu_{l}\left(p_{r_{l}}^{\max }-\sum_{k=1}^{K} \sum_{n=1}^{N} \psi_{k, l} \widetilde{p}_{r_{n, l}, j}\right) \\
& +\sum_{n=1}^{N} v_{n}\left(1-\sum_{k=1}^{K} \tilde{\lambda}_{k, n}^{*, j}\right)
\end{aligned}
$$

Percebe-se pela equação (6.23) que o problema de otimização na $j$-ésima iteração do LDD pode ser resolvido separadamente para cada uma das $K$ MSs. Por outro lado, uma solução distribuída nas $K$ MSs não necessariamente é viável, pois envolve a comunicação dos parâmetros $\boldsymbol{v}, \varsigma_{k, l}$ e $\nu_{l}$ da BS para a $k$-ésima MS (os dois últimos somente se a $l$-ésima RS auxilia a $k$-ésima MS no processo de transmissão), e posteriormente a $k$-ésima MS deve enviar os vetores de alocação de potência e subportadoras.

Considerando apenas a separação entre as $K$ MSs, a função-objetivo do problema de maximização a ser resolvido na $i$-ésima iteração do DCP e $j$-ésima iteração do LDD, para a $k$-ésima MS, é dada por:

$$
\begin{aligned}
& U_{k, \log }^{\varpi, i, j}=\log _{b}\left(\psi_{k, 0} \sum_{n=1}^{N} \widetilde{\lambda}_{k, n} \ell_{k, n} \widetilde{r}_{k, n, 0}+\sum_{l=1}^{N_{\mathrm{RS}}} \psi_{k, l} \sum_{n=1}^{N} \widetilde{\lambda}_{k, n} \ell_{k, n} \widetilde{r}_{k, n, l}^{\varpi}\right) \\
& -\frac{\left(2 \psi_{k, 0} \varrho_{k}+\sum_{l=1}^{N_{\mathrm{RS}}} \psi_{k, l} \varrho_{k}\right) \sum_{n=1}^{N}\left(\widetilde{p}_{k, n}-\widetilde{p}_{k, n}^{*, i-1}\right)+\sum_{n=1}^{N} \sum_{l=1}^{N_{\mathrm{RS}}} \psi_{k, l} \varrho_{r_{l}}\left(\widetilde{p}_{r_{n, l}}-\widetilde{p}_{r_{n, l}}^{*, i-1}\right)}{2 \log (b)\left[\psi_{k, 0} \sum_{m=1}^{N} \varrho_{k} \widetilde{p}_{k, m}^{*, i-1}+\sum_{q=1}^{N_{\mathrm{RS}}} \psi_{k, q}\left[\sum_{m=1}^{N} \frac{1}{2}\left(\varrho_{k} \widetilde{p}_{k, m}^{*, i-1}+\varrho_{r_{q}} \widetilde{p}_{r_{m, q}}^{*, i-1}\right)+\varsigma_{k, q} p_{c, r_{q}}^{\varpi}\right]+p_{c, k}\right]} \\
& -\sum_{n=1}^{N} \tau_{k}^{j-1} \widetilde{p}_{k, n}-\sum_{l=1}^{N_{\mathrm{RS}}} \sum_{n=1}^{N} \nu_{l}^{j-1} \psi_{k, l} \widetilde{p}_{r_{n, l}}-\sum_{n=1}^{N} v_{n}^{j-1} \widetilde{\lambda}_{k, n}
\end{aligned}
$$

Antes de continuar com o desenvolvimento da solução, o problema será separado em dois casos distintos: primeiramente, considera-se o caso em que as MSs se comunicam diretamente com a BS, i.e., para as quais $\psi_{k, 0}=1$, e posteriormente as MSs que utilizam alguma das $N_{\mathrm{RS}}$ RSs. 
Nos casos em que a $k$-ésima MS que se comunica diretamente com a BS, a funçãoobjetivo é dada por:

$$
\begin{aligned}
U_{k, l o g}^{\varpi, i, j}= & \log _{b}\left(\mathrm{w} \sum_{n=1}^{N} \widetilde{\lambda}_{k, n} \ell_{k, n} \log _{2}\left(1+\frac{\widetilde{p}_{k, n} \Gamma_{k, n, 0} \imath_{k}}{\widetilde{\lambda}_{k, n}}\right)\right)-\frac{\varrho_{k} \sum_{n=1}^{N}\left(\widetilde{p}_{k, n}-\widetilde{p}_{k, n}^{*, i-1}\right)}{\log (b)\left[\sum_{m=1}^{N} \varrho_{k} \widetilde{p}_{k, m}^{*, i-1}+p_{c, k}\right]} \\
& -\sum_{n=1}^{N} \tau_{k}^{j-1} \widetilde{p}_{k, n}-\sum_{n=1}^{N} v_{n}^{j-1} \widetilde{\lambda}_{k, n}
\end{aligned}
$$

Note que a função-objetivo $U_{k, \log }^{\varpi, i, j}$ é bastante semelhante à descrita na equação (5.21), pois para as MSs que se comunicam diretamente com a BS a única alteração é a notação do ganho de canal, que agora indica que se trata de comunicação direta. Assim, a alocação de potência e a métrica de alocação de subportadoras para a $k$-ésima MS na $n$-ésima subportadora em comunicação direta com a BS são dadas, respectivamente, por:

$$
p_{k, n}^{*, i, j}=\left[\chi_{k, n}-\frac{1}{\Gamma_{k, n, 0} \imath_{k}}\right]^{+},
$$

em que

$$
\chi_{k, n}=\frac{\exp \left(W\left(\frac{\left(\prod_{\substack{m=1 \\ m \neq n}}^{N}\left(1+p_{k, m} \Gamma_{k, m, 0} \imath_{k}\right)^{\frac{\tilde{\lambda}_{k, m}^{i, j-1} \ell_{k, m}}{\ell_{k, n}}}\right) \Gamma_{k, n, 0} \iota_{k}\left(\sum_{m=1}^{N} \varrho_{k} p_{k, m}^{*, i-1}+p_{c, k}\right)}{\tau_{k}^{j-1} \log (b)\left(\sum_{m=1}^{N} \varrho_{k} p_{k, m}^{*, i-1}+p_{c, k}\right)+\varrho_{k}}\right)\right)}{\left(\prod_{\substack{m=1 \\ m \neq n}}^{N}\left(1+p_{k, m} \Gamma_{k, m, 0} \imath_{k}\right)^{\frac{\tilde{\lambda}_{k, m}^{i, j-1} \ell_{k, m}}{\ell_{k, n}}}\right) \Gamma_{k, n, 0} \imath_{k}}
$$

e

$$
s_{k, n}^{i, j}=\frac{\ell_{k, n}\left(\log \left(1+p_{k, n}^{*, i, j} \Gamma_{k, n, 0} \imath_{k}\right)-\frac{p_{k, n}^{*, i, j} \Gamma_{k, n, 0} \imath_{k}}{\left(1+p_{k, n}^{*, i, j} \Gamma_{k, n, 0} \imath_{k}\right)}\right)}{\log (b) \sum_{m=1}^{N} \tilde{\lambda}_{k, m} \ell_{k, m} \log \left(1+p_{k, m}^{*, i, j} \Gamma_{k, m, 0} \imath_{k}\right)}-v_{n}^{j-1}
$$

O segundo problema considera as MSs que se utilizam da l-ésima RS na comunicação com a BS, i.e., para os quais $\psi_{k, l}=1, l>0$. Considerando o caso em que a $k$-ésima MS utiliza a $l$-ésima RS para se comunicar com a BS, tem-se que:

$$
\begin{aligned}
U_{k, \log }^{\varpi, i, j}= & \log _{b}\left(\sum_{n=1}^{N} \widetilde{\lambda}_{k, n} \ell_{k, n} \widetilde{r}_{k, n, l}^{\varpi}\right)-\sum_{n=1}^{N} \tau_{k}^{j-1} \widetilde{p}_{k, n}-\sum_{n=1}^{N} \nu_{l}^{j-1} \widetilde{p}_{r_{n, l}}-\sum_{n=1}^{N} v_{n}^{j-1} \widetilde{\lambda}_{k, n} \\
& -\frac{\varrho_{k} \sum_{n=1}^{N}\left(\widetilde{p}_{k, n}-\widetilde{p}_{k, n}^{*, i-1}\right)+\varrho_{r_{l}} \sum_{n=1}^{N}\left(\widetilde{p}_{r_{n, l}}-\widetilde{p}_{r_{n, l}}^{*, i-1}\right)}{2 \log (b)\left[\frac{1}{2} \sum_{m=1}^{N}\left(\varrho_{k} \widetilde{p}_{k, m}^{*, i-1}+\varrho_{r_{l}} \widetilde{p}_{r_{m, l}^{*}, i-1}^{* i-1}\right)+\varsigma_{k, l} p_{c, r_{l}}^{\varpi}+p_{c, k}\right]}
\end{aligned}
$$

Tendo definido o problema de otimização na $i$-ésima iteração do DCP e $j$-ésima iteração do LDD, basta tomar a primeira derivada de (6.30) em relação às variáveis de 
otimização para encontrar a solução ótima a cada iteração. Como os protocolos AF e DF possuem particularidades em relação às equações de taxa de dados, a solução será separada em duas subseções.

\subsubsection{AF}

Para o protocolo AF, não é possível determinar as potências ótimas $\widetilde{p}_{k}^{*, i, j}$ e $\widetilde{p}_{r_{n, l}}^{*, i, j}$ diretamente da função-objetivo (6.30), pois a equação de taxa de dados $\widetilde{r}_{k, n, l}^{\mathrm{AF}}$ faz com que os termos de potência das MSs dependam da alocação de potência das RSs, e vice-versa. Uma estratégia para se eliminar essa limitação é substituir as duas variáveis de potência pela potência total consumida nos dois saltos, denotada por $\widetilde{p}_{k, n, l}$, e definida como

$$
\widetilde{p}_{k, n, l}=\widetilde{p}_{k, n}+\widetilde{p}_{r_{n, l}}
$$

e então determinar a razão entre o consumo total de potência e o consumo em cada um dos saltos, de modo que seja possível otimizar a alocação de potência através de $\widetilde{p}_{k, n, l}$. Ou seja, busca-se um termo $\Omega_{k, n, l}^{\mathrm{AF}, i, j}$ de modo que

$$
\begin{aligned}
& \widetilde{p}_{k, n}^{i, j}=\Omega_{k, n, l}^{\mathrm{AF}, i, j} \widetilde{p}_{k, n, l}^{i, j} \\
& \widetilde{p}_{r_{n, l}}^{i, j}=\left(1-\Omega_{k, n, l}^{\mathrm{AF}, i, j}\right) \widetilde{p}_{k, n, l}^{i, j}
\end{aligned}
$$

Note que $\Omega_{k, n, l}^{\mathrm{AF}, i, j}$ indica quanto da potência total de transmissão do protocolo AF é utilizado no primeiro salto, i.e., na comunicação MS-RS, e é dado por:

$$
\begin{aligned}
\Omega_{k, n, l}^{\mathrm{AF}, i, j} & =\frac{\left(2 \nu_{j}^{j-1} \log (b) \mathrm{SP}_{k, l}^{\mathrm{AF}, i-1}+\varrho_{r_{l}}\right) \Gamma_{l, n, 0}}{\left(2 \nu_{l}^{j-1} \log (b) \mathrm{SP}_{k, l}^{\mathrm{AF}, i-1}+\varrho_{r_{l}}\right) \Gamma_{l, n, 0}-\left(2 \tau_{k}^{j-1} \log (b) \mathrm{SP}_{k, l}^{\mathrm{AF}, i-1}+\varrho_{k}\right) \Gamma_{k, n, l}} \\
& -\frac{\sqrt{\left(2 \tau_{k}^{j-1} \log (b) \mathrm{SP}_{k, l}^{\mathrm{AF}, i-1}+\varrho_{k}\right)\left(2 \nu_{j}^{j-1} \log (b) \mathrm{SP}_{k, l}^{\mathrm{AF}, i-1}+\varrho_{r_{l}}\right) \Gamma_{k, n, l} \Gamma_{l, n, 0}}}{\left(2 \nu_{l}^{j-1} \log (b) \mathrm{SP}_{k, l}^{\mathrm{AF}, i-1}+\varrho_{r_{l}}\right) \Gamma_{l, n, 0}-\left(2 \tau_{k}^{j-1} \log (b) \mathrm{SP}_{k, l}^{\mathrm{AF}, i-1}+\varrho_{k}\right) \Gamma_{k, n, l}}
\end{aligned}
$$

$\mathrm{com}$

$$
\mathrm{SP}_{k, l}^{\mathrm{AF}, i-1}=\sum_{m=1}^{N} \frac{1}{2}\left(\varrho_{k} \widetilde{p}_{k, m}^{*, i-1}+\varrho_{r_{l}} \widetilde{p}_{r_{m, l}}^{*, i-1}\right)+\varsigma_{k, l} p_{c, r_{l}}^{\varpi}+p_{c, k}
$$

Os passos intermediários estão descritos no Apêndice C.1.

Substituindo a equação (6.32) na equação (6.15b), a equação de taxa de dados na $j$-ésima iteração do LDD e $i$-ésima iteração do DCP é dada por:

$$
\begin{aligned}
\widetilde{r}_{k, n, l}^{\mathrm{AF}, i, j} & =\frac{\mathrm{W}}{2} \log _{2}\left(1+\frac{l_{k}^{\mathrm{AF}}\left(1-\Omega_{k, n, l}^{\mathrm{AF}, i, j}\right) \Omega_{k, n, l}^{\mathrm{AF}, i, j}\left(\widetilde{p}_{k, n, l}\right)^{2} \Gamma_{k, n, l} \Gamma_{l, n, 0}}{\widetilde{\lambda}_{k, n} \widetilde{p}_{k, n, l}\left(\left(1-\Omega_{k, n, l}^{\mathrm{AF}, i, j}\right) \Gamma_{l, n, 0}+\Omega_{k, n, l}^{\mathrm{AF}, i, j} \Gamma_{k, n, l}\right)}\right) \\
& =\frac{\mathrm{w}}{2} \log _{2}\left(1+\frac{\imath_{k}^{\mathrm{AF}} \Gamma_{k, n, l, 0}^{\mathrm{AF}, i, j} \widetilde{p}_{k, n, l}}{\widetilde{\lambda}_{k, n}}\right)
\end{aligned}
$$


com

$$
\Gamma_{k, n, l, 0}^{\mathrm{AF}, i, j}=\frac{\left(1-\Omega_{k, n, l}^{\mathrm{AF}, i, j}\right) \Omega_{k, n, l}^{\mathrm{AF}, i, j} \Gamma_{k, n, l} \Gamma_{l, n, 0}}{\left(\left(1-\Omega_{k, n, l}^{\mathrm{AF}, i, j}\right) \Gamma_{l, n, 0}+\Omega_{k, n, l}^{\mathrm{AF}, i, j} \Gamma_{k, n, l}\right)}
$$

sendo interpretado como o ganho de canal equivalente aos dois saltos na $i$-ésima iteração do DCP e j-ésima iteração do LDD. É interessante notar que, ao levar em conta a alocação de potência da iteração anterior do DCP e as variáveis duais da iteração anterior do LDD, o ganho de canal equivalente dos dois saltos a cada iteração é variável, sugerindo uma certa habilidade de adaptação do protocolo AF em relação à potência alocada em cada um dos saltos, por mais que essa adaptação seja limitada pela qualidade do salto inicial.

Com as proporções obtidas na equação (6.32) e a equação de taxa de dados apresentada em (6.35), reescreve-se a função-objetivo (6.30) em função da potência total de transmissão em cada subportadora, resultando em:

$$
\begin{aligned}
& U_{k, \log }^{\mathrm{AF}, i, j}=\underbrace{\log }_{\log _{b}\left(\sum_{n=1}^{N} \widetilde{\lambda}_{k, n} \ell_{k, n} \frac{\mathrm{w}}{2} \log _{2}\left(1+\frac{\imath_{k}^{\mathrm{AF}} \Gamma_{k, n, l, 0}^{\mathrm{AF}, i, j} \widetilde{p}_{k, n, l}}{\widetilde{\lambda}_{k, n}}\right)\right)} \\
& \text { (I) } \\
& -\underbrace{\left(\frac{\varrho_{k} \sum_{n=1}^{N}\left(\Omega_{k, n, l}^{\mathrm{AF}, i, j} \widetilde{p}_{k, n, l}-\widetilde{p}_{k, n}^{*, i-1}\right)+\varrho_{r_{l}} \sum_{n=1}^{N}\left(\left(1-\Omega_{k, n, l}^{\mathrm{AF}, i, j}\right) \widetilde{p}_{k, n, l}-\widetilde{p}_{r_{n, l}, i-1}^{*}\right)}{2 \log (b) \mathrm{SP}_{k, l}^{\mathrm{AF}, i-1}}\right)} \\
& \text { (II) } \\
& -\underbrace{\left(\sum_{n=1}^{N} v_{n}^{j-1} \widetilde{\lambda}_{k, n}+\sum_{n=1}^{N} \tau_{k}^{j-1} \Omega_{k, n, l}^{\mathrm{AF}, i, j} \widetilde{p}_{k, n, l}+\sum_{n=1}^{N} \nu_{l}^{j-1}\left(1-\Omega_{k, n, l}^{\mathrm{AF}, i, j}\right) \widetilde{p}_{k, n, l}\right)}_{(\mathrm{III})}
\end{aligned}
$$

Finalizada a definição da função-utilidade $U_{k, \log }^{\mathrm{AF}, i, j}$, basta utilizar as condições de primeira ordem para determinar as alocações ótimas de potência e subportadoras. Derivando então os três termos de $(6.37)$ em relação a $\widetilde{p}_{k, n, l}$, tem-se que:

$$
\begin{aligned}
& \frac{\partial(\mathrm{I})}{\partial \widetilde{p}_{k, n, l}}=\frac{\frac{\mathrm{w}}{2} \widetilde{\lambda}_{k, n} \ell_{k, n} l_{k}^{\mathrm{AF}} \Gamma_{k, n, l, 0}^{\mathrm{AF}, i, j}}{\log (b) \log (2) \widetilde{\lambda}_{k, n}\left(\sum_{m=1}^{N} \widetilde{\lambda}_{k, m} \ell_{k, m} \frac{\mathrm{W}}{2} \log _{2}\left(1+\frac{i_{k}^{\mathrm{AF}} \Gamma_{k, m}^{\mathrm{AF}, i, l, 0}, \widetilde{p}_{k, m, l}}{\widetilde{\lambda}_{k, m}}\right)\right)\left(1+\frac{{ }_{k}^{\mathrm{AF}} \Gamma_{k, n, l, 0}^{\mathrm{AF}, i, 0} \widetilde{p}_{k, n, l}}{\widetilde{\lambda}_{k, n}}\right)} \\
& =\frac{\ell_{k, n} \imath_{k}^{\mathrm{AF}} \Gamma_{k, n, l, 0}^{\mathrm{AF}, i, j}}{\log (b)\left(\sum_{m=1}^{N} \widetilde{\lambda}_{k, m} \ell_{k, m} \log \left(1+\frac{\imath_{k}^{\Lambda \mathrm{F}} \Gamma_{k, m}^{\mathrm{AF}, i, l, 0}, \widetilde{p}_{k, m, l}}{\widetilde{\lambda}_{k, m}}\right)\right)\left(1+\frac{\imath_{k}^{\mathrm{AF}} \Gamma_{k, n, l, 0}^{\mathrm{AF}, i, 0} \widetilde{p}_{k, n, l}}{\widetilde{\lambda}_{k, n}}\right)} \\
& \frac{\partial(\mathrm{II})}{\partial \widetilde{p}_{k, n, l}}=\frac{\varrho_{k} \Omega_{k, n, l}^{\mathrm{AF}, i, j}+\varrho_{r_{l}}\left(1-\Omega_{k, n, l}^{\mathrm{AF}, i, j}\right)}{2 \log (b) \mathrm{SP}_{k, l}^{\mathrm{AF}, i-1}} \\
& \frac{\partial(\mathrm{III})}{\partial \widetilde{p}_{k, n, l}}=\tau_{k}^{j-1} \Omega_{k, n, l}^{\mathrm{AF}, i, j}+\nu_{l}^{j-1}\left(1-\Omega_{k, n, l}^{\mathrm{AF}, i, j}\right)
\end{aligned}
$$


Somando todas as derivadas parciais e igualando a soma a zero, tem-se que:

$$
\begin{aligned}
\left(1+\imath_{k}^{\mathrm{AF}} \Gamma_{k, n, l, 0}^{\mathrm{AF}, i, j} p_{k, n, l}\right) \sum_{m=1}^{N} \frac{\widetilde{\lambda}_{k, m} \ell_{k, m}}{\ell_{k, n}} \log \left(1+\imath_{k}^{\mathrm{AF}} \Gamma_{k, m, l, 0}^{\mathrm{AF}, i, j} p_{k, m, l}\right) & =D_{1}^{\mathrm{AF}} \\
\left(1+\imath_{k}^{\mathrm{AF}} \Gamma_{k, n, l, 0}^{\mathrm{AF}, i, j} p_{k, n, l}\right) \sum_{m=1}^{N} \log \left(\left(1+\imath_{k}^{\mathrm{AF}} \Gamma_{k, m, l, 0}^{\mathrm{AF}, i, j} p_{k, m, l}\right)^{\frac{\widetilde{\lambda}_{k, m} \ell_{k, m}}{\ell_{k, n}}}\right) & =D_{1}^{\mathrm{AF}} \\
\left(1+\imath_{k}^{\mathrm{AF}} \Gamma_{k, n, l, 0}^{\mathrm{AF}, i, j} p_{k, n, l}\right) \log \left(\prod_{m=1}^{N}\left(1+\imath_{k}^{\mathrm{AF}} \Gamma_{k, m, l, 0}^{\mathrm{AF}, i, j} p_{k, m, l}\right)^{\frac{\widetilde{\lambda}_{k, m} \ell_{k, m}}{\ell_{k, n}}}\right) & =D_{1}^{\mathrm{AF}}
\end{aligned}
$$

$\mathrm{com}$

$$
\begin{aligned}
& D_{1}^{\mathrm{AF}}= \\
& \frac{2 l_{k}^{\mathrm{AF}} \Gamma_{k, n, l, 0}^{\mathrm{AF}, i, j} \mathrm{SP}_{k, l}^{\mathrm{AF}, i-1}}{\left(\varrho_{k}+2 \log (b) \mathrm{SP}_{k, l}^{\mathrm{AF}, i-1} \tau_{k}^{j-1}\right) \Omega_{k, n, l}^{\mathrm{AF}, i, j}+\left(\varrho_{r_{l}}+2 \log (b) \mathrm{SP}_{k, l}^{\mathrm{AF}, i-1} \nu_{l}^{j-1}\right)\left(1-\Omega_{k, n, l}^{\mathrm{AF}, i, j}\right)}
\end{aligned}
$$

Reorganizando a equação (6.39), tem-se que

$$
\left(1+\imath_{k}^{\mathrm{AF}} \Gamma_{k, n, l, 0}^{\mathrm{AF}, i, j} p_{k, n, l}\right) \log \left(\left(1+\imath_{k}^{\mathrm{AF}} \Gamma_{k, n, l, 0}^{\mathrm{AF}, i, j} p_{k, n, l}\right)^{\widetilde{\lambda}_{k, n}} D_{2}^{\mathrm{AF}}\right)=D_{1}^{\mathrm{AF}}
$$

com

$$
D_{2}^{\mathrm{AF}}=\prod_{\substack{m=1 \\ m \neq n}}^{N}\left(1+\imath_{k}^{\mathrm{AF}} \Gamma_{k, m, l, 0}^{\mathrm{AF}, i, j} p_{k, m, l}\right)^{\frac{\widetilde{\lambda}_{k, m} \ell_{k, m}}{\ell_{k, n}}}
$$

Como se adota uma solução iterativa, define-se que a alocação de subportadoras na equação (6.41) é dada pela alocação obtida na $(j-1)$-ésima iteração do LDD, de modo que:

$$
\left(1+\imath_{k}^{\mathrm{AF}} \Gamma_{k, n, l, 0}^{\mathrm{AF}, i, j} p_{k, n, l}\right) \log \left(\left(1+\imath_{k}^{\mathrm{AF}} \Gamma_{k, n, l, 0}^{\mathrm{AF}, i, j} p_{k, n, l}\right)^{\widetilde{\lambda}_{k, n}^{i, j-1}} D_{2}^{\mathrm{AF}}\right)=D_{1}^{\mathrm{AF}}
$$

com

$$
D_{2}^{\mathrm{AF}}=\prod_{\substack{m=1 \\ m \neq n}}^{N}\left(1+\imath_{k}^{\mathrm{AF}} \Gamma_{k, m, l, 0}^{\mathrm{AF}, i, j} p_{k, m, l}\right)^{\frac{\widetilde{\lambda}_{k, m}^{i, j-1} \ell_{k, m}}{\ell_{k, n}}}
$$

Assim como descrito na Seção 5.3, considera-se que $\tilde{\lambda}_{k, n}^{i, j-1}=1$ para se calcular $p_{k, n, l}$. Desse modo, obtém-se:

$$
\left(1+\imath_{k}^{\mathrm{AF}} \Gamma_{k, n, l, 0}^{\mathrm{AF}, i, j} p_{k, n, l}\right) \log \left(\left(1+\imath_{k}^{\mathrm{AF}} \Gamma_{k, n, l, 0}^{\mathrm{AF}, i, j} p_{k, n, l}\right) D_{2}^{\mathrm{AF}}\right)=D_{1}^{\mathrm{AF}}
$$

Lembrando que equações do tipo $x \log (x A)=B$ tem como solução $x=\frac{\mathrm{e}^{W(A B)}}{A}$, e adotando

$$
\begin{aligned}
& x=\left(1+\imath_{k}^{\mathrm{AF}} \Gamma_{k, n, l, 0}^{\mathrm{AF}, i, j} p_{k, n, l}\right), \\
& A=D_{2}^{\mathrm{AF}} \\
& B=D_{1}^{\mathrm{AF}}
\end{aligned}
$$


a solução da equação (6.45) é dada por:

$$
p_{k, n, l}^{*, i, j}=\left[\frac{\mathrm{e}^{W\left(D_{2}^{\mathrm{AF}} D_{1}^{\mathrm{AF}}\right)}}{\imath_{k}^{\mathrm{AF}} \Gamma_{k, n, l, 0}^{\mathrm{AF}, i, j} D_{2}^{\mathrm{AF}}}-\frac{1}{\imath_{k}^{\mathrm{AF}} \Gamma_{k, n, l, 0}^{\mathrm{AF}, i, j}}\right]^{+}
$$

As potências em cada salto podem ser determinadas por

$$
\begin{aligned}
& p_{k, n}^{*, i, j}=\Omega_{k, n, l}^{\mathrm{AF}, i, j} p_{k, n, l}^{*, i, j} \\
& p_{r_{n, l}}^{*, i, j}=p_{k, n, l}^{*, i, j}-p_{k, n}^{*, i, j}
\end{aligned}
$$

Para a alocação de subportadoras, a derivada parcial $\frac{\partial U_{k, l_{o g}}^{\mathrm{AF}, i, j}}{\partial \widehat{\lambda}_{k, n}}$ será utilizada como métrica de alocação. Utilizando a mesma estrutura definida na equação (6.37), as derivadas parciais de cada item em relação a $\widetilde{\lambda}_{k, n}$ são dadas por:

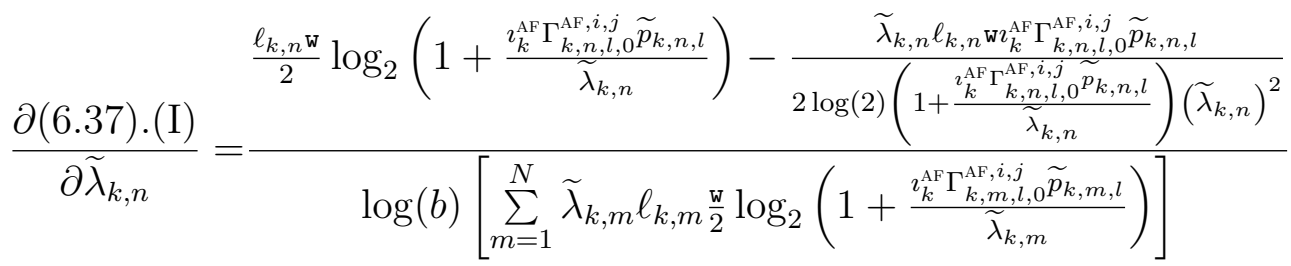

$$
\begin{aligned}
& =\frac{\ell_{k, n}\left[\log \left(1+\imath_{k}^{\mathrm{AF}} \Gamma_{k, n, l, 0}^{\mathrm{AF}, i, j} p_{k, n, l}\right)-\frac{\imath_{k}^{\mathrm{AF}} \Gamma_{k, n, l, 0}^{\mathrm{AF}, i, j} p_{k, n, l}}{\left(1+\imath_{k}^{\mathrm{AF}} \Gamma_{k, n, l, 0}^{\mathrm{AF}, i} p_{k, n, l}\right)}\right]}{\log (b)\left[\sum_{m=1}^{N} \widetilde{\lambda}_{k, m} \ell_{k, m} \log \left(1+\imath_{k}^{\mathrm{AF}} \Gamma_{k, m, l, 0}^{\mathrm{AF}, i, j} p_{k, m, l}\right)\right]} \\
& \frac{\partial(6.37) \cdot(\mathrm{II})}{\partial \widetilde{\lambda}_{k, n}}=0 \\
& \frac{\partial(6.37) \cdot(\mathrm{III})}{\partial \widetilde{\lambda}_{k, n}}=v_{n}^{j-1}
\end{aligned}
$$

Assim, a métrica de alocação da $n$-ésima subportadora à $k$-ésima MS, $s_{k, n}$, na $i$-ésima iteração do DCP e j-ésima iteração do LDD é dada por:

$$
s_{k, n}^{i, j}=\frac{\ell_{k, n}\left[\log \left(1+\imath_{k}^{\mathrm{AF}} \Gamma_{k, n, l, 0}^{\mathrm{AF}, i, j} p_{k, n, l}^{*, i, j}\right)-\frac{\imath_{k}^{\mathrm{AF}} \Gamma_{k, n, l, 0}^{\mathrm{AF}, i, j} p_{k, n, l}^{*, i, j}}{\left(1+l_{k}^{\mathrm{AF}} \Gamma_{k, n, l, 0}^{\mathrm{AF}} p_{k, n, l}^{*, j}\right)}\right]}{\log (b)\left[\sum_{m=1}^{N} \widetilde{\lambda}_{k, m} \ell_{k, m} \log \left(1+\imath_{k}^{\mathrm{AF}} \Gamma_{k, m, l, 0}^{\mathrm{AF}, i, j} p_{k, m, l}^{*, i, j}\right)\right]}-v_{n}^{j-1}
$$

Finalmente, a regra de decisão de alocação de subportadoras é dada por:

$$
\lambda_{k, n}^{*, i, j}= \begin{cases}1, & \text { se } s_{k, n}^{i, j}>0 \\ 0, & \text { caso contrário }\end{cases}
$$

\subsubsection{DF}

O principal problema para a alocação de recursos em protocolo DF é a função de mínimo presente na equação de taxa de dados, equação (6.15c). Na Subseção 3.2.2, que apresenta 
o equacionamento do protocolo DF, se discute essa limitação, apresentando na equação (3.28) a proporção entre as potências no primeiro e segundo saltos. Para se manter unidade de notação com as definições do protocolo AF, também se resolverá o problema de otimização a partir da potência consumida nos dois saltos, definindo um parâmetro de proporção $\Omega_{k, n, l}^{\mathrm{DF}}$. Utilizando os resultados da equação (3.28), e definindo $\widetilde{p}_{k, n, l}$ como a potência total consumida nos dois saltos, tem-se que:

$$
\begin{aligned}
& \widetilde{p}_{k, n, l}=\widetilde{p}_{k, n}+\widetilde{p}_{r_{l, n}} \\
& \widetilde{p}_{k, n, l}=\widetilde{p}_{k, n}+\frac{\widetilde{p}_{k, n} \imath_{k}^{\mathrm{DF}} \Gamma_{k, n, l}}{\imath_{r_{l}}^{\mathrm{DF}} \Gamma_{l, n, 0}} \\
& \widetilde{p}_{k, n, l}=\widetilde{p}_{k, n} \frac{\imath_{r_{l}}^{\mathrm{DF}} \Gamma_{l, n, 0}+\imath_{k}^{\mathrm{DF}} \Gamma_{k, n, l}}{\imath_{r_{l}}^{\mathrm{DF}} \Gamma_{l, n, 0}} \\
& \widetilde{p}_{k, n, l}=\widetilde{p}_{k, n} \Omega_{k, n, l}^{\mathrm{DF}}
\end{aligned}
$$

resultando que

$$
\begin{aligned}
& \widetilde{p}_{k, n}=\Omega_{k, n, l}^{\mathrm{DF}} \widetilde{p}_{k, n, l} \\
& \widetilde{p}_{r_{l, n}}=\left(1-\Omega_{k, n, l}^{\mathrm{DF}}\right) \widetilde{p}_{k, n, l}
\end{aligned}
$$

Percebe-se que, no caso do protocolo DF, a proporção da potência total de transmissão alocada em cada salto em relação ao primeiro salto é fixa durante todo o procedimento de otimização, de modo que os índices de iteração $i$, do DCP, e $j$, do LDD, podem ser omitidos. Um dos resultados de tal fato é que não existe a flexibilidade percebida no protocolo AF, no qual uma eventual limitação de potência na RS pode ser atenuada com a MS utilizando mais potência.

Reescrevendo o problema de alocação de potência para DF, a partir do problema (6.30), com as definições de taxa para DF da equação (6.15c) e as proporções de potência definidas na equação (6.52), tem-se que:

$$
\begin{aligned}
U_{k, \log }^{\mathrm{DF}, i, j}= & \underbrace{\log _{b}\left(\sum_{n=1}^{N} \tilde{\lambda}_{k, n} \ell_{k, n} \frac{\mathrm{W}}{2} \log _{2}\left(1+\frac{l_{k}^{\mathrm{DF}} \Omega_{k, n, l}^{\mathrm{DF}} \widetilde{p}_{k, n, l} \Gamma_{k, n, l}}{\widetilde{\lambda}_{k, n}}\right)\right)}_{(\mathrm{I})} \\
& -\underbrace{\frac{\sum_{n=1}^{N}\left(\varrho_{k} \Omega_{k, n, l}^{\mathrm{DF}}+\varrho_{r_{l}}\left(1-\Omega_{k, n, l}^{\mathrm{DF}}\right)\right)\left(\widetilde{p}_{k, n, l}-\widetilde{p}_{k, n, l}^{*, i-1}\right)}{2 \log (b)\left[\frac{1}{2} \sum_{m=1}^{N}\left(\varrho_{k} \Omega_{k, m, l}^{\mathrm{DF}}+\varrho_{r_{l}}\left(1-\Omega_{k, m, l}^{\mathrm{DF}}\right)\right) \tilde{p}_{k, m, l}^{*, i-1}+\varsigma_{k, l} p_{c, r_{l}}^{\mathrm{DF}}+p_{c, k}\right]}}_{(\mathrm{II})} \\
& -\underbrace{\left(\sum_{n=1}^{N} v_{n}^{j-1} \tilde{\lambda}_{k, n}+\sum_{n=1}^{N} \tau_{k}^{j-1} \Omega_{k, n, l}^{\mathrm{DF}} \widetilde{p}_{k, n, l}+\sum_{n=1}^{N} \nu_{l}^{j-1}\left(1-\Omega_{k, n, l}^{\mathrm{DF}}\right) \widetilde{p}_{k, n, l}\right)}_{(\mathrm{III})}
\end{aligned}
$$

Finalizada a definição de $U_{k, \text { log }}^{\mathrm{DF}, i, j}$, é suficiente utilizar as condições de primeira ordem para calcular as alocações de potência e subportadoras. Tomando inicialmente a derivada 
parcial de cada um dos componentes de $U_{k, \log }^{\mathrm{DF}, j, i}$ em relação à potência consumida nos dois saltos, $\widetilde{p}_{k, n, l}^{\mathrm{DF}}$, tem-se que:

$$
\begin{aligned}
& \frac{\partial(6.53) \cdot(\mathrm{I})}{\partial \widetilde{p}_{k, n, l}}= \\
& \frac{\mathrm{w}}{2} \widetilde{\lambda}_{k, n} \ell_{k, n} \imath_{k}^{\mathrm{DF}} \Omega_{k, n, l}^{\mathrm{DF}} \Gamma_{k, n, l} \\
& \log (b) \log (2) \tilde{\lambda}_{k, n}\left(\sum_{m=1}^{N} \tilde{\lambda}_{k, m} \ell_{k, m} \frac{\mathrm{W}}{2} \log _{2}\left(1+\frac{i_{k}^{\mathrm{DF}} \Omega_{k, m, l}^{\mathrm{DF}} \widetilde{p}_{k, m, l} \Gamma_{k, n, l}}{\widetilde{\lambda}_{k, n}}\right)\right)\left(1+\frac{i_{k}^{\mathrm{DF}} \Omega_{k, n, l}^{\mathrm{DF}} \tilde{p}_{k, n, l} \Gamma_{k, n, l}}{\widetilde{\lambda}_{k, n}}\right) \\
& =\frac{\ell_{k, n} \imath_{k}^{\mathrm{DF}} \Omega_{k, n, l}^{\mathrm{DF}} \Gamma_{k, n, l}}{\log (b)\left(\sum_{m=1}^{N} \widetilde{\lambda}_{k, m} \ell_{k, m} \log \left(1+\frac{\imath_{k}^{\mathrm{DF}} \Omega_{k, m, l}^{\mathrm{DF}} \widetilde{p}_{k, m} \Gamma_{k, m, l}}{\widetilde{\lambda}_{k, m}}\right)\right)\left(1+\frac{\imath_{k}^{\mathrm{DF}} \Omega_{k, n}^{\mathrm{DF}} \widetilde{p}_{k, n} \Gamma_{k, n, l}}{\widetilde{\lambda}_{k, n}}\right)} \\
& \frac{\partial(6.53) \cdot(\mathrm{II})}{\partial \widetilde{p}_{k, n, l}}=\frac{\varrho_{k} \Omega_{k, n, l}^{\mathrm{DF}}+\varrho_{r_{l}}\left(1-\Omega_{k, n, l}^{\mathrm{DF}}\right)}{2 \log (b) \mathrm{SP}_{k, l}^{\mathrm{DF}, i-1}} \\
& \frac{\partial(6.53) \cdot(\mathrm{III})}{\partial \widetilde{p}_{k, n, l}}=\tau_{k}^{j-1} \Omega_{k, n, l}^{\mathrm{DF}}+\nu_{l}^{j-1}\left(1-\Omega_{k, n, l}^{\mathrm{DF}}\right)
\end{aligned}
$$

com

$$
\mathrm{SP}_{k, l}^{\mathrm{DF}, i-1}=\frac{1}{2} \sum_{m=1}^{N}\left(\varrho_{k} \Omega_{k, m, l}^{\mathrm{DF}}+\varrho_{r_{l}}\left(1-\Omega_{k, m, l}^{\mathrm{DF}}\right)\right) \widetilde{p}_{k, m, l}^{*, i-1}+\varsigma_{k, l} p_{c, r_{l}}^{\mathrm{DF}}+p_{c, k}
$$

Somando as derivadas parciais, e lembrando que a derivada parcial de $U_{k, \log }^{\mathrm{DF}, i, j}$ em relação a $\widetilde{p}_{k, n, l}$ deve ser igualada a zero para se obter a potência ótima, tem-se que

$$
\begin{aligned}
\left(1+\frac{\imath_{k}^{\mathrm{DF}} \Omega_{k, n, l}^{\mathrm{DF}} \widetilde{p}_{k, n, l} \Gamma_{k, n, l}}{\widetilde{\lambda}_{k, n}}\right)\left[\sum_{m=1}^{N} \frac{\widetilde{\lambda}_{k, m} \ell_{k, m}}{\ell_{k, n}} \log \left(1+\frac{\imath_{k}^{\mathrm{DF}} \Omega_{k, m, l}^{\mathrm{DF}} \widetilde{p}_{k, m, l} \Gamma_{k, m, l}}{\widetilde{\lambda}_{k, m}}\right)\right] & =D_{1}^{\mathrm{DF}} \\
\left(1+\imath_{k}^{\mathrm{DF}} \Omega_{k, n, l}^{\mathrm{DF}} p_{k, n, l} \Gamma_{k, n, l}\right)\left[\sum_{m=1}^{N} \frac{\widetilde{\lambda}_{k, m} \ell_{k, m}}{\ell_{k, n}} \log \left(1+\imath_{k}^{\mathrm{DF}} \Omega_{k, m, l}^{\mathrm{DF}} p_{k, m, l} \Gamma_{k, m, l}\right)\right] & =D_{1}^{\mathrm{DF}} \\
\left(1+\imath_{k}^{\mathrm{DF}} \Omega_{k, n, l}^{\mathrm{DF}} p_{k, n, l} \Gamma_{k, n, l}\right)\left[\sum_{m=1}^{N} \log \left(\left(1+\imath_{k}^{\mathrm{DF}} \Omega_{k, m, l}^{\mathrm{DF}} p_{k, m, l} \Gamma_{k, m, l}\right)^{\frac{\widetilde{\lambda}_{k, m} \ell_{k, m}}{\ell_{k, n}}}\right)\right] & =D_{1}^{\mathrm{DF}} \\
\left(1+\imath_{k}^{\mathrm{DF}} \Omega_{k, n, l}^{\mathrm{DF}} p_{k, n, l} \Gamma_{k, n, l}\right) \log \left(\prod_{m=1}^{N}\left(1+\imath_{k}^{\mathrm{DF}} \Omega_{k, m, l}^{\mathrm{DF}} p_{k, m, l} \Gamma_{k, m, l}\right)^{\frac{\widetilde{\lambda}_{k, m} \ell_{k, m}}{\ell_{k, n}}}\right) & =D_{1}^{\mathrm{DF}}
\end{aligned}
$$

com

$D_{1}^{\mathrm{DF}}=$

$$
\frac{2 \imath_{k}^{\mathrm{DF}} \Omega_{k, n, l}^{\mathrm{DF}} \Gamma_{k, n, l} \log (b) \mathrm{SP}_{k, l}^{\mathrm{DF}, i-1}}{\left(\varrho_{k}+2 \log (b) \mathrm{SP}_{k, l}^{\mathrm{DF}, i-1} \tau_{k}^{j-1}\right) \Omega_{k, n, l}^{\mathrm{DF}}+\left(\varrho_{r_{l}}+2 \log (b) \mathrm{SP}_{k, l}^{\mathrm{DF}, i-1} \nu_{l}^{j-1}\right)\left(1-\Omega_{k, n, l}^{\mathrm{DF}}\right)}
$$

Isolando o caso em que $m=n$ no produtório, e definindo que a alocação de subportadoras é a obtida na $(j-1)$-ésima iteração do LDD, tem-se que:

$$
\left(1+\imath_{k}^{\mathrm{DF}} \Omega_{k, n, l}^{\mathrm{DF}} p_{k, n, l} \Gamma_{k, n, l}\right) \log \left(\left(1+\imath_{k}^{\mathrm{DF}} \Omega_{k, n, l}^{\mathrm{DF}} p_{k, n, l} \Gamma_{k, n, l}\right)^{\tilde{\lambda}_{k, n}^{i, j-1}} D_{2}^{\mathrm{DF}}\right)=D_{1}^{\mathrm{DF}}
$$


com

$$
D_{2}^{\mathrm{DF}}=\prod_{\substack{m=1 \\ m \neq n}}^{N}\left(1+\imath_{k}^{\mathrm{DF}} \Omega_{k, m, l}^{\mathrm{DF}} p_{k, m, l} \Gamma_{k, m, l}\right)^{\frac{\widetilde{\lambda}_{k, m}^{i, j-1} \ell_{k, m}}{\ell_{k, n}}}
$$

Admitindo que $\tilde{\lambda}_{k, n}^{i, j-1}=1$, aplica-se a solução via função $W$ de Lambert, resultando em:

$$
p_{k, n, l}^{*, i, j}=\left[\frac{\mathrm{e}^{W\left(D_{2}^{\mathrm{DF}} D_{1}^{\mathrm{DF}}\right)}}{D_{2}^{\mathrm{DF}} l_{k}^{\mathrm{DF}} \Omega_{k, n, l}^{\mathrm{DF}} \Gamma_{k, n, l}}-\frac{1}{l_{k}^{\mathrm{DF}} \Omega_{k, n, l}^{\mathrm{DF}} \Gamma_{k, n, l}}\right]^{+}
$$

As potências alocadas pela $k$-ésima MS e pela $l$-ésima $\mathrm{RS}$ na $n$-ésima subportadora podem ser obtidas por:

$$
\begin{aligned}
& p_{k, n}^{*, i, j}=\Omega_{k, n, l}^{\mathrm{DF}} p_{k, n, l}^{*, i, j} \\
& p_{r_{n, l}}^{*, i, j}=p_{k, n, l}^{*, i, j}-p_{k, n}^{*, i, j}
\end{aligned}
$$

Tomando agora a derivada parcial da função-utilidade, equação (6.53), em relação a $\tilde{\lambda}_{k, n}$, para cada um dos termos, tem-se que:

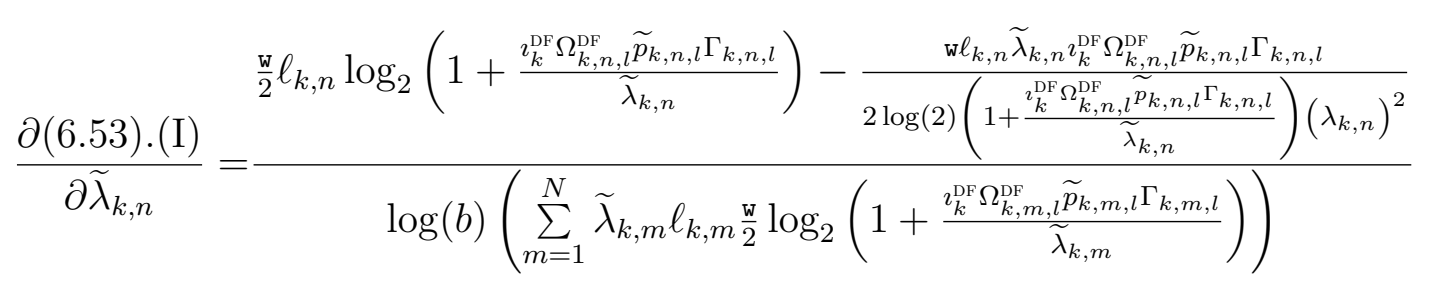

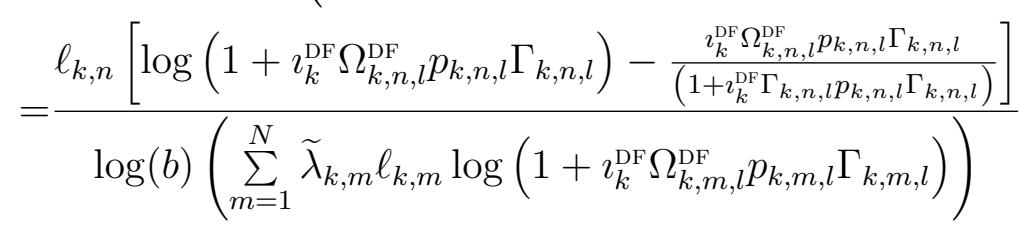

$$
\begin{aligned}
& \frac{\partial(6.53) \cdot(\mathrm{II})}{\partial \widetilde{\lambda}_{k, n}^{\mathrm{DF}}}=0 \\
& \frac{\partial(6.53) \cdot(\mathrm{III})}{\partial \widetilde{\lambda}_{k, n}^{\mathrm{DF}}}=v_{n}^{j-1}
\end{aligned}
$$

Somando os termos das derivadas parciais, e aplicando a alocação de potência obtida na $j$-ésima iteração do LDD, a métrica de alocação é dada por:

$$
s_{k, n}^{i, j}=\frac{\ell_{k, n}\left[\log \left(1+\imath_{k}^{\mathrm{DF}} \Omega_{k, n, l}^{\mathrm{DF}} p_{k, n, l}^{*, i, j} \Gamma_{k, n, l}\right)-\frac{l_{k}^{\mathrm{DF}} \Omega_{k, n, l}^{\mathrm{DF}} p_{k, n, l}^{*, i, j} \Gamma_{k, n, l}}{\left(1+l_{k}^{\mathrm{DF}} \Gamma_{k, n, l}^{*, i, j} l_{k, n}^{*, i} \Gamma_{k, n}\right)}\right]}{\log (b) \sum_{m=1}^{N} \lambda_{k, m} \ell_{k, m} \log \left(1+\imath_{k}^{\mathrm{DF}} \Omega_{k, m, l}^{\mathrm{DF}} p_{k, m, l}^{*, i, j} \Gamma_{k, m, l}\right)}-v_{n}^{j-1}
$$

A regra de definição da alocação de subportadoras é análoga à mostrada na equação (6.50).

Obtidas as alocações de potência e subportadoras tanto para AF quanto para DF, é necessário realizar a etapa de atualização dos multiplicadores de Lagrange. Utiliza-se 
um método de subgradiente para atualizar o valor dos multiplicadores, de acordo com as seguintes equações:

$$
\begin{gathered}
\tau_{k}^{j}=\left[\tau_{k}^{j-1}-\phi_{\tau}\left(p_{k}^{\max }-\sum_{n=1}^{N} \lambda_{k, n}^{*, i, j} p_{k, n}^{*, i, j}\right)\right]^{+} \\
\nu_{l}^{j}=\left[\nu_{l}^{j-1}-\phi_{\nu}\left(p_{r_{l}}^{\max }-\sum_{k=1}^{K} \sum_{n=1}^{N} \psi_{k, l} \lambda_{k, n}^{*, i, j} p_{r_{n, l}^{*, i, j}}^{*}\right)\right]^{+} \\
v_{n}^{j}=\left[v_{n}^{j-1}-\phi_{v}\left(1-\sum_{k=1}^{K} \lambda_{k, n}^{*, i, j}\right)\right]^{+}
\end{gathered}
$$

Sobre a convergência do algoritmo LDD, adota-se uma solução semelhante à discutida na Seção 5.3. Associam-se os erros máximos $\varepsilon_{\tau}^{\max }, \varepsilon_{\nu}^{\max }$ e $\varepsilon_{v}^{\max }$ para os vetores de multiplicadores $\boldsymbol{\tau}, \boldsymbol{\nu}$ e $\boldsymbol{v}$, respectivamente. O erro de convergência dos multiplicadores $\boldsymbol{\tau}, \boldsymbol{\nu}$ e $\boldsymbol{v}$ são dados, respectivamente, por

$$
\begin{aligned}
& \varepsilon_{\tau}^{j}=\max _{k}\left(\left|\tau_{k}^{j}-\tau_{k}^{j-1}\right|\right), \\
& \varepsilon_{\nu}^{j}=\max _{l}\left(\left|\nu_{l}^{j}-\nu_{l}^{j-1}\right|\right) .
\end{aligned}
$$

e

$$
\varepsilon_{v}^{j}=\max _{n}\left(\left|v_{n}^{j}-v_{n}^{j-1}\right|\right) .
$$

Caso as condições $\varepsilon_{\tau}^{j} \leq \varepsilon_{\tau}^{\max }, \varepsilon_{\nu}^{j} \leq \varepsilon_{\nu}^{\max }$ e $\varepsilon_{v}^{j} \leq \varepsilon_{v}^{\max }$ sejam atendidas ao mesmo tempo, na $j$-ésima iteração do LDD, é dito que o algoritmo LDD convergiu. Caso o número de iterações executadas ultrapasse o limite $N_{\text {ldd }}^{i t}$, a execução do algoritmo LDD é finalizada.

As variáveis obtidas na última iteração do LDD (por limite de iterações ou convergência) são definidas como as ótimas para a $i$-ésima iteração do DCP, sendo denotadas por $\lambda_{k, n}^{*, i}$ e $p_{k, n, l}^{*, i}$. Obtidas as matrizes ótimas na $i$-ésima iteração do DCP, verifica-se se o algoritmo convergiu, calculando o erro de convergência como

$$
\varepsilon_{\mathrm{dcp}}^{i}=\left|U_{\log }^{i}\left(\widetilde{\mathbf{P}}^{*, i}, \widetilde{\boldsymbol{\lambda}}^{*, i}\right)-U_{\log }^{i-1}\left(\widetilde{\mathbf{P}}^{*, i-1}, \widetilde{\boldsymbol{\lambda}}^{*, i-1}\right)\right|
$$

e comparando-o com um erro máximo pré-estabelecido, dado por $\varepsilon_{\mathrm{dcp}}^{\max }$. O algoritmo é encerrado se $\varepsilon_{\mathrm{dcp}}^{i} \leq \varepsilon_{\mathrm{dcp}}^{\max }$ ou o limite de iterações, dado por $N_{\mathrm{dcp}}^{i t}$, for atingido.

O algoritmo 6.1 sumariza a operação da solução proposta.

\subsection{Solução via Produtório}

O problema de otimização, em sua descrição inicial, é dado por:

$$
\begin{array}{r}
\widetilde{\mathbf{P}}^{*}, \widetilde{\mathbf{P}}_{r}^{*}, \widetilde{\boldsymbol{\lambda}}^{*}=\underset{\widetilde{\mathbf{P}}, \widetilde{\mathbf{P}}_{r}, \widetilde{\boldsymbol{\lambda}}}{\arg \max } \cdot \widetilde{\xi}_{\text {prod }}^{\varpi}\left(\widetilde{\mathbf{P}}, \widetilde{\mathbf{P}}_{r}, \widetilde{\boldsymbol{\lambda}}\right) \\
\text { s. a:(6.14a) }-(6.14 \mathrm{~g}) .
\end{array}
$$




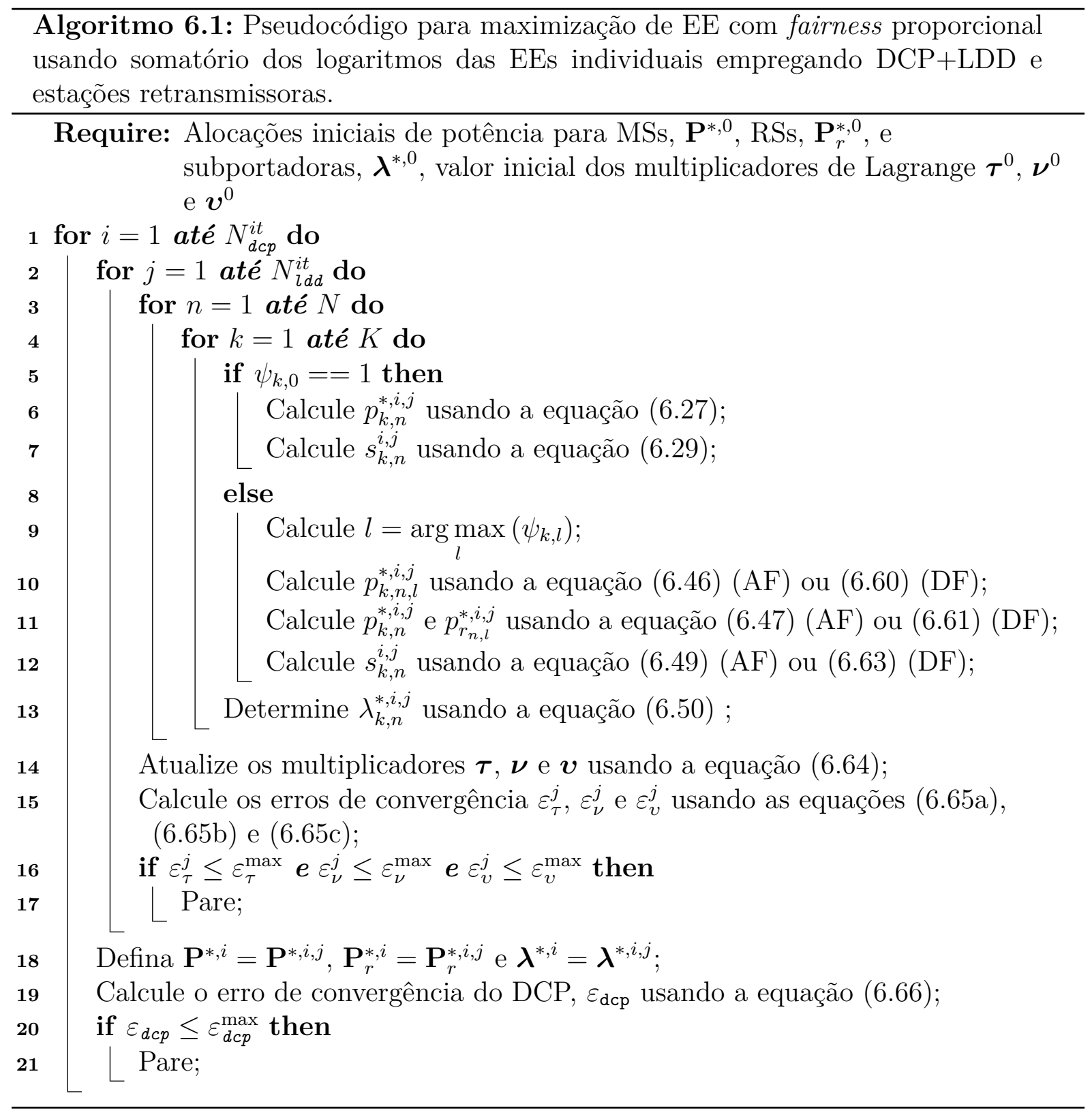

Como $\widetilde{\xi}_{\text {prod }}^{\varpi}\left(\widetilde{\mathbf{P}}, \widetilde{\mathbf{P}}_{r}, \widetilde{\boldsymbol{\lambda}}\right)$ é uma função fracionária, uma possibilidade de solução se dá pelo emprego do algoritmo DKB para obter uma função-objetivo linear. Caso $\widetilde{\xi}_{\text {prod }}^{\varpi}\left(\widetilde{\mathbf{P}}, \widetilde{\mathbf{P}}_{r}, \widetilde{\boldsymbol{\lambda}}\right)$ seja quase-côncava, o algoritmo DKB resulta em um problema de otimização iterativo e côncavo, que converge para a solução ótima dado um erro de convergência máximo $\varepsilon_{\mathrm{dkb}}^{\max }$. Para garantir a quase-concavidade, define-se o seguinte teorema:

Teorema 6.2. A função é quase-côncava em relação às variáveis de otimização $\widetilde{p}_{k, n}, \widetilde{p}_{r_{n, l}}$ $e \tilde{\lambda}_{k, n}$.

Demonstração. A prova é apresentada no Apêndice B.5.

Com a quase-concavidade de $\widetilde{\xi}_{\text {prod }}^{\varpi}\left(\widetilde{\mathbf{P}}, \widetilde{\mathbf{P}}_{r}, \widetilde{\boldsymbol{\lambda}}\right)$ garantida, aplica-se o algoritmo DKB ao problema (6.67). O problema a ser resolvido na $i$-ésima iteração do DKB é dado, então, 
por:

$$
\begin{gathered}
\widetilde{\mathbf{P}}^{*, i}, \widetilde{\mathbf{P}}_{r}^{*, i}, \widetilde{\boldsymbol{\lambda}}^{*, i}=\underset{\widetilde{\mathbf{P}}, \widetilde{\mathbf{P}}_{r}, \widetilde{\boldsymbol{\lambda}}}{\arg \max } \prod_{k=1}^{K}\left(\psi_{k, 0} \sum_{n=1}^{N} \widetilde{\lambda}_{k, n} \ell_{k, n} \widetilde{r}_{k, n, 0}+\sum_{l=1}^{N_{\mathrm{RS}}} \psi_{k, l} \sum_{n=1}^{N} \widetilde{\lambda}_{k, n} \ell_{k, n} \widetilde{r}_{k, n, l}^{\varpi}\right) \\
-q^{\varpi, i-1}\left[\prod_{k=1}^{K}\left(\psi_{k, 0} \sum_{n=1}^{N} \varrho_{k} \widetilde{p}_{k, n}+\sum_{l=1}^{N_{\mathrm{RS}}} \psi_{k, l}\left[\sum_{n=1}^{N} \frac{\varrho_{k} \widetilde{p}_{k, n}+\varrho_{r_{l}} \widetilde{p}_{r_{n, l}}}{2}+\varsigma_{k, l} p_{c, r_{l}}^{\varpi}\right]+p_{c, k}\right)\right]
\end{gathered}
$$

s. a: $(6.14 \mathrm{a})-(6.14 \mathrm{~g})$.

com

$$
\begin{aligned}
& q^{\varpi, i}=q^{\varpi}\left(\widetilde{\mathbf{P}}^{*, i}, \widetilde{\mathbf{P}}_{r}^{*, i}, \widetilde{\boldsymbol{\lambda}}^{*, i}\right)= \\
& \frac{\prod_{k=1}^{K}\left(\psi_{k, 0} \sum_{n=1}^{N} \widetilde{\lambda}_{k, n}^{*, i} \ell_{k, n} \widetilde{r}_{k, n, 0}^{*, i}+\sum_{l=1}^{N_{\mathrm{RS}}} \psi_{k, l} \sum_{n=1}^{N} \widetilde{\lambda}_{k, n}^{*, i} \ell_{k, n} \widetilde{r}_{k, n, l}^{*, \varpi, i}\right)}{\prod_{k=1}^{K}\left(\psi_{k, 0} \sum_{n=1}^{N} \varrho_{k} \widetilde{p}_{k, n}^{*, i}+\sum_{l=1}^{N_{\mathrm{RS}}} \psi_{k, l}\left[\sum_{n=1}^{N} \frac{\varrho_{k} \widetilde{p}_{k, n}^{*, i}+\varrho_{r} \widetilde{p}_{r_{n, l}, i}^{*}}{2}+\varsigma_{k, l} p_{c, r_{l}}^{\varpi}\right]+p_{c, k}\right)}
\end{aligned}
$$

ou seja, o produtório das EEs individuais com as alocações de potência e subportadoras obtidas na $i$-ésima iteração do DKB.

Tendo transformado o problema fracionário em um problema polinomial, é necessário agora aplicar o algoritmo LDD para integrar as restrições do problema de otimização. Define-se o uso dos vetores de multiplicadores de Lagrange $\boldsymbol{\tau}_{[1 \times K]}, \boldsymbol{v}_{[1 \times N]}$ e $\boldsymbol{\nu}_{\left[1 \times N_{\mathrm{RS}}\right]}$ para as restrições de potência das MSs, equação (6.14e), unicidade da alocação de subportadoras, equação (6.14g), e restrição de potência das RSs, equação (6.14f), respectivamente. Assim, o problema de otimização a ser resolvido na $i$-ésima iteração do DKB é dado por:

$$
\begin{aligned}
& \left.\widetilde{\mathbf{P}}^{*, i}, \widetilde{\mathbf{P}}_{r}^{*, i}, \widetilde{\boldsymbol{\lambda}}^{*, i}=\arg \min . \max _{\widetilde{\mathbf{P}}, \widetilde{\mathbf{P}}_{r}, \widetilde{\widetilde{\boldsymbol{\lambda}}}_{k=1}} \prod_{\left(\psi_{k, 0}\right.} \sum_{n=1}^{N} \widetilde{\lambda}_{k, n} \ell_{k, n} \widetilde{r}_{k, n, 0}+\sum_{l=1}^{N_{\mathrm{RS}}} \psi_{k, l} \sum_{n=1}^{N} \widetilde{\lambda}_{k, n} \ell_{k, n} \widetilde{r}_{k, n, l}^{\varpi}\right) \\
& -q^{\varpi, i-1}\left[\prod_{k=1}^{K}\left(\psi_{k, 0} \sum_{n=1}^{N} \varrho_{k} \widetilde{p}_{k, n}+\sum_{l=1}^{N_{\mathrm{RS}}} \psi_{k, l}\left[\sum_{n=1}^{N} \frac{\varrho_{k} \widetilde{p}_{k, n}+\varrho_{r_{l}} \widetilde{p}_{r_{n, l}}}{2}+\varsigma_{k, l} p_{c, r_{l}}^{\varpi}\right]+p_{c, k}\right)\right] \\
& -\sum_{k=1}^{K} \sum_{n=1}^{N}\left(\tau_{k} \widetilde{p}_{k, n}+\sum_{l=1}^{N_{\mathrm{RS}}} \nu_{l} \psi_{k, l} \widetilde{p}_{r_{n, l}}+v_{n} \widetilde{\lambda}_{k, n}\right)+\sum_{k=1}^{K} \tau_{k} p_{k}^{\max }+\sum_{l=1}^{N_{\mathrm{RS}}} \nu_{l} p_{r_{l}}^{\max }+\sum_{n=1}^{N} v_{n}
\end{aligned}
$$

Observando o problema de alocação de recursos da perspectiva da $k$-ésima MS, tem-se que:

$\widetilde{\mathbf{P}}^{*, i}, \widetilde{\mathbf{P}}_{r}^{*, i}, \widetilde{\boldsymbol{\lambda}}^{*, i}=$

$\arg \min . \max _{\widetilde{\mathbf{P}}, \widetilde{\mathbf{P}}_{r}, \tilde{\widetilde{\boldsymbol{\lambda}}}} R_{\bar{k}}^{\varpi}\left(\widetilde{\mathbf{P}}, \widetilde{\mathbf{P}}_{r}, \widetilde{\boldsymbol{\lambda}}\right)\left(\psi_{k, 0} \sum_{n=1}^{N} \widetilde{\lambda}_{k, n} \ell_{k, n} \widetilde{r}_{k, n, 0}+\sum_{l=1}^{N_{\mathrm{RS}}} \psi_{k, l} \sum_{n=1}^{N} \widetilde{\lambda}_{k, n} \ell_{k, n} \widetilde{r}_{k, n, l}^{\varpi}\right)$

$-q^{\varpi, i-1} P_{\bar{k}}^{\varpi}\left(\widetilde{\mathbf{P}}, \widetilde{\mathbf{P}}_{r}, \widetilde{\boldsymbol{\lambda}}\right)\left[\left(\psi_{k, 0} \sum_{n=1}^{N} \varrho_{k} \widetilde{p}_{k, n}+\sum_{l=1}^{N_{\mathrm{RS}}} \psi_{k, l}\left[\sum_{n=1}^{N} \frac{\varrho_{k} \widetilde{p}_{k, n}+\varrho_{r_{l}} \widetilde{p}_{r_{n, l}}}{2}+\varsigma_{k, l} p_{c, r_{l}}^{\varpi}\right]+p_{c, k}\right)\right]$

$-\sum_{k=1}^{K}\left(\sum_{n=1}^{N} \tau_{k} \widetilde{p}_{k, n}+\sum_{n=1}^{N} \sum_{l=1}^{N_{\mathrm{RS}}} \nu_{l} \psi_{k, l} \widetilde{p}_{r_{n, l}}+\sum_{n=1}^{N} v_{n} \widetilde{\lambda}_{k, n}\right)+\sum_{k=1}^{K} \tau_{k} p_{k}^{\max }+\sum_{l=1}^{N_{\mathrm{RS}}} \nu_{l} p_{r_{l}}^{\max }+\sum_{n=1}^{N} v_{n}$ 
com:

$$
\begin{aligned}
& R_{\bar{k}}^{\varpi}\left(\widetilde{\mathbf{P}}, \widetilde{\mathbf{P}}_{r}, \tilde{\boldsymbol{\lambda}}\right)=\prod_{k^{\prime}=1, k^{\prime} \neq k}^{K}\left(\psi_{k^{\prime}, 0} \sum_{n=1}^{N} \widetilde{\lambda}_{k^{\prime}, n} \ell_{k^{\prime}, n} \widetilde{r}_{k^{\prime}, n, 0}+\sum_{l=1}^{N_{\mathrm{RS}}} \psi_{k^{\prime}, l} \sum_{n=1}^{N} \widetilde{\lambda}_{k^{\prime}, n} \ell_{k^{\prime}, n} \widetilde{r}_{k^{\prime}, n, l}^{\varpi}\right) \\
& P_{\bar{k}}^{\varpi}\left(\widetilde{\mathbf{P}}, \widetilde{\mathbf{P}}_{r}, \tilde{\boldsymbol{\lambda}}\right)= \\
& \prod_{k^{\prime}=1, k^{\prime} \neq k}^{K}\left(\psi_{k^{\prime}, 0} \sum_{n=1}^{N} \varrho_{k^{\prime}} \widetilde{p}_{k^{\prime}, n}+\sum_{l=1}^{N_{\mathrm{RS}}} \psi_{k^{\prime}, l}\left[\sum_{n=1}^{N} \frac{\varrho_{k^{\prime}} \widetilde{p}_{k^{\prime}, n}+\varrho_{r_{l}} \widetilde{p}_{r_{n, l}}}{2}+\varsigma_{k^{\prime}, l} p_{c, r_{l}}^{\varpi}\right]+p_{c, k^{\prime}}\right)
\end{aligned}
$$

Assim como mostrado na Seção 5.4, o problema (6.71) será resolvido de modo iterativo, primeiramente resolvendo o problema interior de maximização, considerando os multiplicadores de Lagrange fixos e determinados pela iteração anterior do LDD, e na sequência a resolução do problema de minimização a partir das alocações de potência e subportadoras obtidas no passo anterior. O problema de maximização é dado por:

$$
\begin{aligned}
& \widetilde{\mathbf{P}}^{*, i, j}, \widetilde{\mathbf{P}}_{r}^{*, i, j}, \widetilde{\boldsymbol{\lambda}}^{*, i, j}=\underset{\widetilde{\mathbf{P}}, \widetilde{\mathbf{P}}_{r}, \widetilde{\boldsymbol{\lambda}}}{\arg \max } R_{\bar{k}}^{\varpi}\left(\widetilde{\mathbf{P}}, \widetilde{\mathbf{P}}_{r}, \widetilde{\boldsymbol{\lambda}}\right)\left(\psi_{k, 0} \sum_{n=1}^{N} \widetilde{\lambda}_{k, n} \ell_{k, n} \widetilde{r}_{k, n, 0}+\sum_{l=1}^{N_{\mathrm{RS}}} \psi_{k, l} \sum_{n=1}^{N} \widetilde{\lambda}_{k, n} \ell_{k, n} \widetilde{r}_{k, n, l}^{\varpi}\right) \\
& -q^{\varpi, i-1} P_{\bar{k}}^{\varpi}\left(\widetilde{\mathbf{P}}, \widetilde{\mathbf{P}}_{r}, \widetilde{\boldsymbol{\lambda}}\right)\left[\left(\psi_{k, 0} \sum_{n=1}^{N} \varrho_{k} \widetilde{p}_{k, n}+\sum_{l=1}^{N_{\mathrm{RS}}} \psi_{k, l}\left[\sum_{n=1}^{N} \frac{\varrho_{k} \widetilde{p}_{k, n}+\varrho_{r_{l}} \widetilde{p}_{r_{n, l}}}{2}+\varsigma_{k, l} p_{c, r_{l}}^{\varpi}\right]+p_{c, k}\right)\right] \\
& -\sum_{k=1}^{K}\left(\sum_{n=1}^{N} \tau_{k}^{j-1} \widetilde{p}_{k, n}+\sum_{n=1}^{N} \sum_{l=1}^{N_{\mathrm{RS}}} \nu_{l}^{j-1} \psi_{k, l} \widetilde{p}_{r_{n, l}}+\sum_{n=1}^{N} v_{n}^{j-1} \widetilde{\lambda}_{k, n}\right)
\end{aligned}
$$

enquanto o de minimização é dado por:

$$
\begin{aligned}
\boldsymbol{\tau}^{j}, \boldsymbol{v}^{j}, \boldsymbol{\nu}^{j}=\underset{\boldsymbol{\tau} \succeq \mathbf{0}, \boldsymbol{v} \succeq \mathbf{0}, \boldsymbol{v} \succeq \mathbf{0}}{\arg \min } & -\sum_{k=1}^{K} \sum_{n=1}^{N}\left(\tau_{k} \widetilde{p}_{k, n}^{*, i, j}+\sum_{l=1}^{N_{\mathrm{RS}}} \nu_{l} \psi_{k, l} \widetilde{p}_{r_{n, l}}^{*, i, j}+v_{n} \widetilde{\lambda}_{k, n}^{*, i, j}\right)+\sum_{k=1}^{K} \tau_{k} p_{k}^{\max } \\
& +\sum_{l=1}^{N_{\mathrm{RS}}} \nu_{l} p_{r_{l}}^{\max }+\sum_{n=1}^{N} v_{n}
\end{aligned}
$$

Considerando que a $k$-ésima MS se comunica diretamente com a BS, i.e., $\psi_{k, 0}=1 \mathrm{e}$ $\psi_{k, l}=0,1 \leq l \leq N_{\mathrm{RS}}$, tem-se que o problema de otimização na $i$-ésima iteração do DKB e $j$-ésima iteração do LDD para a $k$-ésima MS é dado por:

$$
\begin{aligned}
& \widetilde{\mathbf{P}}^{*, i, j}, \widetilde{\mathbf{P}}_{r}^{*, i, j}, \widetilde{\boldsymbol{\lambda}}^{*, i, j}=\underset{\widetilde{\mathbf{P}}, \widetilde{\mathbf{P}}_{r}, \widetilde{\boldsymbol{\lambda}}}{\arg \max } R_{\bar{k}}^{\varpi}\left(\widetilde{\mathbf{P}}, \widetilde{\mathbf{P}}_{r}, \widetilde{\boldsymbol{\lambda}}\right)\left(\sum_{n=1}^{N} \widetilde{\lambda}_{k, n} \ell_{k, n} \widetilde{r}_{k, n, 0}\right) \\
& -q^{\varpi, i-1} P_{\bar{k}}^{\varpi}\left(\widetilde{\mathbf{P}}, \widetilde{\mathbf{P}}_{r}, \widetilde{\boldsymbol{\lambda}}\right)\left(\sum_{n=1}^{N} \varrho_{k} \widetilde{p}_{k, n}+p_{c, k}\right)-\sum_{k=1}^{K}\left(\sum_{n=1}^{N} \tau_{k}^{j-1} \widetilde{p}_{k, n}+\sum_{n=1}^{N} v_{n}^{j-1} \widetilde{\lambda}_{k, n}\right)
\end{aligned}
$$

Tal formulação é bastante semelhante à do caso não-cooperativo com fairness apresentada na equação (5.48), tendo como principal modificação a mudança no cálculo de $R_{\bar{k}}^{\varpi}$ e $P_{\bar{k}}^{\varpi}$, que consideram também a potência de transmissão nas RSs. Assim, as expressões de alocação de potência e métrica de alocação de subportadoras na $i$-ésima iteração do DKB e $j$-ésima iteração do LDD para a $k$-ésima MS em comunicação direta serão adaptadas a partir das obtidas no Capítulo 5, sendo dadas, respectivamente, por:

$$
p_{k, n}^{*, i, j}=\left[\frac{R_{\bar{k}}^{\varpi}\left(\widetilde{\mathbf{P}}, \widetilde{\mathbf{P}}_{r}, \widetilde{\boldsymbol{\lambda}}^{*, i, j-1}\right) \ell_{k, n}}{\log (2)\left(\tau_{k}^{j-1}+q^{i-1} \widetilde{P}_{\bar{k}}^{\varpi}\left(\widetilde{\mathbf{P}}, \widetilde{\mathbf{P}}_{r}, \widetilde{\boldsymbol{\lambda}}^{*, i, j-1}\right) \varrho_{k}\right)}-\frac{1}{\Gamma_{k, n, 0} \iota_{k}}\right]^{+}
$$


e

$$
s_{k, n}^{i, j}=\frac{\widetilde{R}_{\bar{k}}^{\varpi}\left(\widetilde{\mathbf{P}}^{*, i, j}, \widetilde{\mathbf{P}}_{r}^{*, i, j}, \widetilde{\boldsymbol{\lambda}}\right) \ell_{k, n}}{\log (2)}\left(\log \left(1+p_{k, n}^{*, i, j} \Gamma_{k, n, 0} \imath_{k}\right)-\frac{p_{k, n}^{*, i, j} \Gamma_{k, n, 0} \imath_{k}}{1+p_{k, n}^{*, i, j} \Gamma_{k, n, 0} \imath_{k}}\right)-v_{n}^{j-1}
$$

Considerando agora que a $k$-ésima MS emprega a l-ésima RS para se comunicar com a BS, i.e. $\psi_{k, l}=1$, tem-se o seguinte problema de maximização:

$$
\begin{aligned}
\widetilde{\mathbf{P}}^{*, i, j}, \widetilde{\mathbf{P}}_{r}^{*, i, j}, \widetilde{\boldsymbol{\lambda}}^{*, i, j}= & \underset{\widetilde{\mathbf{P}}, \widetilde{\mathbf{P}}_{r}, \widetilde{\boldsymbol{\lambda}}}{\arg \max } R_{\bar{k}}^{\varpi}\left(\widetilde{\mathbf{P}}, \widetilde{\mathbf{P}}_{r}, \widetilde{\boldsymbol{\lambda}}\right)\left(\sum_{n=1}^{N} \widetilde{\lambda}_{k, n} \ell_{k, n} \widetilde{r}_{k, n, l}^{\varpi}\right) \\
& -q^{\varpi, i-1} P_{\bar{k}}^{\varpi}\left(\widetilde{\mathbf{P}}, \widetilde{\mathbf{P}}_{r}, \widetilde{\boldsymbol{\lambda}}\right)\left(\sum_{n=1}^{N} \frac{\varrho_{k} \widetilde{p}_{k, n}+\varrho_{r} \widetilde{p}_{r_{n, l}}}{2}+\varsigma_{k, l} p_{c, r_{l}}^{\varpi}+p_{c, k}\right) \\
& -\sum_{k=1}^{K}\left(\sum_{n=1}^{N} \tau_{k}^{j-1} \widetilde{p}_{k, n}+\sum_{n=1}^{N} \sum_{l=1}^{N_{\mathrm{RS}}} \nu_{l}^{j-1} \psi_{k, l} \widetilde{p}_{r_{n, l}}+\sum_{n=1}^{N} v_{n}^{j-1} \widetilde{\lambda}_{k, n}\right)
\end{aligned}
$$

A partir deste ponto, separa-se a solução para os protocolos AF e DF.

\subsubsection{AF}

Para o protocolo AF, o problema de maximização para a $k$-ésima MS que emprega a l-ésima RS é dado por:

$$
\widetilde{\mathbf{P}}^{*, i, j}, \widetilde{\mathbf{P}}_{r}^{*, i, j}, \widetilde{\boldsymbol{\lambda}}^{*, i, j}=\underset{\widetilde{\mathbf{P}}, \widetilde{\mathbf{P}}_{r}, \widetilde{\boldsymbol{\lambda}}}{\arg \max } U_{\mathrm{prod}}^{\mathrm{AF}, i, j}
$$

com

$$
\begin{aligned}
U_{\mathrm{prod}}^{\mathrm{AF}, i, j}= & \frac{\mathrm{w} R_{\bar{k}}^{\mathrm{AF}}\left(\widetilde{\mathbf{P}}, \widetilde{\mathbf{P}}_{r}, \widetilde{\boldsymbol{\lambda}}\right)}{2}\left(\sum_{n=1}^{N} \widetilde{\lambda}_{k, n} \ell_{k, n} \log _{2}\left(1+\frac{l_{k}^{\mathrm{AF}} \widetilde{p}_{r_{n, l}} \widetilde{p}_{k, n} \Gamma_{k, n, l} \Gamma_{l, n, 0}}{\widetilde{\lambda}_{k, n}\left(\widetilde{p}_{r_{n, l}} \Gamma_{l, n, 0}+\widetilde{p}_{k, n} \Gamma_{k, n, l}\right)}\right)\right) \\
& -q^{\mathrm{AF}, i-1} P_{\bar{k}}^{\mathrm{AF}}\left(\widetilde{\mathbf{P}}, \widetilde{\mathbf{P}}_{r}, \widetilde{\boldsymbol{\lambda}}\right)\left(\sum_{n=1}^{N} \frac{\varrho_{k} \widetilde{p}_{k, n}+\varrho_{r_{l}} \widetilde{p}_{r_{n, l}}}{2}+\varsigma_{k, l} p_{c, r_{l}}^{\mathrm{AF}}+p_{c, k}\right) \\
& -\sum_{k=1}^{K}\left(\sum_{n=1}^{N} \tau_{k}^{j-1} \widetilde{p}_{k, n}+\sum_{n=1}^{N} \sum_{l=1}^{N_{\mathrm{RS}}} \nu_{l}^{j-1} \psi_{k, l} \widetilde{p}_{r_{n, l}}+\sum_{n=1}^{N} v_{n}^{j-1} \widetilde{\lambda}_{k, n}\right)
\end{aligned}
$$

Pode se utilizar as condições de KKT para obter as expressões para alocação de potência e subportadoras, porém há um problema: as expressões para alocação de potência da $k$-ésima MS e da l-ésima RS dependem do resultado uma da outra, devendo ser resolvidas conjuntamente. Para resolver esse problema, adota-se a mesma estratégia definida para o somatório de logaritmos, definindo-se a potência total gasta nos dois saltos e então obtendo-se um fator de proporcionalidade $\Omega_{k, n, l}^{\mathrm{AF}, i, j}$ entre a potência total e a potência no primeiro salto. Com tal estratégia, obtêm-se as seguintes equivalências para as potências no primeiro e segundo saltos na $i$-ésima iteração do DKB e $j$-ésima iteração do LDD:

$$
\begin{aligned}
\tilde{p}_{k, n}^{i, j} & =\Omega_{k, n, l}^{\mathrm{AF}, i, j}\left(\widetilde{\mathbf{P}}, \widetilde{\mathbf{P}}_{r}, \widetilde{\boldsymbol{\lambda}}\right) \widetilde{p}_{k, n, l}^{i, j} \\
\widetilde{p}_{r_{n, l}}^{i, j} & =\left(1-\Omega_{k, n, l}^{\mathrm{AF}, i, j}\left(\widetilde{\mathbf{P}}, \widetilde{\mathbf{P}}_{r}, \widetilde{\boldsymbol{\lambda}}\right)\right) \widetilde{p}_{k, n, l}^{i, j}
\end{aligned}
$$


com

$\Omega_{k, n, l}^{\mathrm{AF}, i, j}\left(\widetilde{\mathbf{P}}, \widetilde{\mathbf{P}}_{r}, \widetilde{\boldsymbol{\lambda}}\right)=$

$\frac{q^{\mathrm{AF}, i-1} \widetilde{P}_{\bar{k}}^{\mathrm{AF}}\left(\widetilde{\mathbf{P}}, \widetilde{\mathbf{P}}_{r}, \widetilde{\boldsymbol{\lambda}}\right) \varrho_{r_{l}}+2 \nu_{l}^{j-1} \Gamma_{l, n, 0}}{q^{\mathrm{AF}, i-1} \widetilde{P}_{\bar{k}}^{\mathrm{AF}}\left(\widetilde{\mathbf{P}}, \widetilde{\mathbf{P}}_{r}, \widetilde{\boldsymbol{\lambda}}\right) \varrho_{r_{l}}+2 \nu_{l}^{j-1} \Gamma_{l, n, 0}-q^{\mathrm{AF}, i-1} \widetilde{P}_{\bar{k}}^{\mathrm{AF}}\left(\widetilde{\mathbf{P}}, \widetilde{\mathbf{P}}_{r}, \widetilde{\boldsymbol{\lambda}}\right) \varrho_{k}+2 \tau_{k}^{j-1} \Gamma_{k, n, l}}$

$$
-\frac{\sqrt{q^{\mathrm{AF}, i-1} \widetilde{P}_{\bar{k}}^{\mathrm{AF}}\left(\widetilde{\mathbf{P}}, \widetilde{\mathbf{P}}_{r}, \widetilde{\boldsymbol{\lambda}}\right) \varrho_{k}+2 \tau_{k}^{j-1} q^{\mathrm{AF}, i-1} \widetilde{P}_{\bar{k}}^{\mathrm{AF}}\left(\widetilde{\mathbf{P}}, \widetilde{\mathbf{P}}_{r}, \widetilde{\boldsymbol{\lambda}}\right) \varrho_{r_{l}}+2 \nu_{l}^{j-1} \Gamma_{k, n, l} \Gamma_{l, n, 0}}}{q^{\mathrm{AF}, i-1} \widetilde{P}_{\bar{k}}^{\mathrm{AF}}\left(\widetilde{\mathbf{P}}, \widetilde{\mathbf{P}}_{r}, \widetilde{\boldsymbol{\lambda}}\right) \varrho_{r_{l}}+2 \nu_{l}^{j-1} \Gamma_{l, n, 0}-q^{\mathrm{AF}, i-1} \widetilde{P}_{\bar{k}}^{\mathrm{AF}}\left(\widetilde{\mathbf{P}}, \widetilde{\mathbf{P}}_{r}, \widetilde{\boldsymbol{\lambda}}\right) \varrho_{k}+2 \tau_{k}^{j-1} \Gamma_{k, n, l}}
$$

A obtenção de $\Omega_{k, n, l}^{\mathrm{AF}, i, j}\left(\widetilde{\mathbf{P}}, \widetilde{\mathbf{P}}_{r}, \widetilde{\boldsymbol{\lambda}}\right)$ é descrita no Apêndice C.2.

Definido o fator de proporcionalidade $\Omega_{k, n, l}^{\mathrm{AF}, i, j}\left(\widetilde{\mathbf{P}}, \widetilde{\mathbf{P}}_{r}, \widetilde{\boldsymbol{\lambda}}\right)$, reescreve-se a função-utilidade $U_{\text {prod }}^{\mathrm{AF}, i, j}$ como:

$$
\begin{aligned}
& U_{\mathrm{prod}}^{\mathrm{AF}, i, j}=\underbrace{\frac{\mathrm{W} \widetilde{R}_{\bar{k}}^{\mathrm{AF}}\left(\widetilde{\mathbf{P}}, \widetilde{\mathbf{P}}_{r}, \widetilde{\boldsymbol{\lambda}}\right)}{2} \sum_{n=1}^{N} \widetilde{\lambda}_{k, n} \ell_{k, n} \log _{2}\left(1+\frac{l_{k}^{\mathrm{AF}} \Gamma_{k, n, l, 0}^{\mathrm{AF}, i, j}\left(\widetilde{\mathbf{P}}, \widetilde{\mathbf{P}}_{r}, \widetilde{\boldsymbol{\lambda}}\right) \widetilde{p}_{k, n, l}}{\widetilde{\lambda}_{k, n}}\right)}_{(\mathrm{I})} \\
& -\underbrace{q^{\mathrm{AF}, i-1} \widetilde{P}_{\bar{k}}^{\mathrm{AF}}\left(\widetilde{\mathbf{P}}, \widetilde{\mathbf{P}}_{r}, \widetilde{\boldsymbol{\lambda}}\right)\left(\sum_{n=1}^{N} \frac{\left(\left(\varrho_{k}-\varrho_{r_{l}}\right) \Omega_{k, n, l}^{\mathrm{AF}, i, j}\left(\widetilde{\mathbf{P}}, \widetilde{\mathbf{P}}_{r}, \widetilde{\boldsymbol{\lambda}}\right)+\varrho_{r_{l}}\right) \widetilde{p}_{k, n, l}}{2}+\varsigma_{k, l} p_{c, r_{l}}^{\mathrm{AF}}+p_{c, k}\right)}_{(\mathrm{II})} \\
& -\underbrace{\sum_{k=1}^{K}\left(\sum_{n=1}^{N} \tau_{k}^{j-1} \Omega_{k, n, l}^{\mathrm{AF}, i, j}\left(\widetilde{\mathbf{P}}, \widetilde{\mathbf{P}}_{r}, \widetilde{\boldsymbol{\lambda}}\right) \widetilde{p}_{k, n, l}+\sum_{n=1}^{N} \sum_{l=1}^{N_{\mathrm{RS}}} \nu_{l}^{j-1} \psi_{k, l}\left(1-\Omega_{k, n, l}^{\mathrm{AF}, i, j}\left(\widetilde{\mathbf{P}}, \widetilde{\mathbf{P}}_{r}, \widetilde{\boldsymbol{\lambda}}\right)\right) \widetilde{p}_{k, n, l}\right)}_{(\mathrm{III})} \\
& -\underbrace{\sum_{k=1}^{K} \sum_{n=1}^{N} v_{n}^{j-1} \widetilde{\lambda}_{k, n}}_{(\mathrm{IV})}
\end{aligned}
$$

com

$$
\Gamma_{k, n, l, 0}^{\mathrm{AF}, i, j}\left(\widetilde{\mathbf{P}}, \widetilde{\mathbf{P}}_{r}, \widetilde{\boldsymbol{\lambda}}\right)=\frac{\left(1-\Omega_{k, n, l}^{\mathrm{AF}, i, j}\left(\widetilde{\mathbf{P}}, \widetilde{\mathbf{P}}_{r}, \widetilde{\boldsymbol{\lambda}}\right)\right) \Omega_{k, n, l}^{\mathrm{AF}, i, j}\left(\widetilde{\mathbf{P}}, \widetilde{\mathbf{P}}_{r}, \widetilde{\boldsymbol{\lambda}}\right) \Gamma_{k, n, l} \Gamma_{j, n, 0}}{\left(\left(1-\Omega_{k, n, l}^{\mathrm{AF}, i, j}\left(\widetilde{\mathbf{P}}, \widetilde{\mathbf{P}}_{r}, \widetilde{\boldsymbol{\lambda}}\right)\right) \Gamma_{l, n, 0}+\Omega_{k, n, l}^{\mathrm{AF}, i, j}\left(\widetilde{\mathbf{P}}, \widetilde{\mathbf{P}}_{r}, \widetilde{\boldsymbol{\lambda}}\right) \Gamma_{k, n, l}\right)}
$$

Calculando as derivadas parciais de $U_{\text {prod }}^{\mathrm{AF}, i, j}$ em relação a $\widetilde{p}_{k, n, l}$, tem-se que:

$$
\begin{aligned}
& \frac{\partial(6.82) .(\mathrm{I})}{\partial \widetilde{p}_{k, n, l}}=\frac{\mathrm{w} \widetilde{R}_{\bar{k}}^{\mathrm{AF}}\left(\widetilde{\mathbf{P}}, \widetilde{\mathbf{P}}_{r}, \widetilde{\boldsymbol{\lambda}}\right) \widetilde{\lambda}_{k, n} \ell_{k, n}}{2 \log (2)\left(1+\frac{\lambda_{k}^{\mathrm{AF}} \Gamma_{k, n, l, 0}^{\mathrm{AF}, i, j}\left(\widetilde{\mathbf{P}}_{\overline{\mathbf{P}}} \widetilde{\mathbf{P}}_{r, n}, \widetilde{\boldsymbol{\lambda}}\right) \widetilde{p}_{k, n, l}}{\tilde{\lambda}_{k, n}}\right)} \frac{l_{k}^{\mathrm{AF}} \Gamma_{k, n, l, 0}^{\mathrm{AF}, i, j}\left(\widetilde{\mathbf{P}}, \widetilde{\mathbf{P}}_{r}, \widetilde{\boldsymbol{\lambda}}\right)}{\widetilde{\lambda}_{k, n}} \\
& =\frac{\mathrm{W} \widetilde{R}_{\bar{k}}^{\mathrm{AF}}\left(\widetilde{\mathbf{P}}, \widetilde{\mathbf{P}}_{r}, \widetilde{\boldsymbol{\lambda}}\right) \ell_{k, n} l_{k}^{\mathrm{AF}} \Gamma_{k, n, l, 0}^{\mathrm{AF}, i, j}\left(\widetilde{\mathbf{P}}, \widetilde{\mathbf{P}}_{r}, \widetilde{\boldsymbol{\lambda}}\right)}{2 \log (2)\left(1+\frac{l_{k}^{\mathrm{AF}} \Gamma_{k, n, l, 0}^{\mathrm{AF}, i, j}\left(\widetilde{\mathbf{P}}, \widetilde{\mathbf{P}}_{r}, \widetilde{\boldsymbol{\lambda}}\right) \widetilde{p}_{k, n, l}}{\widetilde{\lambda}_{k, n}}\right)} \\
& \frac{\partial(6.82) .(\mathrm{II})}{\partial \widetilde{p}_{k, n, l}}=\frac{q^{\mathrm{AF}, i-1} \widetilde{P}_{\bar{k}}^{\mathrm{AF}}\left(\widetilde{\mathbf{P}}, \widetilde{\mathbf{P}}_{r}, \widetilde{\boldsymbol{\lambda}}\right)\left(\left(\varrho_{k}-\varrho_{r_{l}}\right) \Omega_{k, n, l}^{\mathrm{AF}, i, j}\left(\widetilde{\mathbf{P}}, \widetilde{\mathbf{P}}_{r}, \widetilde{\boldsymbol{\lambda}}\right)+\varrho_{r_{l}}\right)}{2}
\end{aligned}
$$




$$
\begin{gathered}
\frac{\partial(6.82) .(\mathrm{III})}{\partial \widetilde{p}_{k, n, l}}=\left(\tau_{k}^{j-1}-\nu_{l}^{j-1}\right) \Omega_{k, n, l}^{\mathrm{AF}, i, j}\left(\widetilde{\mathbf{P}}, \widetilde{\mathbf{P}}_{r}, \widetilde{\boldsymbol{\lambda}}\right)+\nu_{l}^{j-1} \\
\frac{\partial(6.82) \cdot(\mathrm{IV})}{\partial \widetilde{p}_{k, n, l}}=0
\end{gathered}
$$

Somando os resultados da equação (6.84) e igualando a soma a zero, tem-se que:

$$
\begin{array}{r}
\frac{\mathrm{W} \widetilde{R}_{\bar{k}}^{\mathrm{AF}}\left(\widetilde{\mathbf{P}}, \widetilde{\mathbf{P}}_{r}, \widetilde{\boldsymbol{\lambda}}\right) \ell_{k, n} \imath_{k}^{\mathrm{AF}} \Gamma_{k, n, l, 0}^{\mathrm{AF}, i, j}\left(\widetilde{\mathbf{P}}, \widetilde{\mathbf{P}}_{r}, \widetilde{\boldsymbol{\lambda}}\right)}{\log (2)\left(1+\frac{\imath_{k}^{\mathrm{AF}} \Gamma_{k, n, l, 0}^{\mathrm{AF}, i, j}\left(\widetilde{\mathbf{P}}, \widetilde{\mathbf{P}}_{r}, \widetilde{\boldsymbol{\lambda}}\right) \widetilde{p}_{k, n, l}}{\widetilde{\lambda}_{k, n}}\right)}=\left(2 \tau_{k}^{j-1}-2 \nu_{l}^{j-1}\right) \Omega_{k, n, l}^{\mathrm{AF}, i, j}\left(\widetilde{\mathbf{P}}, \widetilde{\mathbf{P}}_{r}, \widetilde{\boldsymbol{\lambda}}\right)+2 \nu_{l}^{j-1} \\
+q^{\mathrm{AF}, i-1} \widetilde{P}_{\bar{k}}^{\mathrm{AF}}\left(\widetilde{\mathbf{P}}, \widetilde{\mathbf{P}}_{r}, \widetilde{\boldsymbol{\lambda}}\right)\left(\left(\varrho_{k}-\varrho_{r_{l}}\right) \Omega_{k, n, l}^{\mathrm{AF}, i, j}\left(\widetilde{\mathbf{P}}, \widetilde{\mathbf{P}}_{r}, \widetilde{\boldsymbol{\lambda}}\right)+\varrho_{r_{l}}\right)
\end{array}
$$

$$
\begin{gathered}
\frac{\mathrm{W} \widetilde{R}_{\bar{k}}^{\mathrm{AF}}\left(\widetilde{\mathbf{P}}, \widetilde{\mathbf{P}}_{r}, \widetilde{\boldsymbol{\lambda}}\right) \ell_{k, n} l_{k}^{\mathrm{AF}} \Gamma_{k, n, l, 0}^{\mathrm{AF}, i, j}\left(\widetilde{\mathbf{P}}, \widetilde{\mathbf{P}}_{r}, \widetilde{\boldsymbol{\lambda}}\right)}{\log (2)\left(1+\frac{A_{k}^{\mathrm{AF}} \Gamma_{k, n, l, 0}^{\mathrm{AF}, i, j}\left(\widetilde{\mathbf{P}}, \widetilde{\mathbf{P}}_{r}, \widetilde{\boldsymbol{\lambda}}\right) \widetilde{p}_{k, n, l}}{\widetilde{\boldsymbol{\lambda}}_{k, n}}\right)}=\left(q^{\mathrm{AF}, i-1} \widetilde{P}_{\bar{k}}^{\mathrm{AF}}\left(\widetilde{\mathbf{P}}, \widetilde{\mathbf{P}}_{r}, \widetilde{\boldsymbol{\lambda}}\right) \varrho_{k}+2 \tau_{k}^{j-1}\right) \Omega_{k, n, l}^{\mathrm{AF}, i, j}\left(\widetilde{\mathbf{P}}, \widetilde{\mathbf{P}}_{r}, \widetilde{\boldsymbol{\lambda}}\right) \\
+\left(q^{\mathrm{AF}, i-1} \widetilde{P}_{\bar{k}}^{\mathrm{AF}}\left(\widetilde{\mathbf{P}}, \widetilde{\mathbf{P}}_{r}, \widetilde{\boldsymbol{\lambda}}\right) \varrho_{r_{l}}+2 \nu_{l}^{i, j-1}\right)\left(1-\Omega_{k, n, l}^{\mathrm{AF}, i, j}\left(\widetilde{\mathbf{P}}, \widetilde{\mathbf{P}}_{r}, \widetilde{\boldsymbol{\lambda}}\right)\right)
\end{gathered}
$$$$
1+\frac{l_{k}^{\mathrm{AF}} \Gamma_{k, n, l, 0}^{\mathrm{AF}, i, j}\left(\widetilde{\mathbf{P}}, \widetilde{\mathbf{P}}_{r}, \widetilde{\boldsymbol{\lambda}}\right) \widetilde{p}_{k, n, l}}{\widetilde{\lambda}_{k, n}}=\frac{\mathrm{w} \widetilde{R}_{\bar{k}}^{\mathrm{AF}}\left(\widetilde{\mathbf{P}}, \widetilde{\mathbf{P}}_{r}, \widetilde{\boldsymbol{\lambda}}\right) \ell_{k, n} \ell_{k}^{\mathrm{AF}} \Gamma_{k, n, l, 0}^{\mathrm{AF}, i, j}\left(\widetilde{\mathbf{P}}, \widetilde{\mathbf{P}}_{r}, \widetilde{\boldsymbol{\lambda}}\right)}{\log (2) F_{k, n, l}^{\mathrm{AF}, i, j}\left(\widetilde{\mathbf{P}}, \widetilde{\mathbf{P}}_{r}, \widetilde{\boldsymbol{\lambda}}\right)}
$$

com

$$
\begin{aligned}
F_{k, n, l}^{\mathrm{AF}, i, j}\left(\widetilde{\mathbf{P}}, \widetilde{\mathbf{P}}_{r}, \widetilde{\boldsymbol{\lambda}}\right)= & \left(q^{\mathrm{AF}, i-1} \widetilde{P}_{\bar{k}}^{\mathrm{AF}}\left(\widetilde{\mathbf{P}}, \widetilde{\mathbf{P}}_{r}, \widetilde{\boldsymbol{\lambda}}\right) \varrho_{k}+2 \tau_{k}^{j-1}\right) \Omega_{k, n, l}^{\mathrm{AF}, i, j}\left(\widetilde{\mathbf{P}}, \widetilde{\mathbf{P}}_{r}, \widetilde{\boldsymbol{\lambda}}\right) \\
& +\left(q^{\mathrm{AF}, i-1} \widetilde{P}_{\bar{k}}^{\mathrm{AF}}\left(\widetilde{\mathbf{P}}, \widetilde{\mathbf{P}}_{r}, \widetilde{\boldsymbol{\lambda}}\right) \varrho_{r_{l}}+2 \nu_{l}^{j-1}\right)\left(1-\Omega_{k, n, l}^{\mathrm{AF}, i, j}\left(\widetilde{\mathbf{P}}, \widetilde{\mathbf{P}}_{r}, \widetilde{\boldsymbol{\lambda}}\right)\right)
\end{aligned}
$$

Isolando o termo de potência à esquerda da igualdade, e admitindo que a alocação de subportadoras é obtida na $(j-1)$-ésima iteração do LDD, devido à forma iterativa adotada para a solução, tem-se que:

$$
p_{k, n, l}^{*, i, j}=\left[\frac{\mathrm{w} \widetilde{R}_{\bar{k}}^{\mathrm{AF}}\left(\widetilde{\mathbf{P}}, \widetilde{\mathbf{P}}_{r}, \widetilde{\boldsymbol{\lambda}}^{i, j-1}\right) \ell_{k, n}}{\log (2) F_{k, n, l}^{\mathrm{AF}, i, j}\left(\widetilde{\mathbf{P}}, \widetilde{\mathbf{P}}_{r}, \widetilde{\boldsymbol{\lambda}}^{*, i-1}\right)}-\frac{1}{\imath_{k}^{\mathrm{AF}} \Gamma_{k, n, l, 0}^{\mathrm{AF}, i, j}\left(\widetilde{\mathbf{P}}, \widetilde{\mathbf{P}}_{r}, \widetilde{\boldsymbol{\lambda}}^{*, i-1}\right)}\right]^{+}
$$

As potências em cada salto são dadas por:

$$
\begin{aligned}
& p_{k, n}^{*, i, j}=\Omega_{k, n, l}^{\mathrm{AF}, i, j}\left(\widetilde{\mathbf{P}}, \widetilde{\mathbf{P}}_{r}, \widetilde{\boldsymbol{\lambda}}^{*, i-1}\right) p_{k, n, l}^{*, i, j} \\
& p_{r_{l, n}}^{*, i, j}=p_{k, n, l}^{*, i, j}-p_{k, n}^{*, i, j}
\end{aligned}
$$

Para a alocação de subportadoras, é necessário obter a derivada parcial de $U_{\text {prod }}^{\mathrm{AF}, i, j}$ em relação a $\tilde{\lambda}_{k, n}$. Separando a derivada parcial em cada um dos três componentes de $U_{\text {prod }}^{\mathrm{AF}, i, j}$, 
tem-se que:

$$
\begin{aligned}
& \frac{\partial(6.82) .(\mathrm{I})}{\partial \widetilde{\lambda}_{k, n}}=\frac{\mathrm{w} \widetilde{R}_{\bar{k}}^{\mathrm{AF}}\left(\widetilde{\mathbf{P}}, \widetilde{\mathbf{P}}_{r}, \widetilde{\boldsymbol{\lambda}}\right)}{2}\left[\ell_{k, n} \log _{2}\left(1+\frac{l_{k}^{\mathrm{AF}} \Gamma_{k, n, l, 0}^{\mathrm{AF}, i, j}\left(\widetilde{\mathbf{P}}, \widetilde{\mathbf{P}}_{r}, \widetilde{\boldsymbol{\lambda}}\right) \widetilde{p}_{k, n, l}}{\widetilde{\lambda}_{k, n}}\right)\right]
\end{aligned}
$$

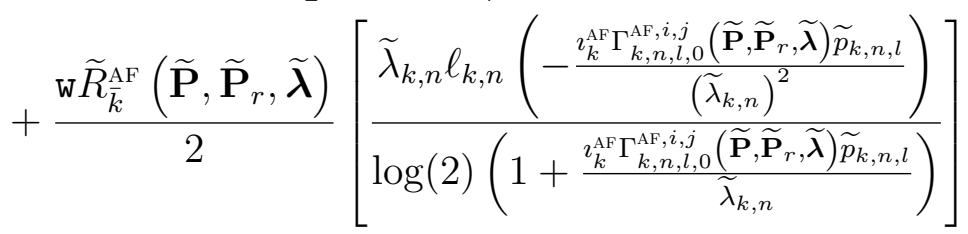

$$
\begin{aligned}
& =\frac{\mathrm{W} \ell_{k, n} \widetilde{R}_{\bar{k}}^{\mathrm{AF}}\left(\widetilde{\mathbf{P}}, \widetilde{\mathbf{P}}_{r}, \widetilde{\boldsymbol{\lambda}}\right)}{2 \log (2)}\left[\log \left(1+\frac{l_{k}^{\mathrm{AF}} \Gamma_{k, n, l, 0}^{\mathrm{AF}, i, j}\left(\widetilde{\mathbf{P}}, \widetilde{\mathbf{P}}_{r}, \widetilde{\boldsymbol{\lambda}}\right) \widetilde{p}_{k, n, l}}{\widetilde{\lambda}_{k, n}}\right)\right] \\
& -\frac{\mathrm{w} \ell_{k, n} \widetilde{R}_{\bar{k}}^{\mathrm{AF}}\left(\widetilde{\mathbf{P}}, \widetilde{\mathbf{P}}_{r}, \widetilde{\boldsymbol{\lambda}}\right)}{2 \log (2)}\left[\frac{l_{k}^{\mathrm{AF}} \Gamma_{k, n, l, 0}^{\mathrm{AF}, i, j}\left(\widetilde{\mathbf{P}}, \widetilde{\mathbf{P}}_{r}, \widetilde{\boldsymbol{\lambda}}\right) \widetilde{p}_{k, n, l}}{\widetilde{\lambda}_{k, n}\left(1+\frac{l_{k}^{\mathrm{AF}} \Gamma_{k, n, l, 0}^{\mathrm{AF}, i, j}\left(\widetilde{\mathbf{P}}, \widetilde{\mathbf{P}}_{r}, \widetilde{\boldsymbol{\lambda}}\right) \widetilde{p}_{k, n, l}}{\widetilde{\lambda}_{k, n}}\right)}\right] \\
& \frac{\partial(6.82) \cdot(\mathrm{II})}{\partial \widetilde{\lambda}_{k, n}}=0 \\
& \frac{\partial(6.82) \cdot(\mathrm{III})}{\partial \widetilde{\lambda}_{k, n}}=0 \\
& \frac{\partial(6.82) \cdot(\mathrm{IV})}{\partial \widetilde{\lambda}_{k, n}}=v_{n}^{j-1}
\end{aligned}
$$

Definindo que $s_{k, n}^{i, j}=\frac{\partial U_{\text {prod }}^{\mathrm{AF}, i, j}}{\partial \widetilde{\lambda}_{k, n}}$ é a métrica de alocação da $n$-ésima subportadora à $k$ ésima MS, e usando a alocação de potência nas MSs e RSs obtida na $j$-ésima iteração do LDD, tem-se que:

$$
\begin{aligned}
s_{k, n}^{i, j}= & \frac{\mathrm{w} \ell_{k, n} \widetilde{R}_{\bar{k}}^{\mathrm{AF}}\left(\widetilde{\mathbf{P}}^{i, j}, \widetilde{\mathbf{P}}_{r}^{i, j}, \widetilde{\boldsymbol{\lambda}}\right)}{2 \log (2)}\left[\log \left(1+\imath_{k}^{\mathrm{AF}} \Gamma_{k, n, l, 0}^{\mathrm{AF}, i, j}\left(\widetilde{\mathbf{P}}^{i, j}, \widetilde{\mathbf{P}}_{r}^{i, j}, \widetilde{\boldsymbol{\lambda}}\right) p_{k, n, l}^{*, i, j}\right)\right] \\
& -\frac{\mathrm{W} \ell_{k, n} \widetilde{R}_{\bar{k}}^{\mathrm{AF}}\left(\widetilde{\mathbf{P}}^{i, j}, \widetilde{\mathbf{P}}_{r}^{i, j}, \widetilde{\boldsymbol{\lambda}}\right)}{2 \log (2)}\left[\frac{l_{k}^{\mathrm{AF}} \Gamma_{k, n, l, 0}^{\mathrm{AF}, i, j}\left(\widetilde{\mathbf{P}}^{i, j}, \widetilde{\mathbf{P}}_{r}^{i, j}, \widetilde{\boldsymbol{\lambda}}\right) p_{k, n, l}^{*, i, j}}{\left(1+\imath_{k}^{\mathrm{AF}} \Gamma_{k, n, l, 0}^{\mathrm{AF}, i, j}\left(\widetilde{\mathbf{P}}^{i, j}, \widetilde{\mathbf{P}}_{r}^{i, j}, \widetilde{\boldsymbol{\lambda}}\right) p_{k, n, l}^{*, i, j}\right)}\right]-v_{n}^{j-1}
\end{aligned}
$$

A regra de decisão da alocação de subportadoras é dada pela equação (6.50), usando a métrica de alocação definida na equação (6.90). Com a alocação de potência e subportadoras da $j$-ésima iteração do LDD, atualizam-se os multiplicadores de Lagrange e verifica-se a convergência do LDD. Esses procedimentos serão descritos após a solução para protocolo DF.

\subsubsection{DF}

Para o protocolo DF, o fator de proporcionalidade $\Omega_{k, n, l}^{\mathrm{DF}}$ é o mesmo que foi determinado na solução por somatório de logaritmos, equação (6.52). Reescrevendo o problema de 
otimização (6.78) em função da potência consumida nos dois saltos, tem-se que:

$$
\widetilde{\mathbf{P}}^{*, i, j}, \widetilde{\mathbf{P}}_{r}^{*, i, j}, \widetilde{\boldsymbol{\lambda}}^{*, i, j}=\underset{\widetilde{\mathbf{P}}, \widetilde{\mathbf{P}}_{r}, \widetilde{\boldsymbol{\lambda}}}{\arg \max } U_{\mathrm{prod}}^{\mathrm{DF}, i, j}
$$

com

$$
\begin{aligned}
& U_{\text {prod }}^{\mathrm{DF}, i, j}=\underbrace{\widetilde{R}_{\bar{k}}^{\mathrm{DF}}\left(\widetilde{\mathbf{P}}, \widetilde{\mathbf{P}}_{r}, \widetilde{\boldsymbol{\lambda}}\right)\left(\sum_{n=1}^{N} \widetilde{\lambda}_{k, n} \ell_{k, n} \frac{\mathrm{W}}{2} \log _{2}\left(1+\frac{l_{k}^{\mathrm{DF}} \Omega_{k, n, l}^{\mathrm{DF}} \widetilde{p}_{k, n, l} \Gamma_{k, n, l}}{\widetilde{\lambda}_{k, n}}\right)\right)}_{(\mathrm{I})} \\
& -\underbrace{q^{\mathrm{DF}, i-1} \widetilde{P}_{\bar{k}}^{\mathrm{DF}}\left(\widetilde{\mathbf{P}}, \widetilde{\mathbf{P}}_{r}, \widetilde{\boldsymbol{\lambda}}\right)\left(\sum_{n=1}^{N} \frac{\left(\varrho_{k} \Omega_{k, n, l}^{\mathrm{DF}}+\varrho_{r_{l}}\left(1-\Omega_{k, n, l}^{\mathrm{DF}}\right)\right) \widetilde{p}_{k, n, l}}{2}+\varsigma_{k, l} p_{c, r_{l}}^{\mathrm{DF}}+p_{c, k}\right)}_{(\mathrm{II})} \\
& -\underbrace{\sum_{k=1}^{K}\left(\sum_{n=1}^{N} \tau_{k}^{j-1} \Omega_{k, n, l}^{\mathrm{DF}} \widetilde{p}_{k, n, l}+\sum_{n=1}^{N} \sum_{l=1}^{N_{\mathrm{RS}}} \nu_{l}^{j-1} \psi_{k, l}\left(1-\Omega_{k, n, l}^{\mathrm{DF}}\right) \widetilde{p}_{k, n, l}+\sum_{n=1}^{N} v_{n}^{j-1} \widetilde{\lambda}_{k, n}\right)}_{(\mathrm{III})}
\end{aligned}
$$

Tomando as derivadas parciais de $U_{\text {prod }}^{\mathrm{DF}, i, j}$ em relação a $\widetilde{p}_{k, n, l}$ para cada um dos itens da equação (6.92), tem-se que:

$$
\begin{gathered}
\frac{\partial(6.92) .(\mathrm{I})}{\partial \widetilde{p}_{k, n, l}}=\frac{\mathrm{w} \widetilde{R}_{\bar{k}}^{\mathrm{DF}}\left(\widetilde{\mathbf{P}}, \widetilde{\mathbf{P}}_{r}, \widetilde{\boldsymbol{\lambda}}\right) \widetilde{\lambda}_{k, n} \ell_{k, n}}{2 \log (2)\left(1+\frac{{ }^{\mathrm{DF}} \Omega_{k, n, l}^{\mathrm{DF}} \widetilde{p}_{k, n, l} \Gamma_{k, n, l}}{\widetilde{\lambda}_{k, n}}\right)} \frac{l_{k}^{\mathrm{DF}} \Omega_{k, n, l}^{\mathrm{DF}} \Gamma_{k, n, l}}{\widetilde{\lambda}_{k, n}} \\
=\frac{\mathrm{w} \widetilde{R}_{\bar{k}}^{\mathrm{DF}}\left(\widetilde{\mathbf{P}}, \widetilde{\mathbf{P}}_{r}, \widetilde{\boldsymbol{\lambda}}\right) \ell_{k, n} l_{k}^{\mathrm{DF}} \Omega_{k, n, l}^{\mathrm{DF}} \Gamma_{k, n, l}}{2 \log (2)\left(1+\frac{\imath_{k}^{\mathrm{DF}} \Omega_{k, n, l}^{\mathrm{DF}}, \widetilde{\lambda}_{k, n, l} \Gamma_{k, n, l}}{\widetilde{\lambda}_{k, n}}\right)} \\
\frac{\partial(6.92) .(\mathrm{II})}{\partial \widetilde{p}_{k, n, l}}=\frac{q^{\mathrm{DF}, i-1} \widetilde{P}_{\bar{k}}^{\mathrm{DF}}\left(\widetilde{\mathbf{P}}, \widetilde{\mathbf{P}}_{r}, \widetilde{\boldsymbol{\lambda}}\right)\left(\varrho_{k} \Omega_{k, n, l}^{\mathrm{DF}}+\varrho_{r_{l}}\left(1-\Omega_{k, n, l}^{\mathrm{DF}}\right)\right)}{2} \\
\frac{\partial(6.92) .(\mathrm{III})}{\partial \widetilde{p}_{k, n, l}}=\tau_{k}^{j-1} \Omega_{k, n, l}^{\mathrm{DF}}+\nu_{l}^{j-1}\left(1-\Omega_{k, n, l}^{\mathrm{DF}}\right)
\end{gathered}
$$

Somando as derivadas parciais obtidas, e igualando o resultado a zero, tem-se que:

$$
\begin{aligned}
\frac{\mathrm{w} \widetilde{R}_{\bar{k}}^{\mathrm{DF}}\left(\widetilde{\mathbf{P}}, \widetilde{\mathbf{P}}_{r}, \widetilde{\boldsymbol{\lambda}}\right) \ell_{k, n} \imath_{k}^{\mathrm{DF}} \Omega_{k, n, l}^{\mathrm{DF}} \Gamma_{k, n, l}}{2 \log (2)\left(1+\frac{\imath_{k}^{\mathrm{DF}} \Gamma_{k, n, l} \Omega_{k, n, l}^{\mathrm{DF}} \widetilde{p}_{k, n}}{\widetilde{\lambda}_{k, n}}\right)}= & \frac{q^{\mathrm{DF}, i-1} \widetilde{P}_{\bar{k}}^{\mathrm{DF}}\left(\widetilde{\mathbf{P}}, \widetilde{\mathbf{P}}_{r}, \widetilde{\boldsymbol{\lambda}}\right)\left(\varrho_{k} \Omega_{k, n, l}^{\mathrm{DF}}+\varrho_{r_{l}}\left(1-\Omega_{k, n, l}^{\mathrm{DF}}\right)\right)}{2} \\
& +\frac{2 \tau_{k}^{j-1} \Omega_{k, n, l}^{\mathrm{DF}}+2 \nu_{l}^{j-1}\left(1-\Omega_{k, n, l}^{\mathrm{DF}}\right)}{2}
\end{aligned}
$$

$$
\begin{aligned}
\log (2)\left(1+\frac{\imath_{k}^{\mathrm{DF}} \Gamma_{k, n, l} \Omega_{k, n, l}^{\mathrm{DF}} \widetilde{p}_{k, n, l}}{\widetilde{\lambda}_{k, n}}\right) & =\frac{\mathrm{w} \widetilde{R}_{\bar{k}}^{\mathrm{DF}}\left(\widetilde{\mathbf{P}}, \widetilde{\mathbf{P}}_{r}, \widetilde{\boldsymbol{\lambda}}\right) \ell_{k, n} \imath_{k}^{\mathrm{DF}} \Omega_{k, n, l}^{\mathrm{DF}} \Gamma_{k, n, l}}{F_{k, n, l}^{\mathrm{DF}, i, j}\left(\widetilde{\mathbf{P}}, \widetilde{\mathbf{P}}_{r}, \widetilde{\boldsymbol{\lambda}}\right)} \\
l_{k}^{\mathrm{DF}} \Gamma_{k, n, l} \Omega_{k, n, l}^{\mathrm{DF}} p_{k, n, l} & =\frac{\mathrm{W} \widetilde{R}_{\bar{k}}^{\mathrm{DF}}\left(\widetilde{\mathbf{P}}, \widetilde{\mathbf{P}}_{r}, \widetilde{\boldsymbol{\lambda}}\right) \ell_{k, n} l_{k}^{\mathrm{DF}} \Omega_{k, n, l}^{\mathrm{DF}} \Gamma_{k, n, l}}{\log (2) F_{k, n, l}^{\mathrm{DF}, i, j}\left(\widetilde{\mathbf{P}}, \widetilde{\mathbf{P}}_{r}, \widetilde{\boldsymbol{\lambda}}\right)}-1
\end{aligned}
$$


em que

$$
\begin{aligned}
F_{k, n, l}^{\mathrm{DF}, i, j}\left(\widetilde{\mathbf{P}}, \widetilde{\mathbf{P}}_{r}, \widetilde{\boldsymbol{\lambda}}\right)= & q^{\mathrm{DF}, i-1} \widetilde{P}_{\bar{k}}^{\mathrm{DF}}\left(\widetilde{\mathbf{P}}, \widetilde{\mathbf{P}}_{r}, \widetilde{\boldsymbol{\lambda}}\right)\left(\varrho_{k} \Omega_{k, n, l}^{\mathrm{DF}}+\varrho_{r_{l}}\left(1-\Omega_{k, n, l}^{\mathrm{DF}}\right)\right) \\
& +2 \tau_{k}^{j-1} \Omega_{k, n, l}^{\mathrm{DF}}+2 \nu_{l}^{j-1}\left(1-\Omega_{k, n, l}^{\mathrm{DF}}\right)
\end{aligned}
$$

Sabendo que será utilizada a alocação de subportadoras da iteração anterior do LDD, tem-se que a potência ótima para a comunicação da $k$-ésima MS na $n$-ésima subportadora, usando a l-ésima RS, é dada por:

$$
p_{k, n, l}^{*, i, j}=\left[\frac{\mathrm{w} \widetilde{R}_{\bar{k}}^{\mathrm{DF}}\left(\widetilde{\mathbf{P}}, \widetilde{\mathbf{P}}_{r}, \widetilde{\boldsymbol{\lambda}}^{i, j-1}\right) \ell_{k, n}}{\log (2) F_{k, n, l}^{\mathrm{DF}, i, j}\left(\widetilde{\mathbf{P}}, \widetilde{\mathbf{P}}_{r}, \widetilde{\boldsymbol{\lambda}}^{i, j-1}\right)}-\frac{1}{\imath_{k}^{\mathrm{DF}} \Omega_{k, n, l}^{\mathrm{DF}} \Gamma_{k, n, l}}\right]^{+}
$$

Computando $p_{k, n, l}^{*, i, j}$, é possível obter as potências em cada um dos saltos através das seguintes equações:

$$
\begin{aligned}
& p_{k, n}^{*, i, j}=\Omega_{k, n, l}^{\mathrm{DF}} p_{k, n, l}^{*, i, j} \\
& p_{r_{l, n}}^{*, i, j}=p_{k, n, l}^{*, i, j}-p_{k, n}^{*, i, j}
\end{aligned}
$$

Tomando a derivada parcial de $U_{\text {prod }}^{\mathrm{DF}, i, j}$ em relação a $\widetilde{\lambda}_{k, n}$ para cada um dos itens, tem-se que:

$$
\begin{aligned}
& \frac{\partial(6.92) .(\mathrm{I})}{\partial \widetilde{\lambda}_{k, n}}= \frac{\mathrm{w} \widetilde{R}_{\bar{k}}^{\mathrm{DF}}\left(\widetilde{\mathbf{P}}, \widetilde{\mathbf{P}}_{r}, \widetilde{\boldsymbol{\lambda}}\right)}{2}\left[\ell_{k, n} \log _{2}\left(1+\frac{\left.l_{k}^{\mathrm{DF}} \Gamma_{k, n, l} \Omega_{k, n, l}^{\mathrm{DF}} \widetilde{p}_{k, n, l}^{\mathrm{DF}}\right)}{\widetilde{\lambda}_{k, n}}\right)\right] \\
&+\frac{\mathrm{w} \widetilde{R}_{\bar{k}}^{\mathrm{DF}}\left(\widetilde{\mathbf{P}}, \widetilde{\mathbf{P}}_{r}, \widetilde{\boldsymbol{\lambda}}\right)}{2}\left[\frac{\widetilde{\lambda}_{k, n} \ell_{k, n}\left(-\frac{\imath_{k}^{\mathrm{DF}} \Omega_{k, n, l}^{\mathrm{DF}} \Gamma_{k, n}, \widetilde{p}_{k, n, l}}{\left(\widetilde{\lambda}_{k, n}\right)^{2}}\right)}{\log (2)\left(1+\frac{\imath_{k}^{\mathrm{DF}} \Omega_{k, n, l}^{\mathrm{DF}} \Gamma_{k, n}, \widetilde{p}_{k, n}}{\widetilde{\lambda}_{k, n}}\right)}\right] \\
&= \frac{\mathrm{W} \ell_{k, n} \widetilde{R}_{\bar{k}}^{\mathrm{DF}}\left(\widetilde{\mathbf{P}}, \widetilde{\mathbf{P}}_{r}, \widetilde{\boldsymbol{\lambda}}\right)}{2 \log (2)}\left[\log \left(1+\frac{\imath_{k}^{\mathrm{DF}} \Omega_{k, n, l}^{\mathrm{DF}} \Gamma_{k, n, l} \widetilde{p}_{k, n, l}}{\widetilde{\lambda}_{k, n}}\right)\right] \\
&-\frac{\mathrm{w}_{k, n} \widetilde{R}_{\bar{k}}^{\mathrm{DF}}\left(\widetilde{\mathbf{P}}, \widetilde{\mathbf{P}}_{r}, \widetilde{\boldsymbol{\lambda}}\right)}{2 \log (2)}\left[\frac{\imath_{k}^{\mathrm{DF}} \Omega_{k, n, l}^{\mathrm{DF}} \Gamma_{k, n, l} \widetilde{p}_{k, n, l}}{\left.\widetilde{\lambda}_{k, n}\left(1+\frac{l_{k}^{\mathrm{DF}} \Omega_{k, n, l}^{\mathrm{DF}} \Gamma_{k, n, l} \widetilde{p}_{k, n, l}}{\widetilde{\lambda}_{k, n}}\right)\right]}\right. \\
& \frac{\partial(6.92) .(\mathrm{II})}{\partial \widetilde{\lambda}_{k, n}}=0 \\
& \frac{\partial(6.92) .(\mathrm{III})}{\partial \widetilde{\lambda}_{k, n}}=v_{n}^{j-1}
\end{aligned}
$$

Definindo $s_{k, n}^{i, j}=\frac{\partial U_{\text {prod }}^{\mathrm{DF}, i, j}}{\partial \widehat{\lambda}_{k, n}}$ como a métrica de alocação de subportadoras, e somando os termos individuais obtidos anteriormente, além de utilizar a alocação de potência obtida 
com a equação 6.96, tem-se que:

$$
\begin{aligned}
s_{k, n}^{i, j}= & \frac{\mathrm{w} \ell_{k, n} \widetilde{R}_{\bar{k}}^{\mathrm{DF}}\left(\widetilde{\mathbf{P}}^{i, j}, \widetilde{\mathbf{P}}_{r}^{i, j}, \widetilde{\boldsymbol{\lambda}}\right)}{2 \log (2)}\left[\log \left(1+\imath_{k}^{\mathrm{DF}} \Omega_{k, n, l}^{\mathrm{DF}} \Gamma_{k, n, l} p_{k, n, l}^{*, i, j}\right)\right] \\
& -\frac{\mathrm{w} \ell_{k, n} \widetilde{R}_{\bar{k}}^{\mathrm{DF}}\left(\widetilde{\mathbf{P}}^{i, j}, \widetilde{\mathbf{P}}_{r}^{i, j}, \widetilde{\boldsymbol{\lambda}}\right)}{2 \log (2)}\left[\frac{\imath_{k}^{\mathrm{DF}} \Omega_{k, n, l}^{\mathrm{DF}} \Gamma_{k, n, l} p_{k, n, l}^{*, i, j}}{\left(1+\imath_{k}^{\mathrm{DF}} \Omega_{k, n, l}^{\mathrm{DF}} \Gamma_{k, n, l} p_{k, n, l}^{*, i, l}\right)}\right]-v_{n}^{i, j-1}
\end{aligned}
$$

A regra de decisão de subportadoras não se altera, sendo dada pela equação (6.50). Após a obtenção das alocações de potência e subportadoras na $j$-ésima iteração do LDD, atualiza-se os multiplicadores de Lagrange de acordo com a equação (6.64) e calculamse os erros de convergência dos multiplicadores usando as equações (6.65a), (6.65b) e (6.65c). A verificação de convergência é feita de modo análogo ao discutido na Seção 6.4, comparando os erros de convergência obtidos aos erros máximos $\varepsilon_{\tau}^{\max }, \varepsilon_{\nu}^{\max } \mathrm{e} \varepsilon_{v}^{\max } \mathrm{e}$ verificando se o limite de iterações $N_{\text {ldd }}^{i t}$ não foi excedido.

Finalizado o algoritmo LDD, e tendo $j$ como a última iteração executada, definese $\widetilde{\mathbf{P}}^{*, i}=\widetilde{\mathbf{P}}^{*, i, j}, \widetilde{\mathbf{P}}_{r}^{*, i}=\widetilde{\mathbf{P}}^{*, i, j}$ e $\widetilde{\boldsymbol{\lambda}}^{*, i}=\widetilde{\boldsymbol{\lambda}}^{*, i, j}$, e então o parâmetro $q$ é atualizado como $q^{i}=q\left(\widetilde{\mathbf{P}}^{*, i}, \widetilde{\mathbf{P}}_{r}^{*, i}, \widetilde{\boldsymbol{\lambda}}^{*, i}\right)$. Define-se ainda a convergência do algoritmo DKB caso o erro da $i$ ésima iteração, dado por $\varepsilon_{\mathrm{dkb}}=\left|q^{i}-q^{i-1}\right|$, seja menor que o erro máximo de convergência tolerado, i.e., $\varepsilon_{\mathrm{dkb}} \leq \varepsilon_{\mathrm{dkb}}^{\max }$.

O algoritmo 6.2 sumariza a operação da solução proposta. 


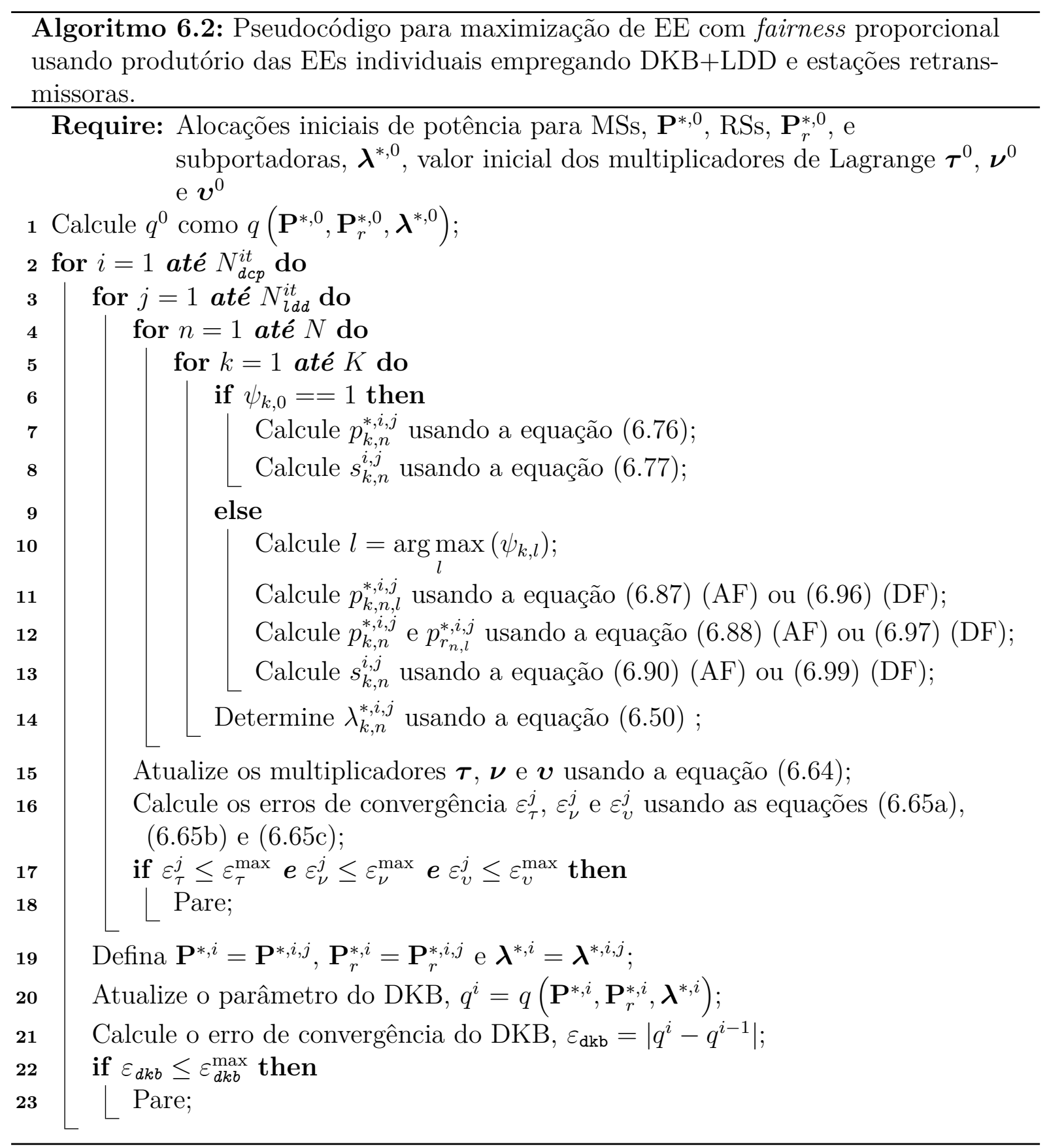




\section{IMPLEMENTAÇÃO COMPUTACIONAL DOS PROBLEMAS COM FAIRNESS PROPORCIONAL}

\subsection{Limitações de Implementação com Somatório de Logaritmos sem RSs}

Apesar de ser possível obter as equações para a alocação de recursos e desenvolver um algoritmo iterativo a partir das equações (5.35) e (5.38)-(5.40b), com estrutura minimamente semelhante à observada no Capítulo 4, algumas limitações foram encontradas no processo de implementação computacional do algoritmo proposto. As principais são:

\subsubsection{Necessidade de Calcular Conjuntamente a Alocação de Potência em Todas as $N$ Subportadoras da $k$-ésima MS}

Como pode ser notado na equação (5.35), o cálculo da alocação de potência da $n$-ésima subportadora da $k$-ésima MS depende da alocação de potência das demais subportadoras da mesma MS, dado que a formulação usando funções logarítmicas resulta que os termos de potência no termo $D_{2}$ se referem aos valores que serão calculados, e não o de iterações anteriores; por outro lado, no Capítulo 4, a primeira derivada para o cálculo da alocação de potência resulta em uma função que não depende da potência de outras subportadoras (não diretamente, apesar do parâmetro q). É possível mostrar que entre duas subportadoras de uma mesma MS existe uma relação de waterfilling semelhante à obtida com a equação de alocação de potência obtida no Capítulo 4, equação (4.12), de modo que se espera que também exista uma noção de waterfilling nos resultados da equação (5.35). Para superar essa limitação, propõe-se que, no cálculo da alocação de potência da $k$-ésima MS na $n$-ésima subportadora, as potências alocadas nas demais subportadoras da $k$-ésima MS sejam definidas como as potência obtidas na iteração anterior do DCP, de modo que a equação (5.35) possa ser computada por:

$$
p_{k, n}^{*, i, j}=\left[\chi_{k, n}-\frac{1}{\Gamma_{k, n} \imath_{k}}\right]^{+}
$$


em que

$$
\chi_{k, n}=\frac{\exp \left(W\left(\frac{\left(\prod_{\substack{m=1 \\ m \neq n}}^{N}\left(1+p_{k, m}^{*, i, j-1} \Gamma_{k, m} \iota_{k} \frac{\tilde{\lambda}_{k, m}^{*, i, j} \ell_{k, m}}{\ell_{k, n}}\right) \Gamma_{k, n} \iota_{k}\left(\sum_{m=1}^{N} \varrho_{k} p_{k, m}^{*, i, j-1}+p_{c, k}\right)\right.}{\tau_{k}^{j-1} \log (b)\left(\sum_{m=1}^{N} \varrho_{k} p_{k, m}^{*, i, j-1}+p_{c, k}\right)+\varrho_{k}}\right)\right)}{\left(\prod_{\substack{m=1 \\ m \neq n}}^{N}\left(1+p_{k, m}^{*, i, j-1} \Gamma_{k, m} \iota_{k}\right)^{\frac{\tilde{\lambda}_{k, m}^{*, i, j-1} \ell_{k, m}}{\ell_{k, n}}}\right) \Gamma_{k, n} \iota_{k}}
$$

Altera-se o Algoritmo 5.1 para que a alocação de potência seja feita usando a equação (7.1), e não mais a equação (5.35).

\subsubsection{Necessidade de Calcular Conjuntamente Todas as $N$ Métricas de Alo- cação de Subportadoras da $k$-ésima MS}

Quando se trata das métricas de alocação de subportadoras, o problema do cálculo conjunto é ainda mais complexo. Percebe-se pela equação (5.38) que a métrica de alocação da $n$-ésima subportadora à $k$-ésima MS depende da alocação ou não das demais subportadoras à $k$-ésima MS. Ou seja, se for necessário calcular uma das métricas, será preciso ter calculado as demais $N-1$ métricas da $k$-ésima MS e realizado a decisão apresentada na equação (5.39), a qual envolve a discretização da alocação de subportadoras. Para evitar tal situação, uma consideração semelhante à feita para o caso da alocação de potência precisa ser determinada: no cálculo da métrica de alocação da $n$-ésima subportadora à $k$-ésima MS, considera-se que a alocação das demais subportadoras da mesma $k$-ésima MS será dada pela iteração anterior do algoritmo DCP+LDD, de modo que a métrica em (5.38) possa ser computada por:

$$
s_{k, n}^{i, j}=\frac{\ell_{k, n}\left(\log \left(1+p_{k, n}^{*, i, j} \Gamma_{k, n} \imath_{k}\right)-\frac{p_{k, n}^{*, i, j} \Gamma_{k, n} \imath_{k}}{\left(1+p_{k, n}^{*, i, j} \Gamma_{k, n} \imath_{k}\right)}\right)}{\log (b) \sum_{m=1}^{N} \lambda_{k, m}^{*, i-1, j} \ell_{k, m} \log \left(1+p_{k, m}^{*, i, j} \Gamma_{k, m} \imath_{k}\right)} .
$$

\subsubsection{Custo Computacional da Função W de Lambert}

Quando um usuário possui muitas portadoras e/ou ganho de canal muito elevado, o produtório utilizado como parâmetro na função $\mathrm{W}$ de Lambert, $D_{2}$, pode tender a infinito em implementação no MATLAB. Quando isso ocorre, resulta em um erro de execução e o código é interrompido. O problema é mais evidente em configurações com poucas MSs e muitas subportadoras, notadamente quando $N=2048$ e $K=30$, devido à concentração de muitas subportadoras em cada MS.

Além disso, como a função $W$ não pode ser expressa em termos de outras funções, a implementação adotada pelo MATLAB utiliza algum método de aproximação para 
determinar o valor da função $W$ em relação aos argumentos $D_{2}$ e $D_{3}$. O problema é que, em alguns casos, essa função consome parte significativa do tempo de execução do algoritmo.

\subsubsection{Determinação de $\lambda_{k, n}$ a partir de $s_{k, n}$}

No método desenvolvido no Capítulo 4, bastava encontrar o máximo da métrica em cada subportadora para determinar qual das $K$ MSs deveria alocar a $n$-ésima subportadora. No caso do problema com adoção de fairness proporcional, a escolha pelo máximo tende a deixar MSs sem portadoras. Isso ocorre porque a capacidade de concorrer pelas portadoras vai aumentando conforme as mesmas são perdidas, pela redução da taxa de dados das MSs. Assim, é possível que, em estágios iniciais, uma MS esteja ainda com pouco poder de concorrência e simplesmente perca todas as subportadoras se uma solução de máximo for adotada. Como será discutido no tópico seguinte, uma MS sem recursos espectrais faz com que o algoritmo de alocação de recursos com métrica de fairness não seja capaz de convergir.

\subsubsection{MSs sem Subportadoras e Discretização da Alocação de Subportadoras}

Um problema observado no processo de simulação utilizando a equação (7.3) é que, no processo de perda de uma subportadora, a métrica de alocação de subportadoras da $k$-ésima MS na $n$-ésima subportadora tende a se tornar instável e resultar na não-convergência do algoritmo de alocação de recursos. Como a alocação de subportadoras é discretizada a partir das métricas de alocação ao fim de cada iteração do LDD, a taxa de dados presente no denominador da equação (7.3) pode oscilar significativamente com a perda de uma subportadora entre duas iterações. Com essa oscilação, o valor de $s_{k, n}^{i, j}$ pode ficar alternando entre dois (ou até mais) valores, sem convergir para alguma solução.

Quando tal oscilação ocorre em apenas uma MS, o algoritmo tende a convergir; porém, quando a oscilação envolve mais de uma MS, um número significativo de casos de teste simulados terminavam com detecção de ciclos nos valores das variáveis de otimização, mesmo utilizando valores menores para a atualização do multiplicador $v_{n}$. Nesses casos, por mais que o algoritmo continuasse a ser executado, a convergência não seria atingida dado que o sistema permanece alternando entre um conjunto de valores. Tal problema é especialmente crítico quando o algoritmo de alocação de recursos está prestes a convergir, com poucas subportadoras ainda sendo disputadas. Nesses cenários, o impacto da perda e ganho de uma subportadora na taxa de dados se torna bastante significativo, o que impacta de maneira sensível em $s_{k, n}$ : com a perda de uma portadora, a taxa de dados cai, a métrica $s_{k, n}$ tende a aumentar e a portadora novamente é alocada. Em seguida, e devido à alocação dessa subportadora, a taxa de dados cresce, a métrica $s_{k, n}$ é reduzida e a portadora é perdida novamente, criando um ciclo "perde-ganha" divergente. 
Há ainda um segundo problema, que corresponde ao caso em que a $k$-ésima MS não aloca nenhum recurso espectral na $j$-ésima iteração do LDD. O problema se manisfestará na alocação de subportadoras na iteração seguinte, pois o denominador da equação (7.3) na $(j+1)$-ésima iteração do LDD será nulo, o que resultará em uma métrica de alocação infinita em todas as $N$ subportadoras para a $k$-ésima MS, e que de acordo com a regra de decisão descrita na equação (5.39) resultará que a $k$-ésima MS alocará todas as $N$ subportadoras. Porém, na iteração seguinte, a k-ésima MS não será capaz de manter tantas subportadoras, e a tendência é que volte a ter nenhum recurso espectral.

Para atenuar essas situações, adota-se $\widetilde{\lambda}_{k, n}^{*, i, j-1}=1$ ao calcular $s_{k, n}^{i, j}$, para que o impacto das alterações de alocação de subportadoras sejam diluídas, principalmente quando apenas uma subportadora está sendo alterada. Visto que a interpretação matemática de $s_{k, n}$ é a taxa de crescimento da EE com a alocação da $n$-ésima subportadora à $k$-ésima MS [34], é possível admitir que no cálculo da métrica se considere que a $n$-ésima subportadora esteja alocada à $k$-ésima MS, independentemente do estado de alocação na iteração anterior. Com tal modificação, a métrica de alocação da $n$-ésima subportadora à $k$-ésima MS é dada por:

$$
s_{k, n}^{i, j}=\frac{\ell_{k, n}\left(\log \left(1+p_{k, n}^{*, i, j} \Gamma_{k, n} \imath_{k}\right)-\frac{p_{k, n}^{*, i, j} \Gamma_{k, n} \imath_{k}}{\left(1+p_{k, n}^{*, i, j} \Gamma_{k, n} \imath_{k}\right)}\right)}{\log (b)\left(\ell_{k, n} \log \left(1+p_{k, n}^{*, i, j} \Gamma_{k, n} \iota_{k}\right)+\sum_{\substack{m=1 \\ m \neq n}}^{N} \lambda_{k, m}^{*, i, j-1} \ell_{k, m} \log \left(1+p_{k, m}^{*, i, j} \Gamma_{k, m} \iota_{k}\right)\right)} .
$$

Altera-se o Algoritmo 5.1 para que o cálculo da métrica $s_{k, n}^{i, j}$ seja feita usando a equação (7.4), e não mais a equação (5.38).

\subsubsection{Oscilação e Erros na Alocação de Subportadoras}

Um problema bastante grave é a questão da oscilação no processo de alocação de subportadoras. A alocação de potência, por mais computacionalmente custosa que seja, é capaz de atingir o ponto de ótimo fixando a alocação de subportadoras. Porém, a alocação de subportadoras não tem um comportamento tão estável, devido à adoção da estratégia de fairness para a alocação de recursos. Primeiramente, o denominador (dependente da taxa de dados) faz com que o número de portadoras alocadas oscile significantemente conforme as iterações avançam. Quando uma MS desaloca subportadoras em uma dada iteração do LDD, a iteração seguinte muitas vezes as recupera e adiciona ainda algumas mais. Na próxima iteração, a métrica $s_{k, n}$ diminui (menor até que o valor de duas iterações antes), e mais subportadoras são perdidas. Tal comportamento oscilatório pode ocorrer de tal forma que a $k$-ésima MS aloque todas as subportadoras e, na sequência, nenhuma, resultando na não-convergência do algoritmo.

Finalmente, em alguns casos de teste escolhidos, nos quais a escolha dos ganhos de canal foi determinada para se ter certos resultados, foram observados alguns erros de 
alocação: inversões simples (quando duas MSs poderiam trocar as portadoras alocadas e melhorar a EE de ambas) e trocas de uma portadora (a alocação ótima indica a alocação da $n$-ésima subportadora para uma MS, e o algoritmo proposto aloca para outra MS). Tal problema pode ser causado pelas modificações que precisaram ser feitas, pela discretização da alocação de subportadoras em cada iteração, entre outros. A análise desse segundo caso de erro mostrou que a portadora alocada erroneamente deveria ser alocada parcialmente pelas duas MSs, o que poderia indicar uma limitação.

\subsection{Limitações de Implementação com Produtório sem RSs}

\subsubsection{Acoplamento das MSs no Cômputo das Alocações de Potência e Sub- portadoras}

Ao contrário da solução obtida no Capítulo 4, as expressões para alocação de potência, equação (5.53), e de cômputo da métrica da alocação de subportadoras, equação (5.55), são acopladas à otimização de variáveis de outras MSs. Para a alocação de potência, os termos $\widetilde{R}_{\bar{k}}$ e $\widetilde{P}_{\bar{k}}$ da equação (5.53) fazem com que a alocação de potência da $k$-ésima MS na $n$-ésima subportadora dependa da alocação de potência de todas as demais MSs em todas as subportadoras. Assim, uma solução ótima, ao menos em termos de sistema, depende da resolução conjunta da alocação de potência em todas as MSs e em todas as subportadoras ao mesmo tempo - um sistema de $K N$ equações. Para o cômputo da alocação de subportadoras, o problema pode ser visto como ainda mais complexo e desafiador, devido à etapa de discretização descrita pela equação (5.39). Como $s_{k, n}^{i, j}$ depende da alocação de todas as subportadoras às demais $K-1 \mathrm{MSs}$, para que seja possível calcular $\widetilde{R}_{\bar{k}}$, e só se sabe a alocação de subportadoras após a etapa de discretização, a solução conjunta da alocação de subportadoras se mostra ainda mais desafiadora que a alocação de potência.

A solução dada para essa limitação é a mesma adotada no caso da solução por somatório de logaritmos, i.e., admitir a utilização das alocações de potência e subportadora da iteração imediatamente anterior para o cálculo de $\widetilde{R}_{\bar{k}}$ e $\widetilde{P}_{\bar{k}}$. Com tal abordagem, as equações de alocação de potência, equação (5.53), e métrica de alocação de subportadoras, equação (5.55), são definidas, respectivamente, como

$$
p_{k, n}^{*, i, j}=\left[\frac{\mathrm{w} \widetilde{R}_{\bar{k}}\left(\widetilde{\mathbf{P}}^{*, i, j-1}, \widetilde{\boldsymbol{\lambda}}^{*, i, j-1}\right) \ell_{k, n}}{\log (2)\left(\tau_{k}^{j-1}+q^{i-1} \widetilde{P}_{\bar{k}}\left(\widetilde{\mathbf{P}}^{*, i, j-1}, \widetilde{\boldsymbol{\lambda}}^{*, i, j-1}\right) \varrho_{k}\right)}-\frac{1}{\Gamma_{k, n} \imath_{k}}\right]^{+}
$$

e

$$
s_{k, n}^{i, j}=\frac{\widetilde{R}_{\bar{k}}\left(\widetilde{\mathbf{P}}^{*, i, j}, \widetilde{\boldsymbol{\lambda}}^{*, i, j-1}\right) \ell_{k, n}}{\log (2)}\left(\log \left(1+p_{k, n}^{*, i, j} \Gamma_{k, n} \iota_{k}\right)-\frac{p_{k, n}^{*, i, j} \Gamma_{k, n} \iota_{k}}{1+p_{k, n}^{*, i, j} \Gamma_{k, n} \iota_{k}}\right)-v_{n}^{j-1}
$$


Altera-se o Algoritmo 5.2 para que a alocação de potência e o cálculo da métrica $s_{k, n}^{i, j}$ sejam feitos usando as equações (7.5) e (7.6), e não mais as equações (5.53) e (5.55).

\subsubsection{Solução Distribuída e Custo Computacional}

Com a adaptação proposta no item anterior, o cômputo da alocação de potência e subportadoras pode ser separado em cada uma das $K$ MSs e $N$ subportadoras, reduzindo a complexidade da obtenção da solução. Por outro lado, mesmo com essa adaptação uma solução distribuída é pouco prática, pois, no mínimo, é necessário que a BS calcule os parâmetros $\widetilde{R}_{\bar{k}}\left(\widetilde{\mathbf{P}}^{*, i, j-1}, \widetilde{\boldsymbol{\lambda}}^{*, i, j-1}\right)$ e $\widetilde{P}_{\bar{k}}\left(\widetilde{\mathbf{P}}^{*, i, j-1}, \widetilde{\boldsymbol{\lambda}}^{*, i, j-1}\right)$ e os transmita para cada uma das $K$ MSs a cada iteração do LDD apenas para calcular a alocação de potência. Além disso, é necessário informar a BS sobre os valores de alocação de potência obtidos, para que essa possa calcular $\widetilde{R}_{\bar{k}}\left(\widetilde{\mathbf{P}}^{*, i, j}, \widetilde{\boldsymbol{\lambda}}^{*, i, j-1}\right)$ e comunicar novamente às MSs, de modo que esses possam calcular a alocação de subportadoras.

Além da comunicação de parâmetros, outro problema associado a $\widetilde{R}_{\bar{k}}$ e $\widetilde{P}_{\bar{k}}$ é o custo computacional para calculá-los. Para $\widetilde{R}_{\bar{k}}$, é necessário calcular a taxa de dados de $(K-1)$ MSs em cada subportadora, somar a taxa de cada MS e então fazer o produtório da taxa de cada MS. É necessário repetir esse procedimento duas vezes a cada iteração do LDD, dado que ocorre uma atualização da alocação de potência. Como os valores são diferentes para cada MS, uma possível redução na complexidade pode ser atingida armazenando as somas de taxa e potência de cada MS, evitando que tais somas precisem ser recalculadas para se obter $\widetilde{R}_{\bar{k}}$ e $\widetilde{P}_{\bar{k}}$ para as $K$ MSs.

\subsubsection{Inicialização de Variáveis}

A obtenção de valores iniciais se mostra muito mais complicada do que para o problema sem fairness desenvolvido no Capítulo 4. Soluções sub-ótimas para a alocação de potência e subportadoras são mais factíveis: por exemplo, a alocação de potência pode ser dada por um método de alocação igualitária de potência (EPA), enquanto a alocação de subportadoras poderia ser feita distribuindo $\lfloor N / K\rfloor$ subportadoras para cada MS, de maneira aleatória, sequencial, em blocos, etc. Porém, tal solução tende a ser muito diferente da solução ótima (ao menos em relação à alocação de subportadoras), ao contrário do que acontece no modelo de inicialização definido para o modelo sem fairness. Por consequência, mesmo que o algoritmo com fairness inicializasse com tais valores, os resultados numéricos preliminares indicavam que a alocação de subportadoras, na primeira iteração, resultava em muitas MSs alocando as mesmas subportadoras ao mesmo tempo, de modo que se fosse tomado o somatório da matriz de alocação de subportadoras $\boldsymbol{\lambda}$, o número obtido tendia a $K N$, ou seja, todas as MSs alocando todas as subportadoras. Com isso, a convergência do algoritmo torna-se demasiadamente lenta, quando atingida; 
afinal lidar com tais extremos na alocação de subportadoras exige um meticuloso controle das variáveis de atualização $\phi_{v}$.

\subsubsection{Evolução da Métrica de Alocação de Subportadoras e dos Multiplica- dores de Lagrange}

Além da dificuldade de convergência, outro problema que surge devido ao incremento exagerado do número de subportadoras alocadas é o controle de múltiplo acesso associado às mudanças introduzidas pela adoção da estratégia de fairness. Como discutido, o termo $\widetilde{R}_{\bar{k}}$ na métrica de alocação de subportadoras é responsável por introduzir a noção de fairness ao problema de alocação de recursos. Quando ocorre um grande aumento no número de subportadoras alocadas, ocorre também, em geral, um aumento significativo na taxa de dados de cada MS, de modo que o produtório $\widetilde{R}_{\bar{k}}$ também cresce, e os resultados numéricos iniciais mostraram que tal aumento é significativo. Como muitas MSs alocavam as mesmas subportadoras, os multiplicadores de Lagrange $\boldsymbol{v}$ crescem ao longo da execução das iterações, de modo que algumas MSs começam a perder subportadoras, acarretando a redução nas métricas de alocação $s_{k, n}$. Em uma determinada iteração, a queda de $\widetilde{R}_{\bar{k}}$, devido à redução no número de subportadoras alocadas, faz com que $v_{n}>s_{k, n} \forall K$ para algumas subportadoras, de modo que essas não são alocadas para nenhuma MS. Tal comportamento não é um problema, uma vez que, ao final, o próprio processo de convergência irá corrigir tal alocação. Um problema grave, e que foi registrado em quase todos os casos de simulação numérica preliminares, é que em uma determinada iteração, a queda na taxa de dados das MSs faz com que $v_{n}>s_{k, n} \forall N$ para uma determinada $k$-ésima MS, ou seja, essa MS fica sem recursos espectrais. Quando isso acontece, o termo

$\widetilde{R}_{\bar{k}}$ de todas as demais MSs torna-se nulo, afinal a taxa nula da $k$-ésima MS está presente no produtório de todas as outras MSs. Com isso, a potência alocada pelas demais MSs se torna nula, nenhuma subportadora é alocada para essas MSs e, a partir daí, o algoritmo fica preso em uma situação em que todas as MSs não possuem qualquer recurso espectral, e a convergência não é atingida.

\subsubsection{Controle de Convergência do Loop DKB}

Finalmente, existe um problema na checagem de convergência do algoritmo de Dinkelbach. A definição da convergência do DKB considerando apenas a diferença entre os parâmetros $q$ das últimas duas iterações não consegue, em alguns casos, retratar a realidade de convergência. Tal situação ocorre pelas ordens de grandeza envolvidas no problema de otimização: como $q$ é determinado pelo produtório das EEs individuais, como mostrado na equação (5.45), algumas simulações numéricas preliminares evidenciam que o parâmetro $q$ pode atingir valores da ordem de $10^{70}$. Como consequência, uma pequena diferença em apenas uma das EEs individuais (e cujo valor pode ser até mesmo menor que o máximo 
erro admitido para o DKB) pode resultar em um erro significativamente grande. Para ilustrar tal problema, considera-se que apenas a EE individual da $k$-ésima MS se alterou durante uma das iterações, de modo que

$$
\xi_{k^{\prime}}^{i}-\xi_{k^{\prime}}^{i-1}=\left\{\begin{array}{ll}
\delta, & k^{\prime}=k \\
0, & k^{\prime} \neq k
\end{array} .\right.
$$

Com isso, na $(i-1)$-ésima iteração do DKB, tem-se $q^{i-1}=\xi_{k}^{i-1} \prod_{\substack{k^{\prime}=1 \\ k^{\prime} \neq k}}^{K} \xi_{k^{\prime}}^{i-1}$, enquanto que ao fim da $i$-ésima iteração do DKB tem-se $q^{i}=\left(\xi_{k}^{i}+\delta\right) \prod_{\substack{k^{\prime}=1 \\ k^{\prime} \neq k}}^{K} \xi_{k^{\prime}}^{i}$. Usando a definição do erro de convergência do DKB, obtém-se

$$
\varepsilon_{\mathrm{dkb}}=\left|q^{i}-q^{i-1}\right|=\delta \prod_{\substack{k^{\prime}=1 \\ k^{\prime} \neq k}}^{K} \xi_{k^{\prime}}^{i}
$$

Considerando $\delta=10^{-10}$ e $\varepsilon_{\mathrm{dkb}}^{\max }=10^{-8}$, basta que a ordem de grandeza de $\prod_{\substack{k^{\prime}=1 \\ k^{\prime} \neq k}}^{K} \xi_{k^{\prime}}^{i}$ seja maior que $10^{2}$ para que, mesmo com erros individuais mínimos, a convergência não seja detectada.

O conjunto de problemas operacionais para ambas as funções-objetivo apresentadas mostra que é necessário formular novas estratégias para que o problema de alocação de recursos em sistemas OFDMA com critério de fairness possa ser efetivamente resolvido, ou seja, que seja possível uma implementação computacional robusta e eficiente, combinando potencialidades de ambos os métodos descritos até aqui.

\subsection{Limitações de Implementação para Fairness Proporcional em Modo Cooperativo}

As questões apontadas nas Seções 7.1 (somatório de logaritmos) e 7.2 (produtório) são pertinentes também às implementações das mesmas soluções quando da utilização de estações retransmissoras. Para que todos os casos não sejam reescritos novamente, comenta-se nesta seção as mudanças geradas no equacionamento das soluções propostas no Capítulo 6.

\subsubsection{Solução por Somatório de Logaritmos}

As equações (6.46) e (6.60) mostram que a alocação ótima de potência na $n$-ésima subportadora da $k$-ésima MS, tanto para AF quanto para DF, deve ser feita conjuntamente em todas as $N$ subportadoras da $k$-ésima MS, devido aos termos $D_{2}^{\mathrm{AF}}$ e $D_{2}^{\mathrm{DF}}$, equações (6.44) e 
(6.59). Tal problema é semelhante ao descrito na Subseção 7.1.1, que foi solucionado com a utilização da alocação de potência obtida na $(j-1)$-ésima iteração do LDD. Utilizando a mesma definição, os termos $D_{2}^{\mathrm{AF}}$ são reescritos, respectivamente, como

$$
D_{2}^{\mathrm{AF}}=\prod_{\substack{m=1 \\ m \neq n}}^{N}\left(1+\imath_{k}^{\mathrm{AF}} \Gamma_{k, m, l, 0}^{\mathrm{AF}, i, j} p_{k, m, l}^{*, i, j-1}\right)^{\frac{\widetilde{\lambda}_{k, m}^{*, i, j-1} \ell_{k, m}}{\ell_{k, n}}}
$$

e

$$
D_{2}^{\mathrm{DF}}=\prod_{\substack{m=1 \\ m \neq n}}^{N}\left(1+\imath_{k}^{\mathrm{DF}} \Omega_{k, m, l}^{\mathrm{DF}} p_{k, m, l}^{*, i, j-1} \Gamma_{k, m, l}\right)^{\frac{{\widetilde{\lambda_{k}^{*}, i, m}}_{\ell_{k, n}} \ell_{k, m}}{\ell_{k}}}
$$

Já no cálculo das métricas de alocação, as discussões apresentadas nas Subseções 7.1.2 e 7.1.5 também se aplicam às equações (6.49) e (6.63). Pode ser percebido que em ambas as equações é necessário decidir conjuntamente a alocação de todas as $N$ subportadoras, lembrando que tal decisão envolve calcular as métricas de alocação e decidir quais das subportadoras devem ser alocadas. Assim sendo, considera-se que a alocação de subportadoras obtida na $i$-ésima iteração do DCP e $(j-1)$-ésima iteração do LDD será utilizada para computar as métricas $s_{k, n}^{i, j}$, além de que $\lambda_{k, n}^{*, i, j-1}=1$. Com isso, $s_{k, n}^{i, j}$ é dada por

$$
s_{k, n}^{i, j}=\frac{\ell_{k, n}\left[\log \left(1+\imath_{k}^{\mathrm{AF}} \Gamma_{k, n, l, 0}^{\mathrm{AF}, i, j} p_{k, n, l}^{*, i, j}\right)-\frac{\imath_{k}^{\mathrm{AF}} \Gamma_{k, n, l, 0}^{\mathrm{AF}, i, j} p_{k, n, l, l}^{*, i, j}}{\left(1+\ell_{k}^{\mathrm{AF}} \Gamma_{k, n, l, 0}^{\mathrm{AF}, j} p_{k, n, l}^{*, i, j}\right)}\right]}{\log (b)\left[\ell_{k, n} \log \left(1+\imath_{k}^{\mathrm{AF}} \Gamma_{k, n, l, 0}^{\mathrm{AF}, i, j} p_{k, n, l}^{*, i, j}\right)+\sum_{\substack{m=1 \\ m \neq n}}^{N} \lambda_{k, m}^{*, i, j-1} \ell_{k, m} \log \left(1+\imath_{k}^{\mathrm{AF}} \Gamma_{k, m, l, 0}^{\mathrm{AF}, i, j} p_{k, m, l}^{*, i, j}\right)\right]}
$$

para o protocolo $\mathrm{AF}$, enquanto que

$$
\begin{aligned}
& \frac{s_{k, n}^{i, j}=}{\ell_{k, n}\left[\log \left(1+\imath_{k}^{\mathrm{DF}} \Omega_{k, n, l}^{\mathrm{DF}} p_{k, n, l}^{*, i, j} \Gamma_{k, n, l}\right)-\frac{\imath_{k}^{\mathrm{DF}} \Omega_{k, n, l}^{\mathrm{DF}} p_{k, n, l}^{*, i, j} \Gamma_{k, n, l}}{\left(1+\imath_{k}^{\mathrm{DF}} \Gamma_{k, n, l} p_{k, n, l}^{*, j} \Gamma_{k, n, l}\right)}\right]} \\
& \log (b)\left(\ell_{k, n} \log \left(1+\imath_{k}^{\mathrm{DF}} \Omega_{k, n, l}^{\mathrm{DF}} p_{k, n, l}^{*, i, j} \Gamma_{k, n, l}\right)+\sum_{\substack{m=1 \\
m \neq n}}^{N} \lambda_{k, m}^{*, i, j-1} \ell_{k, m} \log \left(1+\imath_{k}^{\mathrm{DF}} \Omega_{k, m, l}^{\mathrm{DF}} p_{k, m, l}^{*, i, j} \Gamma_{k, m, l}\right)\right)
\end{aligned}
$$

para o protocolo DF.

Em relação ao Algoritmo 6.1, que sumariza a solução por somatório de logaritmos para ambos os protocolos, os termos $D_{2}^{\mathrm{AF}}$ e $D_{2}^{\mathrm{DF}}$ apresentados nesta subseção substituem os respectivos termos nas equações (6.46) e (6.60), utilizadas para calcular as potências ótimas. Já em relação ao cálculo de $s_{k, n}^{i, j}$, as equações (7.11) e (7.12) substituem, respectivamente, as equações (6.49) e (6.63). Os demais passos do algoritmo permanecem inalterados. 


\subsubsection{Solução por Produtório}

A alocação de potência da $k$-ésima MS na $n$-ésima subportadora auxiliado pela $l$-ésima RS depende da alocação de potência nas demais $K-1$ MSs e $N_{\mathrm{RS}}$ RSs em todas as $N$ subportadoras, devido aos termos $\widetilde{R}_{\bar{k}}^{\mathrm{AF}}\left(\widetilde{\mathbf{P}}, \widetilde{\mathbf{P}}_{r}, \widetilde{\boldsymbol{\lambda}}^{*, i, j-1}\right)$ e $\widetilde{P}_{\bar{k}}^{\mathrm{AF}}\left(\widetilde{\mathbf{P}}, \widetilde{\mathbf{P}}_{r}, \widetilde{\boldsymbol{\lambda}}^{*, i, j-1}\right)$ presentes nas equações (6.76) (MSs diretos), (6.87) (potência total com protocolo AF) e (6.96) (potência total com protocolo DF). Para que não seja necessário ter um sistema de equações para alocar a potência das MSs e RSs, se considera que os termos $\widetilde{\mathbf{P}}$ e $\widetilde{\mathbf{P}}_{r}$ em $\widetilde{R}_{\bar{k}}^{\mathrm{AF}}\left(\widetilde{\mathbf{P}}, \widetilde{\mathbf{P}}_{r}, \tilde{\boldsymbol{\lambda}}^{i, j-1}\right)$ e $\widetilde{P}_{\bar{k}}^{\mathrm{AF}}\left(\widetilde{\mathbf{P}}, \widetilde{\mathbf{P}}_{r}, \widetilde{\boldsymbol{\lambda}}^{i, j-1}\right)$ sejam os obtidos na $(j-1)$-ésima iteração do LDD, de modo que:

$$
\begin{gathered}
p_{k, n}^{*, i, j}=\left[\frac{R_{\bar{k}}^{\varpi}\left(\widetilde{\mathbf{P}}^{*, i, j-1}, \widetilde{\mathbf{P}}_{r}^{* i, j-1}, \widetilde{\boldsymbol{\lambda}}^{*, i, j-1}\right) \ell_{k, n}}{\log (2)\left(\tau_{k}^{j-1}+q^{i-1} \widetilde{P}_{\bar{k}}^{\varpi}\left(\widetilde{\mathbf{P}}^{*, i, j-1}, \widetilde{\mathbf{P}}_{r}^{*, i, j-1}, \widetilde{\boldsymbol{\lambda}}^{*, i, j-1}\right) \varrho_{k}\right)}-\frac{1}{\Gamma_{k, n, 0}}\right]^{+} \quad \text { (7.13a) } \\
p_{k, n, l}^{*, i, j}=\left[\frac{\mathrm{\omega} \widetilde{R}_{\bar{k}}^{\mathrm{AF}}\left(\widetilde{\mathbf{P}}^{*, i, j-1}, \widetilde{\mathbf{P}}_{r}^{*, i, j-1}, \widetilde{\boldsymbol{\lambda}}^{*, i, j-1}\right) \ell_{k, n}}{\log (2) F_{k, n, l}^{\mathrm{AF}, i, j}\left(\widetilde{\mathbf{P}}^{*, i, j-1}, \widetilde{\mathbf{P}}_{r}^{*, i, j-1}, \widetilde{\boldsymbol{\lambda}}^{*, i, j-1}\right)}-\frac{1}{\imath_{k}^{\mathrm{AF}} \Gamma_{k, n, l, 0}^{\mathrm{AF}, i, j}\left(\widetilde{\mathbf{P}}^{*, i, j-1}, \widetilde{\mathbf{P}}_{r}^{*, i, j-1}, \widetilde{\boldsymbol{\lambda}}^{*, i, j-1}\right)}\right]_{(7.13 \mathrm{~b})}^{+} \\
p_{k, n, l}^{*, i, j}=\left[\frac{\mathrm{w} \widetilde{R}_{\bar{k}}^{\mathrm{DF}}\left(\widetilde{\mathbf{P}}^{*, i, j-1}, \widetilde{\mathbf{P}}_{r}^{*, i, j-1}, \widetilde{\boldsymbol{\lambda}}^{*, i, j-1}\right) \ell_{k, n}}{\log (2) F_{k, n, l}^{\mathrm{DF}, i, j}\left(\widetilde{\mathbf{P}}^{*, i, j-1}, \widetilde{\mathbf{P}}_{r}^{*, i, j-1}, \widetilde{\boldsymbol{\lambda}}^{*, i, j-1}\right)}-\frac{1}{l_{k}^{\mathrm{DF}} \Omega_{k, n, l}^{\mathrm{DF}} \Gamma_{k, n, l}}\right]^{+}
\end{gathered}
$$

Com isso, o Algoritmo 6.2 passa a utilizar a equação (7.13a) ao invés da equação (6.76) para as MSs diretas, a equação (7.13b) ao invés da equação (6.85) para as MSs em protocolo $\mathrm{AF}$, e a equação (7.13c) ao invés da equação (6.96).

Para os casos em que a $k$-ésima MS utiliza o protocolo AF, é necessário também considerar o uso das alocações de potência da $(j-1)$-ésima iteração do LDD nas expressões em que se obtêm $p_{k, n}^{*, i, j}$ e $p_{r_{l, n}}^{*, i, j}$, equação (7.14). Com as modificações, as novas expressões são dadas por:

$$
\begin{aligned}
& p_{k, n}^{*, i, j}=\Omega_{k, n, l}^{\mathrm{AF}, i, j}\left(\widetilde{\mathbf{P}}^{*, i, j-1}, \widetilde{\mathbf{P}}_{r}^{*, i, j-1}, \widetilde{\boldsymbol{\lambda}}^{*, i-1}\right) p_{k, n, l}^{*, i, j} \\
& p_{r_{l, n}}^{*, i, j}=p_{k, n, l}^{*, i, j}-p_{k, n}^{*, i, j}
\end{aligned}
$$

Assim, o Algoritmo 6.2 passa a utilizar a equação (7.14) ao invés da equação (6.88) quando a MS utiliza protocolo AF.

O cálculo de $s_{k, n}^{i, j}$ nas equações (6.77) (MS direta), (6.90) (AF) e (6.99) (DF) sofre do mesmo problema analisado para a alocação de potência: devido ao termo $\widetilde{R}_{\bar{k}}^{\varpi}\left(\widetilde{\mathbf{P}}^{*, i, j}, \widetilde{\mathbf{P}}_{r}^{*, i, j}, \widetilde{\boldsymbol{\lambda}}\right)$, o cômputo da métrica de alocação da $k$-ésima MS na $n$-ésima subportadora depende da alocação conjunta de subportadoras nas demais $K-1$ MSs em todas as $N$ subportadoras. A solução adotada será similar à discutida para a alocação de potência, i.e., considerar 
que durante o cálculo de $s_{k, n}^{i, j}$ a alocação de subportadoras nas demais $K-1$ MSs é dada pela alocação obtida na $(j-1)$-ésima iteração do LDD. Desse modo, o cômputo de $s_{k, n}^{i, j}$ para as MSs diretas, com protocolo AF e DF é dado, respectivamente, por

$$
\begin{aligned}
s_{k, n}^{i, j}= & \frac{\widetilde{R}_{\bar{k}}^{\varpi}\left(\widetilde{\mathbf{P}}^{*, i, j}, \widetilde{\mathbf{P}}_{r}^{*, i, j}, \widetilde{\boldsymbol{\lambda}}^{*, i, j-1}\right) \ell_{k, n}}{\log (2)}\left(\log \left(1+p_{k, n}^{*, i, j} \Gamma_{k, n, 0}\right)-\frac{p_{k, n}^{*, i, j} \Gamma_{k, n, 0}}{1+p_{k, n}^{*, i, j} \Gamma_{k, n, 0}}\right) \\
-v_{n}^{j-1}, & \\
s_{k, n}^{i, j}= & \frac{\mathrm{\omega} \ell_{k, n} \widetilde{R}_{\bar{k}}^{\mathrm{AF}}\left(\widetilde{\mathbf{P}}^{*, i, j}, \widetilde{\mathbf{P}}_{r}^{*, i, j}, \widetilde{\boldsymbol{\lambda}}^{*, i, j-1}\right) \log \left(1+\imath_{k}^{\mathrm{AF}} \Gamma_{k, n, l, 0}^{\mathrm{AF}, i, j} p_{k, n, l}^{*, i, j}\right)}{2 \log (2)} \\
& -\frac{\mathrm{\omega} \ell_{k, n} \widetilde{R}_{\bar{k}}^{\mathrm{AF}}\left(\widetilde{\mathbf{P}}^{*, i, j}, \widetilde{\mathbf{P}}_{r}^{*, i, j}, \widetilde{\boldsymbol{\lambda}}^{*, i, j-1}\right) l_{k}^{\mathrm{AF}} \Gamma_{k, n, l, 0}^{\mathrm{AF}, i, j}\left(\widetilde{\mathbf{P}}^{*, i, j}, \widetilde{\mathbf{P}}_{r}^{*, i, j}, \widetilde{\boldsymbol{\lambda}}^{*, i, j-1}\right) p_{k, n, l}^{*, i, j}}{2 \log (2)\left(1+\imath_{k}^{\mathrm{AF}} \Gamma_{k, n, l, 0}^{\mathrm{AF}, i, j}\left(\widetilde{\mathbf{P}}^{*, i, j}, \widetilde{\mathbf{P}}_{r}^{*, i, j}, \widetilde{\boldsymbol{\lambda}}^{*, i, j-1}\right) p_{k, n, l}^{*, i, j}\right)}-v_{n}^{j-1},
\end{aligned}
$$

$\mathrm{e}$

$$
\begin{aligned}
s_{k, n}^{i, j}= & \frac{\mathrm{W} \ell_{k, n} \widetilde{R}_{\bar{k}}^{\mathrm{DF}}\left(\widetilde{\mathbf{P}}^{*, i, j}, \widetilde{\mathbf{P}}_{r}^{*, i, j}, \widetilde{\boldsymbol{\lambda}}^{*, i, j-1}\right)}{2 \log (2)}\left[\log \left(1+\imath_{k}^{\mathrm{DF}} \Omega_{k, n, l}^{\mathrm{DF}} \Gamma_{k, n, l} p_{k, n, l}^{*, i}\right)\right] \\
& -\frac{\mathrm{W} \ell_{k, n} \widetilde{R}_{\bar{k}}^{\mathrm{DF}}\left(\widetilde{\mathbf{P}}^{*, i, j}, \widetilde{\mathbf{P}}_{r}^{*, i, j}, \widetilde{\boldsymbol{\lambda}}^{*, i, j-1}\right)}{2 \log (2)}\left[\frac{\imath_{k}^{\mathrm{DF}} \Omega_{k, n, l}^{\mathrm{DF}} \Gamma_{k, n, l} p_{k, n, l}^{*, i, j}}{\left(1+\imath_{k}^{\mathrm{DF}} \Omega_{k, n, l}^{\mathrm{DF}} \Gamma_{k, n, l} p_{k, n, l}^{*, i}\right)}\right]-v_{n}^{j-1} .
\end{aligned}
$$

Desse modo, o Algoritmo 6.2 utiliza a equação (7.15a) ao invés da equação (6.77) para MSs diretas, a equação (7.15b) ao invés da equação (6.90) para MSs com protocolo AF, e a equação (7.15d) ao invés da equação (6.99) para MSs com protocolo DF.

\subsection{Solução Híbrida para Maximização de EE com Fairness Pro- porcional sem RSs}

A partir das considerações feitas até agora, tanto a solução via DCP+LDD, com funçãoobjetivo dada por somatório de logaritmos, quanto a solução via DKB+LDD, com funçãoobjetivo dada por produtório das EEs individuais, podem ser efetivamente empregadas para solucionar o problema de maximização de EE com fairness. Para a primeira abordagem, utilizando DCP e LDD, calcular a potência pela função $W$ de Lambert, equação (7.1), e também os termos necessários, é bastante lento e sujeito a falhas, tais como MSs sem recurso espectral e parâmetros com valores que extrapolam a precisão numérica da ferramenta de simulação, entre outros. Para a segunda abordagem, DKB+LDD, a falta de uma estratégia efetiva de inicialização dos parâmetros necessários, combinada a uma maior dificuldade do controle de convergência e a possibilidade de não-convergência do algoritmo, devido ao problema de MSs sem recursos espectrais, limitaram a aplicação a alguns poucos casos do conjunto de testes. 
A solução híbrida que será discutida aqui é uma adaptação do algoritmo DKB+LDD apresentado na Seção 5.4, ou seja, considerando a adoção da função-objetivo com produtório de EEs individuais. O pseudocódigo dessa solução é apresentado no Algoritmo 5.2. A escolha da combinação DKB+LDD para a solução do problema de alocação de recursos com fairness proporcional é motivada por:

- O background com tal combinação, advindo da solução descrita e analisada no Capítulo 4;

- Facilidade de análise das expressões de alocação de potência e subportadoras, dado que na combinação DCP+LDD a equação de alocação de potência, equação (7.1), resulta na utilização de uma função que não pode ser expressa em termos de outras funções, de modo que não há como analisar possíveis simplificações ou modos de reduzir a complexidade computacional de cada iteração;

- Como será visto, é possível manipular as expressões para alocação de potência, equação (7.5), e cálculo da métrica de alocação, equação (7.6), obtidas por meio da combinação DKB+LDD para se chegar às expressões utilizadas no modelo híbrido proposto nesta seção.

Quatro problemas devem ser solucionados para se obter um algoritmo robusto e eficiente para o problema de otimização proposto:

1. como calcular a alocação de potência de cada MS em cada subportadora, simplificando a expressão obtida originalmente para a combinação DKB+LDD, equação $(7.5)$;

2. como calcular a alocação de subportadoras, usando uma expressão claramente inspirada na combinação DCP+LDD, equação (7.3), mas que pode ser obtida com algumas manipulações da expressão obtida via DKB+LDD, equação (7.6);

3. um método mais robusto para controlar a convergência do algoritmo DKB, inspirado em resultados de propagação de pequenos erros nas EEs individuais, conforme exposto na equação (7.8);

4. estratégias de inicialização para o algoritmo proposto, dado que a estrutura do pseudocódigo provém da combinação DKB+LDD.

\subsubsection{Simplificação da Alocação de Potência}

Tanto a combinação DCP+LDD quanto a combinação DKB+LDD dependem do cômputo de alguns produtórios em cada iteração de alocação de potência. No caso do método DCP+LDD, para cada tupla de subportadoras e MSs é necessário computar um produtório de $N-1$ termos, equação (7.1), enquanto que para o algoritmo DKB+LDD, cada 
tupla de subportadoras e MSs necessita que se computem dois produtórios, de taxa e potência, cada um com $K-1$ termos que são dados pelo somatório de $N-1$ termos, os quais incluem o cálculo de uma função logaritmo no caso do produtório de taxa, $R_{\bar{k}}$. A complexidade computacional adicionada por esses cálculos é bastante significativa, sem contar a complexidade que o próprio cálculo da expressão de alocação de potência pode ter, no caso do uso da função $W$ de Lambert pelo método DCP+LDD. Tal resultado é oposto ao observado no caso não-cooperativo sem fairness, desenvolvido no Capítulo 4, em que a expressão de alocação de potência possuía baixa complexidade nos termos individuais. Com algumas considerações adicionais, no entanto, é possível definir um método menos complexo para alocar a potência em cada uma das $K$ MSs, utilizando a estrutura básica de um algoritmo do tipo DKB+LDD.

Considere a equação de alocação de potência para DKB+LDD na $i$-ésima iteração do DKB e $j$-ésima iteração do LDD, equação (7.5), repetida aqui por conveniência:

$$
p_{k, n}^{*, i, j}=\left[\frac{\mathrm{w} \widetilde{R}_{\bar{k}}\left(\widetilde{\mathbf{P}}^{*, i, j-1}, \widetilde{\boldsymbol{\lambda}}^{*, i, j-1}\right) \ell_{k, n}}{\log (2)\left(\tau_{k}^{j-1}+q^{i-1} \widetilde{P}_{\bar{k}}\left(\widetilde{\mathbf{P}}^{*, i, j-1}, \widetilde{\boldsymbol{\lambda}}^{*, i, j-1}\right) \varrho_{k}\right)}-\frac{1}{\Gamma_{k, n} \iota_{k}}\right]^{+}
$$

Analisando a alocação de potência na $i$-ésima iteração do DKB e na primeira iteração do LDD, i.e., $j=1$, tem-se que:

$$
p_{k, n}^{*, i, 1}=\left[\frac{\mathrm{w} \widetilde{R}_{\bar{k}}\left(\widetilde{\mathbf{P}}^{*, i, 0}, \widetilde{\boldsymbol{\lambda}}^{*, i, 0}\right) \ell_{k, n}}{\log (2)\left(\tau_{k}^{0}+q^{i-1} \widetilde{P}_{\bar{k}}\left(\widetilde{\mathbf{P}}^{*, i, 0}, \widetilde{\boldsymbol{\lambda}}^{*, i, 0}\right) \varrho_{k}\right)}-\frac{1}{\Gamma_{k, n} \iota_{k}}\right]^{+} .
$$

Pode-se reescrever $q^{i-1}$ como:

$$
\begin{aligned}
& q^{i-1}= \frac{\widetilde{R}_{\bar{k}}\left(\widetilde{\mathbf{P}}^{*, i-1}, \widetilde{\boldsymbol{\lambda}}^{*, i-1}\right) \widetilde{R}_{k}\left(\widetilde{\mathbf{P}}^{*, i-1}, \widetilde{\boldsymbol{\lambda}}^{*, i-1}\right)}{\widetilde{P}_{\bar{k}}\left(\widetilde{\mathbf{P}}^{*, i-1}, \widetilde{\boldsymbol{\lambda}}^{*, i-1}\right) \widetilde{P}_{k}\left(\widetilde{\mathbf{P}}^{*, i-1}, \widetilde{\boldsymbol{\lambda}}^{*, i-1}\right)} \\
&=\frac{\widetilde{R}_{\bar{k}}\left(\widetilde{\mathbf{P}}^{*, i, 0}, \widetilde{\boldsymbol{\lambda}}^{*, i, 0}\right) \widetilde{R}_{k}\left(\widetilde{\mathbf{P}}^{*, i, 0}, \widetilde{\boldsymbol{\lambda}}^{*, i, 0}\right)}{\widetilde{P}_{\bar{k}}\left(\widetilde{\mathbf{P}}^{*, i, 0}, \widetilde{\boldsymbol{\lambda}}^{*, i, 0}\right) \widetilde{P}_{k}\left(\widetilde{\mathbf{P}}^{*, i, 0}, \widetilde{\boldsymbol{\lambda}}^{*, i, 0}\right)}
\end{aligned}
$$

em que $\widetilde{R}_{\bar{k}}\left(\widetilde{\mathbf{P}}^{*, i, 0}, \widetilde{\boldsymbol{\lambda}}^{*, i, 0}\right)$ e $\widetilde{P}_{\bar{k}}\left(\widetilde{\mathbf{P}}^{*, i, 0}, \widetilde{\boldsymbol{\lambda}}^{*, i, 0}\right)$ são, respectivamente, o produtório de taxa e potência das demais $K-1$ MSs no início da $i$-ésima iteração do DKB, enquanto $\widetilde{R}_{k}\left(\widetilde{\mathbf{P}}^{*, i, 0}, \widetilde{\boldsymbol{\lambda}}^{*, i, 0}\right)$ e $\widetilde{P}_{k}\left(\widetilde{\mathbf{P}}^{*, i, 0}, \widetilde{\boldsymbol{\lambda}}^{*, i, 0}\right)$ são, respectivamente, o somatório de taxa e potência do $k$-ésimo usuário no início da $i$-ésima iteração do DKB. Esses termos são obtidos com a alocação de potência e subportadoras definidas como ótimas ao fim da $(i-1)$-ésima iteração do DKB, sendo então utilizadas como estimativa inicial da próxima iteração. 
Substituindo $q^{i-1}$ em (7.17), e considerando apenas o termo equivalente ao nível d'água, tem-se que:

$$
\begin{aligned}
& \frac{\mathrm{w} \widetilde{R}_{\bar{k}}\left(\widetilde{\mathbf{P}}^{*, i, 0}, \widetilde{\boldsymbol{\lambda}}^{*, i, 0}\right) \ell_{k, n}}{\log (2)\left(\tau_{k}^{0}+q^{i-1} \widetilde{P}_{\bar{k}}\left(\widetilde{\mathbf{P}}^{*, i, 0}, \widetilde{\boldsymbol{\lambda}}^{*, i, 0}\right) \varrho_{k}\right)} \\
& =\frac{\mathrm{w} \widetilde{R}_{\bar{k}}\left(\widetilde{\mathbf{P}}^{*, i, 0}, \widetilde{\boldsymbol{\lambda}}^{*, i, 0}\right) \ell_{k, n}}{\log (2)\left(\tau_{k}^{0}+\frac{\widetilde{R}_{\bar{k}}\left(\widetilde{\mathbf{P}}^{*, i, 0}, \widetilde{\boldsymbol{\lambda}}^{*, i, 0}\right) \widetilde{R}_{k}\left(\widetilde{\mathbf{P}}^{*, i, 0}, \widetilde{\boldsymbol{\lambda}}^{*, i, 0}\right)}{\widetilde{P}_{\bar{k}}\left(\widetilde{\mathbf{P}}^{*, i, 0}, \widetilde{\boldsymbol{\lambda}}^{*, i, 0}\right) \widetilde{P}_{k}\left(\widetilde{\mathbf{P}}^{*, i, 0}, \widetilde{\boldsymbol{\lambda}}^{*, i, 0}\right)} \widetilde{P}_{\bar{k}}\left(\widetilde{\mathbf{P}}^{*, i, 0}, \widetilde{\boldsymbol{\lambda}}^{*, i, 0}\right) \varrho_{k}\right)} \\
& =\frac{\mathrm{w} \widetilde{R}_{\bar{k}}\left(\widetilde{\mathbf{P}}^{*, i, 0}, \widetilde{\boldsymbol{\lambda}}^{*, i, 0}\right) \ell_{k, n}}{\log (2)\left(\tau_{k}^{0}+\frac{\widetilde{R}_{\bar{k}}\left(\widetilde{\mathbf{P}}^{*, i, 0}, \widetilde{\boldsymbol{\lambda}}^{*, i, 0}\right) \widetilde{R}_{k}\left(\widetilde{\mathbf{P}}^{*, i, 0}, \widetilde{\boldsymbol{\lambda}}^{*, i, 0}\right)}{\widetilde{P}_{k}\left(\widetilde{\mathbf{P}}^{*, i, 0}, \widetilde{\boldsymbol{\lambda}}^{*, i, 0}\right)} \varrho_{k}\right)} \\
& =\frac{\mathrm{w} \widetilde{R}_{\bar{k}}\left(\widetilde{\mathbf{P}}^{*, i, 0}, \widetilde{\boldsymbol{\lambda}}^{*, i, 0}\right) \widetilde{P}_{k}\left(\widetilde{\mathbf{P}}^{*, i, 0}, \widetilde{\boldsymbol{\lambda}}^{*, i, 0}\right) \ell_{k, n}}{\log (2)\left(\widetilde{P}_{k}\left(\widetilde{\mathbf{P}}^{*, i, 0}, \widetilde{\boldsymbol{\lambda}}^{*, i, 0}\right) \tau_{k}^{0}+\widetilde{R}_{\bar{k}}\left(\widetilde{\mathbf{P}}^{*, i, 0}, \widetilde{\boldsymbol{\lambda}}^{*, i, 0}\right) \widetilde{R}_{k}\left(\widetilde{\mathbf{P}}^{*, i, 0}, \widetilde{\boldsymbol{\lambda}}^{*, i, 0}\right) \varrho_{k}\right)}
\end{aligned}
$$
se:

Dividindo o numerador e o denominador por $\widetilde{R}_{\bar{k}}\left(\widetilde{\mathbf{P}}^{*, i, 0}, \widetilde{\boldsymbol{\lambda}}^{*, i, 0}\right) \widetilde{P}_{k}\left(\widetilde{\mathbf{P}}^{*, i, 0}, \widetilde{\boldsymbol{\lambda}}^{*, i, 0}\right)$, obtém-

$$
\frac{\mathrm{w} \ell_{k, n}}{\log (2) \underbrace{\frac{\tau_{k}^{0}}{\widetilde{R}_{\bar{k}}\left(\widetilde{\mathbf{P}}^{*, i, 0}, \widetilde{\boldsymbol{\lambda}}^{*, i, 0}\right)}}_{\text {(I) }}+\log (2)} \underbrace{\frac{\widetilde{R}_{k}\left(\widetilde{\mathbf{P}}^{*, i, 0}, \widetilde{\boldsymbol{\lambda}}^{*, i, 0}\right)}{\widetilde{P}_{k}\left(\widetilde{\mathbf{P}}^{*, i, 0}, \widetilde{\boldsymbol{\lambda}}^{*, i, 0}\right)}}_{\text {(II) }} \varrho_{k}
$$

onde (I) pode ser visto como um ajuste (ou normalização) no valor dos multiplicadores de Lagrange entre as duas abordagens e (II) como o parâmetro $q_{k}^{i}$ de DKB para o caso de uma solução individual do problema de maximização de EE, dado que

$$
\begin{aligned}
\frac{R_{k}\left(\widetilde{\mathbf{P}}^{*, i, 0}, \widetilde{\boldsymbol{\lambda}}^{*, i, 0}\right)}{P_{k}\left(\widetilde{\mathbf{P}}^{*, i, 0}, \widetilde{\boldsymbol{\lambda}}^{*, i, 0}\right)} & =\frac{R_{k}\left(\widetilde{\mathbf{P}}^{*, i-1}, \tilde{\boldsymbol{\lambda}}^{*, i-1}\right)}{P_{k}\left(\widetilde{\mathbf{P}}^{*, i-1}, \widetilde{\boldsymbol{\lambda}}^{*, i-1}\right)} \\
& =\frac{\mathrm{W} \sum_{n=1}^{N} \widetilde{\lambda}_{k, n} \ell_{k, n} \log _{2}\left(1+\frac{\widetilde{p}_{k, n}^{*, i-1} \Gamma_{k, n} \imath_{k}}{\widetilde{\lambda}_{k, n}^{*, i-1}}\right)}{\sum_{n=1}^{N} \varrho_{k} \widetilde{p}_{k, n}^{*, i-1}+p_{c, k}}
\end{aligned}
$$

Tal relação só vale diretamente no caso da primeira iteração do LDD em cada uma 
das iterações do DKB, pois em qualquer outra $j$-ésima iteração do LDD tem-se que:

$$
\begin{aligned}
& \frac{\widetilde{R}_{\bar{k}}\left(\widetilde{\mathbf{P}}^{*, i, j-1}, \widetilde{\boldsymbol{\lambda}}^{*, i, j-1}\right) \ell_{k, n}}{\log (2)\left(\tau_{k}^{j-1}+q^{i-1} \widetilde{P}_{\bar{k}}\left(\widetilde{\mathbf{P}}^{*, i, j-1}, \widetilde{\boldsymbol{\lambda}}^{*, i, j-1}\right) \varrho_{k}\right)}= \\
& \frac{\widetilde{R}_{\bar{k}}\left(\widetilde{\mathbf{P}}^{*, i, j-1}, \widetilde{\boldsymbol{\lambda}}^{*, i, j-1}\right) \ell_{k, n}}{\log (2)\left(\tau_{k}^{j-1}+\frac{\widetilde{R}_{\bar{k}}\left(\widetilde{\mathbf{P}}^{*, i, 0}, \widetilde{\boldsymbol{\lambda}}^{*, i, 0}\right) \widetilde{R}_{k}\left(\widetilde{\mathbf{P}}^{*, i, 0}, \widetilde{\boldsymbol{\lambda}}^{*, i, 0}\right)}{\widetilde{P}_{\bar{k}}\left(\widetilde{\mathbf{P}}^{*, i, 0}, \widetilde{\boldsymbol{\lambda}}^{*, i, 0}\right) \widetilde{P}_{k}\left(\widetilde{\mathbf{P}}^{*, i, 0}, \widetilde{\boldsymbol{\lambda}}^{*, i, 0}\right)} \widetilde{P}_{\bar{k}}\left(\widetilde{\mathbf{P}}^{*, i, j-1}, \widetilde{\boldsymbol{\lambda}}^{*, i, j-1}\right) \varrho_{k}\right)}= \\
& \frac{\log (2)\left(\frac{\tau_{k}^{j-1}}{\widetilde{R}_{\bar{k}}\left(\widetilde{\mathbf{P}}^{*, i, j-1}, \widetilde{\boldsymbol{\lambda}}^{*, i, j-1}\right)}+\frac{\widetilde{R}_{\bar{k}}\left(\widetilde{\mathbf{P}}^{*, i, 0}, \widetilde{\boldsymbol{\lambda}}^{*, i, 0}\right) \widetilde{R}_{k}\left(\widetilde{\mathbf{P}}^{*, i, 0}, \widetilde{\boldsymbol{\lambda}}^{*, i, 0}\right)}{\widetilde{P}_{\bar{k}}\left(\widetilde{\mathbf{P}}^{*, i, 0}, \widetilde{\boldsymbol{\lambda}}^{*, i, 0}\right) \widetilde{P}_{k}\left(\widetilde{\mathbf{P}}^{*, i, 0}, \widetilde{\mathbf{P}}^{*, i, 0}\right)} \frac{\widetilde{R}_{\bar{k}}\left(\widetilde{\mathbf{P}}^{*, i, j-1}, \widetilde{\boldsymbol{\lambda}}^{*, i, j-1}\right)}{\widetilde{\ell}_{k, n}}\right)}{\log (2)\left(\frac{\tau_{k}^{j-1}}{\widetilde{R}_{\bar{k}}\left(\widetilde{\mathbf{P}}^{*, i, j-1}, \widetilde{\boldsymbol{\lambda}}^{*, i, j-1}\right)}+\frac{\widetilde{R}_{\bar{k}}\left(\widetilde{\mathbf{P}}^{*, i, 0}, \widetilde{\boldsymbol{\lambda}}^{*, i, 0}\right) \widetilde{P}_{\bar{k}}\left(\widetilde{\mathbf{P}}^{*, i, j-1}, \widetilde{\boldsymbol{\lambda}}^{*, i, j-1}\right)}{\widetilde{R}_{\bar{k}}\left(\widetilde{\mathbf{P}}^{*, i, j-1}, \widetilde{\boldsymbol{\lambda}}^{*, i, j-1}\right) \widetilde{P}_{\bar{k}}\left(\widetilde{\mathbf{P}}^{*, i, 0}, \widetilde{\boldsymbol{\lambda}}^{*, i, 0}\right)}\left(\frac{\widetilde{R}_{k}\left(\widetilde{\mathbf{P}}^{*, i, 0}, \widetilde{\boldsymbol{\lambda}}^{*, i, 0}\right)}{\widetilde{P}_{k}\left(\widetilde{\mathbf{P}}^{*, i, 0}, \widetilde{\boldsymbol{\lambda}}^{*, i, 0}\right)}\right) \varrho_{k}\right)}= \\
& \frac{\ell_{k, n}}{\log (2)\left(\frac{\tau_{k}^{j-1}}{\widetilde{R}_{\bar{k}}\left(\widetilde{\mathbf{P}}^{*, i, j-1}, \widetilde{\boldsymbol{\lambda}}^{*, i, j-1}\right)}+\delta_{\mathrm{q}}^{i, j-1}\left(\frac{\widetilde{R}_{k}\left(\widetilde{\mathbf{P}}^{*, i, 0}, \widetilde{\boldsymbol{\lambda}}^{*, i, 0}\right)}{\widetilde{P}_{k}\left(\widetilde{\mathbf{P}}^{*, i, 0}, \widetilde{\boldsymbol{\lambda}}^{*, i, 0}\right)}\right) \varrho_{k}\right)}=
\end{aligned}
$$

onde $\delta_{\mathrm{q}}^{i, j-1}$ resulta da atualização das alocações de potência e subportadoras no decorrer das iterações do LDD. A existência de $\delta_{\mathrm{q}}^{i, j-1}$ pode ser identificada, inclusive, como um dos fatores que limitam a utilização da solução por produtório. No decorrer das simulações preliminares, um problema recorrente era a necessidade de encerrar o loop do LDD devido à instabilidade gerada pela alteração das alocações de potência e subportadoras, principalmente quando as alterações geram significativa mudança em $\widetilde{R}_{\bar{k}}$ e $\widetilde{P}_{\bar{k}}$, ou seja, quando o valor de $\left|\delta_{\mathrm{q}}^{i, j-1}\right|$ se torna significativo.

Considerando todas as instabilidades comentadas até o momento para as soluções por somatório de logaritmos e produtório, juntamente com a complexidade do cômputo dos termos de produtório para ambos os métodos, faz com que o foco seja, agora, analisar a possibilidade de se utilizar expressões simplificadas para a alocação de recursos, que reflitam, por exemplo, as propriedades de simplificação analisadas anteriormente. Considere a função-utilidade com produtório de EEs individuais, dada na equação (5.8) e repetida aqui por conveniência:

$$
\arg \max . \frac{\prod_{k=1}^{K}\left[\mathrm{w} \sum_{n=1}^{N} \tilde{\lambda}_{k, n} \ell_{k, n} \log _{2}\left(1+\frac{\widetilde{p}_{k, n} \Gamma_{k, n} \iota_{k}}{\widetilde{\lambda}_{k, n}}\right)\right]}{\prod_{k=1}^{K}\left[\sum_{n=1}^{N} \varrho_{k} \widetilde{p}_{k, n}+p_{c, k}\right]} .
$$

Admita que exista uma alocação de subportadoras $\boldsymbol{\lambda}$, não necessariamente válida, previamente definida. Considerando que as restrições de potência em uplink sejam individuais, e que não haja interferência entre as MSs (ou que essa interferência não seja 
computada), a maximização do produtório pode ser obtida pela maximização dos termos individuais que compõem o produtório, ou seja, pela maximização das EEs individuais. Assim, a maximização de potência da $k$-ésima MS pode ser feita utilizando-se a seguinte função-objetivo:

$$
\widetilde{\xi}_{k}=\frac{\mathrm{w} \sum_{n=1}^{N} \widetilde{\lambda}_{k, n} \ell_{k, n} \log _{2}\left(1+\frac{\widetilde{p}_{k, n} \Gamma_{k, n} \imath_{k}}{\widetilde{\lambda}_{k, n}}\right)}{\sum_{n=1}^{N} \varrho_{k} \widetilde{p}_{k, n}+p_{c, k}}
$$

Sabendo que o algoritmo DKB é iterativo, e que quando se calcula a alocação de potência de cada uma das $K$ MSs já existe uma alocação de subportadoras pré-definida (dada pela iteração anterior do LDD), a alocação de potência de cada uma das $K$ MSs não deveria interferir na alocação das demais $K-1 \mathrm{MSs}$. Com isso, é possível calcular a alocação de potência utilizando apenas a equação de EE individual, eliminando assim os termos de produtório que se repetem a cada iteração da alocação de potência. Desse modo, cada uma das MSs terá um parâmetro DKB individual em cada uma das iterações do DKB, denotado por $q_{k}^{i}$. A adoção dos parâmetros individuais ainda facilita o controle de convergência do algoritmo DKB, pois como comentado na Subseção 7.2.5 o controle de convergência utilizando apenas o parâmetro DKB do sistema poderia gerar erros.

Assim, para se obter a equação de alocação de potência de cada uma das MSs, considera-se a existência de $K$ problemas de alocação de potência desacoplados. Para a $k$-ésima MS, tem-se:

$$
\begin{gathered}
\widetilde{\mathbf{p}}_{k}^{*}=\underset{\widetilde{\mathbf{p}}_{k}}{\arg \max .} \frac{\mathrm{w} \sum_{n=1}^{N} \widetilde{\lambda}_{k, n} \ell_{k, n} \log _{2}\left(1+\frac{\widetilde{p}_{k, n} \Gamma_{k, n} \iota_{k}}{\widetilde{\lambda}_{k, n}}\right)}{\sum_{n=1}^{N} \varrho_{k} \widetilde{p}_{k, n}+p_{c, k}} \\
\text { s. a: } \quad p_{k, n} \geq 0 \quad \forall n \\
\sum_{n=1}^{N} \widetilde{p}_{k, n} \leq p_{k}^{\max }
\end{gathered}
$$

Com a aplicação do algoritmo de DKB, o problema de alocação de potência individual iterativo é dado por:

$$
\begin{gathered}
\widetilde{\mathbf{p}}_{k}^{*, i}=\underset{\widetilde{\mathbf{p}}_{k}}{\arg \max . \mathrm{w}} \sum_{n=1}^{N} \widetilde{\lambda}_{k, n} \ell_{k, n} \log _{2}\left(1+\frac{\widetilde{p}_{k, n} \Gamma_{k, n} \imath_{k}}{\widetilde{\lambda}_{k, n}}\right)-q_{k}^{i-1}\left(\sum_{n=1}^{N} \varrho_{k} \widetilde{p}_{k, n}+p_{c, k}\right) \\
\text { s. a: } \quad p_{k, n} \geq 0 \quad \forall n \\
\sum_{n=1}^{N} \widetilde{p}_{k, n} \leq p_{k}^{\max }
\end{gathered}
$$


Usando LDD para incorporar a restrição de potência máxima de cada MS, tem-se o seguinte problema de alocação de potência individual equivalente:

$$
\begin{aligned}
\widetilde{\mathbf{p}}_{k}^{*, i}=\arg \min _{\tau_{k} \geq 0} \max _{\widetilde{\mathbf{p}}_{k}} \cdot \mathrm{w} & \sum_{n=1}^{N} \widetilde{\lambda}_{k, n} \ell_{k, n} \log _{2}\left(1+\frac{\widetilde{p}_{k, n} \Gamma_{k, n} \iota_{k}}{\widetilde{\lambda}_{k, n}}\right)-q_{k}^{i-1}\left(\sum_{n=1}^{N} \varrho_{k} \widetilde{p}_{k, n}+p_{c, k}\right) \\
+ & \tau_{k}\left(p_{k}^{\max }-\sum_{n=1}^{N} \widetilde{p}_{k, n}\right)
\end{aligned}
$$

Assim como ocorre com o DKB, adota-se uma solução iterativa para o problema (7.27). A cada iteração do LDD, resolve-se inicialmente o problema de maximização para cada MS, considerando o multiplicador de Lagrange $\tau_{k}^{j-1}$ fixo, resultante da iteração anterior, e depois atualiza-se $\tau_{k}^{j}$ de acordo com a alocação de potência obtida na $j$-ésima iteração do LDD. Considera-se que cada iteração do LDD, dentro da repetição do algoritmo DKB, possui uma alocação de subportadoras já definida. Porém, relembra-se aqui que ela é atualizada a cada iteração, de acordo com uma estratégia a ser definida na Subseção 7.4.2. Finalmente, a alocação de potência é definida através do seguinte problema de maximização:

$$
\widetilde{\mathbf{p}}_{k}^{*, i, j}=\arg \max . \mathrm{w} \sum_{n=1}^{N} \widetilde{\lambda}_{k, n} \ell_{k, n} \log _{2}\left(1+\frac{\widetilde{p}_{k, n} \Gamma_{k, n} \imath_{k}}{\widetilde{\lambda}_{k, n}}\right)-\left(\tau_{k}^{j-1}+\varrho_{k} q_{k}^{i-1}\right) \sum_{n=1}^{N} \widetilde{p}_{k, n}
$$

Derivando a equação (7.28) em relação a $\widetilde{p}_{k, n}$, e igualando o resultado a zero, obtém-se:

$$
p_{k, n}^{*, i, j}=\left[\frac{\ell_{k, n}}{\log (2)\left(\tau_{k}^{j-1}+q_{k}^{i-1} \varrho_{k}\right)}-\frac{1}{\Gamma_{k, n} \iota_{k}}\right]^{+}
$$

cujos termos são muito mais simples de serem calculados do que os presentes nas equações (7.1) e (7.5).

\subsubsection{Modificações na Alocação de Subportadoras}

A alocação de subportadoras remete à solução de dois problemas: em primeiro lugar, como solucionar a questão de possibilidade de nulidade da métrica de alocação, conforme o algoritmo DKB+LDD itera; e em segundo lugar, como reduzir a instabilidade do processo. O primeiro problema, descrito na Subseção 7.2.4, resulta do modo como a métrica de alocação de subportadoras $s_{k, n}^{i, j}$ se altera conforme o algoritmo DKB+LDD executa as iterações, de modo que há possibilidade de que ao menos uma MS fique sem nenhuma portadora alocada, o que inviabiliza a solução. Já o segundo problema, a instabilidade do processo de convergência, é inerente a ambas as soluções propostas, e sua solução depende da proposição de alguma modificação no algoritmo de decisão de alocação, e não propriamente na métrica de alocação.

Analisando inicialmente o problema da métrica se tornar nula conforme o algoritmo DKB +LDD itera, é possível fazer algumas considerações usando a métrica $s_{k, n}^{i, j}$ obtida 
para a solução via somatório de logaritmos, equação (7.3). Ao contrário do que ocorre com a métrica obtida para a solução via produtório, equação (7.6), seu valor tende a crescer conforme o algoritmo empregado (no caso, DCP+LDD) itera, dado que o fator responsável pelo fairness, e que tende a decrescer ao longo das iterações, se encontra no denominador. É possível, porém, fazer com que a equação da métrica de alocação da solução via produtório se torne semelhante à obtida para o somatório de logaritmos, sem prejuízo à solução do problema. Considere $s_{k, n}$ definido de acordo com a equação (7.6), e reproduzido a seguir por conveniência.

$$
s_{k, n}^{i, j}=\frac{\mathrm{w} \widetilde{R}_{\bar{k}}\left(\widetilde{\mathbf{P}}^{*, i, j}, \tilde{\boldsymbol{\lambda}}^{*, i, j-1}\right) \ell_{k, n}}{\log (2)}\left(\log \left(1+p_{k, n}^{*, i, j} \Gamma_{k, n} \imath_{k}\right)-\frac{p_{k, n}^{*, i} \Gamma_{k, n} \iota_{k}}{\left(1+p_{k, n}^{*, i, j} \Gamma_{k, n} \iota_{k}\right)}\right)-v_{n}^{j-1}
$$

Dividindo ambos os lados da equação pelo produtório da taxa de dados de todos os usuários, i.e., $\widetilde{R}\left(\widetilde{\mathbf{P}}^{*, i, j}, \widetilde{\boldsymbol{\lambda}}^{*, i, j-1}\right)$, com

$$
\widetilde{R}\left(\widetilde{\mathbf{P}}^{*, i, j}, \widetilde{\boldsymbol{\lambda}}^{*, i, j-1}\right)=\widetilde{R}_{\bar{k}}\left(\widetilde{\mathbf{P}}^{*, i, j}, \widetilde{\boldsymbol{\lambda}}^{*, i, j-1}\right) \widetilde{R}_{k}\left(\widetilde{\mathbf{P}}^{*, i, j}, \widetilde{\boldsymbol{\lambda}}^{*, i, j-1}\right)
$$

tem-se que

$$
\begin{aligned}
& \frac{s_{k, n}^{i, j}}{\widetilde{R}\left(\widetilde{\mathbf{P}}^{*, i, j}, \widetilde{\boldsymbol{\lambda}}^{*, i, j-1}\right)}=\frac{\mathrm{w} \widetilde{R}_{\bar{k}}\left(\widetilde{\mathbf{P}}^{*, i, j}, \widetilde{\boldsymbol{\lambda}}^{*, i, j-1}\right) \ell_{k, n}}{\log (2) \widetilde{R}_{\bar{k}}\left(\widetilde{\mathbf{P}}^{*, i, j}, \widetilde{\boldsymbol{\lambda}}^{*, i, j-1}\right) \widetilde{R}_{k}\left(\widetilde{\mathbf{P}}^{*, i, j}, \widetilde{\boldsymbol{\lambda}}^{*, i, j-1}\right)}\left(\log \left(1+p_{k, n}^{*, i, j} \Gamma_{k, n} \imath_{k}\right)\right) \\
& -\frac{{ } \widetilde{R}_{\bar{k}}\left(\widetilde{\mathbf{P}}^{*, i, j}, \widetilde{\boldsymbol{\lambda}}^{*, i, j-1}\right) \ell_{k, n}}{\log (2) \widetilde{R}_{\bar{k}}\left(\widetilde{\mathbf{P}}^{*, i, j}, \widetilde{\boldsymbol{\lambda}}^{*, i, j-1}\right) \widetilde{R}_{k}\left(\widetilde{\mathbf{P}}^{*, i, j}, \widetilde{\boldsymbol{\lambda}}^{*, i, j-1}\right)}\left(\frac{p_{k, n}^{*, i, j} \Gamma_{k, n} \imath_{k}}{\left(1+p_{k, n}^{*, i, j} \Gamma_{k, n} \iota_{k}\right)}\right) \\
& -\frac{v_{n}^{j-1}}{\widetilde{R}\left(\widetilde{\mathbf{P}}^{*, i, j}, \widetilde{\boldsymbol{\lambda}}^{*, i, j-1}\right)} \\
& =\frac{\mathrm{w} \ell_{k, n}}{\log (2) \widetilde{R}_{k}\left(\widetilde{\mathbf{P}}^{*, i, j}, \widetilde{\boldsymbol{\lambda}}^{*, i, j-1}\right)}\left(\log \left(1+p_{k, n}^{*, i, j} \Gamma_{k, n} \imath_{k}\right)-\frac{p_{k, n}^{*, i, j} \Gamma_{k, n} \imath_{k}}{\left(1+p_{k, n}^{*, i, j} \Gamma_{k, n} \imath_{k}\right)}\right) \\
& -\frac{v_{n}^{j-1}}{\widetilde{R}\left(\widetilde{\mathbf{P}}^{*, i, j}, \widetilde{\boldsymbol{\lambda}}^{*, i, j-1}\right)}
\end{aligned}
$$

que é bastante semelhante à definição de $s_{k, n}^{i, j}$ para a solução via somatório de logaritmos, equação (7.3). Não há prejuízo à solução, dado que o termo que divide $s_{k, n}^{i, j} \mathrm{e}$ $v_{n}^{j-1}, \widetilde{R}\left(\widetilde{\mathbf{P}}^{*, i, j}, \widetilde{\boldsymbol{\lambda}}^{*, i, j-1}\right)$, é o mesmo para todas as MSs. É possível definir uma nova métrica de alocação, $s_{k, n}^{\prime, i, j}=\frac{s_{k, n}^{i, j}}{\widetilde{R}\left(\widetilde{\mathbf{P}}^{*, i, j}, \widetilde{\lambda}^{*, i, j-1}\right)}$, e um novo multiplicador de Lagrange $v_{n}^{\prime, j-1}=$ $\frac{v_{n}^{j-1}}{\widetilde{R}\left(\widetilde{\mathbf{P}}^{*, i, j}, \widetilde{\boldsymbol{\lambda}}^{*, i, j-1}\right)}$, de modo que a métrica de alocação de subportadoras do método híbrido 
pode ser reescrita como:

$$
\begin{aligned}
s_{k, n}^{\prime, i, j}= & \frac{\mathrm{w} \ell_{k, n}}{\log (2) \widetilde{R}_{k}\left(\widetilde{\mathbf{P}}^{*, i, j}, \widetilde{\boldsymbol{\lambda}}^{*, i, j-1}\right)}\left(\log \left(1+p_{k, n}^{*, i, j} \Gamma_{k, n} \imath_{k}\right)-\frac{p_{k, n}^{*, i, j} \Gamma_{k, n} \imath_{k}}{\left(1+p_{k, n}^{*, i, j} \Gamma_{k, n} \imath_{k}\right)}\right) \\
& -v_{n}^{\prime, j-1}
\end{aligned}
$$

Já em relação à instabilidade durante o processo de alocação de subportadoras, uma das possíveis soluções seria determinar, empiricamente, um valor para as variáveis de atualização dos multiplicadores de Lagrange que não resultasse em instabilidade ao longo das iterações e que também não resulte no estouro do número máximo de iterações. Durante as simulações preliminares, tal possibilidade se mostrou inviável e infrutífera. Inviável devido à quantidade de pontos que deveriam ser testados para se ter um espaço amostral razoável e o tempo de execução de cada tentativa, e infrutífero pois os valores testados não conseguiam evitar o problema.

Para efetivamente resolver o problema, desenvolveu-se uma espécie de amortização para o processo de decisão de quais subportadoras deveriam ser alocadas (ou desalocadas) para a $k$-ésima MS em cada uma das iterações do algoritmo LDD, descrita no Algoritmo 7.1. A amortização tem por objetivo evitar a alocação (ou liberação) de um grande número de subportadoras em uma determinada $j$-ésima iteração, evitando que a iteração seguinte apresente uma oscilação ainda maior e que o problema, em um curto espaço de iterações, resulte em um estado inválido e irreversível.

Após o cômputo das potências ótimas na $i$-ésima iteração do DKB e $j$-ésima iteração do LDD, calcula-se as métricas de alocação e o que seria a nova alocação de subportadoras da $k$-ésima MS. Caso a diferença no número de subportadoras alocadas pela $k$-ésima MS em relação à iteração anterior do LDD, em módulo, seja maior que 1, busca-se alocar (ou liberar) apenas uma subportadora, de modo que a variação da métrica de alocação seja menos abrupta. Após a mudança na alocação de subportadoras, repete-se o cálculo da métrica de alocação e verifica-se novamente as mudanças na alocação de subportadoras. Tal processo é repetido até que a diferença se torne unitária ou ocorra uma inversão na tendência de alocação (por exemplo, a $k$-ésima MS estava liberando subportadoras e, em uma iteração, começa a novamente alocar).

Existem diferentes possibilidades de regras que podem ser escolhidas nos passos alocação/liberação de subportadoras. Além de considerar o ganho de canal, como colocado no Algoritmo 7.1, poderia ser considerada a própria métrica de alocação $s_{k, n}^{i, j}$, que já inclui o multiplicador de Lagrange e poderia indicar qual a portadora que está mais propensa a ser perdida, independente da qualidade de canal. Nos resultados preliminares, entretanto, definir a escolha da subportadora a ser alocada/liberada utilizando o ganho de canal se mostrou mais estável e com mais casos de convergência. 


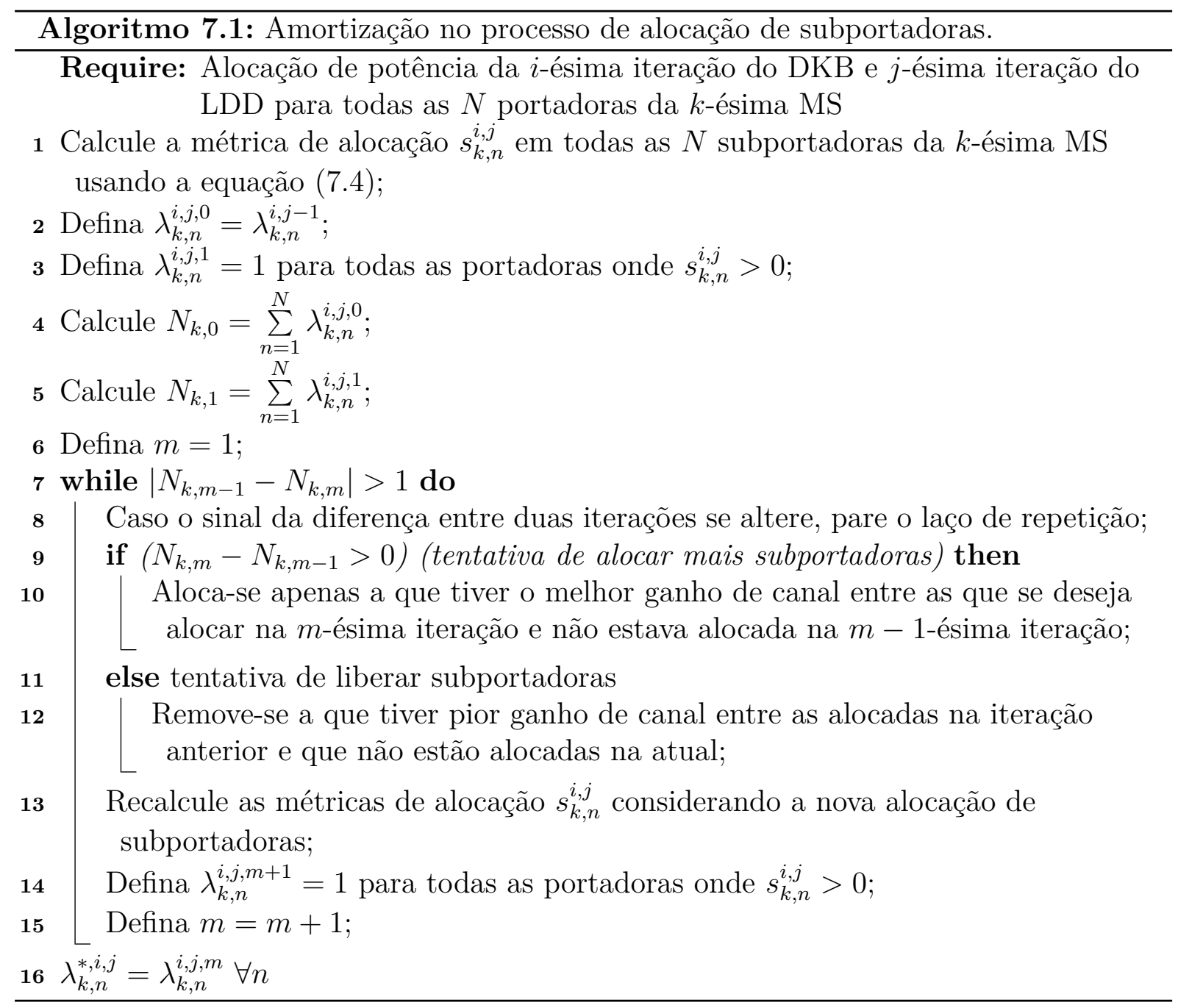

\subsubsection{Controle de Convergência}

Com a alteração proposta para o cômputo da alocação de potência, o controle de convergência do loop externo, i.e. algoritmo DKB, se torna mais simples. É possível utilizar os parâmetros individuais, $q_{k}^{i}$, para determinar a convergência do laço externo. Para verificar se o algoritmo DKB convergiu, toma-se como erro de convergência do DKB, $\varepsilon_{\mathrm{dkb}}$, o maior erro entre todas as MSs, ou seja

$$
\varepsilon_{\mathrm{dkb}}=\max _{1 \leq k \leq K}\left(\left|q_{k}^{i}-q_{k}^{i-1}\right|\right)
$$

$\mathrm{O}$ algoritmo DKB converge quando $\varepsilon_{\mathrm{dkb}} \leq \varepsilon_{\mathrm{dkb}}^{\max }$. Por segurança, verifica-se também se a alocação de subportadoras está em um estado válido, i.e., a restrição de unicidade está sendo atendida. O processo de verificação de convergência do LDD é mantido de acordo com o discutido na Seção 5.3

O Algoritmo 7.2 sumariza a operação da estratégia híbrida discutida. 


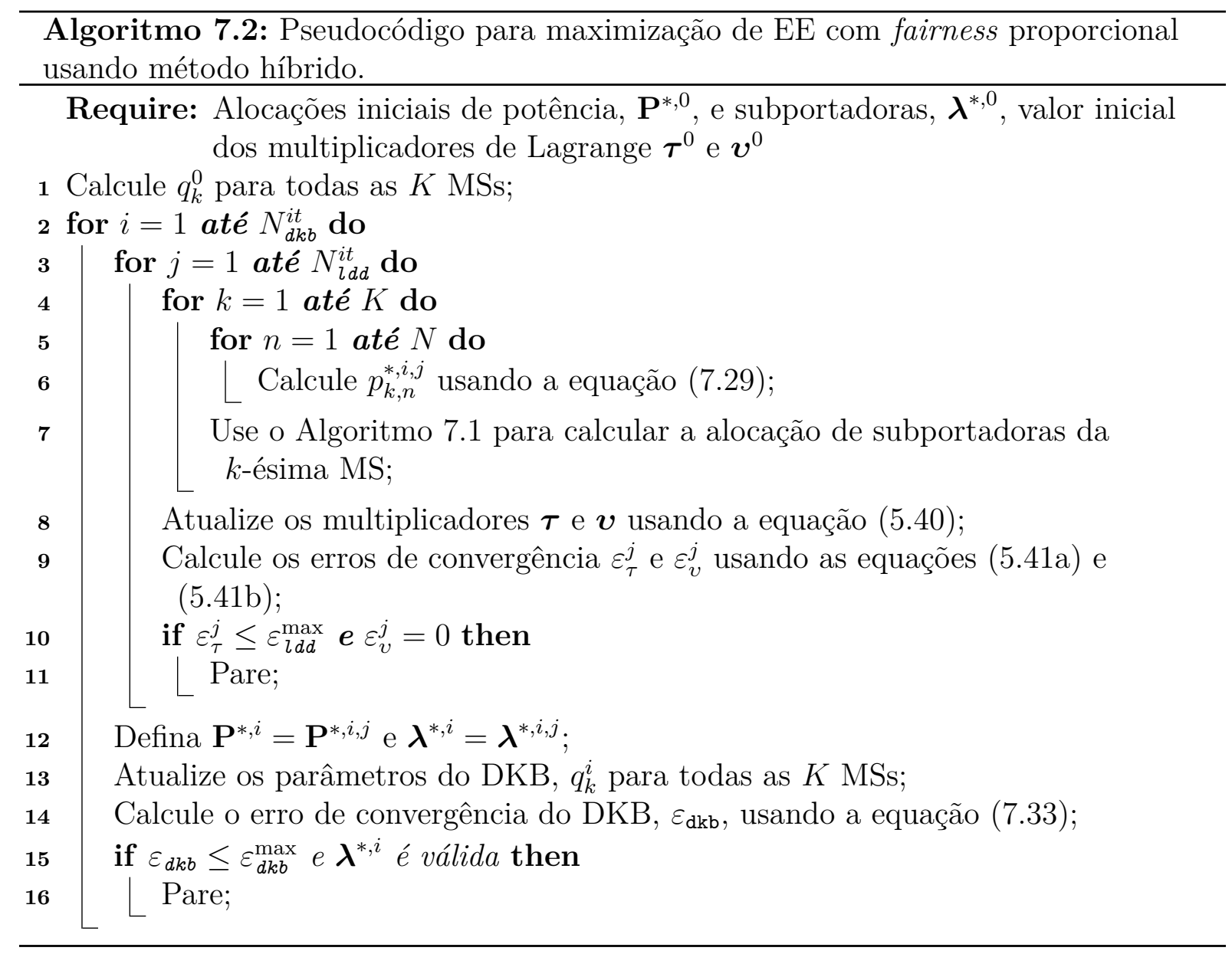

\subsection{Definição dos Valores Iniciais}

No Capítulo 4, a determinação de uma estratégia de valores iniciais para o algoritmo $\mathrm{DKB}+\mathrm{LDD}$ se mostrou bastante promissora e efetiva, uma vez que graças às propriedades de downlink já se conhecia um limite superior, além de que uma estratégia mais simples pôde ser desenvolvida para se aproximar rapidamente desse valor. Por definição, a alocação de recursos para maximizar a EE no downlink torna-se sub-ótimo para uplink, dado que adiciona-se a restrição de potências individuais. Como a alocação de subportadoras para a maximização de EE em downlink é baseada nos ganhos de canal, a busca por uma estratégia que respeitasse as restrições individuais de potência se mostrou mais simples. Não havia a preocupação com a possibilidade de uma subportadora ser alocada a mais de uma MS, dada a função de máximo no processo de decisão, nem com alguma MS sem recursos espectrais, pois isso era comum e aceito pela formulação usada.

Na modelagem não-cooperativa com fairness, definir uma estratégia de inicialização é bem mais complexo. Em primeiro lugar, não há uma tendência clara na definição da matriz de alocação de subportadoras a partir dos ganhos de canal das MSs em cada uma das subportadoras. Sabe-se apenas que as MSs com os maiores ganhos tenderão a ter mais subportadoras alocadas, mas não necessariamente terão as suas melhores subportadoras 
alocadas. Isso foi verificado em simulações numéricas preliminares, testando todas as combinações de alocação de subportadoras possíveis para problemas de baixa dimensão. Tal constatação é embasada pelo fato de que, com a adoção de fairness, pode ser que uma subportadora na qual a $k$-ésima MS possui o maior ganho de canal seja fundamental para uma outra MS em pior situação de canal, de modo que os fatores inseridos pela formulação de fairness na métrica $s_{k, n}$ resultam em um comportamento que não pode ser facilmente previsto.

É possível determinar esquemas sub-ótimos de alocação de subportadoras, como por exemplo através da seguinte regra:

$$
\lambda_{k, n}=\left\{\begin{array}{ll}
1 & ((n-1) \quad \bmod K)+1=k \\
0 & \text { caso contrário }
\end{array} .\right.
$$

O problema em somente definir a alocação de subportadoras é que, no modelo proposto, o processo de alocação é controlado também pelos multiplicadores $\boldsymbol{v}$, de modo que se estes não forem devidamente calculados, os valores iniciais propostos serão severamente modificados logo na execução da primeira iteração do algoritmo proposto. Além disso, uma estratégia equivocada de alocação de subportadoras combinada com uma regra ruim de inicialização de $\boldsymbol{\tau}$ e $\boldsymbol{v}$ pode fazer com que uma determinada MS fique sem recursos espectrais, o que pode resultar em não-convergência do algoritmo.

Para atenuar esse problema, decide-se pela execução de um pré-processamento. Como não se espera que a saída desse pré-processamento seja uma resposta válida, i.e., atendendo as restrições de unicidade de alocação de subportadoras, não será aqui chamado de algoritmo sub-ótimo ou terá seu desempenho comparado com a solução final, como aconteceu no Capítulo 4.

Em uma primeira etapa do pré-processamento, cada MS pode maximizar sua EE de modo separado, resultando que todas as $K$ MSs podem ocupar todas as $N$ subportadoras disponíveis, como se o sistema fosse composto por apenas uma MS. Como resultado dessa etapa inicial, há um grande número de subportadoras alocadas para mais de uma MS, e em geral o somatório em $K$ e $N$ de todos os termos da matriz $\boldsymbol{\lambda}$ inicial tende a $K N$. Para realizar o passo de otimização individual de EE, pode se utilizar os algoritmos subótimos vistos no Capítulo 4, em especial o algoritmo SIPSA-EE, dado que não existe, nesse momento, a concorrência entre as MSs pelas subportadoras. Com essa primeira etapa, obtém-se matrizes de alocação de subportadoras e potência iniciais.

A partir dessa alocação inicial, define-se que $\boldsymbol{v}=\mathbf{0}$, e então busca-se adotar um stepsize $\phi_{v}$ mais agressivo para a atualização de $\boldsymbol{v}$, para rapidamente fazer com que o total de subportadoras alocadas se aproxime de $N$. Esse stepsize não será utilizado no processo de convergência do algoritmo híbrido, mas apenas para se obter as estimativas iniciais necessárias ao Algoritmo 7.2.

Definido um valor de stepsize, executa-se um número pré-definido de iterações, em que cada iteração executa os seguintes passos: 
1. Calcula-se a alocação de potência para cada uma das $K$ MSs e $N$ subportadoras, dados os parâmetros $q_{k}^{i-1}$, usando a equação (7.29);

2. Calcula-se a métrica de alocação de subportadoras para cada uma das $K$ MSs e $N$ subportadoras, usando a equação (7.4);

3. Define-se a alocação de subportadoras a partir da métrica de alocação $s_{k, n}$, usando a equação (5.39);

4. Atualizam-se as variáveis duais $\boldsymbol{v}$, usando a equação (5.40b);

5. Calcula-se $q_{k}^{\prime, i}$ a partir das matrizes de alocação de potência e subportadoras obtidas;

6. Realiza-se uma nova alocação de potências com os parâmetros $q_{k}^{\prime, i}$, usando a equação (7.29), porém não se altera a alocação de subportadoras posteriormente;

7. Calcula-se $q_{k}^{i}$;

É necessário calcular um fator intermediário $q_{k}^{\prime, i}$ e realizar o recálculo da alocação de potências para reduzir a oscilação do algoritmo de alocação de recursos. Em geral, a perda de subportadoras em uma iteração faz com que a métrica de alocação de subportadoras seja aumentada na iteração seguinte, dado que existe a divisão pela taxa de dados da própria $k$-ésima MS, e posteriormente reduzida novamente quando se consegue mais portadoras, afinal a taxa de dados volta a crescer. Quando se considera o conjunto das $K \mathrm{MSs}$, isso pode ser encarado como uma disputa de recursos, e que demora a se estabilizar, quando estabiliza, se a alteração entre duas iterações for significativa. Por outro lado, como o sistema começa em um ponto de operação significativamente distante do atendimento das restrições, é necessário que ao menos nesse estágio o stepsize seja agressivo.

Há ainda uma segunda consideração a ser feita antes de se discutir o roteiro experimental e resultados obtidos: na Subseção 7.4.2, comenta-se sobre a instabilidade na alocação de subportadoras, afirmando que é necessário amortizar a alocação ou liberação de subportadoras para evitar que a solução se torne instável. No estágio de inicialização esse problema é ainda mais grave, pois o stepsize mais agressivo faz com que grandes variações ocorram em todas as iterações: as simulações preliminares mostraram casos em que determinadas MSs podem começar com $N$ subportadoras alocadas e, em poucas iterações, permanecer com apenas 10\% - 20\% dessas portadoras. A abordagem de amortização discutida na Subseção 7.4.2 também funciona para o caso da inicialização, porém é computacionalmente inviável, pois aloca ou libera apenas uma subportadora por vez, se tornando um limitante de desempenho. Para contornar tal situação, resolve-se utilizar um algoritmo baseado em bissecção para definir quantas subportadoras serão alocadas ou liberadas em uma determinada iteração, de modo que se uma MS deseja alocar (ou liberar) um dado número de subportadoras, apenas a metade será concedida. Tal processo 
é repetido até que a diferença de alocação se torne menor, e o método de amortização descrito no Algoritmo 7.1 possa ser utilizado.

\subsection{Resultados Numéricos Parciais}

Os parâmetros de simulação são os mesmos indicados na Tabela 4.1. Para que os resultados obtidos em modo não-cooperativo sem fairness, descritos no Capítulo 4, pudessem ser diretamente comparados aos resultados do modo não-cooperativo com fairness, obtidos com a utilização da abordagem híbrida, se utilizam os mesmos ganhos de canal, que foram armazenados em arquivos e puderam ser acessados nessa etapa.

Discute-se primeiramente os resultados obtidos para determinar o stepsize necessário ao processo de inicialização de variáveis, e em seguida os resultados numéricos parciais obtidos com a aplicação do Algoritmo 7.2. Como será discutido, a estratégia de inicialização de variáveis descrita na Seção 7.5 não se mostrou tão efetiva como a que foi definida no Capítulo 4 para o caso não-cooperativo sem fairness, resultando na não-convergência de alguns casos. De qualquer modo, é possível discutir algumas tendências da abordagem com fairness.

\subsubsection{Estratégia de Inicialização de Variáveis}

Para se obter os valores de stepsize para cada combinação de $K$ e $N$, adota-se o seguinte procedimento experimental:

1. Para um intervalo pré-determinado de valores-teste do stepsize, executa-se o procedimento de inicialização. Procura-se obter nesta etapa: (i) número total de subportadoras alocadas; (ii) número de subportadoras alocadas a mais de uma MS; (iii) o número de subportadoras que não estão alocadas a nenhum usuário; e (iv) verificar se alguma MS perdeu todas as subportadoras, o que inviabiliza a convergência do algoritmo. O intervalo pré-determinado é mais longo e ainda bastante disperso, para que se tenha ideia de quais valores de stepsize fazem com que o total de subportadoras alocadas, normalizado por $N$, se aproxime de 1 ;

2. A partir desse intervalo, por assim dizer, rudimentar, é possível delimitar um intervalo de interesse, e então simular mais detalhadamente apenas o intervalo reduzido. Para cada combinação de $K$ e $N$, determina-se uma faixa de interesse e nova simulação é gerada. Com o resultado dessa etapa, se escolhe qual será o valor do stepsize para a aproximação inicial que será adotado. Adota-se um único valor para cada combinação de $K$ e $N$, para que não seja necessário uma análise caso a caso. Os critérios adotados são: (i) centralidade em 1 (aproximadamente a mesma quantidade de pontos acima e abaixo de 1); (ii) menor variabilidade dos pontos (extremos); (iii) 
menor número de portadoras não-alocadas a nenhuma MS; e (iv) menor número de portadoras duplicadas, i.e., alocadas a mais de uma MS;

Para cada valor de $K$ e $N$ foi gerada uma figura, em que cada snapshot de canal gera três marcadores: no primeiro, apresentado em vermelho, considera-se o valor obtido com a soma de todas as variáveis de alocação de subportadoras, i.e., $\sum_{k=1}^{K} \sum_{n=1}^{N} \lambda_{k, n}$; no segundo, apresentado em verde, soma-se o total de subportadoras que estão alocadas a mais de um usuário, i.e. $\sum_{n=1}^{N} \operatorname{dup}_{n}$, onde

$$
\operatorname{dup}_{n}=\left\{\begin{array}{ll}
1, & \sum_{k=1}^{K} \lambda_{k, n}>1 \\
0, & \text { caso contrário }
\end{array} ;\right.
$$

no terceiro, apresentado em azul, soma-se o total de subportadoras que não estão alocadas a nenhum usuário, i.e. $\sum_{n=1}^{N}$ null $_{n}$, onde

$$
\operatorname{null}_{n}=\left\{\begin{array}{ll}
1, & \sum_{k=1}^{K} \lambda_{k, n}=0 \\
0, & \text { caso contrário }
\end{array} .\right.
$$

Com esses três dados, busca-se equilibrar o valor do stepsize escolhido para a etapa de inicialização. Um valor muito reduzido faz com que poucas subportadoras não estejam alocadas a nenhuma MS, porém reduz muito fracamente o número total de subportadoras alocadas e também o número de portadoras alocadas por mais de uma MS. Por outro lado, um stepsize muito elevado reduz o número total de subportadoras alocadas, porém o número de subportadoras não alocadas a nenhuma MS eleva-se muito rapidamente, e também é possível que alguma (ou algumas) MS perca todas as subportadoras e o algoritmo não consiga mais convergir.

Como não há nenhum indicativo claro de qual o intervalo em que valores candidatos para o stepsize se encontram, e de como tais valores se comportam em relação às variáveis $K$ e $N$, considera-se o intervalo de $10^{-5}$ até $10^{-2}$, com 61 pontos. Além disso, todos os valores plotados são normalizados por $N$, para facilitar a leitura dos resultados. Finalmente, define-se como intervalo de interesse no eixo y o intervalo $[0,2]$, ou seja, o número de subportadoras representado está sempre entre os valores 0 e $2 N$. A partir dos resultados dessa simulação, é possível escolher um intervalo reduzido para cada combinação de $K$ e $N$. Como pode ser visto nas Figuras 7.1-7.4, algumas tendências podem ser observadas:

1. Em um mesmo grupo de valores de $N$, o valor do stepsize para que o total de subportadoras alocadas se aproxime de 2 cresce conforme o valor de $K$ cresce. Uma possível explicação para tal comportamento é que, com um valor de $K$ mais elevado, mais MSs concorrem pelas subportadoras, e maior é a probabilidade de que existam 
MSs com bons canais. Aponta-se também que o valor no eixo y é normalizado apenas por $N$, de modo que quanto maior for o valor de $K$, maior tende a ser o número de subportadoras alocadas;

2. Ainda considerando um grupo com o mesmo valor de $N$, percebe-se que conforme $K$ aumenta, o valor limite do stepsize para que não ocorram MSs sem recursos espectrais é diminuído. A explicação mais provável é que, com o aumento de MSs, a concorrência pelas subportadoras aumenta significativamente, e se torna mais provável que uma MS sujeita a um canal de baixa qualidade perca todas as portadoras quando os multiplicadores $\boldsymbol{v}$ são atualizados de modo abrupto;

3. Percebe-se ainda que, conforme $N$ cresce, o valor mínimo do stepsize para que o total de subportadoras alocadas atinja o intervalo de interesse é reduzido. Para esse comportamento, algumas considerações podem ser feitas: i) com maior número de subportadoras, a taxa de dados de cada MS tende a crescer, fazendo com que o valor da métrica de alocação seja menor; ii) com maior diversidade, a taxa de dados tende a ser mais elevada em cada uma das $K$ MSs, o que explicaria também um menor valor da métrica de alocação de subportadoras.

4. A combinação dos dois primeiros itens torna ainda mais difícil a definição de um valor adequado de stepsize para o processo de inicialização, pois o intervalo de análise vai sendo reduzido conforme $K$ cresce. Tomando em conta ainda o terceiro item, o cenário é ainda mais complicado para $N$ reduzido e $K$ elevado.

Percebe-se ainda como a dispersão do total de subportadoras alocadas aumenta de acordo com o aumento do número de MSs, $K$, e tende a se reduzir conforme o número de subportadoras aumenta. Tal resultado se tornará mais aparente quando os intervalos reduzidos forem considerados, mas percebe-se principalmente que para $N=[256,512] \mathrm{e}$ $K=[90,120]$ a dispersão entre os valores mínimo e máximo se torna muito elevada. Em $N=256$ e $K=120$, percebe-se que o valor máximo nos marcadores vermelhos ainda está acima de 2 , e que em $N=256$ e $K=90$ não está muito a baixo de tal valor. Finalmente, percebe-se que com $N=2048$, há uma tendência bastante definida de redução de acordo com os valores da variável de convergência.

As linhas verticais pretas indicam os valores escolhidos para limitar o intervalo reduzido de simulação, cujos resultados são mostrados nas Figuras 7.5-7.8. A partir da análise dos resultados obtidos nos intervalos reduzidos, a Tabela 7.1 mostra os valores escolhidos para a variável de stepsize na etapa de inicialização de variáveis.

\subsubsection{Resultados Parciais Obtidos com o Algoritmo Híbrido}

Assim como foi feito para a etapa de inicialização, é necessário encontrar o valor do stepsize que será utilizado para atualizar os multiplicadores $\boldsymbol{v}$ durante a execução do Al- 
Figura 7.1 - Intervalos rudimentares de busca para o stepsize da inicialização de variáveis, para $N=256$ e $K=[30,60,90,120]$.

a)
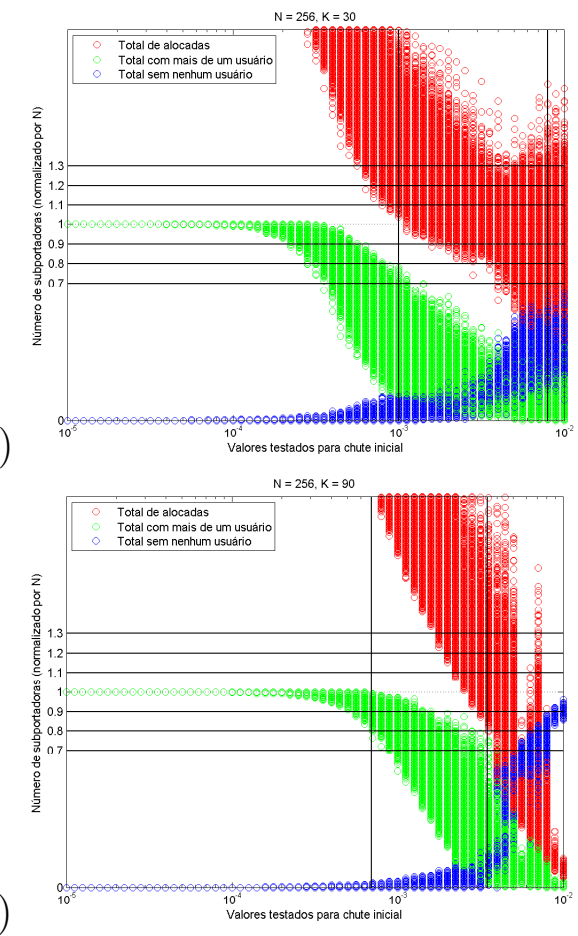

b)

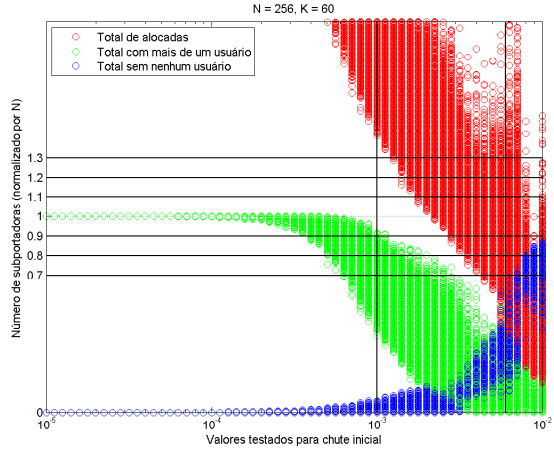

d)

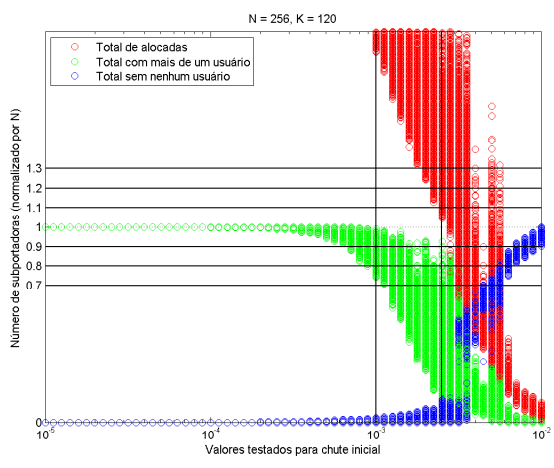

Fonte: o autor

Figura 7.2 - Intervalos rudimentares de busca para o stepsize da inicialização de variáveis, para $N=512$ e $K=[30,60,90,120]$.

a)
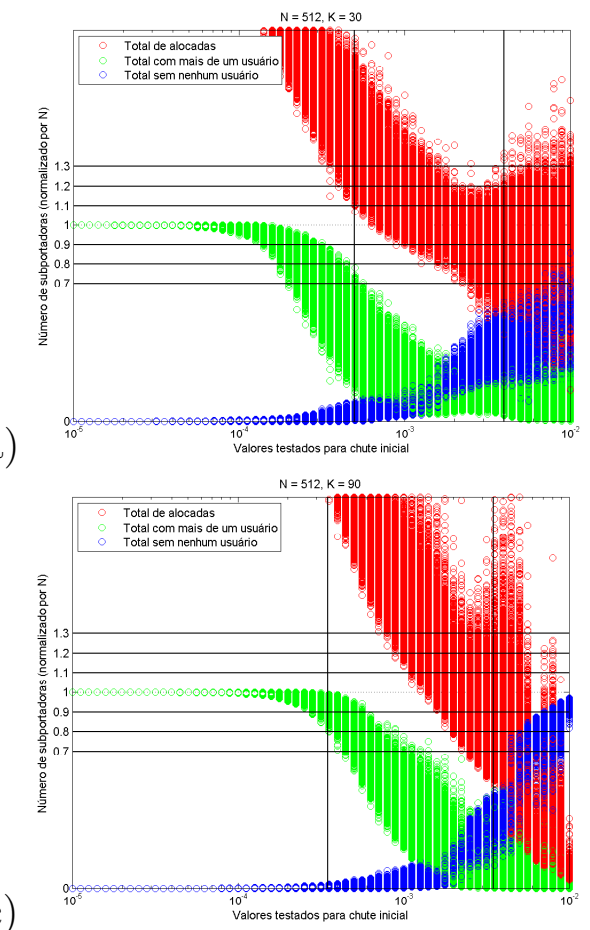

b)

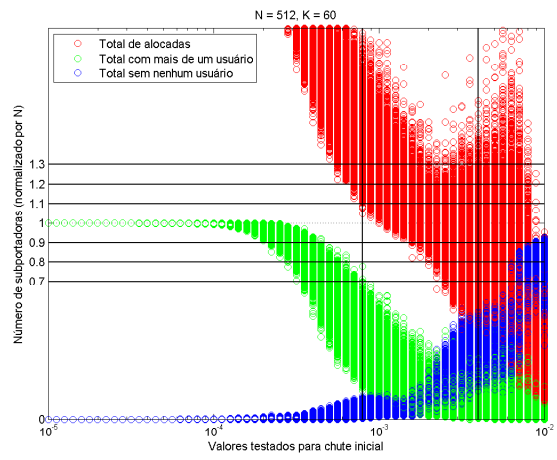

d)

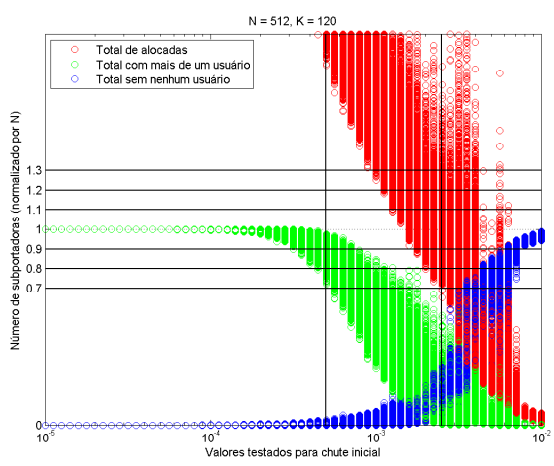

Fonte: o autor 
Figura 7.3 - Intervalos rudimentares de busca para o stepsize da inicialização de variáveis, para $N=1024$ e $K=[30,60,90,120]$.

a)
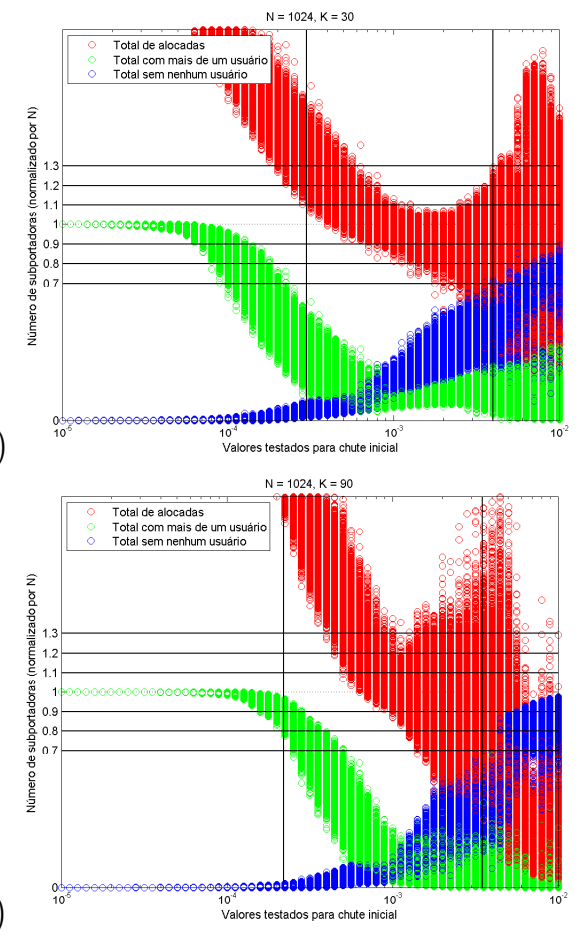

b)

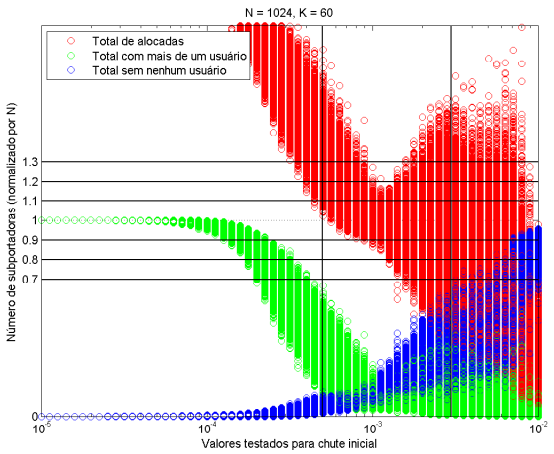

d)

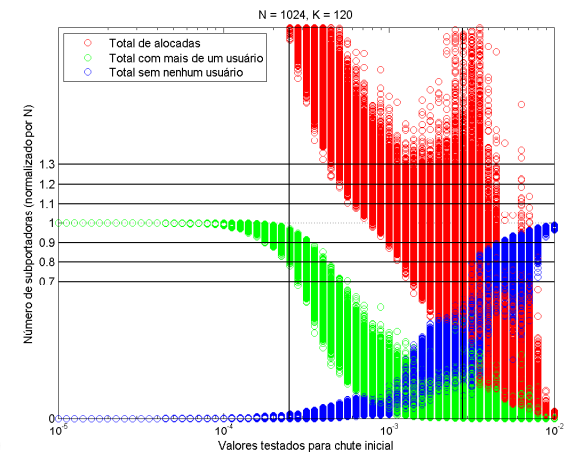

Fonte: o autor

Figura 7.4 - Intervalos rudimentares de busca para o stepsize da inicialização de variáveis, para $N=2048$ e $K=[30,60,90,120]$.

a)
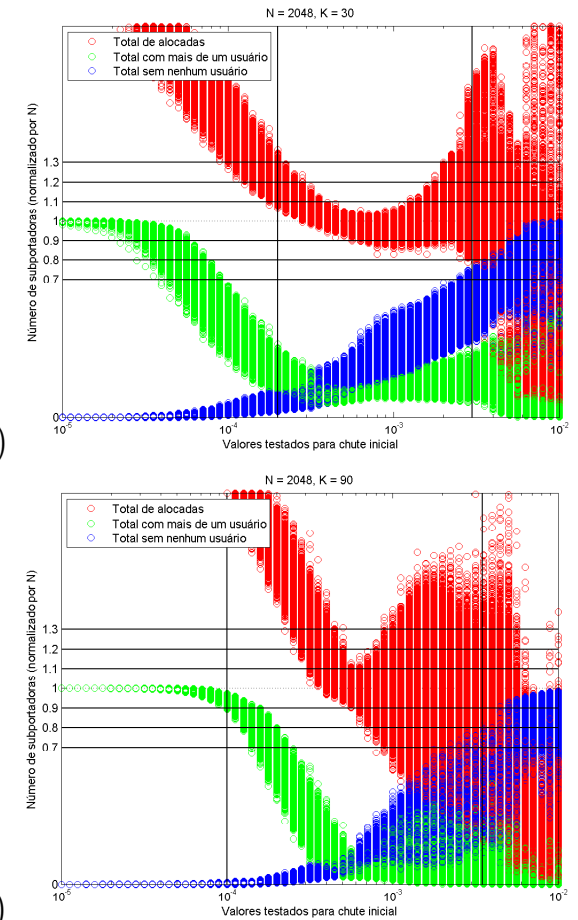

b)

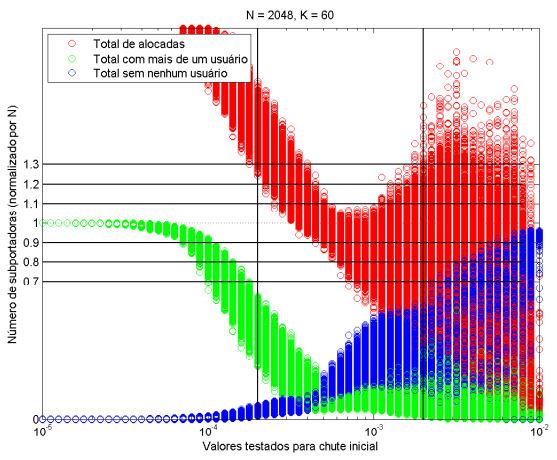

d)

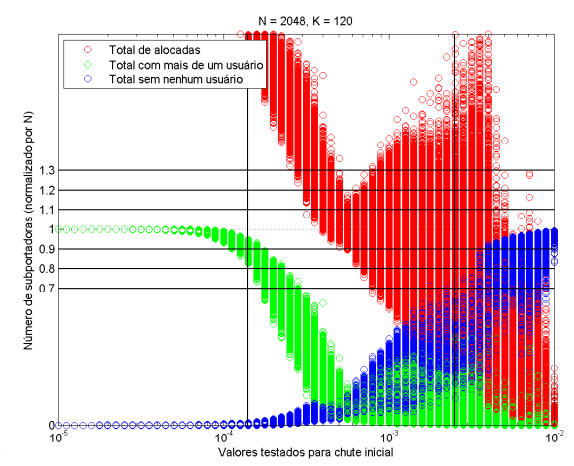

Fonte: o autor 
Figura 7.5 - Intervalos reduzidos de busca para o stepsize da inicialização de variáveis, para $N=256$ e $K=[30,60,90,120]$.

a)
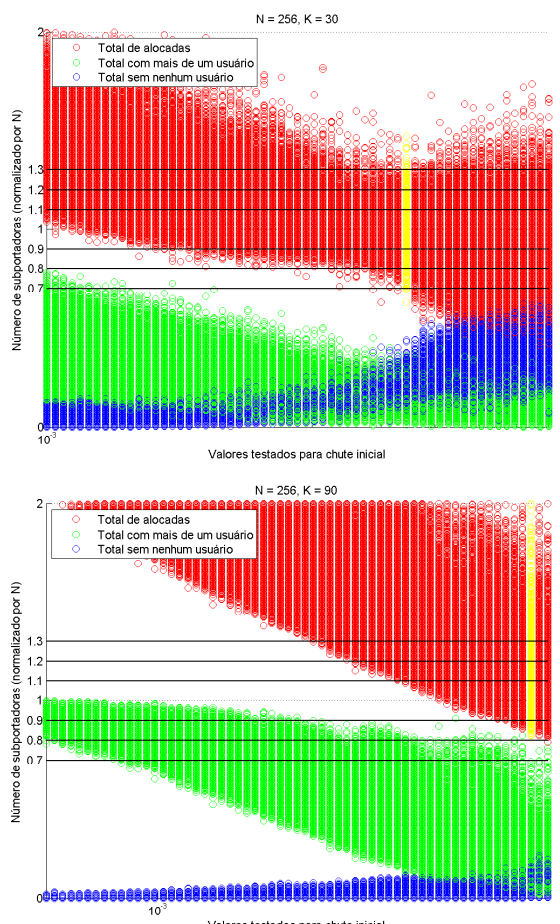

c)

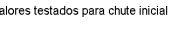

Fonte: o autor

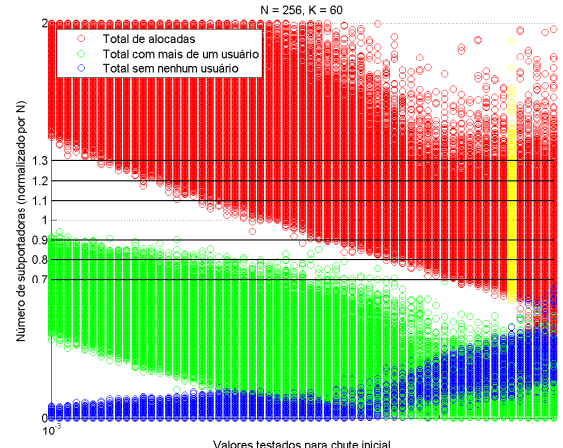

b)

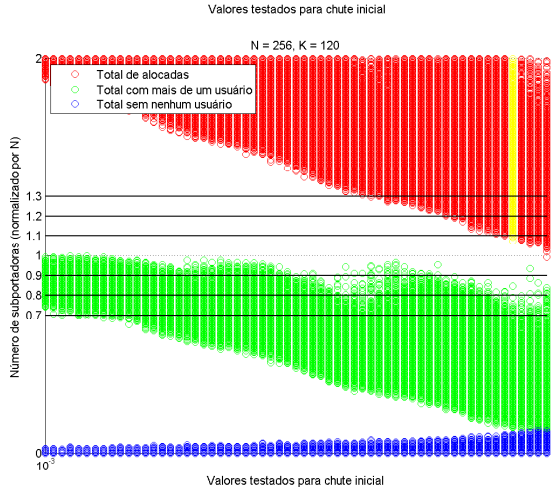

d)

Figura 7.6 - Intervalos reduzidos de busca para o stepsize da inicialização de variáveis, para $N=512$ e $K=[30,60,90,120]$.

a)
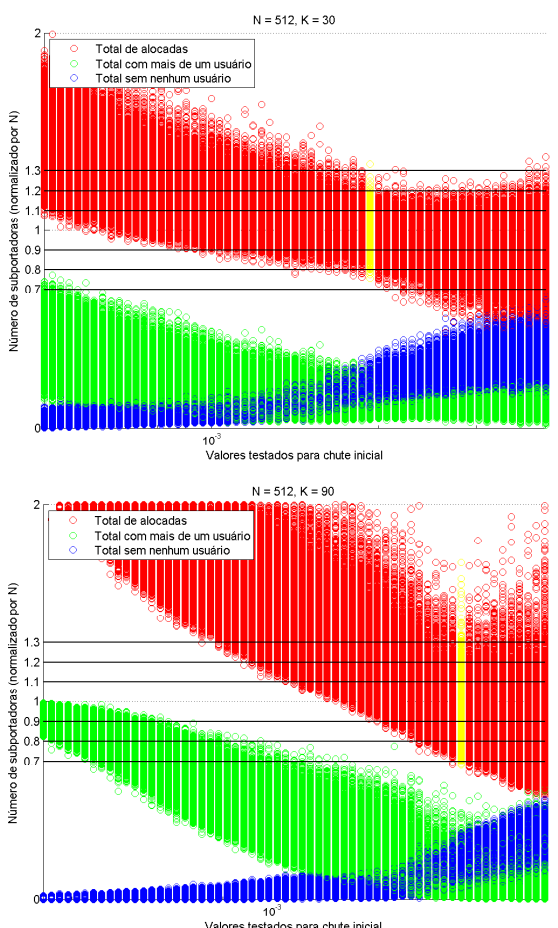

b)
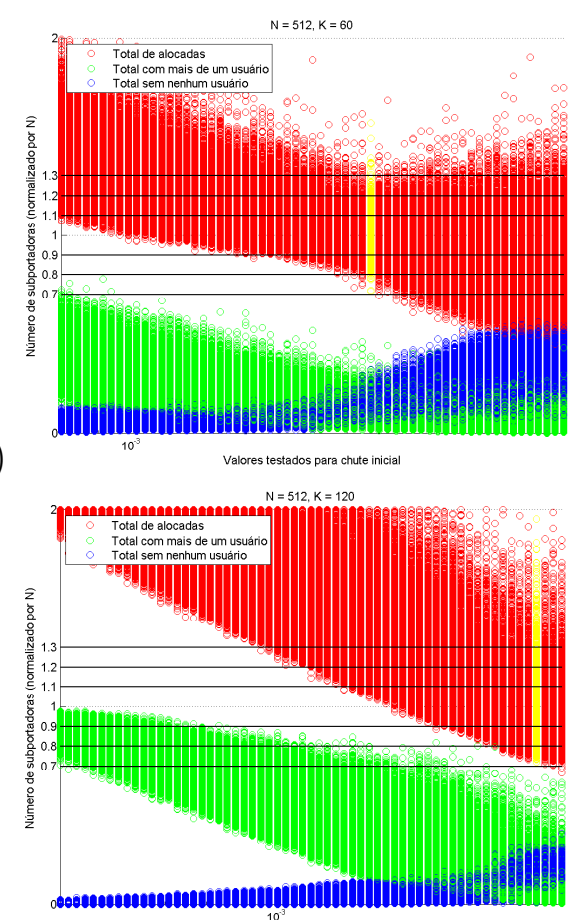

d)

Fonte: o autor 
Figura 7.7 - Intervalos reduzidos de busca para o stepsize da inicialização de variáveis, para $N=1024$ e $K=[30,60,90,120]$.
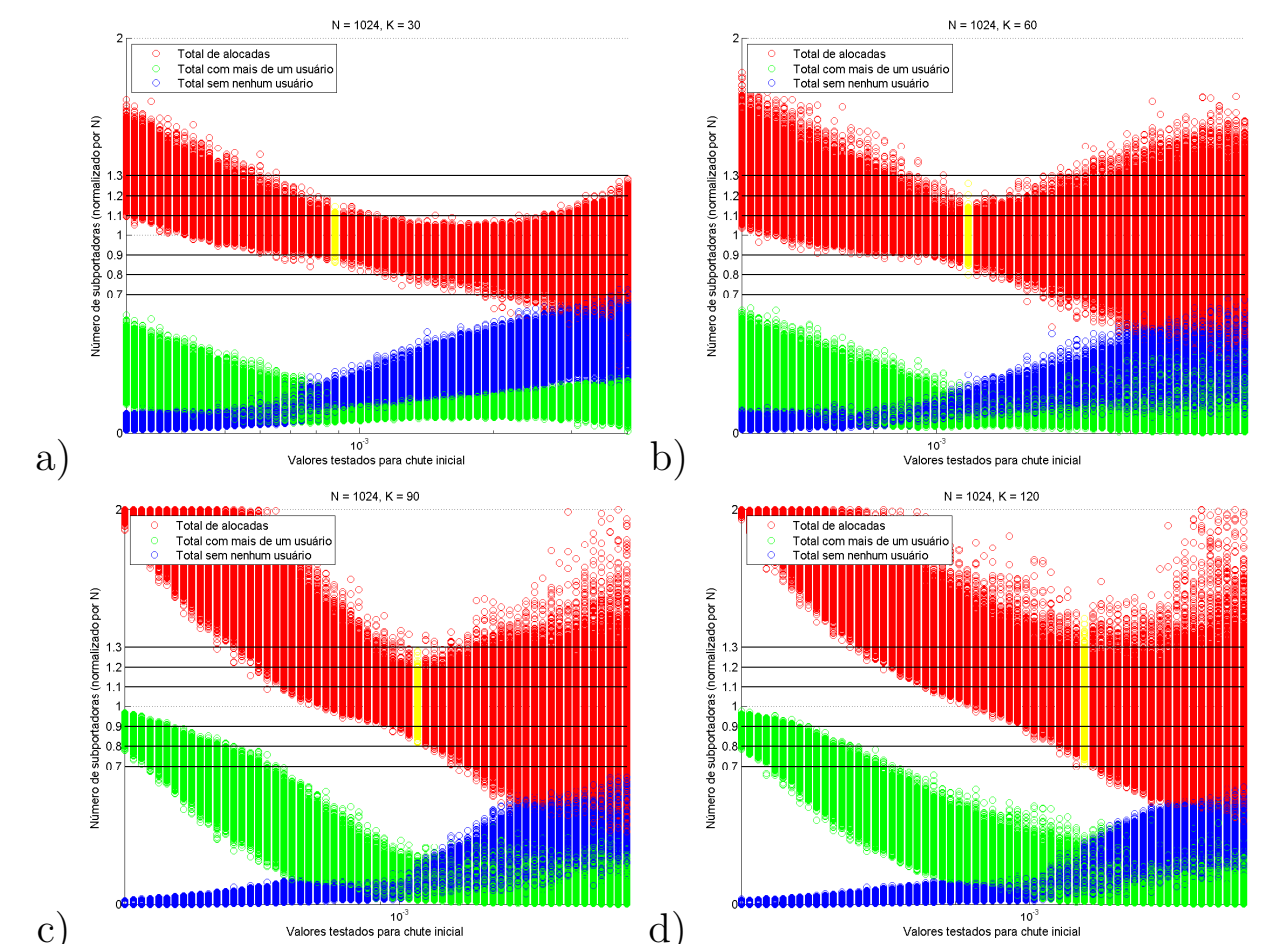

b)

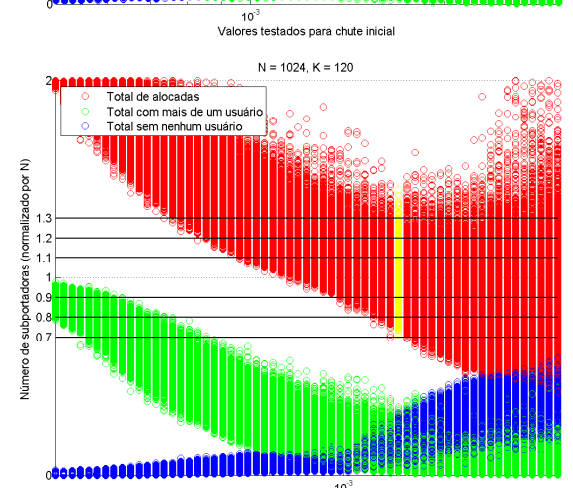

Fonte: o autor

Figura 7.8 - Intervalos reduzidos de busca para o stepsize da inicialização de variáveis, para $N=2048$ e $K=[30,60,90,120]$.

a)
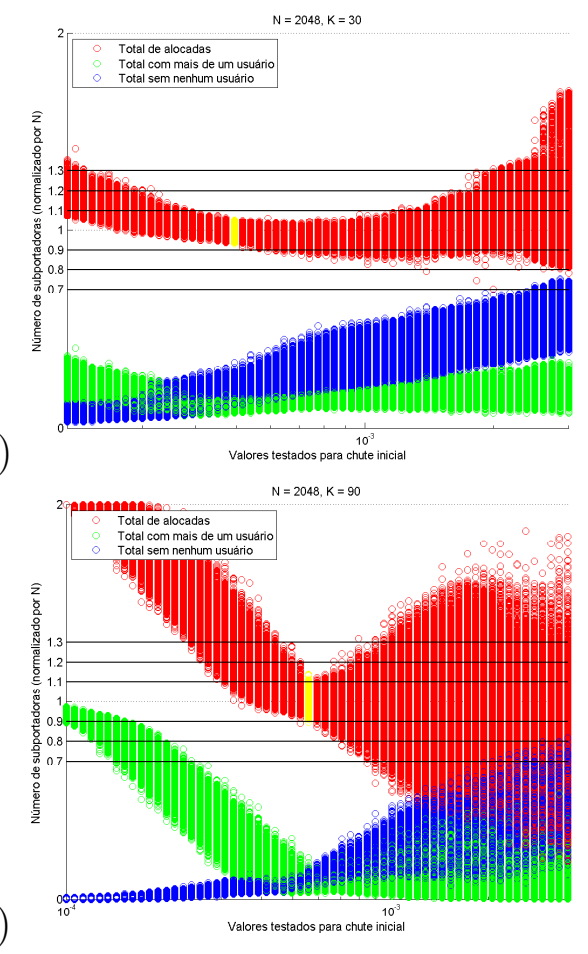

b)
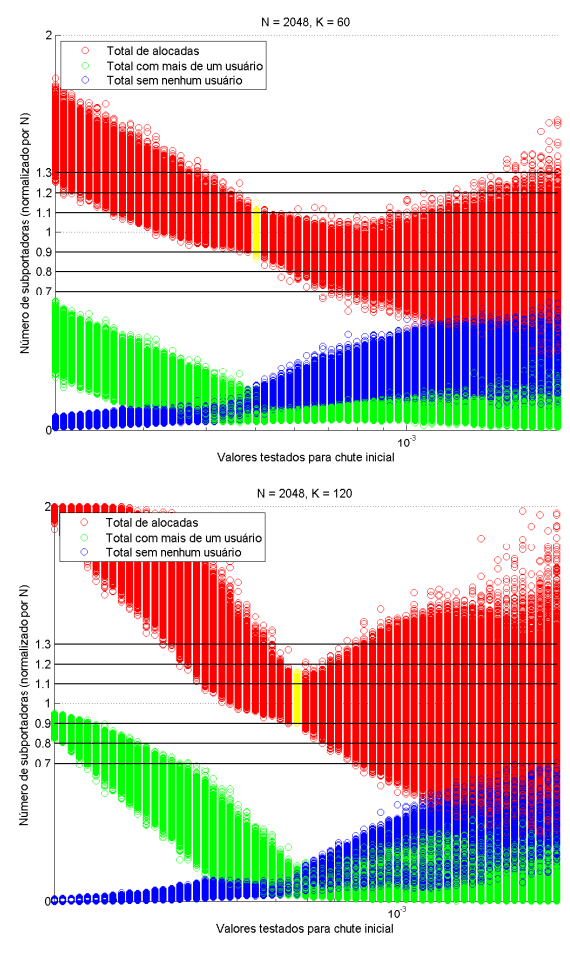

Fonte: o autor 
Tabela 7.1 - Valores para a variável de stepsize para a inicialização de variáveis, para cada valor de $K$ e $N$ considerados.

\begin{tabular}{|c|c|c|c|c|}
\hline & $K=30$ & $K=60$ & $K=90$ & $K=120$ \\
\hline$N=256$ & 0.004438 & 0.005168 & 0.003317 & 0.002352 \\
\hline$N=512$ & 0.001932 & 0.002158 & 0.002385 & 0.002307 \\
\hline$N=1024$ & 0.0008828 & 0.001120 & 0.001105 & 0.001303 \\
\hline$N=2048$ & 0.0004932 & 0.0005024 & 0.0005576 & 0.0005639 \\
\hline
\end{tabular}

Fonte: o autor

goritmo 7.2. Algumas simulações preliminares foram realizadas para se determinar um intervalo de possíveis valores para $\phi_{v}$, partindo de um intervalo mais dilatado, porém com menos pontos de amostra, até se delimitar um intervalo menor, que possui maior probabilidade de convergência, e testado com mais pontos. As Tabelas 7.2 e 7.3 apresentam, respectivamente, os limites inferior e superior do intervalo testado para $\phi_{v}$.

Tabela 7.2 - Valores mínimos para o intervalo de teste da variável de stepsize dos multiplicadores $\boldsymbol{v}$ para o Algoritmo 7.2.

\begin{tabular}{|c|c|c|c|c|}
\hline & $K=30$ & $K=60$ & $K=90$ & $K=120$ \\
\hline$N=256$ & $8 \cdot 10^{-6}$ & $8 \cdot 10^{-6}$ & $8 \cdot 10^{-6}$ & $8 \cdot 10^{-6}$ \\
\hline$N=512$ & $8 \cdot 10^{-7}$ & $8 \cdot 10^{-7}$ & $8 \cdot 10^{-7}$ & $8 \cdot 10^{-7}$ \\
\hline$N=1024$ & $3 \cdot 10^{-7}$ & $3 \cdot 10^{-7}$ & $3 \cdot 10^{-7}$ & $3 \cdot 10^{-7}$ \\
\hline$N=2048$ & $2 \cdot 10^{-7}$ & $2 \cdot 10^{-7}$ & $2 \cdot 10^{-7}$ & $2 \cdot 10^{-7}$ \\
\hline
\end{tabular}

Fonte: o autor

Tabela 7.3 - Valores máximos para o intervalo de teste da variável de stepsize dos multiplicadores $\boldsymbol{v}$ para o Algoritmo 7.2.

\begin{tabular}{|c|c|c|c|c|}
\hline & $K=30$ & $K=60$ & $K=90$ & $K=120$ \\
\hline$N=256$ & $5 \cdot 10^{-2}$ & $5 \cdot 10^{-2}$ & $5 \cdot 10^{-2}$ & $5 \cdot 10^{-2}$ \\
\hline$N=512$ & $10^{-3}$ & $10^{-3}$ & $10^{-3}$ & $10^{-3}$ \\
\hline$N=1024$ & $5 \cdot 10^{-4}$ & $5 \cdot 10^{-4}$ & $5 \cdot 10^{-4}$ & $5 \cdot 10^{-4}$ \\
\hline$N=2048$ & $10^{-4}$ & $10^{-4}$ & $10^{-4}$ & $10^{-4}$ \\
\hline
\end{tabular}

Fonte: o autor

Não se tentou obter um valor ótimo para $\phi_{v}$. Adotou-se a estratégia de encontrar ao menos um valor de $\phi_{v}$ para o qual um dado caso simulado fosse capaz de convergir. Para analisar a taxa de convergência do Algoritmo 7.2, determina-se que o limite de iterações do DKB, $N_{\mathrm{dkb}}^{i t}$, é de 400 iterações.

O intervalo limitado pelos valores apresentados nas Tabelas 7.2 e 7.3 foi discretizado com 61 pontos, utilizando distribuição logarítmica. A Tabela 7.4 apresenta a taxa de convergência obtida com o Algoritmo 7.2, considerando que foram utilizadas como conjunto 
de simulação as 1000 primeiras realizações de canal geradas no Capítulo 4. O número é reduzido de 10000 realizações para 1000 devido à complexidade computacional maior da solução com fairness, além de que deve-se testar exaustivamente os valores candidatos para $\phi_{v}$.

Tabela 7.4 - Porcentagem de convergência do Algoritmo 7.2 com os valores candidatos testados.

\begin{tabular}{|c|c|c|c|c|}
\hline & $K=30$ & $K=60$ & $K=90$ & $K=120$ \\
\hline$N=256$ & 94,4 & 85,3 & 38,9 & 0,1 \\
\hline$N=512$ & 86,0 & 65,5 & 40,8 & 35,6 \\
\hline$N=1024$ & 62,8 & 51,5 & 36,7 & 12,7 \\
\hline$N=2048$ & 65,9 & 47,5 & 35,9 & 16,6 \\
\hline
\end{tabular}

Fonte: o autor

Alguns resultados interessantes podem ser obtidos ao se analisar a Tabela 7.4. Percebese que a taxa de convergência se reduz conforme o número de MSs aumenta. Tal resultado pode ser causado pela concorrência que se estabelece entre as MSs pelas subportadoras conforme $K$ cresce. Note, por exemplo, que somente 1 entre 1000 casos convergiu quando $K=120$ e $N=256$. Nesse cenário em particular, a média é de menos de 3 subportadoras por MS, ou seja, deve ser bastante incomum que uma MS consiga alocar muitas subportadoras. Com um número elevado de MSs, é muito provável que exista um pequeno grupo de MSs com ótimos canais de comunicação, e outro com péssimos canais. A competição entre as MSs faz com que o algoritmo não consiga convergir para uma solução, resultando em um cenário tão drástico.

Por outro lado, percebe-se que conforme $N$ cresce, decresce a taxa de convergência. O resultado até parece contraditório, pois era justamente quando $N$ crescia que a determinação do stepsize para a alocação inicial mostrava uma maior concentração ao redor de 1, indicando possivelmente que todos os casos estavam convergindo. Nesse ponto, são duas explicações possíveis: na primeira, as Figuras 7.1-7.8 estão normalizados por $N$, de modo que a variação, apesar de parecer pequena, resulta em grande variação em números absolutos, de modo que o algoritmo demoraria mais iterações para convergir.

Uma segunda explicação está no cômputo da métrica de alocação, $s_{k, n}^{i, j}$, equação (7.4), copiada a seguir por conveniência. Perceba que o denominador de $s_{k, n}^{i, j}$ é normalizado pela taxa de dados da própria $k$-ésima MS. Conforme aumenta-se o número de subportadoras disponíveis, tende-se a também a aumentar a taxa de dados de cada MS, de modo que é possível ter métricas de alocação com valores reduzidos e com pouca diferença entre duas MSs. Com isso, seria necessário adotar um valor menor para $\phi_{v}$, o que pode resultar na 
não-convergência pelo limite de iterações.

$$
s_{k, n}^{i, j}=\frac{\ell_{k, n}\left(\log \left(1+p_{k, n}^{*, i, j} \Gamma_{k, n}\right)-\frac{p_{k, n}^{*, i, j} \Gamma_{k, n}}{\left(1+p_{k, n}^{*, i j} \Gamma_{k, n}\right)}\right)}{\log (b)\left(\ell_{k, n} \log \left(1+p_{k, n}^{*, i, j} \Gamma_{k, n}\right)+\sum_{\substack{m=1 \\ m \neq n}}^{N} \lambda_{k, m}^{*, i, j-1} \ell_{k, m} \log \left(1+p_{k, m}^{*, i, j} \Gamma_{k, m}\right)\right)} .
$$

\subsection{Solução Híbrida para Modo Cooperativo com Fairness Propor- cional}

Assim como discutido na Seção 7.4, a expressão de alocação de potência da $k$-ésima MS (utilizando ou não uma determinada RS) não deveria depender da alocação de potência nas subportadoras que não lhe pertencem, ou seja, das demais $K-1 \mathrm{MSs}$. Conhecendose a matriz de alocação de subportadoras ótima, $\boldsymbol{\lambda}^{*}$, ou ao menos a matriz de alocação de subportadoras utilizada em uma determinada iteração do problema, $\boldsymbol{\lambda}^{*, i, j}$, bastaria determinar a alocação ótima em cada conjunto MS/RS, afinal a única variável que impede a alocação mais descentralizada é justamente a alocação de subportadoras. Note-se, no entanto, que ainda existe um determinado acoplamento das variáveis, afinal se o problema for separado na dimensão das MSs, as RSs são compartilhadas, porém sem possibilidade de múltiplo acesso em uma determinada subportadora; ocorre apenas a dependência na alocação de potência das RSs, que na soma total poderia ser maior que $p_{r_{l}}^{\max }$.

É possível utilizar o mesmo argumento da Seção 7.4 sobre a iteração inicial do LDD a cada iteração do DKB, onde os termos poderiam ser simplificados, sobrando somente a alocação de potência/subportadoras de cada MS. Com isso, o problema que será tratado a seguir não leva em consideração a alocação de subportadoras, apenas de potência. Nem mesmo a atualização dos multiplicadores de Lagrange será revista, pois as equações desenvolvidas nesta seção substituirão as equações de alocação de potência para MSs e RSs da resolução via produtório definidas nas equações (7.13b) (AF) e (7.13c) (DF).

O problema será resolvido para cada uma das MSs que utilizam RSs (para as MSs que se comunicam diretamente com a BS, basta modificar a notação do equacionamento da Seção 7.4). Com tais considerações, o problema de otimização a ser resolvido na $k$-ésima 
MS que utiliza a l-ésima RS é dado por:

$$
\begin{aligned}
& \widetilde{\mathbf{p}}_{k}, \widetilde{\mathbf{p}}_{r_{l}}= \underset{\widetilde{\mathbf{p}}_{k}, \widetilde{\mathbf{p}}_{r_{l}}}{\arg \max } \frac{\sum_{n=1}^{N} \widetilde{\lambda}_{k, n} \ell_{k, n} \widetilde{r}_{k, n, l}^{\varpi}}{\frac{1}{2} \sum_{n=1}^{N}\left(\varrho_{k} \widetilde{p}_{k, n}+\varrho_{r_{l}} \widetilde{p}_{r_{n, l}}\right)+\varsigma_{k, l} p_{c, r_{l}}^{\varpi}+p_{c, k}} \\
& \text { s. a: } \quad \widetilde{p}_{k, n} \geq 0 \quad \forall n \\
& \widetilde{p}_{r_{n, l}} \geq 0 \quad \forall n \\
& p_{k}^{\max }-\sum_{n=1}^{N} \widetilde{p}_{k, n} \geq 0 \\
& \\
& p_{r_{l}}^{\max }-\sum_{k=1}^{K} \sum_{n=1}^{N} \widetilde{p}_{r_{n, l}} \geq 0
\end{aligned}
$$

Note que as restrições de alocação de subportadoras não são consideradas, afinal não se busca obter expressões de alocação de subportadoras, pois essa alocação pode ser vista como algo definido exteriormente ao problema analisado nesta seção.

O primeiro passo para solucionar o problema (7.38) é aplicar o algoritmo DKB à função-utilidade fracionária, resultando no seguinte problema de otimização iterativo:

$$
\widetilde{\mathbf{p}}_{k}^{i}, \widetilde{\mathbf{p}}_{r_{l}}^{i}=\underset{\widetilde{\mathbf{p}}_{k}, \widetilde{\mathbf{p}}_{r_{l}}}{\arg \max } \sum_{n=1}^{N} \widetilde{\lambda}_{k, n} \ell_{k, n} \widetilde{r}_{k, n, l}^{\varpi}-q_{k}^{\varpi, i-1}\left[\frac{1}{2} \sum_{n=1}^{N}\left(\varrho_{k} \widetilde{p}_{k, n}+\varrho_{r_{l}} \widetilde{p}_{r_{n, l}}\right)+\varsigma_{k, l} p_{c, r_{l}}^{\varpi}+p_{c, k}\right]
$$

s. a.: $(7.38 b)-(7.38 \mathrm{e})$

Com a aplicação do DKB, utilizam-se os multiplicadores de Lagrange $\tau_{k}$ e $\nu_{l}$ às restrições $(7.38 \mathrm{~d})$ e (7.38e), respectivamente. O problema de otimização é dado, então, por:

$$
\begin{aligned}
& \widetilde{\mathbf{p}}_{k}^{*, i}, \widetilde{\mathbf{p}}_{r_{l}}^{*, i}=\arg \min _{\substack{\tau_{k} \geq 0 \\
\nu_{l} \geq 0}} \max _{\substack{\widetilde{\mathbf{p}}_{k} \\
\widetilde{\mathbf{p}}_{r_{l}}}} \sum_{n=1}^{N} \widetilde{\lambda}_{k, n} \ell_{k, n} \widetilde{r}_{k, n, l}^{\varpi}-q_{k}^{\varpi, i-1}\left[\frac{1}{2} \sum_{n=1}^{N}\left(\varrho_{k} \widetilde{p}_{k, n}+\varrho_{r_{l}} \widetilde{p}_{r_{n, l}}\right)+\varsigma_{k, l} p_{c, r_{l}}^{\varpi}+p_{c, k}\right] \\
& +\tau_{k}\left(p_{k}^{\max }-\sum_{n=1}^{N} \widetilde{p}_{k, n}\right)+\nu_{l}\left(p_{r_{l}}^{\max }-\sum_{k=1}^{K} \sum_{n=1}^{N} \widetilde{p}_{r_{n, l}}\right)
\end{aligned}
$$

É necessário adotar uma solução iterativa para o problema, solucionando primeiro o problema de maximização com as variáveis duais definidas na iteração anterior, e posteriormente o de minimização com as alocações de potência e subportadoras definidas no passo anterior. Como o controle das variáveis duais será mantido na estrutura da solução por produtório, nos interessa apenas a solução do problema de maximização, i.e.:

$$
\begin{gathered}
\widetilde{\mathbf{p}}_{k}^{i, j}, \widetilde{\mathbf{p}}_{r_{l}}^{i, j}=\underset{\widetilde{\mathbf{p}}_{k}, \widetilde{\mathbf{p}}_{r_{l}}}{\arg \max .} U_{k, \text { ind }}^{\varpi, i, j} \\
U_{k, \text { ind }}^{\varpi, i, j}=\sum_{n=1}^{N} \widetilde{\lambda}_{k, n} \ell_{k, n} \widetilde{r}_{k, n, l}^{\varpi}-q_{k}^{\varpi, i-1}\left[\frac{1}{2} \sum_{n=1}^{N}\left(\varrho_{k} \widetilde{p}_{k, n}+\varrho_{r_{l}} \widetilde{p}_{r_{n, l}}\right)+\varsigma_{k, l} p_{c, r_{l}}^{\varpi}+p_{c, k}\right] \\
-\tau_{k}^{j-1} \sum_{n=1}^{N} \widetilde{p}_{k, n}-\nu_{l}^{j-1} \sum_{k=1}^{K} \sum_{n=1}^{N} \widetilde{p}_{r_{n, l}}
\end{gathered}
$$

A partir desse ponto, separa-se novamente a solução entre AF e DF. 


\subsubsection{AF}

A solução da alocação de potência para AF depende da definição de um termo $\widetilde{p}_{k, n, l}$, que corresponde à potência total utilizada nos dois saltos, e de um fator de proporcionalidade $\Omega_{k, n, l}^{\mathrm{AF}, i, j}$. O cálculo de $\Omega_{k, n, l}^{\mathrm{AF}, i, j}$ é apresentado no Apêndice C.3, de modo que as potências de cada salto na $i$-ésima iteração do DKB e $j$-ésima iteração do LDD são dadas como na equação (6.80), onde $\Omega_{k, n, l}^{\mathrm{AF}, i, j}$ é dado por:

$$
\Omega_{k, n, l}^{\mathrm{AF}, i, j}=\frac{\left(q^{\mathrm{AF}, i-1} \varrho_{r_{l}}+2 \nu_{l}^{j-1}\right) \Gamma_{l, n, 0}-\sqrt{\left(q^{\mathrm{AF}, i-1} \varrho_{k}+2 \tau_{k}^{j-1}\right)\left(q^{\mathrm{AF}, i-1} \varrho_{r_{l}}+2 \nu_{l}^{j-1}\right) \Gamma_{k, n, l} \Gamma_{l, n, 0}}}{\left(q^{\mathrm{AF}, i-1} \varrho_{r_{l}}+2 \nu_{l}^{j-1}\right) \Gamma_{l, n, 0}-\left(q^{\mathrm{AF}, i-1} \varrho_{k}+2 \tau_{k}^{j-1}\right) \Gamma_{k, n, l}}
$$

Com isso, $U_{k, \text { ind }}^{\mathrm{AF}, i, j}$ é reescrito como:

$$
\begin{aligned}
U_{k, \text { ind }}^{\mathrm{AF}, i, j}= & \underbrace{\frac{\mathrm{w}}{2} \sum_{n=1}^{N} \widetilde{\lambda}_{k, n} \ell_{k, n} \log _{2}\left(1+\frac{l_{k}^{\mathrm{AF}} \Gamma_{k, n, l, 0}^{\mathrm{AF}, i, j} \widetilde{p}_{k, n, l}}{\widetilde{\lambda}_{k, n}}\right)}_{(\mathrm{I})} \\
& -\underbrace{q^{\mathrm{AF}, i-1}\left[\frac{1}{2} \sum_{n=1}^{N}\left(\varrho_{k} \Omega_{k, n, l}^{\mathrm{AF}, i, j} \widetilde{p}_{k, n, l}+\varrho_{r_{l}}\left(1-\Omega_{k, n, l}^{\mathrm{AF}, i, j}\right) \widetilde{p}_{k, n, l}\right)+\varsigma_{k, l} p_{c, r_{l}}^{\mathrm{AF}}+p_{c, k}\right]}_{(\mathrm{II})} \\
& -\underbrace{\left[\sum_{n=1}^{N} \tau_{k}^{j-1} \Omega_{k, n, l}^{\mathrm{AF}, i, j} \widetilde{p}_{k, n, l}+\sum_{n=1}^{N} \nu_{l}^{j-1}\left(1-\Omega_{k, n, l}^{\mathrm{AF}, i, j}\right) \widetilde{p}_{k, n, l}\right]}_{(\mathrm{III})}
\end{aligned}
$$

$\operatorname{com} \Gamma_{k, n, l, 0}^{\mathrm{AF}, i, j}$ sendo definido como na equação (6.83), considerando o parâmetro $\Omega_{k, n, l}^{\mathrm{AF}, i, j}$ definido na equação (7.42).

Tomando a derivada parcial de $U_{k, \text { ind }}^{\mathrm{AF}, i, j}$ em relação a $\widetilde{p}_{k, n, l}$ para cada um dos termos, tem-se que:

$$
\begin{aligned}
& \frac{\partial(\mathrm{I})}{\partial \widetilde{p}_{k, n, l}}=\frac{\mathrm{w} \widetilde{\lambda}_{k, n} \ell_{k, n}}{2 \log (2)\left(1+\frac{\lambda_{k}^{\mathrm{AF}} \Gamma_{k, n, l, 0}^{\mathrm{AF}} \widetilde{p}_{k, n, l}}{\widetilde{\lambda}_{k, n}}\right)} \frac{\lambda_{k}^{\mathrm{AF}} \Gamma_{k, n, l, 0}^{\mathrm{AF}, i, j}}{\widetilde{\lambda}_{k, n}} \\
& =\frac{\mathrm{W} \ell_{k, n} l_{k}^{\mathrm{AF}} \Gamma_{k, n, l, 0}^{\mathrm{AF}, i, j}}{2 \log (2)\left(1+\frac{\imath_{k}^{\mathrm{AF}} \Gamma_{k, n, l, l, 0}^{\mathrm{AF}, i, \widetilde{p}_{k, n}, l}}{\widetilde{\lambda}_{k, n}}\right)} \\
& \frac{\partial(\mathrm{II})}{\partial \widetilde{p}_{k, n, l}}=\frac{q_{k}^{\mathrm{AF}, i-1}\left(\varrho_{k} \Omega_{k, n, l}^{\mathrm{AF}, i, j}+\varrho_{r_{l}}\left(1-\Omega_{k, n, l}^{\mathrm{AF}, i, j}\right)\right)}{2} \\
& \frac{\partial(\mathrm{III})}{\partial \widetilde{p}_{k, n, l}}=\tau_{k}^{j-1} \Omega_{k, n, l}^{\mathrm{AF}, i, j}+\nu_{j}^{j-1}\left(1-\Omega_{k, n, l}^{\mathrm{AF}, i, j}\right)
\end{aligned}
$$

Combinando todos os termos e que deve-se igualar a derivada parcial a zero, tem-se 
que:

$\frac{\mathrm{w} \ell_{k, n} l_{k}^{\mathrm{AF}} \Gamma_{k, n, l, 0}^{\mathrm{AF}, i, j}}{2 \log (2)\left(1+\frac{l_{k}^{\mathrm{AF}} \Gamma_{k, n, l, j}^{\mathrm{AF}, i, 0} \widetilde{p}_{k, n, l}}{\widetilde{\lambda}_{k, n}}\right)}=\frac{q_{k}^{\mathrm{AF}, i-1}\left(\varrho_{k} \Omega_{k, n, l}^{\mathrm{AF}, i, j}+\varrho_{r_{l}}\left(1-\Omega_{k, n, l}^{\mathrm{AF}, i, j}\right)\right)}{2}+\tau_{k}^{j-1} \Omega_{k, n, l}^{\mathrm{AF}, i, j}$

$$
+\nu_{l}^{j-1}\left(1-\Omega_{k, n, l}^{\mathrm{AF}, i, j}\right)
$$

$1+\imath_{k}^{\mathrm{AF}} \Gamma_{k, n, l, 0}^{\mathrm{AF}, i, j} p_{k, n, l}=\frac{\mathrm{w} \ell_{k, n} \imath_{k}^{\mathrm{AF}} \Gamma_{k, n, l, 0}^{\mathrm{AF}, i, j}}{\log (2)\left[\left(q_{k}^{\mathrm{AF}, i-1} \varrho_{k}+2 \tau_{k}^{j-1}\right) \Omega_{k, n, l}^{\mathrm{AF}, i, j}+\left(q^{\mathrm{AF}, i-1} \varrho_{r_{l}}+2 \nu_{l}^{j-1}\right)\left(1-\Omega_{k, n, l}^{\mathrm{AF}, i, j}\right)\right]}$

$p_{k, n, l}^{*, i, j}=\left[\chi_{k, n, l}-\frac{1}{\imath_{k}^{\mathrm{AF}} \Gamma_{k, n, l, 0}^{\mathrm{AF}, i, j}}\right]^{+}$

em que

$$
\chi_{k, n, l}=\frac{\mathrm{w} \ell_{k, n}}{\log (2)\left[\left(q_{k}^{\mathrm{AF}, i-1} \varrho_{k}+2 \tau_{k}^{j-1}\right) \Omega_{k, n, l}^{\mathrm{AF}, i, j}+\left(q_{k}^{\mathrm{AF}, i-1} \varrho_{r_{l}}+2 \nu_{j}^{j-1}\right)\left(1-\Omega_{k, n, l}^{\mathrm{AF}, i, j}\right)\right]}
$$

Note que a equação de alocação de potência do problema individual é muito semelhante ao caso do produtório, equação (6.85), considerando que $R_{\bar{k}}^{\mathrm{AF}}=P_{\bar{k}}^{\mathrm{AF}}=1$ e que cada usuário tem seu próprio parâmetro $q$.

\subsubsection{DF}

Como o fator de proporcionalidade $\Omega_{k, n, l}^{\mathrm{DF}}$ é fixo em todas as iterações e definido pela equação (6.52), e as potências de cada salto são calculadas como na equação

$$
\begin{aligned}
U_{k, \text { ind }}^{\mathrm{DF}, i, j}= & \underbrace{\sum_{n=1}^{N} \widetilde{\lambda}_{k, n} \ell_{k, n} \frac{\mathrm{W}}{2} \log _{2}\left(1+\frac{l_{k}^{\mathrm{DF}} \Omega_{k, n, l}^{\mathrm{DF}} \widetilde{p}_{k, n, l} \Gamma_{k, n, l}}{\widetilde{\lambda}_{k, n}}\right)}_{(\mathrm{I})} \\
& -\underbrace{q_{k}^{\mathrm{DF}, i-1}\left(\frac{1}{2} \sum_{n=1}^{N}\left(\varrho_{k} \Omega_{k, n, l}^{\mathrm{DF}}+\varrho_{r_{l}}\left(1-\Omega_{k, n, l}^{\mathrm{DF}}\right)\right)\right.}_{(\mathrm{II})} \widetilde{p}_{k, n, l}+\varsigma_{k, l} p_{c, r_{l}}^{\mathrm{DF}}+p_{c, k}) \\
& -\underbrace{\left[\sum_{n=1}^{N} \tau_{k}^{j-1} \Omega_{k, n, l}^{\mathrm{DF}} \widetilde{p}_{k, n, l}+\sum_{n=1}^{N} \nu_{l}^{j-1}\left(1-\Omega_{k, n, l}^{\mathrm{DF}}\right) \widetilde{p}_{k, n, l}\right]}_{(\mathrm{III})}
\end{aligned}
$$

Tomando a derivada parcial de $U_{k, \text { ind }}^{\mathrm{DF}, i, j}$ em relação a $\widetilde{p}_{k, n, l}$ para cada um dos itens, 
tem-se que:

$$
\begin{aligned}
\frac{\partial(\mathrm{I})}{\partial \widetilde{p}_{k, n, l}} & =\frac{\mathrm{w} \widetilde{\lambda}_{k, n} \ell_{k, n}}{2 \log (2)\left(1+\frac{\imath_{k}^{\mathrm{DF}} \Omega_{k, n, l}^{\mathrm{DF}} \widetilde{p}_{k, n} \Gamma_{k, n, l}}{\widetilde{\lambda}_{k, n}}\right)} \frac{l_{k}^{\mathrm{DF}} \Omega_{k, n, l}^{\mathrm{DF}} \Gamma_{k, n, l}}{\widetilde{\lambda}_{k, n}} \\
& =\frac{\mathrm{w} \ell_{k, n} \imath_{k}^{\mathrm{DF}} \Omega_{k, n, l}^{\mathrm{DF}} \Gamma_{k, n, l}}{2 \log (2)\left(1+\frac{l_{k}^{\mathrm{DF} \Omega_{k, n, l} \widetilde{p}_{k, n} \Gamma_{k, n, l}}}{\widetilde{\lambda}_{k, n}}\right)} \\
\frac{\partial(\mathrm{II})}{\partial \widetilde{p}_{k, n, l}} & =\frac{q_{k}^{\mathrm{DF}, i-1}\left(\varrho_{k} \Omega_{k, n, l}^{\mathrm{DF}}+\varrho_{r_{l}}\left(1-\Omega_{k, n, l}^{\mathrm{DF}}\right)\right)}{2} \\
\frac{\partial(\mathrm{III})}{\partial \widetilde{p}_{k, n, l}} & =\tau_{k}^{j-1} \Omega_{k, n, l}^{\mathrm{DF}}+\nu_{l}^{j-1}\left(1-\Omega_{k, n, l}^{\mathrm{DF}}\right)
\end{aligned}
$$

Juntando todos os itens e igualando a derivada parcial a zero, tem-se que:

$$
\begin{aligned}
& \frac{\mathrm{w} \ell_{k, n} \imath_{k}^{\mathrm{DF}} \Omega_{k, n, l}^{\mathrm{DF}} \Gamma_{k, n, l}}{2 \log (2)\left(1+\frac{\imath_{k}^{\mathrm{DF}} \Gamma_{k, n, l} \Omega_{k, n, l}^{\mathrm{DF}} \widetilde{p}_{k, n}}{\widehat{\lambda}_{k, n}}\right)}= \\
& \frac{q_{k}^{\mathrm{DF}, i-1}\left(\varrho_{k} \Omega_{k, n, l}^{\mathrm{DF}}+\varrho_{r_{l}}\left(1-\Omega_{k, n, l}^{\mathrm{DF}}\right)\right)+2 \tau_{k}^{j-1} \Omega_{k, n, l}^{\mathrm{DF}}+2 \nu_{l}^{j-1}\left(1-\Omega_{k, n, l}^{\mathrm{DF}}\right)}{2}
\end{aligned}
$$

$1+\imath_{k}^{\mathrm{DF}} \Omega_{k, n, l}^{\mathrm{DF}} \Gamma_{k, n, l} p_{k, n, l}=$

$$
\begin{aligned}
& \frac{\mathrm{w} \ell_{k, n} \imath_{k}^{\mathrm{DF}} \Omega_{k, n, l}^{\mathrm{DF}} \Gamma_{k, n, l}}{\log (2)\left[q_{k}^{\mathrm{DF}, i-1}\left(\varrho_{k} \Omega_{k, n, l}^{\mathrm{DF}}+\varrho_{r_{l}}\left(1-\Omega_{k, n, l}^{\mathrm{DF}}\right)\right)+2 \tau_{k}^{j-1} \Omega_{k, n, l}^{\mathrm{DF}}+2 \nu_{l}^{j-1}\left(1-\Omega_{k, n, l}^{\mathrm{DF}}\right)\right]} \\
& p_{k, n, l}^{*, i, j}=\left[\chi_{k, n, l}-\frac{1}{\imath_{k}^{\mathrm{DF}} \Omega_{k, n, l}^{\mathrm{DF}} \Gamma_{k, n, l}}\right]^{+}
\end{aligned}
$$

em que

$$
\chi_{k, n, l}=\frac{\mathrm{w} \ell_{k, n}}{\log (2)\left[\left(q_{k}^{\mathrm{DF}, i-1} \varrho_{k}+2 \tau_{k}^{j-1}\right) \Omega_{k, n, l}^{\mathrm{DF}}+\left(q_{k}^{\mathrm{DF}, i-1} \varrho_{r_{l}}+2 \nu_{l}^{j-1}\right)\left(1-\Omega_{k, n, l}^{\mathrm{DF}}\right)\right]}
$$

Assim como para o caso do protocolo AF, percebe-se a semelhança da equação de alocação de potência do caso individual com a equação de alocação de potência para solução via produtório, equação $(6.96)$, com $R_{\bar{k}}^{\mathrm{DF}}=P_{\bar{k}}^{\mathrm{DF}}=1$ e os parâmetros individuais de $\mathrm{DKB}$ ao invés do parâmetro único. 



\section{CONCLUSÕES E TRABALHOS FUTU- ROS}

Esta tese analisou e propôs soluções computacionais para a alocação de recursos visando a maximização de eficiência energética para o uplink de sistemas OFDMA, considerando estratégias de máxima eficiência para o sistema como um todo e também com a utilização de estratégias de fairness proporcional. Além da descrição do equacionamento necessário para alocar os recursos de potência e espectro, utilizando ferramentais de otimização convexa, considerou-se também a importância de estratégias computacionalmente eficientes para a resolução dos problemas propostos, de modo que as soluções propostas não fossem viáveis apenas no plano teórico.

O Capítulo 4 apresenta o problema de maximização de EE de um ponto de vista sistêmico, em que se busca a máxima EE atingível sem se considerar o atendimento individual de qualquer requisito de qualidade para as MSs. Apesar de tal problema ser analisado na literatura, não são expostas as limitações de tal abordagem, como a quantidade elevada de MSs sem recursos espectrais após a solução da alocação ser aplicada. Além disso, pouco se discute sobre as estratégias necessárias para que tal problema possa ser executado em cenários de aplicação reais e de interesse prático, nos quais a escolha empírica de parâmetros pode ser inviável, se não impossível. Nesse ponto, o Capítulo 4 apresenta uma profunda e oportuna discussão sobre estratégias de implementação, que ainda resultam em algoritmos sub-ótimos para a alocação de recursos.

Os Capítulos 5 e 6 apresentam a estratégia de fairness proporcional para a alocação de recursos, incorporando as funções de EE individual às funções-objetivo de fairness para os cenários não-cooperativo e cooperativo, respectivamente. Os capítulos apresentam dois ferramentais distintos, que fazem uso de otimização convexa para que seja possível obter algoritmos que podem ser implementados computacionalmente para a alocação de recursos. Apesar de serem capítulos mais analíticos, focados no equacionamento da solução, já apresentam informações sobre a implementação computacional e quais pontos serão críticos no desenvolvimento da solução computacional.

As dificuldades enfrentadas no processo de simulação computacional dos algoritmos propostos nos Capítulos 5 e 6 mostram a importância da discussão apresentada no Capítulo 4, principalmente se for considerada a viabilidade técnica da implementação dos algoritmos. Por mais que os ferramentais apresentados sejam capazes de prover expressões fechadas para o cálculo dos valores ótimos para a alocação dos recursos, há uma significativa distância entre o equacionamento e a viabilidade da solução, seja em termos de estabilidade, seja em relação à complexidade ou calibração de variáveis. Neste sentido, as discussões apresentadas no Capítulo 7 mostram algumas soluções para os problemas 
levantados, propondo algoritmos simplificados que usam propriedades das soluções desenvolvidas nos Capítulos 5 e 6 para melhorar tanto a aplicabilidade quanto a convergência e a velocidade de execução.

Buscou-se nas soluções desenvolvidas manter a eficiência computacional, reduzir a complexidade exigida e gerar ganhos em diferentes áreas, como foi o caso da estratégia de fairness, sem gerar custos elevados em termos de EE e/ou SE - ou ao menos propondo maneiras de se superar tais custos. Com isso, se realizam os objetivos propostos na introdução da tese.

\subsection{Trabalhos Futuros}

Aponta-se como primeira possibilidade de trabalhos futuros a análise de uma nova estratégia de inicialização de variáveis, seja para utilização com os algoritmos híbridos ou mesmo com as estratégias DCP+LDD ou DKB+LDD. Os resultados do Capítulo 4 en relação a convergência e número de iterações executadas mostram que uma eficaz estratégia de inicialização de variáveis é fundamental não só para que os resultados numéricos sejam obtidos, mas para que os algoritmos propostos sejam aplicáveis em cenários comerciais.

É necessário também quantificar a porção de eficiência espectral, e até mesmo energética, são perdidas com a adoção da estratégia de fairness. Como foi discutido no Capítulo 6, a estratégia de fairness faz com que subportadoras sejam alocadas para MSs sujeitas a condições desfavoráveis de propagação, que então devem consumir mais potência para transmitir uma mesma quantidade de informação ou então transmitir menos dados com a mesma quantidade de potência. Pode-se investigar se outras estratégias, como uma média ponderada de EEs individuais, pesos ou classes de MSs possibilitam um melhor compromisso entre fairness e eficiência energética e/ou espectral.

Com a tecnologia $5 \mathrm{G}$ se tornando realidade, com maior conjunto de análise e resultados sendo discutidos na literatura atual, além dos primeiros documentos comerciais em direção à padronização, é interessante verificar a aplicabilidade da estratégia de maximização de EE com fairness proporcional para tais sistemas, e quais técnicas de otimização podem ser aplicadas aos novos problemas.

Por fim, há diversas técnicas de otimização para comunicação cooperativa que podem ser empregadas para contornar a perda de eficiência energética e/ou espectral, aplicáveis tanto a sistemas $4 \mathrm{G}$ quanto $5 \mathrm{G}$, como seleção dinâmica de RSs, otimização nos métodos de duplexação, aproveitamento de diversidade em frequência/espacial e recombinação de subportadoras. A escolha de quais dessas técnicas disponíveis são aplicáveis ao contexto de fairness proporcional em comunicação cooperativa depende da análise dos resultados da alocação de recursos proposta no Capítulo 6. 


\section{REFERÊNCIAS}

[1] DAHLMAN, E. et al. 3G Evolution: HSPA and LTE for Mobile Broadband. Burlington, EUA: Academic Press, 2007.

[2] GAO, L.; ACHARYA, J.; GAUR, S. Heterogeneous Networks - Theory and Standardization in LTE. 2013. Tutorial apresentado no IEEE WCNC 2013. Disponível em: <http://wcnc2013.ieee-wcnc.org/WCNC.T7.Slides.pdf>.

[3] INTERNATIONAL TELECOMMUNICATION UNION. ITU-R M.2134 Requirements related to technical performance for IMT-Advanced radio interface(s). Geneva, Suiça, 2008.

[4] ANDREWS, J. G.; GHOSH, A.; MUHAMED, R. Fundamentals of WiMAX: Understanding Broadband Wireless Networking. EUA: Prentice Hall, 2007. ISBN $0-13-222552-2$.

[5] IEEE Standard for WirelessMAN-Advanced Air Interface for Broadband Wireless Access Systems. IEEE Std 802.16.1-2012, p. 1-1090, 2012.

[6] 3GPP. Overview of 3GPP Release 12 V0.1.2 (2014-03). 2014. Disponível em: $<$ http://www.3gpp.org/FTP/Information/WORK_PLAN/Description_Releases/ Previous_versions/Rel-12_description_20140316.zip>. Acesso em: 16 de Mai. de 2014.

[7] DAMNJANOVIC, A. et al. A survey on 3GPP heterogeneous networks. IEEE Wireless Communications, v. 18, n. 3, p. 10-21, Jun. 2011. ISSN 1536-1284.

[8] DOHLER, M.; LI, Y. Cooperative Communications: hardware, channel \&3 PHY. Reino Unido: Wiley, 2010. ISBN 0-470-74007-8.

[9] WANG, C.-X. et al. Cellular architecture and key technologies for 5G wireless communication networks. IEEE Communications Magazine, v. 52, n. 2, p. 122-130, Fev. 2014. ISSN 0163-6804.

[10] WERNER, M. et al. Cost assessment and optimization methods for multi-node radio access networks. In: IEEE Vehicular Technology Conference (VTC Spring). Singapura: IEEE, 2008. p. 2601-2605. ISSN 1550-2252.

[11] KHIRALLAH, C.; THOMPSON, J.; RASHVAND, H. Energy and cost impacts of relay and femtocell deployments in long-term-evolution advanced. IET Communications, v. 5, n. 18, p. 2617-2628, 2011. ISSN 1751-8628.

[12] NOSRATINIA, A.; HEDAYAT, A. Network architectures and research issues in cooperative cellular wireless networks. In: Cooperative Cellular Wireless Networks. Cambridge, Reino Unido: Cambridge University Press, 2011. p. 3-13. ISBN 978-0-521-76712-5.

[13] IEEE Standard for WirelessMAN-Advanced Air Interface for Broadband Wireless Access Systems -Amendment 2: Higher Reliability Networks. IEEE Std 802.16.1a-2013 (Amendment to IEEE Std 802.16.1-2012), p. 1-319, 2013. 
[14] 3GPP. 3GPP TR 36.836 V12.0.0 - Study on Mobile Relay (Release 12). Valbonne, França, 2014.

[15] SUN, C.; YANG, C. Is two-way relay more energy efficient? In: IEEE Global Telecommunications Conference (GLOBECOM 2011). Houston, EUA: IEEE, 2011. p. 1-6. ISSN 1930-529X.

[16] SOUZA, Á. R. C.; ABRÃO, T. Interference-limited fixed relaying-aided macrocellular CDMA networks. In: Green Networking and Communications: ICT for Sustentability. Boca Raton, EUA: CRC Press, 2013. p. 165-210. ISBN 9781466568747.

[17] PAPADOGIANNIS, A. et al. Pass it on: Advanced relaying concepts and challenges for networks beyond 4G. IEEE Vehicular Technology Magazine, v. 9, n. 2, p. 29-37, Jun. 2014. ISSN 1556-6072.

[18] 3GPP. 3GPP TR 36.814 V9.0.0: Further advancements for E-UTRA physical layer aspects (Release 9). Valbonne, França, 2010.

[19] FLORE, D. 3GPP RAN: Rel-12 and beyond. 2013. Apresentado no ETSI Future Mobile Summit. Disponível em: <http://docbox.etsi.org/Workshop/2013/201311 FUTUREMOBILESUMMIT/06_3GPPRAN_FLORE.pdf $>$.

[20] CHEN, S.; ZHAO, J. The requirements, challenges, and technologies for $5 \mathrm{G}$ of terrestrial mobile telecommunication. IEEE Communications Magazine, v. 52, n. 5, p. 36-43, Mai. 2014. ISSN 0163-6804.

[21] SUN, J.; WU, D.; CI, S. Battery capacity footprinting and optimization analysis for wireless multimedia communication. In: IEEE Global Telecommunications Conference (GLOBECOM 2011). Houston, EUA: IEEE, 2011. p. 1-5. ISSN 1930-529X.

[22] HUQ, K. M. S. et al. Energy efficiency of downlink packet scheduling in CoMP. Transactions on Emerging Telecommunications Technologies, 2013. ISSN 2161-3915.

[23] LI, G. et al. Energy-efficient wireless communications: tutorial, survey, and open issues. IEEE Wireless Communications, v. 18, n. 6, p. 28-35, Dez. 2011. ISSN 1536-1284.

[24] MESHKATI, F. et al. An energy-efficient approach to power control and receiver design in wireless data networks. IEEE Transactions on Communications, v. 53, n. 11, p. 1885-1894, Nov. 2005. ISSN 0090-6778.

[25] SARAYDAR, C.; MANDAYAM, N.; GOODMAN, D. Efficient power control via pricing in wireless data networks. IEEE Transactions on Communications, v. 50, n. 2, p. 291-303, Fev. 2002. ISSN 0090-6778.

[26] MIAO, G. et al. Distributed interference-aware energy-efficient power optimization. IEEE Transactions on Wireless Communications, v. 10, n. 4, p. 1323-1333, Abr. 2011. ISSN 1536-1276.

[27] HUANG, S. et al. Energy efficiency and spectral-efficiency tradeoff in amplify-andforward relay networks. IEEE Transactions on Vehicular Technology, v. 62, n. 9, p. 4366-4378, 2013. ISSN 0018-9545. 
[28] SOUZA, Á. R. C. e. Eficiência Energética e Espectral em Redes Sem Fio Macro-celulares: Ccaracterização, Otimização e Análise De Compromisso. Dissertação (Mestrado) — Universidade Estadual de Londrina, 2013.

[29] CHEN, Y. et al. Fundamental trade-offs on green wireless networks. IEEE Communications Magazine, v. 49, n. 6, p. 30-37, Jun. 2011. ISSN 0163-6804.

[30] ASTELY, D. et al. LTE release 12 and beyond [accepted from open call]. IEEE Communications Magazine, v. 51, n. 7, p. 154-160, Jul. 2013. ISSN 0163-6804.

[31] I, C.-L. et al. Toward green and soft: a 5G perspective. IEEE Communications Magazine, v. 52, n. 2, p. 66-73, Fev. 2014. ISSN 0163-6804.

[32] KLEIN, T. E. Energy Efficient Wireless Networks Beyond 2020. 2014. Apresentado no Workshop do ITU-R sobre "Research Views on IMT Beyond 2020". Disponível em: <http://www.greentouch.org/uploads/GreenTouch_ITU-R_Workshop_Research_ Views_on_IMT_Beyond_2020_02-14-2014.pdf $>$.

[33] ZHENG, Z. et al. Energy-efficient resource allocation for downlink OFDMA systems. In: IEEE International Conference on Communications Workshops (ICC). Budapeste, Hungria: IEEE, 2013. p. 391-395.

[34] CHEUNG, K.; YANG, S.; HANZO, L. Achieving maximum energy-efficiency in multi-relay OFDMA cellular networks: A fractional programming approach. IEEE Transactions on Communications, v. 61, n. 7, p. 2746-2757, Jul. 2013. ISSN 0090-6778.

[35] HAYKIN, S. O.; MOHER, M. Modern Wireless Communications. Upper Saddle River, EUA: Prentice Hall, 2004. ISBN 978-0130224729.

[36] GOLDSMITH, A. Wireless Communications. Nova Iorque, EUA: Cambridge University Press, 2005.

[37] SHANNON, C. E. A mathematical theory of communication. Bell System Technical Journal, v. 27, p. 379-423 e 623-656, 1948.

[38] COVER, T. M.; THOMAS, J. A. Elements of information theory. Hoboken, EUA: John Wiley and Sons, 2006. ISBN 978-0-471-24195-9.

[39] CHEN, Q.; GURSOY, M. Energy efficiency analysis in amplify-and-forward and decode-and-forward cooperative networks. In: IEEE Wireless Communications and Networking Conference (WCNC). Sydney, Austrália: IEEE, 2010. p. 1-6. ISSN 1525-3511.

[40] HANZO, L. et al. OFDM and MC-CDMA for Broadband Multi-User Communications, WLANs and Broadcasting. Chichester, Inglaterra: Wiley e IEEE Press, 2006. ISBN 978-0-470-85879-0.

[41] BAKER, M. LTE-Advanced Physical Layer. 2009. Apresentado no IMT-Advanced Evaluation Workshop, realizado em Beijing, China. Disponível em: <www.3gpp.org/ ftp/workshop/2009-12-17_ITU-R_IMT-Adv_eval/docs/pdf/REV-090003-r1.pdf>.

[42] MALLICK, S. et al. Radio resource optimization in cooperative cellular wireless networks. In: Cooperative Cellular Wireless Networks. Cambridge, Reino Unido: Cambridge University Press, 2011. p. 205-232. ISBN 978-0-521-76712-5. 
[43] YAACOUB, E.; DAWY, Z. A survey on uplink resource allocation in OFDMA wireless networks. IEEE Communications Surveys Tutorials, v. 14, n. 2, p. 322-337, 2012. ISSN 1553-877X.

[44] MESHKATI, F.; POOR, H.; SCHWARTZ, S. Energy-efficient resource allocation in wireless networks. IEEE Signal Processing Magazine, v. 24, n. 3, p. 58-68, Mai. 2007. ISSN 1053-5888.

[45] PALOMAR, D.; CHIANG, M. A tutorial on decomposition methods for network utility maximization. IEEE Journal on Selected Areas in Communications, v. 24, n. 8, p. 1439-1451, Ago. 2006. ISSN 0733-8716.

[46] NG, C. Y.; SUNG, C.-W. Low complexity subcarrier and power allocation for utility maximization in uplink OFDMA systems. IEEE Transactions on Wireless Communications, v. 7, n. 5, p. 1667-1675, Mai. 2008. ISSN 1536-1276.

[47] ETSI. 3GPP TS 36.211 version 11.4.0 Release 11 - Physical channels and modulation. Valbonne, França, 2013.

[48] COLETTI, C.; MOGENSEN, P.; IRMER, R. Deployment of LTE in-band relay and micro base stations in a realistic metropolitan scenario. In: IEEE Vehicular Technology Conference (VTC Fall). São Francisco, EUA: IEEE, 2011. p. 1-5. ISSN 1090-3038.

[49] MINELLI, M. et al. Optimal relay placement in cellular networks. IEEE Transactions on Wireless Communications, v. 13, n. 2, p. 998-1009, Fev. 2014. ISSN 1536-1276.

[50] KIM, D. I. et al. Partial information relaying and relaying in 3GPP LTE. In: Cooperative Cellular Wireless Networks. Cambridge, Reino Unido: Cambridge University Press, 2011. p. 462-494. ISBN 978-0-521-76712-5.

[51] NOURIZADEH, H.; NOURIZADEH, S.; TAFAZOLLI, R. Performance evaluation of cellular networks with mobile and fixed relay station. In: IEEE 64th Vehicular Technology Conference (VTC Fall). Montreal, Canadá: IEEE, 2006. p. 1-5.

[52] CHEN, L. et al. Mobile relay in LTE-advanced systems. IEEE Communications Magazine, v. 51, n. 11, p. 144-151, Nov. 2013. ISSN 0163-6804.

[53] LANEMAN, J. N. Cooperative diversity in wireless networks: algorithms and architectures. Tese (Doutorado) - Massachusetts Institute of Technology, Cambridge, MA, 2002.

[54] RIIHONEN, T.; WICHMAN, R.; WERNER, S. Evaluation of OFDM(A) relaying protocols: Capacity analysis in infrastructure framework. IEEE Transactions on Vehicular Technology, v. 61, n. 1, p. 360-374, 2012. ISSN 0018-9545.

[55] SHEN, G. et al. Multi-hop Relay Operation Modes. IEEE, 2008.

[56] LIEBL, G.; MORAES, T. M. de; WEITKEMPER, P. Advanced Relay Technical Proposals. ARTIST4G, 2011.

[57] YANG, Y. et al. Relay technologies for WiMAX and LTE-advanced mobile systems. IEEE Communications Magazine, v. 47, n. 10, p. 100-105, Out. 2009. ISSN 0163-6804. 
[58] YI, Z.; KIM, I.-M. Relay ordering in a multi-hop cooperative diversity network. IEEE Transactions on Communications, v. 57, n. 9, p. 2590-2596, 2009. ISSN 0090-6778.

[59] SO, A.; LIANG, B. Enhancing WLAN capacity by strategic placement of tetherless relay points. IEEE Transactions on Mobile Computing, v. 6, n. 5, p. 522-535, Mai. 2007. ISSN 1536-1233.

[60] NOKIA, N. S. N. R1-104460 - Type-1 relay performance for uplink. Item 6.6.4 da agenda apresentado para discussão no 3GPP TSG-RAN WG1 Meeting \#62, Madri, Espanha. 2010. Disponível em: <http://www.3gpp.org/ftp/tsg_ran/WG1_RL1/ TSGR1_62/Docs/R1-104460.zip >.

[61] SAMSUNG. R1-100139 - full duplex configuration of Un and Uu subframes for Type I relay. Item 7.5.2 da agenda apresentado para discussão no 3GPP TSG-RAN WG1 Meeting \#59bis, Valencia, Espanha. 2010. Disponível em: <http://www.3gpp.org/ftp/tsg_ran/wg1_rl1/TSGR1_59b/Docs/R1-100139.zip>.

[62] HOYMANN, C. et al. Relaying operation in 3GPP LTE: challenges and solutions. IEEE Communications Magazine, v. 50, n. 2, p. 156-162, 2012. ISSN 0163-6804.

[63] IEEE Standard for Air Interface for Broadband Wireless Access Systems. IEEE Std 802.16-2012 (Revision of IEEE Std 802.16-2009), p. 1-2542, 2012.

[64] INTERNATIONAL TELECOMMUNICATION UNION. ITU-R M.1457-11 Detailed specifications of the terrestrial radio interfaces of International Mobile Telecommunications-2000 (IMT-2000). Geneva, Suiça, 2013.

[65] IEEE Standard for Local and metropolitan area networks Part 16: Air Interface for Broadband Wireless Access Systems Amendment 3: Advanced Air Interface. IEEE Std 802.16m-2011 (Amendment to IEEE Std 802.16-2009), p. 1-1112, 62011.

[66] LOA, K. et al. IMT-advanced relay standards [WiMAX/LTE update]. IEEE Communications Magazine, v. 48, n. 8, p. 40-48, Ago. 2010. ISSN 0163-6804.

[67] ETSI. 3GPP TR 36.912 version 11.0.0 Release 11: Feasibility study for Further Advancements for E-UTRA (LTE-Advanced). Valbonne, França, 2012.

[68] SAMSUNG et al. R1-101659 - text proposal on inband full duplex relay for TR 36.814. Item 8.1 da agenda apresentado para discussão no 3GPP TSGRAN WG1 Meeting \#60, San Francisco, EUA. 2010. Disponível em: <http: //www.3gpp.org/ftp/tsg_ran/wg1_rl1/TSGR1_60/Docs/R1-101659.zip>.

[69] HAIDER, F. et al. Energy-efficient subcarrier-and-bit allocation in multi-user OFDMA systems. In: IEEE 75th Vehicular Technology Conference (VTC Spring). Yokohama, Japão: IEEE, 2012. p. 1-5. ISSN 1550-2252.

[70] KAKITANI, M.; SOUZA, R. D.; IMRAN, M. Energy efficiency contours for amplify-and-forward and decode-and-forward cooperative protocols. In: 8th International Symposium on Communication Systems, Networks and Digital Signal Processing (CSNDSP). Poznan, Polônia: IEEE, 2012. p. 1-5.

[71] AUER, G. et al. Cellular energy efficiency evaluation framework. In: IEEE 73rd Vehicular Technology Conference (VTC Spring). Budapeste, Hungria: IEEE, 2011. p. 1-6. ISSN 1550-2252. 
[72] ETSI. 3GPP TR 36.913 version 11.0.0 Release 11 - Requirements for further advancements for Evolved Universal Terrestrial Radio Access (E-UTRA) (LTEAdvanced). Valbonne, França, 2012.

[73] GOODMAN, D. J.; MANDAYAN, N. B. Power control for wireless data. IEEE Personal Communication Magazine, v. 7, n. 4, p. 48-54, Abr. 2000. ISSN 1070-9916.

[74] BUZZI, S.; POOR, H. Joint receiver and transmitter optimization for energy-efficient CDMA communications. IEEE Journal on Selected Areas in Communications, v. 26, n. 3, p. 459-472, Abr. 2008. ISSN 0733-8716.

[75] RODRIGUEZ, V. An analytical foundation for resource management in wireless communication. In: IEEE Global Telecommunications Conference (GLOBECOM). San Francisco, EUA: IEEE, 2003. v. 2, p. 898-902.

[76] XIONG, C. et al. Energy- and spectral-efficiency tradeoff in downlink OFDMA networks. IEEE Transactions on Wireless Communications, v. 10, n. 11, p. 3874-3886, Nov. 2011. ISSN 1536-1276.

[77] TSE, D.; VISWANATH, P. Fundamentals of Wireless Communications. Inglaterra: Cambridge University Press, 2005. ISBN 0-521-84527-0.

[78] ISHEDEN, C.; FETTWEIS, G. Energy-efficient multi-carrier link adaptation with sum rate-dependent circuit power. In: Global Telecommunications Conference (GLOBECOM 2010), 2010 IEEE. Miami, EUA: IEEE, 2010. p. 1-6. ISSN 1930-529X.

[79] NGO, H. Q.; LARSSON, E.; MARZETTA, T. Energy and spectral efficiency of very large multiuser MIMO systems. IEEE Transactions on Communications, v. 61, n. 4, p. 1436-1449, Abr. 2013. ISSN 0090-6778.

[80] NG, D.; LO, E.; SCHOBER, R. Energy-efficient resource allocation in OFDMA systems with large numbers of base station antennas. IEEE Transactions on Wireless Communications, v. 11, n. 9, p. 3292-3304, Set. 2012. ISSN 1536-1276.

[81] CUI, S.; GOLDSMITH, A.; BAHAI, A. Energy-constrained modulation optimization. IEEE Transactions on Wireless Communications, v. 4, n. 5, p. 2349-2360, Set. 2005. ISSN 1536-1276.

[82] SUN, C.; CEN, Y.; YANG, C. Energy efficient OFDM relay systems. IEEE Transactions on Communications, v. 61, n. 5, p. 1797-1809, Mai. 2013. ISSN 0090-6778.

[83] HAN, C. et al. Green radio: radio techniques to enable energy-efficient wireless networks. IEEE Communications Magazine, v. 49, n. 6, p. 46-54, Jun. 2011. ISSN 0163-6804.

[84] JANG, J.; LEE, K.-B. Transmit power adaptation for multiuser OFDM systems. IEEE Journal on Selected Areas in Communications, v. 21, n. 2, p. 171-178, Fev. 2003. ISSN 0733-8716.

[85] KIM, K.; HAN, Y.; KIM, S.-L. Joint subcarrier and power allocation in uplink OFDMA systems. IEEE Communications Letters, v. 9, n. 6, p. 526-528, Jun. 2005. ISSN 1089-7798. 
[86] SOUZA, Á. R. C. et al. Energy and spectral efficiencies trade-off with filter optimisation in multiple access interference-aware networks. Transactions on Emerging Telecommunications Technologies, 2013. ISSN 2161-3915.

[87] SOUZA, Á. R. Castro e; AMAZONAS, J. R. de A.; ABRÃO, T. Energy-efficiency maximisation for cooperative and non-cooperative OFDMA cellular networks: a survey. Transactions on Emerging Telecommunications Technologies, v. 27, n. 2, p. 216-248, 2016. ISSN 2161-3915. Disponível em: <http://dx.doi.org/10.1002/ett.2850>.

[88] ELGENDY, O.; ISMAIL, M.; ELSAYED, K. On the relay placement problem in a multi-cell LTE-advanced system with co-channel interference. In: IEEE 8th International Conference on Wireless and Mobile Computing, Networking and Communications (WiMob). Barcelona, Espanha: IEEE, 2012. p. 300-307. ISSN 2160-4886.

[89] JOSHI, G.; KARANDIKAR, A. Optimal relay placement for cellular coverage extension. In: National Conference on Communications (NCC). Bangalore, Índia: IEEE, 2011. p. $1-5$.

[90] KRISHNAN, N. et al. Bandwidth sharing for relaying in cellular systems. IEEE Transactions on Wireless Communications, v. 11, n. 1, p. 117-129, 2012. ISSN 1536-1276.

[91] POURAHMADI, V. et al. Relay placement in wireless networks: A study of the underlying tradeoffs. IEEE Transactions on Wireless Communications, v. 10, n. 5, p. 1383-1388, Mai. 2011. ISSN 1536-1276.

[92] NIVEDITA, M.; RAJA, G. Efficient relay station placement strategy for broadband wireless networks - 4G. In: International Conference on Recent Trends In Information Technology (ICRTIT). Índia: IEEE, 2012. p. 282-286.

[93] DENG, N. et al. A stochastic geometry approach to energy efficiency in relayassisted cellular networks. In: IEEE Global Communications Conference (GLOBECOM). Anaheim, EUA: IEEE, 2012. p. 3484-3489. ISSN 1930-529X.

[94] WANG, Y.; FENG, G.; ZHANG, Y. Cost-efficient deployment of relays for LTE-advanced cellular networks. In: IEEE International Conference on Communications (ICC). Kyoto, Japão: IEEE, 2011. p. 1-5. ISSN 1550-3607.

[95] ZHOU, S.; GOLDSMITH, A.; NIU, Z. On optimal relay placement and sleep control to improve energy efficiency in cellular networks. In: IEEE International Conference on Communications (ICC). Kyoto, Japão: IEEE, 2011. p. 1-6. ISSN 1550-3607.

[96] LANEMAN, J.; TSE, D.; WORNELL, G. W. Cooperative diversity in wireless networks: Efficient protocols and outage behavior. IEEE Transactions on Information Theory, v. 50, n. 12, p. 3062-3080, Dez. 2004. ISSN 0018-9448.

[97] NG, D.; SCHOBER, R. Dynamic resource allocation in OFDMA systems with full-duplex and hybrid relaying. In: IEEE International Conference on Communications (ICC). Kyoto, Japão: IEEE, 2011. p. 1-6. ISSN 1550-3607.

[98] CHIN, W. H. Energy efficiency of OFDM systems using shorten-and-forward in outdoor-to-indoor relaying scenarios with short guard intervals. In: IEEE 19th Symposium on Communications and Vehicular Technology in the Benelux (SCVT). Eindhoven, Países Baixos: IEEE, 2012. p. 1-4. 
[99] MOGHADDARI, M.; HOSSAIN, E. Cooperative communications in OFDM and MIMO cellular relay networks: issues and approaches. In: Cooperative Cellular Wireless Networks. Cambridge, Reino Unido: Cambridge University Press, 2011. p. 13-45. ISBN 978-0-521-76712-5.

[100]GORA, J.; REDANA, S. In-band and out-band relaying configurations for dual-carrier LTE-advanced system. In: IEEE 22nd International Symposium on Personal Indoor and Mobile Radio Communications (PIMRC). Toronto, Canadá: IEEE, 2011. p. 1820-1824. ISSN pending.

[101]SUNDARESAN, K.; RANGARAJAN, S. Adaptive resource scheduling in wireless OFDMA relay networks. In: IEEE International Conference on Computer Communications (INFOCOM). Orlando, EUA: IEEE, 2012. p. 1080-1088. ISSN 0743-166X.

[102]RIIHONEN, T.; WERNER, S.; WICHMAN, R. Hybrid full-duplex/halfduplex relaying with transmit power adaptation. IEEE Transactions on Wireless Communications, v. 10, n. 9, p. 3074-3085, Set. 2011. ISSN 1536-1276.

[103]RIIHONEN, T. et al. SINR analysis of full-duplex OFDM repeaters. In: IEEE 20th International Symposium on Personal, Indoor and Mobile Radio Communications (PIMRC). Tokyo, Japão: IEEE, 2009. p. 3169-3173.

[104]ABDULHADI, S.; JASEEMUDDIN, M.; ANPALAGAN, A. A survey of distributed relay selection schemes in cooperative wireless ad hoc networks. Wireless Personal Communications, Springer US, v. 63, n. 4, p. 917-935, 2012. ISSN 0929-6212.

[105]BLETSAS, A. et al. A simple cooperative diversity method based on network path selection. IEEE Journal on Selected Areas in Communications, v. 24, n. 3, p. 659-672, 2006. ISSN 0733-8716.

[106]BADRUDDIN, N.; NEGI, R. Capacity improvement in a CDMA system using relaying. In: IEEE Wireless Communications and Networking Conference (WCNC). Atlanta, EUA: IEEE, 2004. v. 1, p. 243-248. ISSN 1525-3511.

[107]JU, M.; KIM, I.-M.; KIM, D. I. Joint relay selection and relay ordering for DF-based cooperative relay networks. IEEE Transactions on Communications, v. 60, n. 4, p. 908-915, 2012. ISSN 0090-6778.

[108]MADAN, R. et al. Energy-efficient cooperative relaying over fading channels with simple relay selection. IEEE Transactions on Wireless Communications, v. 7, n. 8, p. 3013-3025, 2008. ISSN 1536-1276.

[109]TANG, Z.; WANG, H.; HU, Q. An energy-efficient relay selection strategy based on optimal relay location for AF cooperative transmission. In: IEEE International Symposium on a World of Wireless, Mobile and Multimedia Networks (WoWMoM). São Francisco, EUA: IEEE, 2012. p. 1-4.

[110]YANG, W.; LI, L.; SUN, W. Energy-efficient relay selection and optimal relay location in cooperative cellular networks with asymmetric traffic. CoRR, abs/1009.0078, 2010 . 
[111]AMIN, O.; LAMPE, L. Opportunistic energy efficient cooperative communication. IEEE Wireless Communications Letters, v. 1, n. 5, p. 412-415, 2012. ISSN 2162-2337.

[112]LIM, G.; CIMINI, L. Energy-efficient best-select relaying in wireless cooperative networks. In: 46th Annual Conference on Information Sciences and Systems (CISS). Princeton, EUA: IEEE, 2012. p. 1-6.

[113]FARAZMAND, Y.; ALFA, A. Power allocation framework for OFDMA-based relay-enhanced cellular networks. In: IEEE Consumer Communications and Networking Conference (CCNC). Las Vegas, EUA: IEEE, 2013. p. 534-539.

[114]NG, D.; LO, E.; SCHOBER, R. Dynamic resource allocation in MIMO-OFDMA systems with full-duplex and hybrid relaying. IEEE Transactions on Communications, v. 60, n. 5, p. 1291-1304, Mai. 2012. ISSN 0090-6778.

[115]ZAPPONE, A.; BUZZI, S.; JORSWIECK, E. Energy-efficient power control and receiver design in relay-assisted DS/CDMA wireless networks via game theory. IEEE Communications Letters, v. 15, n. 7, p. 701-703, Jul. 2011. ISSN 1089-7798.

[116]QI, Z. et al. Power allocation for regenerative relay channel with rayleigh fading. In: IEEE 59th Vehicular Technology Conference (VTC). Milão, Itália: IEEE, 2004. v. 2, p. 1167-1171 Vol.2. ISSN 1550-2252.

[117]XIONG, C. et al. Energy-efficient resource allocation in OFDMA networks. IEEE Transactions on Communications, v. 60, n. 12, p. 3767-3778, Dez. 2012. ISSN 0090-6778.

[118]ZHENG, Z. et al. Low-complexity energy-efficient resource allocation for uplink OFDMA systems. In: IEEE Vehicular Technology Conference (VTC Fall). Las Vegas, EUA: IEEE, 2013. p. 1-5. ISSN 1090-3038.

[119]WU, Q. et al. Low complexity energy-efficient design for OFDMA systems with an elaborate power model. In: IEEE Global Communications Conference (GLOBECOM). Las Vegas, EUA: IEEE, 2014. p. 2678-2683.

[120]NG, D.; LO, E.; SCHOBER, R. Energy-efficient resource allocation in multi-cell OFDMA systems with limited backhaul capacity. IEEE Transactions on Wireless Communications, v. 11, n. 10, p. 3618-3631, 2012. ISSN 1536-1276.

[121]DINKELBACH, W. On nonlinear fractional programming. Management Science, v. 13, n. 7, p. 492-498, 1967. ISSN 0025-1909.

[122]BOYD, S.; VANDENBERGHE, L. Convex Optimization. Cambridge, Reino Unido: Cambridge University Press, 2004. ISBN 0-521-83378-7. Disponível em: $<$ http://www.stanford.edu/ boyd/cvxbook/>.

[123]ISHEDEN, C. et al. Framework for link-level energy efficiency optimization with informed transmitter. IEEE Transactions on Wireless Communications, v. 11, n. 8, p. 2946-2957, August 2012. ISSN 1536-1276.

[124]SHI, Q. et al. On the energy efficiency optimality of OFDMA for SISO-OFDM downlink system. IEEE Communications Letters, v. 17, n. 3, p. 541-544, 2013. ISSN 1089-7798. 
[125]ZENG, C.; HOO, L.; CIOFF, J. Efficient water-filling algorithms for a gaussian multiaccess channel with ISI. In: IEEE Vehicular Technology Conference (Fall). Boston, EUA: IEEE, 2000. v. 3, p. 1072-1077. ISSN 1090-3038.

[126]TSIAFLAKIS, P. et al. Improved dual decomposition based optimization for dsl dynamic spectrum management. IEEE Transactions on Signal Processing, v. 58, n. 4, p. 2230-2245, April 2010. ISSN 1053-587X.

[127]FENG, Z. et al. An iterative water-filling based resource allocation scheme in OFDMA systems for energy efficiency optimization. In: IEEE Vehicular Technology Conference (VTC Fall). Quebec, Canadá: IEEE, 2012. p. 1-5. ISSN 1090-3038.

[128]WANG, Y.; ZHANG, J.; ZHANG, P. Energy-efficient power and subcarrier allocation in multiuser OFDMA networks. In: IEEE International Conference on Communications (ICC). Sydney, Austrália: IEEE, 2014. p. 5492-5496.

[129]GARCIA-SAAVEDRA, A. et al. Balancing energy efficiency and throughput fairness in IEEE 802.11 WLANs. Pervasive and Mobile Computing, v. 8, n. 5, p. 631 - 645, 2012. ISSN 1574-1192.

[130]WANG, D. et al. Energy efficient secure communication over decode-and-forward relay channels. IEEE Transactions on Communications, v. 63, n. 3, p. 892-905, Mar. 2015. ISSN 0090-6778.

[131]CORLESS, R. M. et al. Lambert's w function in maple. The Maple Technical Newsletter, v. 9, p. 12-22, 1993.

[132]ROST, P.; FETTWEIS, G. Green communications in cellular networks with fixed relay nodes. In: Cooperative Cellular Wireless Networks. Cambridge, Reino Unido: Cambridge University Press, 2011. p. 300-323. ISBN 978-0-521-76712-5.

[133]WINNER II Channel Models - Part I Channel Models. WINNER, 2008. 


\section{ANEXO A - DEMONSTRAÇÃO DA REGRA DE SELEÇÃO DE RSS}

Admite-se, para simplificação de notação e sem perda de generalidade, que o conjunto de subportadoras $\mathbf{n}_{k}^{s}$ está alocado à $k$-ésima MS. Assim, a taxa de dados da $k$-ésima MS em comunicação direta com a BS pode ser escrita como:

$$
r_{k, 0}=\mathrm{w} \sum_{n \in \mathbf{n}_{k}^{s}} \log _{2}\left(1+\gamma_{k, n, 0} \imath_{k}\right)
$$

Assim, a potência que deve ser alocada para se garantir a taxa mínima de dados da $k$-ésima MS $\left(r_{k}^{\min }\right)$ é dada por:

$$
p_{k, 0}=\sum_{n \in \mathbf{n}_{k}^{s}} p_{k, n, 0}
$$

onde $p_{k, n, 0}$ depende de como a taxa é dividida entre as subportadoras em $\mathbf{n}_{k}^{s}$. Nesta seção, adiciona-se o índice do dispositivo receptor nas variáveis de potência para diferenciar a alocação entre comunicação direta e cooperativa, e omite-se o índice $\varpi$ quando $l=0$ visto que a comunicação direta independe de qual protocolo cooperativo é implementado.

Dada uma divisão qualquer, porém garantindo-se que a taxa em cada subportadora seja diferente de zero $\left(r_{k, n, 0}>0\right)$, a potência necessária em cada subportadora é dada por:

$$
\begin{aligned}
r_{k, n, 0} & =\mathrm{w} \log _{2}\left(1+\gamma_{k, n, 0} \imath_{k}\right) \\
\mathrm{w}^{\prime} r_{k, n, 0} & =\log _{2}\left(1+\gamma_{k, n, 0} \imath_{k}\right) \\
2^{\mathrm{w}^{\prime} r_{k, n, 0}} & =1+\gamma_{k, n, 0} \imath_{k} \\
\frac{p_{k, n, 0}\left|h_{k, n, 0}\right|^{2}}{N_{o} \mathrm{w}} & =\frac{2^{\mathrm{w}^{\prime} r_{k, n, 0}}-1}{\imath_{k}} \\
p_{k, n, 0} & =\frac{\left(2^{\mathrm{w}^{\prime} r_{k, n}}-1\right) N_{o} \mathrm{~W}}{\imath_{k}\left|h_{k, n, 0}\right|^{2}}
\end{aligned}
$$

onde $\mathrm{w}^{\prime}=\frac{1}{\mathrm{w}}$.

Considerando a mesma alocação de subportadoras e taxa por subportadora, calculase a potência de transmissão da $k$-ésima MS quando da utilização da $l$-ésima RS, ou seja, apenas o consumo de potência no primeiro salto. Como os protocolos AF e DF apresentam diferentes expressões para a taxa de dados, analisam-se os casos para cada protocolo. Busca-se demonstrar neste capítulo que a utilização de RSs só valerá a pena se o path-loss entre MS-RS seja menor que o path-loss entre MS-BS, i.e.:

$$
\frac{\mathrm{PL}_{k, n, l}}{\mathrm{PL}_{k, n, 0}}<1
$$


Na verdade essa condição é o mínimo que deve ser garantido, pois ainda existem os gastos de circuitaria e da RS alocada, de modo que não necessariamente haverá ganho na cooperação mesmo com esse método de seleção. Não se considera na formulação deste capítulo a existência de limite de potência nos dispositivos, e apesar de desenvolvidas em termos instantâneos, será posteriormente aplicada a esperança estatística para se obter as expressões desejadas. Para que haja alguma economia de energia, mantendo-se a mesma taxa de dados, é necessário que a energia gasta no link MS-RS seja ao menos menor que a energia gasta se fosse utilizada comunicação direta, i.e:

$$
p_{k, n, l}^{\varpi} \Delta_{t}^{1 \mathrm{~h}}<p_{k, n, 0} \Delta_{t}
$$

onde $\Delta_{t}^{1 \mathrm{~h}}$ é o tempo utilizado para o primeiro salto e $\Delta_{t}$ é o tempo de transmissão em modo direto. Considerando um sistema cooperativo com dois slots temporais de igual duração, i.e., $\Delta_{t}^{1 \mathrm{~h}}=\frac{\Delta_{t}}{2}$, e normalizando a equação (A.5) por $\Delta_{t}$, obtém-se que:

$$
\frac{p_{k, n, l}^{\varpi}}{2}<p_{k, n, 0}
$$

No caso do protocolo AF, é difícil analisar o primeiro salto, pois como descrito em [132] e [16] a estimativa de SINR (e consequentemente de taxa de dados) do primeiro salto é apenas um upper-bound para a real capacidade, devido à inserção de um segundo componente de ruído de fundo no trecho RS-BS. Assim, considera-se nessa análise a taxa de dados após o segundo salto, porém somente observando a potência que deve ser gasta pelo MS em cada subportadora. Considerando a divisão de taxa por subportadora para o caso direto e a equação de capacidade por subportadora para $\mathrm{AF}$, equação (3.17), que já inclui a penalização devido aos dois saltos, temos:

$$
\begin{aligned}
r_{k, n, 0} & =\frac{\mathrm{w}}{2} \log _{2}\left(1+\gamma_{k, n, l}^{\mathrm{AF}, 2 \mathrm{~h}} \imath_{k}\right) \\
2 \mathrm{w}^{\prime} r_{k, n, 0} & =\log _{2}\left(1+\gamma_{k, n, l}^{\mathrm{AF}, 2 \mathrm{~h}} \iota_{k}\right) \\
2^{2 \mathrm{w}^{\prime} r_{k, n, 0}} & =1+\gamma_{k, n, l}^{\mathrm{AF}, 2 \mathrm{~h}} \imath_{k} \\
\frac{2^{2 \mathrm{w}^{\prime} r_{k, n, 0}}-1}{\imath_{k}} & =\frac{\beta_{k, n, l} p_{k, n, l}^{\mathrm{AF}}\left|h_{k, n, l}\right|^{2}\left|g_{n, l}\right|^{2}}{\beta_{k, n, l}\left|g_{n, l}\right|^{2} N_{o} \mathrm{~W}+N_{o} \mathrm{~W}} \\
p_{k, n, l}^{\mathrm{AF}} & =\frac{\left(2^{2 \mathrm{w}^{\prime} r_{k, n, 0}}-1\right)\left(\beta_{k, n, l}\left|g_{n, l}\right|^{2} N_{o} \mathrm{w}+N_{o} \mathrm{~W}\right)}{\beta_{k, n, l}\left|h_{k, n, l}\right|^{2}\left|g_{n, l}\right|^{2} \imath_{k}}
\end{aligned}
$$

Aplicando as equações (A.3) e (A.7) na inequação (A.6), tem-se que:

$$
\begin{aligned}
\frac{\left(2^{2 \mathrm{w}^{\prime} r_{k, n, 0}}-1\right)\left(\beta_{k, n, l}\left|g_{n, l}\right|^{2} N_{o} \mathrm{w}+N_{o} \mathrm{w}\right)}{2 \beta_{k, n, l}\left|h_{k, n, l}\right|^{2}\left|g_{n, l}\right|^{2} \imath_{k}} & <\frac{\left(2^{\mathrm{w}^{\prime} r_{k, n, 0}}-1\right) N_{o} \mathrm{w}}{\imath_{k}\left|h_{k, n, 0}\right|^{2}} \\
\frac{\left(2^{2 \mathrm{w}^{\prime} r_{k, n, 0}}-1\right)\left(\beta_{k, n, l}\left|g_{n, l}\right|^{2}+1\right)}{2 \beta_{k, n, l}\left|h_{k, n, l}\right|^{2}\left|g_{n, l}\right|^{2}} & <\frac{2^{\mathrm{w}^{\prime} r_{k, n, 0}-1}}{\left|h_{k, n, 0}\right|^{2}} \\
\frac{\left|h_{k, n, 0}\right|^{2}}{\left|h_{k, n, l}\right|^{2}} & <\frac{2\left(2^{\mathrm{w}^{\prime} r_{k, n, 0}}-1\right)}{2^{2 \mathrm{w}^{\prime} r_{k, n, 0}}-1} \underbrace{\left[\frac{\beta_{k, n, l}\left|g_{n, l}\right|^{2}}{\beta_{k, n, l}\left|g_{n, l}\right|^{2}+1}\right]}_{(\mathrm{I})}
\end{aligned}
$$


O termo (A.8).(I) é sempre menor que 1 para quaisquer valores válidos de $\beta_{k, n, l}$ e crescente em relação a essa variável. Assim, desconsidera-se esse termo no decorrer da análise, considerando um cenário de melhor caso, i.e., onde a RS utiliza uma grande potência de amplificação, resultando em $\beta_{k, n, l} \rightarrow \infty$ e (A.8).(I) $=1$. Tomando então a esperança da inequação (A.8), tem-se:

$$
\begin{aligned}
\frac{\mathbb{E}\left\{\left|h_{k, n, 0}\right|^{2}\right\}}{\mathbb{E}\left\{\left|h_{k, n, l}\right|^{2}\right\}} & <\frac{E\left\{2\left(2^{\mathrm{w}^{\prime} r_{k, n, 0}}-1\right)\right\}}{E\left\{2^{2 \mathrm{w}^{\prime} r_{k, n, 0}}-1\right\}} \\
\frac{\mathrm{PL}_{k, n, l}}{\mathrm{PL}_{k, n, 0}} & <\frac{2\left(2^{\mathrm{w}^{\prime} r_{k, n, 0}}-1\right)}{2^{2 \mathrm{w}^{\prime} r_{k, n, 0}}-1} \\
\frac{\mathrm{PL}_{k, n, l}}{\mathrm{PL}_{k, n, 0}} & <\frac{2\left(2^{\mathrm{w}^{\prime} r_{k, n, 0}}-1\right)}{\left(2^{\mathrm{w}^{\prime} r_{k, n, 0}}-1\right)\left(2^{\mathrm{w}^{\prime} r_{k, n, 0}}+1\right)} \\
\frac{\mathrm{PL}_{k, n, l}}{\mathrm{PL}_{k, n, 0}} & <\frac{2}{2^{\mathrm{w}^{\prime} r_{k, n, 0}}+1} \leq 1
\end{aligned}
$$

Ou seja, na melhor das hipóteses, é necessário que o path-loss do link MS-RS seja ao menos menor que o existente no link MS-BS. Note-se que $\beta_{k, n, l} \rightarrow \infty$ implica $p_{r_{n, l}} \rightarrow \infty$, o que é impossível. Tomando $\beta_{k, n, l}$ inversamente proporcional ao ganho de canal no link RS-BS, i.e., $\beta_{k, n, l}=\frac{1}{\left|g_{n, l}\right|^{2}}$, é necessário que o path-loss do link MS-RS seja ao menos duas vezes menor que o existente no link MS-BS, demonstrando o impacto da amplificação de ruído do protocolo AF.

Agora para o protocolo DF, sabe-se que no primeiro salto a taxa de dados deve ser o dobro da taxa de dados original, i.e., $r_{k}^{\min , \mathrm{DF}}=2 r_{k}^{\min }$. Assim, basta dobrar a taxa de dados em cada subportadora, considerando a divisão realizada para MSs diretos. Considerando essa divisão de taxa por subportadora e a expressão de capacidade no primeiro salto para DF em cada subportadora, descrita na equação (3.20), obtém-se:

$$
\begin{aligned}
2 r_{k, n, 0} & =\mathrm{w} \log _{2}\left(1+\gamma_{k, n, l, 1 \mathrm{~h}}^{\mathrm{DF}} \imath_{k}\right) \\
2 \mathrm{w}^{\prime} r_{k, n, 0} & =\log _{2}\left(1+\gamma_{k, n, l, 1 \mathrm{~h}}^{\mathrm{DF}} \imath_{k}\right) \\
2^{2 \mathrm{w}^{\prime} r_{k, n, 0}} & =1+\gamma_{k, n, l, 1 \mathrm{~h}}^{\mathrm{DF}} \imath_{k} \\
\frac{p_{k, n, l}^{\mathrm{DF}}\left|h_{k, n, l}\right|^{2}}{N_{o} \mathrm{w}} & =\frac{2^{2 \mathrm{w}^{\prime} r_{k, n, 0}}-1}{\imath_{k}} \\
p_{k, n, l}^{\mathrm{DF}} & =\frac{\left(2^{2 \mathrm{w}^{\prime} r_{k, n, 0}}-1\right) N_{o} \mathrm{w}}{\imath_{k}\left|h_{k, n, l}\right|^{2}}
\end{aligned}
$$

Aplicando os resultados das equações (A.3) e (A.10) na inequação (A.6), obtém-se:

$$
\begin{aligned}
\frac{\left(2^{2 \mathrm{w}^{\prime} r_{k, n, 0}}-1\right) N_{o} \mathrm{w}}{2 \imath_{k}\left|h_{k, n, l}\right|^{2}} & <\frac{\left(2^{\mathrm{w}^{\prime} r_{k, n, 0}}-1\right) N_{o} \mathrm{w}}{\imath_{(k)}\left|h_{k, n, 0}\right|^{2}} \\
\frac{2^{2 \mathrm{w}^{\prime} r_{k, n, 0}}-1}{\left|h_{k, n, l}\right|^{2}} & <\frac{2\left(2^{\mathrm{w}^{\prime} r_{k, n, 0}}-1\right)}{\left|h_{k, n, 0}\right|^{2}} \\
\frac{\left|h_{k, n, 0}\right|^{2}}{\left|h_{k, n, l}\right|^{2}} & <\frac{2\left(2^{\mathrm{w}^{\prime} r_{k, n, 0}}-1\right)}{2^{2 \mathrm{w} r_{k, n, 0}}-1}
\end{aligned}
$$


Aplicando-se a esperança estatística na equação (A.11), e percebendo-se que o termo à direita da desigualdade é constante, obtém-se:

$$
\begin{aligned}
\frac{\mathbb{E}\left\{\left|h_{k, n, 0}\right|^{2}\right\}}{\mathbb{E}\left\{\left|h_{k, n, l}\right|^{2}\right\}} & <\frac{2\left(2^{\mathrm{w}^{\prime} r_{k, n, 0}}-1\right)}{2^{2 \mathrm{w}^{\prime} r_{k, n, 0}}-1} \\
\frac{\mathrm{PL}_{k, n, l}}{\mathrm{PL}_{k, n, 0}} & <\frac{2\left(2^{\mathrm{w}^{\prime} r_{k, n, 0}}-1\right)}{2^{2 \mathrm{w}^{\prime} r_{k, n, 0}}-1} \\
\frac{\mathrm{PL}_{k, n, l}}{\mathrm{PL}_{k, n, 0}} & <\frac{2\left(2^{\mathrm{w}^{\prime}} r_{k, n, 0}-1\right)}{\left(2^{\mathrm{w}^{\prime} r_{k, n}, 0}-1\right)\left(2^{\mathrm{w}^{\prime} r_{k, n, 0}}+1\right)} \\
\frac{\mathrm{PL}_{k, n, l}}{\mathrm{PL}_{k, n, 0}} & <\frac{2}{2^{\mathrm{w}^{\prime} r_{k, n, 0}}+1} \leq 1
\end{aligned}
$$

Assim, observa-se que somente é possível obter economia de energia se ao menos o pathloss do trecho MS-RS for menos que o existente em comunicação direta. Porém, como afirmado anteriormente, tal condição não garante que haverá redução no consumo de energia. A razão mínima entre $\mathrm{PL}_{k, n, l}$ e $\mathrm{PL}_{k, n, 0}$ depende da taxa de dados na $n$-ésima subportadora, e conforme aumenta menor deve ser o path-loss no link MS-RS para que seja possível obter ganhos.

A Figura A.1 mostra a relação entre a eficiência espectral por subportadora $\left(\mathrm{w}^{\prime} r_{k, n, 0}\right)$ estabelecida no link direto e quão menor deve ser o path-loss utilizando a l-ésima RS para que seja possível obter economia de energia para os protocolos AF e DF, considerando para o protocolo AF que $\beta_{k, n, l}=\frac{1}{\left|g_{n, l}\right|^{2}}$. A linha indica onde ocorre a igualdade das inequações (A.9) e (A.12), e qualquer valor abaixo dessas curvas indica possibilidade de redução de consumo de energia. Percebe-se que o AF exige melhor link no salto MS-RS, exatamente por amplificar ruído, e também que conforme aumenta a eficiência espectral por subportadora, melhor deve ser a qualidade do link MS-RS, e rapidamente a qualidade deve aumentar consideravelmente. Caso fosse tomado $\beta_{k, n, l}=\rightarrow \infty$, as curvas para AF e DF seriam as mesmas. 
Figura A.1 - Razão entre o path-loss direto e cooperativo para que haja igualdade na energia consumida nos links MS-RS e MS-BS, em relação à eficiência espectral do link direto. Abaixo dessas curvas, é possível obter redução da energia consumida.

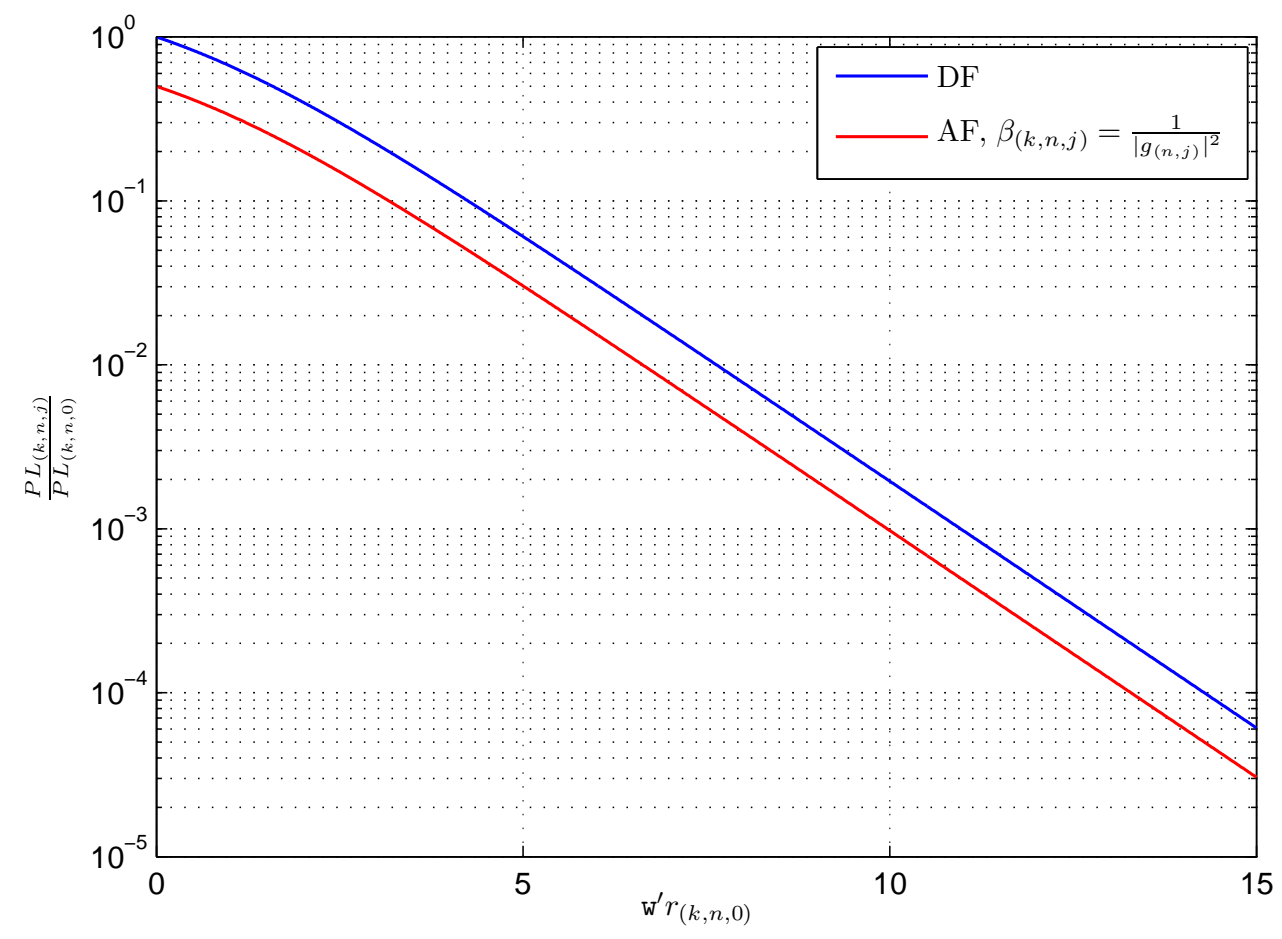

Fonte: o autor 



\section{ANEXO B - DEMONSTRAÇÃO DOS TEOREMAS E LEMAS PROPOSTOS}

\section{B.1 Prova do Teorema 4.1}

Para demonstrar que $\widetilde{\xi}(\widetilde{\mathbf{P}}, \widetilde{\boldsymbol{\lambda}})$ é quase-côncavo em relação a $\widetilde{p}_{k, n}$ e $\widetilde{\lambda}_{k, n}$, é suficiente demonstrar que o numerador de $\widetilde{\xi}(\widetilde{\mathbf{P}}, \widetilde{\boldsymbol{\lambda}})$ é côncavo em relação a essas variáveis e que o denominador é, ao mesmo tempo, afim e positivo em relação às variáveis de otimização [34].

Começando pela demonstração do numerador, será feita uma composição semelhante à desenvolvida em [34]. Inicialmente, busca demonstrar-se que

$$
f_{1}\left(\widetilde{p}_{k, n}\right)=\widetilde{p}_{k, n} \Gamma_{k, n} \imath_{k}
$$

é côncava em relação a $\widetilde{p}_{k, n}$. Para tal, é suficiente demonstrar que $\frac{\partial^{2} f_{1}\left(\widetilde{p}_{k, n}\right)}{\partial\left(\widetilde{p}_{k, n}\right)^{2}} \leq 0$ [122]. Calculando então a derivada parcial pedida, tem-se

$$
\frac{\partial^{2} f_{1}\left(\widetilde{p}_{k, n}\right)}{\partial\left(\widetilde{p}_{k, n}\right)^{2}}=0
$$

de modo que a condição necessária é provada.

Tomando agora $f_{2}\left(\widetilde{p}_{k, n}\right)=\log _{2}\left(1+f_{1}\left(\widetilde{p}_{k, n}\right)\right)$, tem-se que $f_{2}\left(\widetilde{p}_{k, n}\right)$ é côncavo pois a soma da constante 1 não altera a concavidade de $f_{1}\left(\widetilde{p}_{k, n}\right)$, e o logaritmo de uma função côncava é também côncavo [122, 34].

Usando agora a transformação $f_{3}\left(\widetilde{p}_{k, n}, \widetilde{\lambda}_{k, n}\right)=\widetilde{\lambda}_{k, n} f_{2}\left({\widetilde{x_{k}, n}}_{\tilde{\lambda}_{k, n}}\right)$, tem-se que $f_{3}\left(\widetilde{p}_{k, n}, \widetilde{\lambda}_{k, n}\right)$ é também côncavo, pois tal transformação não altera a concavidade [122].

Tendo $\ell_{k, n} \mathrm{w} \geq 0$, tem-se que $\ell_{k, n} \mathrm{w} f_{3}\left(\widetilde{p}_{k, n}, \widetilde{\lambda}_{k, n}\right)$ também é côncavo, de modo que demonstra-se que

$$
\ell_{k, n} \mathrm{w} \widetilde{\lambda}_{k, n} \log _{2}\left(1+\frac{\widetilde{p}_{k, n} \Gamma_{k, n}}{\widetilde{\lambda}_{k, n}}\right)
$$

é côncavo em relação a $\widetilde{p}_{k, n}$ e $\widetilde{\lambda}_{k, n}$.

Finalmente, sabendo que o somatório não-negativo de funções côncavas é também uma função côncava, tem-se que

$$
\sum_{k=1}^{K} \sum_{n=1}^{N} \ell_{k, n} \mathrm{w} \widetilde{\lambda}_{k, n} \log _{2}\left(1+\frac{\widetilde{p}_{k, n} \Gamma_{k, n} \iota_{k}}{\widetilde{\lambda}_{k, n}}\right)
$$

é côncavo em relação a $\widetilde{p}_{k, n}$ e $\widetilde{\lambda}_{k, n}$, provando que o numerador de $\widetilde{\xi}(\widetilde{\mathbf{P}}, \widetilde{\boldsymbol{\lambda}})$ é côncavo em relação às variáveis de otimização. 
Acerca do denominador, percebe-se que é dado pela composição linear de variáveis não negativas (dado que $\widetilde{p}_{k, n} \geq 0$ e $\varrho_{k}>0$ ) com as constantes dadas pelas potências de circuitaria. Assim, é possível afirmar que o denominador de $\widetilde{\xi}(\widetilde{\mathbf{P}}, \widetilde{\boldsymbol{\lambda}})$ é positivo e afim em relação às variáveis de otimização.

Com isso, tem-se que $\widetilde{\xi}(\widetilde{\mathbf{P}}, \widetilde{\boldsymbol{\lambda}})$ é quase-côncavo em relação às variáveis $\widetilde{p}_{k, n}$ e $\widetilde{\lambda}_{k, n}$, provando o teorema.

\section{B.2 Prova do Teorema 5.1}

O objetivo deste teorema é demonstrar que

$$
f(\widetilde{\mathbf{P}}, \widetilde{\boldsymbol{\lambda}})=\sum_{k=1}^{K} \log _{b}\left(\mathrm{w} \sum_{n=1}^{N} \widetilde{\lambda}_{k, n} \ell_{k, n} \log _{2}\left(1+\frac{\widetilde{p}_{k, n} \Gamma_{k, n} \iota_{k}}{\widetilde{\lambda}_{k, n}}\right)\right)
$$

e

$$
g(\widetilde{\mathbf{P}}, \widetilde{\boldsymbol{\lambda}})=\sum_{k=1}^{K} \log _{b}\left(\sum_{n=1}^{N} \varrho_{k} \widetilde{p}_{k, n}+p_{c, k}\right)
$$

são côncavas em relação a $\widetilde{p}_{k, n}$ e $\widetilde{\lambda}_{k, n}$.

Começando por $f(\widetilde{\mathbf{P}}, \widetilde{\boldsymbol{\lambda}})$, tem-se como resultado da Seção B.2 que

$$
\ell_{k, n} \mathrm{w} \widetilde{\lambda}_{k, n} \log _{2}\left(1+\frac{\widetilde{p}_{k, n} \Gamma_{k, n} \imath_{k}}{\widetilde{\lambda}_{k, n}}\right)
$$

é côncavo em relação a ambas as variáveis, de modo que o somatório não-negativo em relação às $N$ subportadoras é também côncavo, ou seja,

$$
\sum_{n=1}^{N} \ell_{k, n} \mathrm{w} \widetilde{\lambda}_{k, n} \log _{2}\left(1+\frac{\widetilde{p}_{k, n} \Gamma_{k, n}}{\widetilde{\lambda}_{k, n}}\right)
$$

é côncavo em relação a $\widetilde{p}_{k, n}$ e $\widetilde{\lambda}_{k, n}$.

Sabendo que o logaritmo de uma função côncava também é côncavo, tem-se que

$$
\log _{b}\left(\sum_{n=1}^{N} \ell_{k, n} \mathrm{w} \widetilde{\lambda}_{k, n} \log _{2}\left(1+\frac{\widetilde{p}_{k, n} \Gamma_{k, n} \imath_{k}}{\widetilde{\lambda}_{k, n}}\right)\right)
$$

mantém a propriedade de concavidade. Assim, o somatório não-negativo em $K$ não altera a concavidade, de modo que

$$
\sum_{k=1}^{K} \log _{b}\left(\sum_{n=1}^{N} \ell_{k, n} \mathrm{w} \widetilde{\lambda}_{k, n} \log _{2}\left(1+\frac{\widetilde{p}_{k, n} \Gamma_{k, n} \imath_{k}}{\widetilde{\lambda}_{k, n}}\right)\right)
$$

é côncavo em relação a $\widetilde{p}_{k, n}$ e $\widetilde{\lambda}_{k, n}$. Desse modo, prova-se que $f(\widetilde{\mathbf{P}}, \widetilde{\boldsymbol{\lambda}})$ é côncavo em relação a $\widetilde{p}_{k, n}$ e $\widetilde{\lambda}_{k, n}$.

Em relação a $g(\widetilde{\mathbf{P}}, \widetilde{\boldsymbol{\lambda}})$, inicia-se a demonstração analisando

$$
\sum_{n=1}^{N} \varrho_{k} \widetilde{p}_{k, n}+p_{c, k}
$$


que pode ser visto como a soma não-negativa de variáveis não negativas (dado que $\widetilde{p}_{k, n} \geq 0$ e $\left.\varrho_{k}>0\right)$ com um termo constante $p_{c, k}$, sendo então afim (e por consequência, côncavo) em relação a $\widetilde{p}_{k, n}$ e $\tilde{\lambda}_{k, n}$.

Com isso, tem-se que

$$
\log _{b}\left(\sum_{n=1}^{N} \varrho_{k} \widetilde{p}_{k, n}+p_{c, k}\right)
$$

é também côncavo em relação às variáveis de otimização, e que

$$
\sum_{k=1}^{K} \log _{b}\left(\sum_{n=1}^{N} \varrho_{k} \widetilde{p}_{k, n}+p_{c, k}\right)
$$

é também côncavo em relação a $\widetilde{p}_{k, n}$ e $\widetilde{\lambda}_{k, n}$, provando que $g(\widetilde{\mathbf{P}}, \widetilde{\boldsymbol{\lambda}})$ é côncavo em relação a $\tilde{p}_{k, n}$ e $\tilde{\lambda}_{k, n}$.

Com isso, prova-se o teorema.

\section{B.3 Prova do Teorema 5.2}

O teorema busca demonstrar que $\widetilde{\xi}_{\text {prod }}^{\text {fair }}(\widetilde{\mathbf{P}}, \widetilde{\boldsymbol{\lambda}})$ é quase-côncavo, o que pode ser feito demonstrando que o numerador de $\widetilde{\xi}_{\text {prod }}^{\text {fair }}(\widetilde{\mathbf{P}}, \widetilde{\boldsymbol{\lambda}})$ é côncavo e que o denominador é positivo e afim em relação a $\widetilde{p}_{k, n}$ e $\widetilde{\lambda}_{k, n}$.

Começando pelo numerador, os resultados da Seção B.2 demonstram que

$$
\sum_{n=1}^{N} \ell_{k, n} \mathrm{w} \widetilde{\lambda}_{k, n} \log _{2}\left(1+\frac{\widetilde{p}_{k, n} \Gamma_{k, n} \ell_{k}}{\widetilde{\lambda}_{k, n}}\right)
$$

é côncavo em relação às variáveis de otimização.

O numerador de $\widetilde{\xi}_{\text {prod }}^{\text {fair }}(\widetilde{\mathbf{P}}, \widetilde{\boldsymbol{\lambda}})$ pode ser reescrito como

$$
\widetilde{R}_{\bar{k}}(\widetilde{\mathbf{P}}, \widetilde{\boldsymbol{\lambda}})\left(\mathrm{w} \sum_{n=1}^{N} \widetilde{\lambda}_{k, n} \ell_{k, n} \log _{2}\left(1+\frac{\widetilde{p}_{k, n} \Gamma_{k, n} \iota_{k}}{\widetilde{\lambda}_{k, n}}\right)\right)
$$

em que

$$
\widetilde{R}_{\bar{k}}(\widetilde{\mathbf{P}}, \tilde{\boldsymbol{\lambda}})=\prod_{k^{\prime}=1, k^{\prime} \neq k}^{K}\left[\mathrm{w} \sum_{n=1}^{N} \widetilde{\lambda}_{k^{\prime}, n} \ell_{k^{\prime}, n} \log _{2}\left(1+\frac{\widetilde{p}_{k^{\prime}, n} \Gamma_{k^{\prime}, n} \imath_{k^{\prime}}}{\widetilde{\lambda}_{k^{\prime}, n}}\right)\right] .
$$

Note que $\widetilde{R}_{\bar{k}}(\widetilde{\mathbf{P}}, \widetilde{\boldsymbol{\lambda}})$ é constante em relação a $\widetilde{p}_{k, n}$ e $\widetilde{\lambda}_{k, n}$, além de que $\widetilde{R}_{\bar{k}}(\widetilde{\mathbf{P}}, \widetilde{\boldsymbol{\lambda}}) \geq 0$. Com isso, tem-se que o numerador de $\widetilde{\xi}_{\text {prod }}^{\text {fair }}(\widetilde{\mathbf{P}}, \widetilde{\boldsymbol{\lambda}})$ é côncavo em relação a $\widetilde{p}_{k, n}$ e $\widetilde{\lambda}_{k, n}$.

Uma discussão semelhante pode ser feita para demonstrar a afinidade do denominador de $\widetilde{\xi}_{\text {prod }}^{\text {fair }}(\widetilde{\mathbf{P}}, \widetilde{\boldsymbol{\lambda}})$. O denominador pode ser reescrito como

$$
\widetilde{P}_{\bar{k}}(\widetilde{\mathbf{P}}, \widetilde{\boldsymbol{\lambda}})\left(\sum_{n=1}^{N} \varrho_{k} \widetilde{p}_{k, n}+p_{c, k}\right)=\sum_{n=1}^{N} \widetilde{P}_{\bar{k}}(\widetilde{\mathbf{P}}, \widetilde{\boldsymbol{\lambda}}) \varrho_{k} \widetilde{p}_{k, n}+\widetilde{P}_{\bar{k}}(\widetilde{\mathbf{P}}, \widetilde{\boldsymbol{\lambda}}) p_{c, k}
$$

em que

$$
\widetilde{P}_{\bar{k}}(\widetilde{\mathbf{P}}, \widetilde{\boldsymbol{\lambda}})=\prod_{k^{\prime}=1, k^{\prime} \neq k}^{K}\left[\sum_{n=1}^{N} \varrho_{k^{\prime}} \widetilde{p}_{k^{\prime}, n}+p_{c, k^{\prime}}\right]
$$


Lembrando que $\widetilde{P}_{\bar{k}}(\widetilde{\mathbf{P}}, \widetilde{\boldsymbol{\lambda}})$ é constante em relação a $\widetilde{p}_{k, n}$ e $\widetilde{\lambda}_{k, n}$, o denominador de $\widetilde{\xi}_{\text {prod }}^{\text {fair }}(\widetilde{\mathbf{P}}, \widetilde{\boldsymbol{\lambda}})$ pode ser visto como a composição linear de termos não-negativos (dado que $\widetilde{P}_{\bar{k}}(\widetilde{\mathbf{P}}, \widetilde{\boldsymbol{\lambda}})>0, \varrho_{k}>0$ e $\left.\widetilde{p}_{k, n} \geq 0\right)$ e uma constante $\widetilde{P}_{\bar{k}}(\widetilde{\mathbf{P}}, \widetilde{\boldsymbol{\lambda}}) p_{c, k}$, sendo então positivo e afim em relação às variáveis de otimização $\widetilde{p}_{k, n}$ e $\widetilde{\lambda}_{k, n}$.

Assim, tem-se que $\widetilde{\xi}_{\text {prod }}^{\text {air }}(\widetilde{\mathbf{P}}, \widetilde{\boldsymbol{\lambda}})$ é quase-côncavo em relação às variáveis de otimização $\widetilde{p}_{k, n}$ e $\widetilde{\lambda}_{k, n}$, provando o teorema.

\section{B.4 Prova do Teorema 6.1}

O teorema 6.1 visa demonstrar que

$$
f\left(\widetilde{\mathbf{P}}, \widetilde{\mathbf{P}}_{r}, \tilde{\boldsymbol{\lambda}}\right)=\sum_{k=1}^{K} \log _{b}\left(\psi_{k, 0} \sum_{n=1}^{N} \widetilde{\lambda}_{k, n} \ell_{k, n} \widetilde{r}_{k, n, 0}+\sum_{l=1}^{N_{\mathrm{RS}}} \psi_{k, l} \sum_{n=1}^{N} \widetilde{\lambda}_{k, n} \ell_{k, n} \widetilde{r}_{k, n, l}^{\varpi}\right)
$$

e

$$
\begin{aligned}
& g\left(\widetilde{\mathbf{P}}, \widetilde{\mathbf{P}}_{r}, \widetilde{\boldsymbol{\lambda}}\right) \\
& =\sum_{k=1}^{K} \log _{b}\left(\psi_{k, 0} \sum_{n=1}^{N} \varrho_{k} \widetilde{p}_{k, n}+\sum_{l=1}^{N_{\mathrm{RS}}} \psi_{k, l}\left[\sum_{n=1}^{N} \frac{1}{2} \varrho_{k} \widetilde{p}_{k, n}+\varrho_{r_{l}} \widetilde{p}_{r_{n, l}}+\varsigma_{k, l} p_{c, r_{l}}^{\varpi}\right]+p_{c, k}\right)
\end{aligned}
$$

são côncavos em relação a $\widetilde{p}_{k, n}, \widetilde{p}_{r_{n, l}}$ e $\widetilde{\lambda}_{k, n}$.

Para determinar a concavidade de $f\left(\widetilde{\mathbf{P}}, \widetilde{\mathbf{P}}_{r}, \widetilde{\boldsymbol{\lambda}}\right)$ e $g\left(\widetilde{\mathbf{P}}, \widetilde{\mathbf{P}}_{r}, \widetilde{\boldsymbol{\lambda}}\right)$, serão analisadas as três possibilidades de cada termo do somatório: MSs diretas, empregando protocolo AF ou protocolo DF. Para o caso de a $k$-ésima MS se comunicar diretamente com a BS, tem-se que:

$$
f_{k}\left(\widetilde{\mathbf{P}}, \widetilde{\mathbf{P}}_{r}, \widetilde{\boldsymbol{\lambda}}\right)=\log _{b}\left(\sum_{n=1}^{N} \widetilde{\lambda}_{k, n} \ell_{k, n} \mathrm{w} \log _{2}\left(1+\frac{\Gamma_{k, n, 0} \widetilde{p}_{k, n}}{\widetilde{\lambda}_{k, n}}\right)\right)
$$

e

$$
g_{k}\left(\widetilde{\mathbf{P}}, \widetilde{\mathbf{P}}_{r}, \widetilde{\boldsymbol{\lambda}}\right)=\log _{b}\left(\sum_{n=1}^{N} \varrho_{k} \widetilde{p}_{k, n}+p_{c, k}\right)
$$

Para esses casos, a concavidade é demonstrada na Seção B.2. Assim, para todas as MSs que se comunicam diretamente com a BS, seus termos são côncavos em relação a $\widetilde{p}_{k, n}$, $\tilde{p}_{r_{n, l}}$ e $\widetilde{\lambda}_{k, n}$.

\section{B.4.1 Protocolo AF}

Para o protocolo AF, tem-se que

$$
f_{k}\left(\widetilde{\mathbf{P}}, \widetilde{\mathbf{P}}_{r}, \widetilde{\boldsymbol{\lambda}}\right)=\log _{b}\left(\sum_{n=1}^{N} \widetilde{\lambda}_{k, n} \ell_{k, n} \frac{\mathrm{W}}{2} \log _{2}\left(1+\frac{\imath_{k}^{\mathrm{AF}} \widetilde{p}_{r_{n, l}} \widetilde{p}_{k, n} \Gamma_{k, n, l} \Gamma_{l, n, 0}}{\widetilde{\lambda}_{k, n}\left(\widetilde{p}_{r_{n, l}} \Gamma_{l, n, 0}+\widetilde{p}_{k, n} \Gamma_{k, n, l}\right)}\right)\right)
$$


e

$$
g_{k}\left(\widetilde{\mathbf{P}}, \widetilde{\mathbf{P}}_{r}, \widetilde{\boldsymbol{\lambda}}\right)=\log _{b}\left(\sum_{n=1}^{N} \frac{1}{2}\left(\varrho_{k} \widetilde{p}_{k, n}+\varrho_{r_{l}} \widetilde{p}_{r_{n, l}}\right)+\varsigma_{k, l} p_{c, r_{l}}^{\mathrm{AF}}+p_{c, k}\right)
$$

O restante da demonstração seguirá o descrito em [34]. Inicia-se demonstrando a concavidade de $f_{k}\left(\widetilde{\mathbf{P}}, \widetilde{\mathbf{P}}_{r}, \widetilde{\boldsymbol{\lambda}}\right)$, definindo

$$
f_{1}\left(\widetilde{p}_{k, n}, \widetilde{p}_{r_{n, l}}\right)=\frac{\widetilde{p}_{r_{n, l}} \widetilde{p}_{k, n} \Gamma_{k, n, l} \Gamma_{l, n, 0}}{\widetilde{\lambda}_{k, n}\left(\widetilde{p}_{r_{n, l}} \Gamma_{l, n, 0}+\widetilde{p}_{k, n} \Gamma_{k, n, l}\right)}
$$

De acordo com os resultados de [34], a matriz Hessiana de $f_{1}\left(\widetilde{p}_{k, n}, \widetilde{p}_{r_{n, l}}\right)$ tem como autovalores

$$
a_{1}=0
$$

e

$$
a_{2}=-\frac{2\left(\Gamma_{k, n, l} \Gamma_{l, n, 0}\right)^{2}\left(\widetilde{p}_{k, n}+\widetilde{p}_{r_{n, l}}\right)}{\left(\widetilde{p}_{r_{n, l}} \Gamma_{l, n, 0}+\widetilde{p}_{k, n} \Gamma_{k, n, l}\right)^{3}}
$$

que, por serem não-positivos, indicam que a matriz Hessiana é semidefinida negativa, implicando que $f_{1}\left(\widetilde{p}_{k, n}, \widetilde{p}_{r_{n, l}}\right)$ é côncavo em relação a $\widetilde{p}_{k, n}$ e $\widetilde{p}_{r_{n, l}}$.

Tomando agora a transformação

$$
f_{2}\left(\widetilde{p}_{k, n}, \widetilde{p}_{r_{n, l}}\right)=\log _{2}\left(1+\imath_{k}^{\mathrm{AF}} f_{1}\left(\widetilde{p}_{k, n}, \widetilde{p}_{r_{n, l}}\right)\right)
$$

tem-se que $f_{2}\left(\widetilde{p}_{k, n}, \widetilde{p}_{r_{n, l}}\right)$ é côncavo em relação a $\widetilde{p}_{k, n}$ e $\widetilde{p}_{r_{n, l}}$, pois a soma da constante 1 e a multiplicação de $f_{1}\left(\widetilde{p}_{k, n}, \widetilde{p}_{r_{n, l}}\right)$ por $\imath_{k}^{\mathrm{AF}}>0$ não modificam a concavidade do argumento do logaritmo, e o logaritmo de uma função côncava é também côncavo.

Finalmente, aplicando a transformação

$$
\begin{aligned}
f_{3}\left(\widetilde{p}_{k, n}, \widetilde{p}_{r_{n, l}}, \widetilde{\lambda}_{k, n}\right) & =\widetilde{\lambda}_{k, n} f_{2}\left(\frac{\widetilde{p}_{k, n}}{\widetilde{\lambda}_{k, n}}, \frac{\widetilde{p}_{r_{n, l}}}{\widetilde{\lambda}_{k, n}}\right) \\
& =\widetilde{\lambda}_{k, n} \log _{2}\left(1+\frac{\imath_{k}^{\mathrm{AF}} \widetilde{p}_{r_{n, l}} \widetilde{p}_{k, n} \Gamma_{k, n, l} \Gamma_{l, n, 0}}{\widetilde{\lambda}_{k, n}\left(\widetilde{p}_{r_{n, l}} \Gamma_{l, n, 0}+\widetilde{p}_{k, n} \Gamma_{k, n, l}\right)}\right)
\end{aligned}
$$

ainda mantém-se a concavidade $[122,34]$ em relação às variáveis $\widetilde{p}_{k, n}, \widetilde{p}_{r_{n, l}}$ e $\widetilde{\lambda}_{k, n}$.

Multiplicando $f_{3}\left(\widetilde{p}_{k, n}, \widetilde{p}_{r_{n, l}}, \tilde{\lambda}_{k, n}\right)$ pelos termos constantes e positivos $\frac{\ell_{k, n} \mathrm{w}}{2}$, e tomando o somatório não-negativo nas $N$ subportadoras, obtém-se que

$$
\sum_{n=1}^{N} \frac{\widetilde{\lambda}_{k, n} \ell_{k, n} \mathrm{~W}}{2} \log _{2}\left(1+\frac{\imath_{k}^{\mathrm{AF}} \widetilde{p}_{r_{n, l}} \widetilde{p}_{k, n} \Gamma_{k, n, l} \Gamma_{l, n, 0}}{\widetilde{\lambda}_{k, n}\left(\widetilde{p}_{r_{n, l}} \Gamma_{l, n, 0}+\widetilde{p}_{k, n} \Gamma_{k, n, l}\right)}\right),
$$

é côncavo em relação às variáveis $\widetilde{p}_{k, n}, \widetilde{p}_{r_{n, l}}$ e $\widetilde{\lambda}_{k, n}$.

Finalmente, tomando o logaritmo da função obtida, que é igual a $f_{k}\left(\widetilde{\mathbf{P}}, \widetilde{\mathbf{P}}_{r}, \widetilde{\boldsymbol{\lambda}}\right)$, tem-se que $f_{k}\left(\widetilde{\mathbf{P}}, \widetilde{\mathbf{P}}_{r}, \widetilde{\boldsymbol{\lambda}}\right)$ é côncavo em relação a $\widetilde{p}_{k, n}, \widetilde{p}_{r_{n, l}}$ e $\widetilde{\lambda}_{k, n}$ 
Em relação a $g_{k}\left(\widetilde{\mathbf{P}}, \widetilde{\mathbf{P}}_{r}, \widetilde{\boldsymbol{\lambda}}\right)$, percebe-se que é bastante semelhante ao termo $g_{k}$ das MSs diretas, sendo dado pela combinação linear de variáveis não-negativas (dado que $\frac{\varrho_{k}}{2}>0$, $\widetilde{p}_{k, n} \geq 0, \frac{\varrho_{r_{l}}}{2}>0 \widetilde{p}_{r_{n, l}} \geq 0, \varsigma_{k, l} p_{c, r_{l}}^{\mathrm{AF}} \geq 0$ e $p_{c, k}>0$ ), sendo portanto positiva, afim e côncava em relação às variáveis $\widetilde{p}_{k, n}, \widetilde{p}_{r_{n, l}}$ e $\widetilde{\lambda}_{k, n}$. Como o logaritmo de uma função côncava é também côncavo, e o somatório não-negativo de funções côncavas é também côncava, tem-se que $g_{k}\left(\widetilde{\mathbf{P}}, \widetilde{\mathbf{P}}_{r}, \widetilde{\boldsymbol{\lambda}}\right)$ é côncavo em relação a $\widetilde{p}_{k, n}, \widetilde{p}_{r_{n, l}}$ e $\widetilde{\lambda}_{k, n}$.

Com isso, demonstra-se que $f_{k}\left(\widetilde{\mathbf{P}}, \widetilde{\mathbf{P}}_{r}, \widetilde{\boldsymbol{\lambda}}\right)$ e $g_{k}\left(\widetilde{\mathbf{P}}, \widetilde{\mathbf{P}}_{r}, \widetilde{\boldsymbol{\lambda}}\right)$ são côncavos em relação a $\widetilde{p}_{k, n}$, $\widetilde{p}_{r_{n, l}}$ e $\widetilde{\lambda}_{k, n}$ quando se utiliza protocolo AF.

\section{B.4.2 Protocolo DF}

Para o protocolo DF, tem-se que as funções $f_{k}\left(\widetilde{\mathbf{P}}, \widetilde{\mathbf{P}}_{r}, \widetilde{\boldsymbol{\lambda}}\right)$ e $g_{k}\left(\widetilde{\mathbf{P}}, \widetilde{\mathbf{P}}_{r}, \widetilde{\boldsymbol{\lambda}}\right)$ são dadas por:

$$
f_{k}\left(\widetilde{\mathbf{P}}, \widetilde{\mathbf{P}}_{r}, \widetilde{\boldsymbol{\lambda}}\right)=\log _{b}\left(\sum_{n=1}^{N} \widetilde{\lambda}_{k, n} \ell_{k, n} \frac{\mathrm{w}}{2} \log _{2}\left(1+\frac{\imath_{k}^{\mathrm{DF}} \Omega_{k, n, l}^{\mathrm{DF}} \widetilde{p}_{k, n, l} \Gamma_{k, n, l}}{\widetilde{\lambda}_{k, n}}\right)\right)
$$

e

$$
g_{k}\left(\widetilde{\mathbf{P}}, \widetilde{\mathbf{P}}_{r}, \widetilde{\boldsymbol{\lambda}}\right)=\log _{b}\left(\sum_{n=1}^{N} \frac{1}{2}\left(\varrho_{k} \widetilde{p}_{k, n}+\varrho_{r_{l}} \widetilde{p}_{r_{n, l}}\right)+\varsigma_{k, l} p_{c, r_{l}}^{\mathrm{DF}}+p_{c, k}\right)
$$

Note que se provará a concavidade de $f_{k}\left(\widetilde{\mathbf{P}}, \widetilde{\mathbf{P}}_{r}, \widetilde{\boldsymbol{\lambda}}\right)$ utilizando a potência consumida nos dois saltos, i.e., $\widetilde{p}_{k, n, l}$. Dado que existe um mapeamento um para um entre $\widetilde{p}_{k, n, l}$ e as potências em cada salto, não haverá prejuízo na demonstração.

Inicia-se considerando que

$$
f_{1}\left(\widetilde{p}_{k, n, l}\right)=\imath_{k}^{\mathrm{DF}} \Omega_{k, n, l}^{\mathrm{DF}} \Gamma_{k, n, l} \widetilde{p}_{k, n, l}
$$

Para demonstrar que $f_{1}\left(\widetilde{p}_{k, n, l}\right)$ é côncavo em relação a $\widetilde{p}_{k, n, l}$, é suficiente verificar se $\frac{\partial^{2} f_{1}\left(\widetilde{p}_{k, n, l}\right)}{\partial\left(\widetilde{p}_{k, n, l}\right)^{2}} \leq 0[122]$. Calculando a derivada parcial necessária, tem-se que

$$
\frac{\partial^{2} f_{1}\left(\widetilde{p}_{k, n, l}\right)}{\partial\left(\widetilde{p}_{k, n, l}\right)^{2}}=0
$$

resultando que $f_{1}\left(\widetilde{p}_{k, n, l}\right)$ é côncavo em relação a $\widetilde{p}_{k, n, l}$.

Definindo agora

$$
f_{2}\left(\widetilde{p}_{k, n, l}\right)=\log _{2}\left(1+f_{2}\left(\widetilde{p}_{k, n, l}\right)\right)
$$

tem-se que $f_{2}\left(\widetilde{p}_{k, n, l}\right)$ é também côncavo em relação a $\widetilde{p}_{k, n, l}$, dado que a soma da constante 1 não afeta a concavidade de $f_{1}\left(\widetilde{p}_{k, n, l}\right)$, e o logaritmo de uma função côncava é também côncavo.

Empregando a transformação

$$
f_{3}\left(\widetilde{p}_{k, n, l}, \widetilde{\lambda}_{k, n}\right)=\widetilde{\lambda}_{k, n} f_{2}\left(\frac{\widetilde{p}_{k, n, l}}{\widetilde{\lambda}_{k, n}}\right)
$$


obtém-se que $f_{3}\left(\widetilde{p}_{k, n, l}, \widetilde{\lambda}_{k, n}\right)$ é côncavo em relação a $\widetilde{p}_{k, n, l}$ e $\widetilde{\lambda}_{k, n}[122]$.

Multiplicando $f_{3}\left(\widetilde{p}_{k, n, l}, \widetilde{\lambda}_{k, n}\right)$ por $\frac{\ell_{k, n} \mathrm{w}}{2}>0$, e tomando o somatório não-negativo em relação a $n$, verifica-se que a função resultante, dada por

$$
\sum_{n=1}^{N} \widetilde{\lambda}_{k, n} \ell_{k, n} \frac{\mathrm{w}}{2} \log _{2}\left(1+\frac{\imath_{k}^{\mathrm{DF}} \Omega_{k, n, l}^{\mathrm{DF}} \widetilde{p}_{k, n, l} \Gamma_{k, n, l}}{\widetilde{\lambda}_{k, n}}\right)
$$

é também côncava em relação a $\widetilde{p}_{k, n, l}$ e $\widetilde{\lambda}_{k, n}$. Por fim, aplicar o logaritmo na função obtida resulta também em uma função côncava, de modo que

$$
\log _{b}\left(\sum_{n=1}^{N} \tilde{\lambda}_{k, n} \ell_{k, n} \frac{\mathrm{w}}{2} \log _{2}\left(1+\frac{l_{k}^{\mathrm{DF}} \Omega_{k, n, l}^{\mathrm{DF}} \widetilde{p}_{k, n, l} \Gamma_{k, n, l}}{\widetilde{\lambda}_{k, n}}\right)\right)
$$

é também côncavo em relação a $\widetilde{p}_{k, n, l}$ e $\widetilde{\lambda}_{k, n}$.

Usando mapeamentos semelhantes aos definidos na equação (6.61), i.e.,

$$
\begin{aligned}
& \widetilde{p}_{k, n}=\Omega_{k, n, l}^{\mathrm{DF}} \widetilde{p}_{k, n, l} \\
& \widetilde{p}_{r_{n, l}}=\widetilde{p}_{k, n, l}-\widetilde{p}_{k, n}
\end{aligned}
$$

tem-se um mapeamento um para um entre $\widetilde{p}_{k, n, l}$ e as variáveis desejadas, $\widetilde{p}_{k, n}$ e $\widetilde{p}_{r_{n, l}}$. Assim, tem-se que $f_{k}\left(\widetilde{\mathbf{P}}, \widetilde{\mathbf{P}}_{r}, \widetilde{\boldsymbol{\lambda}}\right)$ é côncavo em relação a $\widetilde{p}_{k, n}, \widetilde{p}_{r_{n, l}}$ e $\widetilde{\lambda}_{k, n}$.

Acerca da função $g_{k}\left(\widetilde{\mathbf{P}}, \widetilde{\mathbf{P}}_{r}, \widetilde{\boldsymbol{\lambda}}\right)$, note que a única modificação em relação à função $g_{k}\left(\widetilde{\mathbf{P}}, \widetilde{\mathbf{P}}_{r}, \widetilde{\boldsymbol{\lambda}}\right)$ definida para protocolo AF é a troca de $p_{c, r_{l}}^{\mathrm{AF}}$ por $p_{c, r_{l}}^{\mathrm{DF}}$, sendo que ambas são maiores que zero. Assim, é possível definir que se $g_{k}\left(\widetilde{\mathbf{P}}, \widetilde{\mathbf{P}}_{r}, \widetilde{\boldsymbol{\lambda}}\right)$ é côncavo para protocolo AF em relação a $\widetilde{p}_{k, n}, \widetilde{p}_{r_{n, l}}$ e $\widetilde{\lambda}_{k, n}$, então $g_{k}\left(\widetilde{\mathbf{P}}, \widetilde{\mathbf{P}}_{r}, \widetilde{\boldsymbol{\lambda}}\right)$ é côncavo para protocolo DF em relação a $\widetilde{p}_{k, n}, \widetilde{p}_{r_{n, l}}$ e $\tilde{\lambda}_{k, n}$.

Com tais considerações, se forem tomados os somatórios

$$
f\left(\widetilde{\mathbf{P}}, \widetilde{\mathbf{P}}_{r}, \widetilde{\boldsymbol{\lambda}}\right)=\sum_{k=1}^{K} f_{k}\left(\widetilde{\mathbf{P}}, \widetilde{\mathbf{P}}_{r}, \widetilde{\boldsymbol{\lambda}}\right)
$$

e

$$
g\left(\widetilde{\mathbf{P}}, \widetilde{\mathbf{P}}_{r}, \widetilde{\boldsymbol{\lambda}}\right)=\sum_{k=1}^{K} g_{k}\left(\widetilde{\mathbf{P}}, \widetilde{\mathbf{P}}_{r}, \widetilde{\boldsymbol{\lambda}}\right)
$$

obtém-se que $f\left(\widetilde{\mathbf{P}}, \widetilde{\mathbf{P}}_{r}, \widetilde{\boldsymbol{\lambda}}\right)$ e $g\left(\widetilde{\mathbf{P}}, \widetilde{\mathbf{P}}_{r}, \widetilde{\boldsymbol{\lambda}}\right)$ são côncavos em relação a $\widetilde{p}_{k, n}, \widetilde{p}_{r_{n, l}}$ e $\widetilde{\lambda}_{k, n}$, o que prova o teorema.

\section{B.5 Prova do Teorema 6.2}

O teorema afirma que $\widetilde{\xi}_{\text {prod }}^{\varpi}\left(\widetilde{\mathbf{P}}, \widetilde{\mathbf{P}}_{r}, \widetilde{\boldsymbol{\lambda}}\right)$ é quase-côncavo em relação $\widetilde{p}_{k, n}, \widetilde{p}_{r_{n, l}}$ e $\widetilde{\lambda}_{k, n}$, o que é equivalente a afirmar que o numerador de $\widetilde{\xi}_{\text {prod }}^{\varpi}\left(\widetilde{\mathbf{P}}, \widetilde{\mathbf{P}}_{r}, \widetilde{\boldsymbol{\lambda}}\right)$ é côncavo e o denominador de $\widetilde{p}_{k, n}, \widetilde{p}_{r_{n, l}}$ e $\widetilde{\lambda}_{k, n}$ é positivo e afim, ambos em relação às mesmas variáveis. 
A prova será separada em relação às MSs que transmitem diretamente à MS e aquelas que se utilizam de RSs, seja em protocolo AF ou DF. Começando pelas MSs diretas, tem-se que o numerador de $\widetilde{\xi}_{\text {prod }}^{\varpi}\left(\widetilde{\mathbf{P}}, \widetilde{\mathbf{P}}_{r}, \widetilde{\boldsymbol{\lambda}}\right)$ é dado por

$$
R_{\bar{k}}^{\varpi}\left(\widetilde{\mathbf{P}}, \widetilde{\mathbf{P}}_{r}, \widetilde{\boldsymbol{\lambda}}\right)\left(\sum_{n=1}^{N} \widetilde{\lambda}_{k, n} \ell_{k, n} \mathrm{w} \log _{2}\left(1+\frac{\Gamma_{k, n, 0} \widetilde{p}_{k, n}}{\widetilde{\lambda}_{k, n}}\right)\right)
$$

em que

$$
R_{\bar{k}}^{\varpi}\left(\widetilde{\mathbf{P}}, \widetilde{\mathbf{P}}_{r}, \tilde{\boldsymbol{\lambda}}\right)=\prod_{k^{\prime}=1, k^{\prime} \neq k}^{K}\left(\psi_{k^{\prime}, 0} \sum_{n=1}^{N} \widetilde{\lambda}_{k^{\prime}, n} \ell_{k^{\prime}, n} \widetilde{r}_{k^{\prime}, n, 0}+\sum_{l=1}^{N_{\mathrm{RS}}} \psi_{k^{\prime}, l} \sum_{n=1}^{N} \widetilde{\lambda}_{k^{\prime}, n} \ell_{k^{\prime}, n} \widetilde{r}_{k^{\prime}, n, l}^{\varpi}\right)
$$

e $R_{\bar{k}}^{\varpi}\left(\widetilde{\mathbf{P}}, \widetilde{\mathbf{P}}_{r}, \widetilde{\boldsymbol{\lambda}}\right)$ é constante em relação às variáveis $\widetilde{p}_{k, n}, \widetilde{p}_{r_{n, l}}$ e $\widetilde{\lambda}_{k, n}$.

Note que o numerador é semelhante ao analisado na Seção B.3, apenas trocando $R_{\bar{k}}(\widetilde{\mathbf{P}}, \widetilde{\boldsymbol{\lambda}})$ por $R_{\bar{k}}^{\varpi}\left(\widetilde{\mathbf{P}}, \widetilde{\mathbf{P}}_{r}, \widetilde{\boldsymbol{\lambda}}\right)$ devido à inserção das RSs e trocando também $\Gamma_{k, n}$ por $\Gamma_{k, n, 0}$, porém tendo o mesmo significado físico, i.e., a CINR da $k$-ésima MS na $n$-ésima subportadora quando transmitindo para a BS. Tendo que $R_{\bar{k}}^{\varpi}\left(\widetilde{\mathbf{P}}, \widetilde{\mathbf{P}}_{r}, \widetilde{\boldsymbol{\lambda}}\right) \geq 0$ (assim como $\left.R_{\bar{k}}(\widetilde{\mathbf{P}}, \widetilde{\boldsymbol{\lambda}})\right)$, afirma-se que o numerador de $\widetilde{\xi}_{\text {prod }}^{\varpi}\left(\widetilde{\mathbf{P}}, \widetilde{\mathbf{P}}_{r}, \widetilde{\boldsymbol{\lambda}}\right)$ é côncavo em relação a $\widetilde{p}_{k, n}$ e $\widetilde{\lambda}_{k, n}$.

Já o denominador de $\widetilde{\xi}_{\text {prod }}^{\varpi}\left(\widetilde{\mathbf{P}}, \widetilde{\mathbf{P}}_{r}, \widetilde{\boldsymbol{\lambda}}\right)$ para a $k$-ésima MS em comunicação direta é dado por

$$
P_{\bar{k}}^{\varpi}\left(\widetilde{\mathbf{P}}, \widetilde{\mathbf{P}}_{r}, \widetilde{\boldsymbol{\lambda}}\right)\left(\sum_{n=1}^{N} \varrho_{k} \widetilde{p}_{k, n}+p_{c, k}\right)=\sum_{n=1}^{N} P_{\bar{k}}^{\varpi}\left(\widetilde{\mathbf{P}}, \widetilde{\mathbf{P}}_{r}, \widetilde{\boldsymbol{\lambda}}\right) \varrho_{k} \widetilde{p}_{k, n}+P_{\bar{k}}^{\varpi}\left(\widetilde{\mathbf{P}}, \widetilde{\mathbf{P}}_{r}, \widetilde{\boldsymbol{\lambda}}\right) p_{c, k}
$$

em que

$$
\begin{aligned}
& P_{\bar{k}}^{\varpi}\left(\widetilde{\mathbf{P}}, \widetilde{\mathbf{P}}_{r}, \widetilde{\boldsymbol{\lambda}}\right)= \\
& \quad \prod_{k^{\prime}=1, k^{\prime} \neq k}^{K}\left(\psi_{k^{\prime}, 0} \sum_{n=1}^{N} \varrho_{k^{\prime}} \widetilde{p}_{k^{\prime}, n}+\sum_{l=1}^{N_{\mathrm{RS}}} \psi_{k^{\prime}, l}\left[\sum_{n=1}^{N} \frac{\varrho_{k^{\prime}} \widetilde{p}_{k^{\prime}, n}+\varrho_{r_{l}} \widetilde{p}_{r_{n, l}}}{2}+\varsigma_{k^{\prime}, l} p_{c, r_{l}}^{\varpi}\right]+p_{c, k^{\prime}}\right)
\end{aligned}
$$

é constante em relação a $\widetilde{p}_{k, n}, \widetilde{p}_{r_{n, l}}$ e $\widetilde{\lambda}_{k, n}$.

Percebe-se que o denominador é uma combinação linear de termos não negativos (afinal $\left.P_{\bar{k}}^{\varpi}\left(\widetilde{\mathbf{P}}, \widetilde{\mathbf{P}}_{r}, \widetilde{\boldsymbol{\lambda}}\right) \varrho_{k}>0\right)$ e uma constante $P_{\bar{k}}^{\varpi}\left(\widetilde{\mathbf{P}}, \widetilde{\mathbf{P}}_{r}, \widetilde{\boldsymbol{\lambda}}\right) p_{c, k}>0$, sendo então positivo e afim em relação a $\widetilde{p}_{k, n}$ e $\widetilde{\lambda}_{k, n}$.

Assim, demonstra-se que se a MS se comunica diretamente com a BS, $\widetilde{\xi}_{\text {prod }}^{\varpi}\left(\widetilde{\mathbf{P}}, \widetilde{\mathbf{P}}_{r}, \widetilde{\boldsymbol{\lambda}}\right)$ é quase-côncavo em relação a $\widetilde{p}_{k, n}$ e $\widetilde{\lambda}_{k, n}$.

\section{B.5.1 Protocolo AF}

Para o protocolo AF, o numerador de $\widetilde{\xi}_{\text {prod }}^{\mathrm{AF}}\left(\widetilde{\mathbf{P}}, \widetilde{\mathbf{P}}_{r}, \widetilde{\boldsymbol{\lambda}}\right)$ é dado por

$$
R_{\bar{k}}^{\mathrm{AF}}\left(\widetilde{\mathbf{P}}, \widetilde{\mathbf{P}}_{r}, \widetilde{\boldsymbol{\lambda}}\right)\left(\sum_{n=1}^{N} \widetilde{\lambda}_{k, n} \ell_{k, n} \frac{\mathrm{W}}{2} \log _{2}\left(1+\frac{\imath_{k}^{\mathrm{AF}} \widetilde{p}_{r_{n, l}} \widetilde{p}_{k, n} \Gamma_{k, n, l} \Gamma_{l, n, 0}}{\widetilde{\lambda}_{k, n}\left(\widetilde{p}_{r_{n, l}} \Gamma_{l, n, 0}+\widetilde{p}_{k, n} \Gamma_{k, n, l}\right)}\right)\right) .
$$


De acordo com a Seção B.4, tem-se que

$$
\sum_{n=1}^{N} \widetilde{\lambda}_{k, n} \ell_{k, n} \frac{\mathrm{w}}{2} \log _{2}\left(1+\frac{l_{k}^{\mathrm{AF}} \widetilde{p}_{r_{n, l}} \widetilde{p}_{k, n} \Gamma_{k, n, l} \Gamma_{l, n, 0}}{\widetilde{\lambda}_{k, n}\left(\widetilde{p}_{r_{n, l}} \Gamma_{l, n, 0}+\widetilde{p}_{k, n} \Gamma_{k, n, l}\right)}\right)
$$

é côncavo em relação a $\widetilde{p}_{k, n}, \widetilde{p}_{r_{n, l}}$ e $\widetilde{\lambda}_{k, n}$. Dado que $R_{\bar{k}}^{\mathrm{AF}}\left(\widetilde{\mathbf{P}}, \widetilde{\mathbf{P}}_{r}, \widetilde{\boldsymbol{\lambda}}\right)$ é constante em relação a $\widetilde{p}_{k, n}, \widetilde{p}_{r_{n, l}}$ e $\widetilde{\lambda}_{k, n}$, e $R_{\bar{k}}^{\mathrm{AF}}\left(\widetilde{\mathbf{P}}, \widetilde{\mathbf{P}}_{r}, \widetilde{\boldsymbol{\lambda}}\right)>0$, o numerador pode ser visto como a multiplicação de uma função côncava por uma constante não-negativa, de modo que a concavidade é preservada. Assim, demonstra-se que o numerador de $\widetilde{\xi}_{\text {prod }}^{\mathrm{AF}}\left(\widetilde{\mathbf{P}}, \widetilde{\mathbf{P}}_{r}, \widetilde{\boldsymbol{\lambda}}\right)$ é côncavo em relação a $\widetilde{p}_{k, n}, \widetilde{p}_{r_{n, l}}$ e $\widetilde{\lambda}_{k, n}$ também para MSs que utilizam protocolo AF.

Já o denominador de $\widetilde{\xi}_{\mathrm{AF}}^{\varpi}\left(\widetilde{\mathbf{P}}, \widetilde{\mathbf{P}}_{r}, \widetilde{\boldsymbol{\lambda}}\right)$ para a $k$-ésima MS usando protocolo AF é dado por

$$
P_{\bar{k}}^{\mathrm{AF}}\left(\widetilde{\mathbf{P}}, \widetilde{\mathbf{P}}_{r}, \widetilde{\boldsymbol{\lambda}}\right)\left(\frac{1}{2} \sum_{n=1}^{N}\left(\varrho_{k} \widetilde{p}_{k, n}+\varrho_{r_{l}} \widetilde{p}_{r_{n, l}}\right)+\varsigma_{k, l} p_{c, r_{l}}^{\mathrm{AF}}+p_{c, k}\right),
$$

relembrando que $P_{\bar{k}}^{\mathrm{AF}}\left(\widetilde{\mathbf{P}}, \widetilde{\mathbf{P}}_{r}, \widetilde{\boldsymbol{\lambda}}\right)$ é constante em relação a $\widetilde{p}_{k, n}, \widetilde{p}_{r_{n, l}}$ e $\widetilde{\lambda}_{k, n}$.

O denominador pode ser visto, então, como a combinação linear não-negativa das variáveis $\widetilde{p}_{k, n}$ e $\widetilde{p}_{r_{n, l}}\left(\right.$ dado que $\left.\frac{P_{\bar{k}}^{\Delta \mathrm{P}}\left(\widetilde{\mathbf{P}}, \widetilde{\mathbf{P}}_{r}, \widetilde{\boldsymbol{\lambda}}\right) \varrho_{k}}{2}>0 \mathrm{e} \frac{P_{\bar{k}}^{\Delta \mathrm{F}}\left(\widetilde{\mathbf{P}}, \widetilde{\mathbf{P}}_{r}, \widetilde{\boldsymbol{\lambda}}\right) \varrho_{r_{l}}}{2}>0\right)$ somada a duas

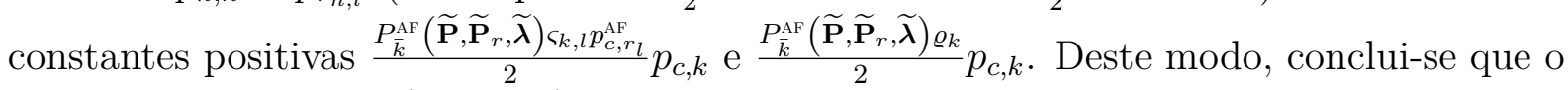
denominador de $\widetilde{\xi}_{\text {prod }}^{\mathrm{AF}}\left(\widetilde{\mathbf{P}}, \widetilde{\mathbf{P}}_{r}, \widetilde{\boldsymbol{\lambda}}\right)$ é positivo e afim em relação a $\widetilde{p}_{k, n}, \widetilde{p}_{r_{n, l}}$ e $\widetilde{\lambda}_{k, n}$ quando utilizado protocolo AF, resultando que $\widetilde{\xi}_{\text {prod }}^{\mathrm{AF}}\left(\widetilde{\mathbf{P}}, \widetilde{\mathbf{P}}_{r}, \widetilde{\boldsymbol{\lambda}}\right)$ é quase-côncavo em relação a $\widetilde{p}_{k, n}$, $\widetilde{p}_{r_{n, l}}$ e $\widetilde{\lambda}_{k, n}$ quando a $k$-ésima MS emprega a l-ésima RS com protocolo AF.

\section{B.5.2 Protocolo DF}

Já para o protocolo DF, o numerador de $\widetilde{\xi}_{\text {prod }}^{\mathrm{DF}}\left(\widetilde{\mathbf{P}}, \widetilde{\mathbf{P}}_{r}, \widetilde{\boldsymbol{\lambda}}\right)$ é dado por

$$
R_{\bar{k}}^{\mathrm{DF}}\left(\widetilde{\mathbf{P}}, \widetilde{\mathbf{P}}_{r}, \widetilde{\boldsymbol{\lambda}}\right)\left(\sum_{n=1}^{N} \widetilde{\lambda}_{k, n} \ell_{k, n} \frac{\mathrm{w}}{2} \log _{2}\left(1+\frac{\imath_{k}^{\mathrm{DF}} \Omega_{k, n, l}^{\mathrm{DF}} \widetilde{p}_{k, n, l} \Gamma_{k, n, l}}{\widetilde{\lambda}_{k, n}}\right)\right)
$$

Note que se provará a concavidade do numerador utilizando a potência consumida nos dois saltos, i.e., $\widetilde{p}_{k, n, l}$. Dado que existe um mapeamento um para um entre $\widetilde{p}_{k, n, l}$ e as potências em cada salto, não haverá prejuízo na demonstração.

De acordo com a Seção B.4, tem-se que

$$
\sum_{n=1}^{N} \widetilde{\lambda}_{k, n} \ell_{k, n} \frac{\mathrm{w}}{2} \log _{2}\left(1+\frac{l_{k}^{\mathrm{DF}} \Omega_{k, n, l}^{\mathrm{DF}} \widetilde{p}_{k, n, l} \Gamma_{k, n, l}}{\widetilde{\lambda}_{k, n}}\right)
$$

é côncavo em relação a $\widetilde{p}_{k, n}, \widetilde{p}_{r_{n, l}}$ e $\widetilde{\lambda}_{k, n}$. Dado que $R_{\bar{k}}^{\mathrm{DF}}\left(\widetilde{\mathbf{P}}, \widetilde{\mathbf{P}}_{r}, \widetilde{\boldsymbol{\lambda}}\right)$ é constante em relação a $\widetilde{p}_{k, n}, \widetilde{p}_{r_{n, l}}$ e $\widetilde{\lambda}_{k, n}$, e $R_{\bar{k}}^{\mathrm{DF}}\left(\widetilde{\mathbf{P}}, \widetilde{\mathbf{P}}_{r}, \widetilde{\boldsymbol{\lambda}}\right)>0$, o numerador pode ser visto como a multiplicação de uma função côncava por uma constante não-negativa, de modo que a concavidade é preservada. Assim, demonstra-se que o numerador de $\widetilde{\xi}_{\text {prod }}^{\mathrm{DF}}\left(\widetilde{\mathbf{P}}, \widetilde{\mathbf{P}}_{r}, \widetilde{\boldsymbol{\lambda}}\right)$ é côncavo em relação a $\widetilde{p}_{k, n}, \widetilde{p}_{r_{n, l}}$ e $\widetilde{\lambda}_{k, n}$ também para MSs que utilizam protocolo DF. 
Já o denominador de $\widetilde{\xi}_{\mathrm{DF}}^{\varpi}\left(\widetilde{\mathbf{P}}, \widetilde{\mathbf{P}}_{r}, \widetilde{\boldsymbol{\lambda}}\right)$ para a $k$-ésima MS usando protocolo DF é dado por

$$
P_{\bar{k}}^{\mathrm{DF}}\left(\widetilde{\mathbf{P}}, \widetilde{\mathbf{P}}_{r}, \widetilde{\boldsymbol{\lambda}}\right)\left(\frac{1}{2} \sum_{n=1}^{N}\left(\varrho_{k} \widetilde{p}_{k, n}+\varrho_{r_{l}} \widetilde{p}_{r_{n, l}}\right)+\varsigma_{k, l} p_{c, r_{l}}^{\mathrm{DF}}+p_{c, k}\right)
$$

relembrando que $P_{\bar{k}}^{\mathrm{DF}}\left(\widetilde{\mathbf{P}}, \widetilde{\mathbf{P}}_{r}, \widetilde{\boldsymbol{\lambda}}\right)$ é constante em relação a $\widetilde{p}_{k, n}, \widetilde{p}_{r_{n, l}}$ e $\widetilde{\lambda}_{k, n}$.

O denominador pode ser visto, então, como a combinação linear não-negativa das variáveis $\widetilde{p}_{k, n}$ e $\widetilde{p}_{r_{n, l}}\left(\right.$ dado que $\left.\frac{P_{\bar{k}}^{\mathrm{DF}}\left(\widetilde{\mathbf{P}}, \widetilde{\mathbf{P}}_{r}, \widetilde{\boldsymbol{\lambda}}\right) \varrho_{k}}{2}>0 \mathrm{e} \frac{P_{\bar{k}}^{\mathrm{DF}}\left(\widetilde{\mathbf{P}}, \widetilde{\mathbf{P}}_{r}, \widetilde{\boldsymbol{\lambda}}\right) \varrho_{r_{l}}}{2}>0\right)$ somada a duas constantes positivas $\frac{P_{\bar{k}}^{\mathrm{DF}}\left(\widetilde{\mathbf{P}}, \widetilde{\mathbf{P}}_{r}, \widetilde{\boldsymbol{\lambda}}\right)_{\kappa, l} p_{c, r}^{\mathrm{DF}}}{2} p_{c, k}$ e $\frac{P_{\bar{k}}^{\mathrm{DF}}\left(\widetilde{\mathbf{P}}, \widetilde{\mathbf{P}}_{r}, \widetilde{\boldsymbol{\lambda}}\right) \varrho_{k}}{2} p_{c, k}$. Deste modo, conclui-se que o denominador de $\widetilde{\xi}_{\text {prod }}^{\mathrm{DF}}\left(\widetilde{\mathbf{P}}, \widetilde{\mathbf{P}}_{r}, \widetilde{\boldsymbol{\lambda}}\right)$ é positivo e afim em relação a $\widetilde{p}_{k, n}, \widetilde{p}_{r_{n, l}}$ e $\widetilde{\lambda}_{k, n}$ quando utilizado protocolo DF, resultando que $\widetilde{\xi}_{\text {prod }}^{\text {DF }}\left(\widetilde{\mathbf{P}}, \widetilde{\mathbf{P}}_{r}, \widetilde{\boldsymbol{\lambda}}\right)$ é quase-côncavo em relação a $\widetilde{p}_{k, n}$, $\widetilde{p}_{r_{n, l}}$ e $\widetilde{\lambda}_{k, n}$ quando a $k$-ésima MS emprega a $l$-ésima RS com protocolo DF.

Assim, demonstra-se que tanto para MSs diretas, quanto para MSs que utilizam protocolo AF ou DF tem-se que $\widetilde{\xi}_{\text {prod }}^{\varpi}\left(\widetilde{\mathbf{P}}, \widetilde{\mathbf{P}}_{r}, \widetilde{\boldsymbol{\lambda}}\right)$ é quase-côncavo em relação a $\widetilde{p}_{k, n}, \widetilde{p}_{r_{n, l}}$ e $\tilde{\lambda}_{k, n}$, provando o teorema. 


\section{ANEXO C - PROPORÇÕES DE POTÊNCIA PARA PROTOCOLO AF}

\section{C.1 Determinação da Proporção de Potência em Protocolo AF para Somatório de Logaritmos}

Para o protocolo AF, não é possível determinar diretamente as potências ótimas a partir da primeira derivada de $U_{k, \log }^{\mathrm{AF}, i, j}$, pois não é possível separar o termo de potência alocada pela MS do termo de potência alocada pela RS na $n$-ésima subportadora. Para solucionar tal problema, utiliza-se uma mudança de variável, a partir do consumo total de potência na $n$-ésima portadora, dado por:

$$
\widetilde{p}_{k, n, l}=\widetilde{p}_{k, n}+\widetilde{p}_{r_{n, l}}
$$

Isolando a potência da RS, obtém-se:

$$
\widetilde{p}_{r_{n, l}}=\widetilde{p}_{k, n, l}-\widetilde{p}_{k, n}
$$

Substituindo $\widetilde{p}_{r_{n, l}}$ pela equação (C.2) nas equações (6.15b) e (6.30), tem-se que:

$$
\widetilde{r}_{k, n, l}^{\mathrm{AF}}=\frac{\mathrm{W}}{2} \log _{2}\left(1+\frac{\imath_{k}^{\mathrm{AF}}\left(\widetilde{p}_{k, n, l}-\widetilde{p}_{k, n}\right) \widetilde{p}_{k, n} \Gamma_{k, n, l} \Gamma_{l, n, 0}}{\widetilde{\lambda}_{k, n}\left(\left(\widetilde{p}_{k, n, l}-\widetilde{p}_{k, n}\right) \Gamma_{l, n, 0}+\widetilde{p}_{k, n} \Gamma_{k, n, l}\right)}\right)
$$

$\mathrm{e}$

$$
\begin{aligned}
U_{k, \log }^{\mathrm{AF}, i, j}= & \log _{b}\left(\sum_{n=1}^{N} \widetilde{\lambda}_{k, n} \ell_{k, n} \widetilde{r}_{k, n, l}^{\mathrm{AF}}\right)-\sum_{n=1}^{N} \tau_{k}^{j-1} \widetilde{p}_{k, n}-\sum_{n=1}^{N} \nu_{l}^{j-1}\left(\widetilde{p}_{k, n, l}-\widetilde{p}_{k, n}\right)-\sum_{n=1}^{N} v_{n}^{j-1} \widetilde{\lambda}_{k, n} \\
& -\frac{\left(\varrho_{k}-\varrho_{r_{l}}\right) \sum_{n=1}^{N}\left(\widetilde{p}_{k, n}-\widetilde{p}_{k, n}^{*, i-1}\right)+\varrho_{r_{l}} \sum_{n=1}^{N}\left(\widetilde{p}_{k, n, l}-\widetilde{p}_{k, n, l}^{*, i-1}\right)}{2 \log (b)\left[\frac{1}{2} \sum_{m=1}^{N}\left(\varrho_{k} \widetilde{p}_{k, m}^{*, i-1}+\varrho_{r_{l}}\left(\widetilde{p}_{k, n, l}^{*, i-1}-\widetilde{p}_{k, n}^{*, i-1}\right)\right)+\varsigma_{k, l} p_{c, r_{l}}^{\mathrm{AF}}+p_{c, k}\right]}
\end{aligned}
$$


Agora, deriva-se (C.4) em relação a $\widetilde{p}_{k, n}$ e $\widetilde{p}_{k, n, l}$, respectivamente. Assim, tem-se que

$$
\begin{aligned}
\frac{\partial U_{k, \log }^{\mathrm{AF}, i, j}}{\partial \widetilde{p}_{k, n}}= & \frac{1}{\log (b)\left(\sum_{m=1}^{N} \widetilde{\lambda}_{k, m} \ell_{k, m} \widetilde{r}_{k, m, l}^{\mathrm{AF}}\right)} \frac{\partial\left[\sum_{n=1}^{N} \widetilde{\lambda}_{k, n} \ell_{k, n} \widetilde{r}_{k, n, l}^{\mathrm{AF}}\right]}{\partial \widetilde{p}_{k, n}}-\left(\tau_{k}^{j-1}-\nu_{l}^{j-1}\right) \\
& -\frac{\varrho_{k}-\varrho_{r_{l}}}{2 \log (b) \mathrm{SP}_{k, l}^{\mathrm{AF}, i, j-1}} \\
& \frac{\widetilde{\lambda}_{k, n} \ell_{k, n}}{\log (b)\left(\sum_{m=1}^{N} \widetilde{\lambda}_{k, m} \ell_{k, m} \widetilde{r}_{k, m, l}^{\mathrm{AF}}\right)} \frac{\partial \widetilde{r}_{k, n, l}^{\mathrm{AF}}}{\partial \widetilde{p}_{k, n}}-\frac{\left(\tau_{k}^{j-1}-\nu_{l}^{j-1}\right) 2 \log (b) \mathrm{SP}_{k, l}^{\mathrm{AF}, i, j-1}+\varrho_{k}-\varrho_{r_{l}}}{2 \log (b) \mathrm{SP}_{k, l}^{\mathrm{AF}, i, j-1}} \\
& \frac{\widetilde{\lambda}_{k, n} \ell_{k, n} \ell_{k}^{\mathrm{AF}} \Gamma_{k, n, l} \Gamma_{l, n, 0}\left[\Gamma_{l, n, 0}\left(\widetilde{p}_{k, n, l}-\widetilde{p}_{k, n}\right)^{2}-\Gamma_{k, n, l}\left(\widetilde{p}_{k, n}\right)^{2}\right]}{\log (b) \log (2)\left(\sum_{m=1}^{N} \widetilde{\lambda}_{k, m} \ell_{k, m} \widetilde{r}_{k, m, l}^{\mathrm{AF}}\right)\left(c \widetilde{\lambda}_{k, n}+\imath_{k}^{\mathrm{AF}} \Gamma_{k, n, l} \Gamma_{l, n, 0} \widetilde{p}_{k, n}\left(\widetilde{p}_{k, n, l}-\widetilde{p}_{k, n}\right)\right)} \\
& -\frac{\left(\tau_{k}^{j-1}-\nu_{l}^{j-1}\right) 2 \log (b) \mathrm{SP}_{k, l}^{\mathrm{AF}, i, j-1}+\varrho_{k}-\varrho_{r_{l}}}{2 \log (b) \mathrm{SP}_{k, l}^{\mathrm{AF}, i, j-1}}
\end{aligned}
$$

$\mathrm{e}$

$$
\begin{aligned}
\frac{\partial U_{k, l o g}^{\mathrm{AF}, i, j}}{\partial \widetilde{p}_{k, n, l}}= & \frac{1}{\log (b)\left(\sum_{m=1}^{N} \widetilde{\lambda}_{k, m} \ell_{k, m} \widetilde{r}_{k, m, l}^{\mathrm{AF}}\right)} \frac{\partial\left[\sum_{n=1}^{N} \widetilde{\lambda}_{k, n} \ell_{k, n} \widetilde{r}_{k, n, l}^{\mathrm{AF}}\right]}{\partial \widetilde{p}_{k, n, l}}-\nu_{l}^{j-1}-\frac{\varrho_{r_{l}}}{2 \log (b) \mathrm{SP}_{k, l}^{\mathrm{AF}, i, j-1}} \\
= & \frac{\widetilde{\lambda}_{k, n} \ell_{k, n}}{\log (b)\left(\sum_{m=1}^{N} \widetilde{\lambda}_{k, m} \ell_{k, m} \widetilde{r}_{k, m, l}^{\mathrm{AF}}\right)} \frac{\partial \widetilde{r}_{k, n, l}^{\mathrm{AF}}}{\partial \widetilde{p}_{k, n, l}}-\frac{2 \nu_{l}^{j-1} \log (b) \mathrm{SP}_{k, l}^{\mathrm{AF}, i, j-1}+\varrho_{r_{l}}}{2 \log (b) \mathrm{SP}_{k, l}^{\mathrm{AF}, i, j-1}} \\
= & \frac{\widetilde{\lambda}_{k, n} \ell_{k, n} l_{k}^{\mathrm{AF}}\left(\Gamma_{k, n, l}\right)^{2} \Gamma_{l, n, 0}\left(\widetilde{p}_{k, n}\right)^{2}}{c \log (b) \log (2)\left(\sum_{m=1}^{N} \widetilde{\lambda}_{k, m} \ell_{k, m} \widetilde{r}_{k, m, l}^{\mathrm{AF}}\right)\left(c \widetilde{\lambda}_{k, n}+\imath_{k}^{\mathrm{AF}} \Gamma_{k, n, l} \Gamma_{l, n, 0} \widetilde{p}_{k, n}\left(\widetilde{p}_{k, n, l}-\widetilde{p}_{k, n}\right)\right)} \\
& -\frac{2 \nu_{l}^{j-1} \log (b) \mathrm{SP}_{k, l}^{\mathrm{AF}, i, j-1}+\varrho_{r_{l}},}{2 \log (b) \mathrm{SP}_{k, l}^{\mathrm{AF}, i, j-1}}
\end{aligned}
$$

com

$$
\mathrm{SP}_{k, l}^{\mathrm{AF}, i, j-1}=\frac{1}{2} \sum_{m=1}^{N}\left(\varrho_{k} \widetilde{p}_{k, m}^{i, j-1}+\varrho_{r_{l}} \widetilde{p}_{r_{m, l}}^{i, j-1}\right)+\varsigma_{k, l} p_{c, r_{l}}^{\mathrm{AF}}+p_{c, k}
$$

e

$$
c=\left(\widetilde{p}_{k, n, l}-\widetilde{p}_{k, n}\right) \Gamma_{l, n, 0}+\widetilde{p}_{k, n} \Gamma_{k, n, l} .
$$

Igualando ambas derivadas parciais a zero, e fazendo algumas manipulações, obtém-se:

$$
\begin{gathered}
\frac{\Gamma_{l, n, 0}\left(\widetilde{p}_{k, n, l}-\widetilde{p}_{k, n}\right)^{2}-\Gamma_{k, n, l}\left(\widetilde{p}_{k, n}\right)^{2}}{\left(\tau_{k}^{j-1}-\nu_{l}^{j-1}\right) 2 \log (b) \mathrm{SP}_{k, l}^{\mathrm{AF}, i, j-1}+\varrho_{k}-\varrho_{r_{l}}}=d \\
\frac{\Gamma_{k, n, l}\left(\widetilde{p}_{k, n}\right)^{2}}{2 \nu_{l}^{j-1} \log (b) \mathrm{SP}_{k, l}^{\mathrm{AF}, i, j-1}+\varrho_{r_{l}}}=d
\end{gathered}
$$


com

$$
d=\frac{c \log (b)\left(\sum_{m=1}^{N} \widetilde{\lambda}_{k, m} \ell_{k, m} \widetilde{r}_{k, m, l}^{\mathrm{AF}}\right)\left(c \widetilde{\lambda}_{k, n}+\imath_{k}^{\mathrm{AF}} \Gamma_{k, n, l} \Gamma_{l, n, 0} \widetilde{p}_{k, n}\left(\widetilde{p}_{k, n, l}-\widetilde{p}_{k, n}\right)\right)}{2 \log (b) \mathrm{SP}_{k, l}^{\mathrm{AF}, i, j-1} \widetilde{\lambda}_{k, n} \ell_{k, n} l_{k}^{\mathrm{AF}} \Gamma_{k, n, l} \Gamma_{l, n, 0}}
$$

Percebe-se, portanto, que

$$
\frac{\Gamma_{l, n, 0}\left(\widetilde{p}_{k, n, l}-\widetilde{p}_{k, n}\right)^{2}-\Gamma_{k, n, l}\left(\widetilde{p}_{k, n}\right)^{2}}{\left(\tau_{k}^{j-1}-\nu_{l}^{j-1}\right) 2 \log (b) \mathrm{SP}_{k, l}^{\mathrm{AF}, i, j-1}+\varrho_{k}-\varrho_{r_{l}}}=\frac{\Gamma_{k, n, l}\left(\widetilde{p}_{k, n}\right)^{2}}{2 \nu_{l}^{j-1} \log (b) \mathrm{SP}_{k, l}^{\mathrm{AF}, i, j-1}+\varrho_{r_{l}}}
$$

Tomando $e=2 \tau_{k}^{j-1} \log (b) \mathrm{SP}_{k, l}^{\mathrm{AF}, i, j-1}+\varrho_{k}$ e $f=2 \nu_{l}^{j-1} \log (b) \mathrm{SP}_{k, l}^{\mathrm{AF}, i, j-1}+\varrho_{r_{l}}$, obtém-se

$$
\begin{aligned}
\frac{\Gamma_{l, n, 0}\left(\widetilde{p}_{k, n, l}-\widetilde{p}_{k, n}\right)^{2}-\Gamma_{k, n, l}\left(\widetilde{p}_{k, n}\right)^{2}}{e-f} & =\frac{\Gamma_{k, n, l}\left(\widetilde{p}_{k, n}\right)^{2}}{f} \\
f \Gamma_{l, n, 0}\left(\widetilde{p}_{k, n, l}-\widetilde{p}_{k, n}\right)^{2}-f \Gamma_{k, n, l}\left(\widetilde{p}_{k, n}\right)^{2} & =(e-f) \Gamma_{k, n, l}\left(\widetilde{p}_{k, n}\right)^{2} \\
f \Gamma_{l, n, 0}\left(\widetilde{p}_{k, n, l}-\widetilde{p}_{k, n}\right)^{2} & =e \Gamma_{k, n, l}\left(\widetilde{p}_{k, n}\right)^{2}
\end{aligned}
$$

que resulta em

$$
\left(f \Gamma_{l, n, 0}-e \Gamma_{k, n, l}\right)\left(\widetilde{p}_{k, n}\right)^{2}-2 f \Gamma_{l, n, 0} \widetilde{p}_{k, n, l} \widetilde{p}_{k, n}+f \Gamma_{l, n, 0}\left(\widetilde{p}_{k, n, l}\right)^{2}=0 .
$$

Utilizando Bhaskara para determinar $\widetilde{p}_{k, n}$ a partir da equação (C.10), tem-se que:

$$
\begin{aligned}
\widetilde{p}_{k, n} & =\frac{2 f \Gamma_{l, n, 0} \widetilde{p}_{k, n, l} \pm \sqrt{4 e f \Gamma_{k, n, l} \Gamma_{l, n, 0}\left(\widetilde{p}_{k, n, l}\right)^{2}}}{2 f \Gamma_{l, n, 0}-2 e \Gamma_{k, n, l}} \\
& =\widetilde{p}_{k, n, l} \underbrace{\left[\frac{f \Gamma_{l, n, 0} \pm \sqrt{e f \Gamma_{k, n, l} \Gamma_{l, n, 0}}}{f \Gamma_{l, n, 0}-e \Gamma_{k, n, l}}\right]}_{\text {(I) }}
\end{aligned}
$$

O termo (C.11).(I) pode ser interpretado como a razão entre a potência utilizada no primeiro salto, $\widetilde{p}_{k, n}$, e a potência total nos dois saltos, $\widetilde{p}_{k, n, l}$, que pode ser denotado por $\Omega_{k, n, l}^{\mathrm{AF}, i, j}$. Se $\Omega_{k, n, l}^{\mathrm{AF}, i, j}$ equivale a uma razão, uma condição que deve ser atendida é dada por

$$
0<\frac{f \Gamma_{l, n, 0} \pm \sqrt{e f \Gamma_{k, n, l} \Gamma_{l, n, 0}}}{f \Gamma_{l, n, 0}-e \Gamma_{k, n, l}}<1
$$

Se fosse tomado $\Omega_{k, n, l}^{\mathrm{AF}, i, j}=\frac{f \Gamma_{l, n, 0}+\sqrt{e f \Gamma_{k, n, l} \Gamma_{l, n, 0}}}{f \Gamma_{l, n, 0}-e \Gamma_{k, n, l}}$, a condição (C.12) não seria atendida, pois o numerador é sempre positivo enquanto o denominador pode ser negativo caso $f \Gamma_{l, n, 0}<e \Gamma_{k, n, l}$.

Adotando então $\Omega_{k, n, l}^{\mathrm{AF}, i, j}=\frac{f \Gamma_{l, n, 0}-\sqrt{e f \Gamma_{k, n, l} \Gamma_{l, n, 0}}}{f \Gamma_{l, n, 0}-e \Gamma_{k, n, l}}$, inicia-se pela demonstração de que $\Omega_{k, n, l}^{\mathrm{AF}, i, j}>0$. Para se obter tal resultado, deve-se demonstrar que o numerador e o denominador possuem o mesmo sinal, i.e:

$$
\begin{aligned}
& f \Gamma_{l, n, 0}-\sqrt{e f \Gamma_{k, n, l} \Gamma_{l, n, 0}}>0 \leftrightarrow f \Gamma_{l, n, 0}-e \Gamma_{k, n, l}>0 \\
& f \Gamma_{l, n, 0}-\sqrt{e f \Gamma_{k, n, l} \Gamma_{l, n, 0}}<0 \leftrightarrow f \Gamma_{l, n, 0}-e \Gamma_{k, n, l}<0
\end{aligned}
$$


Demonstrando primeiramente (C.13a):

$$
\begin{aligned}
f \Gamma_{l, n, 0}-\sqrt{e f \Gamma_{k, n, l} \Gamma_{l, n, 0}} & >0 \\
f \Gamma_{l, n, 0} & >\sqrt{e f \Gamma_{k, n, l} \Gamma_{l, n, 0}} \\
f^{2}\left(\Gamma_{l, n, 0}\right)^{2} & >e f \Gamma_{k, n, l} \Gamma_{l, n, 0} \\
f \Gamma_{l, n, 0} & >e \Gamma_{k, n, l} \\
f \Gamma_{l, n, 0}-e \Gamma_{k, n, l} & >0
\end{aligned}
$$

onde a passagem da inequação (C.14b) para a inequação (C.14c) somente é possível pois ambos os termos da inequação (C.14b) são positivos.

Tomando agora (C.13b):

$$
\begin{aligned}
f \Gamma_{l, n, 0}-\sqrt{e f \Gamma_{k, n, l} \Gamma_{l, n, 0}} & <0 \\
f \Gamma_{l, n, 0} & <\sqrt{e f \Gamma_{k, n, l} \Gamma_{l, n, 0}} \\
f^{2}\left(\Gamma_{l, n, 0}\right)^{2} & <e f \Gamma_{k, n, l} \Gamma_{l, n, 0} \\
f \Gamma_{l, n, 0} & <e \Gamma_{k, n, l} \\
f \Gamma_{l, n, 0}-e \Gamma_{k, n, l} & <0
\end{aligned}
$$

onde a passagem da inequação (C.15b) para a inequação (C.15c) somente é possível pois ambos os termos da inequação (C.15b) são positivos.

Assim, a condição $\Omega_{k, n, l}^{\mathrm{AF}, i, j}>0$ é atendida, faltando então verificar que $\Omega_{k, n, l}^{\mathrm{AF}, i, j}<1$. Para tal, consideram-se duas hipóteses:

- Hipótese 1: $f \Gamma_{l, n, 0}-e \Gamma_{k, n, l}>0$

$$
\begin{aligned}
\frac{f \Gamma_{l, n, 0}-\sqrt{e f \Gamma_{k, n, l} \Gamma_{l, n, 0}}}{f \Gamma_{l, n, 0}-e \Gamma_{k, n, l}} & <1 \\
f \Gamma_{l, n, 0}-\sqrt{e f \Gamma_{k, n, l} \Gamma_{l, n, 0}} & <f \Gamma_{l, n, 0}-e \Gamma_{k, n, l} \\
\sqrt{e f \Gamma_{k, n, l} \Gamma_{l, n, 0}} & >e \Gamma_{k, n, l} \\
e f \Gamma_{k, n, l} \Gamma_{l, n, 0} & >e^{2}\left(\Gamma_{k, n, l}\right)^{2} \\
f \Gamma_{l, n, 0} & >e \Gamma_{k, n, l} \\
f \Gamma_{l, n, 0}-e \Gamma_{k, n, l} & >0
\end{aligned}
$$

onde a passagem da inequação (C.16c) para a inequação (C.16d) somente é possível pois ambos os lados da inequação (C.16c) são positivos. 
- Hipótese 2: $f \Gamma_{l, n, 0}-e \Gamma_{k, n, l}<0$

$$
\begin{aligned}
\frac{f \Gamma_{l, n, 0}-\sqrt{e f \Gamma_{k, n, l} \Gamma_{l, n, 0}}}{f \Gamma_{l, n, 0}-e \Gamma_{k, n, l}} & <1 \\
f \Gamma_{l, n, 0}-\sqrt{e f \Gamma_{k, n, l} \Gamma_{l, n, 0}} & >f \Gamma_{l, n, 0}-e \Gamma_{k, n, l} \\
\sqrt{e f \Gamma_{k, n, l} \Gamma_{l, n, 0}} & <e \Gamma_{k, n, l} \\
e f \Gamma_{k, n, l} \Gamma_{l, n, 0} & <e^{2}\left(\Gamma_{k, n, l}\right)^{2} \\
f \Gamma_{l, n, 0} & <e \Gamma_{k, n, l} \\
f \Gamma_{l, n, 0}-e \Gamma_{k, n, l} & <0
\end{aligned}
$$

onde a passagem da inequação (C.17c) para a inequação (C.17d) somente é possível pois ambos os lados da inequação (C.17c) são positivos.

Assim, as duas hipóteses são confirmadas quando se assume que $\Omega_{k, n, l}^{\mathrm{AF}, i, j}<1$, de modo que as condições estabelecidas pela inequação (C.12) são atendidas. Assim, define-se que

$$
\begin{aligned}
\Omega_{k, n, l}^{\mathrm{AF}, i, j} & =\frac{f \Gamma_{l, n, 0}-\sqrt{e f \Gamma_{k, n, l} \Gamma_{l, n, 0}}}{f \Gamma_{l, n, 0}-e \Gamma_{k, n, l}} \\
& =\frac{\left(2 \nu_{l}^{j-1} \log (b) \mathrm{SP}_{k, l}^{\mathrm{AF}, i, j-1}+\varrho_{r_{l}}\right) \Gamma_{l, n, 0}}{\left(2 \nu_{l}^{j-1} \log (b) \mathrm{SP}_{k, l}^{\mathrm{AF}, i, j-1}+\varrho_{r_{l}}\right) \Gamma_{l, n, 0}-\left(2 \tau_{k}^{j-1} \log (b) \mathrm{SP}_{k, l}^{\mathrm{AF}, i, j-1}+\varrho_{k}\right) \Gamma_{k, n, l}} \\
& -\frac{\sqrt{\left(2 \tau_{k}^{j-1} \log (b) \mathrm{SP}_{k, l}^{\mathrm{AF}, i, j-1}+\varrho_{k}\right)\left(2 \nu_{l}^{j-1} \log (b) \mathrm{SP}_{k, l}^{\mathrm{AF}, i, j-1}+\varrho_{r_{l}}\right) \Gamma_{k, n, l} \Gamma_{l, n, 0}}}{\left(2 \nu_{l}^{j-1} \log (b) \mathrm{SP}_{k, l}^{\mathrm{AF}, i, j-1}+\varrho_{r_{l}}\right) \Gamma_{l, n, 0}-\left(2 \tau_{k}^{j-1} \log (b) \mathrm{SP}_{k, l}^{\mathrm{AF}, i, j-1}+\varrho_{k}\right) \Gamma_{k, n, l}}
\end{aligned}
$$

\section{C.2 Determinação da Proporção de Potência para AF para Produ- tório}

Substituindo $\widetilde{p}_{r_{n, l}}^{\mathrm{AF}}$ como definido na equação (C.2) na função-utilidade $U_{\mathrm{prod}}^{\mathrm{AF}, i, j}$, equação (6.79b), e considerando a equação de taxa de dados dada pela equação (C.3), temos que:

$$
\begin{aligned}
U_{\mathrm{prod}}^{\mathrm{AF}, i, j}= & \frac{\mathrm{w} R_{\bar{k}}^{\mathrm{AF}}\left(\widetilde{\mathbf{P}}, \widetilde{\mathbf{P}}_{r}, \widetilde{\boldsymbol{\lambda}}\right)}{2}\left(\sum_{n=1}^{N} \widetilde{\lambda}_{k, n} \ell_{k, n} \log _{2}\left(1+\frac{\imath_{k}^{\mathrm{AF}}\left(\widetilde{p}_{k, n, l}-\widetilde{p}_{k, n}\right) \widetilde{p}_{k, n} \Gamma_{k, n, l} \Gamma_{l, n, 0}}{\widetilde{\lambda}_{k, n}\left(\left(\widetilde{p}_{k, n, l}-\widetilde{p}_{k, n}\right) \Gamma_{l, n, 0}+\widetilde{p}_{k, n} \Gamma_{k, n, l}\right)}\right)\right) \\
& -q^{\mathrm{AF}, i-1} P_{\bar{k}}^{\mathrm{AF}}\left(\widetilde{\mathbf{P}}, \widetilde{\mathbf{P}}_{r}, \widetilde{\boldsymbol{\lambda}}\right)\left(\frac{1}{2} \sum_{n=1}^{N}\left(\varrho_{k} \widetilde{p}_{k, n}+\varrho_{r_{l}}\left(\widetilde{p}_{k, n, l}\right)-\widetilde{p}_{k, n}\right)+\varsigma_{k, l} p_{c, r_{l}}^{\mathrm{AF}}+p_{c, k}\right) \\
& -\sum_{k=1}^{K}\left(\sum_{n=1}^{N} \tau_{k}^{j-1} \widetilde{p}_{k, n}+\sum_{n=1}^{N} \sum_{l=1}^{N_{\mathrm{RS}}} \nu_{l}^{j-1} \psi_{k, l}\left(\widetilde{p}_{k, n, l}-\widetilde{p}_{k, n}\right)+\sum_{n=1}^{N} v_{n}^{j-1} \widetilde{\lambda}_{k, n}\right)
\end{aligned}
$$


Agora, deriva-se (C.19) em relação a $\widetilde{p}_{k, n}$ e $\widetilde{p}_{k, n, l}$ (considerando que o $k$-ésimo usuário utiliza a $l$-ésima RS), obtendo-se:

$$
\begin{aligned}
\frac{\partial U_{\mathrm{prod}}^{\mathrm{AF}, i, j}}{\partial \widetilde{p}_{k, n}}= & \widetilde{R}_{\bar{k}}^{\mathrm{AF}}\left(\widetilde{\mathbf{P}}, \widetilde{\mathbf{P}}_{r}, \widetilde{\boldsymbol{\lambda}}\right) \widetilde{\lambda}_{k, n} \ell_{k, n} \frac{\partial \widetilde{r}_{k, n, l}^{\mathrm{AF}}}{\partial \widetilde{p}_{k, n}}-\frac{q^{\mathrm{AF}, i-1} \widetilde{P}_{\bar{k}}^{\mathrm{AF}}\left(\widetilde{\mathbf{P}}, \widetilde{\mathbf{P}}_{r}, \widetilde{\boldsymbol{\lambda}}\right)\left(\varrho_{k}-\varrho_{r_{l}}\right)}{2}-\tau_{k}^{j-1}+\nu_{l}^{j-1} \\
= & \frac{\widetilde{R}_{\bar{k}}^{\mathrm{AF}}\left(\widetilde{\mathbf{P}}, \widetilde{\mathbf{P}}_{r}, \widetilde{\boldsymbol{\lambda}}\right) \mathrm{w} \widetilde{\lambda}_{k, n} \ell_{k, n} \imath_{k}^{\mathrm{AF}} \Gamma_{k, n, l} \Gamma_{l, n, 0}\left[\Gamma_{l, n, 0}\left(\widetilde{p}_{k, n, l}-\widetilde{p}_{k, n}\right)^{2}-\Gamma_{k, n, l}\left(\widetilde{p}_{k, n}\right)^{2}\right]}{2 c \log (2)\left(c \widetilde{\lambda}_{k, n}+l_{k}^{\mathrm{AF}} \Gamma_{k, n, l} \Gamma_{l, n, 0} \widetilde{p}_{k, n}\left(\widetilde{p}_{k, n, l}-\widetilde{p}_{k, n}\right)\right)} \\
& -\left[\frac{q^{\mathrm{AF}, i-1} \widetilde{P}_{\bar{k}}^{\mathrm{AF}}\left(\widetilde{\mathbf{P}}, \widetilde{\mathbf{P}}_{r}, \widetilde{\boldsymbol{\lambda}}\right)\left(\varrho_{k}-\varrho_{r_{l}}\right)+2 \tau_{k}^{j-1}-2 \nu_{l}^{j-1}}{2}\right] \\
\frac{\partial U_{\mathrm{prod}}^{\mathrm{AF}, i, j}}{\partial \widetilde{p}_{k, n, l}}= & \widetilde{R}_{\bar{k}}^{\mathrm{AF}}\left(\widetilde{\mathbf{P}}, \widetilde{\mathbf{P}}_{r}, \widetilde{\boldsymbol{\lambda}}\right) \widetilde{\lambda}_{k, n} \ell_{k, n} \frac{\partial \widetilde{r}_{k, n, l}^{\mathrm{AF}}}{\partial \widetilde{p}_{k, n, l}}-\frac{q^{\mathrm{AF}, i-1} \widetilde{P}_{\bar{k}}^{\mathrm{AF}}\left(\widetilde{\mathbf{P}}, \widetilde{\mathbf{P}}_{r}, \widetilde{\boldsymbol{\lambda}}\right) \varrho_{r_{l}}}{2}-\nu_{l}^{j-1} \\
= & \frac{\widetilde{R}_{\bar{k}}^{\mathrm{AF}}\left(\widetilde{\mathbf{P}}, \widetilde{\mathbf{P}}_{r}, \widetilde{\boldsymbol{\lambda}}\right) \mathrm{w} \widetilde{\lambda}_{k, n} \ell_{k, n} \imath_{k}^{\mathrm{AF}}\left(\Gamma_{k, n, l}\right)^{2} \Gamma_{l, n, 0}\left(\widetilde{p}_{k, n}\right)^{2}}{2 c \log (2)\left(c \widetilde{\lambda}_{k, n}^{\mathrm{AF}}+l_{k}^{\mathrm{AF}} \Gamma_{k, n, l} \Gamma_{l, n, 0} \widetilde{p}_{k, n}\left(\widetilde{p}_{k, n, l}-\widetilde{p}_{k, n}\right)\right)} \\
& -\left[\frac{q^{\mathrm{AF}, i-1} \widetilde{P}_{\bar{k}}^{\mathrm{AF}}\left(\widetilde{\mathbf{P}}, \widetilde{\mathbf{P}}_{r}, \widetilde{\boldsymbol{\lambda}}\right) \varrho_{r_{l}}+2 \nu_{l}^{j-1}}{2}\right]
\end{aligned}
$$

$\mathrm{com}$

$$
c=\left(\widetilde{p}_{k, n, l}-\widetilde{p}_{k, n}\right) \Gamma_{l, n, 0}+\widetilde{p}_{k, n} \Gamma_{k, n, l}
$$

Igualando ambas derivadas parciais a zero, e fazendo algumas manipulações, obtém-se:

$$
\begin{gathered}
\frac{\left[\Gamma_{l, n, 0}\left(\widetilde{p}_{k, n, l}-\widetilde{p}_{k, n}\right)^{2}-\Gamma_{k, n, l}\left(\widetilde{p}_{k, n}\right)^{2}\right]}{q^{\mathrm{AF}, i-1} \widetilde{P}_{\bar{k}}^{\mathrm{AF}}\left(\widetilde{\mathbf{P}}, \widetilde{\mathbf{P}}_{r}, \widetilde{\boldsymbol{\lambda}}\right)\left(\varrho_{k}-\varrho_{r_{l}}\right)+2 \tau_{k}^{j-1}-2 \nu_{l}^{j-1}}=d \\
\frac{\Gamma_{k, n, l}\left(\widetilde{p}_{k, n}\right)^{2}}{q^{\mathrm{AF}, i-1} \widetilde{P}_{\bar{k}}^{\mathrm{AF}}\left(\widetilde{\mathbf{P}}, \widetilde{\mathbf{P}}_{r}, \widetilde{\boldsymbol{\lambda}}\right) \varrho_{r_{l}}+2 \nu_{l}^{j-1}}=d
\end{gathered}
$$

com

$$
d=\frac{c \log (2)\left(c \widetilde{\lambda}_{k, n}+\imath_{k}^{\mathrm{AF}} \Gamma_{k, n, l} \Gamma_{l, n, 0} \widetilde{p}_{k, n}\left(\widetilde{p}_{k, n, l}-\widetilde{p}_{k, n}\right)\right)}{\widetilde{R}_{\bar{k}}^{\mathrm{AF}}\left(\widetilde{\mathbf{P}}, \widetilde{\mathbf{P}}_{r}, \widetilde{\boldsymbol{\lambda}}\right) \mathrm{w} \widetilde{\lambda}_{k, n} \ell_{k, n} \imath_{k}^{\mathrm{AF}} \Gamma_{k, n, l} \Gamma_{l, n, 0}}
$$

Com isso, tem-se que

$$
\frac{\left[\Gamma_{l, n, 0}\left(\widetilde{p}_{k, n, l}-\widetilde{p}_{k, n}\right)^{2}-\Gamma_{k, n, l}\left(\widetilde{p}_{k, n}\right)^{2}\right]}{q^{\mathrm{AF}, i-1} \widetilde{P}_{\bar{k}}^{\mathrm{AF}}\left(\widetilde{\mathbf{P}}, \widetilde{\mathbf{P}}_{r}, \widetilde{\boldsymbol{\lambda}}\right)\left(\varrho_{k}-\varrho_{r_{l}}\right)+2 \tau_{k}^{j-1}-2 \nu_{l}^{j-1}}=\frac{\Gamma_{k, n, l}\left(\widetilde{p}_{k, n}\right)^{2}}{q^{\mathrm{AF}, i-1} \widetilde{P}_{\bar{k}}^{\mathrm{AF}}\left(\widetilde{\mathbf{P}}, \widetilde{\mathbf{P}}_{r}, \widetilde{\boldsymbol{\lambda}}\right) \varrho_{r_{l}}+2 \nu_{l}^{j-1}}
$$

Tomando $e=q^{\mathrm{AF}, i-1} \widetilde{P}_{\bar{k}}^{\mathrm{AF}}\left(\widetilde{\mathbf{P}}, \widetilde{\mathbf{P}}_{r}, \widetilde{\boldsymbol{\lambda}}\right) \varrho_{k}+2 \tau_{k}^{j-1}$ e $f=q^{\mathrm{AF}, i-1} \widetilde{P}_{\bar{k}}^{\mathrm{AF}}\left(\widetilde{\mathbf{P}}, \widetilde{\mathbf{P}}_{r}, \widetilde{\boldsymbol{\lambda}}\right) \varrho_{r_{l}}+2 \nu_{l}^{j-1}$, obtém-se:

$$
\begin{aligned}
\frac{\Gamma_{l, n, 0}\left(\widetilde{p}_{k, n, l}-\widetilde{p}_{k, n}\right)^{2}-\Gamma_{k, n, l}\left(\widetilde{p}_{k, n}\right)^{2}}{e-f} & =\frac{\Gamma_{k, n, l}\left(\widetilde{p}_{k, n}\right)^{2}}{f} \\
f \Gamma_{l, n, 0}\left(\widetilde{p}_{k, n, l}-\widetilde{p}_{k, n}\right)^{2}-f \Gamma_{k, n, l}\left(\widetilde{p}_{k, n}\right)^{2} & =(e-f) \Gamma_{k, n, l}\left(\widetilde{p}_{k, n}\right)^{2} \\
f \Gamma_{l, n, 0}\left(\widetilde{p}_{k, n, l}^{\mathrm{AF}}-\widetilde{p}_{k, n}^{\mathrm{AF}}\right)^{2} & =e \Gamma_{k, n, l}\left(\widetilde{p}_{k, n}^{\mathrm{AF}}\right)^{2}
\end{aligned}
$$


que pode ser rearranjado como

$$
\left(f \Gamma_{l, n, 0}-e \Gamma_{k, n, l}\right)\left(\widetilde{p}_{k, n}\right)^{2}-2 f \Gamma_{l, n, 0} \widetilde{p}_{k, n, l} \widetilde{p}_{k, n}+f \Gamma_{l, n, 0}\left(\widetilde{p}_{k, n, l}\right)^{2}=0 .
$$

Perceba que a equação (C.26) é semelhante à que se obtém para o método de somatório de logaritmos, equação (C.10), apenas com diferentes valores para e e $f$. Apesar disso, ainda tem-se que $e>0$ e $f>0$, de modo que as conclusões obtidas com as equações (C.11)-(C.17) são também válidas para esse caso. Assim, define-se que

$$
\begin{aligned}
& \Omega_{k, n, l}^{\mathrm{AF}, i, j}\left(\widetilde{\mathbf{P}}, \widetilde{\mathbf{P}}_{r}, \widetilde{\boldsymbol{\lambda}}\right)= \\
& \frac{\left(q^{\mathrm{AF}, i-1} \widetilde{P}_{\bar{k}}^{\mathrm{AF}}\left(\widetilde{\mathbf{P}}, \widetilde{\mathbf{P}}_{r}, \widetilde{\boldsymbol{\lambda}}\right) \varrho_{r_{l}}+2 \nu_{l}^{j-1}\right) \Gamma_{l, n, 0}}{\left(q^{\mathrm{AF}, i-1} \widetilde{P}_{\bar{k}}^{\mathrm{AF}}\left(\widetilde{\mathbf{P}}, \widetilde{\mathbf{P}}_{r}, \widetilde{\boldsymbol{\lambda}}\right) \varrho_{r_{l}}+2 \nu_{l}^{j-1}\right) \Gamma_{l, n, 0}-\left(q^{\mathrm{AF}, i-1} \widetilde{P}_{\bar{k}}^{\mathrm{AF}}\left(\widetilde{\mathbf{P}}, \widetilde{\mathbf{P}}_{r}, \widetilde{\boldsymbol{\lambda}}\right) \varrho_{k}+2 \tau_{k}^{j-1}\right) \Gamma_{k, n, l}} \\
& -\frac{\sqrt{\left(q^{\mathrm{AF}, i-1} \widetilde{P}_{\bar{k}}^{\mathrm{AF}}\left(\widetilde{\mathbf{P}}, \widetilde{\mathbf{P}}_{r}, \widetilde{\boldsymbol{\lambda}}\right) \varrho_{k}+2 \tau_{k}^{j-1}\right)\left(q^{\mathrm{AF}, i-1} \widetilde{P}_{\bar{k}}^{\mathrm{AF}}\left(\widetilde{\mathbf{P}}, \widetilde{\mathbf{P}}_{r}, \widetilde{\boldsymbol{\lambda}}\right) \varrho_{r_{l}}+2 \nu_{l}^{j-1}\right) \Gamma_{k, n, l} \Gamma_{l, n, 0}}}{\left(q^{\mathrm{AF}, i-1} \widetilde{P}_{\bar{k}}^{\mathrm{AF}}\left(\widetilde{\mathbf{P}}, \widetilde{\mathbf{P}}_{r}, \widetilde{\boldsymbol{\lambda}}\right) \varrho_{r_{l}}+2 \nu_{l}^{j-1}\right) \Gamma_{l, n, 0}-\left(q^{\mathrm{AF}, i-1} \widetilde{P}_{\bar{k}}^{\mathrm{AF}}\left(\widetilde{\mathbf{P}}, \widetilde{\mathbf{P}}_{r}, \widetilde{\boldsymbol{\lambda}}\right) \varrho_{k}+2 \tau_{k}^{j-1}\right) \Gamma_{k, n, l}}
\end{aligned}
$$

\section{C.3 Cálculo da Proporção de Potência para AF para Método Hí- brido}

Substituindo $\widetilde{p}_{r_{n, l}}^{\mathrm{AF}}$ como definido na equação (C.2) na função-utilidade $U_{k, \text { ind }}^{\mathrm{AF}, i, j}$, equação (7.41b), e considerando a equação de taxa de dados dada pela equação (C.3), temos que:

$$
\begin{aligned}
U_{k, \text { ind }}^{\mathrm{AF}, i, j}= & \sum_{n=1}^{N} \widetilde{\lambda}_{k, n} \ell_{k, n} \widetilde{r}_{k, n, l}^{\mathrm{AF}}-q_{k}^{\mathrm{AF}, i-1}\left(\frac{1}{2} \sum_{n=1}^{N}\left(\varrho_{k} \widetilde{p}_{k, n}+\varrho_{r_{l}}\left(\widetilde{p}_{k, n, l}-\widetilde{p}_{k, n}\right)\right)+\varsigma_{k, l} p_{c, r_{l}}^{\mathrm{AF}}+p_{c, k}\right) \\
& -\sum_{n=1}^{N} \tau_{k}^{j-1} \widetilde{p}_{k, n}-\sum_{n=1}^{N} \nu_{l}^{j-1}\left(\widetilde{p}_{k, n, l}-\widetilde{p}_{k, n}\right)
\end{aligned}
$$

Agora, deriva-se (C.28) em relação a $\widetilde{p}_{k, n}$ e $\widetilde{p}_{k, n, l}$ e posteriormente iguala-se as duas equações a zero para se obter as potências ótimas. Assim, tem-se que:

$$
\begin{aligned}
& \frac{\partial U_{k, \text { ind }}^{\mathrm{AF}, i, j}}{\partial \widetilde{p}_{k, n}}= \widetilde{\lambda}_{k, n} \ell_{k, n} \frac{\partial \widetilde{r}_{k, n, l}^{\mathrm{AF}}}{\partial \widetilde{p}_{k, n}}-\frac{q_{k}^{\mathrm{AF}, i-1}\left(\varrho_{k}-\varrho_{r_{l}}\right)}{2}-\tau_{k}^{j-1}+\nu_{l}^{j-1} \\
&= \frac{\mathrm{w} \widetilde{\lambda}_{k, n} \ell_{k, n} \imath_{k}^{\mathrm{AF}} \Gamma_{k, n, l} \Gamma_{l, n, 0}\left[\Gamma_{l, n, 0}\left(\widetilde{p}_{k, n, l}-\widetilde{p}_{k, n}\right)^{2}-\Gamma_{k, n, l}\left(\widetilde{p}_{k, n}\right)^{2}\right]}{2 c \log (2)\left(c \widetilde{\lambda}_{k, n}+\imath_{k}^{\mathrm{AF}} \Gamma_{k, n, l} \Gamma_{l, n, 0} \widetilde{p}_{k, n}\left(\widetilde{p}_{k, n, l}-\widetilde{p}_{k, n}\right)\right)} \\
&-\left[\frac{q_{k}^{\mathrm{AF}, i-1}\left(\varrho_{k}-\varrho_{r_{l}}\right)+2 \tau_{k}^{j-1}-2 \nu_{l}^{j-1}}{2}\right] \\
& \frac{\partial U_{k, \text { ind }}^{\mathrm{AF}, i,}}{\partial \widetilde{p}_{k, n, l}}=\widetilde{\lambda}_{k, n} \ell_{k, n} \frac{\partial \widetilde{r}_{k, n, l}^{\mathrm{AF}}-\frac{q_{k}^{\mathrm{AF}, i-1} \varrho_{r_{l}}}{\partial \widetilde{p}_{k, n, l}}-\nu_{l}^{j-1}}{2} \\
&=\frac{\mathrm{w} \widetilde{\lambda}_{k, n} \ell_{k, n} l_{k}^{\mathrm{AF}}\left(\Gamma_{k, n, l}\right)^{2} \Gamma_{l, n, 0}\left(\widetilde{p}_{k, n}\right)^{2}}{2 c \log (2)\left(c \widetilde{\lambda}_{k, n}^{\mathrm{AF}}+\imath_{k}^{\mathrm{AF}} \Gamma_{k, n, l} \Gamma_{l, n, 0} \widetilde{p}_{k, n}\left(\widetilde{p}_{k, n, l}-\widetilde{p}_{k, n}\right)\right)} \\
&-\left[\frac{q_{k}^{\mathrm{AF}, i-1} \varrho_{r_{l}}+2 \nu_{l}^{j-1}}{2}\right]
\end{aligned}
$$


com

$$
c=\left(\widetilde{p}_{k, n, l}-\widetilde{p}_{k, n}\right) \Gamma_{l, n, 0}+\widetilde{p}_{k, n} \Gamma_{k, n, l}
$$

Igualando ambas as derivadas parciais a zero, e fazendo algumas manipulações, obtémse:

$$
\begin{gathered}
\frac{\left[\Gamma_{l, n, 0}\left(\widetilde{p}_{k, n, l}-\widetilde{p}_{k, n}\right)^{2}-\Gamma_{k, n, l}\left(\widetilde{p}_{k, n}\right)^{2}\right]}{q_{k}^{\mathrm{AF}, i-1}\left(\varrho_{k}-\varrho_{r_{l}}\right)+2 \tau_{k}^{j-1}-2 \nu_{l}^{j-1}}=d \\
\frac{\Gamma_{k, n, j}\left(\widetilde{p}_{k, n}\right)^{2}}{q_{k}^{\mathrm{AF}, m-1} \varrho_{r_{j}}+2 \nu_{j}^{m, l-1}}=d
\end{gathered}
$$

com

$$
d=\frac{c \log (2)\left(c \widetilde{\lambda}_{k, n}+\imath_{k}^{\mathrm{AF}} \Gamma_{k, n, l} \Gamma_{l, n, 0} \widetilde{p}_{k, n}\left(\widetilde{p}_{k, n, l}-\widetilde{p}_{k, n}\right)\right)}{\mathrm{w} \widetilde{\lambda}_{k, n} \ell_{k, n} \imath_{k}^{\mathrm{AF}} \Gamma_{k, n, l} \Gamma_{l, n, 0}}
$$

Percebe-se, portanto, que

$$
\frac{\left[\Gamma_{l, n, 0}\left(\widetilde{p}_{k, n, l}-\widetilde{p}_{k, n}\right)^{2}-\Gamma_{k, n, l}\left(\widetilde{p}_{k, n}\right)^{2}\right]}{q_{k}^{\mathrm{AF}, i-1}\left(\varrho_{k}-\varrho_{r_{l}}\right)+2 \tau_{k}^{j-1}-2 \nu_{l}^{j-1}}=\frac{\Gamma_{k, n, l}\left(\widetilde{p}_{k, n}\right)^{2}}{q_{k}^{\mathrm{AF}, i-1} \varrho_{r_{l}}+2 \nu_{l}^{j-1}}
$$

Tomando $e=q_{k}^{\mathrm{AF}, i-1} \varrho_{k}+2 \tau_{k}^{j-1}$ e $f=q_{k}^{\mathrm{AF}, i-1} \varrho_{r_{l}}+2 \nu_{l}^{j-1}$, obtém-se:

$$
\begin{aligned}
\frac{\Gamma_{l, n, 0}\left(\widetilde{p}_{k, n, l}-\widetilde{p}_{k, n}\right)^{2}-\Gamma_{k, n, l}\left(\widetilde{p}_{k, n}\right)^{2}}{e-f} & =\frac{\Gamma_{k, n, l}\left(\widetilde{p}_{k, n}\right)^{2}}{f} \\
f \Gamma_{l, n, 0}\left(\widetilde{p}_{k, n, l}-\widetilde{p}_{k, n}\right)^{2}-f \Gamma_{k, n, l}\left(\widetilde{p}_{k, n}\right)^{2} & =(e-f) \Gamma_{k, n, l}\left(\widetilde{p}_{k, n}\right)^{2} \\
f \Gamma_{l, n, 0}\left(\widetilde{p}_{k, n, l}^{\mathrm{AF}}-\widetilde{p}_{k, n}^{\mathrm{AF}}\right)^{2} & =e \Gamma_{k, n, l}\left(\widetilde{p}_{k, n}^{\mathrm{AF}}\right)^{2}
\end{aligned}
$$

que resulta em

$$
\left(f \Gamma_{l, n, 0}-e \Gamma_{k, n, l}\right)\left(\widetilde{p}_{k, n}\right)^{2}-2 f \Gamma_{l, n, 0} \widetilde{p}_{k, n, l} \widetilde{p}_{k, n}+f \Gamma_{l, n, 0}\left(\widetilde{p}_{k, n, l}\right)^{2}=0
$$

Perceba que a equação (C.36) é semelhante à que se obtém para o método de somatório de logaritmos, equação (C.10), apenas com diferentes valores para e e $f$. Ainda tem-se que $e>0$ e $f>0$, de modo que as conclusões obtidas com as equações (C.11)-(C.17) são também válidas para esse caso. Assim, define-se que

$$
\begin{aligned}
& \Omega_{k, n, l}^{\mathrm{AF}, i, j}= \\
& \frac{\left(q_{k}^{\mathrm{AF}, i-1} \varrho_{r_{l}}+2 \nu_{l}^{j-1}\right) \Gamma_{l, n, 0}-\sqrt{\left(q_{k}^{\mathrm{AF}, i-1} \varrho_{k}+2 \tau_{k}^{j-1}\right)\left(q_{k}^{\mathrm{AF}, i-1} \varrho_{r_{l}}+2 \nu_{l}^{j-1}\right) \Gamma_{k, n, l} \Gamma_{l, n, 0}}}{\left(q_{k}^{\mathrm{AF}, i-1} \varrho_{r_{l}}+2 \nu_{l}^{j-1}\right) \Gamma_{l, n, 0}-\left(q_{k}^{\mathrm{AF}, i-1} \varrho_{k}+2 \tau_{k}^{j-1}\right) \Gamma_{k, n, l}}
\end{aligned}
$$




\section{ANEXO D - FERRAMENTAIS UTILIZADOS NA TESE}

\section{D.1 Modelo de Canal WINNER C2}

Utiliza-se o modelo WINNER C2 para gerar a componente de perda de percurso da comunicação MS-BS [133]. Os modelos LoS e NLoS são dados, respectivamente, por

$$
\begin{gathered}
P L_{\mathrm{LoS}}=\left\{\begin{array}{cc}
26 \log _{10}(d)+39+20 \log _{10}\left(f_{c} / 5\right) & 10 \mathrm{~m}<d<d_{\mathrm{BP}}^{\prime} \\
40 \log _{10}(d)+13,47-14 \log _{10}\left(h_{\mathrm{rx}}^{\prime}\right)-14 \log _{10}\left(h_{\mathrm{tx}}^{\prime}\right) & d_{\mathrm{BP}}^{\prime}<d<5 \mathrm{~km} \\
& +6 \log _{10}\left(f_{c} / 5\right)
\end{array}\right. \\
P L_{\mathrm{NLoS}}=\left[\begin{array}{ll}
\left.44,9-6,55 \log _{10}\left(h_{\mathrm{rx}}\right)\right] \log _{10}(d[m])+34,46+5,83 \log _{10}\left(h_{\mathrm{rx}}\right) \\
+
\end{array}\right. \\
+23 \log _{10}\left(f_{c}[\mathrm{GHz}] / 5\right), \quad 50 \mathrm{~m}<d<5 \mathrm{~km},
\end{gathered}
$$

em que $h_{\mathrm{tx}}$ é a altura da antena do transmissor, em metros; $h_{\mathrm{rx}}$ é a altura da antena do receptor, em metros; $h_{\mathrm{tx}}^{\prime}=\left(h_{\mathrm{tx}}-1\right)$ é a altura efetiva da antena do transmissor, em metros; $h_{\mathrm{rx}}^{\prime}=\left(h_{\mathrm{rx}}-1\right)$ é a altura efetiva da antena do receptor, em metros; $d$ é a distância entre transmissor e receptor, em metros; $f_{c}$ é a frequência da portadora em GHz; e $d_{\mathrm{BP}}^{\prime}$ é a distância de ruptura do componente LoS,

$$
d_{\mathrm{BP}}^{\prime}=\frac{4 h_{\mathrm{rx}}^{\prime} h_{\mathrm{tx}}^{\prime} f_{c}}{c}
$$

em que $c$ é a velocidade da luz.

A equação de probabilidade de LoS para o cenário C2 é dada por

$$
P_{\mathrm{LoS}}=\min (18 / d, 1)(1-\exp (-d / 63))+\exp (-d / 63) .
$$

\section{D.2 Diferença de Funções Côncavas}

Sabendo que as funções são côncavas, pode-se pensar na aplicação do ferramental de diferença de funções convexas ao problema, fazendo a devida conversão do ferramental. Mas antes, mostra-se o próprio ferramental, que ainda não foi discutido. Considere um problema de otimização descrito da seguinte forma:

$$
\min _{\mathbf{x} \in \mathbb{R}^{L}} s(\mathbf{x})-t(\mathbf{x})
$$

em que tanto $s(\mathbf{x})$ quanto $t(\mathbf{x})$ são convexos em relação a $\mathbf{x}$. 
A solução de tal problema pode ser determinada através de um algoritmo iterativo, que a partir de uma estimativa inicial $\mathbf{x}^{0}$ resolve o seguinte problema na $i$-ésima iteração:

$$
\min s(\mathbf{x})-t\left(\mathbf{x}^{i-1}\right)-\sum_{l=1}^{L}\left[\left.\left(x_{l}-x_{l}^{i-1}\right) \frac{\partial t(\mathbf{x})}{\partial x_{l}}\right|_{\mathbf{x}=\mathbf{x}^{i-1}}\right]
$$

onde $\mathbf{x}^{i-1}$ é a estimativa do vetor-solução obtida na $(i-1)$-ésima iteração e $L$ o tamanho do vetor $\mathbf{x}$, e a função-objetivo gerada é convexa em relação a $\mathbf{x}$.

Considere agora um problema na forma

$$
\max _{\mathbf{x} \in \mathbb{R}^{n}} f(\mathbf{x})-g(\mathbf{x})
$$

em que $f(\mathbf{x})$ e $g(\mathbf{x})$ são côncavos em relação a $\mathbf{x}$. É possível reescrever o problema em forma convexa, através da seguinte formulação:

$$
\min _{\mathbf{x} \in \mathbb{R}^{n}}(-f(\mathbf{x}))-(-g(\mathbf{x}))
$$

onde $-f(\mathbf{x})$ e $-g(\mathbf{x})$ são, por definição, convexos.

Adotando $s(\mathbf{x})=-f(\mathbf{x})$ e $t(\mathbf{x})=-g(\mathbf{x})$, e substituindo esses valores na solução da equação (D.6), tem-se que a solução equivalente é dada por

$$
\min -f(\mathbf{x})+g\left(\mathbf{x}^{i-1}\right)+\sum_{l=1}^{L}\left[\left.\left(x_{l}-x_{l}^{i-1}\right) \frac{\partial g(\mathbf{x})}{\partial x_{l}}\right|_{\mathbf{x}=\mathbf{x}^{i-1}}\right],
$$

cuja forma dual é dada por

$$
\max f(\mathbf{x})-g\left(\mathbf{x}^{i-1}\right)-\sum_{l=1}^{L}\left(x_{l}-x_{l}^{i-1}\right) \frac{\partial g(\mathbf{x})}{\partial x_{l}},
$$

que é semelhante à solução apresentada em (D.6) para o problema (D.5).

Desse modo, problemas na forma

$$
\max _{\mathbf{x} \in \mathbb{R}^{L}} f(\mathbf{x})-g(\mathbf{x})
$$

com funções $f$ e $g$ côncavas podem ser solucionados através da seguinte estratégia iterativa:

$$
\max f(\mathbf{x})-g\left(\mathbf{x}^{i-1}\right)-\sum_{l=1}^{L}\left[\left.\left(x_{l}-x_{l}^{i-1}\right) \frac{\partial g(\mathbf{x})}{\partial x_{l}}\right|_{\mathbf{x}=\mathbf{x}^{i-1}}\right]
$$

